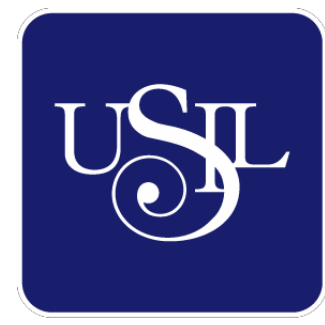

UNIVERSIDAD

SAN IGNACIO

DE LOYOLA

ESCUELA DE POSTGRADO

Maestría en Ciencias Empresariales

\title{
ALBERGUE VIVENCIAL "LA HACIENDA KACHI RAQAY" UBICADO EN EL POBLADO DE MARAS, CUSCO - PERÚ
}

Trabajo de Investigación para optar el grado de Maestro en Ciencias Empresariales

VERÓNICA CECILIA INDO VELA

DENISSE ELENA OLIVOS PÉREZ

CARMEN AMALIA VILLAGARCÍA GONZALES

MARCO ANTONIO VILLENA HEREDIA

Asesor:

Dra. Patricia Mercedes Rodríguez Román

$$
\text { Lima - Perú }
$$

2018 
ALBERGUE VIVENCIAL "LA HACIENDA KACHI RAQAY" UBICADO EN EL POBLADO DE MARAS, CUSCO-PERÚ 


\section{Resumen Ejecutivo}

1. Unidad ejecutora
a. Verónica Indo
b. Denisse Olivos
c. Carmen Villagarcía
d. Marco Villena

2. Información general del proyecto

a. Razon social: Kachi Raqay S.A.C

b. Ubicación: Distrito de Maras, provincia de Urubamba del departamento del Cusco.

c. Actividad de la empresa: Hotelera

\section{Oportunidad del negocio}

La mayor oportunidad detectada son las tendencias actuales del turismo, actualmente las personas desean conectar con el destino visitado de forma sostenible y viviendo experiencias nuevas. Que redunde en el beneficio de las comunidades locales, y la preservación de los valores culturales y naturales. A ello se suma la ubicación del poblado de Maras, (pueblo pintoresco de origen colonial), a tan solo a 20 kilómetros de distancia de la estación ferroviaria de Ollantaytambo, de donde parten los trenes al santuario histórico de Machu Picchu. En este distrito se ubican también los restos arqueológicos de Moray, (laboratorio agrícola incaico y espacio espiritual) y las salineras de Maras, reconocidas por la sal producida de manera natural y utilizada en nuestra gastronomía. 


\section{Estrategia del proyecto:}

Estrategia el enfoque de alto valor. Enfocando el servicio en un segmento específico del mercado interesado en vivir experiencias vivenciales, con la mejor relación valor-precio disponible en el mercado.

\section{Competencia:}

Se han reconocido 10 hospedajes categorizados como albergues (que se delimitó como competencia por sus características) ninguno de ellos se encuentra ubicado en la zona de Maras. Los precios por habitación por noche por huésped, van desde S/. 115 (Albergue municipal) hasta S/. 480 (Albergue "El Mercado").

\section{Definición del producto:}

Kachi Raqay es un albergue que brinda servicio de hospedaje en el distrito de Maras, pueblo pintoresco de la provincia del Cusco, rodeado de la belleza paisajística de los andes del Cusco. El albergue brinda una experiencia vivencial, es decir que los huéspedes tendrán la oportunidad de compartir con pobladores locales su día a día en el albergue, compartirán el hacer la comida en base a los productos de zona como la quinua, ollucos, y bebidas como la chicha. Irán al mercado, compartirán la mesa y sus historias. El albergue brindara también paquetes de entretenimiento para disfrutar de las actividades y atractivos turísticos de la zona. Se presentan tres paquetes: Full day" (un día), "Aventura en Maras" (dos días-una noche) y "Experiencia Kachi Raqay" (tres días-dos noche). En los que se incluye la visita a Moray, reconocido como laboratorio agrícola de los Incas, las salineras de Maras, etc. 
El servicio de alojamiento cumplirá los estándares de infraestructura y operativos delimitados por Mincetur (Ministerio de Comercio exterior y Turismo).

El Ecolodge "Kachi Raqay” inicia teniendo una capacidad para 18 habitaciones entre simples (9), dobles (6) y matrimoniales (3) debido a que se pretende dar un concepto vivencial personalizado, dirigiéndonos a un público que invertiría en este tipo de experiencia, más no por el bajo precio.

7. Usos y beneficios.

Con este proyecto de negocio se beneficiarán los accionistas y la comunidad, pues serán ellos los gestores de la operación del albergue.

\section{Información financiera:}

Se ha planteado una tasa de ocupación del $44 \%$ el primer año, con una proyección de crecimiento de 4\%. Por debajo del promedio establecido por Dircetur en el cuarto año de operación; con una proyección de crecimiento del sector hotelero del $9 \%$ anual.

Se estima invertir un total de S/. 4`504,774 los cuales estarán distribuidos en; $83 \%$ para adquisición de activo fijo, $16 \%$ para capital de trabajo y $1 \%$ en activo intangible.

La estructura del financiamiento será $100 \%$ capital propio, debido a que la mayoría de las entidades financieras tienen como requisito el que la empresa esté en funcionamiento para aprobar un financiamiento bancario. El costo del capital 
$\left(\mathrm{COK}_{\text {real }}\right)$ para los inversionistas se había determinado en un $10,06 \%$, pero para considerar una tasa holgada, se plantea un escenario pesimista y se asume que el riesgo se aumente, por lo que el inversionista solicita un COK de 35\%; la tasa de impuesto a la renta será de $29,5 \%$ y no se tomará en cuenta el costo de la deuda debido a que el proyecto no tendrá financiamiento bancario. En base a estos tampoco se podría ponderar un costo promedio de capital, ya que el COK ya representa la tasa a la que se descontarán los flujos del proyecto.

El horizonte financiero del proyecto se calculó en base a 5 años. Al finalizar dicho plazo, se estima recuperar el valor en libros además del capital de trabajo.

La actualización de flujos proyectados arroja que el VANE es superior a cero por lo cual se sugiere aceptar el proyecto.

Como la rentabilidad esperada $(\mathrm{COK}=35 \%)$ es menor que la TIRE $(36,14 \%)$, fortalece la sugerencia de aceptar el proyecto.

Los ingresos del Ecolodge provienen de 2 fuentes: venta de 3 tipos de paquetes y ventas por consumo en el bar. El primer año se proyecta conseguir ventas por valor de S/. 4`438,983, y llegar a S/. 6`245,716 el último año. En promedio la mezcla de venta estará dada por $13 \%$ paquete "Full day", $60 \%$ paquete "Aventura en Maras", 26\% paquete "Experiencia Kachi Raqay" y menos de uno por ciento provendrá de las ventas en el bar. El margen de contribución de dichos productos es de: $12 \%, 53 \%, 59 \%$ y $76 \%$ respectivamente. 
El punto de equilibro en soles está alrededor de S/. 1'449,976, las unidades proyectadas de venta, no solo alcanzan el punto de equilibrio sino que lo superan hasta en tres veces el primer año llegado a cuadruplicar el punto de equilibrio en el quinto año.

Para que el proyecto siga siendo viable según los indicadores VANE y TIRE: el tipo de cambio debe ser superior a 3,21 soles por dólar, la inversión en activo fijo debe ser inferior al $103.45 \%$ proyectado, y la demanda debe ser superior al $98 \%$ del mercado objetivo estimado. 


\section{Contenido}

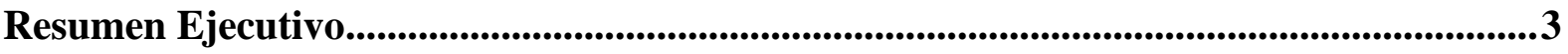

Contenido

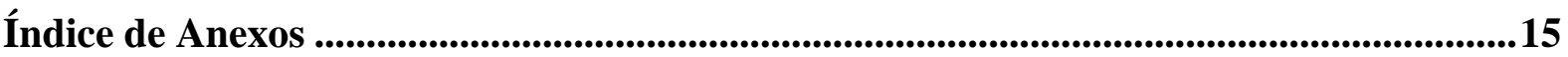

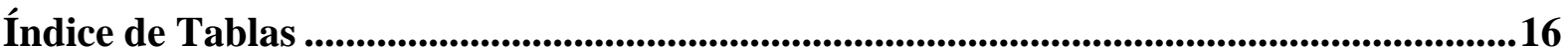

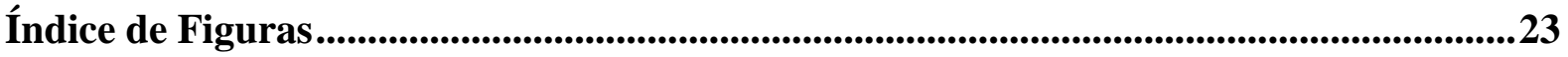

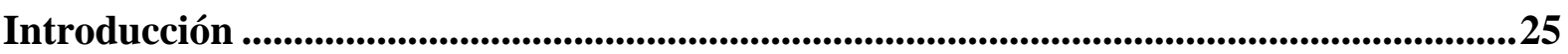

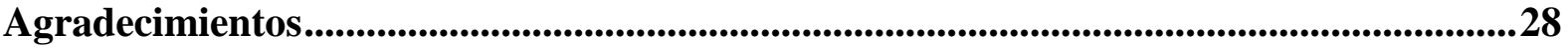

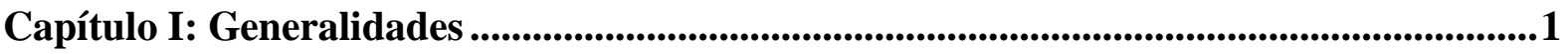

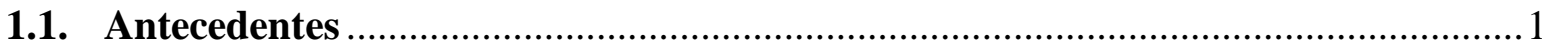

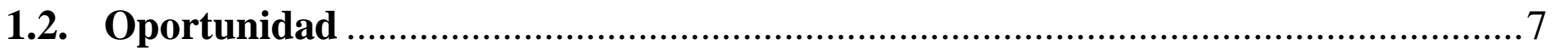

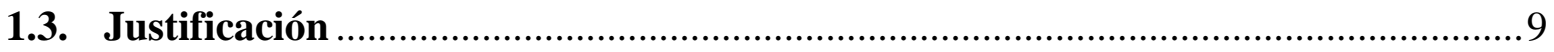

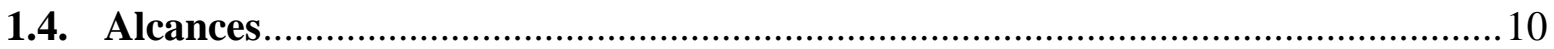

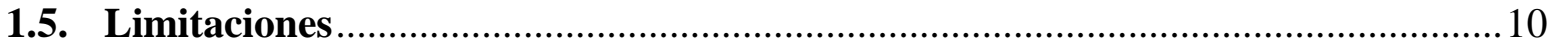

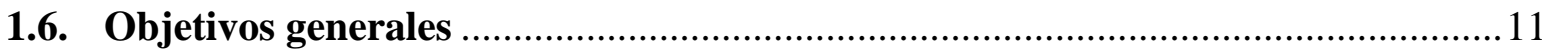

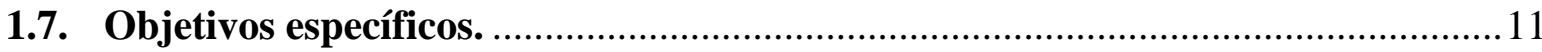

Capítulo II: Estructura Económica del Sector...........................................................................12

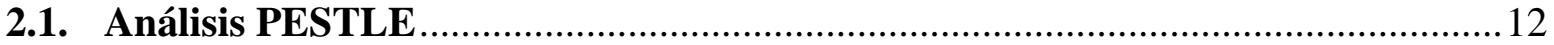

2.1.1. Análisis del entorno político y lega............................................................. 12

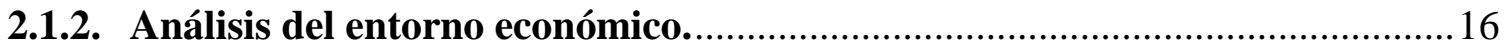

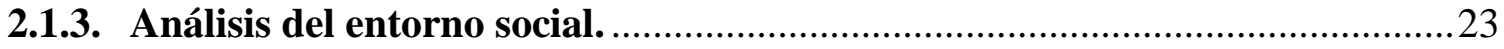

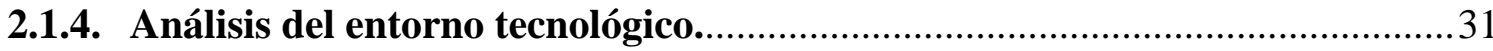


2.1.5. Análisis del entorno ecológico.

2.2. Fuerzas de Porter.

2.2.1. Poder de negociación clientes.

2.2.2. Poder de negociación de los proveedores.

2.2.3. Amenaza de nuevos competidores. .51

2.2.4. Amenaza de productos y servicios sustitutos. .54

2.2.5. Rivalidad entre competidores actuales. .56

Capítulo III: Estudio de Mercado .74

3.1. Descripción del servicio y producto .74

3.2. Investigación cualitativa .75

3.2.1. Estudio cualitativo a turistas vacacionales. .76

3.2.2. Estudio cualitativo a agencias de turismo. .80

3.3. Investigación cuantitativa. 94

3.3.1. Estudio cuantitativo a turistas vacacionales. 94

3.3.2. Estudio cuantitativo a agencias de turismo. 100

Capítulo IV: Proyección del Mercado Objetivo 106

4.1. El objetivo de la proyección 106

4.2. El ámbito de la proyección 106

4.3. Método de proyección 106

4.4. Cálculo del mercado objetivo 109

4.4.1. Mercado potencial. 109

4.4.2. Mercado disponible. 
4.4.3. Mercado efectivo.

4.4.4. Mercado objetivo.

4.4.5. Pronóstico de ventas.

4.5. Aspectos críticos que impactan el pronóstico de ventas.

Capítulo V: Estudio de Ingeniería del Proyecto.

5.1. Modelamiento y selección de procesos productivos.

5.1.1. Distribución de equipos y maquinarias.

5.2. Determinación del tamaño.

5.2.1. Tamaño normal del proyecto.

5.2.2. Tamaño máximo.

5.2.3. Porcentaje de utilización de capacidad instalada.

5.2.4. Programa de ventas.

5.2.5. Materias primas e insumos

5.2.6. Maquinarias y equipos.

5.2.7. Programa de compras materia prima e insumos. 146

5.2.8. Requerimiento de mano obra.

5.2.9. Tecnología.

5.3. Estudio de localización.

5.3.1. Macrolocalización.

5.3.2. Microlocalización.

5.4. Lay-out y costos de construcción. 
5.5. Consideraciones legales.

5.5.1. Formalización de empresa.

5.5.2. constitución de empresa.

5.5.3. Autorizaciones 163

Capítulo VI: Aspectos Organizacionales 169

6.1. Caracterización de la cultura organizacional deseada.

6.1.1. Visión.

6.1.2. Misión. 170

6.1.3. Principios. 171

6.2. Formulación de objetivos.

6.2.1. Objetivos estratégicos.

6.2.2. Objetivos financieros.

6.3. Formulación de estrategia del negocio.

6.4. Determinación de las ventajas competitivas críticas

6.5. Diseño de la estructura organizacional deseada.

6.6. Diseño de los perfiles de puesto clave

6.7. Remuneraciones, compensaciones e incentivos.

6.8. Política de Recursos Humanos

Capitulo VII: Plan de Marketing 
7.3. Mix de Marketing.

7.3.1. Servicio

7.3.2. Branding: 218

7.3.3. Precio

7.3.4. Plaza 236

7.3.5. Promoción 237

7.3.6. Personas

7.3.7. Procesos

7.3.8. Evidencia Física. 252

Capítulo VIII: Estudio de Inversiones y Financiamiento 255

8.1. Inversiones.

8.1.1. Inversión en activo fijo.

8.1.2. Inversión en activo intangible.

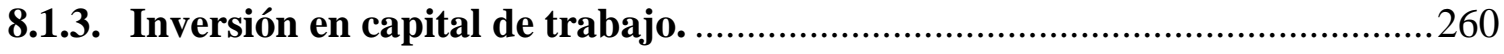

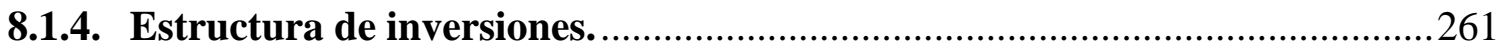

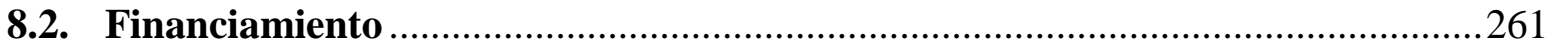

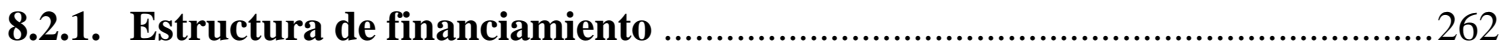

Capítulo IX: Estudio de Ingresos y Costos ........................................................................................263

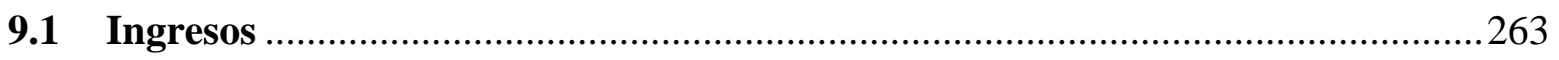

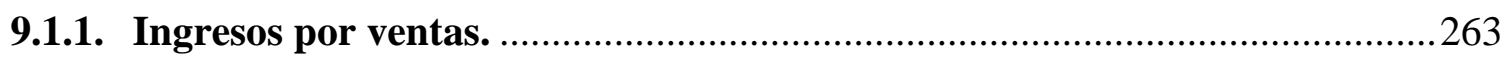


9.1.2. Recuperación capital de trabajo.

9.2 Costos y Gastos Anuales

9.2.1. Egresos desembolsables. .268

9.2.2. Egresos no desembolsables. .274

Capítulo X: Estados Financieros Proyectados .277

10.1. Premisas del estado de resultado y del flujo de caja. 277

10.2. Estado de resultados proyectado .277

10.3. Flujo de caja operativo proyectado .278

10.4. Cálculo de la perpetuidad. .279

10.5. Flujo de caja de inversión proyectado 279

10.6. Flujo de caja económico proyectado .280

10.7. Premisas del estado de situación financiera 281

Capítulo XI: Evaluación económica financiera . 283

11.1. Cálculo de la tasa de descuento. .283

11.1.1. Cálculo de la tasa de descuento 283

11.1.1.1. Determinación de la tasa de descuento mediante el CAPM .283

11.1.1.2. Determinación de la tasa de descuento mediante valoración de experto .. 287

11.2. Indicadores de rentabilidad. .288

11.2.1. Cálculo del VANE .288

11.2.2. Cálculo de la TIRE. .289

11.2.3. Período de recuperación descontado. 290

11.3. Análisis del punto de equilibrio .291 
11.3.1. Costos fijos y costos variables.

11.3.2. Estado de resultados por costeo directo .294

11.3.3. Análisis de la mezcla de ventas 294

11.3.4. Cálculo del margen de contribución de la mezcla de ventas 295

11.3.5. Cálculo de las ventas necesarias para alcanzar el punto de equilibrio 296

11.3.6. Cálculo de las unidades necesarias para alcanzar el punto de equilibrio....298

11.4. Análisis de sensibilidad 299

11.4.1. Análisis unidimensional 299

11.5. Análisis de mitigación 302

11.5.1. Análisis de mitigación al tipo de cambio 302

11.5.2. Análisis de mitigación a la inversión de activo fijo 303

11.5.3. Análisis de mitigación a la demanda .304

11.5.4. Análisis de mitigación a fenómenos climatológicos. 304

11.5.5. Análisis de mitigación a los conflictos sociales 305

11.5.6. Análisis de mitigación a la guerra de precios 306

11.5.7. Análisis de mitigación a emergéncias médicas en Maras 306

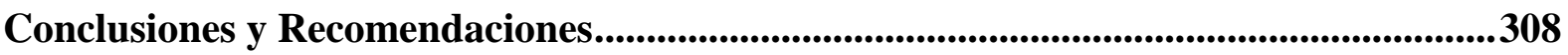

Conclusiones. 308

Recomendaciones

Referencias. 315

Anexos 326 


\section{Índice de Anexos}

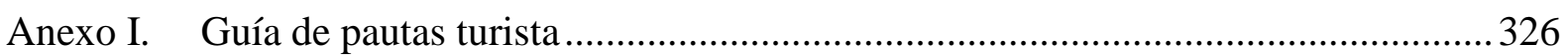

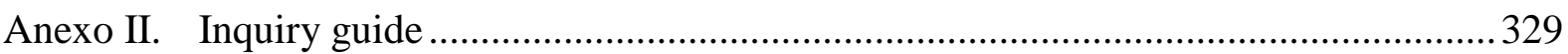

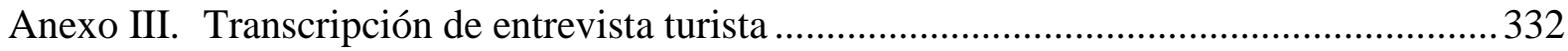

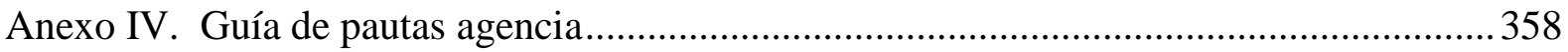

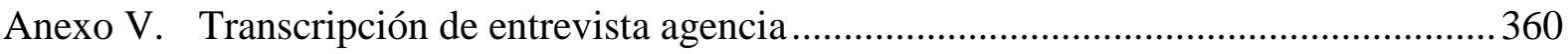

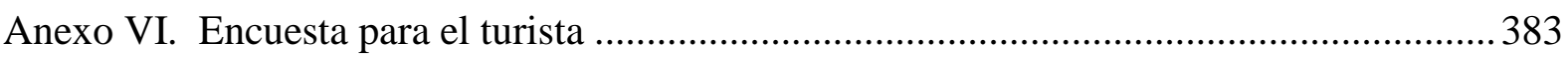

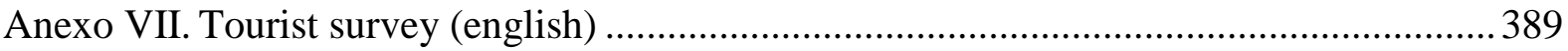

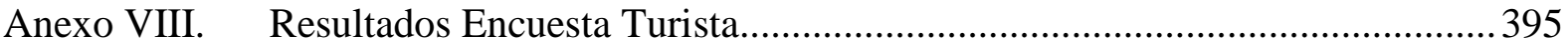

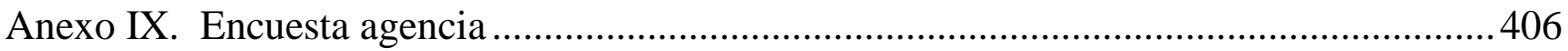

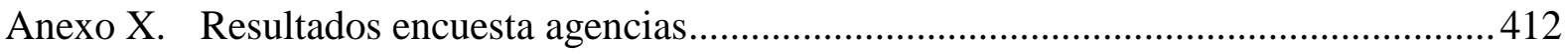

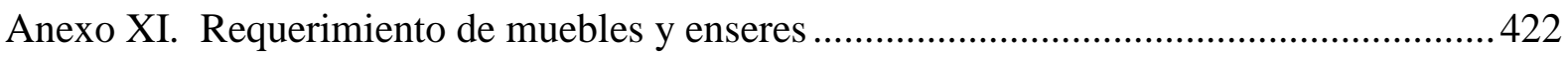

Anexo XII. Proformas de algunos muebles y enseres .................................................. 426

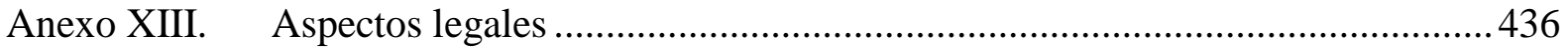

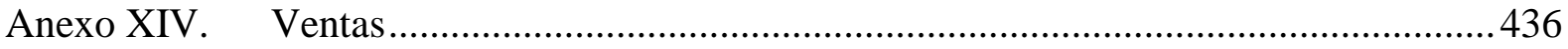

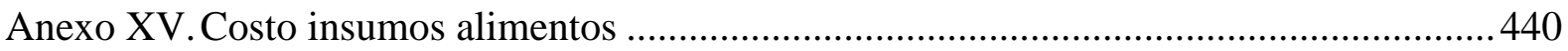

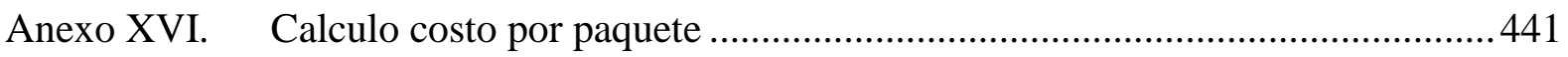

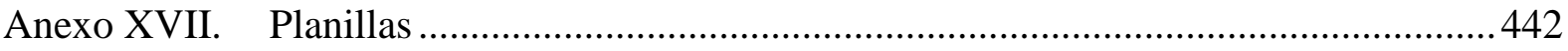

Anexo XVIII. Cálculo de servicios y cálculo de costo variable unitario..........................445

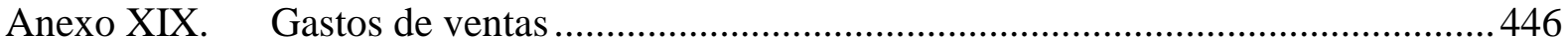

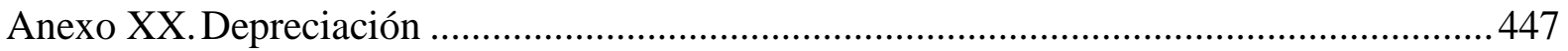




\section{Índice de Tablas}

Tabla 1. Aporte de la actividad económica “Alojamiento y restaurantes al PBI peruano"

2012-2016

Tabla 2. Flujo de Llegada de Visitantes Nacionales y Extranjeros al Complejo

Arqueológico de Moray .....

Tabla 3. Principales motivos de viaje al Perú

Tabla 4. Clientes indirectos Agencias de Turismo Minoristas.

Tabla 5. Clientes indirectos Agencias de Turismo Mayoristas. 44

Tabla 6. Clientes indirectos Operadores de Turismo .45

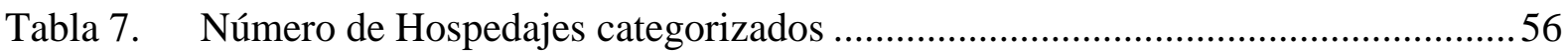

Tabla 8. Hospedajes categorizados como Albergue ....................................................58

Tabla 9. Albergues inscritos en la Dirección Regional de Turismo con información de hospedaje.

Tabla 10. Albergue municipal 60

Tabla 11. Ausangate lodge 61

Tabla 12. Collpapampa Lodge 62

Tabla 13. Eco Quechua Lodge. .63

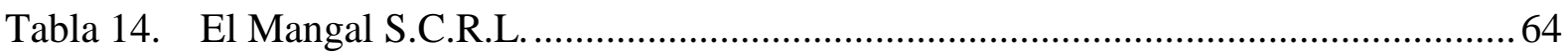

Tabla 15. El Mercado by Mountain Lodges of Peru ........................................................... 65

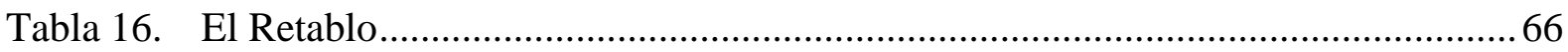

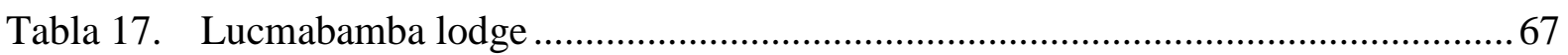

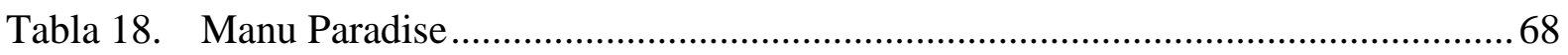

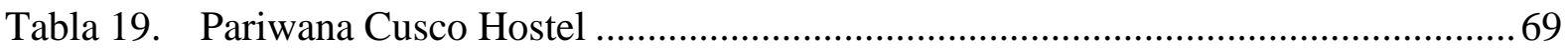

Tabla 20. Oportunidades y Amenazas del mercado en estudio ......................................... 71 
Tabla 21. Objetivos del estudio de mercado cualitativo del turista .77

Tabla 22. Distribución muestral de entrevistas en profundidad:.......................................... 79

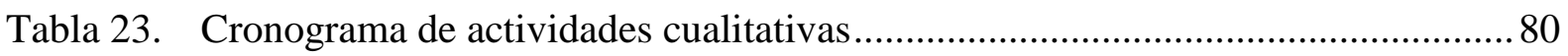

Tabla 24. Objetivos del estudio de mercado cualitativo de agencias de turismo...................82

Tabla 25. Distribución muestral de entrevistas en profundidad:........................................ 85

Tabla 26. Información de entrevistado por agencias de turismo: ...................................... 85

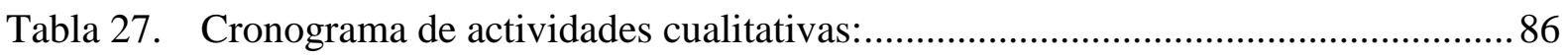

Tabla 28. Conclusiones del estudio de mercado cualitativo del turista ................................ 86

Tabla 29. Conclusiones del estudio de mercado cualitativo por agencia de turismo............90

Tabla 30. Objetivos del estudio de mercado cuantitativo del turista ..................................95

Tabla 31. Distribución muestral del cuestionario presencial (papel) y online (Survey Monkey): .97

Tabla 32. Conclusiones del estudio de mercado cuantitativo del turista ............................98

Tabla 33. Objetivos del estudio de mercado cuantitativo de agencias de turismo.............. 101

Tabla 34. Conclusiones del estudio de mercado cuantitativo de agencias de turismo.........103

Tabla 35. Turistas que ingresaron a la Ciudad del Cusco entre el 2005 y el 2016 ............. 107

Tabla 36. Turistas que ingresarán a la Ciudad del Cusco los años 2017 al 2022 ............... 109

Tabla 37. Turistas que Visitaron Cusco Por Vacaciones 2013-2016 (Expresado en \%) .... 110

Tabla 38. Turistas que Visitaron Cusco Por Vacaciones 2017-2022 …........................... 110

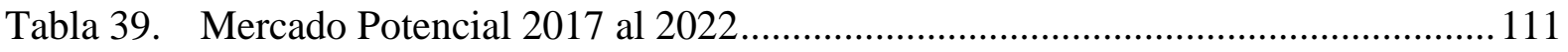

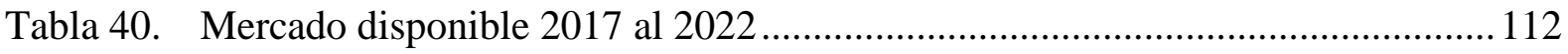

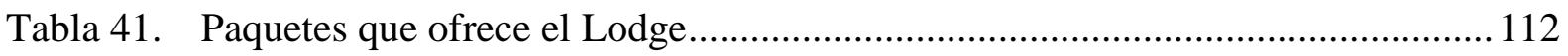

Tabla 42. Intención de compra por paquetes según estudio de mercado ............................ 113

Tabla 43. Probabilidad de consumo aplicando índice McDaniel..................................... 113

Tabla 44. Mercado efectivo de los paquetes del Ecolodge "Kachi Raqay" ........................114 
Tabla 45. Mercado efectivo Paquete 1 del Ecolodge "Kachi Raqay"....

Tabla 46. Potenciales camas Ecolodge "Kachi Raqay"

Tabla 47. Mercado objetivo Paquetes 2 y 3 atendidos por el Ecolodge "Kachi Raqay" según la tasa de ocupabilidad.

Tabla 48. Pronóstico de ventas Ecolodge "Kachi Raqay"

Tabla 49. Blueprint servicios más cotizados

Tabla 50. Tamaño normal Ecolodge "Kachi Raqay" para los paquetes 2 y 3

Tabla 51. Tamaño máximo del Ecolodge "Kachi Raqay"

Tabla 52. Capacidad instalada en el Ecolodge "Kachi Raqay” expresado en personas ..... 137

Tabla 53. Proyección de ventas por paquete

Tabla 54. Insumos Restaurante por año

Tabla 55. Insumos Bar por año

Tabla 56. Insumos Pan por año

Tabla 57. Amenities por habitación 2017-2022.

Tabla 58. Equipos Recepción y Sala de Estar.

Tabla 59. Equipos Oficina.

Tabla 60. Equipos Restaurante Planta Baja

Tabla 61. Equipos Baño Restaurante Planta Baja

Tabla 62. Equipos Restaurante Planta Alta

Tabla 63. Equipos Baño Restaurante Planta Alta

Tabla 64. Equipos Cocina y Horno de Barro

Tabla 65. Equipos Habitaciones.

Tabla 66. Requerimiento de mano de obra

Tabla 67. Ponderación de factores críticos para determinar el destino óptimo de un

$$
\text { Ecolodge. }
$$


Tabla 68. Características de terrenos potenciales

Tabla 69. Ponderación de factores críticos para determinar el terreno óptimo de un

Ecolodge.

Tabla 70. Metros cuadrados de construcción

Tabla 71. Valores por partidas en nuevos soles por metro cuadrado de área techada según el CAP, para la categoría A 160

Tabla 72. Presupuesto estimado de construcción del edificio. 161

Tabla 73. Costos de aspectos legales (expresado en soles) 162

Tabla 74. Clasificación de hospedajes 164

Tabla 75. Puestos Ejecutivos 194

Tabla 76. Puestos Supervisores 194

Tabla 77. Puestos Operativos 194

Tabla 78. Puestos Ejecutivos

Tabla 79. Puestos Supervisores 195

Tabla 80. Puestos Operativos 196

Tabla 81. Planilla de trabajadores: 196

Tabla 82. Disposición a pagar por los turistas por un día de actividades de turismo y alimentación en Cusco (Expresada en dólares americanos)

Tabla 83. Disposición a pagar por los turistas por una noche de alojamiento en Cusco. (Expresada en dólares americanos) 228

Tabla 84. Disposición de los turistas a pagar por paquete (Expresada en dólares americanos) 228

Tabla 85. Precio Rack Para los paquetes del Ecolodge "Kachi Raqay", en base a acomodación doble, expresado en dólares americanos 
Tabla 86. Precios por turista de los paquetes según tarifa, en base a acomodación doble (expresado en dólares americanos).

Tabla 87. Precios por turista de los paquetes según tarifa, en base a acomodación simple (expresado en dólares americanos).

Tabla 88. Precios de los paquetes por persona expresado en dólares

Tabla 89. Precios de los paquetes por persona expresado en soles, incluye pago por servicios

Tabla 90. Precios Ecolodge Kachi Raqay: Operadores de Turismo 235

Tabla 91. Costo Total Terreno Ecolodge (expresado en soles) 255

Tabla 92. Costo Total Construcción Ecolodge (expresado en soles) 256

Tabla 93. Costo Equipos de Procesamiento de Datos (expresado en soles) 256

Tabla 94. Costo Maquinaria y Equipos (expresado en soles) 257

Tabla 95. Costo Muebles y Enseres (expresado en soles) 257

Tabla 96. Costo Vehículo de Transporte (expresado en soles) 258

Tabla 97. Consolidado Activos Fijos (expresado en soles) 259

Tabla 98. Inversión en Activo Intangible (expresado en soles). 260

Tabla 99. Determinación del capital de trabajo (expresado en soles)..... 261

Tabla 100. Estructura de Inversiones (expresada en soles) 261

Tabla 101. Estructura de Financiamiento (expresado en soles). 262

Tabla 102. Estructura de aportes del capital propio 262

Tabla 103. Precio por persona por paquete (expresado en dólares) 263

Tabla 104. Precio por persona por paquete (expresado en soles) 264

Tabla 105. Precio Ponderado Canal Directo (expresado en dólares) 264

Tabla 106. Precio Ponderado Canal Operador (expresado en dólares). 264

Tabla 107. Precio Ponderado Final Paquetes Kachi Raqay (expresado en soles) .265 
Tabla 108. Ingresos por paquetes 2018-2022 (expresado en soles) ...................................265

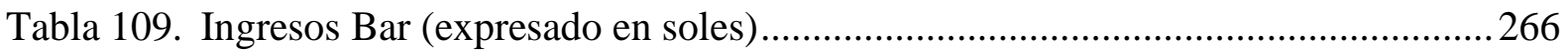

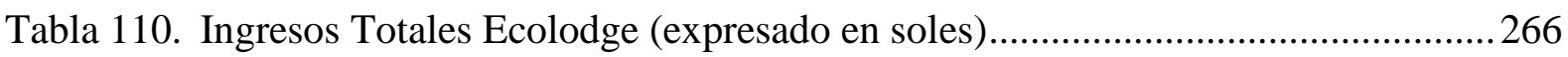

Tabla 111. Determinación IGV por ventas por año (expresado en soles) ….........................267

Tabla 112. Recuperación del capital de trabajo (expresado en soles) ..................................267

Tabla 113. Presupuesto de Gastos por Paquete (expresado en soles) .................................268

Tabla 114. Mano de obra directa (expresado en soles) ......................................................269

Tabla 115. Presupuesto de Mano de Obra Directa (expresado en soles) .............................269

Tabla 116. Remuneraciones Administrativas (expresado en soles) ..................................270

Tabla 117. Presupuesto Remuneraciones Administrativas (expresado en soles) .................270

Tabla 118. Presupuesto de Servicio de Luz, Agua, Cable e Internet (expresado en soles) ..271

Tabla 119. Costo Consumo Combustible (expresado en soles) ..........................................2272

Tabla 120. Presupuesto Consumo de Combustible (expresado en soles) ............................2 272

Tabla 121. Presupuesto Gastos Administrativos (expresado en soles) ...............................272

Tabla 122. Presupuesto de Gastos de Ventas y Marketing (expresado en soles) .................2274

Tabla 123. Depreciación Anual de Activos Fijos (expresado en soles) ...............................275

Tabla 124. Depreciación Anual de Activos Fijos 2018-2022 (expresado en soles) .............275

Tabla 125. Amortización de Activos Intangibles (expresado en soles) ...............................2276

Tabla 126. Amortización Anual de Intangibles 2018-2022 (expresado en soles) ................276

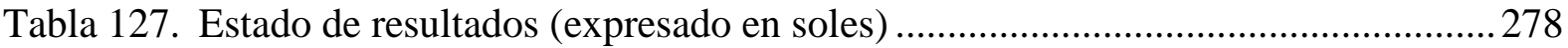

Tabla 128. Flujo de Caja Operativo Proyectado (expresado en soles) ................................278

Tabla 129. Flujo de Caja de Inversión Proyectado (expresado en soles)..............................280

Tabla 130. Flujo de Caja Económico (expresado en soles) ..................................................2280

Tabla 131. 282

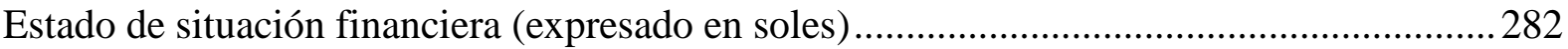


Tabla 132. 291

Período de recuperación descontado (expresado en años) 291

Tabla 133. Costos fijos 2018-2022 (expresado en soles) 292

Tabla 134. Costos Variables 2018-2022 (expresado en soles) 293

Tabla 135. Costos totales unitarios expresados en soles (expresado en soles) 293

Tabla 136. Estado de Resultados por Costeo Directo (expresado en soles) 294

Tabla 137. Mezcla de venta (expresada en soles) 295

Tabla 138. Mezcla de venta (expresada en porcentaje) 295

Tabla 139. Cálculo del margen de contribución por producto (expresado en porcentaje) ...296

Tabla 140. Cálculo del margen de contribución de la mezcla de ventas (expresado en porcentaje) 296

Tabla 141. Punto de equilibrio de las ventas (expresado en soles) 297

Tabla 142. Punto de equilibrio de las ventas por paquetes (expresado en soles) 297

Tabla 143. Punto de equilibrio de las ventas por paquetes (expresado en unidades) 298

Tabla 144. Porcentaje de ventas proyectadas con respecto al punto de equilibrio 298

Tabla 145. Análisis de sensibilidad al tipo de cambio 300

Tabla 146. 301

Análisis de sensibilidad a la inversión en activo fijo 301

Tabla 147. Análisis de sensibilidad a la demanda. 302 


\section{Índice de Figuras}

Figura 1. Mapa de distancia Cusco-Machu Picchu. ............................................................ 8

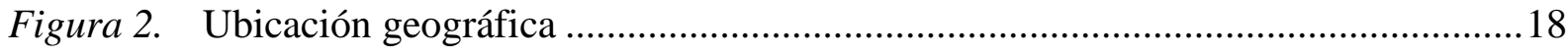

Figura 3. Cusco: Proyección 2015-2060 de afluencia de pasajeros (Vía Aérea) ..................19

Figura 4. Gasto diario del turista extranjero por país de procedencia .................................26

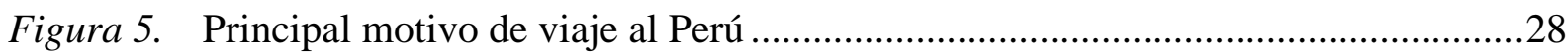

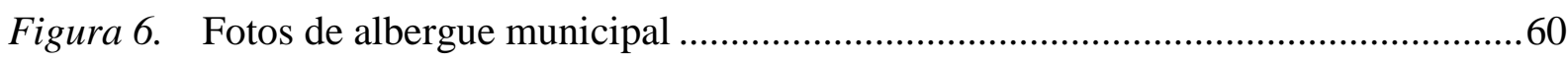

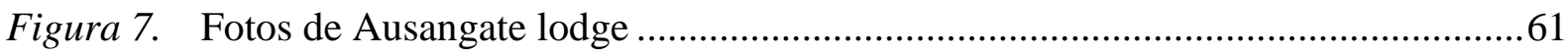

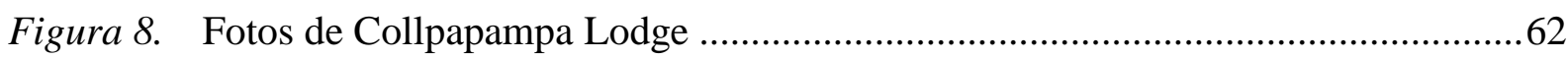

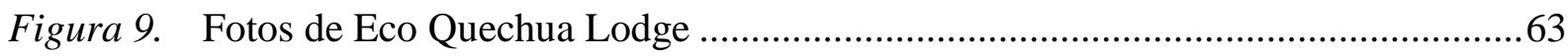

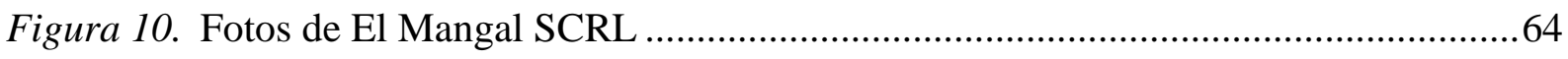

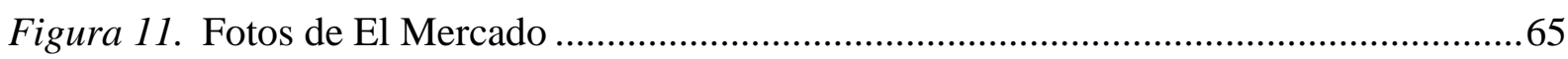

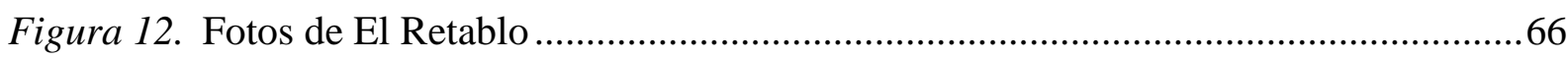

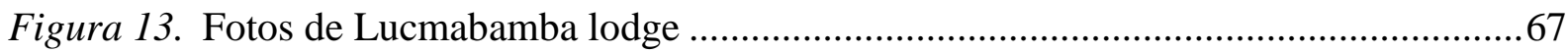

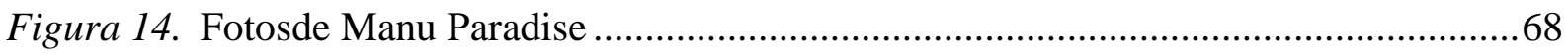

Figura 15. Fotos de Pariwana Cusco Hostel....................................................................69

Figura 16. Regresión lineal para proyección de turistas que ingresarán al Cusco los años

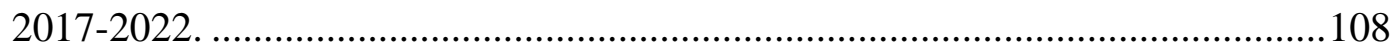

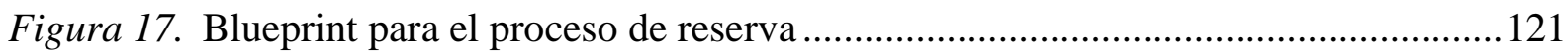

Figura 18. Blueprint para check in -Rooming -Porter.................................................123

Figura 19. Blueprint para check out - Porter. …....................................................... 125

Figura 20. Blueprint para restaurante ........................................................................ 127

Figura 21. Blueprint para house keeping ................................................................ 129 
Figura 22. Representación de la habitación, las fechas representan que se debe circular por todos los ambientes para identificar detalles.

Figura 23. Ciclo de Compras. Recuperado de (Schroeder, 2011)

Figura 24. Opción: "Maras 1"

Figura 25. Opción: "Maras 2"

Figura 26. Opción: "Moray"

Figura 27. Plano planta baja Ecolodge "Kachi Raqay"

Figura 28. Plano planta alta Ecolodge "Kachi Raqay"....

Figura 29. Cuadro De Mando Integral

Figura 30. Tipo de habitaciones Ecolodge Kachi Raqay

Figura 31. Tipo de habitaciones Ecolodge Kachi Raqay

Figura 32. Baño habitación Estándar

Figura 33. Recepción

Figura 34. Restaurant/Bar

Figura 35. Servicios higiénicos

Figura 36. branding

Figura 37. Formas del logotipo

Figura 38. Íconos naranja

Figura 39. Ícono verde

Figura 40. Ícono café oscuro

Figura 41. Tipografía

Figura 42. Diagrama de flujo proceso de recepción sin intermediario.....

Figura 43. Diagrama de flujo proceso de recepción con intermediario

Figura 44. Diagrama de atención al cliente vía telefónica. 249 


\section{Introducción}

En la última década el turismo en el Perú ha evolucionado de manera significativa, posicionándolo como el segundo país de la región donde más gastan los turistas, identificando que el principal motivo de viaje es por vacaciones y este tipo de turista busca alternativas relajantes que difieran de su vida cotidiana. De estos hechos surgen la idea de realizar un plan de negocio direccionado al turismo. Al ser el Cusco la segunda ciudad más visitada después de Lima, fue que se determinó desarrollar el proyecto en esa zona, adicionalmente porque una de las integrantes del equipo es del Cusco y es especialista en Administración Hotelera.

Por lo expuesto anteriormente, el presente plan de negocios tiene como objetivo determinar la viabilidad económica de crear un albergue para turismo vivencial en el poblado de Maras (Cusco, Perú).

El plan de negocio contiene detalladamente la siguiente información: En el primer capítulo se presentan los antecedentes del sector turístico en el Perú y las oportunidades que brinda el mercado para justificar las razones por las que se considera que el proyecto tendría aceptación. Además, se especifican los objetivos del proyecto.

El segundo capítulo, se basa en la estructura económica del sector, donde se plantean el análisis PESTLE junto con las Fuerzas de Porter para identificar cuáles serían las oportunidades y amenazas con las que se enfrenta el proyecto de un albergue vivencial. 
En el tercer capítulo de estudio de mercado, se presenta el plan para ejecutar el estudio, identificando los objetivos que se quieren obtener y con el uso de herramientas específicas para conseguir la información. Interpretación de resultados que permiten tener una visión más clara hacia dónde y a quienes se debe direccionar el proyecto para tener mayor aceptación.

El cuarto capítulo de proyección del merado objetivo se cuantifica la demanda existente para así determinar el pronóstico de ventas del Ecolodge "Kachi Raqay” en el poblado de Maras, Cusco. Finalmente se presentan los aspectos críticos que podrían impactar a dicho pronóstico de ventas.

En el quinto capítulo de estudio de ingeniería del proyecto, se presenta el modelamiento y procesos productivos del Ecolodge "Kachi Raqay"; se determina el tamaño de todo el proyecto. Dentro del estudio de localización se distingue la ubicación geográfica real del proyecto. Distribución y costos de construcción del Ecolodge. Asímismo se presentan las consideraciones legales para que el proyecto se implemente.

El sexto capítulo de aspectos organizacionales se elabora la visión, misión y principios que transformaran el proyecto en una realidad. Se formulan las estrategias, el diseño de la estructura organizacional y perfil de los puestos (remuneración y políticas) del Ecolodge "Kachi Raqay".

En el séptimo capítulo de plan de marketing se escogen las estrategias de segmentación y posicionamiento del proyecto y se plantean las consideraciones a tomar en cuenta para crear valor al cliente a través del marketing mix. 
En el octavo capítulo de estudio de inversiones y financiamiento se describen la composición de las inversiones (activos fijos, intangibles y capital de trabajo) y la estructura del financiamiento.

El noveno capítulo de estudio de ingresos y costos describe de dónde se obtienen los ingresos, por la venta y servicios que se produzcan en el Ecolodge "Kachi Raqay" al igual que los costos y gastos en los que se incurren.

En el décimo capítulo de estados financieros proyectados se presenta el análisis y descripción del estado de resultados y flujos de caja proyectado; asimismo se hace el cálculo de la perpetuidad y se presenta el estado de situación financiera para el Ecolodge "Kachi Raqay".

Por último, en el décimo primer capítulo de evaluación económica financiera se describen el cálculo y determinación de tasa de descuento, los indicadores de rentabilidad (VANE y TIRE); así como los análisis de punto de equilibrio, sensibilidad y mitigación para que el proyecto necesita para todos los escenarios.

Este plan de negocios finaliza con las conclusiones y recomendaciones obtenidas con el análisis del mercado y resultados económicos para realizar el Ecolodge "Kachi Raqay” en el poblado de Maras (Cusco, Perú). 


\section{Agradecimientos}

“Gracias a mi familia por su constante apoyo. A mi esposo Nate por motivarme siempre a seguir adelante con el proyecto y no permitir que me dé por vencida estando lejos, gracias a mi hija Luciana por soportar mis ratos de mal humor y cansancio durante los años de estudio y elaboración del proyecto.

Gracias a mi grupo de amigos maravillosos Marco, Denisse y Carmen, que me motivaron a terminar el proyecto y no darme por vencida. Finalmente, gracias a nuestra magnífica asesora Patty, quien siempre recibió nuestras consultas con una sonrisa y buen humor, haciendo posible que no perdiéramos el entusiasmo y las ganas; y quien además nos brindó su amistad sincera."

\section{Verónica Cecilia Indo Vela}

"Gracias a mi familia por el apoyo constante, durante el tiempo de estudios y de elaboración de la tesis. Mis papas Eugenio y Miriam, a mi hermana Pilar, esposo Juan Carlos y a mi hijo César André, por ser mi motivo principal para terminar lo que inicié. Gran equipo de profesionales con los que tuve el agrado de realizar el proyecto, son unos capos, Marquito, Camu, Verito y por supuesto a nuestra asesora Patty que siempre supo corregir y motivar para alcanzar esta gran meta."

Denisse Elena Olivos Pérez 
“Gracias a mis papás, Miguel y Carmiña por su constante apoyo, tanto en los estudios previos cómo durante la elaboración de esta tesis. A mis hermanos Carlos y Moira por su eterna presencia. A mis tíos Nelson, Nancy y Mecha, por inculcarme el amor por lo académico. A mi esposa Paty; gracias Gata por el aliento y la paciencia ...tranquis, iya se acabó! A mis hijas Cata y Maca, todavía no existían antes de esto y espero que me acompañen en la graduación. Finalmente, a mi super equipo de profesionales superpoderosas; Denisa, Vero, Camu, y super Paty, gracias por ser parte de esta maravillosa odisea, i las quiero y respeto un montón!!”

\section{Marco Antonio Villena Heredia}

“Agradezco a mis padres Fredi y Carmen, mis hermanos Franco y Cinthia, a mi asesora Patrícia y a mi equipo y amigos de tesis Marco, Vero y Denisse. Por qué en ellos me apoyo e impulso. A todos mi admiración y cariño."

Carmen Amalia Villagarcía Gonzales 


\section{Capítulo I: Generalidades}

\subsection{Antecedentes}

El turismo representa para nuestro país el principal sector no tradicional generador de divisas que aportó alrededor del 3,9\% del PBI y generó más de un millón de empleos en el 2015, así lo expresa la Cuenta Satélite de Turismo (CST) en el reporte anual del Plan Estratégico Nacional de Turismo 2025 (PENTUR) (MINCETUR, 2016, pág. 29). Entre los años 1990 al 2015, el turismo en el Perú ha evolucionado de manera significativa, luego de superar y renacer de la etapa del terrorismo. Jorge Jochamowitz presidente de CANATUR en el periodo 2014-2016 señaló que en los 90s el Perú recibía entre 450000 o medio millón de turistas, y que a inicios del año 2000 el Perú ya recibía un millón y medio de turistas y en la actualidad se superan los tres millones (Vasquez, 2015, págs. 16-17). Este crecimiento también se ve reflejado en el incremento del tráfico aéreo, de acuerdo con la Dirección Regional de comercio exterior y turismo (DIRCETUR) el Cusco registró un incremento en el arribo de vuelos nacionales e internacionales al Aeropuerto internacional Velazco Astete entre los años 2012-2015. En el 2012 se registró el arribo de 2,357,062 vuelos en total; en el 2013 2,532,869; en el 2014 de 2,747,098; y en el 2015 fueron 2,881,677, creciendo en promedio un $4.9 \%$ en el último año. (DIRCETUR, 2016, pág. 13).

Con el propósito de impulsar la actividad turística se creó PromPerú en el año 1995, sobre la base del Foptur, del mismo modo se creó el fondo de promoción de turismo receptivo, para desarrollar este tipo turismo. Gracias a ello, se ha permitido que el Perú ahora cuente con recursos importante para la promoción del turismo (Vasquez, 2015, págs. 16-17). 
Según el Ministerio de Comercio Exterior y Turismo (MINCETUR), entre los años 2011 al 2016 se registró un crecimiento en el turismo receptivo peruano de 40\%; asimismo se registró un crecimiento en la llegada de turistas extranjeros al Perú en 7.1\% durante el primer trimestre del 2016, periodo en el que arribaron 61,916 visitantes más que en el mismo período del 2015 (Andina, 2016). De acuerdo con el último reporte de PromPerú sobre el Perfil del Turista Extranjero 2015, en ese año el principal motivo de viaje de los turistas que visitaron el Perú fue por vacaciones (64\%), registrando un tiempo de permanencia promedio de 9 noches y un gasto promedio de US\$ 1,108 por noche; siendo Chile el país que genera mayor flujo de vacacionistas al Perú con un total 951,000 turistas (31\%), seguido de Los Estados Unidos con un total de 490,000 turista (16\%), generando divisas de US\$ 335 millones y US\$ 707 millones respectivamente; adicionalmente se registró que el departamento del Cusco es el más visitado (38\%) después de la capital Lima (72\%), debido a que la motivación de estos vacacionistas es visitar Machu Picchu (PromPerú, 2016, págs. $8,9,15)$.

Machu Picchu fue declarado por la UNESCO como patrimonio de la Humanidad en 1983 y actualmente es considerada una de las siete maravillas del mundo moderno. El número de visitantes nacionales y extranjeros a este monumento arqueológico incrementa año tras año. En el 2014 se registró un flujo de 1,079,350 visitantes; en el 2015 de 1,221,660; y en el 2016 de 1,344,119, creciendo en 10\% en este último año (DIRCETUR, 2016, pág. 118). Dada esta afluencia turística, los gestores turísticos en Cusco han desarrollado paquetes, que incluyen tours o actividades para diversificar la industria, añadiendo experiencias a los circuitos tradicionales dependiendo de los gustos y las preferencias del mercado, así por ejemplo se oferta el turismo de aventura, gastronómico, místico, entre otros. 
Para afrontar esta demanda se necesita capacidad hotelera instalada. En Cusco existen aproximadamente 1,740 establecimientos de hospedaje registrados por la Dirección Regional de Comercio Exterior y Turismo Cusco (DIRCETUR, 2016, pág. 7). La mayoría de los hospedajes se encuentran en el centro histórico de la ciudad (a $3400 \mathrm{msnm}$ ) y en el poblado de Urubamba (a $2792 \mathrm{msnm}$ ). Siendo este último poblado muy favorable geográficamente debido a que brinda a los turistas las condiciones necesarias para poder adaptar su organismo a la falta de oxígeno por la localización sobre el nivel del mar. Según el informe del Perfil del Vacacionista Nacional los visitantes en su mayoría eligieron dentro de las opciones de hospedaje pagado Hoteles de entre 1-2 estrellas (18\%) (PromPerú, 2016, pág. 21); y según el informe del Perfil del Turista Extranjero el 48\% indicó como preferencia Hoteles de entre 1-2 estrellas también (PromPerú, 2016, págs. 8-9).

El turismo es un fenómeno que produce cambios significativos tanto en las poblaciones receptoras como en los visitantes. La circulación de poblaciones propiciada por esta industria tiende a romper fronteras culturales, generar espacios de encuentro (Chaparro Ortiz de Zevallos, 2008). Resulta importante involucrar a las comunidades en las actividades y beneficios que genera el turismo para contribuir a su desarrollo. El Plan Estratégico Nacional de Turismo 2025 (PENTUR) contempla las tendencias claves en la demanda por viajes y turismo, en la que destaca la búsqueda de autenticidad, porque hoy en día los viajeros demandan nuevos destinos, culturas, gastronomía, viajes temáticos y deseo por experiencias que sean auténticas, aunadas con el confort, calidad y altos estándares de servicio (MINCETUR, 2016, pág. 26).

En esta búsqueda de autenticidad nacen nuevas formas de turismo no convencional, denominado Turismo Rural comunitario, que PromPerú define como: 
Una especie de encuentro de culturas en el marco de una visita al lugar de residencia de una familia o comunidad, donde se comparte por horas o días el estilo de vida del poblador. Se puede desarrollar en zonas rurales como urbanas, alejándose principalmente del turismo masivo o convencional. Tipo de turismo que se caracteriza por ser sostenible y en algunos casos solidario (pág. 6).

Adicionalmente se desprenden tres variantes a este Turismo Rural Comunitario, que serían (Romero Córdova, 2016):

- Agroturismo (Integra de manera sostenible las actividades productivas rurales administradas por productores locales);

- Ecoturismo (La Sociedad Internacional de Turismo conceptualiza al Ecoturismo como "un viaje responsable a áreas naturales que conserva el ambiente valora la cultura y apoya el desarrollo sostenible de las poblaciones locales generando un mínimo impacto negativo"); y

- Turismo Vivencial (turismo generado solamente por el interés hacia una o varias comunidades campesinas y/o nativas, pueblos Afro peruanos y Pueblos indígenas u originarios, los fines pueden ser culturales, educativos y vivenciales).

En la actualidad estas prácticas de turismo rural comunitario se desarrollan sobre todo en los departamentos ubicados en la amazonia, la zona Sur en Taquile-Puno y Cusco, por la gran afluencia de turistas. La problemática de este tipo de turismo yace en su mala gestión, 
porque muchas veces no contempla el impacto social en la comunidad receptora, como en los visitantes.

Anahi Chaparro, Antropóloga de la Pontificia Universidad Católica del Perú, en el año 2008, estudió el caso del grupo de nativos Yagua que fue persuadido de asentarse en los terrenos de una agencia de viajes en la cercanía de Iquitos, con el exclusivo propósito de que los turistas que iban a conocer la selva amazónica tengan la experiencia de contacto con un grupo nativo de esta región y con su estilo de vida. En este caso se cuestionó la autenticidad de las expresiones culturales, se colocó a los nativos en posición de objetos donde se usufructuaban sus cuerpos por la empresa gestora, pues los "nativos" debían portar el atuendo tradicional hasta que los turistas se retiraban. En cuanto a los turistas, ellos se sentían engañados y estafados (Chaparro Ortiz de Zevallos, 2008). Otro claro ejemplo de la mala gestión del turismo se puede apreciar en el caso de Taquile en Puno, que al tener muy poca población solo se ven beneficiados aquellos pobladores de un lado de la Isla que practican este turismo, creando diferencias sociales que no existían antes de estas prácticas. Por otro lado, el uso de sus expresiones culturales tradicionales corre el riesgo de ser usadas bajo una simple formalidad por la imposición autoritaria de líderes que actúan incentivados por intereses específicos (Alcantara, 2005).

Dado el impacto social que esta práctica turística puede generar, el MINCETUR protege e incentiva una mejor utilización y valoración del patrimonio natural, cultural y arquitectónico de las comunidades rurales mediante normativas contempladas en documentos como: "Lineamientos para el desarrollo del turismo rural comunitario en el Perú". El desarrollo del Turismo Rural se enmarca dentro del objetivo uno del Plan Estratégico Nacional de Turismo - PENTUR, como estrategia para la lucha contra la pobreza, ya que 
contribuye a diversificar la oferta turística nacional, a través de la promoción del desarrollo de productos turísticos en el ámbito rural, garantizando la participación de la comunidad local, la conservación de los recursos naturales y culturales, así como la generación de empleo y mejora de ingresos, teniendo como eje fundamental y base sólida la capacitación al prestador del servicio turístico en el ámbito rural (MINCETUR, 2016, pág. 58).

El Cusco al ser el principal destino de los vacacionistas nacionales y extranjeros, es también considerado para el desarrollo del turismo rural comunitario. En la actualidad el MINCETUR y PromPerú tienen como destino para este tipo de turismo el poblado de Maras ubicado en la provincia de Urubamba, Cusco (Servicio Holandés de coperación al Desarrollo - SNV, 2016).

En el poblado de Maras se encuentran los restos arqueológicos de Moray y las famosas salineras de Maras, ambos son atractivos que conforman el circuito valle sagrado siendo foco del turismo cultural.

El equipo de trabajo consideró que dadas las condiciones de la ubicación Maras y sus prácticas culturales, es un potencial recurso turístico en pleno crecimiento. Por lo que se propone desarrollar y poner en marcha un hospedaje categorizado como albergue, con servicios y características vivenciales, creando así un producto turístico capaz de ir de la mano del plan nacional de turismo y a su vez ser un negocio rentable para los socios que lo conforman y sin dejar de lado a la comunidad. 


\subsection{Oportunidad}

El Perú es el segundo país en la región donde más gastan los turistas extranjeros, el promedio de gasto de acuerdo con el Perfil del Turista Extranjero 2015 de PromPerú es de US\$ 994 y específicamente el turista vacacionista extranjero es de US\$ 1108 (PromPerú, 2016, págs. 8,9).

El régimen cambiario de nuestro país dispone, de acuerdo al Banco Central de Reservas, la libre circulación de divisas, a diferencia de otros países latinoamericanos como Venezuela y anteriormente Argentina, lo que significa que los turistas que visitan el Perú tienen control de su moneda de manera transparente, para considerar la relación preciocalidad, de los servicios adquiridos.

El turismo vacacional busca alternativas relajantes que difieran de su vida cotidiana, es así que las opciones a campo abierto con paisajes campestres y noches estrelladas generan un atractivo agregado a la hora de buscar lugares de descanso.

El poblado de Maras se encuentra a 20 kilómetros de distancia de la estación ferroviaria de Ollantaytambo, de donde parten los trenes al santuario histórico de Machu Picchu, (atractivo que genera mayor flujo de turistas en Cusco). Las distancias entre la estación de Ollantaytambo y Aguas Calientes (Machu Picchu) es de 26 kilómetros que en tren equivalen a 30 minutos de recorrido. Dados los horarios establecidos por las empresas ferroviarias, la cercanía a dicha estación representa una oportunidad para los visitantes, pues de iniciar el recorrido desde la ciudad de Cusco representan un recorrido de 94 kilómetros que en tren equivalen a 3 horas de viaje (ver Figura 1). 


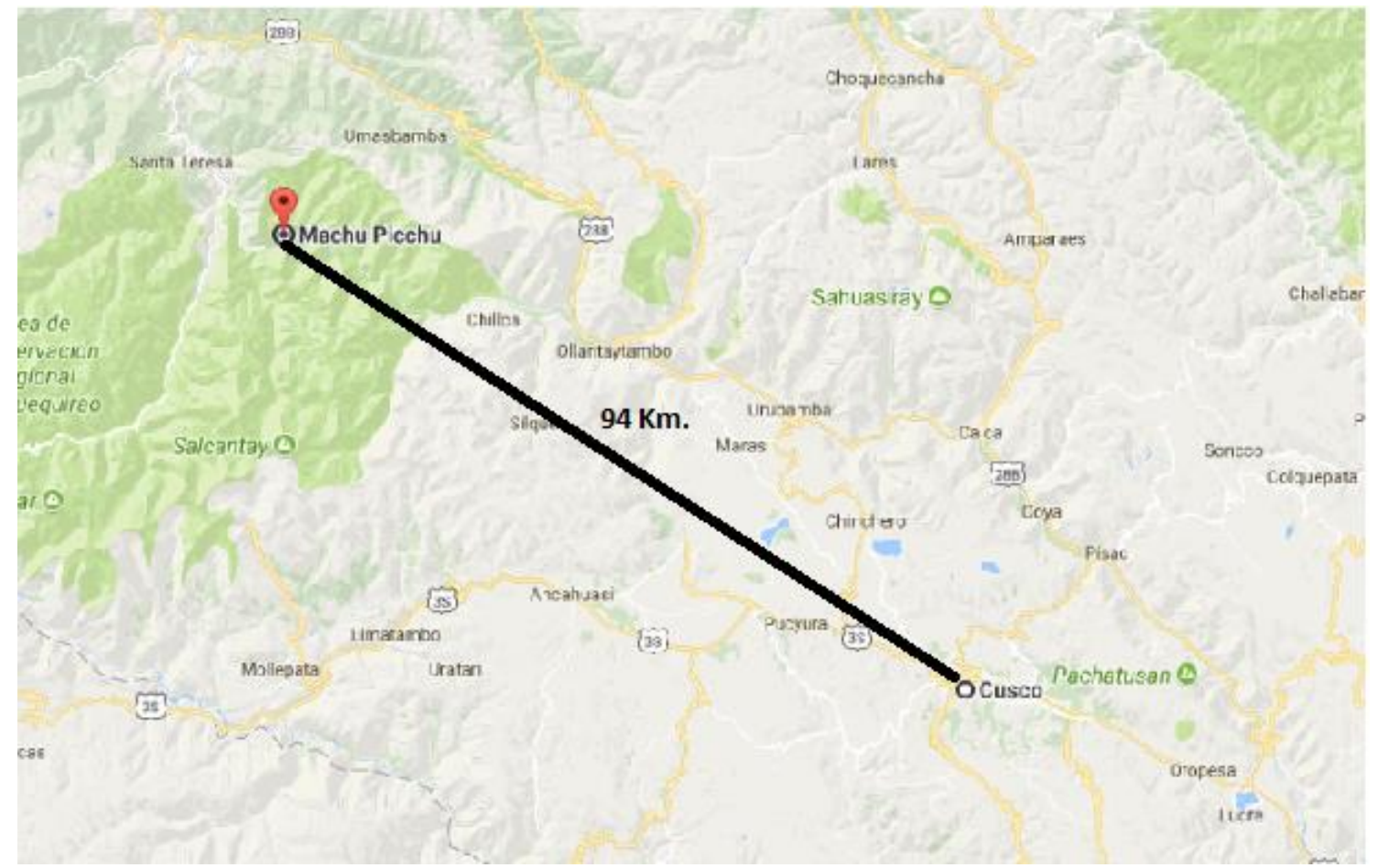

Figura 1. Mapa de distancia Cusco-Machu Picchu. Imagen tomada del GoopleMap.

La cercanía del poblado de Maras a los restos arqueológicos de Moray, incrementan el valor agregado de visitar la zona debido a ser reconocido como un laboratorio agrícola y a su vez como un punto energético para realizar prácticas espirituales.

Gracias a la actual tendencia gastronómica, el Perú es uno de los principales destinos culinarios por su sazón y sus especies, entre las cuales se encuentra la sal de Maras, ingrediente que despierta curiosidad por la zona productora (Kachi Raqay, nombre en quechua de las salineras de Maras).

Actualmente, los turistas que visitan países en vías de desarrollo valoran el turismo sostenible al momento de elegir los destinos turísticos. Según las tendencias de la Organización Mundial del Turismo (OMT): 
Se enfatiza el potencial del turismo para el desarrollo de todos los países en el marco de los Objetivos de Desarrollo Sostenible y la necesidad de continuar avanzando hacia un sector más sostenible que redunde en el beneficio de las comunidades locales, y la preservación de los valores culturales y naturales. (2017)

Una de las integrantes del equipo es natural de la ciudad de Cusco, licenciada en hotelería y turismo, con más de 5 años de experiencia en el rubro. Oportunidad que le brinda al equipo las facilidades para acceder a información que se pueda considerar importante para el estudio.

\subsection{Justificación}

En el ámbito social, el plan de negocio propone una alternativa de ingresos al poblado de Maras, preservando su cultura y respetando tanto las costumbres como la dignidad de la población en sí.

Además, contribuye con su estudio a aquellos emprendedores interesados en la creación de establecimientos de turismo vivencial en la ciudad del Cusco.

En cuanto a conveniencia para el equipo, el presente plan de negocio justifica su importancia debido a que se pretende obtener el título de máster en ciencias empresariales de los integrantes. 


\subsection{Alcances}

El presente plan de negocio busca comprobar la factibilidad de hacer desarrollar y poner en marcha un hotel con la experiencia de turismo vivencial en el poblado de Maras, en la provincia de Urubamba, en el departamento de Cusco, Perú.

El objeto de estudio serán los turistas vacacionales extranjeros que visiten la ciudad de Cusco.

Este estudio se inicia en el mes de diciembre de 2016, y se planea culminar para el último semestre de 2017.

\subsection{Limitaciones}

Las restricciones con las que cuenta el equipo para realizar dicho proyecto son:

- Condición muestral: Para que la muestra sea representativa y real, se requiere información de un grupo del mercado con difícil acceso porque son personas que están de paso y con baja disposición en tiempo para responder encuestas y/o entrevistas.

- Limitaciones de tiempo: El plazo de tiempo para realizar el proyecto es de un año, tiempo que limita realizar un estudio exhaustivo en el segmento de mercado objetivo.

- Limitaciones geográficas: Por la ubicación elegida, los plazos de tiempo para realizar el estudio y costos de traslado que el estudio implique, se tiene presencia limitada de todos los integrantes del equipo en el poblado de Maras, Cusco. 


\subsection{Objetivos generales}

- Elaborar un plan de negocio durante el 2017, para determinar la viabilidad económica de la creación de un albergue para turismo vivencial en el poblado de Maras (Cusco, Perú)

\subsection{Objetivos específicos.}

- Identificar y determinar el mercado objetivo para realizar un albergue vivencial en el poblado de Maras para el último semestre de 2017.

- Identificar el mercado potencial efectivo, la competencia, proveedores, precios y productos que permitan la viabilidad de un albergue para turismo vivencial en el poblado de Maras (Cusco, Perú) para el último semestre de 2017.

- Desarrollar hasta marzo de 2017 el plan de marketing para un albergue vivencial en el poblado de Maras.

- Determinar la estrategia de operaciones del negocio, y la estructura organizacional a junio de 2017.

- Formular una estrategia financiera del proyecto que permita crear valor por medio de la venta del servicio hotelero vivencial de tal manera que los resultados financieros sean iguales o superiores al costo de oportunidad de los accionistas. 


\section{Capítulo II: Estructura Económica del Sector}

\subsection{Análisis PESTLE}

\subsubsection{Análisis del entorno político y lega.}

La industria turística está regida actualmente por el Ministerio de Comercio Exterior y Turismo, específicamente por el Vice ministro de Turismo. Este ente estatal es el encargado de formular, proponer, dirigir, ejecutar y evaluar la Política Nacional de Turismo y Artesanía (MINCETUR - Reglamento, 2016, pág. 1). En tanto PromPerú es el ente nacional encargado de formular, aprobar, ejecutar y evaluar las estrategias y planes de promoción de bienes y servicios exportables, así como de turismo interno y receptivo (PromPerú - Institucional, 2017).

En tanto cada región cuenta con una dirección de turismo (DIRCETUR), como entes encargados de proponer y ejecutar la política regional de la actividad turística.

El marco normativo que regula la actividad turística está compuesto por las siguientes leyes (MINCETUR - NORMATIVIDAD, 2016):

- Ley No 29408, Ley general del Turismo: “Contiene el marco legal para el desarrollo y la regulación de la actividad turística, los principios básicos de la actividad turística y los objetivos de la política estatal, declarando al MINCETUR como el ente rector a nivel nacional competente en materia turística". 
- Ley No 27790, Ley de organización y funciones de MINCETUR: “(...) En materia de turismo promueve, orienta y regula la actividad turística, con el fin de impulsar su desarrollo sostenible, incluyendo la promoción, orientación y regulación de la artesanía”. - Ley N 27889, Ley que crea el Fondo y el Impuesto Extraordinario para la Promoción y Desarrollo Turístico Nacional y su Reglamento plan anual de promoción y desarrollo turístico nacional: "se crea el fondo con la finalidad de financiar las actividades y proyectos destinados a la promoción y desarrollo del turismo nacional”.

El segmento Hotelero en el Perú, esta normado por el decreto supremo No 001-2015MINCETUR, denominado reglamento de establecimientos de hospedaje, este reglamento derogo al decreto supremo 029-2004-MINCETUR, dados los cambios en diversas normas, adecuando este nuevo decreto al marco legal existente al 2015. Dentro de los principales cambios de esta nueva normativa, se actualizo la clasificación, categorización, operación y supervisión de los servicios de hospedaje. Este decreto homologa sus disposiciones con la norma técnica $\mathrm{N}^{\mathrm{o}} 30$ Hospedaje, del decreto 006-2014- Vivienda, que actualizo los requisitos de infraestructura para los centros de hospedaje de acuerdo con su clasificación (MINCETUR - NORMATIVIDAD, 2016).

El Gobierno Peruano cuenta con el Plan estratégico Nacional de turismo, PENTUR 2012-2021 "consolidando el turismo sostenible" emitido por el MINCETUR, con la finalidad de impulsar la competitividad del turismo y de proponer una metodología al 2021 para desarrollar planes de acción para gobiernos regionales y locales. A la fecha se cuenta con un informe más actualizado denominado PENTUR 2025 "Turismo con Futuro". 
Se puede observar que existen organismos que promueven el turismo y lo regulan, el estado tiene una política expansiva en este sentido. (Oportunidad)

Con la nueva clasificación de hospedajes, a partir de la publicación del nuevo decreto, ya no es posible hacer uso de la categorización denominada "Ecolodge", definida en el derogado decreto ley 029-2004-MINCETUR como: “aquellos establecimientos de hospedaje cuyas actividades se desarrollan en espacios naturales, cumpliendo los principios del Ecoturismo". A pesar de que la ubicación del proyecto y que esta categoría sea más oportuna logrando un mejor posicionamiento, debido a la relación que brinda el término "lodge" y el turismo vivencial (Amenaza).

Por otro lado, cabe mencionar que el derogado reglamento de hospedaje, no se ajustaba a las necesidades reales del sector como a la normatividad respecto a la infraestructura de los centros de hospedaje, por ejemplo, exigía dentro de su reglamento el uso de cocheras, no siendo viable en el centro histórico del cusco dada la categorización de casonas patrimoniales de la ciudad; así, al definirse la nueva norma técnica, los hospedajes pueden cumplir con lo estipulado por el nuevo reglamento. (Oportunidad)

Dentro de la normatividad en la industria turística, se puede mencionar que, en las estrategias planteadas por el plan nacional de turismo, se toma al turismo rural comunitario como una de las principales oportunidades para el país. (Oportunidad)

Para incentivar el turismo receptor, el gobierno peruano ha creado los beneficios tributarios que dejan inafectados del impuesto general a la venta (IGV) a los clientes extranjeros (sujetos no domiciliados) en los servicios de alojamiento y alimentación (dentro 
del alojamiento) según el decreto legislativo Nº 919 (Oportunidad). Para efectos de este beneficio, el sujeto no domiciliado debe haber adquirido estos servicios de forma individual o a través de un paquete turístico, por un periodo de permanencia no mayor de 60 días, requiriéndose la presentación del pasaporte correspondiente (MINCETUR NORMATIVIDAD, 2016).

Respecto al proceso legal y administrativo para la dotación de licencias, autorizaciones, etc. El congreso aprobó el proyecto de ley 4487-2014 que determina a MINCETUR la gestión de la Ventanilla Única de Turismo- VIT que establece que los actores del sector turismo puedan agilizar los trámites para el desarrollo de sus actividades (oportunidad).

Sera necesario también gestionar la licencia de funcionamiento con la municipalidad distrital de Maras, en cumplimiento a la ley $\mathrm{N}^{\circ}$ 28976, Ley del marco de licencias de funcionamiento. El registro único de contribuyentes en SUNAT en cumplimiento a la resolución de superintendencia N ${ }^{\circ}$ 210-2004-Sunat.

Dado que el proyecto también tiene relación con el manejo de alimentos, en cumplimiento a la ley general de la salud No 26842, Decreto Legislativo Nº62 Ley de inocuidad de Alimentos, se deberá cumplir con el reglamento sobre vigilancia y control sanitario de alimentos. Esta Ley define como inocuo:

Todo alimento que sea calificado para el consumo humano por la autoridad sanitaria competente y no cause daño al consumidor cuando se prepare y/o consuma de acuerdo con el uso a que se destina. (Congreso del Perú, 28) 
Debido a la elección del nuevo periodo de gobierno del 2016, lo variable de las propuestas y lo volátil del ambiente político y social que se generan en los diferentes gremios, se prevé el freno de inversiones en la industria turística a causa de la incertidumbre en las nuevas políticas económicas, sociales, el tipo de cambio, la seguridad, etc. (amenaza)

\subsubsection{Análisis del entorno económico.}

\subsubsection{Situación económica actual del Perú.}

Según el Instituto Nacional de Estadística e Informática (INEI), en el 2015 el Perú cerro con un crecimiento del PBI del 2.7\% y el 2016 con 3.9\% (Diario Gestión, 2017, págs. 8-9). El Fondo Monetario Internacional en sus expectativas económicas manifestó que el Perú podría alcanzar un crecimiento de $3.5 \%$ en el 2017, siendo la segunda economía de mayor crecimiento en Sudamérica (Diario Gestión, 2017).

Según el economista Carlos Parodi, tres factores claves marcarán el ritmo de la economía peruana para el 2016-2017: la desaceleración económica de China, la caída de los precios de las materias primas y el petróleo y el aumento de la tasa de interés de los Estados Unidos. Estos tres factores, se mantuvieron durante el 2016, lo que contribuyó a la desaceleración que actualmente se vive en el Perú (Parodi, 2016). Esto podría contraer la demanda interna de turistas al poblado de Maras. (Amenaza)

Por otro lado, el riesgo país es el índice que mide el grado de "peligro" que entraña un país para las inversiones extranjeras (Diario Gestión, 2016, págs. 9,10). El Ministerio de Economía y Finanzas en su informe sobre "la situación del riesgo país" explica que existen 
tres tipos de factores que podrían incrementar este riesgo: (1) la política macroeconómica doméstica, como por ejemplo la tasa de interés internacional o la inflación, en un contexto internacional; (2) la situación política doméstica, por ejemplo la incertidumbre que se provoca durante el tiempo de elecciones; y (3) el riesgo en la región, cuando el Perú se ve afectado por eventos económicos que puedan afectar a países de la región como Argentina, Brasil o actualmente Venezuela (Ministerio de Economía y Finanzas, 2010).(Amenaza)

\subsubsection{El turismo en la economía peruana.}

En Perú, de acuerdo con el INEI, el sector "alojamiento y restaurantes" ha incrementado su participación en el PBI llegando a 3.2\% en el 2016 (Ver Tabla 1), lo cual favorece a la oportunidad antes mencionada sobre una política expansiva del gobierno a la promoción del turismo. A continuación, se muestra la evolución en el PBI de la actividad económica de "alojamiento y restaurantes" desde el 2012 al 2016 (último dato registrado):

Tabla 1.

Aporte de la actividad económica “Alojamiento y restaurantes al PBI peruano”20122016

\begin{tabular}{llllll}
\hline \multicolumn{1}{c}{ Año } & \multicolumn{1}{c}{2012} & \multicolumn{1}{c}{2013} & \multicolumn{1}{c}{2014} & \multicolumn{1}{c}{2015} & \multicolumn{1}{c}{2016} \\
\hline Producto Bruto Interno (*) & 431.199 .017 & 456.434 .784 & 467.180 .690 & 482.369 .679 & 501.097 .616 \\
Alojamiento y restaurantes $(*)$ & 13.413 .000 & 14.323 .000 & 15.066 .000 & 15.520 .000 & 15.924 .000 \\
Porcentaje que representa & 3,1 & 3,1 & 3,2 & 3,2 & 3,2
\end{tabular}

(*) Miles de soles Nota: INEI Producto Bruto Interno según Actividad Económica, extraído de la página web del INEI, recuperado de https://www.inei.gob.pe/estadisticas/indice-tematico/economia/ 


\subsubsection{Futuras inversiones en turismo.}

De acuerdo a Carlos Canales, presidente de la comisión de turismo de la Municipalidad de Lima, también presidente de Buró de convenciones y visitantes a Lima, las inversiones en hotelería tienen una proyección de crecimiento de US\$ 2,500 millones de dólares al 2021, de los cuales el 65\% del monto estará destinado a la construcción de hoteles de tres estrellas como también los inferiores a esta categoría, esto con capitales familiares (Diario Gestión, 2015), lo que quiere decir que la oferta en hospedaje se incrementará y generará un entorno más competitivo en el sector. (Amenaza)

Entre otras inversiones relacionadas, se encuentra el aeropuerto internacional de Chinchero-Cusco (AICC), ubicado en el distrito de Chinchero, provincia Urubamba, departamento de Cusco, Perú.

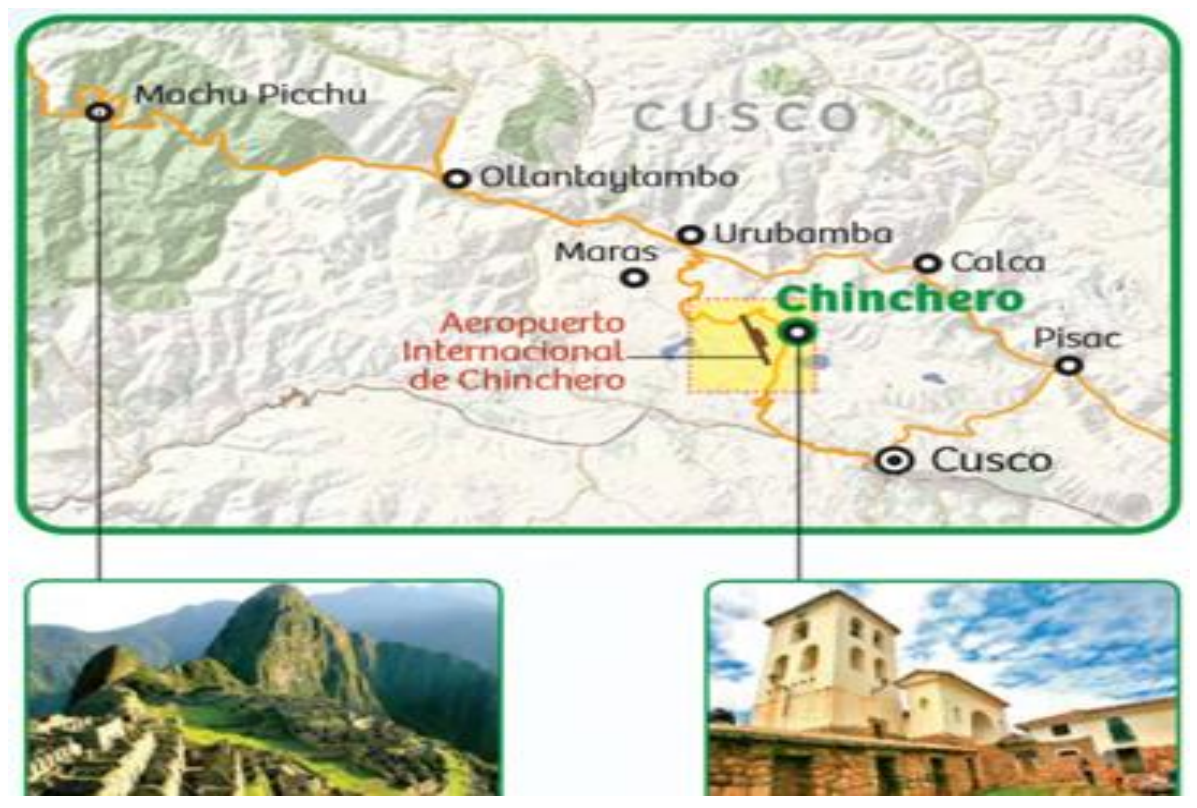

Figura 2. Ubicación geográfica. Tomado de "Aeropuerto internacional de chinchero (Cusco): El gran aeropuerto Inca" por Agencia de Promoción de la Inversión Privada (PROINVERSIÓN), 2014. Recuperado de http://www.proinversion.gob.pe/RepositorioAPS/0/1/JER/SALA_PRENSA_INFOGRAFIAS /infografia_chinchero_final.pdf 
En abril del 2014, el Consorcio KunturWasi integrado por la Corporación América S.A. (capitales argentinos) y Andino Investment Holding S.A. (capitales peruanos) ganó la buena Pro para el diseño, construcción, financiamiento, operación y mantenimiento del futuro Aeropuerto Internacional de Chinchero.

El actual aeropuerto internacional Velasco Astete tiene una extensión de 130 hectáreas y el futuro aeropuerto internacional de Chinchero tendrá una extensión de 357 hectáreas. Esta nueva infraestructura aeroportuaria ayudará a sostener el crecimiento del número de turistas locales e internacionales hacia la ciudad imperial, fomentando el desarrollo del departamento de Cusco y del país. Se prevé que en los siguientes años la cifra de la demanda de pasajeros irá en constante aumento (ProInversión, 2014).

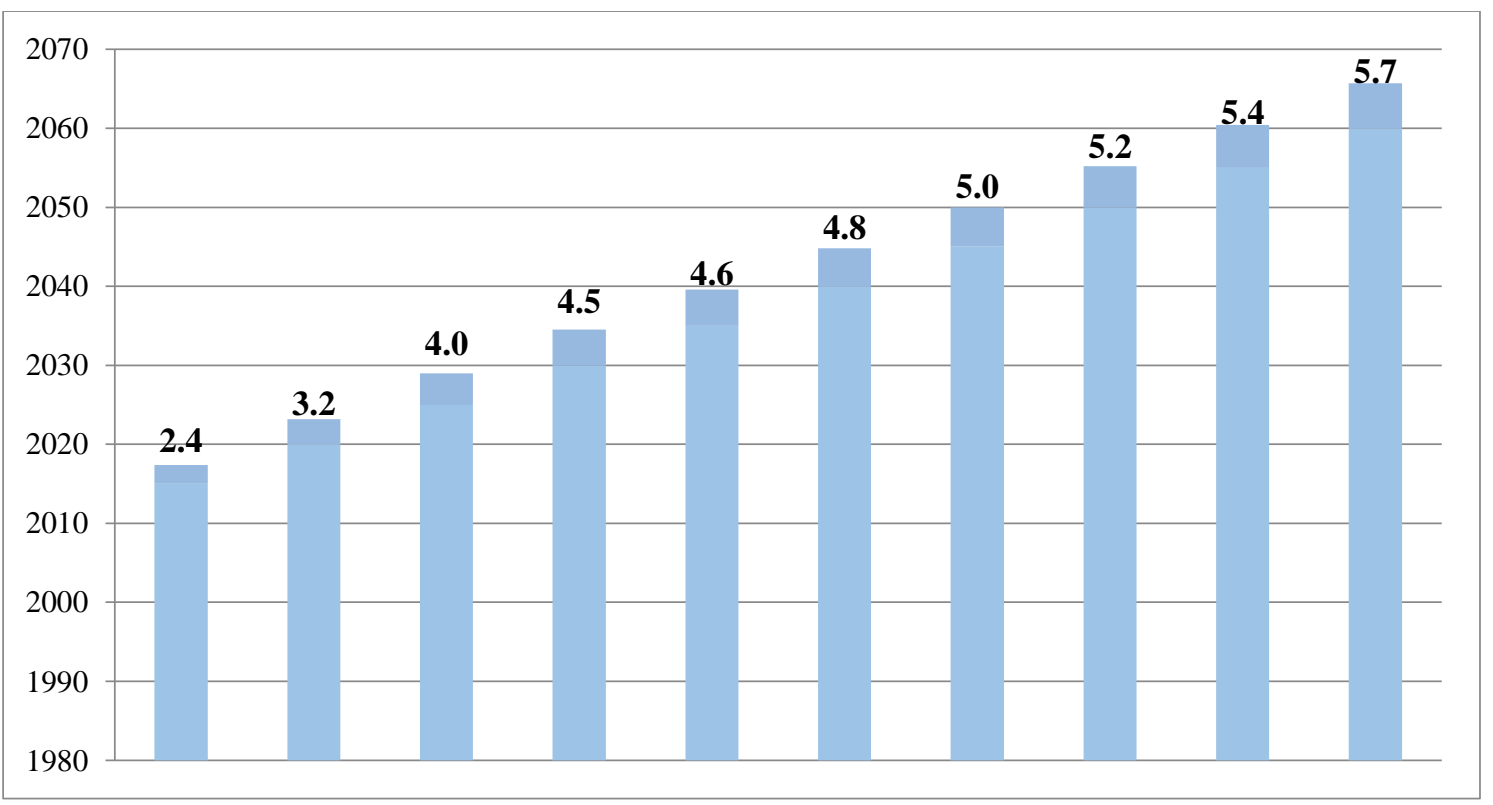

Figura 3. Cusco: Proyección 2015-2060 de afluencia de pasajeros (Vía Aérea) (expresado en millones). Tomado de "Aeropuerto internacional de chinchero (Cusco): El gran aeropuerto Inca” por Agencia de Promoción de la Inversión Privada (PROINVERSIÓN), 2014. Recuperado de http://www.proinversion.gob.pe/RepositorioAPS/0/1/JER/SALA_PRENSA_INFOGRAFIAS /infografia_chinchero_final.pdf 
Como se puede apreciar en la Figura 2 y 3. Dada la ubicación geográfica del aeropuerto y las proyecciones de pasajeros, al estar cerca del poblado de Maras se incrementará considerablemente la necesidad de hospedaje cercano. (Oportunidad)

\section{Tendencias}

El Plan Estratégico Nacional de turismo del Perú (PENTUR 2025) recoge las principales tendencias de viaje en el mercado internacional, de las cuales se destaca, en lo referido a lo económico:

- El crecimiento del turismo en economías emergentes.

Según las previsiones a largo plazo de la Organización Mundial de Turismo, incluidas en Turismo hacia el 2030, entre el 2010 y el 2030, las llegadas de turistas internacionales crecerán un 3,3\% cada año a nivel mundial, hasta alcanzar los 1800 millones. Se estima que para el año 2030, el 57\% de las llegadas internacionales serán registradas en países con economías emergentes. Luego de África (4,6\%), el mayor crecimiento se verá en el Asia y las regiones del Pacífico (4,2\%) hasta alcanzar los 535 millones de llegadas internacionales. Para el caso de las Américas, se estima que los arribos alcanzarán los 199 millones para el año 2020 y los 248 millones para el año 2030. Mientras que en Sudamérica se registrarán alrededor de 58 millones de llegadas de turistas internacionales, abarcando el 3,2\% de la cuota del mercado mundial para el 2030 (MINCETUR, 2016, pág. 20).

Teniendo en cuenta que el turismo está incrementando su volumen a nivel mundial y que existirán nuevos jugadores en la demanda de este mercado, el escenario para las inversiones en hotelería resulta atractivo, sobre todo en economías emergentes, como el Perú. (Oportunidad) 


\subsubsection{Principales fuentes de ingresos del poblado de Maras.}

La principal fuente de ingresos de la comunidad es la agricultura. El segundo lugar lo pelean la ganadería y el turismo, el cual ha ido en aumento en la última década y finalmente el comercio, principalmente de la sal producida en el salar (Montoya Pérez, 2013).

En el informe antes mencionado de María Paz Montoya detalla que, para desarrollar las actividades turísticas, la comunidad de Maras se ha puesto en contacto con ONGs, entre las cuales destaca la asociación Arariwa, quien se encarga actualmente de capacitar al poblado en temas de hospedaje y turismo. De la misma manera, la inversión privada apoya y promueve las actividades turísticas en el poblado, entre estas iniciativas se pueden citar a las empresas Lima Tours, Pacífico Tours, Sola tours entre otros, quienes ayudan también en el desarrollo de nuevas actividades.

De estas alianzas estratégicas, los resultados más tangibles en la actualidad son:

- Los pobladores están mejor capacitados y sensibilizados en temas turísticos. (Oportunidad)

- Los atractivos turísticos propios de la zona se están posicionando en el mercado y cada vez más hoteles ubicados en Cusco están ofreciendo el servicio de tour (amenaza); aunque todavía no hay hoteles que ofrezcan alojamiento en el mismo poblado. (Oportunidad)

Cóndor Travel, por ejemplo, con su proyecto Misminay, hace 5 años invierte en la capacitación de los pobladores, y en infraestructura en la localidad para brindar hospedaje de 
calidad, servicios culinarios, programas turísticos, programas de aventura y turismo vivencial con las comunidades dónde el turista se pone en contacto con la naturaleza y aprende el teñido de los tejidos, el arte culinario propio del distrito, ganado, agricultura, y sobretodo comparte la experiencia de convivir con la naturaleza. El objetivo del proyecto Misminay comprende (Wings Working Together, 2017):

a) Gestión y desarrollo de destinos de turismo con base en las comunidades.

b) Generación de proyectos sociales para mejorar ingresos y estilo de vida de las comunidades, seguridad en los alimentos y acceso a la educación, proyectos de agua saludable.

c) Asegurar el acceso al mercado y viabilidad de proyectos.

d) Garantizar turismo responsable y sostenible.

Todo esto ha generado un incremento el número de visitantes a la zona, así lo evidencia la Tabla 2, el flujo de llegada de visitantes nacionales y extranjeros al complejo arqueológico de Moray, ubicado a 7 km de Maras: (oportunidad)

Tabla 2.

Flujo de Llegada de Visitantes Nacionales y Extranjeros al Complejo Arqueológico de Moray

\begin{tabular}{cccccccccc}
\hline Año & \multicolumn{3}{c}{2013} & \multicolumn{3}{c}{2014} & \multicolumn{3}{c}{2015} \\
\hline Turista & Nacional & Extranjero & Total & Nacional & Extranjero & Total & Nacional & Extranjero & Total \\
Cifra & $19.430,0$ & $28.408,0$ & 47.838 & 25.887 & 60.833 & 86.720 & 87.979 & 171.537 & 259.516 \\
\hline
\end{tabular}

Nota: Tomado del Boletín estadístico de Turismo 2015 (pág. 140), por la DIRCETUR. Recuperado de http://www.dirceturcusco.gob.pe/wp-content/uploads/2017/07/BOLETINESTADISTICO-2015-Final.pdf 


\subsubsection{Análisis del entorno social.}

\subsubsection{El turismo en el mundo.}

Con respecto al comportamiento social del turista, costumbres y tendencias a nivel mundial, se rescata del Plan Estratégico Nacional de turismo del Perú (PENTUR 2012-2021) las principales tendencias de viaje:

\section{Motivos de viaje.}

Según estimaciones de la OMT: vacaciones, recreación u ocio son el principal y más dinámico motivador de viaje debido a que crece a una tasa anual de 3.3\%. Los viajes motivados por las visitas de amigos y parientes, salud, religión y otros propósitos mantendrán una importante influencia en la generación del flujo turístico en los próximos años, creciendo a una tasa ligeramente mayor (3.5\% anual). Al 2030, los viajes por motivo de vacaciones, recreación u ocio representarán el 54\%; seguido de visitas de amigos y parientes, salud, religión y otros propósitos con un 31\%. Por su parte, el 15\% restante realizará viajes por motivos profesionales y de negocios (MINCETUR, n.d., pág. 16).

\section{Búsqueda de autenticidad.}

De acuerdo con estudios realizados se ha identificado que hoy en día los viajeros están en la búsqueda de nuevos destinos, culturas, gastronomía, viajes temáticos y deseo por experiencias que sean auténticas, aunadas con el confort, calidad y altos estándares de servicio. En este sentido, el Perú, así como otros destinos en América del Sur, Europa 
Oriental y Medio Oriente, se verán favorecidos por esta tendencia (MINCETUR, n.d., pág. 16).

En la búsqueda por la autenticidad, según la revista digital española ABC Economía (Funes, 2015):

Los turistas muestran con mayor frecuencia preferencia por las experiencias que tengan que ver con el destino en cuestión. Vivir la vida de los "nativos", visitar sus lugares de ocio y adaptarse a su gastronomía, su folclore y su ritmo, es la nueva experiencia de "lujo". Tras años visitando hoteles impersonales y playas de foto, el cliente busca lo auténtico, lo diferente. (Oportunidad)

Otra tendencia que se remarca es la gastronomía. En este aspecto, "Perú el 2014 fue distinguido como el mejor destino culinario del mundo y "mejor site de turismo"" (El Comercio, 2014). (Oportunidad)

A todas estas tendencias se suma la del uso del celular. Según el portal turístico "Hosteltur":

Una de las tendencias que afectará a la industria turística en el 2015 es el binomio redes sociales-millennials, definiendo a la Generación Millennials como a los nacidos entre 1981 y 1995 . Ofrecer productos y servicios susceptibles de ser compartidos en internet, para mostrar a amigos y conocidos dónde están y qué están haciendo, es una táctica de marketing cada vez más extendida, sobre todo en los hoteles (Hosteltur, 2015). 
Esto está cambiando el comportamiento de la oferta de hospedaje; algunos establecimientos incluso aconsejan dónde hacerse los mejores selfies y convocan concursos animando a los clientes a compartir dichas fotografías, como el comportamiento de la demanda; los clientes están mejor informados, por lo cual están cambiando su comportamiento de consumo, fomentando el Boom de reservas anticipadas y fortaleciendo la publicidad boca a boca de otros clientes.

Esto supone un gran potencial para Perú, porque cuenta con auténticos y variados destinos en comparación con los resorts "enlatados” de algunas zonas del mundo. (Oportunidad)

\subsubsection{El perfil del turista que visita el Perú.}

Según el perfil del turista extranjero 2015, elaborado por PromPerú, el turista que visita el Perú tiene las siguientes características (PromPerú, 2016):

- Veintidós países generan el 89\% de las llegadas de turistas extranjeros. Los principales países emisores de turistas son chile (31\%) y Los Estados Unidos (16\%).

- $\quad$ El $63 \%$ del total de turistas es de género masculino y el $37 \%$ restante de género femenino.

- Según el estado civil del turista, el $60 \%$ declaró estar casado o conviviente.

- $\quad$ El 58\% reportaron tener ingresos familiares de US\$ 40,000.

- Los vacacionistas de nacionalidad japonesa fueron los que realizaron el mayor gasto diario (US\$255); seguido por vacacionistas australianos (US\$243), del Reino Unido (US\$ 171) e Italia (US\$ 151). 


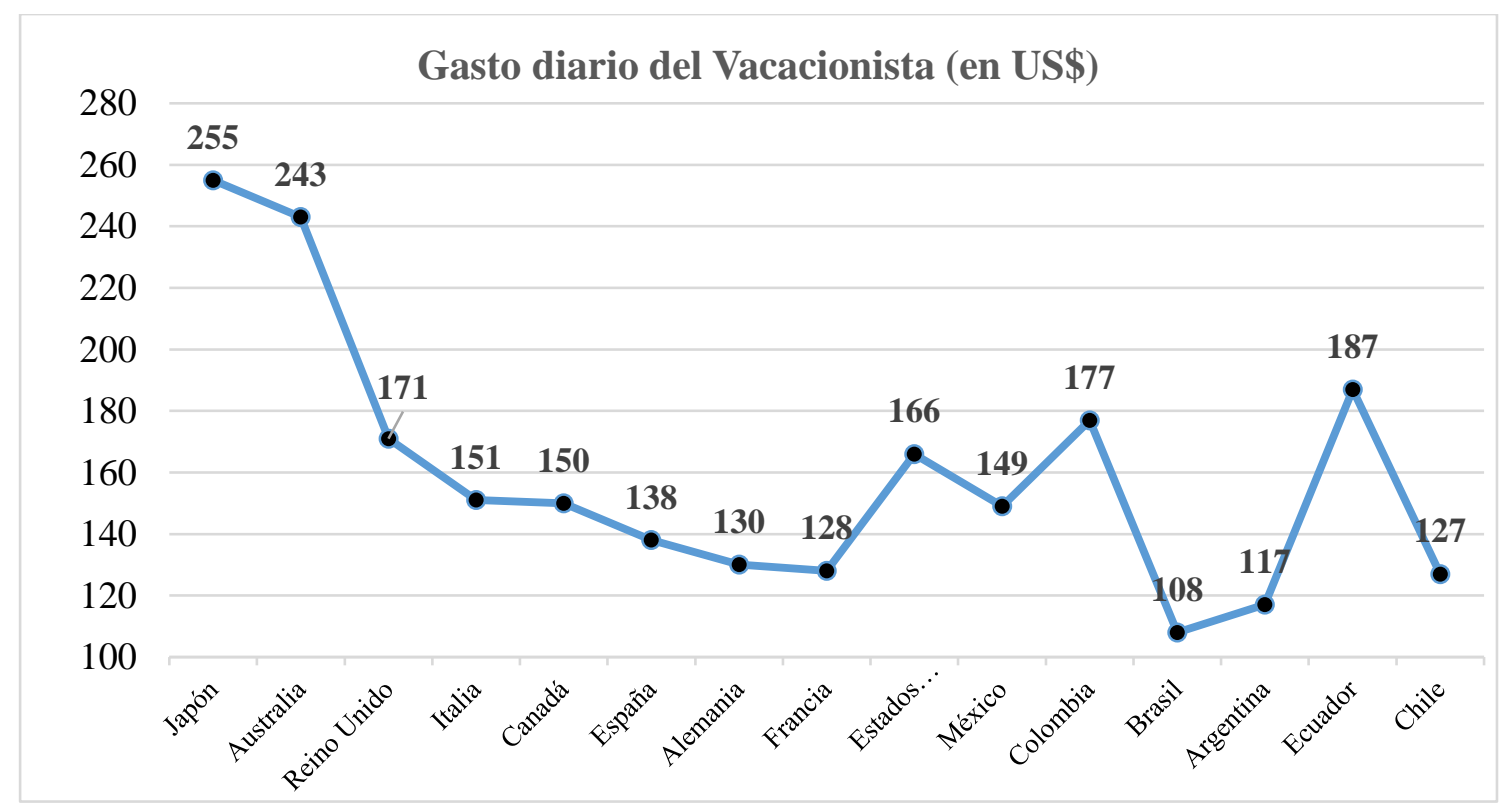

Figura 4. Gasto diario del turista extranjero por país de procedencia. Tomado de perfil del turista Extranjero 2015 por PROMPERU, 2016. Recuperado de http://www.promperu.gob.pe/TurismoIN/sitio/VisorDocumentos?titulo=Perfil\%20del\%20Tur ista\%20Extranjero\%202015\&url= /Uploads/perfiles_extranjeros/38/PERFIL\%20EXTRANJ ERO\%20SPREAD.pdf\&nombObjeto=PerfTuristaExt\&back=/TurismoIN/sitio/PerfTuristaExt \&issuuid=1760695/42132098.

- El 64\% indicó visitar el Perú por motivos vacacionales y un 15\% por negocios, el resto fueron motivos diversos.

\subsubsection{El perfil del turista vacacionista que visita el Perú.}

Según PROMPERU en el documento "Perfil del turista extranjero 2015” el turismo de vacaciones en el 2015 lideró la preferencia de los turistas que visitó el Perú; presentando un perfil con las siguientes características (PromPerú, 2016, págs. 24-31):

- Aquellos que vinieron por vacaciones declararon gastar por día US\$ 123 con una permanencia promedio de 9 noches, es decir que gastaron en total US\$1,108. (oportunidad)

- El 65\% de vacacionistas no contrataron un paquete turístico, es decir viajaron por su propia cuenta. (Amenaza) 
- El 20\% de los vacacionistas que adquirieron un paquete turístico, lo hicieron a través de Internet. (Oportunidad)

- Aquellos que adquirieron un paquete turístico, fueron los que realizaron un mayor gasto promedio durante toda su estadía (US\$ 1,935). (Oportunidad)

- El vacacionista prefiere realizar algún tipo de actividad cultural en primer lugar. Dejando en segundo plano, en el caso del vacacionista de larga distancia, las que realizan actividades de naturaleza; y en el caso del vacacionista latinoamericano deja en segundo plano las actividades de diversión.

- Dentro de los vacacionistas, se considera Premium aquellos que entran por el aeropuerto Jorge Chávez.

- Los principales destinos turísticos además de Lima, fueron la ciudad de Cusco y Tacna. (Oportunidad)

Tabla 3.

Principales motivos de viaje al Perú

\begin{tabular}{llc}
\hline & Principal Motivo de Viaje al Perú & Llegadas de turistas extranjeros 2015 \\
\hline 1 & Vacaciones & $2,100,909$ \\
2 & Negocios & 492,401 \\
3 & Visita a Familiares & 393,921 \\
4 & Tratamiento médico & 131,307 \\
5 & Asistir a conferencias & 98,480 \\
6 & Otros & 65,653 \\
\hline & Total & $3,282,671$ \\
\hline
\end{tabular}

Nota: Tomado de perfil del turista Extranjero 2015 por PROMPERU, 2016. Recuperado de http://www.promperu.gob.pe/TurismoIN/sitio/VisorDocumentos?titulo=Perfil\%20del\%20Tur ista\%20Extranjero\%202015\&url= /Uploads/perfiles_extranjeros/38/PERFIL\%20EXTRANJ ERO\%20SPREAD.pdf\&nombObjeto=PerfTuristaExt\&back=/TurismoIN/sitio/PerfTuristaExt \&issuuid=1760695/42132098 


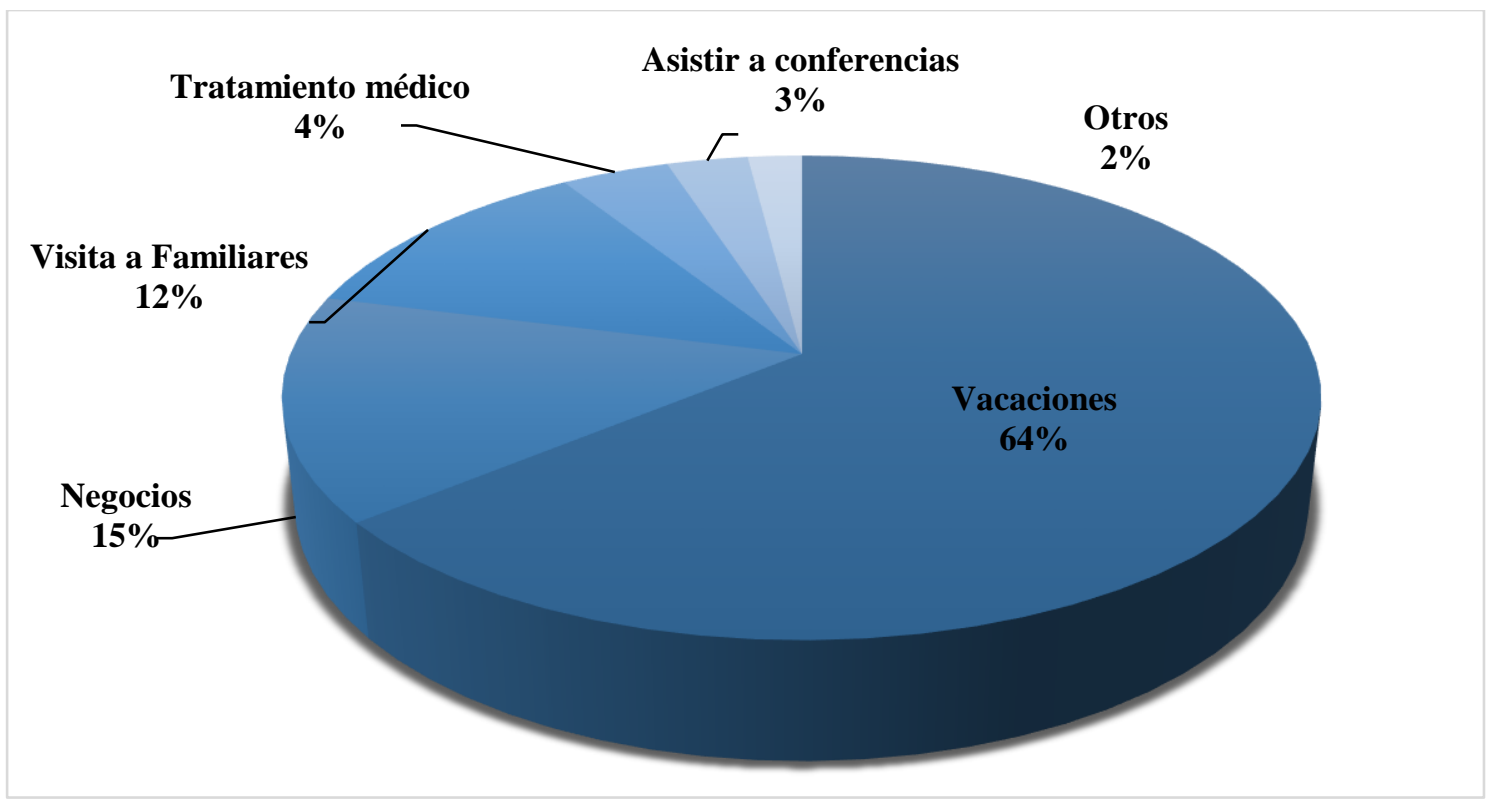

Figura 5. Principal motivo de viaje al Perú. Tomado de perfil del turista Extranjero 2015 por PROMPERU, 2016. Recuperado de http://www.promperu.gob.pe/TurismoIN/sitio/VisorDocumentos?titulo=Perfil\%20del\%20Tur ista\%20Extranjero\%202015\&url= /Uploads/perfiles_extranjeros/38/PERFIL\%20EXTRANJ ERO\%20SPREAD.pdf\&nombObjeto=PerfTuristaExt\&back=/TurismoIN/sitio/PerfTuristaExt \&issuuid $=1760695 / 42132098$

\subsubsection{El poblado de Maras.}

El poblado de Maras se creó el 02 de enero de 1867, dada su extensión constituye el segundo poblado más grande de la provincia de Urubamba, tuvo ocupación pre inka (cultura Chanapata). Su origen está ligado a la tradición oral del mito de los hermanos Ayar, pues se dice que estos hermanos salieron del cerro Tamputoqo, Ayar cachi sale de la ventana Marast'oqo, dando nombre a todo el grupo de pobladores de Maras. El modelo de ciudad es implementado al producirse la conquista y la colonización. Este distrito está ubicado a 3380 msnm, a 48km de la ciudad del Cusco, su población actual es de aproximadamente 5800 habitantes de acuerdo con el INEI, cuenta con dos accesos carrozables, cada uno de $6 \mathrm{~km}$ de extensión, uno al complejo arqueológico de Moray y otro a las salineras de Maras (Dirección Desconcentrada de cultutra de Cusco, 2016). 
El pueblo de Maras, fue reconocido como Villa de San Francisco de Asís de Maras, al ser despojados de sus palacios los nobles del Incario migraron a este pueblo, así como también lo hicieron los invasores durante la gesta de MankoInka, quien ocupaba Ollantaytambo, es por esto que dentro del patrimonio tangible del pueblo de Maras destacan los escudos y blasones en las portadas de piedra del pueblo, así como la capilla de barro construida sobre la base de mampostería de piedra, denotando así la importancia del pueblo de Maras en el pasado. Su principal festividad es la de San Francisco de Asís. (Dirección Desconcentrada de cultutra de Cusco, 2016)

Según el libro, ¿El turismo es cosa de pobres? Patrimonio cultural, pueblos indígenas y nuevas formas de turismo de América Latina de Raúl Asensio y Beatriz Pérez Galán, son múltiples las ventajas de la práctica de turismo sostenible en sus múltiples denominaciones como etnoturismo, turismo cultural o turismo comunitario entre otras, como por ejemplo: la articulación de estrategias que otorgan valor económico a los recursos físicos, naturales, sociales, el protagonismo de los segmentos más pobres, la diversificación de las actividades económicas que contribuye a elevar la autoestima y el sentido de ciudadanía de esta población, sin optar por la migración, así como el fomento de las relaciones interculturales (Asensio \& Pérez Galán, 2012, pág. 3) (Oportunidad)

Así también se mencionan las principales consecuencias de estas prácticas como la segmentación de las sociedades rurales, el incremento en las diferencias sociales, la diversificación de las redes, el impacto en la educación que propicia nuevas narrativas de la identidad cultural. A nivel doméstico, según Raúl Asensio y Beatriz Pérez Galán, el turismo comunitario genera una doble colonización: (Amenaza) 
(...) por un lado una colonización macro, en tanto que las consolidaría como poblaciones subalternas, para ser exhibidas dentro de un país fragmentado étnica y socialmente. En paralelo una colonización micro, en su propia intimidad a través de la reconfiguración del hogar y de los usos y prácticas culturales que lo significan. La necesidad de proporcionar al turista “autenticidad con confort potenciaría cambios en prácticas culturales profundamente asentadas. Un cambio que en última instancia supondría "sacar los cuyes de la cocina. (Asensio \& Pérez Galán, 2012, pág. 10)

Así se puede evidenciar que de estas prácticas se desprenden las tendencias de los últimos años, que las sociedades valoran mucho más el conocimiento de las comunidades nativas o ancestrales, creando así un mercado demandante de estas relaciones interculturales, y por otro lado tras las declaraciones de UNESCO: Declaración Universal sobre la diversidad Cultural (2001), así como la Convención para la Salvaguardia del patrimonio inmaterial (2003), permite la apertura a la patrimonializacion de representaciones, costumbres, manifestaciones musicales etc. (Oportunidad)

Para el presente estudio esto se reflejaría como los nuevos flujos de visitantes al poblado de Maras, y la industrialización de la sal con la marca "Sal de Maras" como producto comunal, aportando así el sentido de apropiación a la comunidad de un producto único y diferenciado. (Oportunidad) 


\subsubsection{Análisis del entorno tecnológico.}

La tecnología de la información ha revolucionado y modificado la industria del turismo, cumpliendo ahora un papel fundamental en la forma de acercarse al cliente, pues son muchos los cambios generados en la manera de ofrecer los servicios.

Desde hace algunos años Internet es la tecnología de la información que más impacta al turismo por su funcionamiento continuo en cualquier parte del mundo. Junto con ello, la decisión del lugar turístico a visitar se ve influenciado por el desarrollo de las redes sociales. Según un estudio de Facebook un 89\% de sus usuarios encuentran inspiración en las vacaciones de familiares y amigos (Diario Gestión, 2015). Esta conexión funciona como canal de fidelización y socialización. (Oportunidad)

En la actualidad, algunas de las redes sociales y plataformas más usadas por los viajeros para decidir sus viajes son:

- TripAdvisor: Es la mayor web de viajes del mundo, esta plataforma escogió los mejores destinos del mundo del 2015 en base a las recomendaciones que realizaron sus propios usuarios. En esta lista el Perú aparece en el puesto 16 con la ciudad de Cusco, superando a ciudades como San Petesburgo (Rusia), Bangkok (Tailandia) o Atenas (Grecia).

- CouchSurfing: Este sitio web proporciona una plataforma para que sus miembros puedan alojarse en casas de anfitriones en los destinos elegidos. Funciona como un sistema de intercambio de alojamiento, en casas de personas desconocidas previamente contactadas por la página web.

- Facebook: Es una red social que aporta al turismo de diversas formas, por medio de perfiles para las empresas, destinos, agentes etc., como también formando grupos de 
viajes, sugerencias, tendencias y recomendaciones. Actualmente la medida y el resultado de esta red se da gracias al número de visitas a cada perfil, la cantidad de "me gusta" en cada página o publicación, así como las veces que una publicación ha sido compartida. Es una herramienta bastante completa para las empresas, pues permite generar estadísticas, es una plataforma para descubrir mercados, etc.

- Instagram: Es una red social y aplicación utilizada para subir fotos y videos, sirve a la vez para editar imágenes. Es utilizada a manera de motivador de viajes, así como para compartir experiencias de viajeros por medio de recursos visuales.

En tanto algunas de las aplicaciones más descargadas por los viajeros son (Levante: El Mercantil Valenciano, 2017): (oportunidad)

- Trover: Apodado “el hijo de Instagram y TripAdvisor”, esta aplicación anima a los usuarios a subir fotos y presentar recomendaciones para cada lugar. Dicho esto, al igual que con cualquier aplicación o servicio de fuente pública, la información no es necesariamente $100 \%$ fiable. Así que antes de dar por hecho las citas de Trover, se sugiere consultar las guías de turista.

- Localeur: Con el objetivo de ser "más que una guía turística”, este sitio web y aplicación se focaliza en las experiencias locales y los destinos recomendados por las personas que viven en cada ciudad. Cada escritor tiene un perfil y una foto, explicando quiénes son y qué tipo de intereses que tienen. En un correo electrónico, el fundador JoaSpearman explica que aunque Localeur paga a sus colaboradores, la aplicación apunta a que las recomendaciones se lean como un texto o un correo electrónico dirigido a un amigo.

- Kayak: ayuda a los usuarios a buscar vuelos económicos, hoteles y alquiler de autos. Ayuda a comparar webs, horarios de vuelos, transporte público, etc. Es una app gratuita. 
- Tripit: almacena todos los correos enviados y los ordena de manera que puedan ser de fácil consulta para pautear el viaje.

- Airbnb: esta aplicación muestra al viajero el mercado de lugares disponibles para el alquiler de apartamentos, habitaciones, etc. La web también gestiona toda la transacción económica.

- Minube: las personas pueden por esta web acceder a consejos de viajes, dispone la posibilidad de crear un blog de viaje para contar experiencias y anécdotas en cada destino.

En la actualidad Google, es el principal motor de búsqueda de información, según la BBC (BBC Mundo, 2016), siendo así el termino maras, es relacionado en sus primeros resultados a la popularidad de los grupos armados de centro América, "maras salva trucha", por lo que el costo a pagar por publicidad en este motor podría significar un alto costo al plan de negocio para alejarnos del homónimo. (Amenaza)

Por otro lado, respecto a las tendencias de uso de tecnología en la promoción y publicidad turística, destaca el uso de Drones, (aparatos voladores teledirigidos, con cámara de video acoplada). Según un informe de "Hosteltur":

Su abaratamiento y facilidad de uso permite que estos aparatos teledirigidos, equipados con una cámara de televisión o fotos, tomen por ejemplo espectaculares imágenes que luego se usarán en acciones de promoción turística, principalmente a través de internet y redes sociales. (Hosteltur, 2015) (Oportunidad) 
Respecto a la tecnología utilizada en centros de hospedaje podemos mencionar los recursos tecnológicos de vanguardia para acelerar la respuesta a las necesidades de los turistas, como por ejemplo el uso software especializado en servicios hoteleros, sistemas de reservas, caja, recepción, etc. Así como el uso de tablets, no obstante, su inversión supone una fuerte inversión inicial, a largo plazo los resultados se medirán en la experiencia de los clientes. El uso de estos aparatos beneficia en tanto: la venta y upsell de habitaciones (tomar otra categoría mejor de habitación dentro del establecimiento), los pedidos a la habitación de los clientes. De acuerdo a Hosteltur los hoteles que cuentan con este servicio han aumentado en $41 \%$ en los ingresos por habitación ocupada. (Hosteltur, 2014) (Oportunidad)

Algunos recursos tecnológicos utilizados en Cusco, dada la ubicación geográfica de la ciudad respecto el nivel del mar es el uso de programas y sistemas de oxígeno en las habitaciones, enriqueciendo los sistemas de aire acondicionados con oxígeno bombeado, para ayudar a la aclimatación del turista. Los pioneros en el uso de este servicio fue el Hotel Monasterio en Cusco. La prestación de este servicio es operada y controlada por medio de una central computarizada. (Oportunidad)

Debemos mencionar también que la zona de estudio del proyecto podría, por su ubicación, carecer de la conectividad de internet necesaria, por lo que el costo de conexiones podría significar una amenaza para el proyecto. (Amenaza). 


\subsubsection{Análisis del entorno ecológico.}

\subsubsection{Gestión ambiental en el Perú.}

La gestión ambiental en el Perú se encuentra reglamentada en la Ley General de Ambiental $N^{\circ} 28611$ publicada el 15 de octubre del 2005. Esta ley, en su Artículo dos menciona:

Las disposiciones contenidas en la presente Ley, así como en sus normas complementarias y reglamentarias, son de obligatorio cumplimiento para toda persona natural o jurídica, pública o privada, dentro del territorio nacional. Ley creada para regular todas las acciones destinada a la protección del medio ambiente que deben adoptarse en el desarrollo de todas las actividades humanas. La regulación de actividades productivas y aprovechamiento de recursos naturales se rigen por sus respectivas leyes, debiendo aplicarse la presente Ley en lo que concierne a las políticas, normas e instrumentos de gestión ambiental. Entiéndase, para los efectos de la presente Ley, que toda mención hecha al “ambiente" o a "sus componentes" comprende a los elementos físicos, químicos y biológicos de origen natural o antropogénico que conforman el medio en el que se desarrolla la vida. (Ministerio del Ambiente, 2005, pág. 23)

El Artículo 9 de la misma Ley menciona que el principal objetivo de la Ley es: (...) mejorar la calidad de vida de las personas, garantizando la existencia de ecosistemas saludables, viables y funcionales en el largo plazo; y el desarrollo sostenible del país, mediante la prevención, protección y recuperación del 
ambiente y sus componentes, la conservación y el aprovechamiento sostenible de los recursos naturales, de una manera responsable y congruente con el respeto de los derechos fundamentales de la persona. (Ministerio del Ambiente, 2005, págs. 24-25)

El Artículo 24 de la Ley hace referencia al Sistema Nacional de Impacto AmbientalSEIA, administrado por la Autoridad Ambiental Nacional, el cual está encargado de la prevención, control y corrección de los impactos ambientales de carácter significativo; y en el artículo 26 se establece los lineamientos de los Programas de Adecuación y Manejo Ambiental-PAMA los cuales facilitan que las actividades económicas cumplan con los objetivos de desempeño ambiental explícitos, así como las medidas de prevención, control, mitigación, recuperación y eventual compensación que corresponda; en caso de incumplimiento se establece una sanción administrativa independiente de las sanciones civiles o penales que se deriven de la falta cometida. (Amenaza)

Las sanciones y medidas correctivas a las que se encuentra expuesto el centro de hospedaje son las siguientes (Ministerio del Ambiente, 2005, págs. 67-68):

a) Amonestación.

b) Multa no mayor de 10,000 Unidades Impositivas Tributarias vigentes a la fecha en que se cumpla el pago.

c) Decomiso, temporal o definitivo, de los objetos, instrumentos, artefactos o sustancias empleados para la comisión de la infracción.

d) Paralización o restricción de la actividad causante de la infracción.

e) Suspensión o cancelación del permiso, licencia, concesión o cualquier otra autorización, según sea el caso. 
f) Clausura parcial o total, temporal o definitiva, del local o establecimiento donde se lleve a cabo la actividad que ha generado la infracción.

g) De persistir el incumplimiento éste se sanciona con una multa proporcional a la impuesta en cada caso, de hasta 100 UIT por cada mes en que se persista en el incumplimiento transcurrido el plazo otorgado por la autoridad competente.

Son medidas correctivas:

a) Cursos de capacitación ambiental obligatorios, cuyo costo es asumido por el infractor y cuya asistencia y aprobación es requisito indispensable.

b) Adopción de medidas de mitigación del riesgo o daño.

c) Imposición de obligaciones compensatorias sustentadas en la Política Ambiental Nacional, Regional, Local o Sectorial, según sea el caso.

d) Procesos de adecuación conforme a los instrumentos de gestión ambiental propuestos por la autoridad competente.

Existen parámetros que debe cumplir cualquier entidad pública o privada que inicie actividades para recibir la certificación ambiental requerida por la Ley del Sistema Nacional de Evaluación del Impacto Ambiental, para ello se establece el ECA, Estándar de Calidad Ambiental que establece el nivel o grado de sustancias que podrían afectar la salud de las personas y el ambiente (Ministerio del Ambiente, 2005, pág. 31); es por ello que los programas de manejo ambiental que proponga el hospedaje debe considerar dichos estándares dentro de sus obligaciones.(Amenaza)

El Artículo 75 de la misma Ley hace referencia al Manejo Integral y Prevención en la Fuente y menciona que los estudios para proyectos de inversión deben considerar los costos para preservar el ambiente de la localidad donde se llevara a cabo el proyecto y se deben 
adoptar medidas de prevención de riesgo y daño ambiental dentro del ciclo de vida de los productos y servicios ofrecidos, así como programas de mejora continua de sus niveles de desempeño ambiental (Ministerio del Ambiente, 2005, pág. 50);lo que representa un costo que debe ser considerado para el análisis de rentabilidad del proyecto. (Amenaza)

En cuanto al manejo de residuos sólidos, aguas residuales y tratamiento de residuos líquidos, existen límites máximos permisibles controlados por el sector Vivienda, Construcción y Saneamiento, en coordinación con las municipalidades. (Amenaza)

Un tema delicado actualmente es la gestión de las poblaciones indígenas, las comunidades campesinas y nativas, es por ello que la Ley 28611 considera una serie de artículos relacionados con este tema, desde la relación entre cultura y ambiente que constituye parte de los pueblos, hasta la tecnología y el conocimiento que se transmite con la llegada de una nueva actividad a la localidad. Es importante preservar la integridad cultural, social y económica, así como los valores tradicionales de cada pueblo y garantizar beneficios y el desarrollo de las comunidades por la explotación de sus recursos.

La Ley establece que los pueblos indígenas y comunidades nativas y campesinas tienen derecho preferente de acceder a los recursos para su subsistencia y rituales culturales de forma libre y de forma parcial a aquellos que son reserva del Estado o propiedad de terceros, pero siempre con una participación equitativa y recibiendo los beneficios económicos derivados de ellos. Es por esta razón, que los hospedajes vivenciales que respeten la diversidad cultural y tengan políticas de inclusión, pueden obtener ventajas estratégicas de su relacionamiento con la comunidad. (Oportunidad) 


\subsubsection{Tendencia turismo.}

Como se mencionó en el análisis social, sobre el perfil del turista internacional, este ha ido evolucionando a través de los años y ahora está a la búsqueda de nuevos productos, nuevos destinos, nueva comida, pero sobre todo nuevas experiencias, es así que entre las nuevas tendencias para el turismo se encuentra el turismo vivencial.

Las salineras de Maras es uno de los lugares más visitados del distrito, el uso de la sal de Mara (sal rosada) es una costumbre que se hereda de familia en familia, los pobladores conservan aun sus técnicas ancestrales para la cosecha de la sal, estas técnicas son mostradas a los turistas permitiéndoles participar en la recolección de esta, así como en las fiestas y rituales del pueblo.

La vista en conjunto de las pozas se ha convertido también en un lugar preferido para los amantes de la fotografía y la zona es ideal para el ciclismo de aventura y las caminatas. (Oportunidad)

Otra tendencia que acompaña al turismo vivencial es la conciencia por la salud y la buena alimentación, Maras cuenta con una gran extensión de tierras que favorece el cultivo de la papa y la quinua que son fuentes nutritivas por excelencia; siendo la agricultura la principal actividad del distrito, el turista que visita Maras puede disfrutar de una gran variedad de alimentos preparados de forma $100 \%$ natural, sin preservantes, sin contaminantes, sin insecticidas garantizando una alimentación sana y nutritiva. (Oportunidad) 


\subsection{Fuerzas de Porter.}

\subsubsection{Poder de negociación clientes.}

Para conocer el poder que tienen los clientes en la industria, se debe analizar la capacidad que tienen para negociar precios, plazos y condiciones, todo ello en base a los siguientes factores:

- Número de clientes importantes.

- Grado de estandarización del servicio.

- Amenaza integración hacia adelante o hacia atrás.

- Costo de cambio.

- Información que maneja el cliente.

- Importancia del servicio para asegurar la calidad de los clientes.

En el caso de la industria hotelera, los clientes pueden ser directos e indirectos.

Directos son aquellos turistas que hacen uso de los servicios del hotel y los clientes indirectos serían los operadores de turismo, las cuales captan más huéspedes para el hotel mediante el uso de su equipo comercial.

a. Poder de negociación de los clientes directos

Según el boletín estadístico de turismo 2015 que emite DIRCETUR-CUSCO, el departamento de Cusco recibió 2,881,677 visitantes, de los cuales 1,858,258 fueron extranjeros y 1,023,419 fueron nacionales (DIRCETUR, 2016, pág. 12). Como se describió 
en el perfil del turista (capítulo 1), la mayoría de los turistas extranjeros compran el paquete turístico completo, es decir que mediante una agencia de viajes o por internet, eligen las actividades que realizaran durante su estadía minimizando las decisiones in situ.

En base a estos hábitos de consumo, el costo de cambio por otro servicio es bajo debido a la alta oferta existente en la ciudad del Cusco y la información brindada por internet. Dentro de esta información las redes sociales juegan un rol importante por la influencia que las opiniones pueden generar en las decisiones de clientes potenciales. Debido a esto, su poder de negociación es alto.

Dado que no existe un grupo concentrado de clientes "importantes" dentro de la población total de visitantes $(2,881,677)$, con respecto a este rubro su poder de negociación es bajo.

En cuanto a la estandarización del servicio, si bien el turismo vivencial sale totalmente de lo estándar lo que hace que el poder del cliente sea débil, al haber tantos productos (hospedajes) sustitutos, el cliente tiene poder de negociación al momento de exigir el nivel de servicio.

Por otro lado, no existe una amenaza de integración hacia adelante o hacia atrás, es decir, las probabilidades de que el turista pueda auto-brindarse servicios de hospedaje y turismo son bajas debido a los costos (barreras) que esto le implicaría.

En conclusión; el cliente directo tiene barreras que le impiden una integración vertical y por sí solo no representa un volumen significativo en la demanda; sin embargo, al tener 
acceso a la información, el poder cambiar de proveedor turístico con facilidad, y al poder influir en las decisiones de clientes potenciales, presenta un alto poder de negociación. (Amenaza)

b. Poder de negociación de los clientes indirectos

Los clientes indirectos están formados por las agencias de turismo que trabajan con paquetes de turismo vivencial en el Cusco.

Para obtener una lista de posibles clientes indirectos se empleó la base de datos de la Dirección Regional de Turismo en cuanto a agencias de turismo en Cusco, la cual se filtró según los servicios que brindan en relación a ecoturismo, turismo histórico-cultural y turismo ecológico, debido a que estos tres servicios son los que más se asemejan al servicio del proyecto en estudio.

Las agencias de turismo en el Cusco han ido aumentando a raíz del crecimiento turístico en Cusco y principalmente en Machu Picchu, por el reconocimiento a nivel mundial como mejor destino turístico. Estas agencias se clasifican de la siguiente forma:

- Agencias de turismo minoristas: Vende directamente al cliente paquetes turísticos creados por agencias de turismo mayoristas u operadores de turismo. 
Tabla 4.

Clientes indirectos Agencias de Turismo Minoristas.

\begin{tabular}{|c|c|c|c|}
\hline Nombre Comercial & Dirección & Distrito & Provincia \\
\hline Action Peru Treks E.I.R.L & Urb. Independencia K-16 & Santiago & Cusco \\
\hline Agencia De Viajes Misky & Avenida Sol N³46 Of.101 1er Piso & Cusco & Cusco \\
\hline Agencia De Viajes Purisunchis & A.p.v. Kari Grande M-13 San Sebastián & San Sebastián & Cusco \\
\hline Andean Pathways & Portal Confituria 265, INT. 02 & Ollantaytambo & Urubamba \\
\hline Andes Dream Travel & Calle Lloque Yupanqui $N^{\circ} 105$ Ofic. 302 & Wanchac & Cusco \\
\hline Aquarius Reps & Calle Garcilaso $N^{\circ} 206$ & Cusco & Cusco \\
\hline Ausangate & Calle Procuradores 350 & Cusco & Cusco \\
\hline Clap Travel Service & Urb. Ttio D-1-11 & Wanchac & Cusco \\
\hline Comfort Tours Peru & Calle Plateros $\mathrm{N}^{\circ} 365$ Ofic.01 - 2? Piso & Cusco & Cusco \\
\hline Cooperativa Coclatours & Jr. Ricardo Palma N? 1175 - Quillabamba & Santa Ana & La Convención \\
\hline Crytalis Travel Y Tours & Calle Cuichipuncu 299-a & Cusco & Cusco \\
\hline Cusco Inside Tours & Pje. Constanza N? 102 - Of. 303 & Wanchac & Cusco \\
\hline Cusco Turistik & Calle Triunfo No 393 Int. 301 & Cusco & Cusco \\
\hline David Coffee Tours Eirl & Prol. Vilcabamba E-6 & Santa Ana & La Convención \\
\hline Dery Tours & Portal Confituria 385 A- B & Cusco & Cusco \\
\hline Elohim Tours & Urb. Larapa Grande Mza. H-14 Lote 11 Dpto. 2do piso & San Jerónimo & Cusco \\
\hline Escapedtoperu.Com & Av. Garcilaso N- 411-a-ofic.203 & Cusco & Cusco \\
\hline Esteban Adventures & Calle Tandapata $\mathrm{N}^{\circ} 300$ & Wanchac & Cusco \\
\hline From Peru Tours & Av. El Sol 806, Ofic. 105 & Cusco & Cusco \\
\hline Gran Picol Travel & Prolongación Avenida De La Cultura N- 1409 & San Sebastián & Cusco \\
\hline Green Peru Adventures E.I.R.L. & Calle Triunfo Nro 392 Int. 208 & Cusco & Cusco \\
\hline Inca'S Knowledge Travel & Av. Sol N 106 Of. 303 & Cusco & Cusco \\
\hline Incas Connections & Av. El Sol 345, Interior 2 & Cusco & Cusco \\
\hline Inka Routes & Av. De La Cultura 2222 & San Sebastián & Cusco \\
\hline Inka Sol Travel & Av. Sol 101 Ofic.02 & Cusco & Cusco \\
\hline Inkaland Group & Portal comercio $\mathrm{N}^{\circ} 141$ int. 4 & Cusco & Cusco \\
\hline Interoceanica Travel Service & Portal Confituria 265, Int. 02 & Cusco & Cusco \\
\hline Inversiones Turísticas Aynitours & Portal Comercio 177 Ofic. 01 & Cusco & Cusco \\
\hline \multirow[t]{2}{*}{ Jampuyqui Tours Agencia De Viajes Y Servicios } & Ap.v. Santa Rosa P-5 & San Sebastián & Cusco \\
\hline & Total & 29 & \\
\hline
\end{tabular}

Nota: Tomado de la base de datos de la Dirección Regional de Turismo de Cusco 2016. 
- Agencias de turismo mayoristas: Crea todo tipo de servicios, paquetes y viajes turísticos que serán vendidos por otras agencias de turismo. No vende directamente al cliente.

Tabla 5.

Clientes indirectos Agencias de Turismo Mayoristas.

\begin{tabular}{|c|c|c|c|}
\hline Nombre Comercial & Dirección & Distrito & Provincia \\
\hline Acitur & Cuesta Del Almirante $\mathrm{N}^{\circ} 232$ & Cusco & Cusco \\
\hline Angel Hands Tours & Portal Confituria 265, INT. 02 & Cusco & Cusco \\
\hline Cooperativa Coclatours & Jr. Ricardo Palma N 1175 - Quillabamba & Santa Ana & La Convención \\
\hline Ethnias Peru & Urb. Tupac Amaru G-1-12 & San Sebastián & Cusco \\
\hline Independent Travelers Destinations & Urb. San Luis A-ii & San Jerónimo & Cusco \\
\hline Joli Tours & A.p.v. Las Palmeras B-4 & San Sebastián & Cusco \\
\hline Lan & Av Collasuyo $N^{\circ} 2964$ Int. Lc-1 & Cusco & Cusco \\
\hline Latika Adventures E.I.R.L & Calle Triunfo 392 Of.209 & Cusco & Cusco \\
\hline Peru Travelco Sac & Urb. Mateo Pumacahua B-2 & Wanchac & Cusco \\
\hline Rian Tours & Av. Pardo $N^{\circ} 975$ & Cusco & Cusco \\
\hline S C Tours And Travel & Av. Los Incas $\mathrm{N}^{\circ} 700$ Int 403 & Wanchac & Cusco \\
\hline Trips To Peru & Av. De La Cultura N² 01 & San Sebastián & Cusco \\
\hline \multirow[t]{2}{*}{ Vacation Peru } & Calle Choquechaca $\mathrm{N}^{\circ} 229-\mathrm{B}$ & Cusco & Cusco \\
\hline & Total & 13 & \\
\hline
\end{tabular}

Nota: Tomado de la base de datos de la Dirección Regional de Turismo de Cusco 2016.

- Operadores de turismo: Crea programas y servicios turísticos para el territorio nacional que pueden ser vendidos por agencias de turismo minorista y mayorista en el Perú y extranjero, y directamente a los clientes también. 
Tabla 6.

Clientes indirectos Operadores de Turismo.

\begin{tabular}{|c|c|c|c|}
\hline Nombre comercial & Dirección & Distrito & Provincia \\
\hline A.A.E. & Calle Perú 43 San Jerónimo & San Jerónimo & Cusco \\
\hline Acllas Peru Tour & A.P.V. Kary Grande I - 6 San Sebastian & San Sebastián & Cusco \\
\hline Agencia De Viajes Y Turismo H Y L & Urb. Los Nogales Q-25 & Cusco & Cusco \\
\hline Amazing Cusco Travel Agency & Calle Tecsecocha $415 \mathrm{~A}$ & Cusco & Cusco \\
\hline American Travel Exprorer & Calle Agustin Gamarra 30 San Jerónimo & San Jerónimo & Cusco \\
\hline Andean Challenger & San Judas Chico I I F-7 C & Wanchac & Cusco \\
\hline Andean Life Tours & Calle Plateros 368 & Cusco & Cusco \\
\hline Andean Odyssey Peru & Av. Don Bosco N? A-7 & Cusco & Cusco \\
\hline Andina Empresas Del Norte & Calle Triunfo 392 Int.212- A & Cusco & Cusco \\
\hline Aventuras X Treme Tourbulencia En Cusco & Plateros 364 & Cusco & Cusco \\
\hline Bamba Experience & Picchu San Isidro K-3 & Cusco & Cusco \\
\hline Btp & Av. El Sol 948 Ofic. 324 & Cusco & Cusco \\
\hline C.A. Peru Turismo & Calle Garcilaso $N^{\circ} 265$ Inter.08 & Cusco & Cusco \\
\hline Camat Voyages & Urb. Larapa Grande D-2 Condominio Los Ruiseñores & San Jerónimo & Cusco \\
\hline Casa Cusiwasi & Av. Arcopata 466 Y Calle Fierro 584 & Cusco & Cusco \\
\hline Cbc Tupay & Avenida Tullumayo $\mathrm{N}^{\circ} 465$ & Cusco & Cusco \\
\hline Centro De Operaciones Turisticas & Av. Tomasa Ttito Condemayta 506 & Wanchac & Cusco \\
\hline Chacana Tour E.I.R.L. & Calle Triunfo No 392 Int. & Cusco & Cusco \\
\hline Chaski Peru Treks & calle suecia $n^{\circ} 380$ & Cusco & Cusco \\
\hline Chaski Ventura Sur & Av. Manco Ccapac 515 & Wanchac & Cusco \\
\hline Cholo Viajes Exclusive & A.v Cusco 108 & San Sebastian & Cusco \\
\hline Class Travel Peru S.R.L. & Urb. Los Sauces D-4 & Wanchac & Cusco \\
\hline Coca Tours & Portal Confituria 265, INT. 02 & Cusco & Cusco \\
\hline Cusco Andean Paradise & Av. Infancia Residencial Sta. Lucia 452 Intr.202 & Wanchac & Cusco \\
\hline Cusco Experience & Calle Primavera Lote 08 & San Jerónimo & Cusco \\
\hline Cusco Travel & Urb. Ttio Z-26 & Wanchac & Cusco \\
\hline Cusi Wasi Tours & Calle Fierro 584 & Cusco & Cusco \\
\hline Day Hikes And Self Guided Peru & Urb. Kennedy A G-7 & Wanchac & Cusco \\
\hline Daydream Travel Agency & Calle Almagro 202 Ofic.202 Cusco & Cusco & Cusco \\
\hline Discover The New Wonder & Calle Marquez 259 & Cusco & Cusco \\
\hline Ecoinka & Calle Saphi 456 & Cusco & Cusco \\
\hline Epitours Trek & Urbanización Ladrillera A-7 San Sebastian & San Sebastian & Cusco \\
\hline Etran Diamante Inversiones & Calle Ccasccaparo $\mathrm{N}^{\circ} 140$ & Cusco & Cusco \\
\hline
\end{tabular}




\begin{tabular}{|c|c|c|c|}
\hline Nombre comercial & Dirección & Distrito & Provincia \\
\hline Fistuk House & Calle Meloc 422 Interior 04 & Cusco & Cusco \\
\hline Go To Peru & Calle Procuradores 332 Int. & Cusco & Cusco \\
\hline Go2 Inkas & Urb. Mariscal Gamarra 5- D & Cusco & Cusco \\
\hline Green Heart Adventures & AV. Tomas Tuyrotupac N? 119 2? Piso & San Sebastian & Cusco \\
\hline Gris Peru Adventures & Urb. Ttio Q-1-2 & Wanchac & Cusco \\
\hline Gtperu S.A.C. & Av. Pardo 994 & Cusco & Cusco \\
\hline Heroinka & Calle Nueva Alta N- 458 - Interior & Cusco & Cusco \\
\hline Hope Machupicchu & Urb. Los Nogales I-1 & San Sebastian & Cusco \\
\hline Imperio Inca Tour & Portal De Carnes 288 & Cusco & Cusco \\
\hline Inca Kumaru & Av. Velasco Astete $\mathrm{N}^{\circ}$ A-3 Urb. Los Alamos & Wanchac & Cusco \\
\hline Inca Trail & Urbanización San Blas K-2 & Cusco & Cusco \\
\hline Inca Trail Reservations Reservations & Urb. Mariscal Gamarra 2 Etapa A-11-207 & Cusco & Cusco \\
\hline Incas Machupicchu Viajes Y Turismo & Av. Cusco 100-201 & San Sebastian & Cusco \\
\hline Inka Elite Dynasty & Avenida Sol 948 Ofic. 222 & Cusco & Cusco \\
\hline Inka S Paradise & Calle Choquechaca $\mathrm{N}^{\circ} 152$ Int. 1 & Santiago & Cusco \\
\hline Inkapal Intertravel & Calle Santa Catalina Ancha N ${ }^{\circ} 353$,int. 361 & Cusco & Cusco \\
\hline Inkas Destination & Calle Triunfo 120 & Cusco & Cusco \\
\hline Inkas Planet Explorers & Apv. Corimachahuayniyoc B - 10 Santiago & Santiago & Cusco \\
\hline Inkas Wonder Travel Service & Av. Tupac Amaru ( Picchu Alto) E - 1 & Cusco & Cusco \\
\hline Intense Peru & Teofilo Benavente K-9 Ofic.507 Condominio Las Orquideas Magisterio & Cusco & Cusco \\
\hline Inti Sun Trek & Urb. Villa Mirador A-5 & San Sebastian & Cusco \\
\hline Intiparadise & Calle Marquez 259 Ofc. 13 & Cusco & Cusco \\
\hline Inversiones Andean Golden Experience & Portal Panes No 123 Int. 205 & Cusco & Cusco \\
\hline Iskay Treks \& Travel Sac & Av. Micaela Bastidas $\mathrm{N}^{\circ} 805$ & Wanchac & Cusco \\
\hline Jau Southern Journeys & Av. Pachacuteq N 207- A & Wanchac & Cusco \\
\hline Kana Travel & Calle Tecsecocha 148 & Cusco & Cusco \\
\hline Katty’S Travel Agency & Av. Sol 839 & Cusco & Cusco \\
\hline Latnina Travel & Urb. Huancaro Av. Asociacion H - 20 Dpto 301 & Santiago & Cusco \\
\hline Liz's Explorer & Calle Del Medio 114 & Cusco & Cusco \\
\hline Llama Tours Peru & Urb. Santa Rosa V2-8 - San Sebastian & San Sebastian & Cusco \\
\hline Loki Travel & Cuesta Santa Ana No 601 & Cusco & Cusco \\
\hline Lucas Cusco Tours & Urb. Pueblo Libertador G-6 & San Sebastian & Cusco \\
\hline Lucky Peru Tour & Calle Suecia 338 & Cusco & Cusco \\
\hline Machu Travel Peru & APV. Los Nogales JR. NAZCA A-07 & San Sebastian & Cusco \\
\hline Machupicchu Brasil & Calle Garcilaso 265 Oficina 01 & Cusco & Cusco \\
\hline Machupicchu Kosmos Peru & Calle Garcilaso 265 Interior 5 & Cusco & Cusco \\
\hline Machupicchu Magic Travel & Av. 28 De Julio X-30 Urb Ttio & Wanchac & Cusco \\
\hline Machupicchu Master Travel & Av. El Sol Int. Of. 118 & Cusco & Cusco \\
\hline
\end{tabular}




\begin{tabular}{|c|c|c|c|}
\hline Nombre comercial & Dirección & Distrito & Provincia \\
\hline Machupicchu Team Srl & Calle Collacalle $\mathrm{N}^{\circ} 318$ & Cusco & Cusco \\
\hline Madec Tours Peru & Urb. Larapa H-7-1 & San Jerónimo & Cusco \\
\hline Manuexplorers Peru & Calle Triunfo $\mathrm{N}^{\circ} 392$ Inter. 207 & Cusco & Cusco \\
\hline Mapi Agency & Calle San Juan De Dios N 264 & Cusco & Cusco \\
\hline Marlons Travel & Calle Nueva Baja 496 & Cusco & Cusco \\
\hline Minkas Expeditions & Av. Ejercito $\mathrm{N}^{\circ} 800$ & Santiago & Cusco \\
\hline Mitos Tours Peru & Aeropuerto Velasco Astete S/n & San Sebastian & Cusco \\
\hline Munayki Journeys & Urb. La Florida Las Gadenias Ll-10 & Wanchac & Cusco \\
\hline Nikol Expeditions & Calle Triunfo N-392 Int-212 & Cusco & Cusco \\
\hline Nustas Del Inka World Travel A & Carceleta De La Santa Inquisición (Plaza De Armas) & Cusco & Cusco \\
\hline Oat & Calle Suytuccato 710 San Blas & Cusco & Cusco \\
\hline Odyssey Cusco & Av. Sol 948 Cc.sol Plaza Ofic. 304 & Cusco & Cusco \\
\hline Ogs.Tours & Parque España C-30 Urb Ucchullo Grande & Cusco & Cusco \\
\hline Ojco Travel & Ur Larapa Grande C-6-lote 10 & San Jerónimo & Cusco \\
\hline Out Limits Adventures & Urb. Naciones Unidas -av. Alemania Federal H-12 & San Sebastian & Cusco \\
\hline P.T.I. & Calle Nueva Baja 464 & Cusco & Cusco \\
\hline Pachatusantrek & Villa Unión Huancaro - Los Fresnos G-4B-502 & Santiago & Cusco \\
\hline Panorama International Travel Agency & Calle Concepción No 300 Urb. Santa Ana & Cusco & Cusco \\
\hline Pc Travel & Avenida Tullumayo 257 & Cusco & Cusco \\
\hline Peru Adventure Trek & Portal Panes $\mathrm{N}^{\mathrm{o}} 123$ Int. 1- A & Cusco & Cusco \\
\hline Peru Andean Tours & Apv. Los Incas Calle Nazca V-04 & Cusco & Cusco \\
\hline Peru Brasil & Ub. Los Sauces A - 10 & Wanchac & Cusco \\
\hline Peru Forever Young & Prolongación Av. Cusco 85- A San Sebastián & San Sebastian & Cusco \\
\hline Peru Inka Land \& River & Puente Santa Maria S/n & Maranura & La Convención \\
\hline Peru Planet & Calle Garcilaso 210 Interior 201 & Cusco & Cusco \\
\hline Peru Viajes O Globo & Couter $\mathrm{N}^{\circ} 1$ del Aeropuerto & Wanchac & Cusco \\
\hline Peru-Indian Experience & Urb Ttio P-2-9 & Wanchac & Cusco \\
\hline Peruqori & Urbanización Las Mercedes L-9 San Sebastián & San Sebastian & Cusco \\
\hline Qhapaqñan Adventure & Urb Zaguan Del Cielo L-8 & Cusco & Cusco \\
\hline Qollana Travel & Heladeros $\mathrm{N}^{\circ} 129-\mathrm{A}$ & Cusco & Cusco \\
\hline Qori Tika Tours & Urb. La Florida D-9 Psje. Los Kantus & Wanchac & Cusco \\
\hline Quechua Treks Peru & Calle Teofilo Benavente K- 8 Urb. Magisterial & Cusco & Cusco \\
\hline Quechuas Expeditions & Procuradores 358 & Cusco & Cusco \\
\hline Ruthbela Travel Tour & Av. El Sol Nº 679 Int. 101 & Cusco & Cusco \\
\hline Saywa Travel & C.h. Pachacutec B-402 & Wanchac & Cusco \\
\hline Soncco Travel & Av. Sol N 166 & Cusco & Cusco \\
\hline Sota Adventure And Travel & Av. El Sol Cc.cc. Ollanta 346 Ofc. 304 & Cusco & Cusco \\
\hline South Travel Sudamerica & Calle Resbaloza N 500 & Cusco & Cusco \\
\hline
\end{tabular}




\begin{tabular}{|c|c|c|c|}
\hline Nombre comercial & Dirección & Distrito & Provincia \\
\hline South Wild & Urb. Ttio Av. 28 De Julio I -2 - 1 & Wanchac & Cusco \\
\hline Sumac Coca Travel & Calle San Agustin $N^{\circ} 245$ & Cusco & Cusco \\
\hline Super Tour Cusco & Portal Mantas N 117 & Cusco & Cusco \\
\hline Tanit Trails & Urbanización Mariscal Gamarra I Etapa E-10 -202 & Cusco & Cusco \\
\hline The Inca Adventure & Calle Retiro 435 & Cusco & Cusco \\
\hline The Peru Travel & Urb. Zaguan Del Cielo L-8 & Cusco & Cusco \\
\hline Tikariy & Plazoleta Santo Domingo 259 & Cusco & Cusco \\
\hline Travel Adn Dreams & Calle Arequipa No 251 Ofic. 26 2do Piso & Cusco & Cusco \\
\hline Tucanos Peru & Calle Tres Marias Mz. D, Lote 8 & Santiago & Cusco \\
\hline Viajes De Primera & Urb. Marcavalle N-25 & Wanchac & Cusco \\
\hline Viandina & Calle San Andres 400 & Cusco & Cusco \\
\hline Voaa & Urb. Pueblo Libertador Mz. E - 6 - San Sebastian & San Sebastian & Cusco \\
\hline Walking Peru & Urb Covituc B-3 San Sebastian & San Sebastian & Cusco \\
\hline Wasi Tours & Counter Aeropuerto Llegada & San Sebastian & Cusco \\
\hline Wawanaje Tours & Jiron Libertad H-2 Urb. San Francisco & Wanchac & Cusco \\
\hline Wayna Peru Expeditions & Calle Triunfo $N^{\circ} 338$ Int. & Cusco & Cusco \\
\hline \multirow[t]{2}{*}{ Zarahemla Tours } & Urb. Manahuahuncca E - 5 Tercer Piso & Santiago & Cusco \\
\hline & Total & 126 & \\
\hline
\end{tabular}

Nota: Tomado de la base de datos de la Dirección Regional de Turismo de Cusco 2016. 
Dichas agencias son muy competitivas y brindan un servicio de calidad a diferentes precios incluso para una misma ruta o paquete, el poder que tienen radica en la facilidad que brindan en los trámites que los turistas necesitan, llámese tickets, reservas de hoteles, pasajes en tren, y todo esto como parte del servicio que ofrecen, la ventaja es que al trabajar con muchas empresas entre ellas hoteles, movilidad restaurantes, elevan su poder de negociación ya que el servicio es estandarizado, y pueden trabajar con uno u otro cliente sin problema.

Dado el nivel de conocimiento de mercado de estas agencias, existe la posibilidad de integración hacia atrás lo que les da mayor poder, la barrera en este sentido son los costos fijos altos con los que lidiar para entrar al sector; sin embargo, al trabajar de forma cercana con los hoteles pueden conocer los procesos y ventas y elevar su poder de negociación.

Si se considera que los clientes indirectos son quienes logran mayores ventas para el hotel, entonces su poder de negociación es alto. (Amenaza)

\subsubsection{Poder de negociación de los proveedores.}

Para una empresa que brinde hospedaje en el poblado de Maras Moray, los principales insumos son: alimentos, menaje, página web, servicios básicos, servicios de limpieza y seguridad, transporte de turistas, y los capacitadores de la mano de obra.

En alimentos, la zona es rica por su agronomía y ganadería, por lo cual los proveedores de los principales insumos para la elaboración de comida que serían las verduras y la carne tienen un poder muy bajo de negociación ya que la oferta es amplia y fácilmente sustituible por otro proveedor local. 
Para los insumos más especializados como condimentos específicos, bebidas gaseosas, cerveza y otros licores, debido a la lejanía del poblado a zonas comerciales, se depende de los proveedores que atienden el distrito de Urubamba los cuales no son fácilmente sustituibles. Por lo cual estos tienen un alto poder de negociación.

En cuestiones de menaje, (conjunto de utensilios, mueblería y ropas de cama) el hotel se proveerá de las tiendas especializadas en las ciudades de Cusco y de Lima, las cuales, debido a su variada oferta, presentan un bajo poder de negociación.

En cuanto a los proveedores de la página web, al poder ser elegidos a distancia y ser sustituidos fácilmente, tiene bajo poder de negociación.

El servicio básico de agua es provisto por Sedacusco S.A. el servicio de luz está a cargo de la empresa de generación eléctrica Machu Picchu (EGEMSA), el servicio de telefonía móvil e internet es suministrado por las empresas Telefónica, Claro, y Entel. Para todos los servicios básicos (mencionados en este párrafo) el poder de negociación es alto ya que las tarifas y condiciones de servicio son impuestas por los mismos proveedores y no se cuenta (o son escasos) con productos sustitutos.

Generalmente, un hotel cuenta con servicios externos de seguridad y limpieza, pero debido a la lejanía de la zona y la poca concentración de oferta hotelera en el lugar, no hay proveedores para estos servicios, por lo cual deberán ser provistos por el mismo hotel. 
La cercanía a otros lugares turísticos ha generado un alto tráfico de visitantes al poblado, los cuales se desplazan constantemente de un lugar a otro. Debido a esto la zona cuenta con una variada oferta de transporte, haciéndolos fácilmente sustituibles.

El personal provendrá en su mayoría de la gente del mismo poblado. Como se mencionó en el análisis social de esta investigación, la capacitación a los pobladores en temas de hospedaje, turismo y gastronomía depende fuertemente de ONGs, principalmente la asociación Arariwa y el apoyo de otras empresas de turismo, principalmente la empresa CondorTravel a través de su proyecto "Misminay". Debido a la falta de centros educativos especializados en turismo, estas organizaciones serían proveedores de mano de obra calificada con alto poder de negociación.

En conclusión, los proveedores de; alimentos básicos, menaje, página web y transporte de pasajeros, presentan un bajo poder de negociación. (Oportunidad) Sin embargo, los proveedores de insumos especializados, servicios básicos y proveedores de mano de obra calificada tienen un alto poder de negociación. (Amenaza)

\subsubsection{Amenaza de nuevos competidores.}

La amenaza de nuevos competidores indica el grado de dificultad que un negocio tiene para ingresar en un mercado; es decir, las opciones que tiene el negocio de triunfar en un mercado, dependiendo de las barreras de entrada. Según Porter, existen siete tipos de barreras diferentes: La economía de escala, la diferenciación, costos para los clientes por cambiar de proveedor, el requerimiento de capital, acceso a canales de distribución, ventajas de los costos independientes y políticas gubernamentales restrictivas (Porter M. E., 2008). 
Cuando el ingreso de una empresa a un mercado es sencillo, la intensidad de la competencia aumenta. Para el caso del Albergue vivencial ubicado en el poblado de Maras, se identificaron las siguientes barreras.

- Economía de escala: La ciudad del Cusco recibe al año cada vez más turistas; en el 2015 un 38\% de los turistas extranjeros que ingresó al Perú, visitó el Cusco (PromPerú, 2016, pág. 8); por lo que la demanda de un hospedaje para cualquier fin está incrementando, y con ello la competencia de precios. Según la revista SEMANA económica, el Perú es el mercado más atrayente para las inversiones hoteleras en la región; y en la actualidad tenemos inversionistas de grandes cadenas hoteleras que estarían ingresando en este mercado a más tardar para el 2018 (Vega, 2015).

- La diferenciación: Se trata de un Albergue vivencial; por lo que se conoce de la zona, los que brindan servicios similares son las Asociaciones y Agencias de Turismo que lo ofrecen como "Turismo Vivencial" abarcando este tipo de actividades, donde el hospedaje se realiza en el hogar de los mismos pobladores. El valor agregado de ser un Albergue Vivencial es que se construye en un espacio para que los huéspedes puedan vivir la experiencia de estar en una comunidad, pero con las comodidades de un Hotel.

- Requerimiento de capital: Para ingresar a la industria hotelera no es necesario un recurso alto, además de tener una rentabilidad bastante atractiva y positiva para los inversionistas y desarrolladores, confirman los economistas. Según Arturo García, presidente de la Conferencia Anual de Hotelería y Turismo de Sudamérica "la rentabilidad de los hoteles en Perú no está amenazada y no se ve que la desaceleración la vaya a amenazar en el corto plazo" (Vega, 2015). 
- Acceso a canales de distribución: Cuando una empresa cuenta con varios canales de distribución es complicado que puedan aparecer competidores; sin embargo, al tratarse de un servicio de experiencia como el Albergue Vivencial, termina teniendo una trayectoria más tradicional.

- Políticas gubernamentales: Para la implementación de un negocio como un Albergue son necesarios permisos, licencias, requisitos y certificaciones que piden las Municipalidades y Defensa Civil. En la actualidad, este tipo de papeleo que solían demorar años y espantaban a los potenciales inversores del sector, razón por la que se ve reflejado un déficit en hoteles de cuatro o cinco estrellas en Lima y más en provincia, con la puesta en marcha de la Ventanilla Única de Turismo busca facilitar todo proceso de proyectos hotelero. Según Javier Hundskopf, presidente de la Asociación Peruana de Hoteles, Restaurantes y Afines, señaló que existen 80 inversiones hoteleras en espera debido a trámites burocráticos. Esto representa un aproximado de 2,000 millones de dólares paralizados (Diario Gesión, 2015).

El Albergue Vivencial, es un servicio que ofrece al huésped la experiencia de vivir el día a día de una familia/comunidad. Participar activamente de las actividades diarias, así como de las festividades. El competidor potencial será todo aquel que invierta en realizar las mismas actividades teniendo un espacio donde hospedar al cliente dentro de sus propias viviendas. El turismo vivencial viene incrementando rápidamente, siendo las agencias de turismo las que están ofreciendo este tipo de experiencias donde el turista ingresa a la comunidad con la que la agencia tiene convenio. 
En conclusión, las barreras de entrada mencionadas, pero sobre todo las barreras políticas gubernamentales representan una oportunidad para el proyecto en estudio.

\subsubsection{Amenaza de productos y servicios sustitutos.}

Según Michael E. Porter, los productos sustitutos son aquellos que satisfacen la misma necesidad de los clientes de una manera distinta; en la industria hotelera en Cusco para determinar la fuerza de los productos sustitutos se debe conocer primero cuales son las necesidades que están siendo satisfechas (Porter M. E., 2008).

Los hoteles para turistas en Cusco satisfacen tres necesidades puntuales: hospedaje, servicio alimentación y bebidas, y experimentar el turismo vivencial. En cuanto a hospedaje (descanso) el turista tiene únicamente dos opciones, ir a un establecimiento de hospedaje o alquilar un departamento de turista por unos días (timeshare), se podría considerar una tercera opción hospedarse en la casa de un conocido, pero para el caso del turista extranjero es algo difícil que suceda, por lo que se considera como sustituto el timeshare debido a que satisface de otra forma la necesidad de descanso.

En cuanto a la alimentación y bebidas en Cusco la oferta es variada y abundante, se puede encontrar desde el restaurante más sencillo hasta una franquicia reconocida en el mercado local, lo mismo sucede con los bares y discotecas e incluso se considera en este rubro la Plaza de Armas de la ciudad del Cusco, donde turistas de todo el mundo se dedican a beber hasta altas hora de la madrugada. 
Por otro lado, se encuentra la necesidad de experimentar el turismo vivencial, el sustituto en este caso sería cada uno de los operadores turísticos independientes que ofrecen tours en la ciudad del Cusco, dichos tours incluyen la oportunidad de vivir la realidad de la zona que visita, las costumbres de los pobladores, degustar sus alimentos, convertirse en un habitante más de la población, es decir un turismo más humano. Cabe mencionar que muchos de los servicios ofrecidos pueden ser en un tour de un sólo día. Dentro de estos operadores se encuentran:

- Santu Tour Operador.

- Maras Adventure.

- KantuPeru Tours.

- Guías independientes.

Son cinco los factores que se debe tener en cuenta para conocer si la amenaza de los productos sustitutos mencionados es fuerte o débil: Precio de los sustitutos, relación precio calidad, cercanía de los sustitutos, costo de cambio y preferencia del cliente por el sustituto (Porter M. E., 2008).

En el caso del sustituto timeshare la cercanía sería el primer factor para determinar, no es una amenaza muy fuerte debido a que se encuentran alejados de los principales lugares turísticos de la ciudad y además no existe mucha oferta.

En cuanto a los sustitutos de alimentación y bebidas, habría que considerar la preferencia del turista en cuanto a recorrer diversos restaurantes y bares o permanecer en un hotel donde encuentre estos servicios, además del costo que implica movilizarse de un lugar a 
otro y sobretodo la seguridad al encontrarse en una ciudad que no conoce; por lo tanto, es una amenaza medianamente fuerte dependiendo como se mencionó de los gustos y preferencias del cliente; sin embargo, los operadores turísticos se consideran una amenaza fuerte ya que podrían cubrir muy bien la relación precio calidad ya que conocen la ciudad, las costumbres y pueden cobrar un precio menor o igual al de un hotel; ofrecen servicios de movilidad desde el punto que el turista prefiera, cubriendo el factor cercanía; y además logran satisfacer de igual forma que un hotel o incluso mejor al poder brindar un servicio personalizado, la necesidad de experimentar el turismo vivencial incluso en tours de un solo día.

\subsubsection{Rivalidad entre competidores actuales.}

La competencia en el sector hotelero de la ciudad del Cusco es basta. Para inicios del 2016, la Dirección regional de Comercio Exterior y Turismo (DIRCETUR) registraba 1740 establecimientos de hospedaje en toda la región del Cusco, de los cuales solo 253 se encuentran categorizados (DIRCETUR, 2016). (Amenaza)

Tabla 7.

Número de Hospedajes categorizados

\begin{tabular}{cccc}
\hline Categoría & $\mathrm{N}^{\circ}$ Hospedajes & $\mathrm{N}^{\circ}$ Habitaciones & $\mathrm{N}^{\circ}$ Camas \\
\hline 1 estrella & 45 & 776 & 1317 \\
2 estrellas & 109 & 2113 & 3755 \\
3 estrellas & 74 & 2578 & 5129 \\
4 estrellas & 7 & 748 & 1386 \\
5 estrellas & 9 & 960 & 1903 \\
Albergue & 9 & 126 & 385 \\
\hline Total general & 253 & 7301 & 13875 \\
\hline
\end{tabular}

Nota: Tomado de Boletín Estadístico de Turismo 2015 (pág. 7) por DIRCETUR Cusco, 2016. Recuperado de http://www.dirceturcusco.gob.pe/wp-content/uploads/2017/07/BOLETINESTADISTICO-2015-Final.pdf 
De acuerdo el caso de estudio, para delimitar la competencia directa, se hace énfasis en el papel que juegan los recursos intangibles como la ventaja competitiva, marca, estrategia, etc. de los establecimientos de hospedaje participantes de la industria.

Definimos inicialmente como competencia directa a aquellos centros de hospedaje categorizados como Albergues que ofrecen experiencias vivenciales en los alrededores de Cusco. Según el Reglamento de Establecimientos de Hospedaje, se define de la siguiente manera (Ministerio de Comercio Exterior y Turismo, 2015).

Albergue: Establecimiento de hospedaje que presta servicio de alojamiento, preferentemente en habitaciones comunes, a un grupo de huéspedes que comparten uno o varios intereses y actividades a fines. Su ubicación y/o los intereses y actividades de sus huéspedes determinan la modalidad de este.

En este sentido la rivalidad con los competidores es alta, pues a pesar de que muchos hospedajes no estén categorizados e inscritos en la dirección de turismo, se pueden encontrar hoteles y albergues en Maras y cerca de la zona de estudio.

El Mincetur actualiza todos los años el Directorio Nacional de Servicio Turístico Calificados donde se encuentra la información más reciente sobre la calificación y categorización de los establecimientos de hospedaje, además de otros rubros del turismo. Esta fuente indica los siguientes datos con respecto a la categoría de albergues (Ministerio de Comercio Exterior y Turismo, 2017): 
Tabla 8 .

Hospedajes categorizados como Albergue

\begin{tabular}{cccc}
\hline Categoría & $\mathrm{N}^{\circ}$ Hospedajes & $\mathrm{N}^{\circ}$ Habitaciones & $\mathrm{N}^{\circ}$ Camas \\
\hline Albergue & 10 & 149 & 422
\end{tabular}

Nota: Adaptado de Directorio Nacional de Prestadores de Servicios Turísticos Clasificados por MINCETUR, 2017. Recuperado de http://consultasenlinea.mincetur.gob.pe/setregiones/(S(wyfqntyhjpk4c1oyioj5ikfk))/Reportes/WebReportes/RptListadoCoincidencias.as px?StrTipo=2\&Var=01|||05|12||080000|

Para el análisis de los competidores actuales se usarán los albergues categorizados según el directorio en mención y con ubigeo en el departamento del Cusco. 
Tabla 9.

Albergues inscritos en la Dirección Regional de Turismo con información de hospedaje.

\begin{tabular}{|c|c|c|c|c|c|c|c|c|}
\hline Categoría & Nombre Comercial & Distrito & $\begin{array}{c}\text { Precio s/. } \\
\text { desde }\end{array}$ & $\begin{array}{c}\text { Precio US\$ } \\
(3.35)\end{array}$ & Estilo & \# hab. & \# Camas & Tiempo en el mercado \\
\hline Albergue & Albergue Municipal & Cusco & 115 & 34 & Moderno & 12 & 40 & Desde 15 de mayo de 2015 \\
\hline Albergue & Ausangate Logde & Ocongate & 280 & 84 & Campestre-romántico & 15 & 27 & Desde 02 de octubre de 2015 \\
\hline Albergue & Collpapampa Lodge & Santa Teresa & 280 & 84 & Campestre moderno & 6 & 12 & Desde 06 de mayo de 2015 \\
\hline Albergue & Eco Quechua Lodge & Santa Teresa & 184 & 55 & Campestre moderno & 10 & 16 & Desde 17 de mayo de 2017 \\
\hline Albergue & El Mangal S.C.R.L. & Maranura & 290 & 87 & Colonial moderno & 7 & 9 & Desde 04 de diciembre de 2012 \\
\hline Albergue & El Mercado & Cusco & 480 & 143 & Colonial moderno & 32 & 64 & Desde 06 de mayo de 2015 \\
\hline Albergue & El Retablo & Cusco & 469 & 140 & Colonial moderno & 17 & 17 & Desde 04 de mayo de 2017 \\
\hline Albergue & Lucmabamba Lodge & Santa Teresa & 280 & 84 & Campestre moderno & 6 & 12 & Desde 06 de mayo de 2015 \\
\hline Albergue & Manu Paradise & Kosñipata & 304 & 91 & Moderno-natural & 6 & 20 & Desde 27 de diciembre de 2012 \\
\hline \multirow[t]{2}{*}{ Albergue } & Pariwana Cusco & Cusco & 182 & 54 & Moderno & 38 & 205 & Desde 06 de octubre de 2015 \\
\hline & & & & & Total & 149 & 422 & \\
\hline
\end{tabular}

Nota: Adaptado de Directorio Nacional de Prestadores de Servicios Turísticos Clasificados por MINCETUR, 2017. Recuperado de http://consultasenlinea.mincetur.gob.pe/set-

regiones/(S(wyfqntyhjpk4c1oyioj5ikfk))/Reportes/WebReportes/RptListadoCoincidencias.aspx?StrTipo=2\&Var=01||05|12||080000| 
Delimitando la competencia al hospedaje categorizados como albergue, la competencia en esta zona se limita a 10 hospedajes, con una capacidad de 422 camas. A continuación, se presentan las principales características de esos 10 albergues:

Tabla 10.

Albergue municipal

Razón Social: $\quad$ Municipalidad Provincial Del Cusco

Web Site:

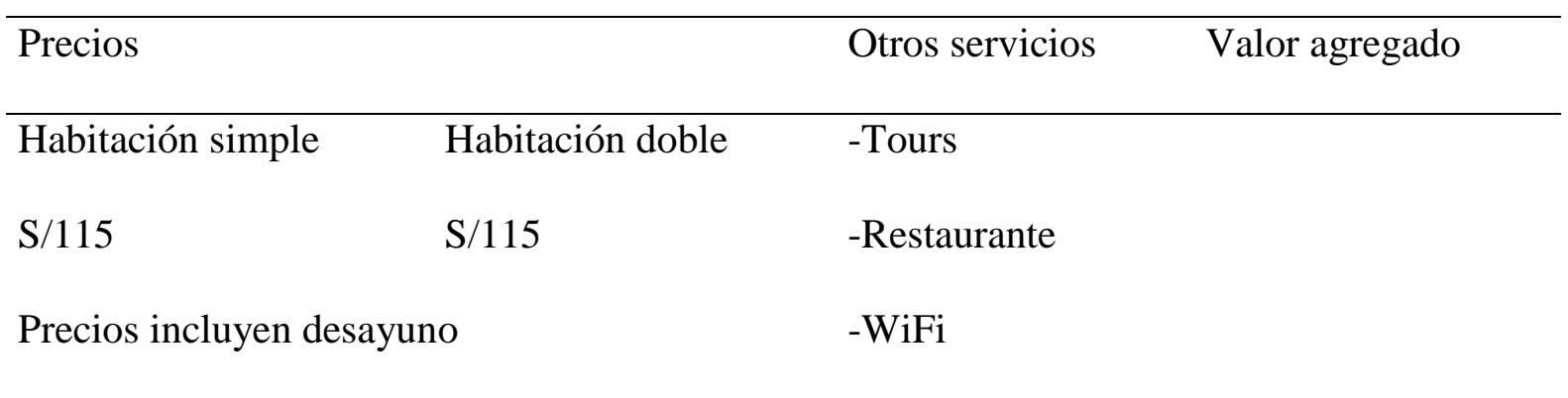

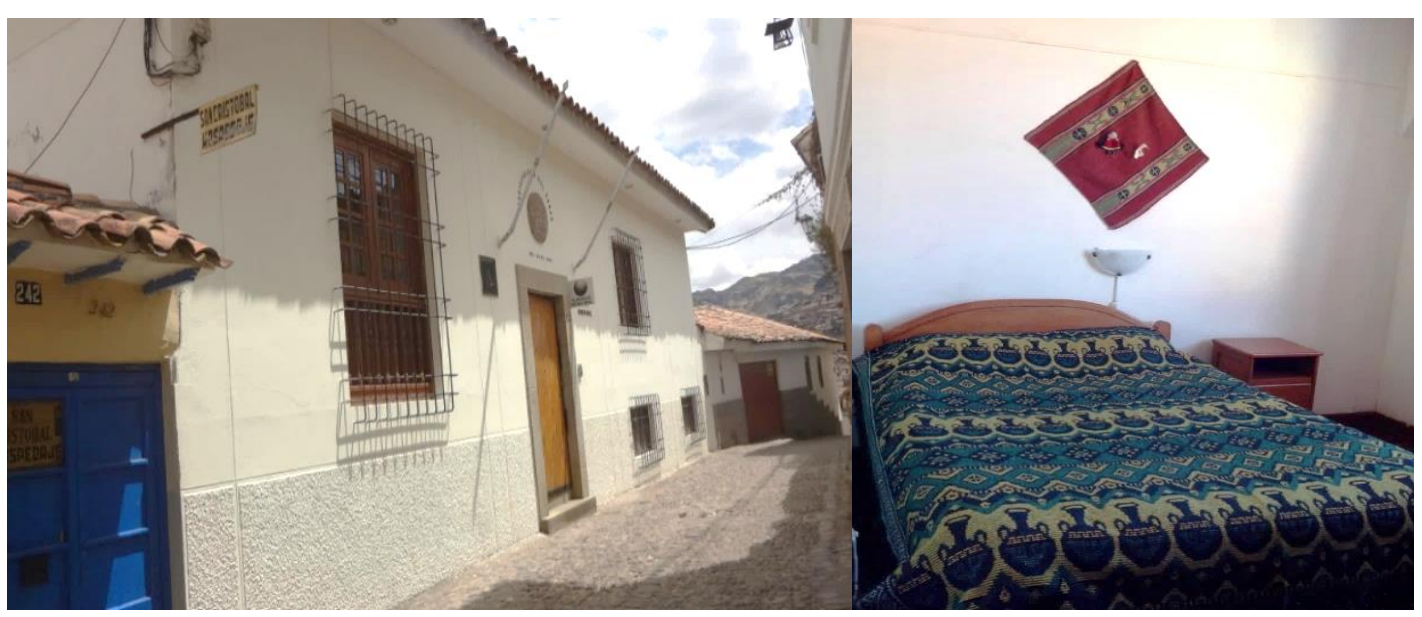

Figura 6. Fotos de albergue municipal. Recuperadas de booking.com 
Tabla 11.

Ausangate lodge

Razón Social: $\quad$ Ausangate Logde E.I.R.L

Web Site: $\quad$ www.infoausangatelogde.com

\begin{tabular}{|c|c|c|c|}
\hline Precios & & Otros servicios & Valor agregado \\
\hline Habitación simple & Habitación doble & -Tours & \\
\hline $\mathrm{S} / 280$ & $\mathrm{~S} / 280$ & -Restaurante & \\
\hline Precios incluyen de & & $-\mathrm{WiFi}$ & \\
\hline
\end{tabular}

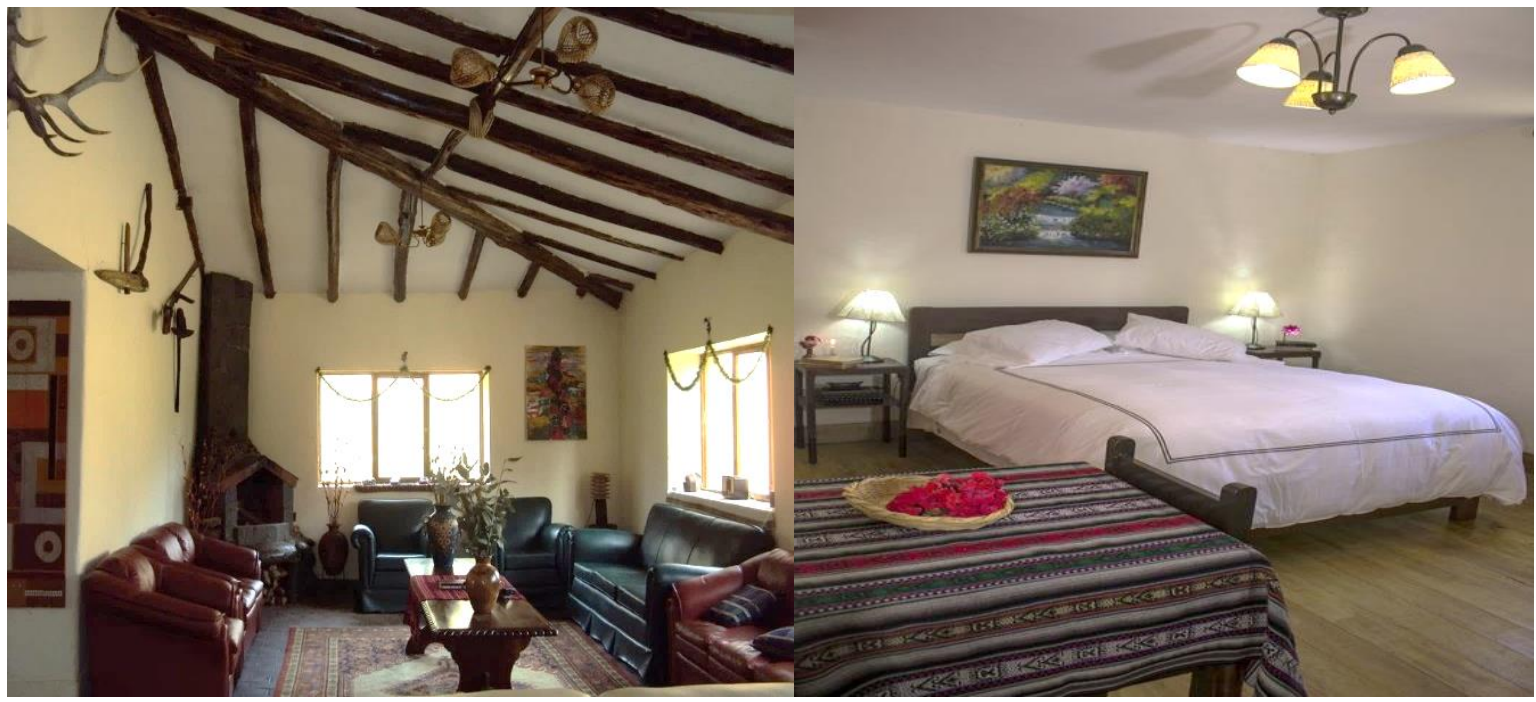

Figura 7. Fotos de Ausangate lodge. Recuperadas de booking.com 
Tabla 12.

Collpapampa Lodge

Razón Social: $\quad$ Mountain Lodges of Peru S.A.C.

Web Site: $\quad$ www.mountainlodgesofperu.com/salkantay/the-lodges

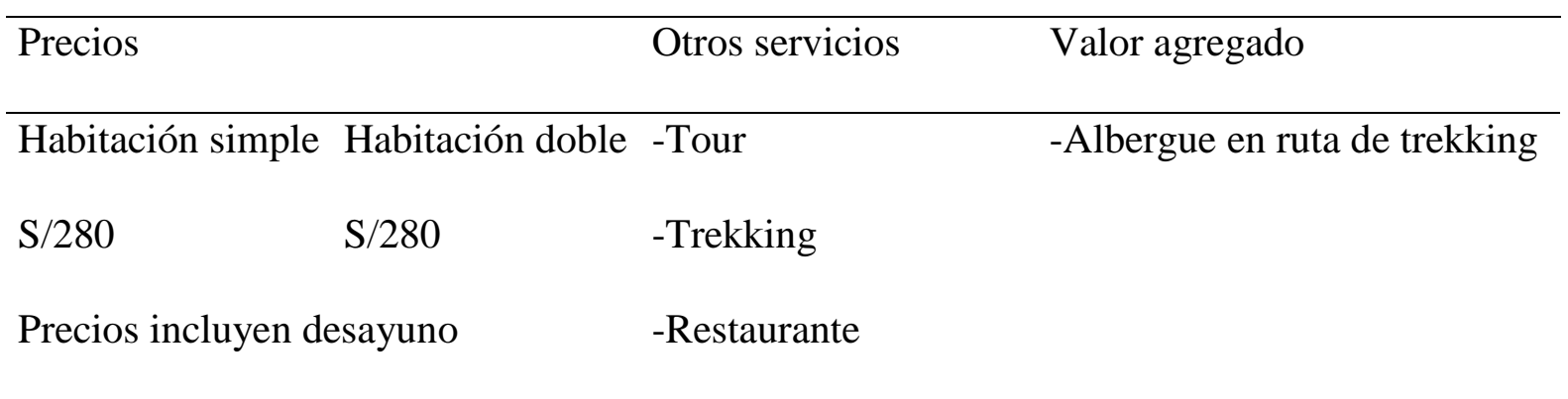

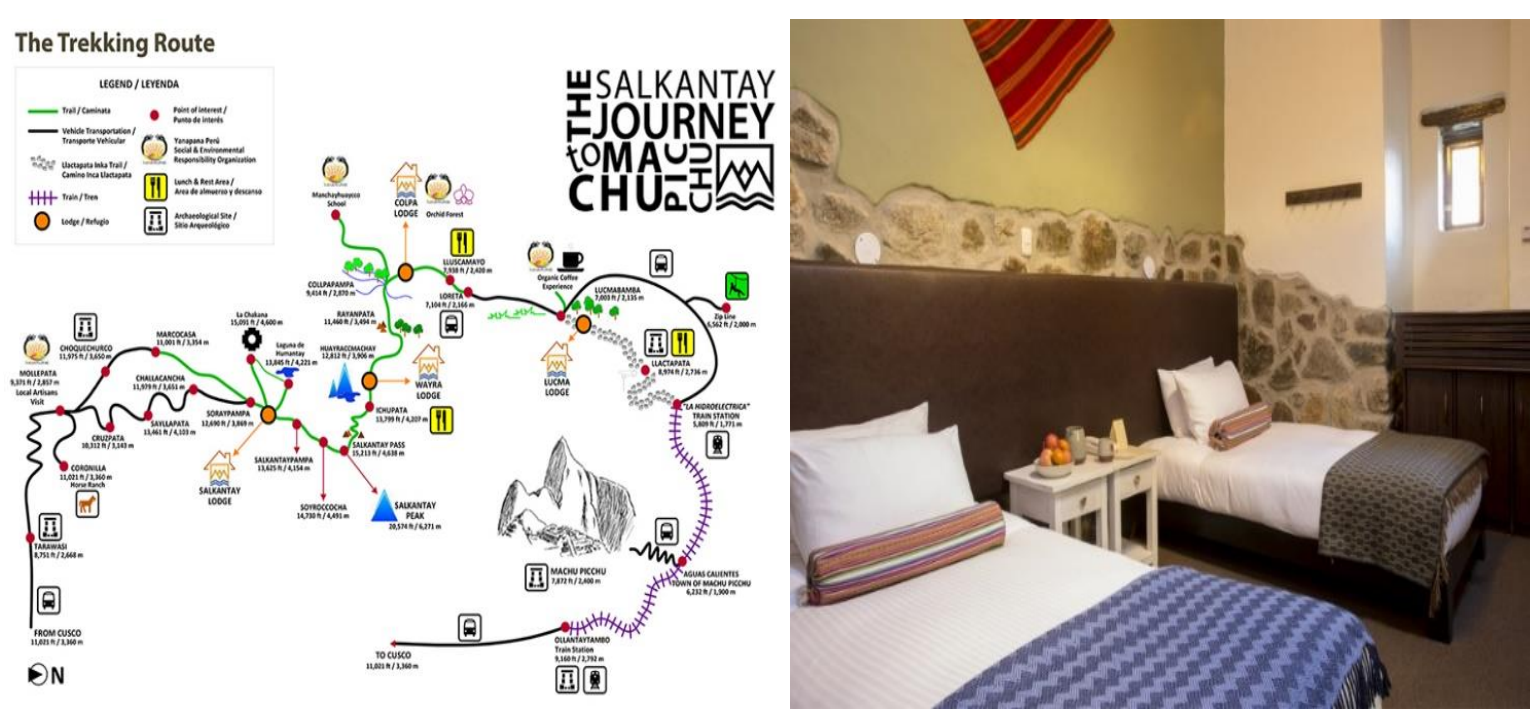

Figura 8. Fotos de Collpapampa Lodge: Recuperadas de booking.com y mountainlodgesofperu.com/salkantay/the-lodges 
Tabla 13.

Eco Quechua Lodge

Razón Social: $\quad$ Eco Quechua Lodge E.I.R.L.

Web Site:

\begin{tabular}{llll}
\hline Precios & & Otros servicios & Valor agregado \\
\hline Habitación simple & Habitación doble & -Tour & -Visita comunidades indígenas \\
S/184 & S/184 & -Restaurante & \\
Precios incluyen desayuno & -WiFi & \\
\end{tabular}

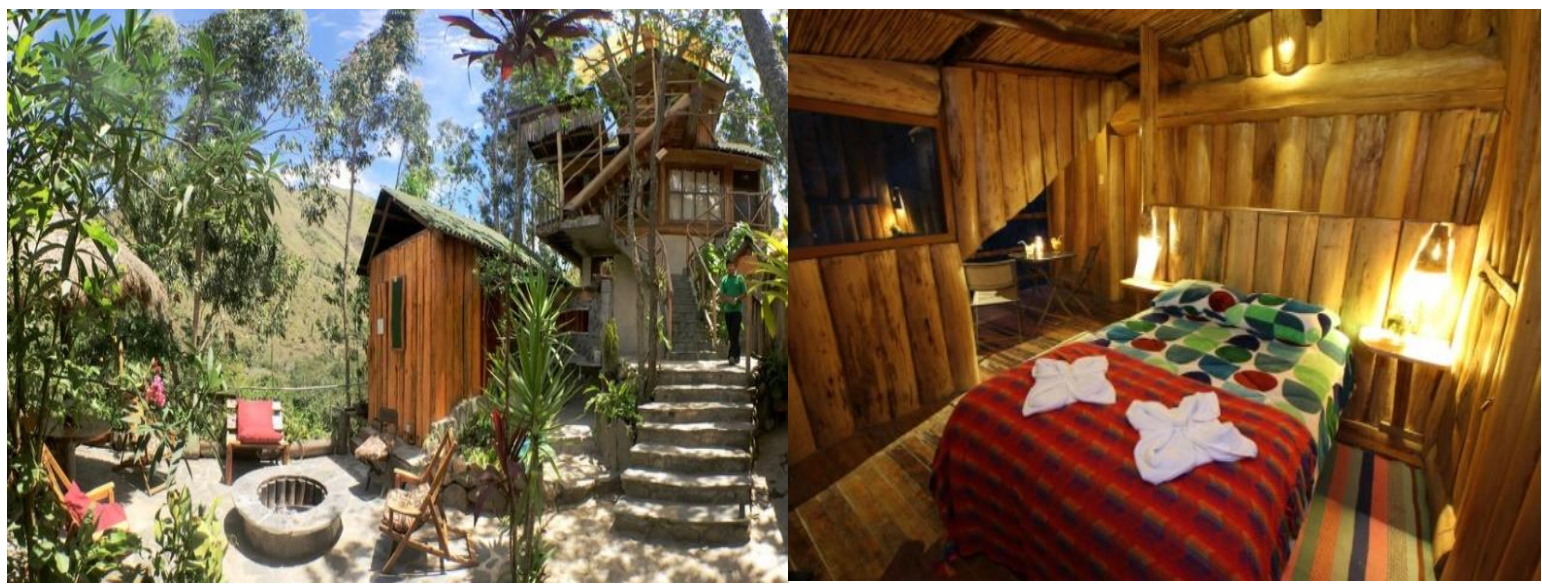

Figura 9. Fotos de Eco Quechua Lodge. Recuperadas de booking.com 
Tabla 14.

El Mangal S.C.R.L.

Razón Social: $\quad$ El Mangal S.C.R.L.

Web Site: $\quad$ www.elmangal.com

\begin{tabular}{llll}
\hline Precios & & Otros servicios & Valor agregado \\
\hline Habitación simple & Habitación doble & -Tour & -Agroturismo \\
S/300 & S/290 & -Restaurante & \\
Precios incluyen desayuno & -Piscina & \\
\end{tabular}

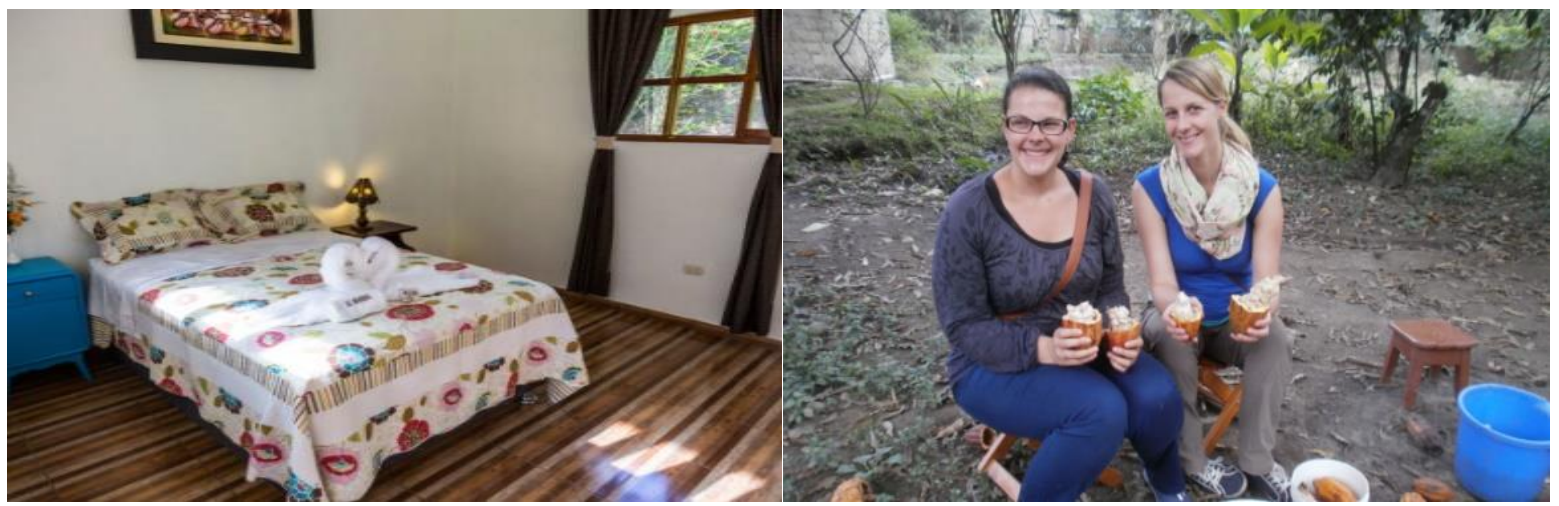

Figura 10. Fotos de El Mangal SCRL. Recuperadas de elmangal.com 
Tabla 15.

El Mercado by Mountain Lodges of Peru

Razón Social: $\quad$ Mountain Lodges of Peru S.A.C.

Web Site: $\quad$ www.elmercadocusco.com/es-es/

\begin{tabular}{llll}
\hline Precios & & Otros servicios & Valor agregado \\
\hline Habitación simple & Habitación doble & -Tour & -Mercado dentro del hospedaje \\
S/480 & S/580 & -Restaurante/Bar & \\
Precios incluyen desayuno & -Lavandería & \\
& & -Masajes &
\end{tabular}

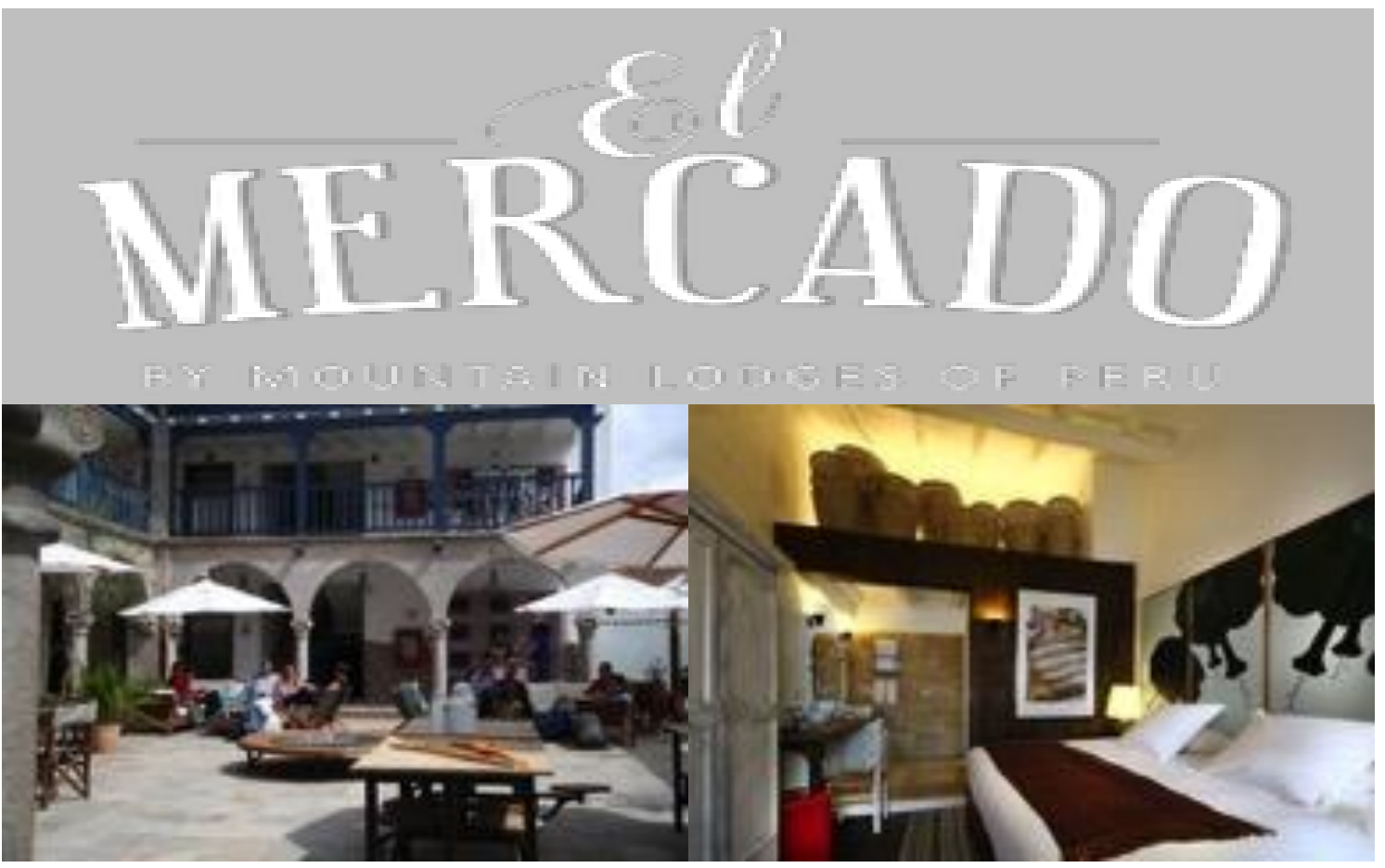

Figura 11. Fotos de El Mercado. Recuperado de elmercadocusco.com 
Tabla 16.

El Retablo

Razón Social: $\quad$ Mountain Lodges of Peru S.A.C.

Web Site: $\quad$ www.elretablo.com

\begin{tabular}{|c|c|c|c|}
\hline Precios & & Otros servicios & Valor agregado \\
\hline Habitación simple & Habitación doble & -Tour & \\
\hline $\mathrm{S} / 469$ & S/469 & -Restaurante & \\
\hline Precios incluyen de & & $-\mathrm{WiFi}$ & \\
\hline
\end{tabular}

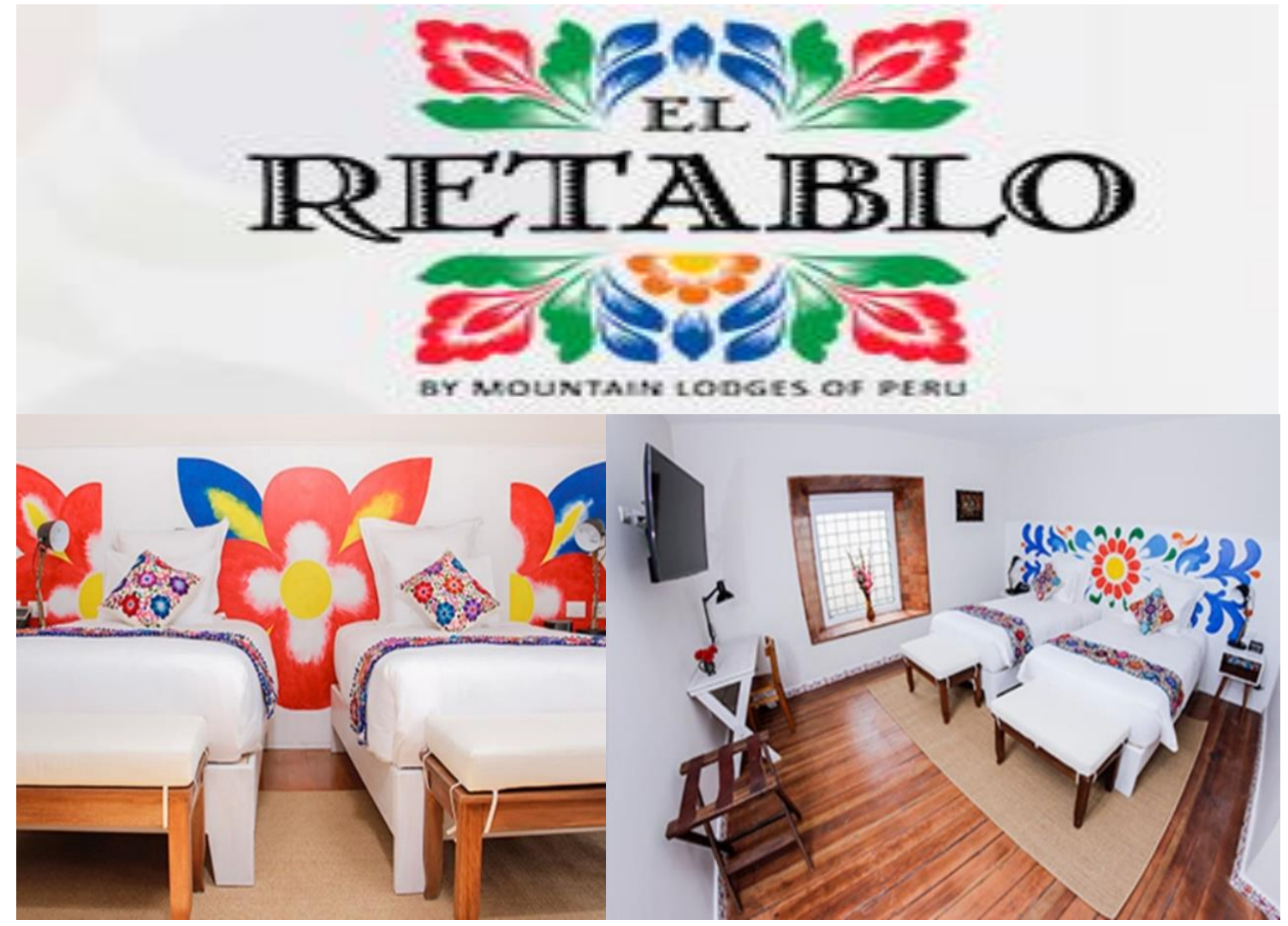

Figura 12. Fotos de El Retablo. Recuperadas de elretablo.com 
Tabla 17.

\section{Lucmabamba lodge}

Razón Social: Mountain Lodges Of Peru S.A.C.

Web Site: www.mountainlodgesofperu.com/salkantay/the-lodges

\begin{tabular}{llll}
\hline Precios & Otros servicios & Valor agregado \\
\hline Habitación & Habitación doble & -Tour & -Albergue en ruta de trekking \\
simple & & & \\
S/280 & S $/ 280$ & -Trekking & \\
Precios incluyen desayuno & -Restaurante & \\
\end{tabular}

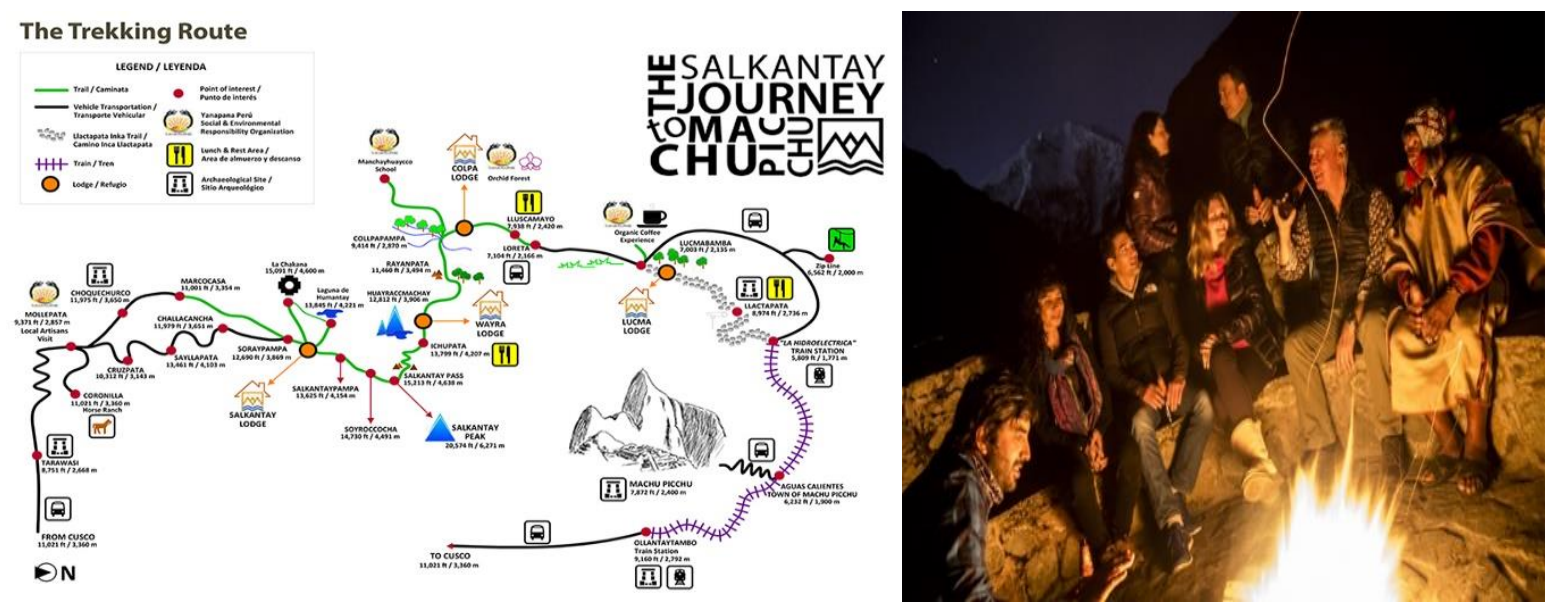

Figura 13. Fotos de Lucmabamba lodge. Recuperado de mountainlodgesofperu.com/salkantay/the-lodges 
Tabla 18.

Manu Paradise

Razón Social: $\quad$ Inversiones Quinsamayo Sociedad Anonima Cerrada

Web Site: $\quad$ www.manuparadiselodge.com

\begin{tabular}{llll}
\hline Precios & & Otros servicios & Valor agregado \\
\hline Habitación simple & Habitación doble & -Nature tour & -Birdwatching \\
S/350 & S/308 & -Restaurante & -Plena naturaleza \\
\multicolumn{2}{l}{ Precios incluyen desayuno } & &
\end{tabular}

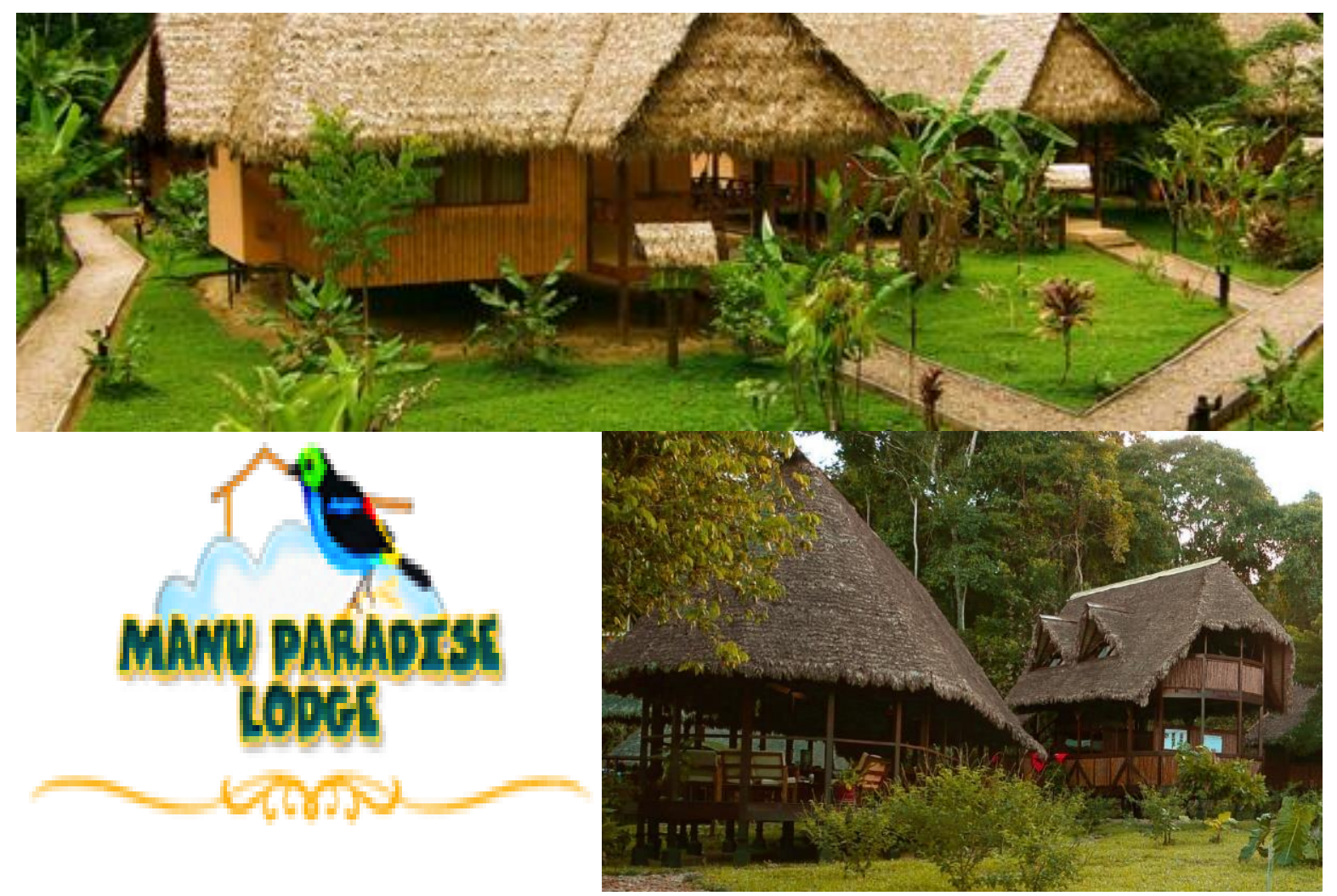

Figura 14. Fotosde Manu Paradise. Recuperadas de flickr.com/photos/134426640@N02/ 
Tabla 19.

Pariwana Cusco Hostel

Razón Social: $\quad$ Investur Cusco S.A.C.

Web Site: $\quad$ www.pariwana-hostel.com

\begin{tabular}{|c|c|c|c|}
\hline Precios & & Otros servicios & Valor agregado \\
\hline Habitación simple & Habitación doble & -Restaurante/Bar & \\
\hline S/182 & $\mathrm{S} / 182$ & $-\mathrm{WiFi}$ & \\
\hline
\end{tabular}

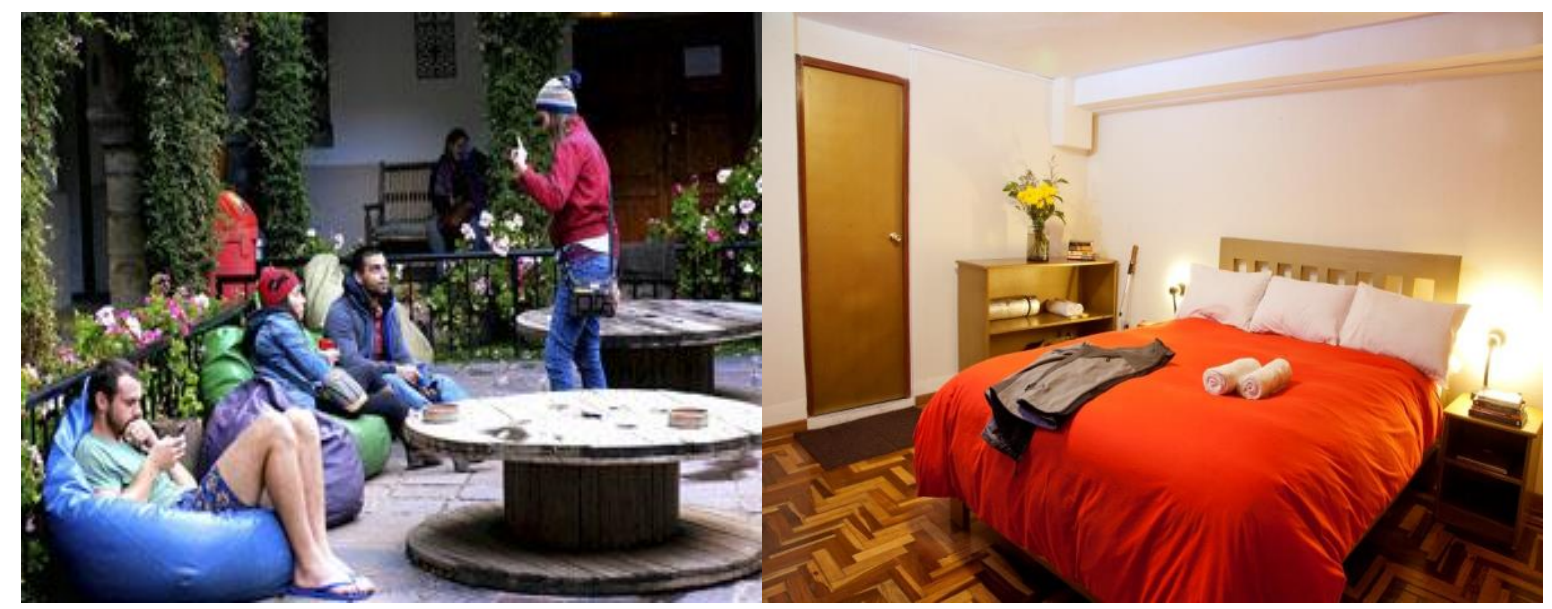

Figura 15. Fotos de Pariwana Cusco Hostel. Recuperadas de booking.com

En cuanto al turismo vivencial que se practica en la zona a través de actividades de turismo rural y comunitario, es importante mencionar a los poblados que disponen de hogares para recibir a flujos de turistas interesados en este tipo de experiencias en la provincia de Urubamba. Como las listadas a continuación:

- Asociación de Turismo Vivencial Misminay-Moray

- Asociación de Turismo Vivencial Wañinmarca-Moray

- Comunidad de Willoq- Ollantaytambo 
- La tierra de los Yachaqs- Ollantaytambo

- Asociación de turismo Vivencial Huilloq Ayllu Inca

La rivalidad con ellos no sería alta pues, el proyecto pretende brindar infraestructura hotelera acorde lo delimitado por el MINCETUR. 
Tabla 20.

Oportunidades y Amenazas del mercado en estudio

\begin{tabular}{|ccc|}
\hline Bajo & Medio & Alto \\
\hline $1,50 \%$ & $2,00 \%$ & $2,50 \%$ \\
\hline
\end{tabular}

\section{FACTORES EXTERNOS CLAVES}

\begin{tabular}{|c|c|c|c|c|c|}
\hline \# & OPORTUNIDAD & ENTORNO & $\begin{array}{c}\text { Peso } \\
\text { Relativ } \\
\text { o }\end{array}$ & Valor & $\begin{array}{l}\text { Sopesa } \\
\text { do }\end{array}$ \\
\hline 1 & Política expansiva del gobierno a la promoción del turismo & Político y legal & $2,00 \%$ & 4 & 0,08 \\
\hline 2 & El nuevo reglamento de hospedaje se ajusta a las necesidades reales del sector & Político y legal & $1,50 \%$ & 3 & 0,045 \\
\hline 3 & $\begin{array}{l}\text { El PENTUR contempla el turismo vivencial como una de sus principales } \\
\text { oportunidades }\end{array}$ & Político y legal & $2,00 \%$ & 4 & 0,08 \\
\hline 4 & Los clientes extranjeros no pagan IGV ni en hospedaje ni en alimentación & Político y legal & $1,50 \%$ & 4 & 0,06 \\
\hline 5 & $\begin{array}{l}\text { Creación de la ventanilla única de turismo que permite agilizar permisos, licencias, } \\
\text { etc. }\end{array}$ & Político y legal & $1,50 \%$ & 2 & 0,03 \\
\hline 6 & Aeropuerto en Chinchero-Cusco incrementará la demanda de hospedaje de la zona & Económico & $2,50 \%$ & 4 & 0,1 \\
\hline 7 & Incremento de la demanda de turismo a nivel mundial & Económico & $2,00 \%$ & 2 & 0,04 \\
\hline 8 & Los pobladores de maras están capacitados en temas turísticos & Económico & $2,00 \%$ & 2 & 0,04 \\
\hline 9 & Poca oferta hotelera formal en Maras & Económico & $2,50 \%$ & 3 & 0,075 \\
\hline 10 & Incremento en los visitantes al complejo arqueológico de Moray & Económico & $2,50 \%$ & 4 & 0,1 \\
\hline 11 & El cliente busca experiencias únicas y diferentes & Social & $2,50 \%$ & 4 & 0,1 \\
\hline 12 & Boom del turismo gastronómico & Social & $1,50 \%$ & 4 & 0,06 \\
\hline 13 & Los millennials, la nueva forma de marketing hotelero y la oferta en Perú & Social & $2,00 \%$ & 3 & 0,06 \\
\hline 14 & Permanencia promedio de 9 noches y Gasto promedio US\$ 1108 & Social & $2,50 \%$ & 2 & 0,05 \\
\hline 15 & $\begin{array}{l}\text { Los asiáticos y los estadounidenses, que son los que más gastan en su estadía } \\
\text { contratan paquetes turísticos }\end{array}$ & Social & $2,50 \%$ & 3 & 0,075 \\
\hline 16 & $\begin{array}{l}\text { Los que adquirieron un paquete turístico, fueron los que realizaron un mayor gasto } \\
\text { promedio durante toda su estadía }\end{array}$ & Social & $2,50 \%$ & 2 & 0,05 \\
\hline 17 & El 95\% de los vacacionistas Premium que llegaron al Perú, visitaron Cusco & Social & $2,50 \%$ & 4 & 0,1 \\
\hline 18 & El incentivar el turismo vivencial contribuye a elevar el desarrollo socioeconómico & Social & $1,50 \%$ & 4 & 0,06 \\
\hline 19 & $\begin{array}{l}\text { Organismos internacionales impulsan la preservación del patrimonio material e } \\
\text { inmaterial }\end{array}$ & Social & $1,50 \%$ & 1 & 0,015 \\
\hline 20 & La sal de Maras revalora al poblado y sus costumbres & Social & $2,00 \%$ & 4 & 0,08 \\
\hline 21 & Uso de redes sociales como motivadores de viajes & Tecnológico & $2,00 \%$ & 3 & 0,06 \\
\hline
\end{tabular}


22 Uso de apps como plataformas de promoción para negocios turísticos

23 Uso de drones en promoción turística

24 Uso de equipos tecnológicos de vanguardia (tablets')

25 Habitaciones oxigenadas por sistemas computarizados

26 Hospedajes vivenciales que respeten la diversidad cultural y tengan políticas de inclusión, pueden obtener ventajas estratégicas de su relacionamiento con la comunidad

27 El paisaje contribuye a prácticas de turismo sostenible como la fotografía y el ciclismo

28 Tendencia de turismo vivencial y alimentación saludable

29 Bajo poder de negociación de proveedores de alimentos básicos en hotel: alimentación, menaje, página web y transporte.

30 Barreras de entrada que el gobierno establece no permite fácilmente el ingreso de nuevos competidores.

31 Oferta de turismo vivencial muy precaria en la zona

\begin{tabular}{|c|c|c|c|}
\hline Tecnológico & $2,00 \%$ & 3 & 0,06 \\
\hline Tecnológico & $1,50 \%$ & 4 & 0,06 \\
\hline Tecnológico & $1,50 \%$ & 4 & 0,06 \\
\hline Tecnológico & $1,50 \%$ & 2 & 0,03 \\
\hline Ecológico & $2,50 \%$ & 4 & 0,1 \\
\hline Ecológico & $2,50 \%$ & 4 & 0,1 \\
\hline Ecológico & $2,50 \%$ & 4 & 0,1 \\
\hline Porter & $2,50 \%$ & 3 & 0,075 \\
\hline Porter & $2,00 \%$ & 2 & 0,04 \\
\hline Porter & $1,50 \%$ & 3 & 0,045 \\
\hline \multicolumn{3}{|c|}{ Subtotal oportunidades } & 2,03 \\
\hline ENTORNO & Peso Relativo & $\begin{array}{c}\text { Val } \\
\text { or }\end{array}$ & $\begin{array}{c}\text { Sopesa } \\
\text { do }\end{array}$ \\
\hline Político y legal & $1,50 \%$ & 2 & 0,03 \\
\hline Político y legal & $1,50 \%$ & 1 & 0,015 \\
\hline Económico & $2,00 \%$ & 1 & 0,02 \\
\hline Económico & $1,50 \%$ & 1 & 0,015 \\
\hline Económico & $2,00 \%$ & 1 & 0,02 \\
\hline Económico & $2,50 \%$ & 2 & 0,05 \\
\hline Social & $2,00 \%$ & 2 & 0,04 \\
\hline Social & $1,50 \%$ & 4 & 0,06 \\
\hline Tecnológico & $1,50 \%$ & 2 & 0,03 \\
\hline Tecnológico & $2,00 \%$ & 4 & 0,08 \\
\hline Ecológico & $1,50 \%$ & 2 & 0,03 \\
\hline Ecológico & $2,00 \%$ & 2 & 0,04 \\
\hline
\end{tabular}


13 Alto poder de negociación de los clientes directos

14 Alto poder de negociación de los clientes indirectos

15 Alto poder de negociación de proveedores de insumos especializados, servicios básicos y proveedores de mano de obra calificada.

16 Operadores turísticos, que brindan los mismos servicios de turismo vivencial

17 Alta oferta de hospedaje (1740 establecimientos registrados en Cusco)

18 No es necesario un capital muy alto para iniciar un negocio en la industria hotelera.

19 El Perú es el mercado más atrayente para la inversión hotelera lo cual atrae nueva competencia

20 Agencias de viajes ofrecen servicios de turismo vivencial en la zona de Urubamba como excursión.

\begin{tabular}{|c|c|c|c|}
\hline Porter & $2,00 \%$ & 2 & 0,04 \\
\hline Porter & $1,50 \%$ & 2 & 0,03 \\
\hline Porter & $2,00 \%$ & 2 & 0,04 \\
\hline Porter & $2,00 \%$ & 1 & 0,02 \\
\hline Porter & $2,50 \%$ & 1 & 0,025 \\
\hline Porter & $2,00 \%$ & 1 & 0,02 \\
\hline Porter & $1,50 \%$ & 2 & 0,03 \\
\hline Porter & $2,00 \%$ & 3 & 0,06 \\
\hline \multicolumn{2}{|c|}{ Subtotal Amenazas } & & 0,695 \\
\hline Total & $100,00 \%$ & & 2,725 \\
\hline
\end{tabular}




\section{Capítulo III: Estudio de Mercado}

\subsection{Descripción del servicio y producto}

El albergue vivencial "La hacienda Kachi Raqay" en Maras, brinda el servicio de hospedaje con categoría de albergue, donde el huésped tendrá la oportunidad de vivir y experimentar las costumbres propias del pueblo en convivencia con gente del lugar, gozando de servicios de calidad. A continuación, se describen brevemente los servicios (intangibles); así como los productos (tangibles) que se entregan a los huéspedes durante su estadía:

Como se mencionó en el capítulo anterior, definimos albergue como: el establecimiento de hospedaje que presta servicio de alojamiento, preferentemente en habitaciones comunes, a un grupo de huéspedes que comparten uno o varios intereses y actividades a fines. Su ubicación y/o los intereses y actividades de sus huéspedes determinan la modalidad de este (Ministerio de Comercio Exterior y Turismo, 2015).

- El albergue vivencial “La Hacienda Kachi Raqay” ofrecerá servicios de alojamiento bajo los estándares de calidad de una experiencia hotelera. Estos servicios serán brindados de la mano de pobladores locales, quienes compartirán sus tradiciones, usos y costumbres, durante su estadía.

- En las comidas los huéspedes compartirán la mesa con pobladores locales, probarán la sazón de una cocina tradicional elaborada en base a productos del lugar y preparación propia de la zona, con cocineros locales. 
- Podrán degustar la chicha de jora, bebida clásica de la zona. Se ofrecerán tours guiados en diversos medios (motos, caballo, a pie), al centro arqueológico de Moray y a las salineras de Maras.

- La infraestructura del albergue tendrá una apariencia rústica con elementos de construcción propios de la zona.

- Las zonas comunes serán el restaurante, un bar, una habitación oxigenada, una sala de entretenimiento con televisión, juegos de mesa, biblioteca y áreas verdes con bancas.

\subsection{Investigación cualitativa}

Propuesta estudio cualitativo del proyecto para el albergue vivencial "La hacienda Kachi Raqay” en Maras, Cusco.

\section{Antecedentes}

Como se mencionó en el capítulo I de antecedentes, el 64\% del turismo receptivo en el Perú durante el 2015 estuvo conformado por aquellos turistas que viajan por motivos vacacionales y de esparcimiento, los cuales tienen una permanencia promedio de 9 noches gastando alrededor de US\$ 1108 por noche. De acuerdo con la investigación expuesta en el capítulo 2 sobre el perfil del turista vacacionista que visita el Perú, el 31\% de los turistas fueron de origen chileno y $16 \%$ de los Estados Unidos. Siendo el turista de los Estados Unidos el que generó mayores divisas para el país (US\$ 707 millones). De los cuales solo un $35 \%$ contrató un paquete turístico para visitar el Perú. 


\subsubsection{Estudio cualitativo a turistas vacacionales.}

\subsubsection{Propósito general.}

En función a estos datos, se decide investigar el nivel de aceptación o rechazo de un albergue vivencial en el distrito de Maras, en la provincia de Urubamba, por parte de las personas que viajan con motivos vacacionales al departamento del Cusco, Perú.

\subsubsection{Público objetivo}

Personas que viajan con motivos vacacionales al departamento del Cusco, Perú.

\subsubsection{Propósitos específicos del estudio}

- Determinar la percepción y los hábitos, gustos y preferencias del público objetivo mencionado.

- Determinar el proceso de compra de un paquete turístico: (a) personas que intervienen y están a cargo de la compra; (b) quienes ejercen influencia, factores críticos de compra y barreras.

- Determinar quienes toman la decisión y quienes influyen en el proceso de compra de un paquete turístico para visitar el Cusco.

- Explorar el nivel de conocimiento sobre el poblado de Maras en Urubamba.

- Averiguar la percepción sobre el turismo vivencial: ventajas y desventajas.

- Identificar la apreciación que tienen sobre los albergues en el departamento del Cusco, el conocimiento sobre lo que ofrece la competencia y su concepto de albergue ideal. 
- Determinar las expectativas sobre un albergue vivencial, los aspectos tangibles e intangibles esperados.

- Indagar sobre el nivel de aceptación del proyecto.

Tabla 21.

Objetivos del estudio de mercado cualitativo del turista

\begin{tabular}{|c|c|}
\hline $\begin{array}{l}\text { Objetivo } \\
\text { General: }\end{array}$ & Objetivos Específicos \\
\hline $\begin{array}{l}\text { 1. Acerca del } \\
\text { público objetivo }\end{array}$ & $\begin{array}{l}\text { País de origen } \\
\text { Idioma } \\
\text { Genero } \\
\text { Edad } \\
\text { Estado civil }\end{array}$ \\
\hline $\begin{array}{l}\text { 2. Acerca de los } \\
\text { hábitos de viaje }\end{array}$ & $\begin{array}{l}\text { Últimos destinos visitados en los últimos dos años. } \\
\text { Número de viajes al año. } \\
\text { Motivo de viaje al cusco específicamente. } \\
\text { Acompañamiento. } \\
\text { Decisor de compra de destino y canal. } \\
\text { Influencia en la decisión de compra (búsqueda del destino). } \\
\text { Medios consultados para el destino. } \\
\text { Tiempo de planeamiento del viaje. } \\
\text { Agente de viajes utilizado (cual). } \\
\text { Tiempo de permanencia. } \\
\text { Promedio de gasto por persona. } \\
\text { Lugares visitados en Cusco. } \\
\text { Medio de transporte utilizado para llegar a Cusco. } \\
\text { Lugar de estadía (Hospedaje). } \\
\text { Factores que determinan elección de hospedaje. Ranking de los } \\
\text { principales. } \\
\text { Ventajas y desventajas de su viaje (razones). }\end{array}$ \\
\hline $\begin{array}{l}\text { 3. Acerca del } \\
\text { Distrito de Maras }\end{array}$ & $\begin{array}{l}\text { Nivel de Conocimiento } \\
\text { Medio de comunicación por el que se enteró del destino } \\
\text { Conocimiento de atractivos turísticos en Maras } \\
\text { Número de visita a Maras } \\
\text { Motivo de visita a Maras } \\
\text { Tiempo de permanencia en Maras } \\
\text { Medio de transporte utilizado para llegar a Maras } \\
\text { Ventajas y desventajas percibidas en Maras (razones). } \\
\text { Nivel de recomendación de visita a Maras. }\end{array}$ \\
\hline $\begin{array}{l}\text { 4. Acerca del } \\
\text { turismo vivencial }\end{array}$ & $\begin{array}{l}\text { Conocimiento del concepto. } \\
\text { Principales asociaciones (modernidad, rustico, social, etc) } \\
\text { Experiencia previa (lugar, calificación, tiempo promedio de estadía, etc.) } \\
\text { Ventajas y desventajas del turismo vivencial (razones). } \\
\text { Nivel de recomendación del turismo vivencial. }\end{array}$ \\
\hline
\end{tabular}




\begin{tabular}{ll}
\hline 5. Acerca de los & Conocimiento del concepto. \\
Albergues & $\begin{array}{l}\text { Principales asociaciones. } \\
\text { Percepción acerca de los servicios en un albergue ideal. }\end{array}$ \\
\hline 6. Evaluación de & Nivel de conocimiento de albergues en cusco. \\
la competencia & Nivel de satisfacción con los albergues en el cusco. \\
de albergues en & Evaluación de infraestructura. \\
el Cusco & Ventajas y desventajas del albergue utilizado. \\
& Nivel de recomendación del albergue. \\
\hline & Evaluación del concepto de turismo vivencial en el hotel. \\
& Evaluación de atributos tangibles (infraestructura, acabado, materiales) \\
& Evaluación de atributos intangibles. \\
7. Acerca del & Servicio esperado. \\
Albergue & Valoración precio Calidad (tarifas). \\
Vivencial & Medios de comunicación ideales. \\
& Forma de Pago. \\
& Promociones ideales. \\
& Nivel de recomendación del albergue vivencial. \\
\hline
\end{tabular}

\subsubsection{Metodología}

En la investigación cualitativa los procesos se clasifican en directos e indirectos, dependiendo si los participantes conocen o no el verdadero propósito de la investigación (Malhotra, 2008, pág. 145). El proceso que se desarrollar en el presente proyecto es de enfoque directo debido a que el propósito de la investigación se revela a los entrevistados.

Se propone un estudio de carácter exploratorio con la aplicación de la técnica cualitativa de entrevista a profundidad. Según Kotler y Armstong la investigación exploratoria se define como la que busca recabar información preliminar que ayudará a definir problemas y a sugerir hipótesis (Kotler \& Armstrong, 2012, pág. 103).

La entrevista cualitativa a profundidad consiste en: "los reiterados encuentros cara a cara entre el investigador y los informantes, dirigidos hacia la comprensión de las perspectivas que tienen los informantes respecto de sus vidas, experiencias o situaciones, tal como las expresan con sus propias palabras” (Taylor \& Bogdan, 2000, pág. 101) 
Para la realización de las entrevistas a profundidad se elaboró la guía de pautas alineada con los objetivos de la investigación. Asimismo, se realizó un cuestionario filtro para confirmar que la muestra cumpla con los requisitos de segmentación. Ver guía de pautas en el Anexo I.

\subsubsection{Determinación de la muestra}

Población: Personas extranjeras que viajan fuera de su país con motivos vacacionales que visitaron el departamento de Cusco, Perú en los últimos dos años (2015 y 2016).

Tipo y técnica de muestreo: Al ser una investigación que requiere mucho tiempo y resulte ser costosa es que se denomina de tipo no probabilístico; teniendo como técnica de muestra por conveniencia debido a que se selecciona a los miembros de la población de quienes será más fácil obtener información (Kotler \& Armstrong, 2012, pág. 114 y 116).

\section{Tabla 22.}

Distribución muestral de entrevistas en profundidad:

\begin{tabular}{lc}
\hline Condición Muestral & Cantidad \\
\hline Turistas que han experimentado turismo vivencial & 5 \\
Turistas que no han experimentado turismo vivencial & 5 \\
\hline
\end{tabular}

La muestra fue hecha a turistas que visitaron el territorio peruano, en los últimos meses. Muchos de ellos y ellas aceptaron nuestra entrevista, pero dado que estuvieron de paso fue necesario hacerles seguimiento y llevar a cabo las entrevistas vía skype. En la mayoría de los casos las entrevistas se hicieron en la ciudad del Cusco e incluso en Estados Unidos, lugar 
de origen de los visitantes. El proceso de entrevista incluyo también el uso del idioma ingles dada la proveniencia de nuestros entrevistados.

Cronograma de la investigación cualitativa a clientes directos: La elaboración del material se inició durante el mes de junio del 2017, tras el levantamiento de observaciones se pasó al trabajo de campo durante las últimas semanas del mes de Julio 2017 para iniciar luego el análisis y la elaboración de los resultados descritos más adelante.

Tabla 23.

Cronograma de actividades cualitativas

Semana

\begin{tabular}{l|llll}
\hline Actividad & 1 & 2 & 3 & 4 \\
\hline Elaboración de material & & & & \\
Trabajo de campo & & & & \\
Análisis y elaboración de resultados & & & & \\
\hline
\end{tabular}

\subsubsection{Estudio cualitativo a agencias de turismo.}

\subsubsection{Antecedentes}

Como se mencionó en las fuerzas de Porter, capítulo II, existen tres clases de agencia:

- Agencias de turismo minoristas: Vende directamente al cliente paquetes turísticos creados por agencias de turismo mayoristas u operadores de turismo. 
- Agencias de turismo mayoristas: Crea todo tipo de servicios, paquetes y viajes turísticos que serán vendidos por otras agencias de turismo. No vende directamente al cliente.

- Operadores de turismo: Crea programas y servicios turísticos para el territorio nacional que pueden ser vendidos por agencias de turismo minorista y mayorista en el Perú y extranjero, y directamente a los clientes también.

Debido a que los operadores de turismo son los que crean los programas y venden directamente al cliente final, se decide analizarlos como canal de venta en el Perú y en el extranjero.

\subsubsection{Propósito general}

En función a los antecedentes, se decide investigar el proceso de compra de los operadores de turismo, establecer qué valoran, cuáles son sus expectativas sobre proveedores y el nivel de aceptación o rechazo de un albergue vivencial en el distrito de Maras, en la provincia de Urubamba.

\subsubsection{Público objetivo}

La muestra pertenece a operadores de turismo residentes en los departamentos de Lima y Cusco. Un operador de turismo se define como:

Aquella agencia que proyecta elabora, diseña, organiza y opera programas y servicios turísticos dentro del territorio nacional, para ser ofrecidos y vendidos a través de las agencias de viajes y turismo minoristas y mayoristas del Perú y el extranjero, pudiendo también ofrecerlos y venderlos directamente al cliente. (Ministerio de Economía y Finanzas, 2016) 
En este caso se consideraron operadores turísticos medianos pequeños y medianos grandes.

\subsubsection{Propósitos específicos del estudio}

- Determinar el proceso de compra de un operador turístico.

- Indagar cómo venden al distrito de Maras dentro de sus paquetes.

- Investigar las experiencias previas y percepciones acerca de la venta de turismo vivencial.

- Investigar las experiencias previas y percepciones acerca de venta de albergues.

- Averiguar la percepción sobre el turismo vivencial, sus ventajas y desventajas.

- Identificar la apreciación que tienen sobre los albergues en el departamento del Cusco, el conocimiento sobre lo que ofrece la competencia y su concepto de albergue ideal.

- Determinar las expectativas sobre un albergue vivencial, los aspectos tangibles e intangibles esperados.

- Indagar sobre el nivel de aceptación del proyecto.

Tabla 24.

Objetivos del estudio de mercado cualitativo de agencias de turismo.

\begin{tabular}{|c|c|}
\hline $\begin{array}{l}\text { Objetivo } \\
\text { general: }\end{array}$ & Objetivos específicos \\
\hline $\begin{array}{l}\text { 1. Acerca del } \\
\text { público objetivo }\end{array}$ & $\begin{array}{l}\text { Ciudad } \\
\text { Clasificación (tipo de empresa, número de trabajadores, número de } \\
\text { locales por ciudad). } \\
\text { Rubro/Especialidad. } \\
\text { Número de turistas atendidos al mes. } \\
\text { Cuenta con servicio de ticket aéreo (IATA) }\end{array}$ \\
\hline $\begin{array}{l}\text { 2. Acerca del } \\
\text { proceso de } \\
\text { compra de } \\
\text { paquete }\end{array}$ & $\begin{array}{l}\text { Principales destinos vendidos (razones). } \\
\text { Frecuencia de venta de dichos destinos. } \\
\text { Principales rutas. } \\
\text { Servicios brindados (principales y complementarios). } \\
\text { Requerimientos de selección de proveedores (ranking de principales } \\
\text { proveedores). }\end{array}$ \\
\hline
\end{tabular}


Principales procesos y requerimientos de operación de selección de hospedaje.

Políticas de reservas, tiempo de antelación, condiciones requeridas, forma de pago, etc.

Principales alianzas (hospedajes).

Principales convenios comerciales (comisiones, tarifas corporativas).

Principales problemas presentados con hospedajes (soluciones).

Ventajas y desventajas de los tres principales proveedores de hospedaje.

Hospedajes mejor considerados (razones).

Gasto promedio por hospedaje.

Tiempo promedio por visita de los turistas.

Nacionalidad de los turistas que atienden (razones).

Hospedaje rechazado (razones).

Nivel de venta del destino.

Principales argumentos de venta del destino (tradicional, aventura,

3. Acerca del espiritual, vivencial) (razones).

Distrito de Maras

Maras como opción en paquetes (flujo y frecuencia).

\begin{tabular}{l} 
\\
\hline \\
4. Acerca del \\
turismo
\end{tabular}

Proveedores en Maras.

Tiempo de permanencia en Maras (razones).

Gasto promedio por turista en Maras (razones).

Ventajas y desventajas de Maras (razones).

Nivel de conocimiento del concepto.

Principales asociaciones (moderno, rústico, social, etc.).

turismo

vivencial

Experiencia previa (lugar, calificación, tiempo promedio de estadía, etc.).

Ventajas y desventajas del turismo vivencial (razones).

Nivel de recomendación de turismo vivencial.

Opciones de turismo vivencial (destino).

Proveedores de turismo vivencial.

Relación precio servicio.

Nivel de conocimiento del concepto de albergue.

5. Acerca los Principales proveedores.

Albergues

Proveedor de hospedaje en albergue mejor considerado (razones).

Proveedor de hospedaje en albergue rechazado (razones).

Razones de elección.

Evaluación del concepto de turismo vivencial.

Evaluación de atributos tangibles (infraestructura, acabados, materiales).

Evaluación de atributos intangibles.

6. Acerca del Servicio esperado.

Albergue

Valoración precio/calidad (tarifas).

Vivencial

Promoción y contacto.

Formas de pago.

Promociones ideales.

Nivel de margen esperado.

Nivel de recomendación de albergue vivencial. 


\subsubsection{Metodología}

El proceso que desarrollar para el presente proyecto es de enfoque directo debido a que el propósito de la investigación es revelado a los entrevistados.

Se propone un estudio de carácter exploratorio con la aplicación de la técnica cualitativa de entrevista a profundidad.

La entrevista a profundidad consiste en "encuentros cara a cara entre el investigador y los informantes, dirigidos hacia la comprensión de las perspectivas que tienen los informantes respecto de sus vidas, experiencias o situaciones, tal como las expresan con sus propias palabras”. (Taylor \& Bogdan, 2000, pág. 101)

Para la realización de las entrevistas a profundidad se elaboró la guía de pautas alineada con los objetivos de la investigación. Asimismo, se realizó un cuestionario filtro para confirmar que la muestra cumpla con los requisitos de segmentación. Ver guía de pautas en el Anexo II.

\subsubsection{Determinación de la muestra}

Población: Operadores de turismo residentes en los departamentos de Lima y Cusco.

Tipo y técnica de muestreo: Al ser una investigación que requiere mucho tiempo y resulte ser costosa es que se denomina de tipo no probabilístico; teniendo como técnica de 
muestra por conveniencia debido a que se selecciona a los miembros de la población de quienes será más fácil obtener información (Kotler \& Armstrong, 2012, pág. 114 y 116).

Tabla 25.

Distribución muestral de entrevistas en profundidad:

\begin{tabular}{ll}
\hline Condición Muestral & Cantidad \\
\hline Operador Tamaño mediano grande & 2 \\
Operador Tamaño mediano pequeño & 1 \\
Minoristas & 1 \\
\hline
\end{tabular}

Definimos y separamos a los Tour operadores como medianos grandes y mediano pequeños, por la cantidad de files o clientes que atienden semanalmente. Así reconocemos a los operadores medianos o pequeños a aquellos que tienen menos de 20 clientes al mes siendo los tours operadores medianos grandes aquellos que manejan carteras de clientes mucho más grandes.

Tabla 26.

Información de entrevistado por agencias de turismo:

\begin{tabular}{ll}
\hline Operador Mediano-Grande & Entrevistado \\
\hline Cóndor Travel & Jennifer \\
Andean Lodge & Juan Carlos Flores \\
\hline Operador Mediano-Pequeño & Entrevistado \\
\hline Travex Security & Jessica Murga \\
\hline Operador Minorista & Entrevistado \\
\hline Auqui & Alberto Valencia \\
\hline
\end{tabular}




\subsubsection{Cronograma de la investigación cualitativa a clientes directos}

La elaboración del material se dio a inicios del mes de agosto 2017, tras el levantamiento de las observaciones en el material se procedió al trabajo de campo y el análisis de resultados en la última semana del mes de agosto 2017.

Tabla 27.

Cronograma de actividades cualitativas:

Semana

\begin{tabular}{l|llll}
\hline \multicolumn{1}{c|}{ Actividad } & 1 & 2 & 3 & 4 \\
\hline Elaboración de material & & & & \\
Trabajo de campo & & & & \\
Análisis y elaboración de resultados & & & \\
\hline
\end{tabular}

Tabla 28.

Conclusiones del estudio de mercado cualitativo del turista

\begin{tabular}{ll}
\hline \multicolumn{1}{c}{ Generales } & \multicolumn{1}{c}{ Específicas } \\
\hline & - Los turistas entrevistados fueron de: Perú, Estados Unidos, Argentina, \\
& Bolivia, Bélgica y Chile. \\
& - Total de entrevistados \\
& Con experiencia en turismo vivencial: 05 \\
1. Acerca del & Sin experiencia en turismo vivencial: 05 \\
público objetivo & - Se realizaron entrevistas en inglés y español. \\
& - El estado civil predominante fueron los solteros, seguido de los \\
& casados. \\
- & El rango de edad entre 20-39 años. \\
- & Frecuencia de viaje: De 1 a 6 veces al año. \\
& - Principales destinos visitados: Asia, India, Bolivia, Lima, Cusco, \\
& Arequipa, Puno, Europa, Costa Rica, Estados Unidos, Australia, Nepal, \\
& Tailandia, Chile, Brasil y Jamaica. \\
\hline - & Motivo de los destinos por: eventos y publicidad en redes sociales; \\
& Internet; recomendación de amigos; e intereses personales como \\
& conocer lugares arqueológicos o actividades al aire libre. \\
hábitos de viaje. & La decisión de compra por lo general se ve influenciado por familiares \\
& o amigos, y la información en Internet.
\end{tabular}


- La mayoría de turistas no usa agencia de viajes, arman el viaje por internet. Quienes utilizaron los servicios de agencias de viajes fueron los que adquirieron tours como a Machu Picchu, y para encontrar hoteles en dichos destinos.

- Por lo general las personas de la tercera sí usa los servicios de agencia, al igual que turistas que realizan viajes largos como Asia.

- Los turistas conocen la agencia por referencia de amistades o cuentan con una agencia de confianza donde consigue pasajes baratos y sin pago anticipado. Otros por internet y en el lugar de visita.

- El tiempo de preparación del viaje es dependiendo de la lejanía del destino: de 6 meses a 1 año antes (internacional); de 1 a 4 meses antes (nacional).

- La mayoría de turistas indicó haber viajado al Cusco para conocer las ruinas de Machu Picchu, la cultura andina; y algunos porque estaban de paso por Latinoamérica. Los turistas consideran importante los comentarios boca o boca y publicidad en redes sociales al elegir el destino.

- Los viajes los realizaron solo, con amigos o familia.

- Los tiempos de permanencia fueron entre 1 semana a un mes.

- Los gastos promedio fueron entre US\$ 400 a US\$1,000 por 3 semanas.

- Los mejores atractivos visitados en Cusco fueron: Machu Picchu y el Valle Sagrado y los lugares históricos.

- Lo que no agradó a los turistas fue: la insistencia de los comerciantes por venderles; que las agencias no den información si no se adquiría con ellos un tour; en algunos hospedajes no había servicios de agua caliente o la presión de agua era baja; no había agua potable directa del caño, en algunos casos el clima frío; y para todos los extranjeros el costo de las cosas para ellos.

- Los medios de transportes más utilizados por los turistas fueron el transporte público en Cusco, o algunos cuentan con el servicio de movilidad de la agencia que contrataron.

- El medio de transporte más recurrente para llegar a Cusco fue por avión y servicios de bus.

- En el ranking de los principales hospedajes se encuentran (Point Hostal; Hotel Apu; Eco Packers).

- Se enteraron de los hospedajes a través del Trip Advisor, leyendo comentarios de otras personas o por recomendación de amigos.

- Se considera hospedaje en Cusco: San Blas, Ticahuasi

- Para quien viaja sólo un hostal backpacker es lo mejor para conocer personas. Depende mucho de objetivo de viaje y presupuesto.

Qué le gusto más de los hospedajes:

- Buena proporción costo beneficio, excelente servicio.

- Conocer nueva gente

- La ubicación, en Ollantaytambo rodeado de vertientes de agua y con un jardín muy bonito. La idea no es un hotel 5 estrellas, mínimo que incluya desayuno y que esté limpio.

- El personal a cargo del hotel.

- La cercanía, el desayuno y la infraestructura.

- Bar y sala acogedora.

Qué no le gustó del hospedaje 
- Mucho ruido.

- La infraestructura, muy viejo y no se pueda tirar los papeles en el inodoro.

- Muchas camas por habitación.

- Muy frío y mala infraestructura.

- Los turistas que conocen Maras afirmaron que les gustó el lugar; convirtiéndose en un lugar muy visitado y a la gente le agrada por ser un espacio de comunidades. Los turistas la visitan por ser un atractivo visual, y compran productos en ayuda a la comunidad.

- Algunos afirmaron haber conocido Maras por recomendación de la agencia de viaje o gente local.

- Entre las principales atracciones turísticas se encuentran las Salineras y los Andenes de Moray.

- El principal propósito de viaje fue para conocer las Salineras.

3. Acerca del Distrito de Maras
4. Acerca del turismo vivencial
- El tiempo de permanencia promedio en Maras es entre 30' a 40', a lo mucho un día.

- El medio de transporte más recurrente es el que provee la agencia.

Ventajas

- Turistas ven proceso de cosechar la sal, compra de sales con hierbas.

\section{Desventaja}

- Se cobran una entrada de S/.10 (no incluye servicios higiénicos) no hay muchas actividades por realizar.

- Carece de buena infraestructura.

- Los turistas sí recomendarían definitivamente Maras; sobre todo por las actividades cerca de la zona.

- Los atractivos de Maras y el tiempo de visita son adecuado. En poco tiempo el turista logra visitar todo. En el poblado se tiene solamente una iglesia y antiguos graneros.

- En el turismo vivencial el visitante logra experimentar sobre la vida diaria de quien lo ha hospedado, se da alimentación y se le involucra en la vida diaria (aprenden hacer chicha).

- Se trata de hospedarse en la casa de algún poblador de la zona; sin ser un hospedaje formal, es una forma diferente e interesante de viajar y vivir en un pueblo con una familia.

- Una experiencia distinta a lo tradicional y turístico.

- Algunos turistas indicaron haber tenido experiencias de turismo vivencial en el Valle sagrado del Cusco en una comunidad de tejedoras; en Puno, un par de islas; y en África. El tiempo de estadía es de 4 días 3 noches en casa de comuneros con habitaciones designadas, aunque se trata de una experiencia vivencial no se llegó a conocer $100 \%$ la vida de los comuneros. La idea es que se venda el concepto, pero mejorado para evitar un shock cultural fuerte.

- Otra experiencia vivencial en Nepal, en un home-stay pagando sobreprecio por quedarse con una familia.

- La mayoría recomienda la experiencia, por ser muy edificante y definitivamente para que prueben, aunque sea por una vez.

\section{Ventajas}

- Experimentar un estilo de vida más sencillo lo podría llevar a valorar lo que se tiene en casa. 
- Intercambio cultural, experimentar la vida de los pobladores y soporte financiero.

- Fuente de trabajo.

- Forma más activa de hacer turismo.

Desventajas

- Ver al turista como alguien con quien lucrar.

- Quita tiempo para conocer otros lugares.

- Los pobladores han cambiado sus hábitos para complacer al turista, y la barrera de lenguaje.

- Falta de privacidad.

- El albergue es un espacio de hospedaje, cercano a lugares de conservación de la vida salvaje, sitios arqueológicos; debe estar alejado de la civilización. Lugar de descanso cómodo que reemplaza un campamento. Se relaciona con el término lodge.

- Un albergue es más barato que un hotel, es para gente con bajos recursos. Lodge lo relacionan a cabaña, y más exclusivo; y relacionado a la naturaleza lejos del pueblo o la ciudad.

- Un tipo de hospedaje barato y con mucha gente en una misma habitación.

- Espacio donde vives con mucha gente y conviven ayudándose entre ellos.

- Lugar que brinda alojamiento y comida sin grandes pretensiones.

- Algunos de los turistas conocen el albergue "Andean Lodges", donde

5. Acerca de los después de 7 horas de caminata llegas a un lugar exclusivo, con agua

Albergues caliente, comida y chimenea, dándole mayor valor a la experiencia.

- Los costos del "Andean Lodges" están alrededor de US\$ 1,400 (incluye recojo y regreso al hotel, guía, comida, albergue).

Entre los servicios que debe tener un albergue:

- Cama limpia y cómoda, restaurant, internet, lavandería, cocina, lugar de limpieza y tour. Debe tener buena ubicación, céntrico.

- Servicios higiénicos completos y limpios.

- Algunos turistas lo asocian como un lugar donde los mismos turistas colaboran en todos los servicios.

\section{Otra experiencia:}

- En África no tiene estructura de hotel (cemento). Son como casitas alejadas. Como después de una caminata el esfuerzo físico une a la gente, el llegar a un lugar para compartir las experiencias del día, consigue que se implante la idea del viaje.

6. Evaluación

de la

competencia de

- No se tiene conocimiento de otros albergues en el Cusco.

albergues en el

Cusco

- No se conoce bien sobe ese tipo de alojamiento. Pero se entiende que es

7. Acerca del

Albergue

Vivencial en

Cusco un espacio para llegar, descansar una noche y volver a partir.

- El albergue vivencial más conocido es el Andean Lodges. Pero no tiene actividades para compartir con la comunidad.

- Los medios para conocer mejor esta propuesta de hospedaje son a través de: Internet, agencias de viaje, redes sociales, Trip Advisor.

- Las formas de pago más usadas son Tarjeta Crédito. 
- Las mejores promociones son en los pasajes.

- Los turistas esperan encontrar servicios de Tours.

- El turista consideró que se trata de un excelente proyecto; pero que no se debe olvidar que el turista viene de vacaciones no a trabajar, se debe encontrar un equilibrio entre involucrar al turista y engreírlo. Lo que más valora el turista es cuando se involucra con la gente de la zona y sus actividades. Con respecto a la ubicación, se necesita mayor promoción porque se visita la ciudad en un día, pero con el nuevo

Aceptación del aeropuerto aumentará la demanda y las opciones de atracciones. proyecto

- Dirigido a un mercado para adultos y familias. El concepto parece caro, como opción podría ser en Ollantaytambo porque Maras es alto y la gente huye a la altura.

- Algunos turistas manifestaron que estarían dispuestos a pagar 50\% más que un hotel o probablemente igual que un hotel. Entre US\$ 70 y US\$ 80 que incluya, tour, alojamiento y comidas, y un precio adicional por actividades extra.

Tabla 29.

Conclusiones del estudio de mercado cualitativo por agencia de turismo

\begin{tabular}{|c|c|}
\hline Generales & Específicas \\
\hline $\begin{array}{l}\text { 1. Acerca del } \\
\text { público objetivo }\end{array}$ & $\begin{array}{l}\text { - Se entrevistaron agencias en Cusco y Lima, en su mayoría operadores } \\
\text { turísticos. } \\
\text { - Las agencias entrevistadas tienen como sede o sucursal la ciudad del } \\
\text { Cusco como principal punto de operaciones y flujos. } \\
\text { Total de agencias entrevistadas: } \\
\text {. Operadores grandes: 02; Promedio de trabajadores: } 250 \\
\text {. Operadores medianos 01; Promedio de trabajadores: } 20 \\
\text {. Albergue: 01; Promedio de trabajadores: } 20 \\
\text { - La mayoría de las agencias está enfocada en turismo tradicional (city } \\
\text { tours, valle sagrado, Machu Picchu) brindando también servicios } \\
\text { complementarios. } \\
\text { - En el mercado de grandes operadores como Condor travel y Travex se } \\
\text { atienden aproximadamente el } 50 \% \text { de los flujos a Cusco. } \\
\text { - Los operadores cuentan con servicio de ticket aéreo (IATA) } \\
\text { - Los grandes operadores cuentan con IATA. }\end{array}$ \\
\hline $\begin{array}{l}\text { 2. Acerca del } \\
\text { proceso de } \\
\text { compra de } \\
\text { paquete }\end{array}$ & $\begin{array}{l}\text { - Los principales destinos vendidos son al sur del Perú, se atiende el } \\
\text { norte pero en menor escala. La razón de vender el sur es que el circuito } \\
\text { se arma tomando como referencia Machu Picchu, el principal atractivo } \\
\text { que genera mayor flujo. Por tanto crear un tour en el sur hace el circuito } \\
\text { accesible y rentable. } \\
\text { - La frecuencia de venta de estos destinos es diaria. } \\
\text { - Entre los destinos más vendidos (al sur) las principales rutas son: City- } \\
\text { tours, Colca (Arequipa), valle sagrado y tren a Machu Picchu (Cusco); } \\
\text { y Lago Titicaca (Puno). } \\
\text { Servicios brindados (principales y complementarios). } \\
\text { - Entre los principales servicios están el aprovisionamiento de traslados, } \\
\text { guías profesionales, compra de tickets y traslados. Como servicios }\end{array}$ \\
\hline
\end{tabular}


complementarios, se definen los adicionales que el turista solicite como ceremonias andinas, reservas y actividades especiales con hoteles, etc.

\section{Requerimientos de selección de proveedores.}

- El ranking de proveedores de hospedaje está determinado dependiendo el mercado que atiende cada agencia. Entre nuestros encuestados se mencionan las empresas Belmont, Marriot, Inkaterra, casa andina, Sol y Luna, que aunque la mayor diferencia entre ellos es el precio, comparten la calidad de los servicios y la autenticidad en la atención brindada al turista.

Principales procesos y requerimientos de operación de selección de hospedaje:

- La selección del proveedor de servicios de hospedaje está dada por el mercado que atiende, el precio y sobre todo las políticas de reservas, cancelación y flexibilidad en la operación.

\section{Principales alianzas (hospedajes)}

- La mayoría de los encuestados no mantienen alianzas específicas con proveedores de hospedaje.

Principales convenios comerciales (comisiones, tarifas corporativas)

- Dentro del proceso de negociación en el acuerdo comercial entre ambas partes, figuran las tarifas corporativas y no un sistema de comisiones. Destacan también los liberados, (habitaciones no pagadas), esto dependiendo el número de habitaciones reservadas por grupos numerosos. También los complementary, (habitaciones gratis en cualquier fecha).

Principales problemas presentados con hospedajes, formas de solucionarlos.

- Los entrevistados no mencionan problemas, pero todos concuerdan que la mayor de las dificultades es la poca flexibilidad en la operatividad de hotel, por ejemplo, con las horas de check-in y check-out.

Ventajas y desventajas de los tres principales proveedores de hospedaje:

- Entre las principales ventajas que los operadores mencionan, es la buena relación comercial con estos hoteles, pues suelen ser más flexibles en las políticas de no show y/o cancelación. Así como de la calidad de los servicios recibidos.

- Respecto la categoría de hotel, muchos de los operadores coinciden en nombrar como el mejor a "Palacio Nazarenas", un hotel nuevo, caracterizado por la atención personalizada del Butler (Mayordomo) a cargo de cada habitación.

- El gasto promedio de los hoteles usados por nuestros entrevistados, en el caso de las tarifas confidenciales fluctúan entre US\$150 y US\$ 400 por noche.

- El tiempo promedio de visita de los turistas suelen ser de 9 días, de los cuales toman 3 noches de hospedaje en cusco y/o en el valle sagrado.

- En su mayoría, los operadores atienden al mercado americano, algunos atienden el mercado europeo que aún se caracteriza por estar más instruido respecto el lugar que visita. El mercado corporativo tiene muchas más nacionalidades que el receptivo.

- Los operadores no mencionaron haber rechazado ningún hospedaje. 
- Todos los operadores incluyen la visita al salar de Maras a sus turistas, siendo el nivel de ventas el mismo que el de ventas de cusco como destino.

- Maras actualmente es vendido como parte del circuito valle sagrado, y se ofrece de diversas maneras:

Como parte del turismo tradicional.

Algunos incluyen actividades como motos, caballos, bicicletas y picnics en la zona de tiobamba.

Como turismo vivencial.

Como turismo místico al complementar el tour con Moray.

- Con respecto a los proveedores, en Maras los operadores no trabajan con ninguno, pero en algunos casos mencionaron los siguientes restaurantes:

Iskay

Maras restaurant

El parador de Moray

- Los tres restaurantes comparten una propuesta orgánica y gourmet, valorizando el uso de la sal.

3. Acerca del Distrito de Maras

- Al ser un atractivo parte de un circuito al valle sagrado (que en conjunto toma 8 horas aproximadamente) el tiempo de permanencia suele ser de 2 a 3 horas aproximadamente.

- El gasto promedio actual es mínimo, pues las agencias gestionan toda la operatividad, como transporte, guía, etc. En este sentido el gasto directo en maras esta dado en el pago del ticket de ingreso a las Salineras (S/. 10 nuevos soles) más los suvenir de la zona.

- Respecto al gasto que implica para el turista el total del tour este puede variar desde US\$ 35 a US\$ 150 dólares americanos aproximadamente. Incluyendo el total de los servicios.

\section{Ventajas}

- Es un pueblo pintoresco.

- El boom de la sal hace que la zona sea más atractiva y capaz de generar flujos.

- La belleza paisajística de la zona.

- La zona aún mantiene muchas costumbres y personas propias de la zona.

\section{Desventajas}

- No existe planificación turística adecuada para atender el flujo de turistas.

- La atención turística es empírica.

- Carece aún de infraestructura turística (implementación de baños, ampliación de carretera, parqueo adecuado, indicaciones al turista respecto lo permitido en la zona).

- Los operadores definen el turismo vivencial como una gran oportunidad

4. Acerca del turismo vivencial para que los turistas comprendan los usos y costumbres, pero sobre todo la idiosincrasia del lugar visitado. Definen este turismo como un producto potencial.

- Asocian el concepto a un tema comercial y social, capaz de generar ingresos en las comunidades. Lo asocian con un concepto rústico, 
ligado a esta práctica. En algunos casos es asociado con representaciones de la realidad de la forma de vida de las comunidades.

- Los operadores ofrecen diferentes actividades relacionadas al turismo vivencial, especialmente Cóndor Travel en el poblado de Patacancha, Travex por el contrario al manejar un mercado corporativo no vende este tipo de turismo pues no es interés de su público consumidor. Entre otras experiencias mencionadas destaca los Uros en Puno y sesiones de renovación de votos y ofrendas a la tierra en ceremonias andinas.

\section{Ventajas}

- Fuente de ingreso para la comunidad.

- Imagen real de la idiosincrasia de la comunidad visitada.

- Experiencia significativa y emocional del turista.

Desventajas

- Conocimiento empírico de los pobladores sobre atención.

- Incomodidad en el hospedaje y la alimentación de los turistas.

- Si esta práctica no se desarrolla dentro de un circuito, implica un mayor tiempo de tránsito y alza de costos al paquete en general.

- Los operadores manifestaron un nivel de recomendación alta a la práctica del turismo vivencial.

- Para Condor Travel sus principales proveedores de turismo vivencial es a través de las comunidades de Patacancha, Misminay y Uros. Para Auqui las comunidades cercanas a Ocongate. También se mencionó de turismo vivencial en Raqchy.

- Los operadores mencionan que el costo promedio es de US\$80 por noche, por pernoctar en la casa de los campesinos. En este sentido no existe una relación costo calidad de servicio, porque el monto no está relacionado a un pago, sino más bien al apoyo a las familias involucradas.

- El nivel de conocimiento del concepto "albergue" es alto. Lo definen como un espacio de hospedaje donde comparten grupos de personas con intereses comunes, siendo este hospedaje alejado de la ciudad y guarda características propias del lugar donde se encuentra ubicado.

- Los operadores mencionan como principales proveedores a: Andean Lodge y Mountain Lodge.

- Entre los albergues mencionados, lo "mejor" depende de lo que busca el turista. Si se busca calidad en el servicio, concuerdan que Mountain

5. Acerca de los Lodge lidera este rubro; pero si el turista busca experiencias más Albergues "reales" Andean Lodge es el indicado.

- Los operadores no mencionan ningún hospedaje en albergue rechazado, probablemente por la poca oferta lo cual hace complicado rechazar proveedores de este servicio.

- Las principales razones de elección de un proveedor de hospedajes en albergues son de acuerdo:

1. Interés del turista.

2. Ubicación.

3. Precio.

6. Acerca del Albergue Vivencial
- Los operadores lo definen como un hospedaje donde de manera complementaria el turista disfrutará de actividades más locales.

- Con respecto a la infraestructura debe ir acorde con la arquitectura del lugar y debe ser segura. 
- Las actividades complementarias que debe realizar el albergue vivencial deben ser en pro de la comunidad.

- Los operadores manifestaron que los precios podrían oscilar entre US\$ 70 y US\$ 80 fuera de impuestos por noche dependiendo de los servicios que incluyen.

- Los operadores sugieren que se brinden actividades adicionales creando paquetes turísticos y se asegure la venta de otras actividades y mayores ingresos.

- El turismo vivencial aún no está explotado en el Perú, pero hay tendencia que sea un tipo de turismo tendencia en el futuro. La oferta en precio y calidad debe incrementar.

Debido a la asociación presentada por los turistas y por las agencias, se reemplazará el término albergue por "lodge", para ser evaluado en la investigación cualitativa.

\subsection{Investigación cuantitativa.}

Propuesta estudio cuantitativo del proyecto para el albergue vivencial "La hacienda Kachi Raqay” en Maras, Cusco

\subsubsection{Estudio cuantitativo a turistas vacacionales.}

\subsubsection{Propósito general}

Confirmar los datos de la investigación cualitativa y la información provista por el ministerio de comercio exterior y turismo, haciendo uso de la estadística descriptiva acerca del nivel de aceptación o rechazo de un albergue vivencial en el distrito de Maras, en la provincia de Urubamba, por parte de las personas que viajan con motivos vacacionales al departamento del Cusco, Perú. 
Tabla 30.

Objetivos del estudio de mercado cuantitativo del turista

\begin{tabular}{|c|c|}
\hline $\begin{array}{c}\text { Objetivo } \\
\text { general }\end{array}$ & Objetivos específicos \\
\hline $\begin{array}{l}\text { 1. Acerca de los } \\
\text { hábitos de viaje } \\
\text { a la ciudad del } \\
\text { Cusco }\end{array}$ & $\begin{array}{l}\text { - Establecer el principal motivo, de los turistas, por el cual viajan a } \\
\text { - Dusco. } \\
\text { - Determinar el cómo planifican su viaje a Cusco, y que página web o } \\
\text { agencia de viajes es la más utilizada para tal efecto. } \\
\text { - Conocer qué servicios son los que se adquiere, ya sea mediante página } \\
\text { web o agencia de viaje. } \\
\text { - Establecer cuánto tiempo se quedan los turistas en Cusco. } \\
\text { - Comprobar el gasto promedio en alojamiento, comida y actividades. } \\
\text { - Determinar cuáles son las actividades que más les gusto en Cusco. } \\
\text { - Conocer el tipo de hospedaje preferido durante su estadía en Cusco. } \\
\text { - Saber cuál es el hospedaje más utilizado en Cusco y el por qué. } \\
\text { - Determinar las provincias o poblados más visitados en Cusco. } \\
\text { - Conocer los medios por los cuales se informan de los hospedajes a } \\
\text { elegir. }\end{array}$ \\
\hline $\begin{array}{l}\text { 2. Acerca del } \\
\text { Distrito de } \\
\text { Maras }\end{array}$ & $\begin{array}{l}\text { - Determinar el nivel de conocimiento del distrito de Maras. } \\
\text { - Establecer el principal motivo de viaje a Maras. } \\
\text { - Conocer el o los medios por los cuales se enteraron del distrito de } \\
\text { Maras. } \\
\text { - Determinar las principales actividades que se realizan en Maras y su } \\
\text { nivel de satisfacción. } \\
\text { - Determinar el tiempo de permanencia en Maras. } \\
\text { - Establecer las principales ventajas y desventajas percibidas durante su } \\
\text { viaje a Maras. } \\
\text { - Establecer el nivel de recomendación de Maras. }\end{array}$ \\
\hline $\begin{array}{l}\text { 3. Acerca del } \\
\text { turismo } \\
\text { vivencial }\end{array}$ & $\begin{array}{l}\text { - Determinar el nivel de conocimiento de turismo vivencial. } \\
\text { - Establecer cuantos turistas tuvieron experiencia en turismo vivencial y } \\
\text { cuáles fueron las actividades durante esta. }\end{array}$ \\
\hline $\begin{array}{l}\text { 4. Acerca de los } \\
\text { Lodge }\end{array}$ & $\begin{array}{l}\text { Durante el estudio cualitativo, se estableció que el término más adecuado } \\
\text { en vez de "albergue" sería "ecolodge", por lo cual: } \\
\text { - Conocer la percepción del término lodge y con qué conceptos está } \\
\text { asociado. }\end{array}$ \\
\hline $\begin{array}{l}\text { 5. Evaluación } \\
\text { de la } \\
\text { competencia de } \\
\text { lodge en el } \\
\text { Cusco }\end{array}$ & - Saber si existe un lodge posicionado en la mente del turista. \\
\hline $\begin{array}{l}\text { 6. Acerca del } \\
\text { Lodge } \\
\text { Vivencial en } \\
\text { Maras, Cusco }\end{array}$ & $\begin{array}{l}\text { - Determinar los factores percibidos como ventajas, y su orden de } \\
\text { importancia, de la ubicación de un lodge vivencial en Maras. } \\
\text { - Determinar los factores percibidos como desventajas, y su orden de } \\
\text { importancia, de la ubicación de un lodge vivencial en Maras. }\end{array}$ \\
\hline
\end{tabular}


- Estimar el gasto promedio que un turista estaría dispuesto a pagar por alojamiento, alimentación y actividades de turismo y/o entretenimiento en un lodge vivencial en Maras.

- Determinar la disposición a adquirir los paquetes ofrecidos por el lodge vivencial Kachy Raqay.

\subsubsection{Metodología}

El proceso que desarrollar para el presente proyecto es de enfoque directo debido a que el propósito de la investigación es revelado a los entrevistados.

Debido a que la investigación incluye dos factores innovadores como la ubicación (Maras) y el concepto de lodge vivencial, y tras haber analizado los instrumentos de medición existentes, no se encontró ninguno que mida los objetivos trazados, ni ninguno que pueda ser adaptado, por lo cual se procedió a desarrollar un nuevo instrumento de medición. (Sampieri Hernández, 2006).

Para tal efecto se desarrolló un cuestionario aplicado mediante entrevista personal de respuestas abiertas, cerradas, múltiples y con escalas de likert. (Sampieri Hernández, 2006). Ver "Encuesta para el turista" Anexo IV.

El cuestionario será aplicado en soporte papel y en soporte informático mediante la herramienta survey monkey.

\subsubsection{Determinación de la muestra}

Población: Todas las personas que visitaron la Ciudad de Cusco, con motivos vacacionales durante los meses de agosto, septiembre y octubre del año 2016. 
Unidad de análisis: cada persona que visitó la Ciudad de Cusco, con motivos vacacionales durante los meses de agosto, septiembre y octubre del año 2016.

Debido a la magnitud de la población, se utilizará el método de muestreo.

Tipo y técnica de muestreo: Debido al difícil acceso a la unidad de análisis ya que está en movimiento y no está dispuesto a designar 20 minutos a un cuestionario, al no tener un marco muestral y a que es difícil determinar la probabilidad de que cada elemento del universo sea elegido dentro de la muestra, la muestra será de tipo no probabilístico, sin repetición, por conveniencia. (Sampieri Hernández, 2006)

Tabla 31.

Distribución muestral del cuestionario presencial (papel) y online (Survey Monkey):

\begin{tabular}{lccc}
\hline Tipo de soporte & Idioma & Número de encuestas & $\%$ \\
\hline Papel & Ingles & 72 & $36 \%$ \\
Papel & Español & 95 & $48 \%$ \\
Informático (Survey Monkey) & Español & 31 & $16 \%$ \\
Informático (Survey Monkey) & Ingles & 2 & $1 \%$ \\
Total & & 200 & \\
\hline
\end{tabular}

Estudio probabilístico (Ochoa, 2015), se ha utilizado la fórmula estadística para poblaciones infinitas, con un nivel de confianza del 95\%:

Nivel de confianza: $95 \%$

Z: 1,65

Error: $6 \% n=\frac{Z^{2} \cdot P \cdot Q}{E^{2}}=\frac{1,65^{2}(0,5)(0,5)}{0,06^{2}}=188$ 
Tabla 32.

Conclusiones del estudio de mercado cuantitativo del turista

\begin{tabular}{|c|c|}
\hline Generales & Específicas \\
\hline $\begin{array}{l}\text { 1. Acerca del } \\
\text { público objetivo }\end{array}$ & $\begin{array}{l}\text { - El } 60 \% \text { de la muestra encuestada fueron mujeres. } \\
\text { - El } 86 \% \text { de los encuestados estuvo en el rango de edades entre } 21 \text { a } 50 \\
\text { años; y el } 38,5 \% \text { de } 30 \text { a } 39 \text { años. } \\
\text { - El } 61 \% \text { de los encuestados eran de países como: Perú, Brasil, Estados } \\
\text { Unidos, Argentina, Canadá y Chile; por lo que se tomará a estos países } \\
\text { en cuenta para futuros análisis. }\end{array}$ \\
\hline $\begin{array}{l}\text { 2. Acerca de los } \\
\text { hábitos de viaje } \\
\text { a la ciudad del } \\
\text { Cusco }\end{array}$ & 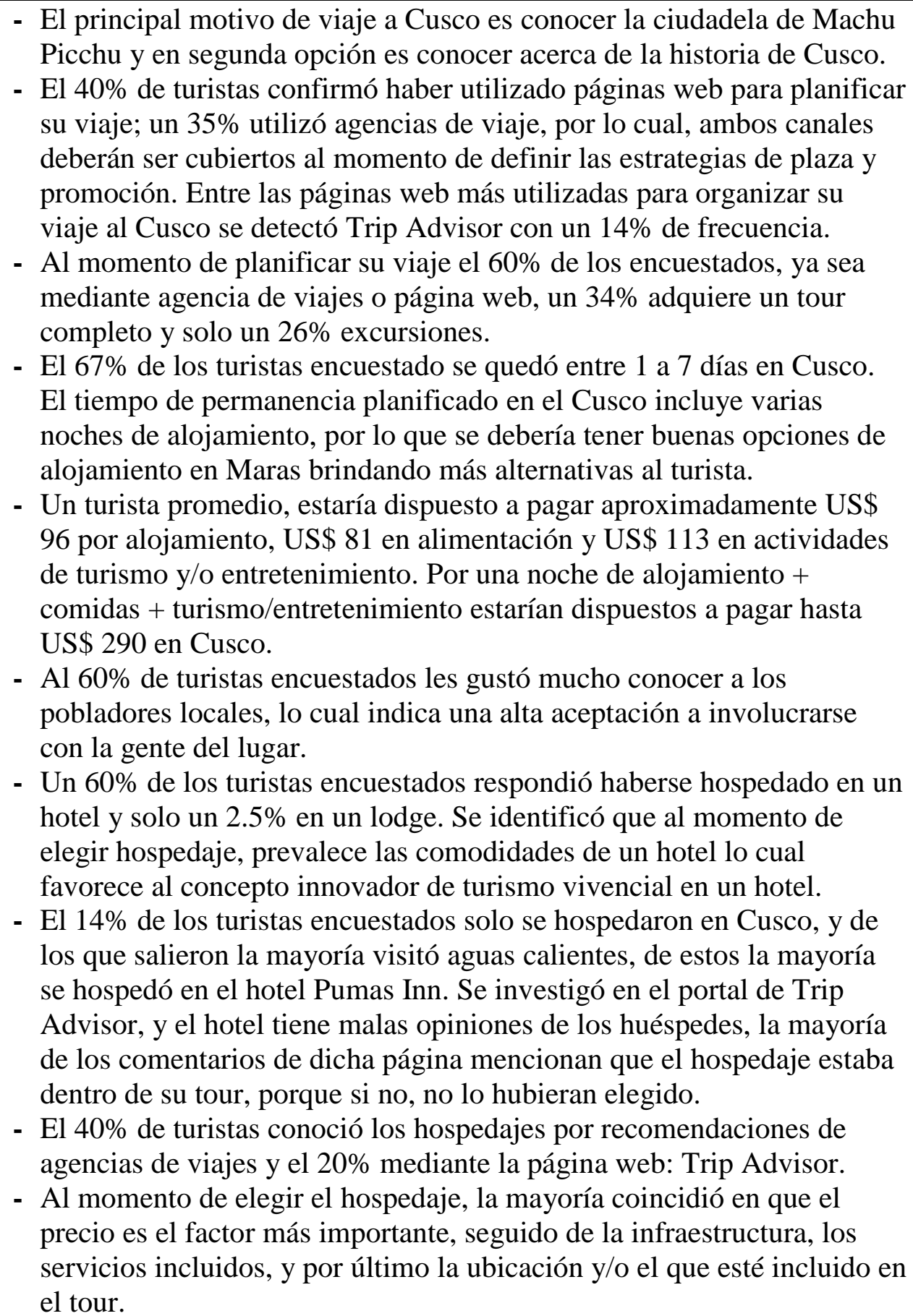 \\
\hline
\end{tabular}

- El 68\% de los turistas encuestados conoce el distrito de Maras. 
- Del total de turistas que conoció el distrito de Maras, el 53\% respondió que el motivo de viaje a Maras fue debido a que se encontraba incluido en el tour. Lo que refuerza la razón por la que se debe incluir a las agencias de viaje en el plan de marketing para este tipo de negocios.

- La mayoría de los turistas que visitaron Maras, indicaron haber

3. Acerca del permanecido en el poblado solo durante el día. Se pretende cambiar Distrito de Maras este hábito de viaje para aumentar el tiempo de permanencia; sin embargo, también se ve como un destino potencial al no tener competencia posicionada.

- Las actividades que más gustaron en Maras, fueron el recorrido a las salineras (60\% concordaron en esta apreciación) y los restos arqueológicos de Moray (55\%).

- Más del 60\% de encuestados sugeriría visitar Maras a otros turistas.

- El 88\% de encuestados confirmaron no haber tenido experiencia en

4. Acerca del turismo vivencial. Del 12\% que sí experimento el turismo vivencial, la turismo vivencial mayoría coincidió en que las actividades principales en este tipo de turismo son la gastronomía, las fotografías y las artesanías.

- Más del 55\% de los turistas encuestados asocia el término lodge con un

5. Acerca de los Lodge alojamiento rústico y alejado de la ciudad. Para fines comerciales se optó por utilizar el término Ecolodge en adelante para el presente proyecto debido a que resultaba ser más atractivo para el tipo de actividad del negocio.

6. Evaluación de la competencia de lodge en el

- La mayoría (97\%) de los turistas encuestados, no se hospedo ni conoce Cusco un lodge en Cusco.

- Ventajas de la ubicación de Maras según orden de importancia valorizados por los turistas encuestados:

1. Cercanía a Machu Picchu

2. El estar en pleno Valle Sagrado

3. La cercanía a las salineras de Maras

4. La cercanía al complejo de Moray

5. La cercanía al nuevo aeropuerto de Chinchero

Además de la cercanía a Machu Picchu, la cual es el principal motivo de viaje a Cusco, y los atractivos propios de Maras como las salineras y el complejo de Moray, se deberá tomar en cuenta tours al valle sagrado.

7. Acerca del - Desventajas de la ubicación de Maras según orden de importancia Lodge Vivencial valorizados por los turistas encuestados:

en Maras, Cusco 1. Acceso limitado a internet

2. Altura (3028 msnm)

3. Temperatura y clima en la ciudad.

4. Alejado de las actividades nocturnas del Cusco.

Factores que consideramos tomar en cuenta al momento de establecer el plan de marketing.

- Un turista promedio, estaría dispuesto a pagar hasta US\$50 por alojamiento, hasta US\$ 50 en alimentación y hasta US\$ 50 en actividades de turismo y/o entretenimiento. Por una noche de alojamiento + comidas + turismo/entretenimiento estarían dispuestos a pagar hasta US\$ 150 en el distrito de Maras. 
- Ante la pregunta de si hubieran adquirido uno de los paquetes propuestos, estas fueron las respuestas:

- El $51 \%$ de los turistas encuestados respondió que posiblemente o definitivamente adquiriría el paquete "full day"; el 35\% respondió que posiblemente o definitivamente tomaría el paquete " 2 días/1 noche"; y solo el $16 \%$ contestaron que podrían tomar el paquete " 3 días/2 noches".

- En base al género, edad, nacionalidad y estado civil, los que mostraron una mayor predisposición a comprar el paquete "full day" fueron: de género femenino; los menores de 29 años y aquellos mayores de 60 años; los turistas chilenos y aquellos que estaban solteros, viudos o divorciados.

- En base al género, edad, estado civil y nacionalidad, los que mostraron una mayor predisposición a comprar el paquete " 2 días/1 noche" fueron: de género femenino, los turistas menores de 20 años y aquellos comprendidos entre 51 y 59 años, los casados, y los de nacionalidad argentina y peruana.

- En base al género, edad, estado civil y nacionalidad, los que mostraron una mayor predisposición a comprar el paquete "3 días/2 noches" fueron: de género femenino, los turistas menores de 20 años, los casados, y los de nacionalidad brasilera y estadounidense.

\subsubsection{Estudio cuantitativo a agencias de turismo.}

\subsubsection{Propósito general.}

Confirmar los datos de la investigación cualitativa y la información provista por el ministerio de comercio exterior y turismo, haciendo uso de la estadística descriptiva acerca del nivel de aceptación o rechazo de un albergue vivencial en el distrito de Maras, en la provincia de Urubamba, por parte de las agencias y operadoresque venden paquetes en el departamento del Cusco, Perú. 
Tabla 33.

Objetivos del estudio de mercado cuantitativo de agencias de turismo

\begin{tabular}{|c|c|}
\hline Objetivo general: & Objetivos específicos \\
\hline $\begin{array}{l}\text { 1. Acerca de los } \\
\text { hábitos de viaje a la } \\
\text { ciudad del Cusco }\end{array}$ & $\begin{array}{l}\text { - Establecer el principal motivo, de los turistas, por el cual viajan a } \\
\text { - Dusco. } \\
\text { - Determinar el cómo planifican su viaje a Cusco, y que página web o } \\
\text { agencia de viajes es la más utilizada para tal efecto. } \\
\text { - Conocer qué servicios son los que se adquiere, ya sea mediante } \\
\text { página web o agencia de viaje. } \\
\text { - Establecer cuánto tiempo se quedan los turistas en Cusco. } \\
\text { - Comprobar el gasto promedio en alojamiento, comida y actividades. } \\
\text { - Determinar cuáles son las actividades que más les gusto en Cusco. } \\
\text { - Conocer el tipo de hospedaje preferido durante su estadía en Cusco. } \\
\text { - Saber cuál es el hospedaje más utilizado en Cusco y el por qué. } \\
\text { - Determinar las provincias o poblados más visitados en Cusco. } \\
\text { - Conocer los medios por los cuales se informan de los hospedajes a } \\
\text { - elegir. }\end{array}$ \\
\hline $\begin{array}{l}\text { 2. Ac } \\
\text { Distri }\end{array}$ & $\begin{array}{l}\text { - Determinar el nivel de conocimiento del distrito de Maras. } \\
\text { - Establecer el principal motivo de viaje a Maras. } \\
\text { - Conocer el o los medios por los cuales se enteraron del distrito de } \\
\text { Maras. } \\
\text { - Determinar las principales actividades que se realizan en Maras y su } \\
\text { nivel de satisfacción. } \\
\text { - Determinar el tiempo de permanencia en Maras. } \\
\text { - Establecer las principales ventajas y desventajas percibidas durante } \\
\text { - } \text { su viaje a Maras. } \\
\text { - Establecer el nivel de recomendación de Maras. }\end{array}$ \\
\hline $\begin{array}{l}\text { 3. Acc } \\
\text { turism }\end{array}$ & $\begin{array}{l}\text { - Determinar el nivel de conocimiento de turismo vivencial. } \\
\text { - Establecer cuantos turistas tuvieron experiencia en turismo vivencial } \\
\text { y cuáles fueron las actividades durante esta. }\end{array}$ \\
\hline $\begin{array}{l}\text { 4. Acerca de los } \\
\text { Lodge }\end{array}$ & $\begin{array}{l}\text { Durante el estudio cualitativo, se estableció que el término más } \\
\text { adecuado en vez de “albergue" sería “ecolodge", por lo cual: } \\
\text { - Conocer la percepción del término lodge y con qué conceptos está } \\
\text { asociado. }\end{array}$ \\
\hline $\begin{array}{l}\text { 5. Evaluación de la } \\
\text { competencia de } \\
\text { lodge en el Cusco }\end{array}$ & $\begin{array}{l}\text { - Conocer los lodges más utilizados en Maras. } \\
\text { - Saber si existe un lodge posicionado en la mente del turista. }\end{array}$ \\
\hline $\begin{array}{l}\text { 6. Acerca del } \\
\text { Lodge Vivencial en } \\
\text { Maras, Cusco }\end{array}$ & $\begin{array}{l}\text { - Determinar los factores percibidos como ventajas, y su orden de } \\
\text { importancia, de la ubicación de un lodge vivencial en Maras. } \\
\text { - Determinar los factores percibidos como desventajas, y su orden de } \\
\text { importancia, de la ubicación de un lodge vivencial en Maras. } \\
\text { - Estimar el gasto promedio que un turista estaría dispuesto a pagar } \\
\text { por alojamiento, alimentación y actividades de turismo y/o } \\
\text { entretenimiento en un lodge vivencial en Maras. } \\
\text { - Determinar la disposición a adquirir los paquetes ofrecidos por el } \\
\text { lodge vivencial Kachy Raqay. }\end{array}$ \\
\hline
\end{tabular}




\subsubsection{Metodología}

El proceso por desarrollar para el presente proyecto es de enfoque directo debido a que el propósito de la investigación es revelado a los entrevistados.

Debido a que la investigación incluye dos factores innovadores como la ubicación (Maras) y el concepto de lodge vivencial, y tras haber analizado los instrumentos de medición existentes, no se encontró ninguno que mida los objetivos trazados, ni ninguno que pueda ser adaptado, por lo cual se procedió a desarrollar un nuevo instrumento de medición. (Sampieri Hernández, 2006).

Para tal efecto se desarrolló un cuestionario aplicado mediante entrevista personal de respuestas abiertas, cerradas, múltiples y con escalas de likert. (Sampieri Hernández, 2006). Ver "Encuesta Agencia” Anexo IX. El cuestionario será aplicado en soporte papel.

\subsubsection{Determinación de la muestra}

Población: Las agencias de turismo ubicados en la ciudad del Cusco que quedaron luego del filtro respectivo de la lista de operadores turísticos y minoristas (Ver Tabla 34).

Unidad de análisis: cada persona responsable de la agencia de turismo de la Ciudad del Cusco listadas (Ver Tabla 34).

Debido a la magnitud de la población, se utilizará el método de muestreo. 
Tipo y técnica de muestreo: Debido al difícil acceso a la unidad de análisis que no está dispuesto a designar 20 minutos a una encuesta, al no tener un marco muestral y a que es difícil determinar la probabilidad de que cada elemento del universo sea elegido dentro de la muestra, la muestra será de tipo no probabilístico, sin repetición, por conveniencia. (Sampieri Hernández, 2006)

Tabla 34 .

Conclusiones del estudio de mercado cuantitativo de agencias de turismo

\begin{tabular}{|c|c|}
\hline Generales & Específicas \\
\hline $\begin{array}{l}\text { 1. Acerca del } \\
\text { público objetivo }\end{array}$ & $\begin{array}{l}\text { - Se encuestó a personal de administración, marketing y ventas, y } \\
\text { operaciones de agencias de turismo en Cusco, que tienen poder de } \\
\text { decisión en la selección de proveedores. } \\
\text { - El } 74 \% \text { de encuestados cuentan con una sola sede en el Perú. } \\
\text { - El } 77.9 \% \text { de las agencias tiene menos de } 50 \text { empleados. } \\
\text { - El } 59.4 \% \text { se especializa en turismo tradicional, el } 13.9 \text { en ecoturismo el } \\
13 \% \text { en turismo de aventura y el } 10 \% \text { en turismo vivencial. } \\
\text { - El } 35 \% \text { de las agencias atiende menos de } 100 \text { turistas por mes y el } \\
32.5 \% \text { entre } 101 \text { y } 400 \text { turistas por mes. } \\
\text { - Del total de agencias encuestadas el } 67.5 \% \text { no cuenta con IATA. } \\
\text { - El } 68.8 \% \text { de encuestados es operador de turismo, } 16.9 \text { minorista y } 13 \% \\
\text { mayorista. }\end{array}$ \\
\hline $\begin{array}{l}\text { 2. Acerca del } \\
\text { proceso de } \\
\text { compra de } \\
\text { paquete }\end{array}$ & $\begin{array}{l}\text { - El principal circuito vendido es Sur Altiplano que abarca las ciudades } \\
\text { de Cusco, Puno, Arequipa y Tambopata, la venta se debe en su mayoría } \\
\text { a que son productos turísticos desarrollados, tendencia turística o moda } \\
\text { para viajeros, y poseen una alta jerarquía de atractivos. } \\
\text { - El } 52 \% \text { de los encuestados vende los circuitos Sur Altiplano de forma } \\
\text { diaria y un } 26 \% \text { de forma semanal. } \\
\text { - El } 46 \% \text { de los encuestados incluye al Cusco al inicio del circuito, el } \\
24 \% \text { al final y el } 18 \% \text { al intermedio del circuito. } \\
\text { - Los principales factores para la selección de proveedores son: calidad } \\
\text { del servicio, ubicación e instalaciones del hospedaje y tarifas } \\
\text { corporativas. } \\
\text { - El } 87 \% \text { realiza convenios comerciales con hospedajes en Cusco y en su } \\
\text { mayoría los convenios son en relación a las tarifas corporativas y } \\
\text { habitaciones liberadas. } \\
\text { - Para el mantenimiento de las alianzas entre agencias y hospedaje se } \\
\text { exige en primer lugar que sean socialmente responsables con sus } \\
\text { trabajadores, en segundo lugar, que sean ambientalmente responsables, } \\
\text { en tercer lugar, que ofrezcan un buen trato y servicio a los clientes y por } \\
\text { último que tengan un sistema de reservas directas. } \\
\text { - El } 46 \% \text { de agencias paga por noche entre US } \$ 50 \text { y más de US\$ } 120 \\
\text { por noche. }\end{array}$ \\
\hline
\end{tabular}


- El 75\% de turistas permanece de 1 y 3 noches en Cusco y el $20 \%$ de 4 a 7 noches.

- Las agencias ofrecen en su mayoría los siguientes servicios: traslados, venta de tickets a atractivos turísticos, guías profesionales, venta de tours y reserva de hospedajes.

- El 63\% de turistas que atienden las agencias provienen de Estados Unidos, seguidos por un 33\% de Perú, luego Chile, Brasil, Alemania y otros países de Europa.

- El 91\% de los encuestados vende un tour o incluye a Maras en el circuito de visita al Cusco.

- El 80\% de turistas pasan unas horas en Maras como parte del tour al Valle Sagrado y pagan entre US\$ 50 y US\$ 100 por tour o paquete.

- Las actividades que más venden las agencias son las siguientes:

City tour.

Valle Sagrado.

Machu Picchu.

Cuatrimotos

Trekking

3. Acerca del Tejido

Distrito de Pago a la tierra

Maras Ayahuasca

- No cuentan con proveedores de hospedaje en Maras, y trabajan con dos restaurantes Parador de Moray y Iskay Scrl, ambos con buen servicio; para los tours trabajan con operadores de la zona.

- En Maras el 44\% ofrece snacks a los turistas, 24\% no ofrece alimentación y el $32 \%$ los lleva a un restaurante orgánico o típico. Por lo que se considera importante contar con un buen restaurante en el hospedaje.

- Las agencias destacan como ventajas en Maras: Las salineras, pueblo tradicional, aventura, su ubicación y las expresiones culturales. Mientras que las desventajas son: organización, atención al cliente, infraestructura, accesibilidad y es aún un destino por descubrir.

- Un 40\% de los encuestados brinda turismo vivencial, y lo ofrecen en un $19 \%$ como una experiencia social y benéfica para la comunidad receptora, un $17 \%$ experiencia urbana para conocer los usos y costumbres diarias de un poblador en la ciudad y un $13 \%$ como actividad rural de estadía y convivencia en zonas alejadas.

4. Acerca del - Las poblaciones que brindan turismo vivencial, las más importantes turismo son: Ocongate, Raqchy, Patacancha, Wacawasi, Mollepata, vivencial Lucmabamba y Maras.

- El 23\% paga por noche en hospedaje entre US\$ 50 y más de US\$100, el $22 \%$ paga por comida entre US\$ 50 y más de US\$100; en actividades agrícolas entre US\$ 50 y US\$ 80; un $26 \%$ en preparación de tejidos gasta entre US\$50 y más de US\$100; y el 9\% gasta en vestirse con trajes típicos entre US $\$ 50$ y US $\$ 80$.

- Los albergues en Cusco más utilizados por las agencias son:

5. Acerca de los Saraypampa. Albergues Mountain Lodge of Perú. 
Luqmabamba.

Andean Lodge.

Inkaterra Reserva Amazónica.

Wagawasi.

- Según los agentes un albergue vivencial debe contar con:

Elementos rústicos.

Decoración típica de la zona.

Arquitectura tradicional.

Personal capacitado.

Instalaciones modernas.

- Ante la pregunta de si venderían los paquetes propuestos, estas fueron las respuestas:

- El 93\% de los encuestados respondió que posiblemente o definitivamente vendería el paquete "Full Day"; el 66\% respondió que posiblemente vendería el paquete " 2 días/1 noche"; y el $26 \%$ estaría dispuesto a vender el paquete "3 días/2 noches".

6. Acerca del Albergue Vivencial en Cusco
- Los paquetes "Full Day" y el paquete "2 días/1 noche", en base al número de sedes, posiblemente o definitivamente las agencias con una sede venderían estos paquetes, las agencias con menos de 50 empleados y que atienden a más de 100 turistas venderían los paquetes, en cuanto a la especialidad las agencias de turismo tradicional se encontrarían dispuestas a vender los paquetes; las agencias con Iata y sin Iata también venderían el paquete. En cuanto a la clasificación de la agencia, los operadores de turismo son quienes en su mayoría venderían los paquetes.

- En cuanto al paquete "3 días noche/ 2 noches", las agencias muestran poco interés en vender este paquete a los turistas que atienden. 


\section{Capítulo IV: Proyección del Mercado Objetivo}

\subsection{El objetivo de la proyección}

El objetivo de este capítulo es cuantificar la demanda existente para determinar el pronóstico de ventas del Ecolodge "Kachi Raqay” en el poblado de Maras, Cusco.

\subsection{El ámbito de la proyección}

Se proyectará el número de personas que estarían dispuestas a adquirir los paquetes de servicios turísticos en un lodge vivencial en el poblado de Maras en Cusco.

\subsection{Método de proyección}

Para la proyección del cálculo de la demanda del proyecto se emplearán las siguientes herramientas, fuentes secundarias y fuentes primarias:

- El método de regresión lineal simple. (Andderson, 2011)

- Boletín Dircetur (Dirección Regional de Comercio Exterior y Turismo) del Cusco sobre turistas que llegan a la ciudad del Cusco cada año. (DIRCETUR, 2016)

- Boletín Turismo In de PromPerú sobre los perfiles del turista extranjero y nacional.

(Promperú, 2016)

- Investigación de mercado de fuente primaria realizada para tal fin.

- $\quad$ Índice de Mc Daniels (Mc Daniel \& Gates, 2016). ${ }^{1}$

\footnotetext{
${ }^{1}$ Teoría donde se explica que el $70 \%$ de quienes indican que van a comprar el producto lo adquirirán; al igual que el $35 \%$ de los que indican que quizá van a comprarlo lo adquieren, un 10\% de los que comentan que quizás no lo compren no lo adquieren y un $0 \%$ de los que dicen que no lo comprarán.
} 
- Tasa de ocupabilidad en hoteles del Cusco. (Perú C. E., 2015)

El análisis de regresión es una técnica estadística para investigar la relación funcional entre dos o más variables. La regresión lineal simple utiliza una sola variable de regresión y el caso más sencillo es el modelo de línea recta, el cual, mediante un conjunto de pares de observaciones $(\mathrm{x}, \mathrm{y})$; busca encontrar una recta que describa de mejor manera cada uno de esos pares observados, donde x es la variable independiente \& y es la variable dependiente para cada valor específico de x. (Levin, 2004)

Para aplicar la regresión lineal simple en el presente proyecto, se cuenta con información de la Dirección Regional de Comercio Exterior y Turismo del Cusco, acerca del número de turistas (extranjero y nacional) que ingresaron a esta ciudad entre los años 2005 al 2016 (DIRCETUR, 2016), dicha data es la base para la proyección del número de turistas que ingresará a la ciudad del Cusco dentro de los años 2017 a 2022.

Tabla 35 .

Turistas que ingresaron a la Ciudad del Cusco entre el 2005 y el 2016

\begin{tabular}{ccc}
\hline Año & Turistas que ingresaron al Cusco & Variación porcentual \\
\hline 2005 & $1,098,816$ & - \\
2006 & $1,181,292$ & $8 \%$ \\
2007 & $1,423,445$ & $20 \%$ \\
2008 & $1,657,524$ & $16 \%$ \\
2009 & $1,668,287$ & $1 \%$ \\
2010 & $1,747,952$ & $5 \%$ \\
2011 & $2,074,291$ & $19 \%$ \\
2012 & $2,357,062$ & $14 \%$ \\
2013 & $2,532,869$ & $7 \%$ \\
2014 & $2,747,098$ & $8 \%$ \\
2015 & $3,000,000$ & $9 \%$ \\
2016 & $3,053,279$ & $2 \%$ \\
\hline
\end{tabular}

Nota: Dircetur-Cusco 


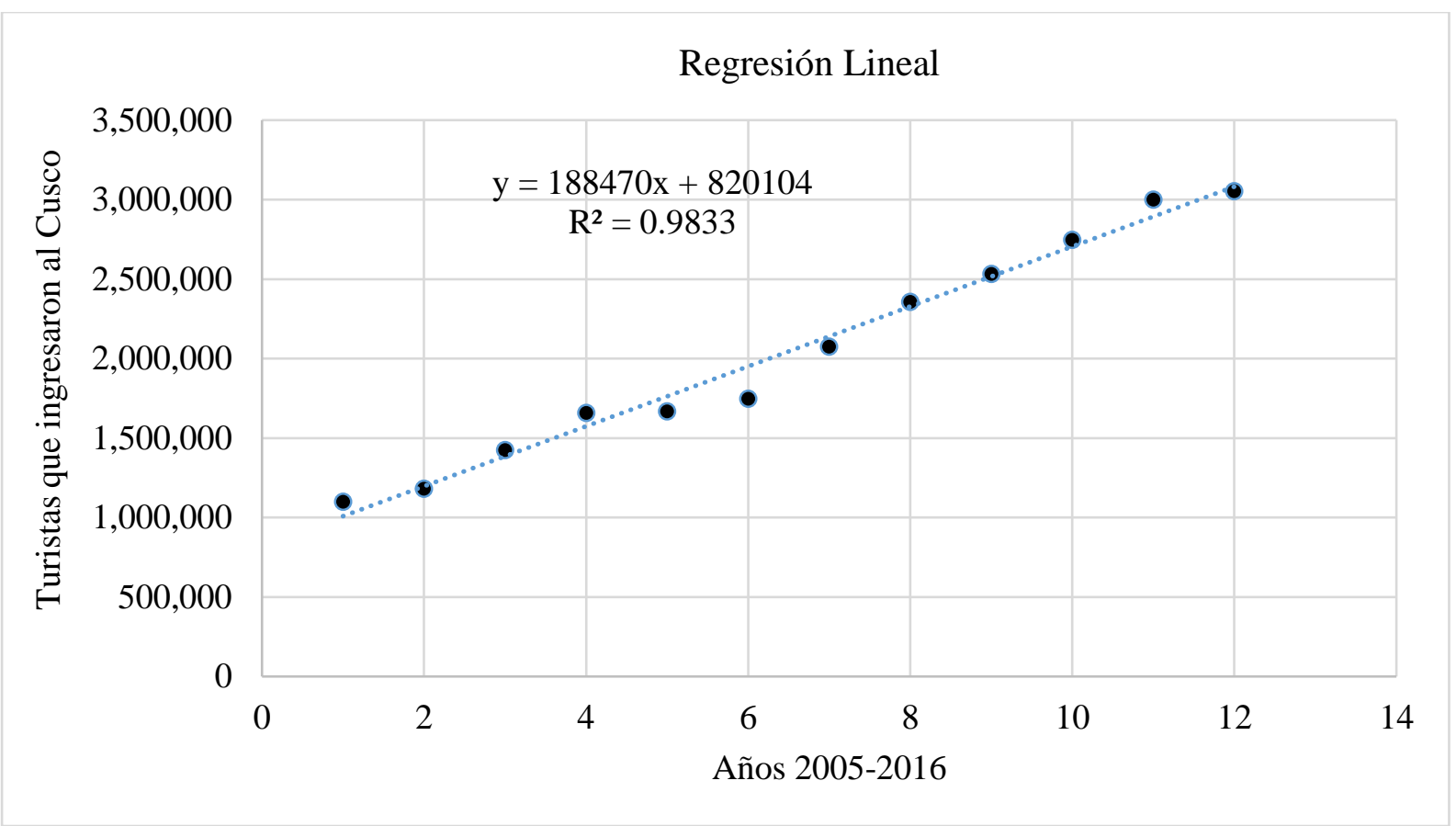

Figura 16. Regresión lineal para proyección de turistas que ingresarán al Cusco los años 2017-2022. Adaptado de Boletín Dircetur.

La ecuación de la recta para este número de observaciones es: $\mathrm{Y}=188,470 \mathrm{x}+820,104$

Siendo ' $\mathrm{Y}^{\prime}$ el número de turistas, ' $\mathrm{X}$ ' el período correspondiente.

Por lo tanto, aplicando la ecuación de la recta, se proyecta el número de turistas que visitarán Cusco los años 2017 al 2022, como sigue: 
Tabla 36.

Turistas que ingresarán a la Ciudad del Cusco los años 2017 al 2022

\begin{tabular}{ccc}
\hline Año & Turistas que ingresarán al Cusco & Variación porcentual \\
\hline 2017 & $3,270,214$ & \\
2018 & $3,458,684$ & $6 \%$ \\
2019 & $3,647,154$ & $5 \%$ \\
2020 & $3,835,624$ & $5 \%$ \\
2021 & $4,024,094$ & $5 \%$ \\
2022 & $4,212,564$ & $5 \%$ \\
\hline
\end{tabular}

Nota: Dircetur. Elaboración propia método regresión lineal.

Asimismo, se obtuvo el coeficiente de determinación $\mathrm{R}^{2}$ el cual es una buena medida de bondad de ajuste para explicar el comportamiento de la proyección (Rodriguez, 2005). El 98.33\%, indica que la calidad del modelo para replicar los resultados es confiable.

\subsection{Cálculo del mercado objetivo}

\subsubsection{Mercado potencial.}

El mercado potencial es el conjunto de usuarios que podrían necesitar el bien o servicio. Este mercado estará formado por los turistas que llegarán al Cusco por vacaciones entre los años 2018 a 2022.

Para el cálculo del mercado potencial, se ha tomado como base la información de turistas que llegaron al Cusco por motivo de vacaciones, según el boletín Turismo In de PromPerú durante los años 2013 al 2016 como se muestra en la tabla 37: 
Tabla 37.

Turistas que Visitaron Cusco Por Vacaciones 2013-2016 (Expresado en \%)

\begin{tabular}{ccccc}
\hline \multirow{2}{*}{ Años } & \multicolumn{2}{c}{ Perfil del turista extranjero } & \multicolumn{2}{c}{ Perfil del turista nacional } \\
\cline { 2 - 5 } & Vacaciones & Otros & Vacaciones & Otros \\
\hline 2013 & $86 \%$ & $14 \%$ & $51 \%$ & $49 \%$ \\
2014 & $90 \%$ & $10 \%$ & $48 \%$ & $52 \%$ \\
2015 & $89 \%$ & $11 \%$ & $52 \%$ & $48 \%$ \\
2016 & $93 \%$ & $7 \%$ & $65 \%$ & $35 \%$ \\
Promedio & $90 \%$ & $10.5 \%$ & $54 \%$ & $46.5 \%$ \\
\hline
\end{tabular}

Nota: Turismo In de PromPerú: Perfil del vacacionista extranjero y nacional.

Asimismo, Dircetur estimó que del total de turistas que ingresaron al Cusco el 2016, el $80 \%$ fueron extranjeros y el $20 \%$ turistas nacionales; con esta información y los datos de la Tabla 38 se obtendrá finalmente el porcentaje de turistas que ingresaron al Cusco por vacaciones entre los años 2013 a 2016 como se ve a continuación:

Tabla 38 .

Turistas que Visitaron Cusco Por Vacaciones 2017-2022

\begin{tabular}{lccc}
\hline \multirow{2}{*}{ Tipo de turistas } & $\begin{array}{c}\text { Procedencia de turistas que } \\
\text { visitaron Cusco según Dircetur }\end{array}$ & $\begin{array}{c}\text { Turistas que visitaron Cusco } \\
\text { por vacaciones según } \\
\text { Turismo In }\end{array}$ & Total \\
\hline Extranjeros & $80 \%$ & $90 \%$ & $71.6 \%$ \\
Nacionales & $20 \%$ & $54 \%$ & $10.8 \%$ \\
& Turistas que visitaron Cusco por vacaciones & $82.4 \%$ \\
\hline
\end{tabular}

Nota: Elaboración propia

Los datos de las tablas 37 y 38 proporcionan información sólida y confiable para los años 2013 a 2016, por tanto, se asume, que para los años 2017 a 2022 el promedio de turistas que visitará el Cusco por vacaciones será también de un $82 \%$, lo que permite obtener la proyección del mercado potencial para los años 2017 a 2022 como se muestra en la Tabla 39. 
Tabla 39.

Mercado Potencial 2017 al 2022

\begin{tabular}{cccc}
\hline Año & $\begin{array}{c}\text { Turistas que ingresarán } \\
\text { al Cusco }\end{array}$ & $\begin{array}{c}\text { Turistas que visitarán } \\
\text { Cusco por vacaciones (\%) }\end{array}$ & $\begin{array}{c}\text { Mercado Potencial (Turistas } \\
\text { que visitarán Cusco por } \\
\text { vacaciones) }\end{array}$ \\
\hline 2017 & $3,270,214$ & $82 \%$ & $2,694,656$ \\
2018 & $3,458,684$ & $82 \%$ & $2,849,956$ \\
2019 & $3,647,154$ & $82 \%$ & $3,005,255$ \\
2020 & $3,835,624$ & $82 \%$ & $3,160,554$ \\
2021 & $4,024,094$ & $82 \%$ & $3,315,853$ \\
2022 & $4,212,564$ & $82 \%$ & $3,471,153$ \\
\hline
\end{tabular}

Nota: Turistas que ingresarán a la ciudad del Cusco 2017-2022. Turismo In PromPerú. Elaboración propia.

\subsubsection{Mercado disponible.}

El mercado disponible está formado por la porción del mercado potencial que visitará la ciudad de Cusco por vacaciones, pero además visitará la ciudad de Maras.

Para el cálculo del mercado disponible se castiga el mercado potencial por el $37 \%$ de turistas que además visita la ciudad de Maras, dato extraído del boletín Turismo In de PromPerú para el año 2016.

Como se cuenta únicamente con información del 2016, se debe considerar que el turismo en la ciudad de Maras está en desarrollo y no se encuentra data histórica sobre la visita de turistas a dicha ciudad, siendo ésta una limitación de las fuentes secundarias consultadas. Sin embargo, la fuente es confiable para asumir que para los años 2017 al 2022 el ingreso de turistas a la ciudad de Maras por vacaciones continuará con la frecuencia de visitas de un $37 \%$ del total de turistas que llegarán al Cusco. El mercado disponible para los años 2017 a 2022 se presenta en la Tabla 40: 
Tabla 40.

Mercado disponible 2017 al 2022

\begin{tabular}{cccc}
\hline Año & $\begin{array}{c}\text { Mercado Potencial } \\
\text { (Turistas que visitarán } \\
\text { Cusco por vacaciones) }\end{array}$ & $\begin{array}{c}\text { Turistas que visitarán } \\
\text { Maras por vacaciones (\%) }\end{array}$ & $\begin{array}{c}\text { Mercado Disponible } \\
\text { (Turistas que visitarán } \\
\text { Maras por vacaciones) }\end{array}$ \\
\hline 2017 & $2,694,656$ & $37 \%$ & 983,550 \\
2018 & $2,849,956$ & $37 \%$ & $1,040,234$ \\
2019 & $3,005,255$ & $37 \%$ & $1,096,918$ \\
2020 & $3,160,554$ & $37 \%$ & $1,153,602$ \\
2021 & $3,315,853$ & $37 \%$ & $1,210,287$ \\
2022 & $3,471,153$ & $37 \%$ & $1,266,971$ \\
\hline
\end{tabular}

Nota: Elaboración propia con la información de Tabla 39 Mercado Potencial 2017-2022. Turismo In PromPerú.

\subsubsection{Mercado efectivo.}

Es el mercado disponible de turistas que visitan Cusco por vacaciones, que además visitan la ciudad de Maras y que adicionalmente han mostrado la intención de comprar uno de los paquetes del Ecolodge "Kachi Raqay".

Tabla 41.

Paquetes que ofrece el Lodge

\begin{tabular}{clcc}
\hline Paquetes "Kachi Raqay” & Paquete 1 & Paquete 2 & Paquete 3 \\
\hline Días & 1 Full day & 2 días 1 noche & 3 días 2 noches \\
\hline
\end{tabular}

Para el cálculo del mercado efectivo se hará uso de los resultados del estudio de mercado aplicando el índice de Mc Daniels (Mc Daniel \& Gates, 2016). Los resultados del estudio de muestran a continuación: 
Tabla 42.

Intención de compra por paquetes según estudio de mercado

\begin{tabular}{lccc}
\hline \multicolumn{1}{c}{ Paquetes } & Paquete 1 & Paquete 2 & Paquete 3 \\
\hline Definitivamente no tomaría el paquete & $15 \%$ & $9 \%$ & $14 \%$ \\
Posiblemente no tomaría el paquete & $6 \%$ & $11 \%$ & $18 \%$ \\
Me sería indiferente tomar el paquete o no & $29 \%$ & $45 \%$ & $52 \%$ \\
Posiblemente tomaría el paquete & $31 \%$ & $22 \%$ & $8 \%$ \\
Definitivamente tomaría el paquete & $19 \%$ & $13 \%$ & $8 \%$ \\
\hline
\end{tabular}

Nota: Estudio de Mercado. Elaboración Propia.

Tabla 43.

Probabilidad de consumo aplicando índice McDaniel

\begin{tabular}{|c|c|c|c|c|c|c|c|}
\hline \multirow[b]{2}{*}{ Paquetes } & \multirow{2}{*}{$\begin{array}{c}\text { Probabilidad } \\
\text { de consumo } \\
\text { según Mc } \\
\text { Daniel } \\
\end{array}$} & \multicolumn{2}{|c|}{ Paquete 1} & \multicolumn{2}{|c|}{ Paquete 2} & \multicolumn{2}{|c|}{ Paquete 3} \\
\hline & & $\begin{array}{l}\text { Resultado } \\
\text { Estudio } \\
\text { Mercado } \\
\end{array}$ & $\begin{array}{c}\text { Demanda } \\
\text { efectiva }\end{array}$ & $\begin{array}{c}\text { Resultado } \\
\text { Estudio } \\
\text { Mercado } \\
\end{array}$ & $\begin{array}{c}\text { Demanda } \\
\text { efectiva }\end{array}$ & $\begin{array}{c}\text { Resultado } \\
\text { Estudio } \\
\text { Mercado } \\
\end{array}$ & $\begin{array}{l}\text { Demanda } \\
\text { efectiva }\end{array}$ \\
\hline $\begin{array}{l}\text { Definitivamente no } \\
\text { tomaría el paquete }\end{array}$ & $0 \%$ & $15 \%$ & $0 \%$ & $9 \%$ & $0 \%$ & $14 \%$ & $0 \%$ \\
\hline $\begin{array}{l}\text { Posiblemente no tomaría } \\
\text { el paquete }\end{array}$ & $10 \%$ & $6 \%$ & $1 \%$ & $11 \%$ & $1 \%$ & $18 \%$ & $2 \%$ \\
\hline $\begin{array}{l}\text { Me sería indiferente } \\
\text { tomar el paquete o no }\end{array}$ & $25 \%$ & $29 \%$ & $7 \%$ & $45 \%$ & $11 \%$ & $52 \%$ & $13 \%$ \\
\hline $\begin{array}{l}\text { Posiblemente tomaría el } \\
\text { paquete }\end{array}$ & $35 \%$ & $31 \%$ & $11 \%$ & $22 \%$ & $8 \%$ & $8 \%$ & $3 \%$ \\
\hline $\begin{array}{l}\text { Definitivamente tomaría } \\
\text { el paquete }\end{array}$ & $70 \%$ & $19 \%$ & $13 \%$ & $13 \%$ & $9 \%$ & $8 \%$ & $6 \%$ \\
\hline Total & & & $32 \%$ & & $29 \%$ & & $23 \%$ \\
\hline
\end{tabular}

Luego de aplicar la metodología del índice de Mc Daniels, se obtiene el mercado efectivo por paquetes del Ecolodge "Kachi Raqay" como sigue: 
Tabla 44.

Mercado efectivo de los paquetes del Ecolodge "Kachi Raqay"

\begin{tabular}{ccccc}
\hline Año & $\begin{array}{c}\text { Mercado Disponible } \\
\text { (Turistas que visitarán } \\
\text { Maras por vacaciones) }\end{array}$ & $\begin{array}{c}\text { Mercado Efectivo } \\
\text { Paquete 1 }\end{array}$ & $\begin{array}{c}\text { Mercado } \\
\text { Efectivo } \\
\text { Paquete 2 }\end{array}$ & $\begin{array}{c}\text { Mercado } \\
\text { Efectivo } \\
\text { Paquete 3 }\end{array}$ \\
\hline 2017 & 983,550 & 314,736 & 286,705 & 228,183 \\
2018 & $1,040,234$ & 332,875 & 303,228 & 241,334 \\
2019 & $1,096,918$ & 351,014 & 319,752 & 254,485 \\
2020 & $1,153,602$ & 369,153 & 336,275 & 267,636 \\
2021 & $1,210,287$ & 387,292 & 352,799 & 280,786 \\
2022 & $1,266,971$ & 405,431 & 369,322 & 293,937 \\
\hline
\end{tabular}

Elaboración propia.

\subsubsection{Mercado objetivo.}

Es la porción del mercado efectivo que visita el Cusco por vacaciones, que además visita la ciudad de Maras, tiene disposición de compra de uno de los paquetes del lodge y a su vez será atendido por el proyecto.

Para el cálculo del mercado objetivo se tendrá en cuenta dos criterios:

1. El mercado objetivo del paquete 1 estará en función del número de vehículos y del personal disponible para el recorrido de los turistas que solicitan el paquete full day. Para el año 2017 se tomará el 0,5\% del mercado efectivo como sigue: 
Tabla 45.

Mercado efectivo Paquete 1 del Ecolodge "Kachi Raqay"

\begin{tabular}{ccc}
\hline Año & Mercado Efectivo Paquete 1 & Mercado Objetivo 0,5\% \\
\hline 2017 & 314,736 & 1,574 \\
2018 & 332,875 & 1,664 \\
2019 & 351,014 & 1,748 \\
2020 & 369,153 & 1,835 \\
2021 & 387,292 & 1,927 \\
2022 & 405,431 & 2,023 \\
\hline
\end{tabular}

Nota: Elaboración propia.

El mercado objetivo de 1,664 turistas el primer año (2018), representa un total de 139 turistas por mes atendidos en el paquete full day y 35 turistas por semana; lo que se plantea como un escenario conservador para incrementar en $5 \%$ a partir del $3 \mathrm{er}$ año ${ }^{2}$.

2. El mercado objetivo de los paquetes 2 y 3 estará en función del número de camas que ofrece el Ecolodge "Kachi Raqay" y la tasa de ocupabilidad de las mismas.

La tasa de ocupabilidad indica el porcentaje en que se utilizan las camas disponibles en un hotel. Al no contar con la tasa de ocupabilidad de un hotel de igual capacidad al Ecolodge en estudio para el cálculo de dicha tasa para el proyecto, se tendrá como referencia la tasa de 68\% correspondiente al promedio de ocupación de hoteles en Cusco en el 2015, según la Cámara Española de Comercio Perú.

El potencial de camas del lodge se determina en base al número de camas por habitaciones, como sigue:

\footnotetext{
${ }^{2}$ Porcentaje promedio de incremento de turistas extraído de la Tabla 36 Turistas que ingresarán a la Ciudad del Cusco los años 2017 al 2022 del presente trabajo.
} 
El número de habitaciones será 18 habitaciones. Categorizadas como habitaciones estándar: 9 simples, 6 dobles y 3 matrimoniales.

Tabla 46.

Potenciales camas Ecolodge "Kachi Raqay"

\begin{tabular}{lccccc}
\hline \multicolumn{1}{c}{ Tipo habitaciones } & $\begin{array}{c}\mathrm{N}^{\circ} \text { de } \\
\text { habitaciones }\end{array}$ & $\begin{array}{c}\text { Camas x } \\
\text { habitación }\end{array}$ & $\begin{array}{c}\mathrm{N}^{\circ} \text { Camas } \\
\text { máximo por } \\
\text { habitación al día }\end{array}$ & $\begin{array}{c}\text { Días al } \\
\text { Año }\end{array}$ & $\begin{array}{c}\text { Camas al } \\
\text { año por } \\
\text { habitación }\end{array}$ \\
\hline Habitación Simple & 9 & 1 & 9 & 360 & 3,240 \\
Habitación doble & 6 & 2 & 12 & & 2,320 \\
$\begin{array}{l}\text { Habitación matrimonial } \\
\text { Total }\end{array}$ & 3 & 2 & 6 & & 9,760 \\
\hline
\end{tabular}

Elaboración propia

El mercado objetivo total del Ecolodge "Kachi Raqay" puede ser atendido por una ocupabilidad total de 9,720 camas, de las cuales; siendo conservadores, se ha planteado mantener una tasa de ocupabilidad del $45 \%$ el primer año, para incrementar $9.5 \%$ año tras año teniendo en cuenta los objetivos comerciales trazados en el presente plan de negocio. En este escenario conservador la tasa planteada de $9.5 \%$ se encuentra dentro del crecimiento anual $9.6 \%$ del sector hotelero. ${ }^{3}$

\footnotetext{
${ }^{3}$ Reporte estadístico de turismo disponible en https://www.mincetur.gob.pe/wpcontent/uploads/documentos/turismo/estadisticas/Octubre_2016.pdf (consultado 10 Enero 2017)
} 
Tabla 47.

Mercado objetivo Paquetes 2 y 3 atendidos por el Ecolodge "Kachi Raqay" según la tasa de ocupabilidad.

\begin{tabular}{cccccc}
\hline Año & $\begin{array}{c}\text { Ocupabilidad } \\
\text { total Paquetes } \\
2 \text { y 3 }\end{array}$ & $\begin{array}{c}\text { \% de Mercado } \\
\text { Objetivo del proyecto } \\
\text { (tasa de ocupabilidad) }\end{array}$ & $\begin{array}{c}\text { Mercado } \\
\text { Objetivo } \\
\text { Paquetes 2 y } \\
3\end{array}$ & $\begin{array}{c}\text { Mercado } \\
\text { Objetivo } \\
\text { Paquete 2 } \\
60 \%\end{array}$ & $\begin{array}{c}\text { Mercado } \\
\text { Objetivo } \\
\text { Paquete 3 } \\
40 \%\end{array}$ \\
\hline 2018 & 9,720 & $44 \%$ & 4,257 & 2,554 & 1,703 \\
2019 & 9,720 & $48 \%$ & 4,662 & 2,797 & 1,865 \\
2020 & 9,720 & $53 \%$ & 5,105 & 3,063 & 2,042 \\
2021 & 9,720 & $58 \%$ & 5,590 & 3,354 & 2,236 \\
2022 & 9,720 & $63 \%$ & 6,121 & 3,672 & 2,448 \\
\hline
\end{tabular}

Como se observa en la Tabla 47, se plantea dirigir e impulsar mayor promoción y empuje de la fuerza de ventas el mayor esfuerzo de ventas al paquete 2 con un $60 \%$ y un $40 \%$ para el paquete 3 , siguiendo la tendencia mostrada en la encuesta.

\subsubsection{Pronóstico de ventas.}

Tomando en cuenta que el paquete 3 consume 2 noches por paquete, se presenta a continuación el pronóstico de ventas del Ecolodge "Kachi Raqay":

Tabla 48.

Pronóstico de ventas Ecolodge "Kachi Raqay"

\begin{tabular}{rcccc}
\hline \multirow{2}{*}{ Año } & \multicolumn{4}{c}{ Mercado Objetivo } \\
\cline { 2 - 5 } & Paquete 1 & Paquete 2 & Paquete 3 & Total \\
\hline 2018 & 1,664 & 2,554 & 851 & 5,070 \\
2019 & 1,748 & 2,797 & 932 & 5,477 \\
2020 & 1,835 & 3,063 & 1,021 & 5,919 \\
2021 & 1,927 & 3,354 & 1,118 & 6,398 \\
2022 & 2,023 & 3,672 & 1,224 & 6,920 \\
\hline
\end{tabular}

Elaboración propia 


\subsection{Aspectos críticos que impactan el pronóstico de ventas.}

Además de las oportunidades y amenazas mencionadas en el capítulo II, a continuación, se resaltan algunos aspectos críticos que podrían afectar las proyecciones mencionadas:

Aspectos Socioculturales: Huelgas, muy recurrentes debido a factores mineros, comerciales y políticos.

Económicos: Que el tipo de cambio desfavorezca al extranjero, sobre todo a los de países limítrofes.

Climatológicos: Como por ejemplo los Huaicos vividos en el 2017, o lluvias que impidan las llegadas y las salidas de los aeropuertos.

Inseguridad civil: Que el nivel de crimen crezca tanto que genere mala publicidad. O el normal desplazamiento de los trenes camino a Machu Picchu. 


\section{Capítulo V: Estudio de Ingeniería del Proyecto}

\subsection{Modelamiento y selección de procesos productivos.}

Para definir los procesos de servicio ${ }^{4}$ se hace uso del Blueprint del servicio, que según María Pérez Savelli investigadora de la Universidad de Puerto Rico: "permite identificar como deben realizarse las interacciones entre clientes y empleados y la manera en que los sistemas y las actividades que se realizan tras bambalinas apoyan estas interacciones para generar una proposición de valor para el cliente y los stakeholders" (Savelli, 2017). Se describe a continuación los principales procesos, así como el Blueprint del programa más aceptado en la encuesta para los clientes directos.

1. Reservas

Se describe el proceso de reservas por Blueprint:

- El cliente cuenta con diversos medios para reservar el alojamiento y servicios del hospedaje, entre ellos la plataforma web de la empresa, las plataformas como booking, expedia, etc, así también puede reservar por medio de los agentes de viaje, o directamente por la línea telefónica y la reserva directa en el front-desk también conocido como venta walk-in.

- En todos estos casos la reserva se atenderá en un plazo máximo de 24 horas.

\footnotetext{
${ }^{4}$ Neologismo en el ámbito de la gestión empresarial para referirse al proceso que se lleva a cabo al momento de ofrecer un servicio
} 
- Si la reserva es hecha por medio de una plataforma la respuesta se dará por medio de una carta de confirmación de servicios vía correo electrónico.

- Si la reserva es hecha directamente por un agente o una ejecutiva de reserva se atenderá al huésped con una bienvenida, se solicitarán los datos completos del huésped como nombre completo, nacionalidad, número de pasaporte, fecha de nacimiento. Se requerirá también un número de tarjeta de crédito para garantizar la reserva.

- Se confirmará el tipo de acomodación, es decir en uso simple, doble de la habitación. Fechas de ingreso y salida, horarios de check-in (ingreso) y check-out (salida) las restricciones alimenticias, etc. de forma escrita, vía correo electrónico o carta de confirmación.

- Se presentará de forma escrita las políticas de cancelación y reducción de habitaciones y servicios

- En caso de grupos de más de cinco habitaciones, se presentará por escrito las policitas de consumo de alimentos y bebidas. 


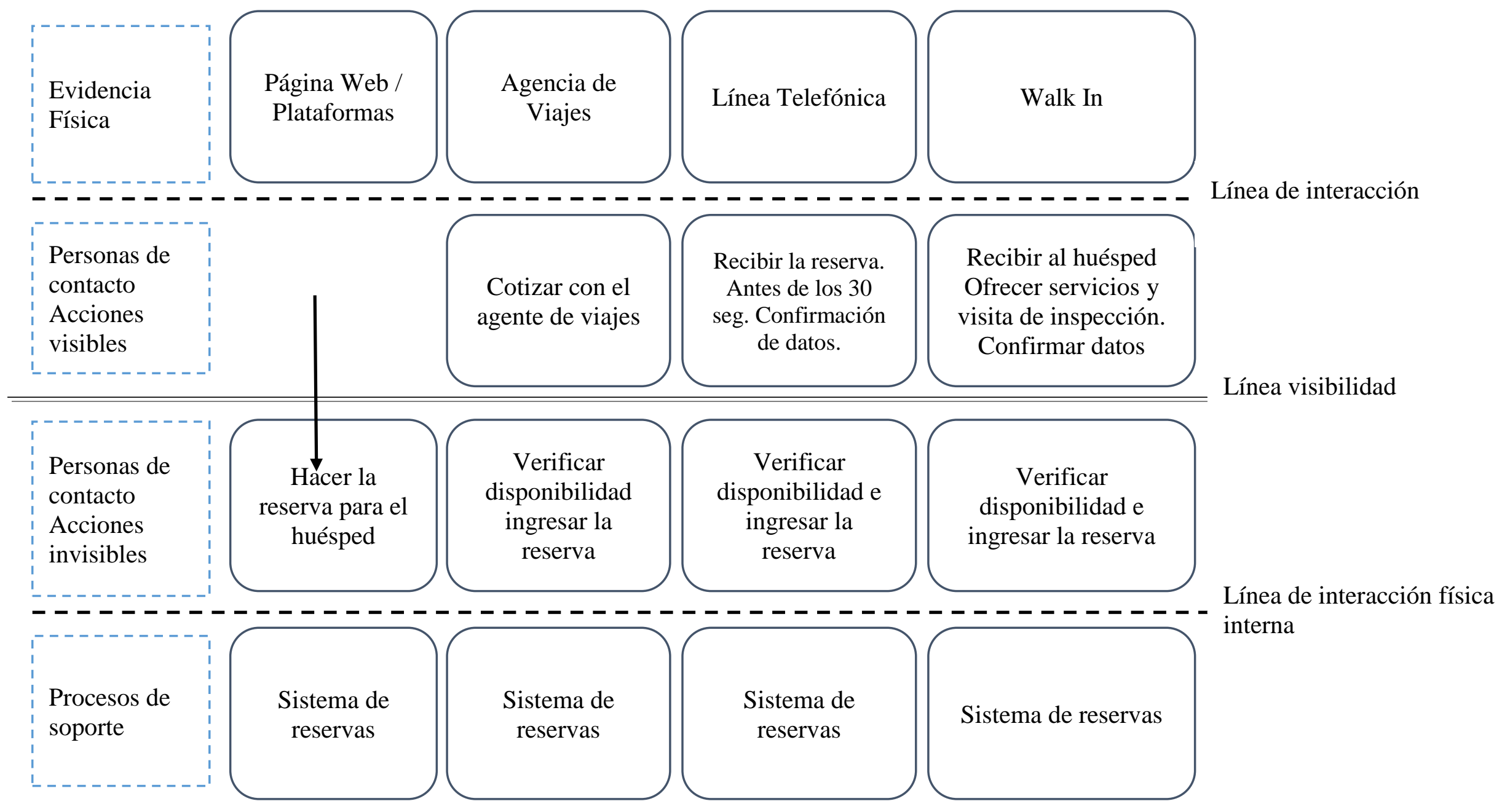

Figura 17. Blueprint para el proceso de reserva. Adaptado de la información 
2. Check-in -Rooming-Porter

Se describe el proceso de Check-in por Blueprint:

- Personal de Seguridad deberá recibir a las unidades móviles, contara el número de personas que ingresan, la unidad motorizada, numero de equipajes. De haber equipos electrónicos el huésped podrá solicitar se ingrese esta información al reporte.

- Conserjería recibe a los huéspedes de forma cálida, se reconocerá a los huéspedes a los 30 segundos de interacción. La comunicación entre el personal será siempre discreta. Se ofrece bebida de bienvenida y se cuenta y confirma con el huésped el número de maletas recibidas.

- Recepción tomara el documento de identidad más la tarjeta de migración del huésped para ser escaneada para efectos de facturación. Tomará también una pre autorización de la tarjeta de crédito.

- Huésped firmara la tarjeta de registro, confirmando así que los datos ingresados en la tarjeta corresponden con sus datos personales y con las fechas y servicios de la reserva.

- Conserjería acompañara al huésped hasta su habitación, le mostrar las zonas comunes y los horarios de alimentación y servicios del hotel. 


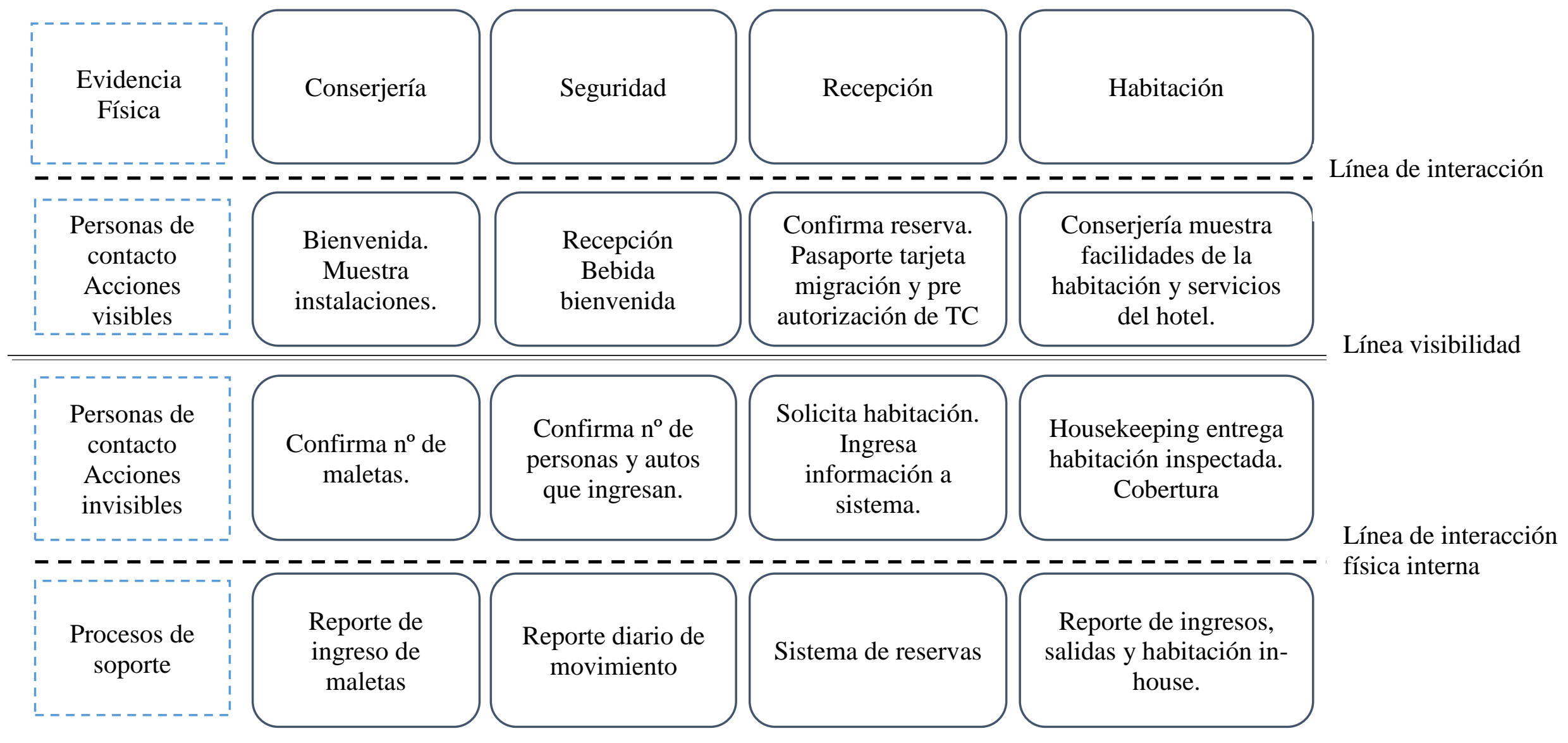

Figura 18. Blueprint para check in -rooming - porter. Adaptado de la información 
3. Check Out - Porter

Se describe el proceso de Check-out por Blueprint:

- Huésped coordina con el personal la hora de salida.

- Recepción prepara la cuenta y confirma cargos adicionales. Carga el monto final a la tarjeta de crédito o en cash y genera boleta, se carga sin IGV Alojamiento y alimentación. Se carga con IGV servicios adicionales.

- Tras el check-out de las habitaciones, recepción genera reportes de auditoría para el área contable, que incluye: ingresos diarios por área, cargos complementary, cuadre de caja diario en cada turno.

- Conserjería ayuda con las maletas y confirma el número de equipaje vs el registro de ingreso.

- Housekeeping se despide de los huéspedes con regalo en la habitación. Recepción dicta la salida y la habitación es registrada como pendiente de limpieza. Housekeeping deberá ingresará a la habitación y dar conformidad a recepción de la salida, así como de objetos olvidados en las habitaciones.

- Seguridad dará conformidad del número de personas que se retiran, así como del número de equipaje y características de la unidad móvil que traslada a los huéspedes. 


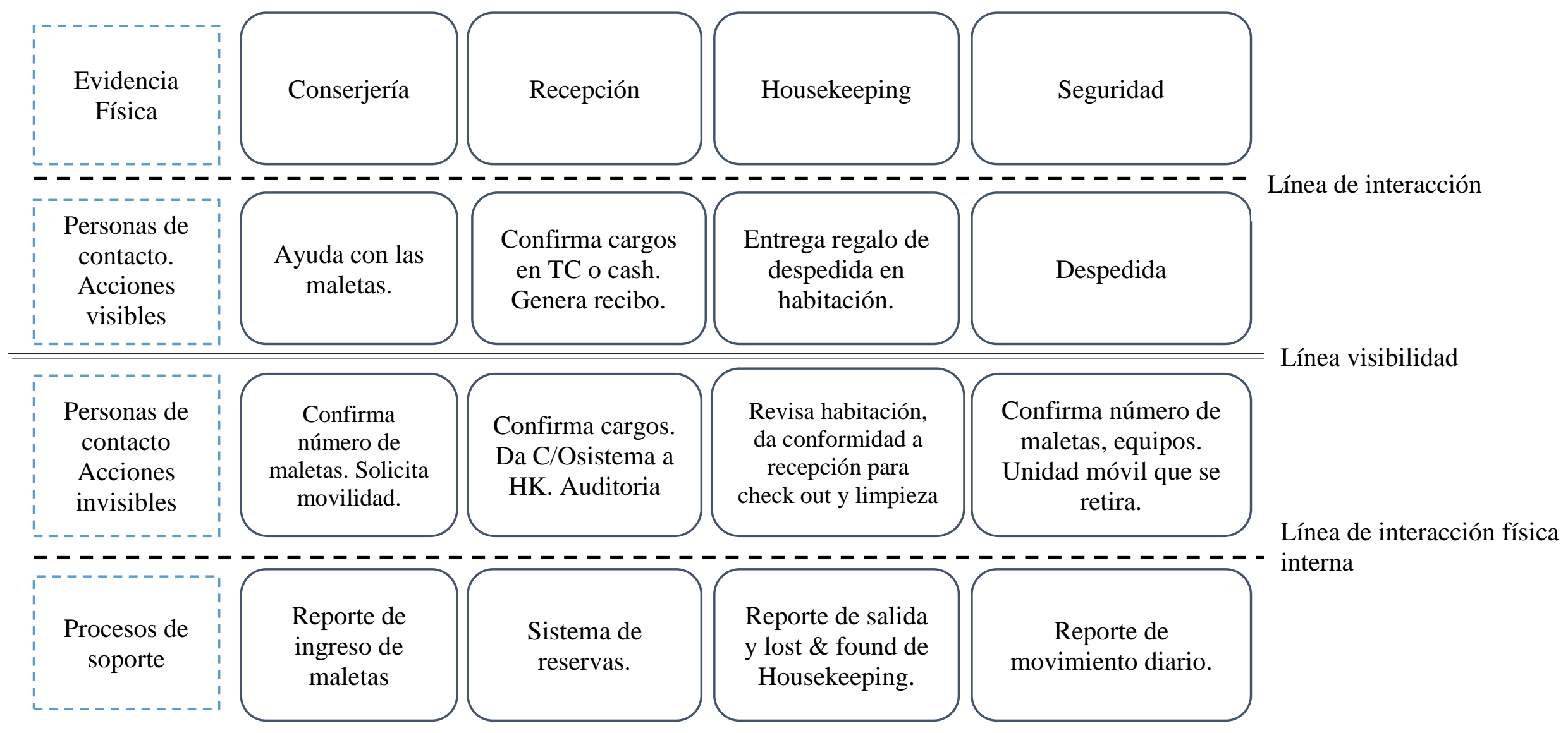

Figura 19. Blueprint para check out - porter. 
4. Restaurante:

Se describe el proceso de Restaurante por Blueprint:

- Al momento del check in se informa la modalidad de restaurante.

- Staff anuncia el servido de cada alimentación

- En el desayuno de hornean los panes por la madrugada y el staff atiende y comparte con los clientes los alimentos que cocina ha preparado previamente.

- Durante el desayuno se presenta el menú de almuerzo y cena que el cliente preferirá

- El almuerzo se atiende por llegada de acuerdo al pedido previo, entre tanto los clientes pueden participar del preparado.

- Para la cena se hará el llamado para compartir en una mesa del menú elegido. Pueden atenderse pedidos especiales solicitados previamente.

- La Preparación de panes inicia al anochecer para poder hornearse durante la madrugada. 


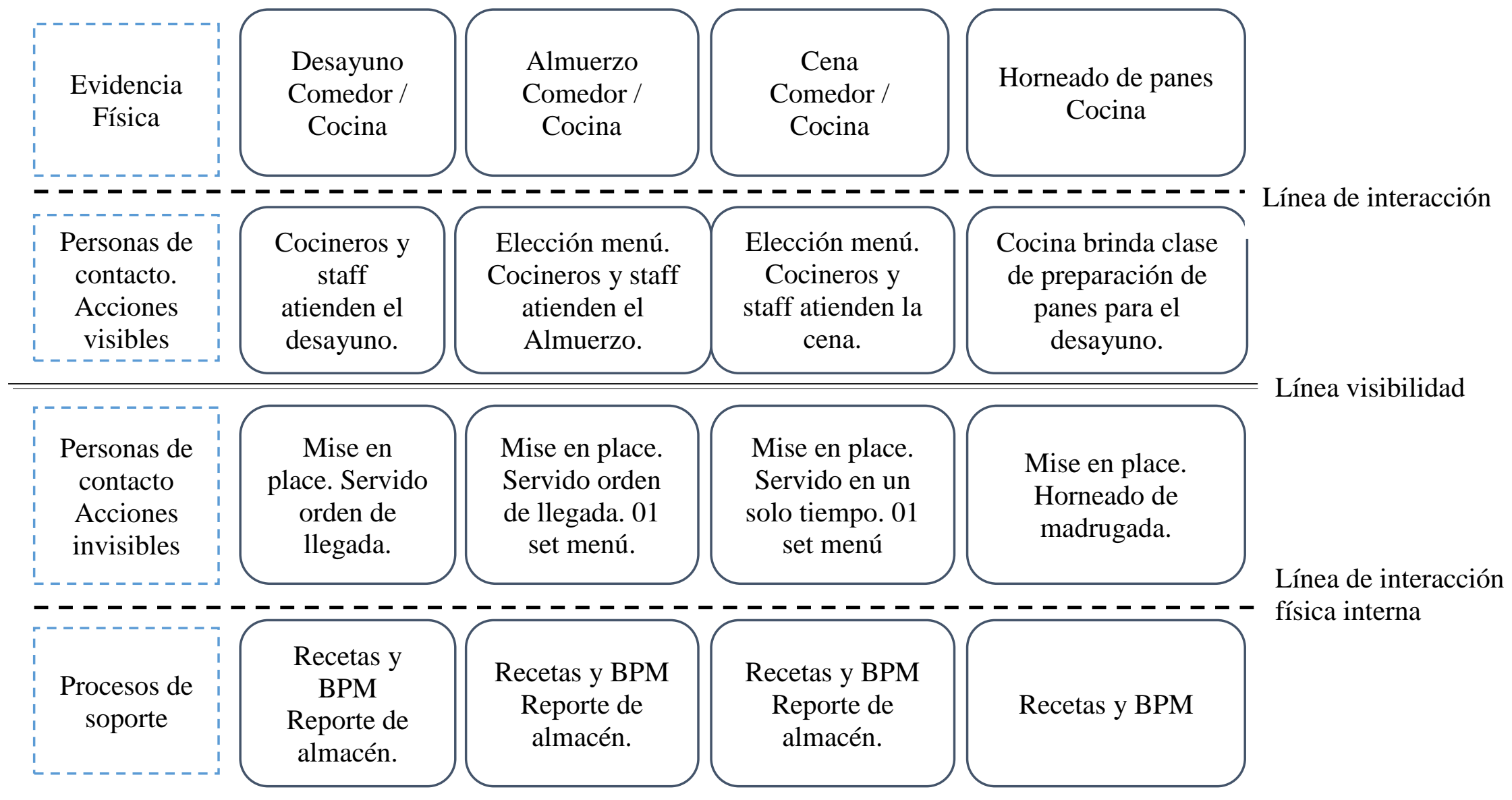

Figura 20. Blueprint para restaurante 


\section{Housekeeping}

Se describirá el proceso de Housekeeping por Blueprint:

- Los huéspedes hacen uso de sábanas, ropa de cama y toallas en habitación. Estos deben recogerse y enviarse a lavandería. Todo lo hallado será reportado.

- Luego del check-out la habitación debe ventilarse, limpiarse, los amenities deben ser repuestos, finalmente debe ponerse a la venta nuevamente.

- De solicitar lavandería, la habitación contara con un formato de lavandería para confirmar el número de prendas entregadas y recibidas.

- Las áreas públicas se limpian todos los días. El trato es siempre cordial entre trabajadores y huéspedes. 


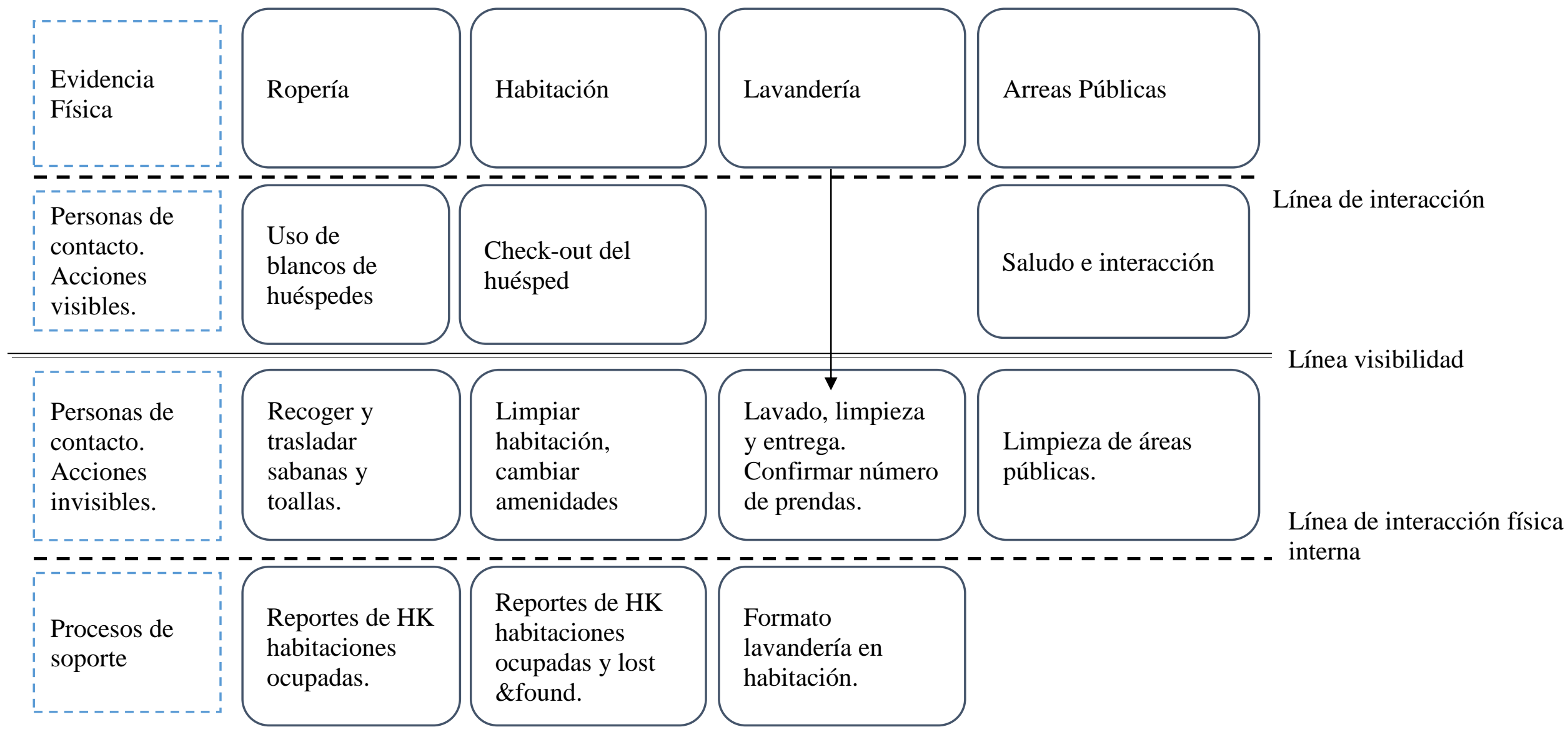

Figura 21. Blueprint para house keeping 
Dado que la acomodación es el servicio más importante, se describe el paso a paso del servicio de housekeeping. Para comenzar el servicio en habitación es circular para cubrir así cada detalle en la habitación.

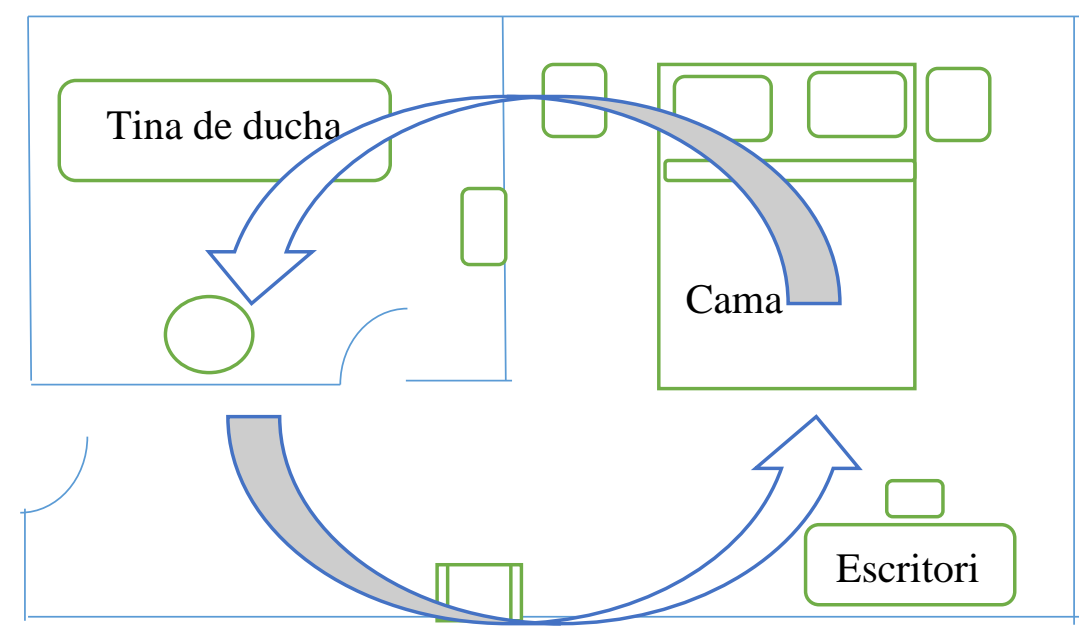

Figura 22. Representación de la habitación, las fechas representan que se debe circular por todos los ambientes para identificar detalles.

Paso a paso en la habitación:

- Cortina y ventanas ventiladas.

- Se retira ropa de cama.

- Se sacan los residuos

- La cama es el personaje más impórtame, se debe tender sin arrugas.

- Limpieza.

- Reposición.

- Se comprueba el funcionamiento de todos los elementos tanto electrónicos como manijas, persianas, etc. 
- El personal de Housekeeping recibirán la asignación de sus habitaciones, estatus de estas y las llaves al inicio de su turno, para proceder con la preparación de todos los implementos de trabajo necesarios (lencería, amentéis, productos de limpieza, etc.).

- La comunicación entre recepción y housekeeping es fundamental para el buen desarrollo de las actividades.

- Normalmente los check-outs' son las primeras habitaciones en limpiarse, la excepción a esta regla serán las habitaciones con el letrero de limpiar habitación. Después de limpiar estas habitaciones, se seguirá con las habitaciones stay-over.

- Cuando un huésped rechaza el servicio de limpieza, la supervisora debe llamar a la habitación para acordar un horario para el servicio u ofrecer toallas limpias, así también se verifica que el huésped este bien y no necesite alguna asistencia

- En el caso de habitaciones check-out, se debe retirar las sabanas sucias y dejar la cama casi para el final de esta manera esta se podrá ventilar.

- Limpieza del baño: Generalmente la limpieza de los baños inicia con la ducha, luego el lavatorio, inodoro y finalmente el piso.

- Dejar el baño con un aromatizante fresco (evitar olores fuertes).

- Dejar los amenities correspondientes y toallas limpias y frescas. 


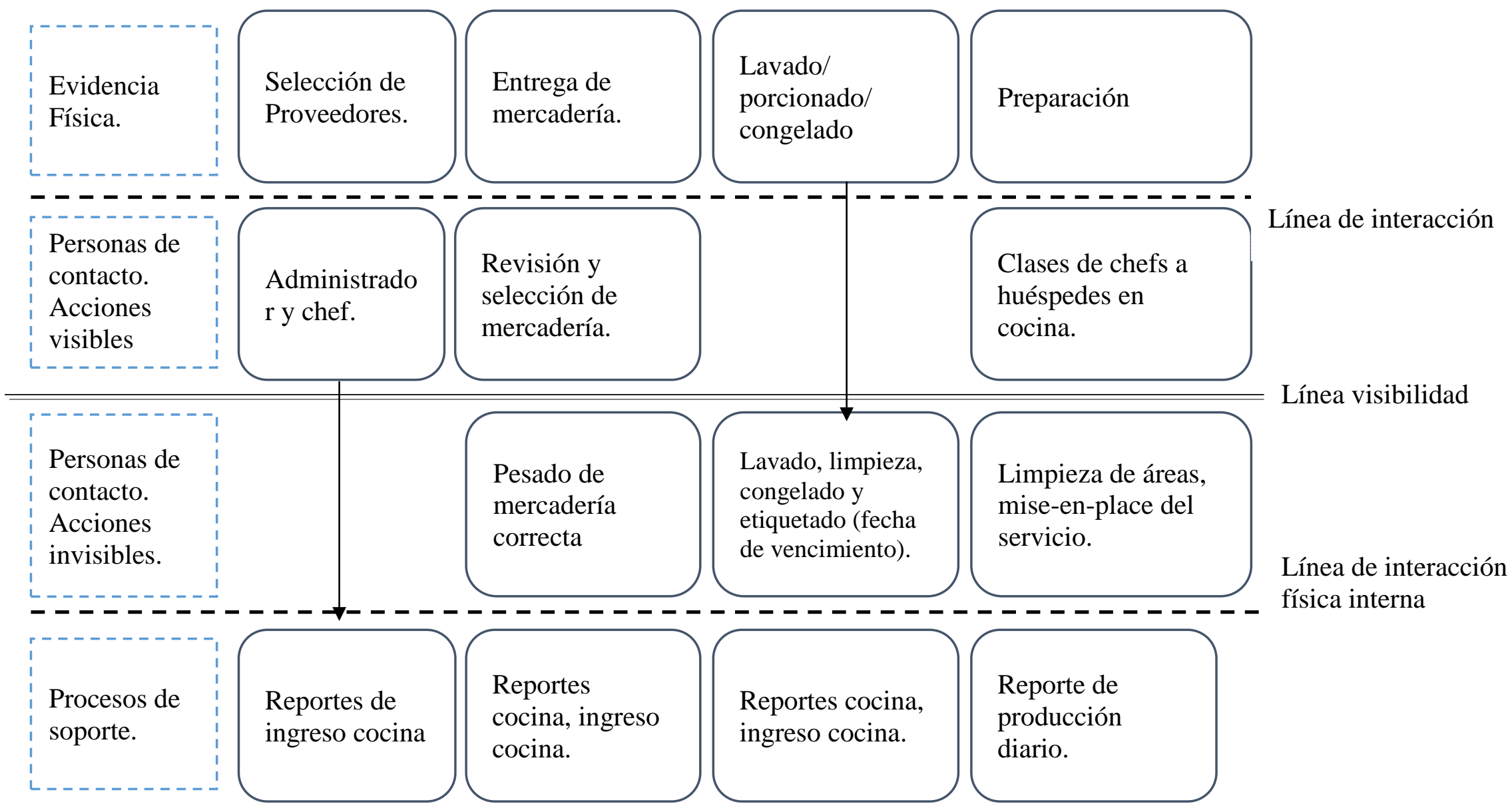

Tabla 49. Blueprint servicios más cotizados. 


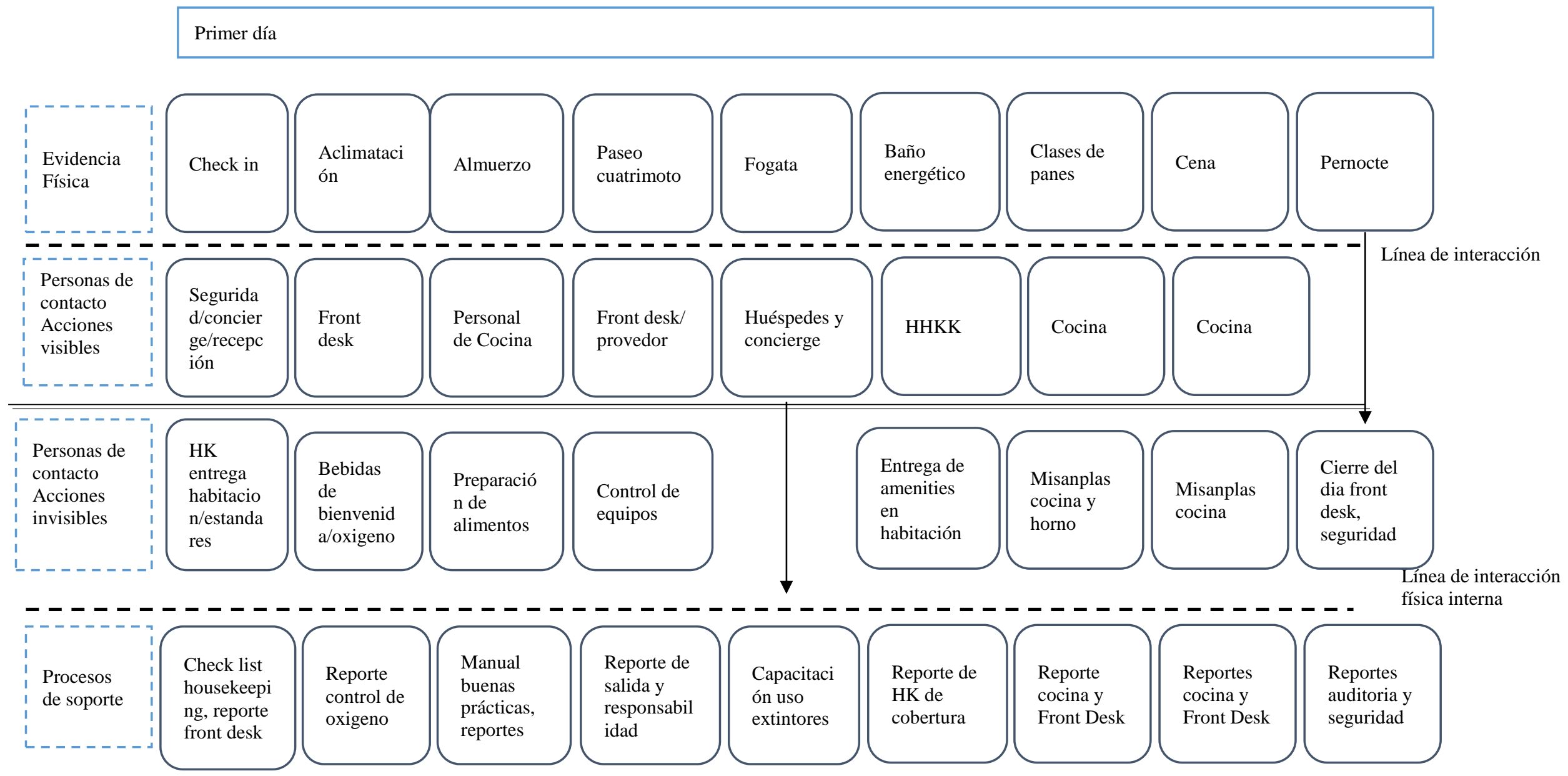




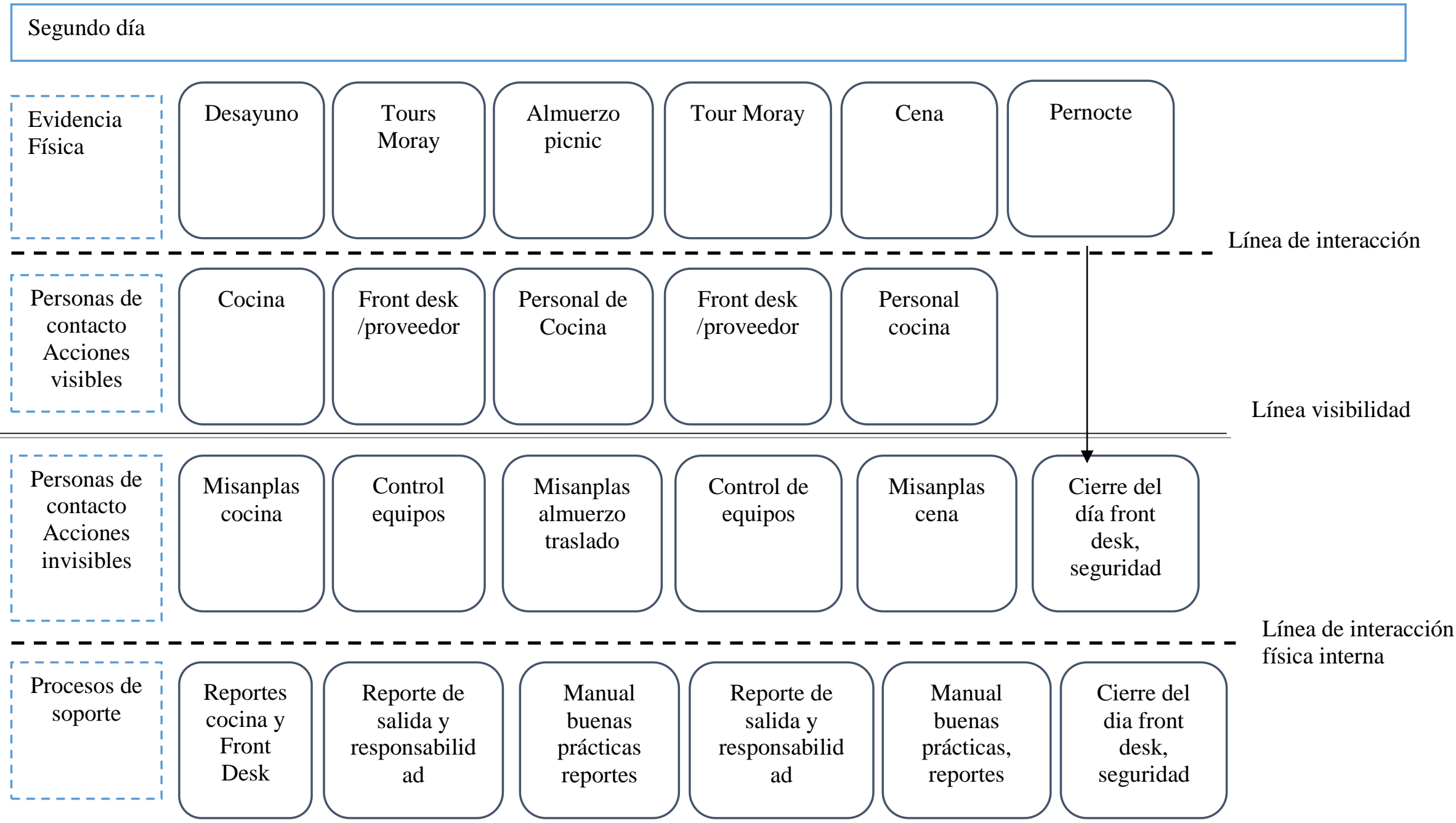




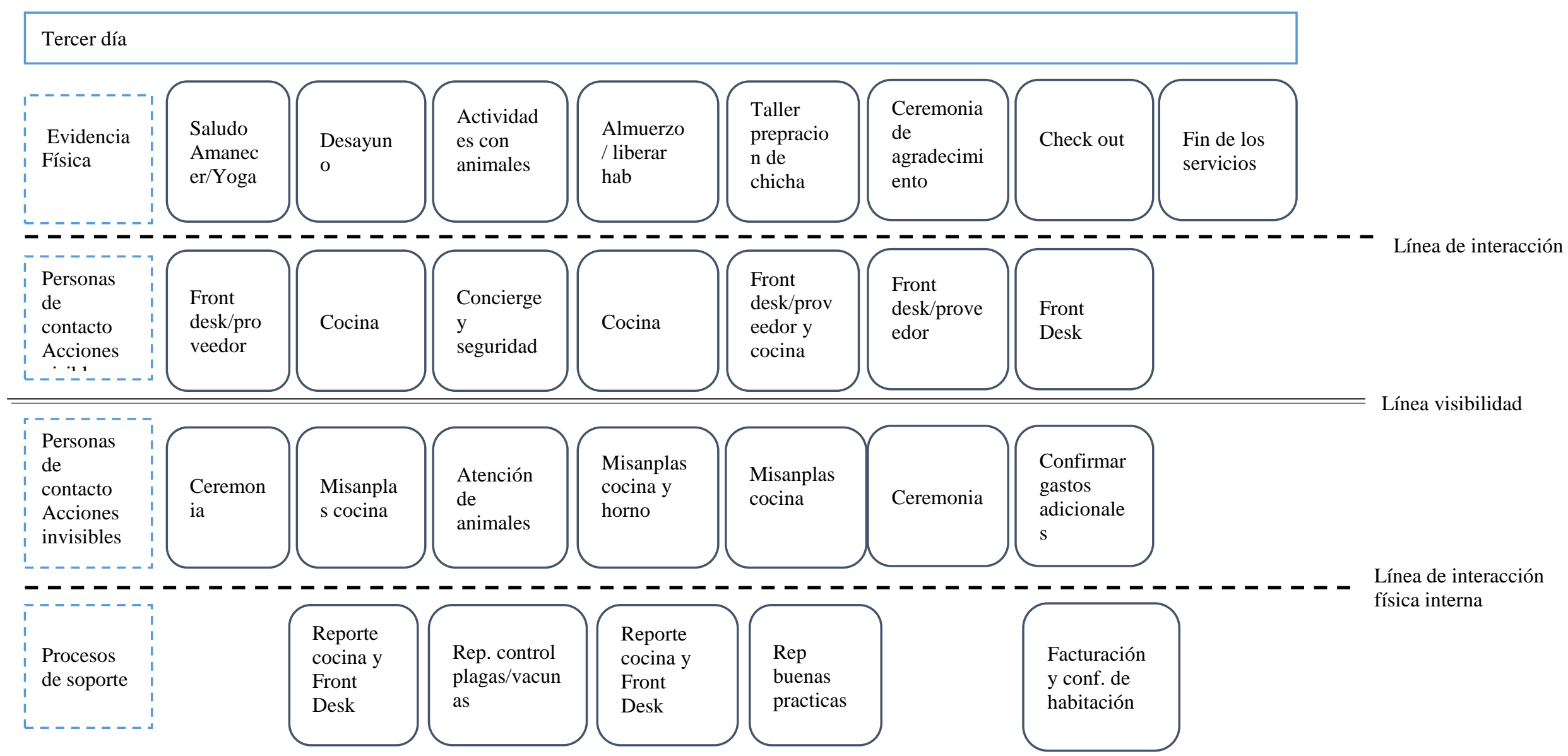


5.1.1. Distribución de equipos y maquinarias.

Las compras de maquinaria se realizarán en Lima y Cusco dependiendo de los precios y la facilidad para el transporte.

\subsection{Determinación del tamaño.}

\subsubsection{Tamaño normal del proyecto.}

El tamaño del proyecto es el número de turistas para los paquetes 2 y 3 que cuentan con hospedaje y que el Ecolodge "Kachi Raqay" planea recibir cada año según lo obtenido en la proyección del mercado objetivo.

Tabla 50.

Tamaño normal Ecolodge "Kachi Raqay" para los paquetes 2 y 3

\begin{tabular}{cccc}
\hline \multirow{2}{*}{ Año } & \multicolumn{3}{c}{ Mercado Objetivo } \\
\cline { 2 - 4 } & Paquete 2 & Paquete 3 & Total \\
\hline 2017 & 2,624 & 875 & 3,499 \\
2018 & 2,874 & 958 & 3,832 \\
2019 & 3,147 & 1,049 & 4,196 \\
2020 & 3,446 & 1,149 & 4,595 \\
2021 & 3,773 & 1,258 & 5,031 \\
2022 & 4,131 & 1,377 & 5,508 \\
\hline
\end{tabular}

Nota: Elaboración propia 


\subsubsection{Tamaño máximo.}

El Ecolodge "Kachi Raqay” contará con 18 habitaciones (entre habitaciones simples y dobles), lo cual significa un total de 27 personas máximo por noche, haciendo un total de 9,720 camas al año como capacidad máxima por noche.

Tabla 51.

Tamaño máximo del Ecolodge "Kachi Raqay"

\begin{tabular}{lccccc}
\hline \multicolumn{1}{c}{ Tipo habitaciones } & $\begin{array}{c}\mathrm{N}^{\circ} \text { de } \\
\text { habitaciones }\end{array}$ & $\begin{array}{c}\text { Camas } \mathrm{x} \\
\text { habitación }\end{array}$ & $\begin{array}{c}\mathrm{N}^{\circ} \text { Camas } \\
\text { máximo por } \\
\text { habitación al día }\end{array}$ & $\begin{array}{c}\text { Días } \\
\text { al } \\
\text { Año }\end{array}$ & $\begin{array}{c}\text { Total Camas por } \\
\text { Habitación por } \\
\text { año }\end{array}$ \\
\hline $\begin{array}{l}\text { Habitación Simple } \\
\text { Habitación doble }\end{array}$ & 9 & 1 & 9 & & 3,240 \\
$\begin{array}{l}\text { Habitación matrimonial } \\
\text { Total }\end{array}$ & 6 & 2 & 12 & 360 & 4,320 \\
\hline
\end{tabular}

Nota: Elaboración propia.

\subsubsection{Porcentaje de utilización de capacidad instalada.}

Teniendo en cuenta la capacidad máxima del hotel de 9,720 camas, el porcentaje de ocupación real del Ecolodge "Kachi Raqay" sería como sigue:

Tabla 52.

Capacidad instalada en el Ecolodge "Kachi Raqay" expresado en personas

\begin{tabular}{lcccccc}
\hline \multicolumn{1}{c}{ Año } & 2017 & 2018 & 2019 & 2020 & 2021 & 2022 \\
\hline Capacidad normal & 4,374 & 4,790 & 5,245 & 5,743 & 6,288 & 6,886 \\
Capacidad máxima & 9,720 & 9,720 & 9,720 & 9,720 & 9,720 & 9,720 \\
$\%$ Ocupación Kachi Raqay & $45 \%$ & $49 \%$ & $54 \%$ & $59 \%$ & $65 \%$ & $71 \%$ \\
\hline
\end{tabular}

Nota. Elaboración propia 
Como se mencionó en el capítulo de proyección de mercado, el mercado objetivo total del Ecolodge "Kachi Raqay” es de una ocupabilidad total de 9,720 camas, de las cuales; siendo conservadores, se ha planteado mantener una tasa de ocupabilidad del $45 \%$ el primer año 2017, para incrementar $9.5 \%$ año tras año teniendo en cuenta los objetivos comerciales trazados en el presente plan, así como la tasa de ocupación visible en el valle sagrado como referencia. El crecimiento de $9.5 \%$ conservador, se encuentra dentro del crecimiento anual de 9.6\% del sector hotelero. (Mincetur, 2014)

\subsubsection{Programa de ventas.}

La unidad de venta del Ecolodge "Kachi Raqay" son los paquetes ofrecidos. A continuación, se muestra el número de paquetes que se planea vender cada año y que se determinó en el capítulo de proyección:

Tabla 53.

Proyección de ventas por paquete

\begin{tabular}{ccccc}
\hline \multirow{2}{*}{ Año } & \multicolumn{4}{c}{ Mercado Objetivo } \\
& Paquete 1 & Paquete 2 & Paquete 3 & Total \\
\hline 2017 & 3,147 & 2,624 & 875 & 6,647 \\
2018 & 3,329 & 2,874 & 958 & 7,160 \\
2019 & 3,495 & 3,147 & 1,049 & 7,691 \\
2020 & 3,670 & 3,446 & 1,149 & 8,264 \\
2021 & 3,853 & 3,773 & 1,258 & 8,884 \\
2022 & 4,046 & 4,131 & 1,377 & 9,555 \\
\hline
\end{tabular}

\subsubsection{Materias primas e insumos.}

Los insumos y materias primas a utilizar en restaurante y bar se nombran a continuación: 
1. Alimentos Restaurant, Bar y Panadería

Serán provistos en su mayoría por proveedores que suministren a los hoteles de Urubamba. Aquellos productos que no puedan ser abastecidos por este medio, serán comprados en el mercado de Urubamba en base al requerimiento semanal. Etapa crítica del ciclo de compras: selección del proveedor.

En la Tabla 54 se muestra el costo de tres comidas al día, desayuno, almuerzo y cena y los insumos para la elaboración de cocteles en el bar, así como la elaboración del pan.

Tabla 54.

Insumos Restaurante por año

\begin{tabular}{|c|c|c|c|c|c|c|c|c|c|c|}
\hline Categoría & Ingrediente & Cant. & $\begin{array}{l}\text { Unidad } \\
\text { de } \\
\text { medida }\end{array}$ & $\mathrm{S} /$. & 2017 & 2018 & 2019 & 2020 & 2021 & 2022 \\
\hline \multirow{5}{*}{ Abarrotes } & Aceite & 360 & Ml. & 5.10 & 1,836 & 1,836 & 1,836 & 1,836 & 1,836 & 1,836 \\
\hline & Agua & 15,600 & Ml. & 3.56 & 1,282 & 1,282 & 1,282 & 1,282 & 1,282 & 1,282 \\
\hline & Azúcar & 150 & Gr. & 1.20 & 432 & 432 & 432 & 432 & 432 & 432 \\
\hline & Canela & 112 & Gr. & 0.90 & 324 & 324 & 324 & 324 & 324 & 324 \\
\hline & Leche & 500 & Ml. & 3.50 & 1,260 & 1,260 & 1,260 & 1,260 & 1,260 & 1,260 \\
\hline \multirow{3}{*}{ Carnes } & $\begin{array}{l}\text { Carne de } \\
\text { cerdo }\end{array}$ & 250 & Gr. & 6.00 & 2,160 & 2,160 & 2,160 & 2,160 & 2,160 & 2,160 \\
\hline & Carne de res & 250 & $\mathrm{Gr}$. & 6.00 & 2,160 & 2,160 & 2,160 & 2,160 & 2,160 & 2,160 \\
\hline & Vísceras & 100 & Gr. & 3.50 & 1,260 & 1,260 & 1,260 & 1,260 & 1,260 & 1,260 \\
\hline \multirow[t]{2}{*}{ Hortalizas } & $\begin{array}{l}\text { Culantro/orég } \\
\text { ano/wacatay }\end{array}$ & 230 & Atado & 2.50 & 900 & 900 & 900 & 900 & 900 & 900 \\
\hline & Hierba buena & 15 & Atado & 0.20 & 72 & 72 & 72 & 72 & 72 & 72 \\
\hline \multirow{16}{*}{$\begin{array}{l}\text { Frutas y } \\
\text { Vegetales }\end{array}$} & Ajos & 105 & Gr. & 1.75 & 630 & 630 & 630 & 630 & 630 & 630 \\
\hline & Alverjas & 60 & Gr. & 0.80 & 288 & 288 & 288 & 288 & 288 & 288 \\
\hline & Camote & 100 & Gr. & 0.63 & 227 & 227 & 227 & 227 & 227 & 227 \\
\hline & Cebolla & 300 & Gr. & 1.20 & 432 & 432 & 432 & 432 & 432 & 432 \\
\hline & Choclos & 1,100 & Gr. & 2.20 & 792 & 792 & 792 & 792 & 792 & 792 \\
\hline & Limón & 60 & Gr. & 2.20 & 792 & 792 & 792 & 792 & 792 & 792 \\
\hline & Lisas/Olluco & 300 & Gr. & 0.70 & 252 & 252 & 252 & 252 & 252 & 252 \\
\hline & Maíz morado & 150 & Gr. & 0.90 & 324 & 324 & 324 & 324 & 324 & 324 \\
\hline & Mote, habas & 650 & Gr. & 8.50 & 3,060 & 3,060 & 3,060 & 3,060 & 3,060 & 3,060 \\
\hline & Papa blanca & 1,300 & Gr. & 2.60 & 936 & 936 & 936 & 936 & 936 & 936 \\
\hline & Quinua & 500 & Gr. & 6.00 & 2,160 & 2,160 & 2,160 & 2,160 & 2,160 & 2,160 \\
\hline & Rocoto & 360 & Gr. & 3.50 & 1,260 & 1,260 & 1,260 & 1,260 & 1,260 & 1,260 \\
\hline & Manzana & 150 & Gr. & 0.80 & 288 & 288 & 288 & 288 & 288 & 288 \\
\hline & Zanahoria & 120 & Gr. & 1.30 & 468 & 468 & 468 & 468 & 468 & 468 \\
\hline & Zapallo & 40 & Gr. & 0.30 & 108 & 108 & 108 & 108 & 108 & 108 \\
\hline & Chuño & 100 & Gr. & 0.30 & 108 & 108 & 108 & 108 & 108 & 108 \\
\hline
\end{tabular}




\begin{tabular}{llccccccccc}
\hline & Condimentos & 230 & Gr. & 2.90 & 1,044 & 1,044 & 1,044 & 1,044 & 1,044 & 1,044 \\
& Esencia & 10 & Ml. & 1.00 & 360 & 360 & 360 & 360 & 360 & 360 \\
& vainilla & & & & & & & & \\
& Maicena & 20 & Gr. & 0.20 & 72 & 72 & 72 & 72 & 72 & 72 \\
& Maní & 240 & Gr. & 2.00 & 720 & 720 & 720 & 720 & 720 & 720 \\
& Mantequilla & 30 & Barra & 1.50 & 540 & 540 & 540 & 540 & 540 & 540 \\
& Nata & 50 & Gr. & 6.30 & 2,268 & 2,268 & 2,268 & 2,268 & 2,268 & 2,268 \\
& Panes & 6 & Unidad & 3.84 & 1,382 & 1,382 & 1,382 & 1,382 & 1,382 & 1,382 \\
& Queso & 200 & Gr. & 11.00 & 3,960 & 3,960 & 3,960 & 3,960 & 3,960 & 3,960 \\
& Siete Harinas & 150 & Gr. & 0.50 & 180 & 180 & 180 & 180 & 180 & 180 \\
Total & & 23,898 & & 95.38 & 34,337 & 34,337 & 34,337 & 34,337 & 34,337 & 34,337 \\
general & & & & & & & & & &
\end{tabular}

Elaboración propia.

Tabla 55.

\section{Insumos Bar por año}

\begin{tabular}{|c|c|c|c|c|c|c|c|c|c|}
\hline Ingredientes & Cant. & $\begin{array}{l}\text { Unidad de } \\
\text { Medida }\end{array}$ & $\begin{array}{l}\text { Costo } \\
\text { por día }\end{array}$ & 2017 & 2018 & 2019 & 2020 & 2021 & 2022 \\
\hline $\begin{array}{l}\text { Pisco Quebranta (Cuatro } \\
\text { Gallos) }\end{array}$ & 85 & Ml. & 6.80 & 2,448 & 2,448 & 2,448 & 2,448 & 2,448 & 2,448 \\
\hline Zumo de limón & 65 & Ml. & 2.60 & 936 & 936 & 936 & 936 & 936 & 936 \\
\hline $\begin{array}{l}\text { Jarabe de goma } \\
\text { (Vargas) }\end{array}$ & 16 & Ml. & 0.48 & 173 & 173 & 173 & 173 & 173 & 173 \\
\hline Clara de huevo & 1 & Unidad & 0.40 & 144 & 144 & 144 & 144 & 144 & 144 \\
\hline $\begin{array}{l}\text { Amargo de angostura } \\
\text { (Chuncho) }\end{array}$ & 10 & Ml. & 2.50 & 900 & 900 & 900 & 900 & 900 & 900 \\
\hline Hielo & 11 & Unidad & 0.33 & 119 & 119 & 119 & 119 & 119 & 119 \\
\hline $\begin{array}{l}\text { Macerado de hojas de } \\
\text { coca con Pisco } \\
\text { Quebranta }\end{array}$ & 30 & Ml. & 2.40 & 864 & 864 & 864 & 864 & 864 & 864 \\
\hline Hojas de coca & 2 & Unidad & 0.06 & 22 & 22 & 22 & 22 & 22 & 22 \\
\hline Ginger & 75 & Ml. & 0.30 & 108 & 108 & 108 & 108 & 108 & 108 \\
\hline Cointreau & 25 & Ml. & 3.50 & 1,260 & 1,260 & 1,260 & 1,260 & 1,260 & 1,260 \\
\hline Limón en trozos & 1 & Unidad & 0.20 & 72 & 72 & 72 & 72 & 72 & 72 \\
\hline Sal & 2 & Gr. & 0.02 & 7 & 7 & 7 & 7 & 7 & 7 \\
\hline
\end{tabular}

Elaboración propia.

Tabla 56.

\section{Insumos Pan por año}

\begin{tabular}{lccccccccc}
\hline Insumo & Cant. & Unidad de medida & Costo Soles & 2017 & 2018 & 2019 & 2020 & 2021 & 2022 \\
\hline Harina & 500 & Gr. & 0.002 & 8.7 & 9.6 & 10.5 & 11.5 & 12.6 & 13.8 \\
Sal & 10 & Gr. & 0.00 & 6.6 & 7.2 & 7.9 & 8.6 & 9.4 & 10.3 \\
Agua & 300 & Ml. & 0.00 & 4.4 & 4.8 & 5.2 & 5.7 & 6.3 & 6.9 \\
Levadura & 5 & Gr. & 0.05 & 227.4 & 249.1 & 272.7 & 298.6 & 327.0 & 358.1 \\
\hline
\end{tabular}

Elaboración propia. 


\section{Amenities}

Conformado por los productos de aseo en cada habitación. Serán provistos por proveedores que suministren a los hoteles de Urubamba. Debido a los tiempos (diez días desde recibida la orden de compra según la empresa "Todo para hoteles Perú") y cantidades mínimas requeridas para hacer un pedido, se trabajará con un stock de seguridad que cubra trece días, entendiendo que cada día se espera consumir 20 combos (jabón, shampoo y acondicionador) se harán los pedidos cuando se llegue a 260 combos en stock. Los pedidos se realizarán aproximadamente de 600 combos (cifra en la cual la entrega es gratis según la empresa mencionada, sin embargo, puede variar dependiendo de las ofertas que realicen las empresas de Urubamba). Por lo tanto, se espera realizar pedidos cada 18 días. Etapa crítica del ciclo de compras: selección del proveedor.

Tabla 57.

Amenities por habitación 2017-2022

\begin{tabular}{llllllll}
\hline \multicolumn{1}{c}{$\begin{array}{c}\text { Insumos } \\
\text { Unidades }\end{array}$} & $\begin{array}{c}\text { Cantidad } \\
\text { Diaria }\end{array}$ & 2017 & 2018 & 2019 & 2020 & 2021 & 2022 \\
\hline Jabón & 40 & 14,400 & 14,400 & 14,400 & 14,400 & 14,400 & 14,400 \\
Shampoo & 20 & 7,200 & 7,200 & 7,200 & 7,200 & 7,200 & 7,200 \\
Acondicionador & 20 & 7,200 & 7,200 & 7,200 & 7,200 & 7,200 & 7,200 \\
Papel higiénico & 20 & 7,200 & 7,200 & 7,200 & 7,200 & 7,200 & 7,200 \\
\hline
\end{tabular}

\subsubsection{Maquinarias y equipos.}

Se detalla a continuación la maquinaria y equipos requeridos para el funcionamiento del Ecolodge "Kachi Raqay” en cada área: 
a. Recepción y sala de estar

Tabla 58.

Equipos Recepción y Sala de Estar

\begin{tabular}{lcc}
\hline Concepto & Unidades & Precio Unitario (S/.) \\
\hline Escritorio de recepción & 1 & 1300 \\
Mesa de centro & 2 & 200 \\
Computadora & 1 & 900 \\
Impresora multifuncional & 1 & 600 \\
Sillones & 3 & 300 \\
Sofá & 1 & 650 \\
Organizador de llaves & 1 & 190 \\
Alfombra central (1.40 x 2.00) & 1 & 450 \\
Teléfono inalámbrico & 1 & 185 \\
POS Visa & 1 & 0 \\
POS MasterCard & 1 & 0 \\
POS Contingencia & 1 & 0 \\
Florero de cerámica & 1 & 80 \\
Lámpara & 1 & 400 \\
Cuadros & 2 & 350 \\
Espejo & 1 & 500 \\
\hline
\end{tabular}

b. Oficina

Tabla 59.

Equipos Oficina

\begin{tabular}{lcc}
\hline Concepto & Unidades & Precio Unitario (S/.) \\
\hline Escritorio & 1 & 1300 \\
Computadora & 1 & 900 \\
Impresora multifuncional & 1 & 600 \\
Trituradora de papel & 1 & 700 \\
Engrapadora & 1 & 9.6 \\
Perforador & 1 & 22.5 \\
Archivadores & 10 & 4.5 \\
Pizarra blanca & 1 & 32.3 \\
Sillas & 2 & 185 \\
Útiles de oficina & Varios & 150 \\
Teléfono inalámbrico & 1 & 185 \\
Cuadros & 2 & 350 \\
\hline
\end{tabular}


c. Restaurante planta baja y baño

Tabla 60.

Equipos Restaurante Planta Baja

\begin{tabular}{lcc}
\hline \multicolumn{1}{c}{ Concepto } & Unidades & Precio Unitario (S/.) \\
\hline Juego de comedor cuatro sillas & 4 & 500 \\
Juego de comedor ocho sillas & 2 & 750 \\
Bar & 1 & 3050 \\
Espejo pared & 1 & 750 \\
Computadora & 1 & 900 \\
Silla para barra & 1 & 99 \\
Silla para niños & 2 & 125 \\
Credenza para platos & 1 & 500 \\
Plato mediano de piedra granito & 48 & 50 \\
Plato grande de piedra granito & 48 & 50 \\
Plato hondo de madera & 48 & 10 \\
Taza de latón & 36 & 7 \\
Docena de juego de Cubiertos & 4 & 40 \\
\hline
\end{tabular}

Tabla 61.

Equipos Baño Restaurante Planta Baja

\begin{tabular}{lcc}
\hline Concepto & Unidades & Precio Unitario (S/.) \\
\hline Espejo & 2 & 400 \\
Toallero & 2 & 60 \\
Porta Papel higiénico & 2 & 20 \\
Basurero & 2 & 40 \\
Sanitario (Italgrif) & 18 & 289 \\
Lavatorio + llave de caño (Italgrif) & 18 & 69 \\
\hline
\end{tabular}

d. Restaurante planta alta y baño

Tabla 62.

Equipos Restaurante Planta Alta

\begin{tabular}{lcc}
\hline Concepto & Unidades & Precio Unitario (S/.) \\
\hline Juego de comedor cuatro sillas & 5 & 500 \\
Juego de comedor ocho sillas & 1 & 750 \\
Credenza para platos & 1 & 500 \\
Silla para barra & 1 & 99 \\
\hline
\end{tabular}


Tabla 63.

Equipos Baño Restaurante Planta Alta

\begin{tabular}{lcc}
\hline Concepto & Unidades & Precio Unitario (S/.) \\
\hline Espejo & 2 & 400 \\
Toallero & 2 & 60 \\
Porta Papel higiénico & 2 & 20 \\
Basurero & 2 & 40 \\
Sanitario (Italgrif) & 18 & 289 \\
Lavatorio + llave de caño (Italgrif) & 18 & 69 \\
\hline
\end{tabular}

e. Cocina y horno de barro

Tabla 64.

Equipos Cocina y Horno de Barro

\begin{tabular}{lcc}
\hline Concepto & Unidades & Precio Unitario (S/.) \\
\hline Cocina industrial & 1 & 4500 \\
Campana de extracción & 1 & 2500 \\
Refrigeradora industrial & 1 & 2999 \\
Licuadora & 2 & 190 \\
Extractor de jugos & 1 & 249 \\
Horno microondas & 1 & 279 \\
Cafetera & 1 & 199 \\
Batidora & 1 & 294 \\
Tostadora de pan & 1 & 150 \\
Maquina congeladora & 1 & 799 \\
Mesas de acero & 1 & 480 \\
Tachos de acero & 3 & 320 \\
Juego de ollas $* 10$ piezas & 1 & 770 \\
Juego de sartenes*3 piezas & 3 & 34.9 \\
Asadera con tapa & 2 & 35.9 \\
1 olla a presión & 1 & 194 \\
Juego de cuchillos $* 12$ & 1 & 200 \\
Juego de cucharones $* 12$ & 1 & 125 \\
Horno de Barro & 1 & 1100 \\
\hline
\end{tabular}


f. Habitaciones y baño

Tabla 65.

\section{Equipos Habitaciones}

\begin{tabular}{|c|c|c|}
\hline Concepto & Unidades & Precio Unitario (S/.) \\
\hline Estructura de cama Twin (Komfort) & 21 & 899 \\
\hline Estructura de cama King (Komfort) & 3 & 399 \\
\hline Mesa de noche & 18 & 69 \\
\hline Mesa & 3 & 59 \\
\hline Silla & 6 & 49 \\
\hline Tocador & 18 & 99 \\
\hline Sábanas Twin (Mica) & 32 & 89.5 \\
\hline Sábanas King (Mica) & 6 & 89.5 \\
\hline Funda almohada & 48 & \\
\hline Toalla de manos & 36 & 49 \\
\hline Toalla de cuerpo & 36 & 59 \\
\hline Colchón Twin (Komfort) & 21 & 650 \\
\hline Colchón King (Komfort) & 3 & 300 \\
\hline Almohada & 48 & 49 \\
\hline Edredón & 24 & 89 \\
\hline Cortinas (black out) & 36 & 120 \\
\hline Cortinas (ducha) & 18 & 59 \\
\hline Alfombra central $(90 \mathrm{~cm} . \times 70 \mathrm{~cm})$ & 18 & 180 \\
\hline Florero de cerámica & 9 & 80 \\
\hline Cuadro de telares & 18 & 190 \\
\hline Focos led amarillos & 72 & 15 \\
\hline Lámpara de mesa & 18 & 89 \\
\hline Estufas & 18 & 120 \\
\hline Teléfono & 18 & 65 \\
\hline Espejos & 18 & 59 \\
\hline Sanitario (Italgrif) & 18 & 289 \\
\hline Ducha (Stretto) & 18 & 89 \\
\hline Llave para ducha (Italgrif) & 36 & 51 \\
\hline Lavatorio + llave de caño (Italgrif) & 18 & 69 \\
\hline
\end{tabular}


5.2.7. Programa de compras materia prima e insumos.

Si bien un ciclo de compra incluye los siguientes pasos:

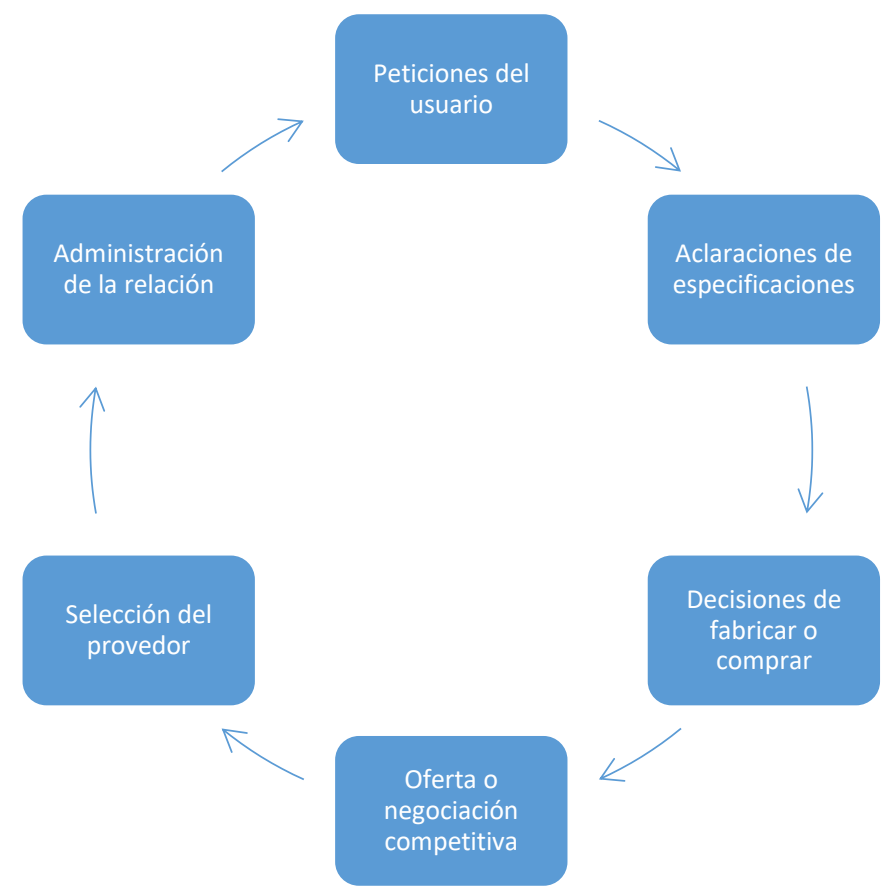

Figura 23. Ciclo de Compras. Recuperado de (Schroeder, 2011)

Existen 4 rubros que requerirán abastecimiento constante: Alimentos y bebidas, amenities (útiles de baño), servicios de transporte y servicio de guías turísticos.

En cuanto a los servicios de transporte y de guías turísticos: Debido al volumen de turistas en Cusco, tanto las empresas de transporte como la oferta de guías turísticos son variadas y no hay costos de transacción ni condiciones mínimas de consumo. La adquisición de estos servicios será en base a la demanda planificada por semana. Se buscará establecer relaciones sólidas con los mejores. Etapa crítica del ciclo de compras: administración de la relación con los proveedores. Se tomará un proveedor líder, y luego dos opcionales. 


\subsubsection{Requerimiento de mano obra.}

Se necesitará un Gerente, un Administrador y tres recepcionistas en el área de administración. Como mano de obra directa, es decir aquellos trabajadores directamente relacionados con la entrega del servicio, se necesitará un Supervisor de Housekeeping, un Supervisor de front-desk, tres conserjes, un Jefe de Cocina, tres Housekeepers, dos personas de mantenimiento, y tres personas para cocina. Para servicios adicionales o no relacionados directamente se requiere un Contador y un Ejecutivo Comercial.

Tabla 66.

Requerimiento de mano de obra

\begin{tabular}{lcc}
\hline \multicolumn{1}{c}{ Tipo } & Cargo & Personas \\
\hline \multirow{2}{*}{ Administrativos } & Gerente & 1 \\
& Administrador & 1 \\
& Recepcionista & 3 \\
\hline \multirow{3}{*}{ Mano de obra directa } & Supervisor HHKK & 1 \\
& Supervisor FD & 1 \\
& Conserje & 3 \\
& Jefe de cocina & 1 \\
& Housekeeper & 3 \\
\multirow{2}{*}{ Mano de obra indirecta } & Mantenimiento & 2 \\
& Personal de cocina & 3 \\
\hline \multirow{2}{*}{} & Contador & 1 \\
\hline
\end{tabular}

Además, se contratará los servicios de guías turísticos dependiendo de la cantidad de turistas. 


\subsubsection{Tecnología.}

El Ecolodge "Kachi Raqay” contará con equipos de última tecnología tanto para la comunicación en su central telefónica y sistema de alarmas en todas las áreas del hotel, así como de equipo audiovisual en cada habitación y sala de estar.

Se utilizarán los softwares de hotelería Zigma que es un ERP especializado en hotelería.

\subsection{Estudio de localización.}

Como ya se mencionó, el Ecolodge "Kachi Raqay” estará ubicado en la ciudad de Cusco, Perú. A continuación, se determina la ubicación óptima para el proyecto.

\subsubsection{Macrolocalización.}

Para determinar el lugar óptimo del Ecolodge "Kachi Raqay” se tomará en cuenta los siguientes factores críticos:

- Debido a que se necesita un lugar concurrido por turistas, evaluaremos el lugar más visitado por los turistas según el informe de turismo in, de PromPerú (Turismo In de PromPerú, 2016).

- Se tomarán en cuenta los principales motivos de viaje vacacional al Cusco: La cercanía a Machu Picchu, la cantidad de atractivos culturales, naturales y arqueológicos. (Promperu, 2015). 
- Para optimizar los recursos financieros, también se priorizará el precio más barato de mts ${ }^{2}$ de construcción y el potencial que tiene el terreno de incrementar su valor. (adondevivir.com)

Para brindar un servicio de calidad, se debe tomar en cuenta: el acceso a agua potable, la facilidad de abastecimiento de insumos, la disponibilidad de mano de obra, la seguridad pública y el acceso a telecomunicaciones (celular e internet).

Para determinar el lugar oportuno, se ponderan los factores críticos y se comparan entre sí los posibles destinos: 
Tabla 67.

Ponderación de factores críticos para determinar el destino óptimo de un Ecolodge

\begin{tabular}{|c|c|c|c|c|c|c|c|c|c|}
\hline \multicolumn{2}{|l|}{ Posibles ubicaciones: } & \multicolumn{2}{|c|}{ Aguas calientes } & \multicolumn{2}{|c|}{ Ciudad de Cusco } & \multicolumn{2}{|c|}{ Ollantaytambo } & \multicolumn{2}{|c|}{ Maras } \\
\hline Factor relevante & Peso & Calificación & Ponderación & Calificación & Ponderación & Calificación & Ponderación & Calificación & Ponderación \\
\hline Lugar más visitado & 0,12 & 4 & 0,48 & 3 & 0,36 & 2 & 0,24 & 1 & 0,12 \\
\hline Cercanía a Machu Picchu & 0,12 & 4 & 0,48 & 1 & 0,12 & 3 & 0,36 & 2 & 0,24 \\
\hline Precio más barato de mts 2 de construcción & 0,12 & 2 & 0,24 & 1 & 0,12 & 3 & 0,36 & 4 & 0,48 \\
\hline Cantidad de atractivos culturales & 0,11 & 1 & 0,11 & 4 & 0,44 & 3 & 0,33 & 2 & 0,22 \\
\hline Cantidad de atractivos naturales y arqueológicos & 0,11 & 2 & 0,22 & 4 & 0,44 & 1 & 0,11 & 3 & 0,33 \\
\hline Incremento del valor futuro del terreno & 0,10 & 2 & 0,2 & 1 & 0,1 & 3 & 0,3 & 4 & 0,4 \\
\hline Disponibilidad de agua potable & 0,09 & 2 & 0,18 & 4 & 0,36 & 3 & 0,27 & 1 & 0,09 \\
\hline Facilidad de abastecimiento de insumos & 0,07 & 1 & 0,07 & 4 & 0,28 & 2 & 0,14 & 3 & 0,21 \\
\hline Disponibilidad de mano de obra & 0,07 & 1 & 0,07 & 4 & 0,28 & 3 & 0,21 & 2 & 0,14 \\
\hline Seguridad pública & 0,06 & 2 & 0,12 & 1 & 0,06 & 3 & 0,18 & 4 & 0,24 \\
\hline \multirow[t]{2}{*}{ Acceso a telecomunicaciones (celular e internet) } & 0,03 & 2 & 0,06 & 4 & 0,24 & 1 & 0,24 & 3 & 0,72 \\
\hline & Totales: & & 2,23 & & 2,8 & & 2,74 & & 3,19 \\
\hline
\end{tabular}


Tras sumar los resultados ponderados, se confirma el poblado de Maras como el lugar óptimo para un Ecolodge vivencial.

\subsubsection{Microlocalización.}

Dadas las características del ecolodge, se determina un terreno para comprar con las siguientes características:

- Ubicación: En el poblado de Maras o en los alrededores.

- Metros cuadrados: 3500 a 6500

- Servicios: Agua, luz, telefonía e internet.

Habiendo realizado la búsqueda de posibles ubicaciones en las páginas “casas.mitula.pe" y “adondevivir.com”, se encontraron las siguientes tres posibles alternativas: 


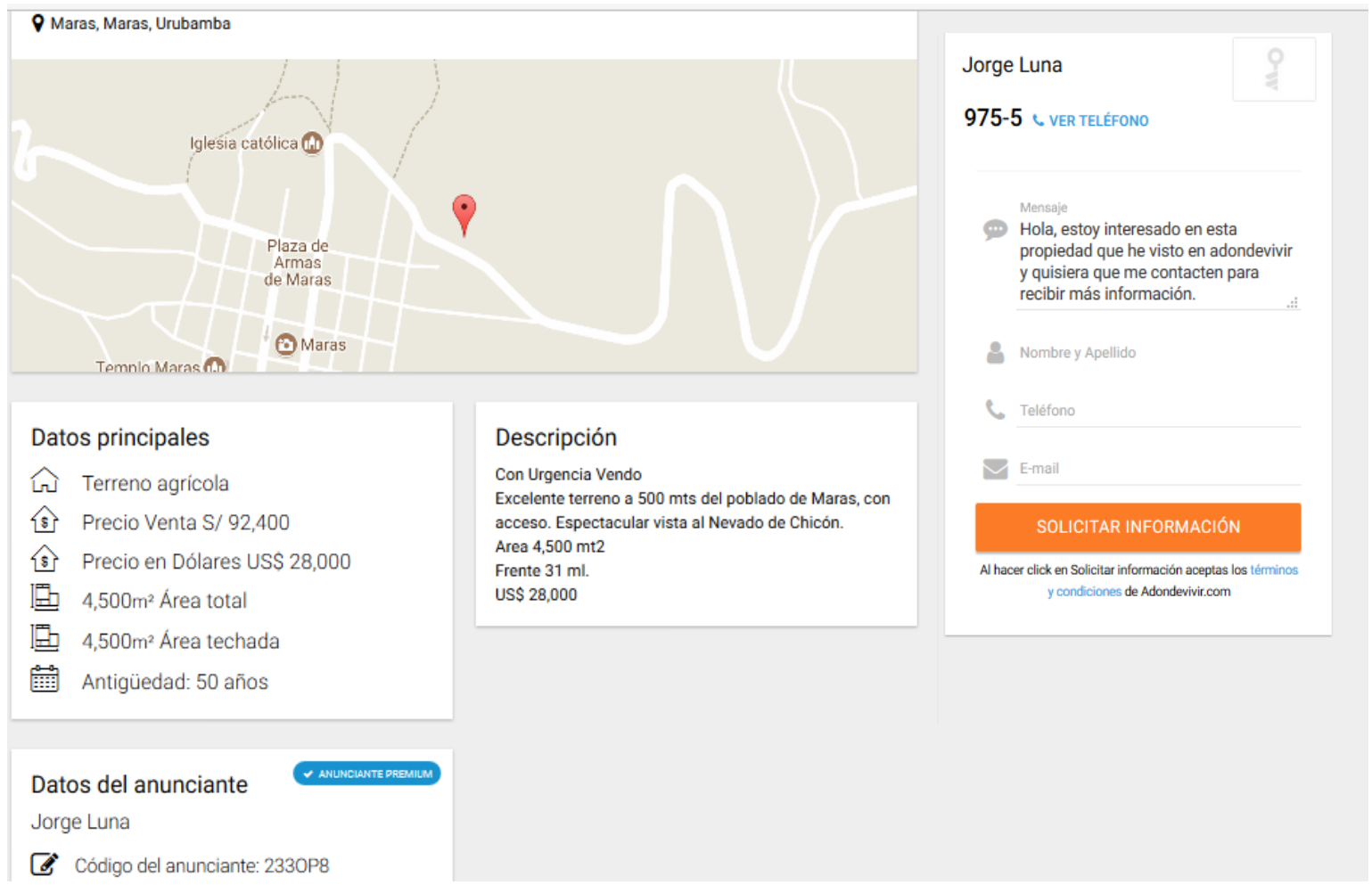

Figura 24. Opción: "Maras 1" Fuente: http://www.adondevivir.com
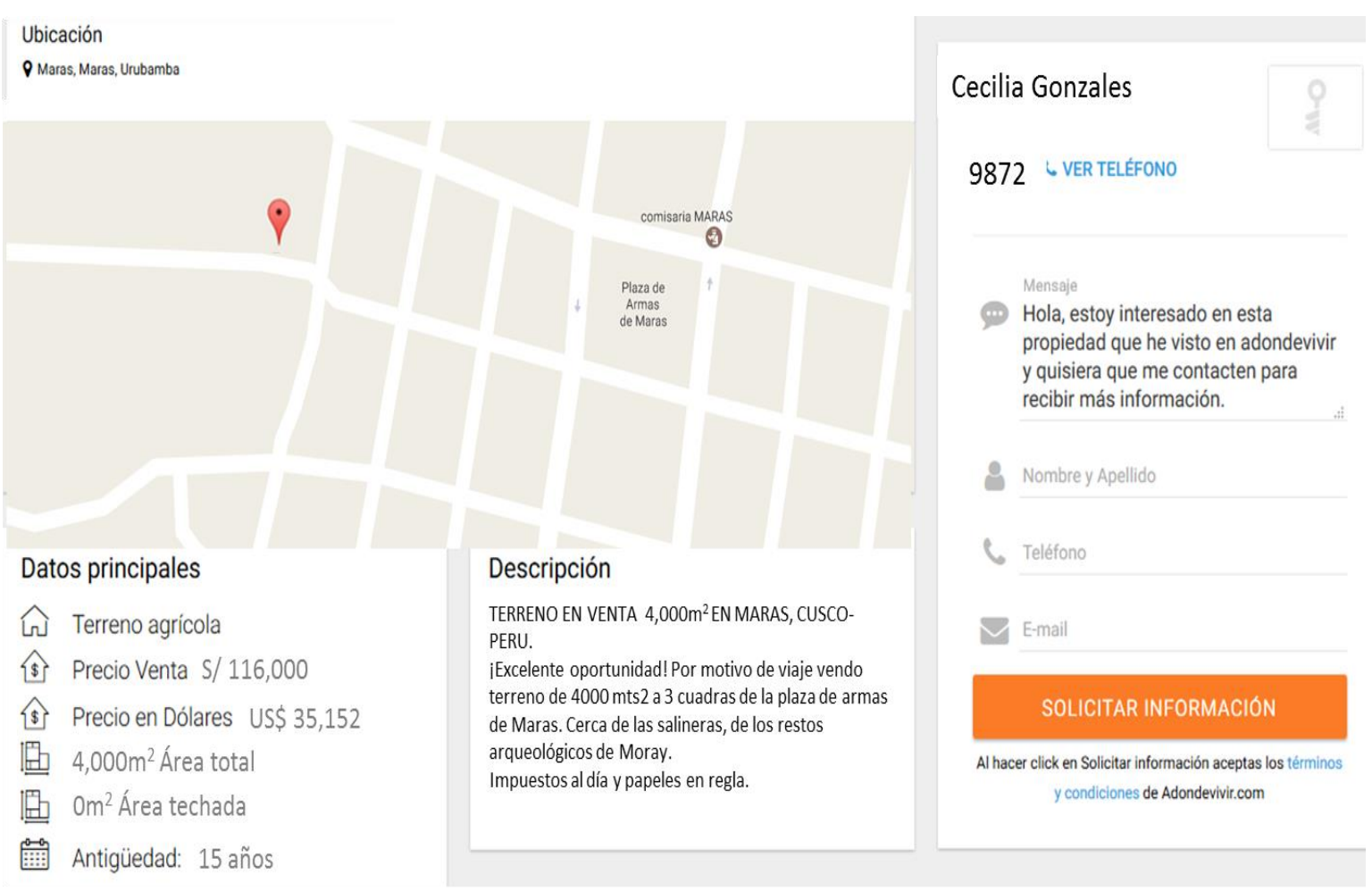

Figura 25. Opción: “Maras 2" Fuente: http://www.adondevivir.com 
Ubicación

C Carretera a Maras, Peru, Maras, Urubamba

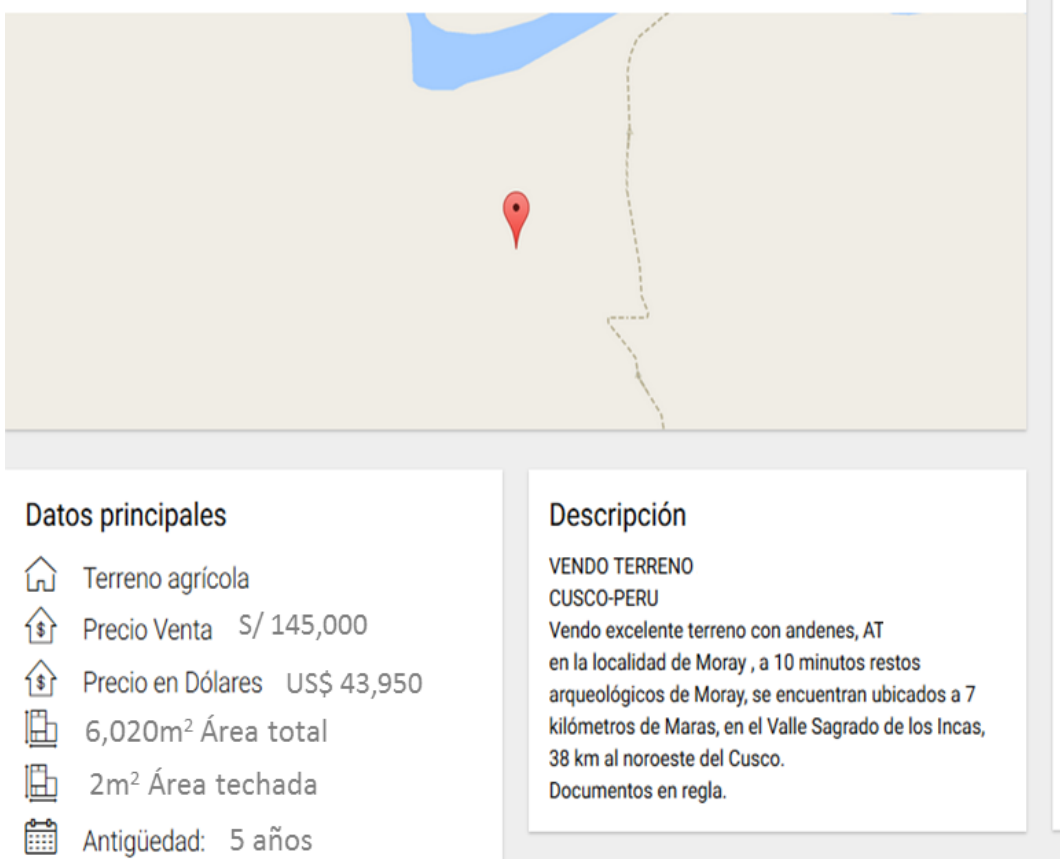

Fiorella Salazar

$9899 \&$ Q VER TELÉFONO

Mensaje

Hola, estoy interesado en esta propiedad que he visto en adondevivir y quisiera que me contacten para recibir más información.

Nombre y Apellido

C. Teléfono

E-mail

\section{SOLICITAR INFORMACIÓN}

Al hacer click en Solicitar información aceptas los términos y condiciones de Adondevivir.com

Figura 26. Opción: "Moray” Fuente: http://www.adondevivir.com

Tabla 68.

Características de terrenos potenciales

\begin{tabular}{cccc}
\hline Opción & Maras 1 & Maras 2 & Moray \\
\hline Precio (S/.) & 92.400 & 116.000 & 145.000 \\
Área $(\mathrm{m} 2)$ & 4.500 & 4.000 & 6.020 \\
$\mathrm{~S} / \mathrm{m} 2$ & 20.5 & 29 & 24 \\
\hline
\end{tabular}

Nota. "adondevivir.com"

Para determinar el terreno óptimo del Ecolodge se tomará en cuenta los siguientes factores críticos:

- El precio y el área: debido a la relación entre sí y a su impacto en la inversión, tendrán la mayor ponderación. Se valora el menor precio, y la mayor área.

- Ubicación: Se valora la cercanía al poblado de Maras.

- La disponibilidad de los servicios de agua y luz. 
- Facilidad de abastecimiento de insumos: Tomando en cuenta el restaurante, se valorará positivamente aquellos terrenos que presenten los menores problemas logísticos para los insumos.

- Disponibilidad de mano de obra: Se valorará la cercanía a poblados con mayor población.

- Transporte: Se tomará en cuenta la accesibilidad por carretera y cercanía a medios de transporte.

Al ponderar los factores mencionados, y calificarlos del 1 al 3, siendo 3 la mejor opción, se obtiene el siguiente cuadro comparativo. 
Tabla 69.

Ponderación de factores críticos para determinar el terreno óptimo de un Ecolodge

\begin{tabular}{|c|c|c|c|c|c|c|c|}
\hline \multirow{2}{*}{$\begin{array}{l}\text { Opción: } \\
\text { Factor relevante }\end{array}$} & \multirow[b]{2}{*}{ Peso } & \multicolumn{2}{|c|}{ Maras 1} & \multicolumn{2}{|c|}{ Maras 2} & \multicolumn{2}{|c|}{ Moray } \\
\hline & & Calificación & Ponderación & Calificación & Ponderación & Calificación & Ponderación \\
\hline Precio & 0,25 & 1 & 0,25 & 3 & 0,75 & 2 & 0,5 \\
\hline Área & 0,25 & 2 & 0,5 & 1 & 0,25 & 3 & 0,75 \\
\hline Cercanía a Maras & 0,15 & 2 & 0,3 & 3 & 0,45 & 1 & 0,15 \\
\hline Disponibilidad de agua y luz & 0,10 & 2 & 0,2 & 3 & 0,3 & 1 & 0,1 \\
\hline Facilidad de abastecimiento de insumos & 0,10 & 2 & 0,2 & 3 & 0,3 & 1 & 0,1 \\
\hline Disponibilidad de mano de obra & 0,10 & 2 & 0,2 & 3 & 0,3 & 1 & 0,1 \\
\hline \multirow[t]{2}{*}{ Transporte } & 0,05 & 2 & 0,1 & 3 & 0,15 & 1 & 0,05 \\
\hline & Totales: & & 1,75 & & 2,5 & & 1,75 \\
\hline
\end{tabular}

Elaboración Propia 
Tras sumar los resultados ponderados, se confirma la opción Maras 2, terreno que está a 3 cuadras de la plaza de armas. Si bien presenta un mayor costo por $\mathrm{m}^{2}$, dada la actual oferta de terrenos, esta opción reúne las mejores condiciones para el presente proyecto.

\subsection{Lay-out y costos de construcción.}

\subsubsection{Lay-out Ecolodge "Kachi Raqay".}

A continuación, se muestran los planos del Ecolodge "Kachi Raqay", los cuales se realizaron con el apoyo de la empresa Sotein S.R.L.

En la planta baja se encuentra ubicado la recepción, un baño, comedor, sala de estar, 6 habitaciones dobles y un restaurante.

En la planta alta se encuentra ubicado un baño, comedor, 9 habitaciones simples y 3 matrimoniales y el restaurante. 


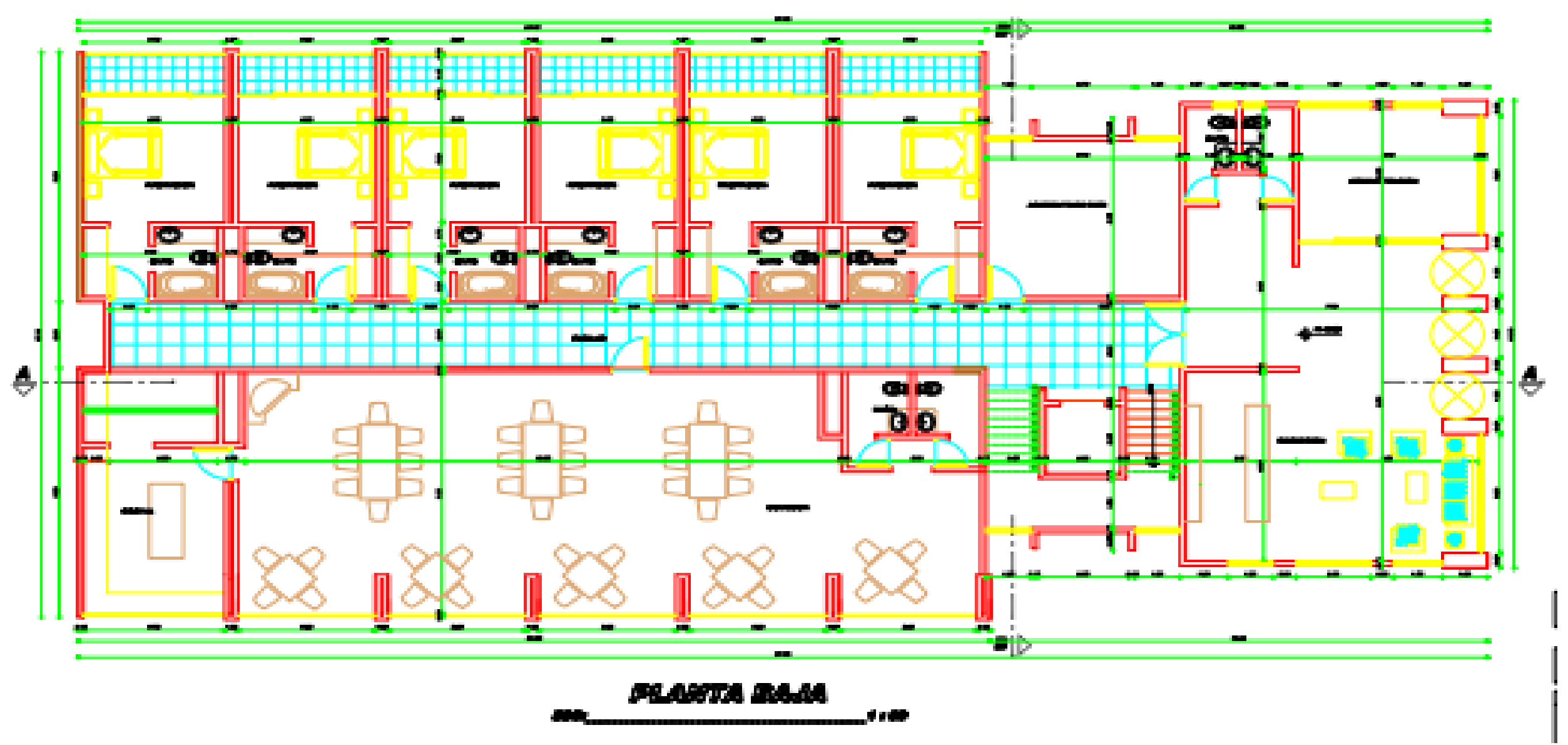

Figura 27. Plano planta baja Ecolodge "Kachi Raqay" 


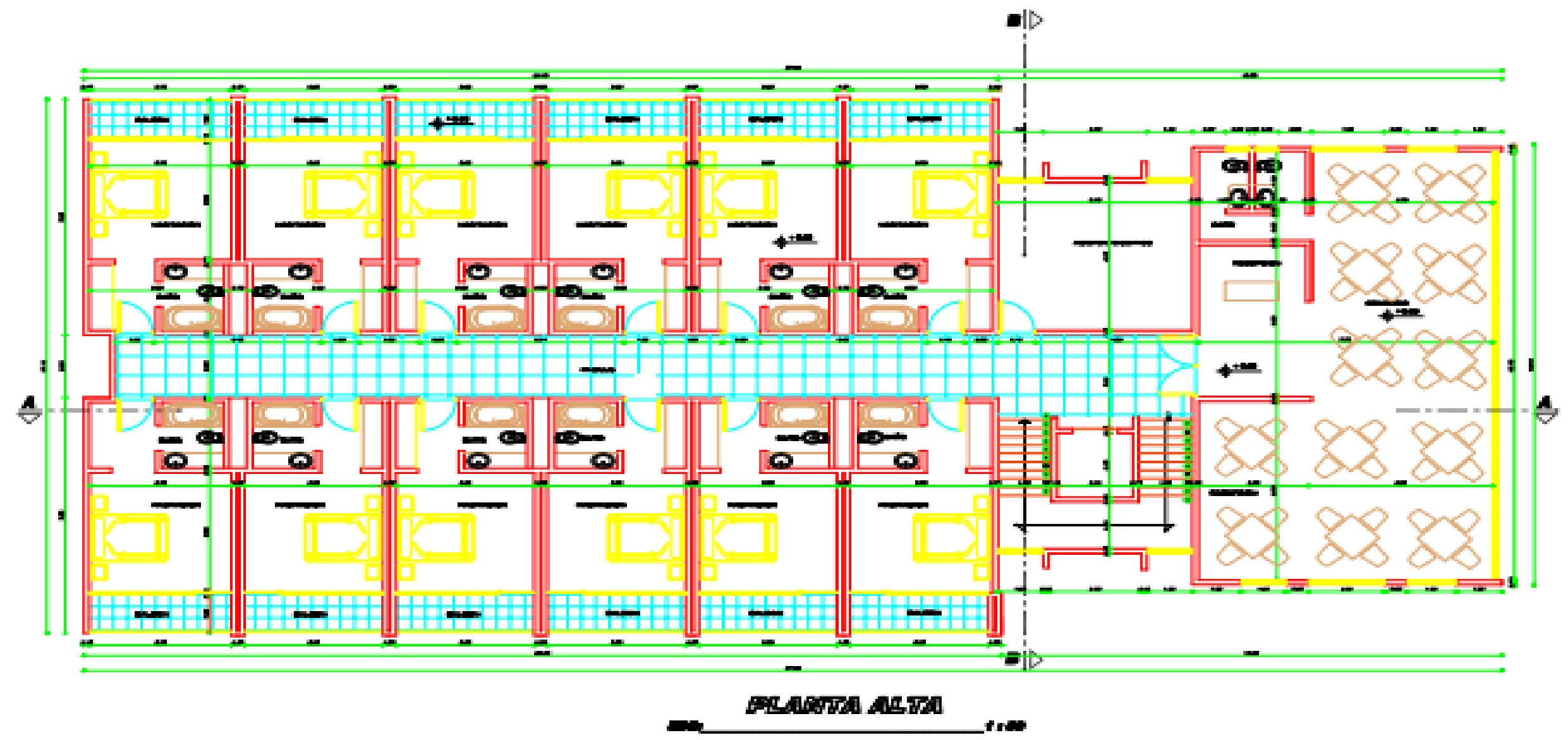

Figura 28. Plano planta alta Ecolodge "Kachi Raqay" 


\subsubsection{Costos de construcción Ecolodge "Kachi Raqay"}

En el siguiente cuadro se resume el área total de metros cuadrados a construir:

Tabla 70.

Metros cuadrados de construcción

\begin{tabular}{cc}
\hline Descripción & Área $\left(\mathrm{m}^{2}\right)$ \\
\hline Primer piso & 601 \\
Segundo piso & 543 \\
Total área construida & 1.144 \\
\hline
\end{tabular}

Nota. Sotein S.R.L.

Para determinar el costo de construcción se tomaron dos fuentes: el Colegio de Arquitectos del Perú (CAP) y la opinión de un arquitecto experto en construcción de hoteles.

El CAP, publica mensualmente el "Cuadro de Valores Unitarios" (CAP, 2017), el cual consiste en los valores referenciales de construcción expresados en soles por $\mathrm{m}^{2}$, según la categoría de edificio y el tipo de partida de construcción. Debido a que el Ecolodge "Kachi Raqay" cumplirá con los requisitos establecidos por Mincetur para un Albergue; la categoría establecida para el cálculo en el cuadro mencionado será la más alta en cuanto a calidad:

Categoría A, la cual se muestra a continuación: 
Tabla 71.

Valores por partidas en nuevos soles por metro cuadrado de área techada según el CAP, para la categoría $A$

\begin{tabular}{lcc}
\hline Partidas & Sub partidas & $\mathrm{S} / \mathrm{m}^{2}$ \\
\hline Estructuras & Muros y columnas & 477 \\
& Pisos & 256 \\
Acabados & Puertas y ventanas & 259 \\
& Revestimientos & 279 \\
Instalaciones eléctricas y sanitarias & Baños & 94 \\
\hline Costo total por $\mathrm{m}^{2}$ & & 277 \\
\hline
\end{tabular}

Nota. Cuadro de Valores Unitarios, CAP-agosto del 2017.

Para validar dicha cifra, se consultó vía telefónica al Mg. Julian Jones (arquitecto del estudio Lima Design Group), quien en base a su experiencia y para el tipo de proyecto propuesto, él recomienda incrementar el costo por $\mathrm{m} 2$ en un $80 \%$, principalmente para cubrir 2 factores críticos:

1. El tipo de acabados y tránsito de personas que requiere un hotel.

2. Costos de logística asociados a la construcción en un poblado como Maras, el cual está lejos de la ciudad

Al multiplicar los $1641 \mathrm{~s} / \mathrm{m}^{2}$ por $180 \%$, se obtiene que el costo de construcción por metro cuadrado del hotel ascendería a S/ 2 955. Dentro del costo, también se debe incluir un cercado al terreno de $4000 \mathrm{~m}^{2}$, y una puerta. Para cuantificar, se utilizará la tabla de Valores Unitarios de Obras Complementarias e Instalaciones Fijas, (CAP, 2017) con lo cual el costo de construir el hotel sería el siguiente: 
Tabla 72.

Presupuesto estimado de construcción del edificio

\begin{tabular}{lccc}
\hline & Área $\left(\mathrm{m}^{2}\right)$ & Costo $\left(\mathrm{S} / \mathrm{m}^{2}\right)$ & Coto total $(\mathrm{S} /)$. \\
\hline Costo de construcción: & 1144 & 2954 & 3.379 .519 \\
Puerta de madera $(2,2 \times 2)$ & 4,4 & 317,5 & 1.397 \\
Muros perimétricos o cercos de adobe & 4000 & 10 & 40.000 \\
Costo total edificio + muros y puerta de ingreso: & & 3.420 .916 \\
\hline
\end{tabular}

\subsection{Consideraciones legales.}

\subsubsection{Formalización de empresa.}

El Ecolodge "Kachi Raqay” desarrollará la actividad empresarial como persona jurídica porque se considera importante que, al ser un negocio representado por 4 socios, la empresa sea quien asuma todos los derechos y obligaciones de esta, y que la responsabilidad quede limitada al patrimonio de la empresa sin afectar el patrimonio personal de cada uno de los socios por las deudas o actos de la empresa.

Como persona jurídica existen diferentes tipos de sociedades, en el caso del Ecolodge “Kachi Raqay”, se decidió optar por una Sociedad Anónima Cerrada (S.A.C.) debido a que este tipo de sociedad permite el número de cuatro socios (siendo el mínimo de 2 socios y como máximo de 20); el capital social se encuentra representado por acciones que se distribuyen según los aportes de los socios a este capital social; y las decisiones de la empresa se toman por mayoría votos y por Junta de Socios (siendo los votos equivalentes al capital que representan). Con este tipo de sociedad las acciones del Ecolodge "Kachi Raqay" no estarán inscritas en los registros públicos de mercado de valores, por lo que si uno de los cuatro socios decidiera vender su participación, primero deberá ofrecerla a los otros tres socios. Las acciones dentro de una Sociedad Anónima Cerrada pueden emitirse en diferentes 
clases y cada clase ofrecer un derecho diferente a sus socios (acciones sin derecho a voto, dividendos preferenciales, etc.). Este tipo de sociedad le permite al Ecolodge "Kachi Raqay" crear una sociedad sin directorio, por tener un número reducido de cuatro socios según la Ley General de Sociedades, dejando toda autoridad sobre la Gerencia General (Propia, 2016). Adicionalmente, el artículo 229 de la Ley General de Sociedades establece que este tipo de sociedad debe asignar un mínimo del diez por ciento de la utilidad de cada año, luego del impuesto la renta, a una reserva legal. La reserva legal debe alcanzar un monto igual a la quinta parte del capital, y estará destinada a cubrir las pérdidas correspondientes al ejercicio (Pacífico, 2011).

Tabla 73.

Costos de aspectos legales (expresado en soles)

\begin{tabular}{lc} 
Aspectos legales & $\mathrm{S} /$. \\
\hline Elaboración de minuta & 100.00 \\
Constitución de sociedad (Notaria y Registros) & 500.00 \\
Certificado de Inspección de Seguridad en Edificaciones & 223.75 \\
Pago por categorización y registro en la dirección regional de & \\
turismo & 74.40 \\
Registro Públicos (SUNARP) & 36.85 \\
Registro sanitario de alimentos y bebidas (DIGESA) & 360.00 \\
\hline Total & 1295.00
\end{tabular}

\subsection{2. constitución de empresa.}

Para iniciar la constitución de la empresa se debe seguir los siguientes pasos:

(SUNARP, 2017)

1. Inscribir a la empresa mediante el Sistema de Intermediación Digital a través de la SUNARP para reservar el nombre que tendrá la empresa "Kachi Raqay".

2. Los cuatro socios se deben presentar al notario para tramitar la escritura pública (documento público que guarda los acuerdos pactados entre los socios). 
3. Los socios se deben presentar la solicitud de inscripción en la oficina registral de la SUNARP con el domicilio que tendrá la empresa "Kachi Raqay".

4. El documento ingresado se denominará "Título" y se le asignará un número (“Título" con fecha y hora de ingreso).

5. En el caso que el Registrador Público no encuentre ningún defecto en el título, se procederá a extender la inscripción en el registro de persona Jurídicas, donde se da a conocer la empresa como "Kachi Raqay".

6. Inscribir a la empresa "Kachi Raqay” en el RUC (a cargo de la SUNAT).

7. Obtener las autorizaciones complementarias: licencia de funcionamiento, permisos especiales de acuerdo al giro del negocio y autorizaciones de planilla de trabajadores.

8. Obtener comprobantes de pago físico o electrónico.

9. Legalizar los libros contables físicos o electrónicos.

\subsubsection{Autorizaciones}

1. Reglamento de establecimientos de hospedaje

Mediante el Decreto Supremo N001-2015-MINCETUR “Reglamento de

Establecimientos de Hospedaje" se establece las disposiciones para las clasificaciones, categorización, operación y supervisión de los establecimientos de hospedaje. La Dirección Nacional de Desarrollo Turístico del Ministerio de Comercio Exterior y Turismo es el órgano competente de designa del Registro de Calificadores de Establecimientos de Hospedaje al encargado de emitir Informe Técnico para clasificación y categorización del hospedaje. Siendo la clasificación y categorización como se menciona a continuación (Perú R. d., 2015): 
Tabla 74.

Clasificación de hospedajes

\begin{tabular}{|c|c|}
\hline Clase & Categoría \\
\hline Hotel & Una a cinco estrellas \\
\hline Apart Hotel & Tres a cinco estrellas \\
\hline Hostal & Una a tres estrellas \\
\hline Albergue & -.- \\
\hline
\end{tabular}

Nota. Recuperado de DS N0001-2015-MINCETUR "Reglamento de Establecimientos de Hospedaje."

La clase de hospedaje para la actividad económica de Ecolodge "Kachi Raqay" es albergue, de acuerdo a la definición del Ministerio de Comercio Exterior y Turismo. Albergue es el establecimiento de hospedaje que presta servicio de alojamiento preferentemente en habitaciones comunes, a un determinado grupo de huéspedes que comparten uno o varios intereses y actividades afines. Su ubicación y/o los intereses y actividades de sus huéspedes, determinaran la modalidad del mismo. (Ministerio de Comercio Exterior y Turismo, 2015)

El mencionado Reglamento (Perú R. d., 2015) del mismo modo establece las condiciones mínimas con las que debe contar el hospedaje previo al inicio de la actividad comercial en cuanto a:

Infraestructura (Perú G. d., 2015):

a) El número de habitaciones debe ser de seis (6) o más.

b) Tener un ingreso diferenciado para la circulación de los huéspedes y personal de servicio.

c) Contar con un área de recepción y consejería.

d) El área de las habitaciones (incluyendo el área de clóset y guardarropa) debe tener como mínimo $6 \mathrm{~m}^{2}$. 
e) El área total de los servicios higiénicos privados o comunes debe tener como mínimo $2 \mathrm{~m}^{2}$

f) Los Servicios Higiénicos: Deberán contar con pisos y paredes de material impermeable. El revestimiento de la pared debe tener una altura mínima de $1.80 \mathrm{~m}$.

g) Para el caso de un establecimiento de cuatro (4) o más pisos, este debe contar por lo menos con un ascensor. No aplica para la estructura del Ecolodge "Kachi Raqay".

h) La edificación debe guardar armonía con el entorno en el que se ubica.

i) Para personas con discapacidad y/o personas adultas mayores se deberá tomar en cuenta lo estipulado en la norma de Accesibilidad.

j) Para el diseño de accesos y salidas de emergencia, pasajes de circulación de personas, escaleras, sistema contra incendios, etc. se debe tomar en cuenta la norma A. 130 Requisitos de Seguridad.

k) Los muros y divisiones interiores, especialmente entre dormitorios, deberán cumplir con los requisitos de seguridad del presente Reglamento siendo incombustibles, higiénicos y de fácil limpieza, que brinden condiciones de privacidad y de aislamiento acústico.

Equipamiento:

a) Contar con teléfono de uso público y para uso exclusivo del huésped.

b) Contar con un botiquín de primero auxilios, según las especificaciones técnicas del Ministerio de Salud.

c) Contar con sistemas de agua fría y caliente las veinticuatro (24) horas del día.

Servicios:

a) Realizar limpieza diaria de habitaciones y todos los ambientes del establecimiento.

b) Brindar el servicio de custodia de equipaje. 
c) El cambio de sábanas y toallas debe ser regular, o a solicitud del cliente que ese cambio no sea regularmente.

Pago por categorización, de acuerdo con el Texto Único de Procedimientos Administrativos MINCETUR 2017: S/74.40. (MINCETUR, 2017, pág. 16)

2. Licencia de funcionamiento

Dentro del marco legal, la licencia de funcionamiento es la autorización que otorgan las municipalidades para el desarrollo de actividades económicas en un establecimiento determinado. La licencia de funcionamiento se debe obtener de carácter obligatorio previo al inicio de las actividades de comercio de la empresa. Para la actividad económica del Ecolodge "Kachi Raqay" la Municipalidad Provincial del Cusco es la encargada de evaluar la solicitud y otorgar la licencia de funcionamiento; así como de fiscalizar la actividad económica y aplicar las sanciones correspondientes en caso de incumplimiento de obligaciones. La vigencia de la licencia de funcionamiento es indeterminada; sin embargo, en caso se requiera cesar la actividad económica, el representante legal debe informar a la municipalidad correspondiente para dejar sin efecto la licencia de funcionamiento. (Republica, 2007)

El requisito para solicitar la licencia de funcionamiento es llenar el formulario de solicitud con Carácter de Declaración Jurada de Licencia de Funcionamiento, que incluya: número de RUC, número de DNI, número de recibo de pago, copia simple de Vigencia de Poder del representante legal (por ser Persona Jurídica), y copia simple del Certificado de Inspección de Seguridad en Edificaciones, que se explica más adelante. 
El plazo máximo para otorgar la licencia de funcionamiento es de quince días hábiles; pero previo a ello es necesario contar con las condiciones de seguridad en defensa civil. Para el caso de la actividad económica del Ecolodge "Kachi Raqay" el representante legal debe obtener el Certificado de Inspección Técnica de Seguridad en Defensa Civil de Detalle expedido por el Instituto Nacional de Defensa Civil (INDECI). Inspección Técnica de Seguridad en Edificaciones de Detalle debido a las características y dimensiones de la estructura del Lodge. Para armar el expediente para la Inspección técnica de Seguridad en Edificaciones es necesario incluir: (Peruano, 2014)- Pago aproximado de S/ $223.75^{5}$

- Plan de Seguridad en Edificaciones.

- Plano de ubicación (firmado por un Arquitecto).

- Plano de arquitectura (distribución) y detalles de cálculo de aforo por áreas (firmado por un Arquitecto).

- Planos de señalización y rutas de evacuación (firmado por un Arquitecto).

- Planos de diagramas unifilares y tableros electrónicos y cuadro de cargas (firmado por un Electricista).

- Protocolos de pruebas de operatividad y mantenimiento de los equipos de seguridad (capacitación en primeros auxilios, certificado de operatividad de extintores, alarmas contra incendios, sistemas de rociadores, luces de emergencia, entre otros.

- Constancia de mantenimiento de caleras (si corresponde).

- Certificado vigente de medición de resistencia del pozo de tierra.

- Certificados de conformidad emitidos por OSINERGMIN (si corresponde).

\footnotetext{
${ }^{5}$ https://www.indeci.gob.pe/faqs.php
} 
- Autorización del Ministerio de Cultura, en caso de edificaciones integrantes del Patrimonio Cultural de la Nación.

\section{DIGESA}

- De acuerdo a lo indicado en el texto único ordenado 2017 de Digesa, es necesario para un establecimiento que gestionar alimentos para el público, contar con los siguientes requerimientos 6 :

- Registro sanitario de alimentos

- Solicitud de inspección y acreditación de la implementación del sistema Haccp, para identificar los riesgos de seguridad alimentaria y evitar peligros de inocuidad en la producción de alimentos y bebidas.

Dotar a todos los trabajadores del carnet de sanidad expedido por Digesa.

\footnotetext{
${ }^{6} \mathrm{http}: / /$ www.digesa.minsa.gob.pe/expedientes/tupas.aspx
} 


\section{Capítulo VI: Aspectos Organizacionales}

\subsection{Caracterización de la cultura organizacional deseada.}

Para la creación de una nueva empresa es importante comenzar por la declaración de su visión y misión; las mejores declaraciones van a permitir tanto que directivos como trabajadores puedan tener un sentido compartido de los objetivos de la misma empresa, según Philip Kotler y Kevin Lane Keller.

\subsubsection{Visión.}

"Ser reconocidos por la comunidad (nacional e internacional) como Ecolodge modelo de apoyo comunitario e inclusión cultural; que protege el ecosistema y promueve la identidad cultural y turismo sostenible. Con un equipo de trabajo bien identificado con la empresa."

Fred R David asegura que la declaración de la visión se debe establecer en primer lugar, y además debe responder a las preguntas sobre ¿qué se quiere llegar a ser?, ¿cuál es la imagen deseada? y ¿qué haremos en el futuro?, es decir el sueño o declaración de aspiración del Ecolodge "Kachi Raqay” al largo plazo, la imagen y propósito a futuro.

A continuación, se muestra lo ítems que responde a cada una de las interrogantes con las que se definió la visión. 
¿Qué se quiere llegar a ser? El Ecolodge modelo de apoyo comunitario e inclusión cultural.

¿Cuál es la imagen deseada? Ser reconocidos por la comunidad (nacional e internacional) y autoridades.

\subsubsection{Misión.}

"En el Ecolodge Kachi Raqay ofrecemos una inolvidable experiencia de turismo vivencial al viajero nacional y extranjero, a través de su personal capacitado; promoviendo el desarrollo de Maras y las comunidades aledañas, protegiendo la identidad cultural y conservando el medio ambiente.”

Para la declaración de la misión, Fred R David, propone que se debe responder a las preguntas sobre ¿cuál es el negocio?, ¿qué se busca con el negocio?, ¿quién es el cliente del negocio?, ¿dónde se hace el negocio? y ¿por qué se hace el negocio? es decir el propósito o razón de ser del negocio siguiendo los comportamientos presentes del negocio. Según Philip Kotler y Kevin Lane Keller, una buena declaración de la misión debe resaltar los principios de la empresa.

A continuación, se muestra el cuadro que responde a cada una de las interrogantes con las que se definió la misión.

¿Cuál es el negocio?

¿Qué se busca con el negocio?

¿Quién es el cliente del negocio? ¿Dónde se hace el negocio?

¿Por qué se hace el negocio?
Ecolodge de turismo vivencial. Ofrecer una inolvidable experiencia de turismo vivencial.

Viajeros nacionales y extranjeros. Comunidades aledañas a Maras. Para promover el desarrollo en las comunidades de Maras, proteger la identidad cultural y conservar el medio ambiente.

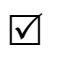

$\nabla$

$\nabla$

$\nabla$ 


\subsubsection{Principios.}

Los principios del negocio son el soporte de la visión y la misión empresarial; y hacen referencia a la ideología que influye de manera decisiva en el comportamiento de los miembros de la organización. En este sentido, en el Ecolodge "Kachi Raqay" se busca que los miembros de la organización se sientan identificados. A continuación, se detallas los principios que rigen el negocio.

Inclusión e Identidad cultural: Trabajamos como asociados con las comunidades aledañas al poblado de Maras, generando oportunidades de desarrollo para todos por igual

Respeto: Respetamos y protegemos las manifestaciones culturales de las comunidades aledañas al poblado de Maras, así como la conservación de los ecosistemas y paisajes locales.

Autenticidad: Nos enfocamos en el cambio constante y positivo, ofreciendo servicios con mejores alternativas turísticas, para nuestros clientes.

Calidad humana: Tenemos como base del desarrollo de nuestro trabajo el compañerismo, así como el trabajo en equipo.

Orientación al cliente: Nos enfocamos en ofrecer el mejor servicio de calidad dirigida al turista que nos visita. 


\subsection{Formulación de objetivos.}

Para la formulación de objetivos se hizo uso del modelo S.M.A.R.T que hace referencia sobre las principales características que debería tener un objetivo al momento de su formulación. El modelo S.M.A.R.T, según George T. Doran, indican que los objetivos deben ser eficaces siguiendo los siguientes requisitos que representan el nombre del acrónimo en inglés. Es decir, siendo: Específicos, Medibles, Alcanzables, Realistas, en un Tiempo determinado.

El Ecolodge "Kachi Raqay” requiere definir dos tipos de objetivos. Los estratégicos, para lograr mejoras en el posicionamiento y competitividad en el mercado; y los objetivos financieros para lograr un buen desempeño financiero del negocio.

A continuación, se definen los objetivos estratégicos y financieros, usando el modelo SMART que el Ecolodge "Kachi Raqay" logrará durante los primeros cinco años de implementación del negocio. Estos objetivos fueron identificados de acuerdo al análisis de oportunidades del entorno de la industria.

\subsubsection{Objetivos estratégicos.}

- Lograr una captación de clientes, en un 50\%, a través de redes sociales durante los tres primeros años de implementación del negocio.

- Posicionar el Ecolodge "Kachi Raqay” como líder en innovación de servicios de experiencia vivencial, en la región del Cusco, al tercer año de implementación del negocio. Manteniendo en adelante ese liderazgo en el rubro. 
- Obtener un crecimiento en los niveles de satisfacción del cliente no menor al $80 \%$ durante los primeros 2 años de gestión del negocio. En adelante, poder incrementar en un 5\% al año.

- Cumplir al 100\% los lineamientos planteados por MINCETUR en el manual de buenas prácticas de gestión de servicios para alojamientos en zonas rurales, así como los lineamientos para el desarrollo del turismo rural comunitario en Peru en pro de gestionar el Ecolodge "Kachi Raqay" de manera planificada y sostenible y en beneficio de la comunidad.

\subsubsection{Objetivos financieros.}

- Lograr un retorno de la inversión no menor al $25 \%$ en promedio de forma anual, durante un periodo de los cinco años.

- Incrementar los niveles de ventas, en porcentaje de ocupabilidad, en un 8\% de manera anual, respecto del año anterior. Siendo este incremento en volumen, es decir, el número de huéspedes que se hospedarían en el Ecolodge "Kachi Raqay".

- Lograr que la inversión en campañas B2B y B2C consigan un impacto positivo en la Penetración del mercado durante el primer año de gestión del negocio y adelante mantener la fidelización del cliente.

\subsection{Formulación de estrategia del negocio.}

Mediante la formulación de la estrategia del negocio el Ecolodge "Kachi Raqay" indicará cómo logrará conseguir los objetivos antes mencionados. En este sentido se propone utilizar como estrategia el enfoque de alto valor. 
Esta estrategia consiste en enfocarse en un segmento específico del mercado, es decir; ofrece productos o servicios a una pequeña variedad de clientes con la mejor relación valorprecio disponible en el mercado. (Porter M. , s.f.)

Estas necesidades se verán satisfechas dado el valor agregado que posee el Ecolodge “Kachi Raqay”, tanto por su ubicación geográfica especial, en el poblado de Maras, como por los servicios de turismo vivencial que brindará; ambos aspectos muy valoradas en la investigación de mercado; por otro lado el equipo de profesionales y pobladores involucrados y expertos en las actividades de la región, y la excelente infraestructura hotelera que conserva los elementos naturales del poblado de Maras como lo es el adobe, madera, piedra; así como el concepto familiar que guardará el Ecolodge.

Para poder identificar y generar oportunidades de crecimiento se utilizó el método de valoración de oportunidades de crecimiento según Kothler, donde explica que en primer lugar se debe identificar oportunidades para conseguir un mayor crecimiento en el negocio actual (oportunidad de crecimiento intensivo); posteriormente, se debe identificar oportunidades para crear o adquirir negocios adicionales (oportunidad de crecimiento integrado); y finalmente, identificar oportunidades para añadir negocios atractivos que carecen de relación con los actuales (Oportunidad de crecimiento diversificado) (Keller, 2006).

a) Crecimiento Intensivo:

El Ecolodge “Kachi Raqay” pertenece a un mercado que, según el estudio de mercado, aún no ha sido explotado, debido a que únicamente el $12 \%$ de los encuestados ha 
experimentado una experiencia de turismo vivencial; y donde el público no tiene un concepto claro de todo lo que implica un Lodge.

Por lo que enfocamos el crecimiento al turista que quiera conocer un tipo experiencias vivenciales y de aventura, con paquetes completos donde los pobladores de la región participen en las actividades diarias con ellos mismos. Haciendo que puedan conocer más sobre la historia del Cusco desde sus mismos pobladores.

Todo bajo los estándares de hospedajes del MINCETUR (Ministerio de Comercio exterior y Turismo).

Logrando experiencias únicas donde los visitantes puedan hacer sus propias recomendaciones y poder incrementar la cantidad de visitantes nacionales como extranjeros año tras año.

b) Crecimiento Integrado:

El Ecolodge "Kachi Raqay” inicia con un concepto de alojamiento vivencial; sin embargo, al trabajar directamente con las comunidades aledañas a los poblados de Maras tiene la oportunidad de poder crecer un negocio adicional.

Dentro de las actividades de los visitantes junto con los pobladores de Maras está las actividades diarias de la región (hacer el pan, visitar los mercados, alimentar animales, etc.). Actividades que pueden generar interés entre los visitantes el deseo por adquirir los mismos productos trabajado por ellos durante su estadía. Por lo que el Ecolodge "Kachi Raqay" 
ofrece en venta dichos productos a los visitantes como recuerdo de las actividades en las que pudieron participar.

\subsection{Determinación de las ventajas competitivas críticas.}

Tomando como referencia a Robert kaplan y David Norton, se utilizará el Cuadro de Mando Integral como herramienta para alinear la estrategia de enfoque de alto valor en la organización.

a. Traducir la estrategia en términos operativos:

\section{$\underline{\text { Perspectiva financiera }}$}

Refiere a los intereses de los socios accionistas, la estrategia está relacionada con los resultados financieros.

- Lograr que la inversión en campañas B2B y B2C consigan un impacto positivo en la Penetración del mercado durante el primer año de gestión del negocio y adelante mantener la fidelización del cliente.

- Incrementar ventas al 8\% anualmente.

- Crecimiento de expansión: Lograr un retorno de la inversión no menor al 25\% en 5 años.

\section{Perspectiva del cliente}

Elegir la estrategia en lo que concierne a los intereses del cliente.

- Selección del cliente: Atraer al segmento turismo vivencial, turismo rural comunitario, y relacionados. 
- Satisfacción del cliente: relación valor-precio al $80 \%$ anualmente

- Generar relación con los clientes: Conocerlos y generar una relación pre y post venta.

\section{Perspectiva interna:}

Relacionado a los procesos internos que permiten satisfacer las expectativas de los clientes y de los accionistas

- Gestión de calidad de servicios: Compromiso de la organización por aplicar y gestionar procesos de calidad.

- Optimizar procesos: eficiencia y cumplimiento de estándares

- Conservar un ambiente tradicional: las actividades, usos y costumbres se respetarán en el día a día. Ser líderes en innovación de servicios de hospedaje.

$\underline{\text { Perspectiva de aprendizaje y crecimiento }}$

Concierne al comportamiento organizacional para impulsar el crecimiento.

- La búsqueda más importante es lograr la motivación y satisfacción de los colaboradores.

- Capacitación en valores culturales, usos y costumbres (Conservación del Patrimonio material e inmaterial)

- Impulsar la formación profesional de los colaboradores con especialización en gestión de calidad de servicio, aplicando coaching organizacional para mejorar rendimiento. 


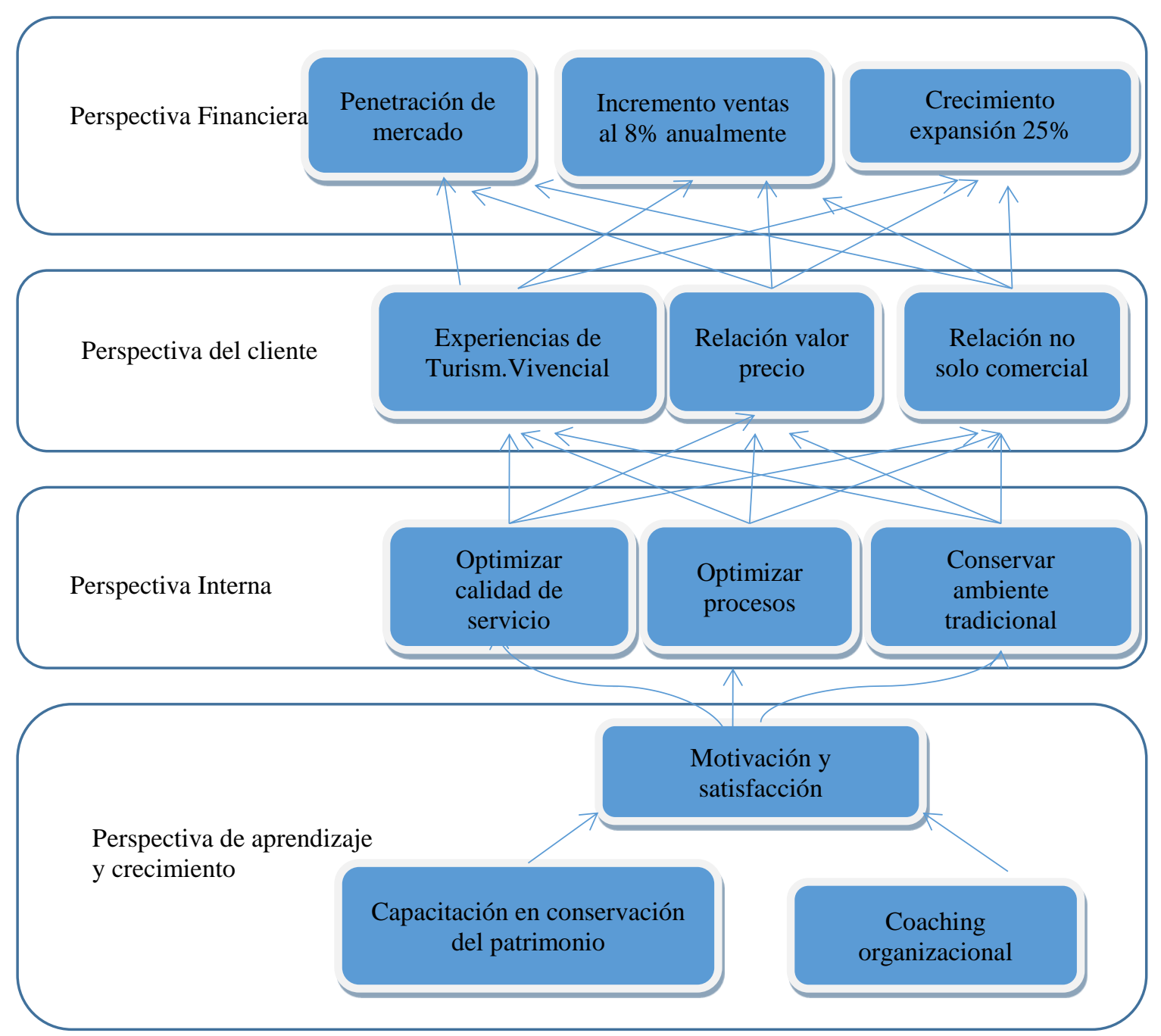

Figura 29. Cuadro De Mando Integral

\subsection{Diseño de la estructura organizacional deseada.}

Tal como cita Idalberto Chiavenato, las organizaciones están conformadas por personas de las cuales dependen para conseguir sus objetivos y cumplir sus misiones. Así las organizaciones surgen para aprovechar la sinergia de los esfuerzos de varios individuos que trabajan en conjunto. En su libro Administración de Recursos Humanos, él describe que la tendencia cual busca que todas las personas en todos los niveles sean administradores de su propia tarea y no solo los ejecutores, pues más allá de ejecutar la tarea, cada persona debe 
tomar conciencia de que ha de ser elemento de diagnóstico y solución de problemas en pro del mejoramiento continuo.

La estructura organizativa está dada por la Departamentalización funcional: Esto basado en la agrupación de actividades. Así la departamentalización será de función, debido a que las unidades de la organización se definirían por la naturaleza del trabajo, pues sigue los principios de especialización ocupacional, simplifica la capacitación, proporciona medios de control para cada área funcional. Esta Organización está conformada como se explica a continuación:

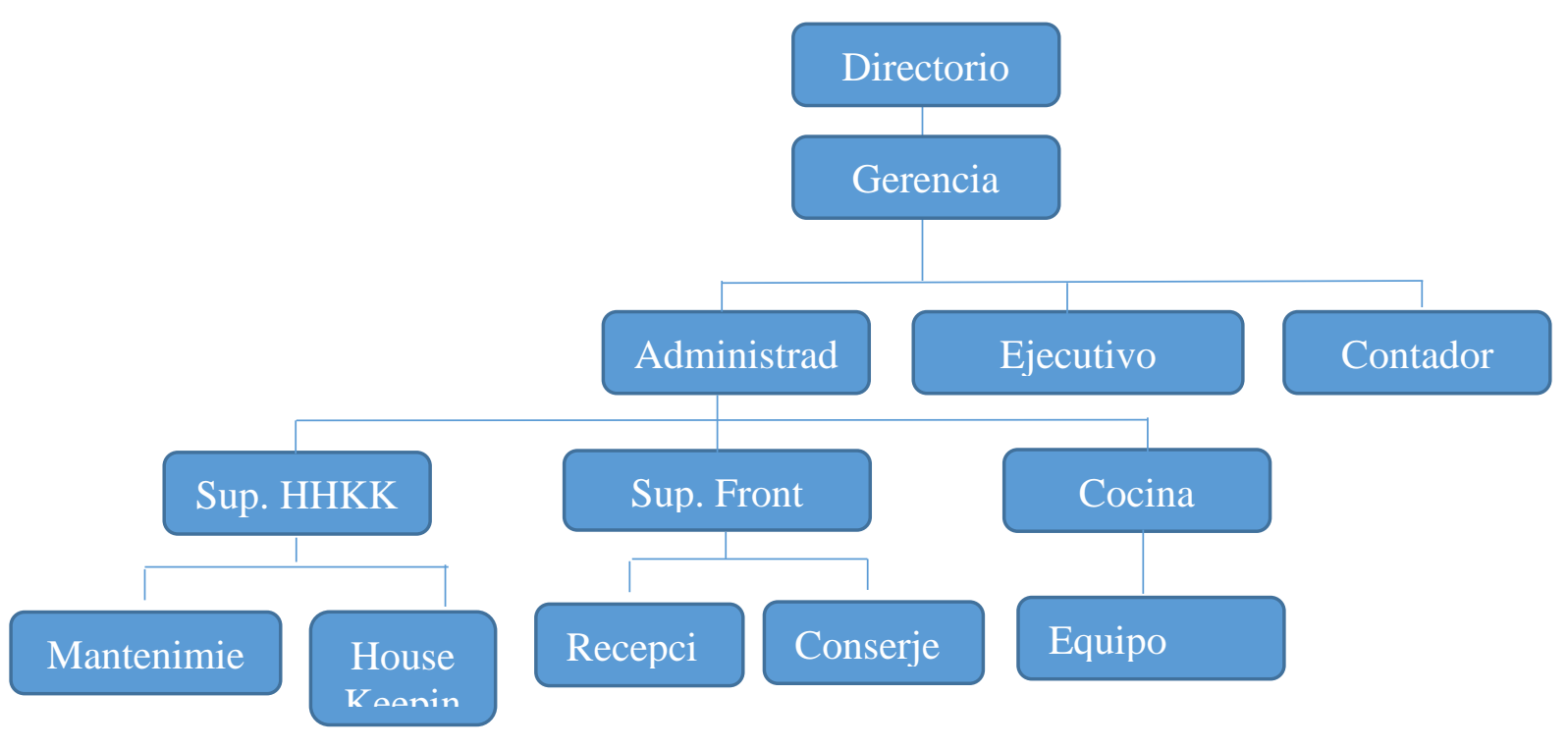




\subsection{Diseño de los perfiles de puesto clave}

\begin{tabular}{|c|c|c|c|c|c|}
\hline & \multicolumn{5}{|c|}{ Ficha de puesto de trabajo } \\
\hline & \multicolumn{5}{|c|}{ Denominación: Gerente General } \\
\hline & \multicolumn{5}{|c|}{ Gerencia } \\
\hline \multicolumn{2}{|c|}{ Dependencia Jerárquica } & $\begin{array}{l}\mathrm{N}^{\circ} \\
\text { plazas }\end{array}$ & \begin{tabular}{|l|} 
Equipo a \\
cargo
\end{tabular} & Horario & Jornada \\
\hline \multicolumn{2}{|l|}{ Socios } & 1 & Todos & $8 \mathrm{am}$ a $5 \mathrm{pm}$ & Continua \\
\hline \multicolumn{6}{|l|}{ Especificación } \\
\hline \multicolumn{4}{|l|}{ Formación } & \multicolumn{2}{|l|}{ Habilidades } \\
\hline \multirow{2}{*}{\multicolumn{4}{|c|}{$\begin{array}{l}\text { Titulación y formación en Administración Hotelera- Gestión } \\
\text { Comercial y finanzas } \\
\text { Experiencia en resolución de conflictos }\end{array}$}} & \multicolumn{2}{|c|}{ Empatía, sociabilidad } \\
\hline & & & & \multicolumn{2}{|l|}{ Pro actividad } \\
\hline \multicolumn{4}{|c|}{ Experiencia en manejo de personal } & \multicolumn{2}{|c|}{ Facilidad de } \\
\hline \multicolumn{4}{|c|}{ Experiencia en trato al cliente } & \multicolumn{2}{|c|}{ Escucha activa } \\
\hline \multirow{2}{*}{\multicolumn{4}{|c|}{$\begin{array}{l}\text { Conocimiento del idioma ingles a nivel avanzado. Dominio de } \\
\text { sistema office y de sistemas hoteleros } \\
\text { Experiencia mínima de } 5 \text { años en hoteles tres estrellas }\end{array}$}} & \multicolumn{2}{|c|}{ Espíritu de servicio } \\
\hline & & & & Asertividad & y liderazgo \\
\hline \multicolumn{6}{|l|}{ Descripción } \\
\hline \multicolumn{6}{|c|}{$\begin{array}{l}\text { Ejecución de labores de dirección general, formulación de políticas institucionales y } \\
\text { adaptación de planes, programas, proyectos. Control en la administración y gestión en base } \\
\text { de las disposiciones legales. Dirige las actividades financieras, comerciales, suscribe los } \\
\text { actos administrativos y contratos. El gerente de operaciones estará cargo del desarrollo y } \\
\text { control de todas las operaciones relacionadas al servicio en el hotel. Estará a cargo de } \\
\text { asegurar el correcto funcionamiento de todas las aéreas, respecto el equipo de } \\
\text { colaboradores, la estructura y equipos que hagan posible la atención oportuna a los clientes, } \\
\text { asegurando también la alta calidad de los servicios ofertados }\end{array}$} \\
\hline \multicolumn{6}{|c|}{ Actividades principales } \\
\hline \multicolumn{6}{|c|}{$\begin{array}{l}\text { Realizar la gestión necesaria para lograr el desarrollo de la empresa, de acuerdo con la } \\
\text { misión, visión y objetivos establecidos }\end{array}$} \\
\hline \multicolumn{6}{|c|}{$\begin{array}{l}\text { Velar por la utilización eficiente de los recursos, técnicos, financieros y talento humano; y } \\
\text { la preservación de este. }\end{array}$} \\
\hline \multicolumn{6}{|c|}{$\begin{array}{l}\text { Dirigir la empresa, manteniendo la unidad y control del cumplimiento de los procesos de la } \\
\text { organización. }\end{array}$} \\
\hline \multicolumn{6}{|c|}{$\begin{array}{l}\text { Cumplir y hacer cumplir las normas legales, reglamentarias vigentes y ejecutar las } \\
\text { decisiones tomadas por la junta de socios. }\end{array}$} \\
\hline \multicolumn{6}{|c|}{$\begin{array}{l}\text { Presentar a la junta de socios el proyecto de presupuesto de rentas y gastos de la empresa, } \\
\text { una vez aprobado proceder a su ejecución. }\end{array}$} \\
\hline \multicolumn{6}{|c|}{$\begin{array}{l}\text { Suscribir los contratos y convenios necesarios con clientes y proveedores como } \\
\text { representante de la organización. }\end{array}$} \\
\hline \multicolumn{6}{|c|}{$\begin{array}{l}\text { Promover la mejora continua, de normas técnicas, modelos y prestación de servicios al } \\
\text { cliente }\end{array}$} \\
\hline \multicolumn{6}{|c|}{$\begin{array}{l}\text { Nombrar, designar y remover el personal de la empresa de acuerdo a las disposiciones } \\
\text { legales y reglamentarias vigentes. }\end{array}$} \\
\hline
\end{tabular}


Liderar el sistema de información que soporte la gestión de la organización en sus procesos técnicos y administrativos

Aplicar las sanciones disciplinarias que le corresponden por ley o por reglamento.

Revisión de trámites oficiales, y control de costos.

Desarrollar objetivos, estrategias y actividades dirigidas a mejorar las condiciones laborales, el clima organizacional, la salud ocupacional y el nivel de capacitación y entrenamiento, y en especial ejecutar un proceso de aprendizaje continuo para todos los colaboradores.

Dirigir y fomentar las relaciones comerciales nacionales e internacionales de la Empresa con clientes potenciales

Resolución de conflictos y atención personalizada a clientes

Atención personalizada a clientes potenciales en posibles inspecciones y oportunidades de negocio

Las demás que su representación merezca. 


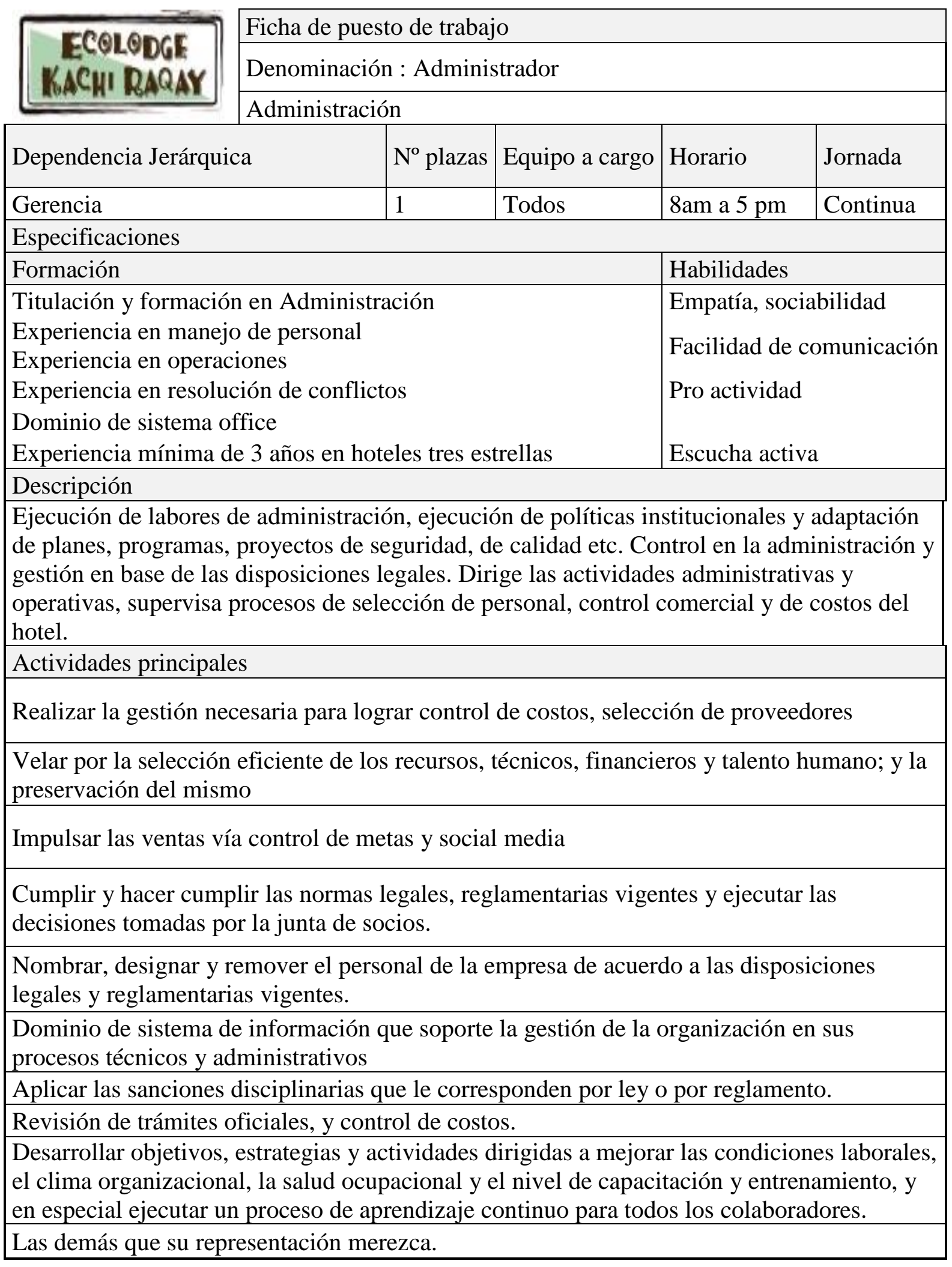




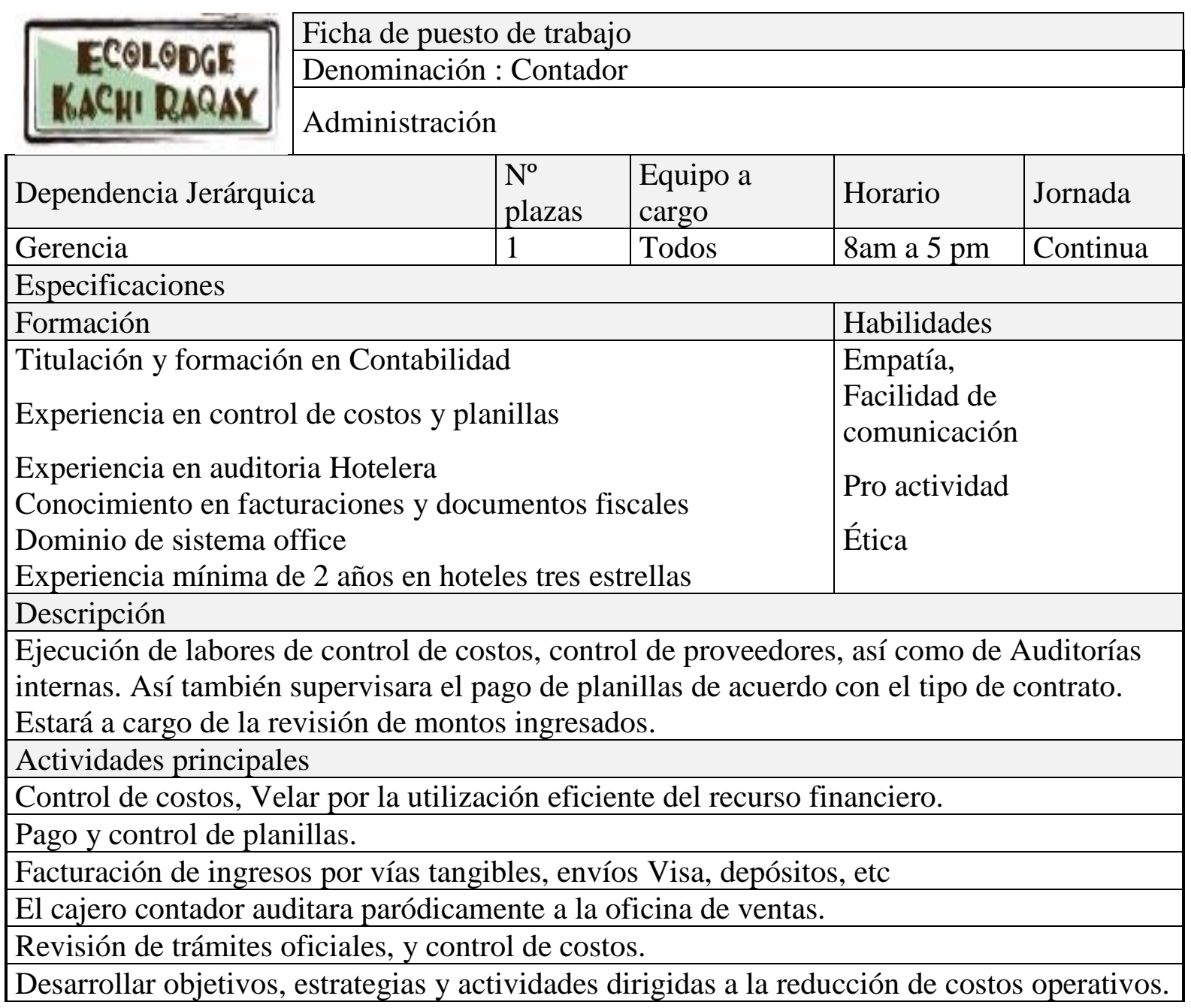




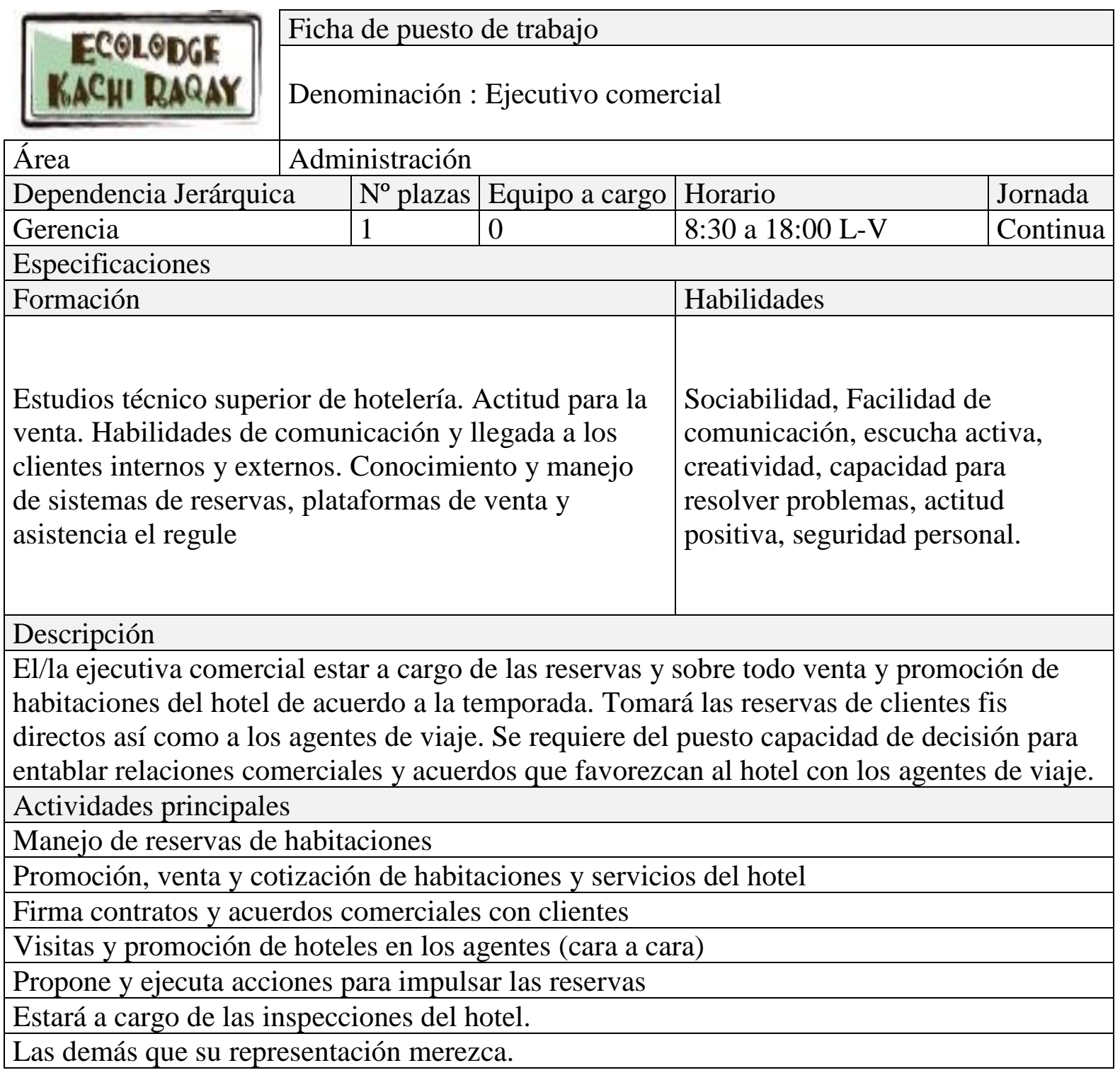




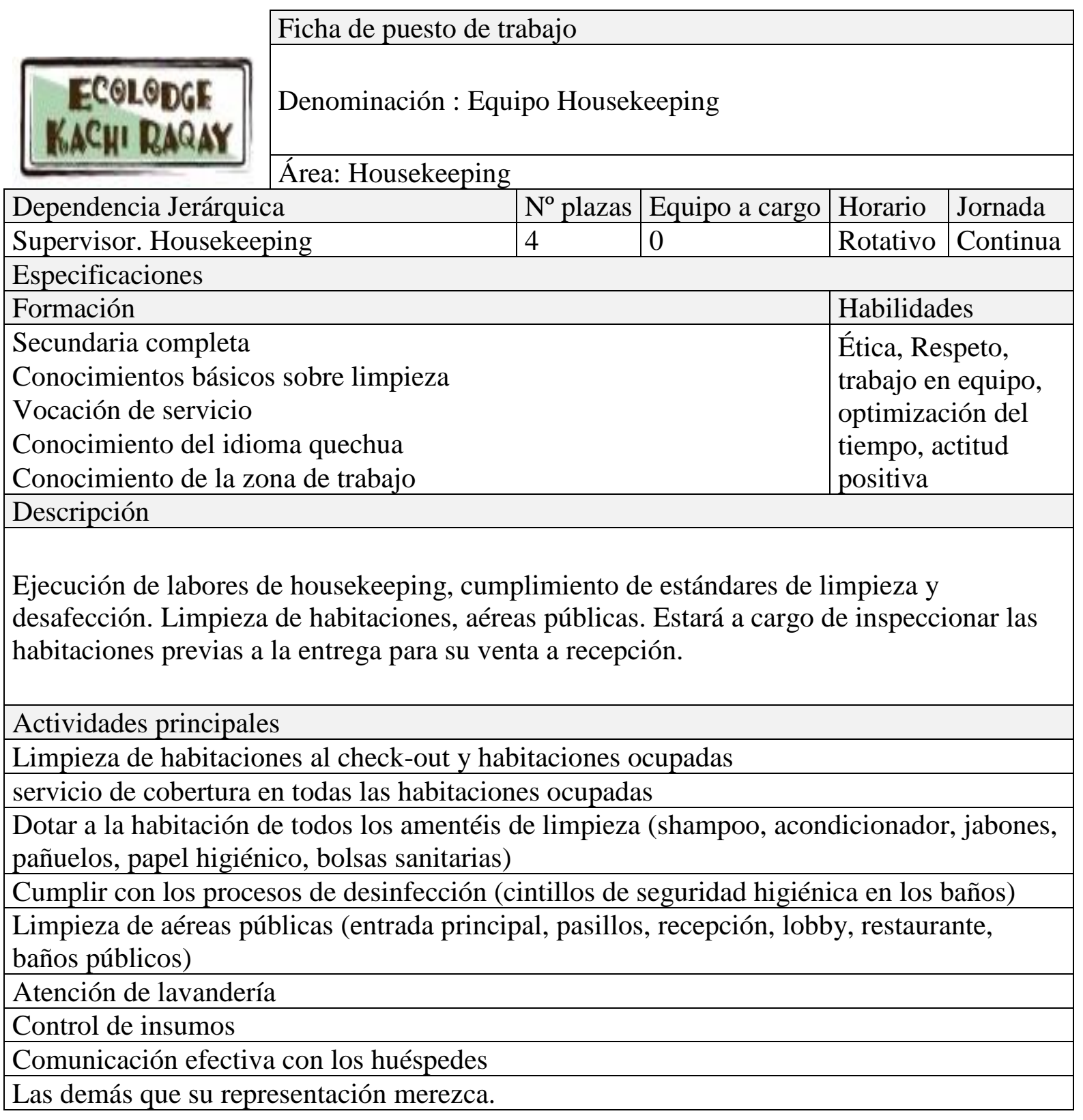




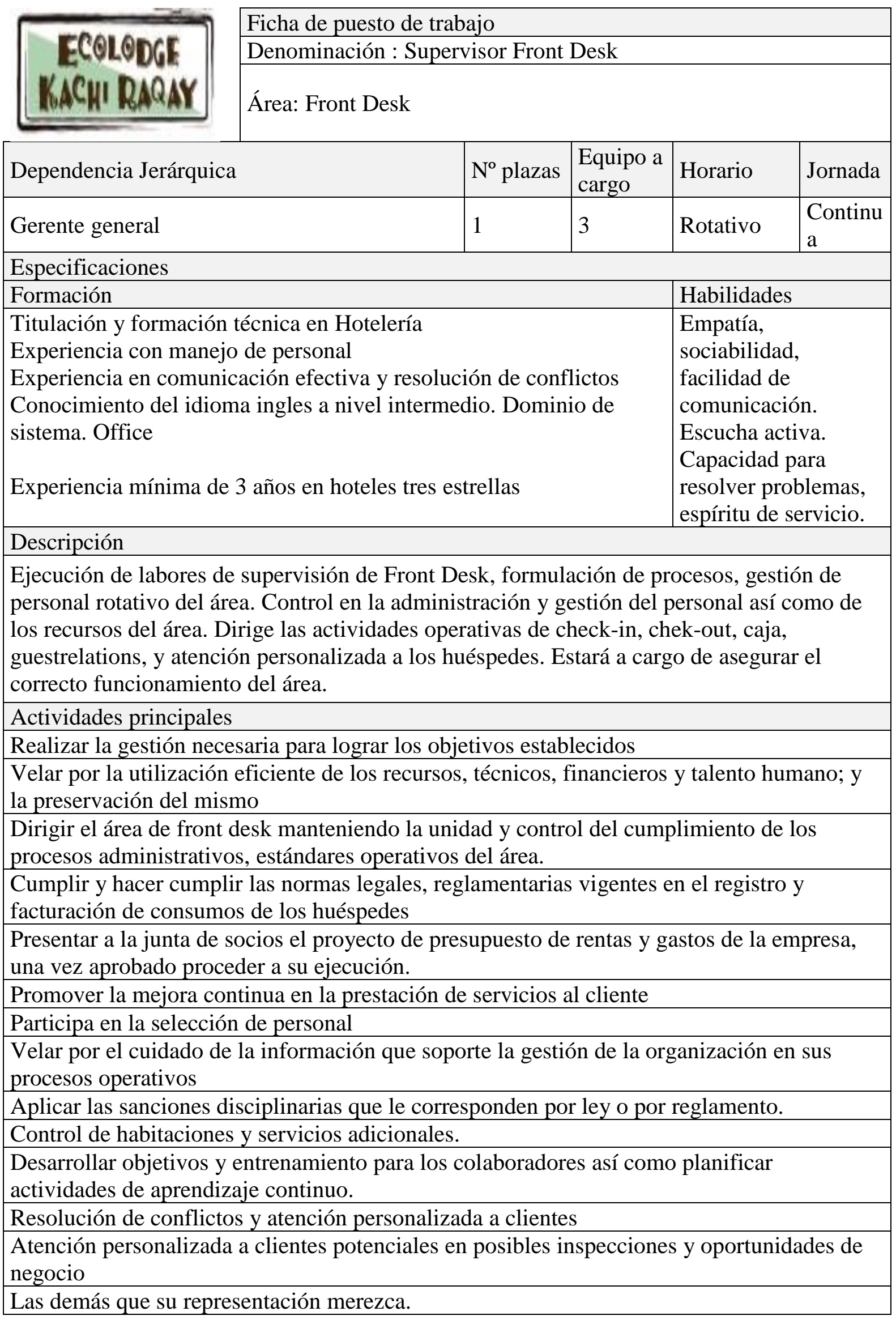




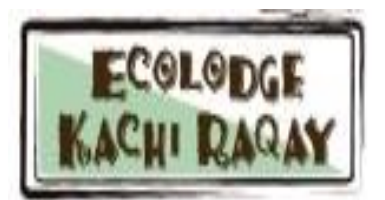

Ficha de puesto de trabajo

Denominación : Recepcionista

Área: Front Desk

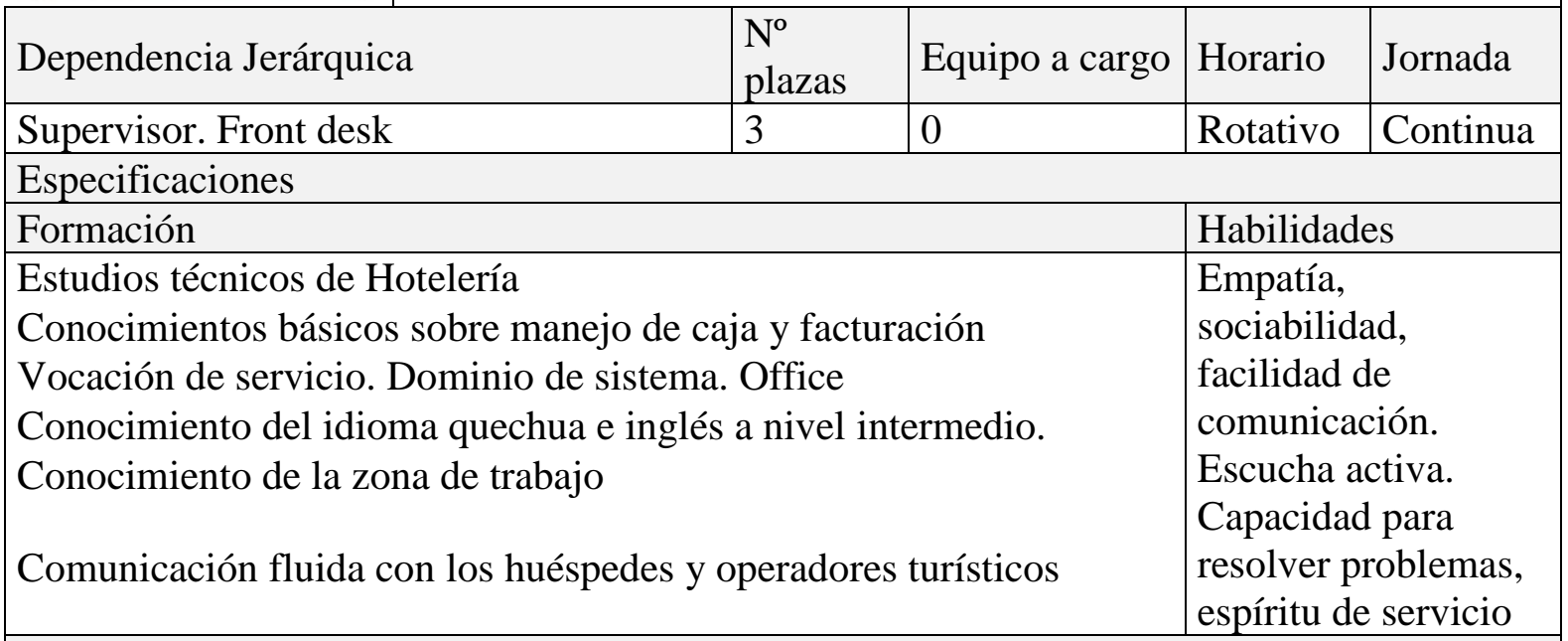

\section{Descripción}

Ejecución de labores de Recepción, registro y salida de huéspedes. Atención y soporte a los clientes en todos los servicios requeridos (organizar actividades, monitoreo). Atención a operadores turísticos, en ambos casos brinda información precisa de la oferta del hotel tanto en habitaciones como en actividades adicionales.

Actividades principales

Registro de ingreso a las habitaciones

Registro de salida, confirmación de servicios adicionales para la facturación con diferentes medios de pago

Brinda información exacta a las otras aéreas

Recepcionista nocturno, prepara la papelería necesaria para el siguiente turno

Recepcionista nocturno hace la auditoría interna de ingresos del hotel

coordina con HK el inventario de habitaciones para su venta

Coordina las actividades diarias de los turistas de acuerdo a los paquetes

Vela por el cumplimiento y legalidad de los procesos establecidos por los entes supervisores manejo de caja chica del hotel, previa autorización del supervisor

Resolución de conflictos, seguimiento y monitoreo a quejas.

Up sell de habitaciones, así como de servicios adicionales

Atención personalizada de huéspedes

Las demás que su representación merezca. 


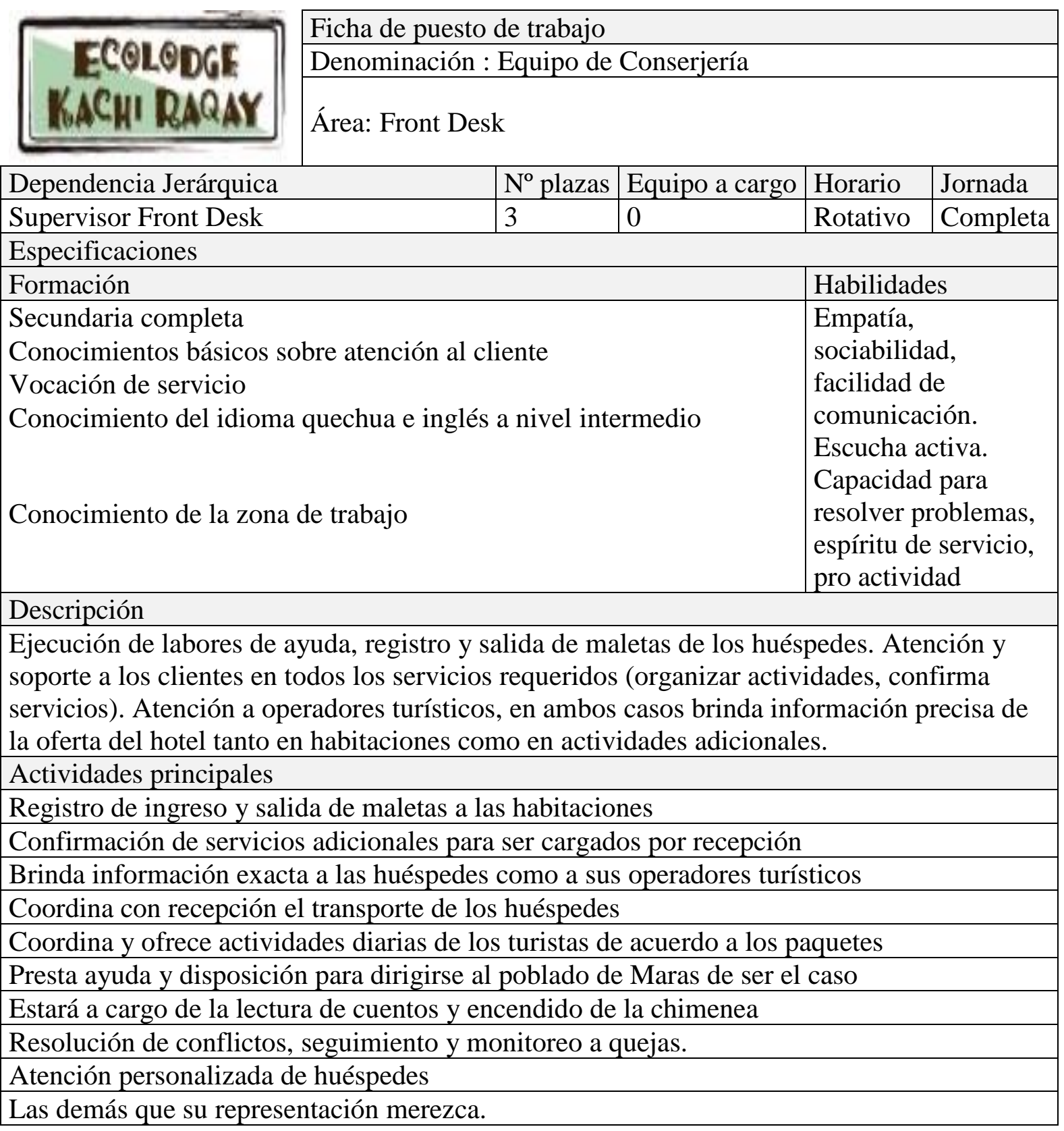




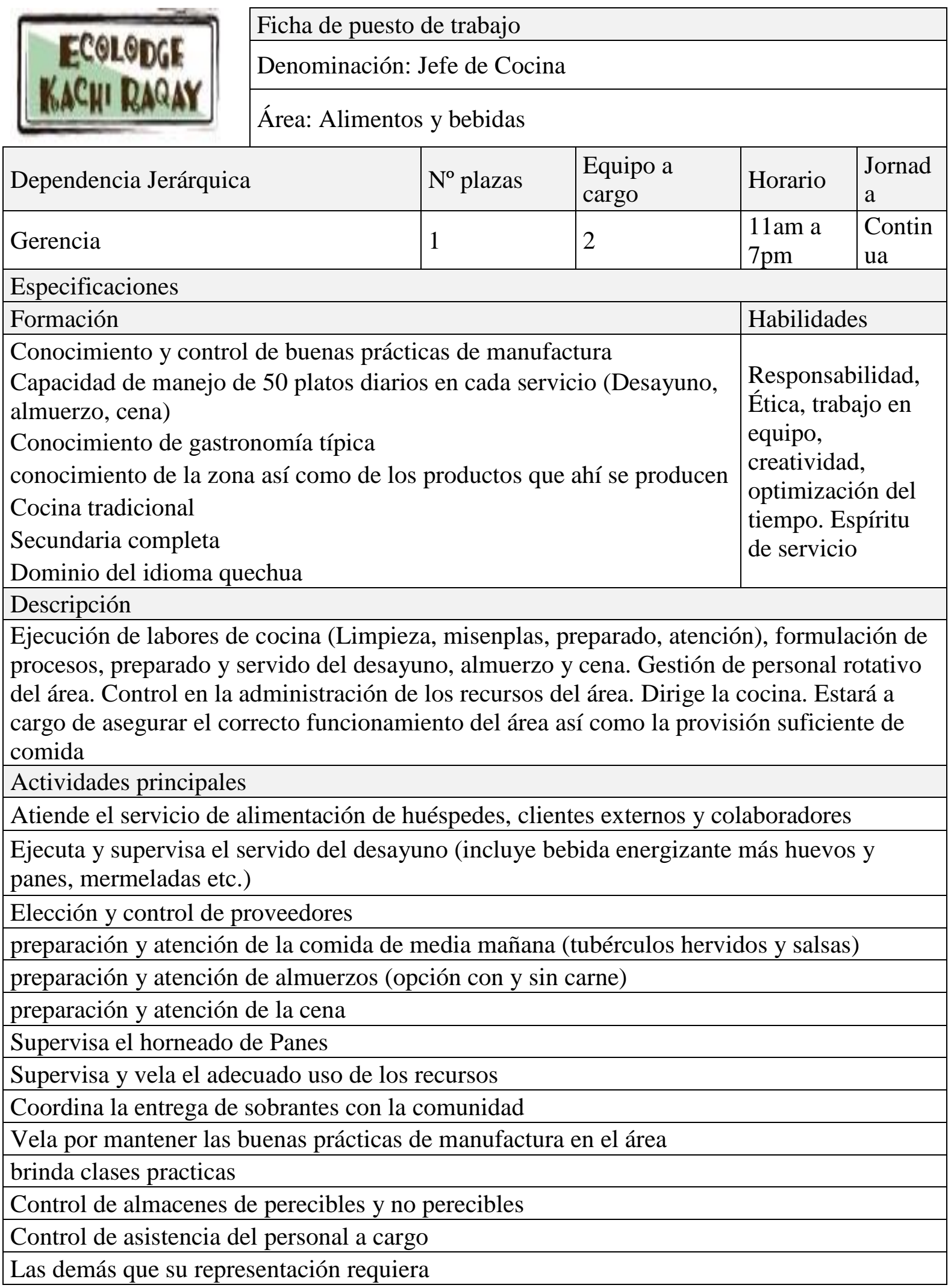




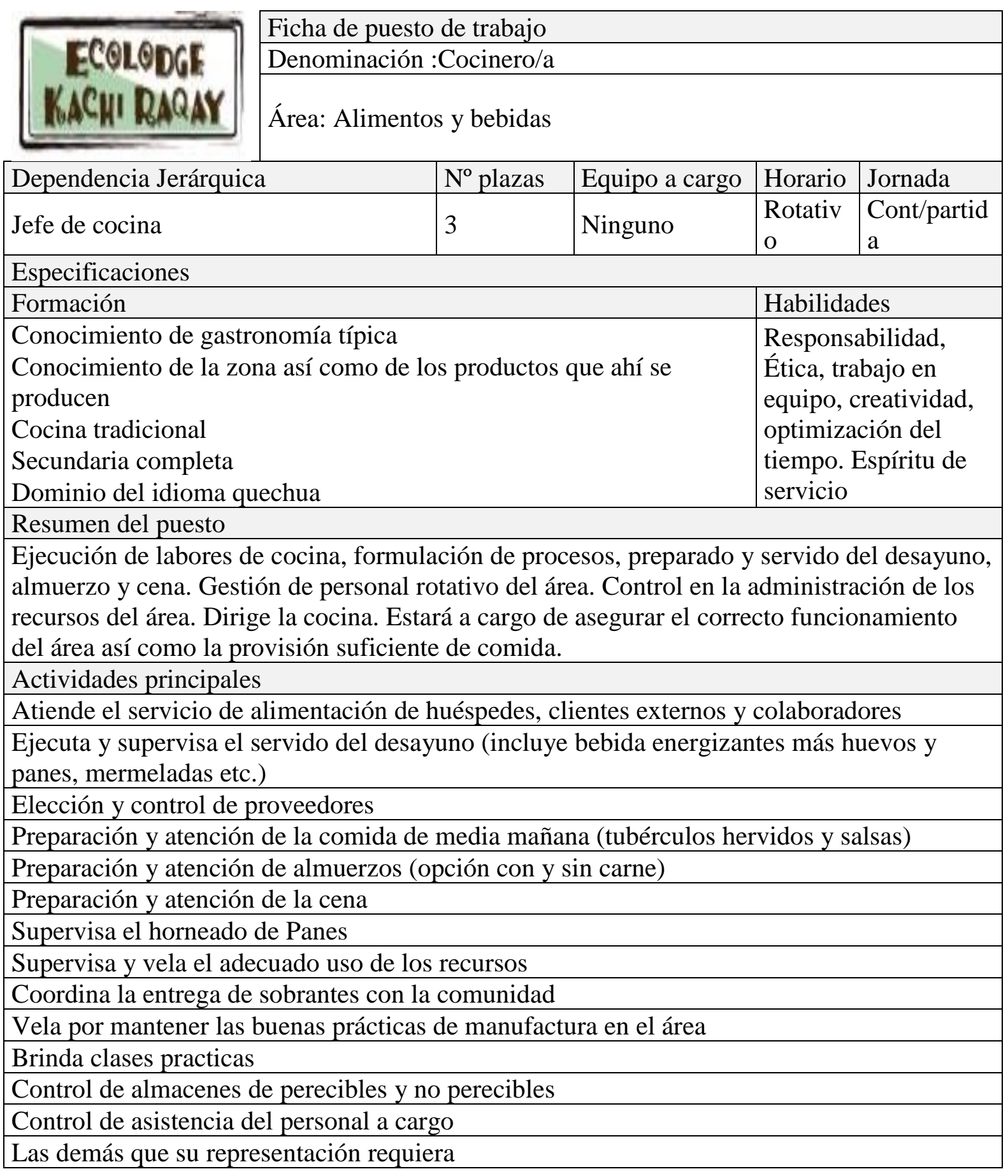




\begin{tabular}{|c|c|c|c|c|}
\hline \multirow{3}{*}{$\begin{array}{c}\text { ECOLODGE } \\
\text { KACHI RAQAY } \\
\end{array}$} & \multicolumn{4}{|c|}{ Ficha de puesto de trabajo } \\
\hline & \multicolumn{4}{|l|}{ Mantenimiento } \\
\hline & \multicolumn{4}{|l|}{ Mantenimiento } \\
\hline Dependencia Jerárquica & $\mathrm{N}^{\mathrm{o}}$ plazas & Equipo a cargo & Horario & Jornada \\
\hline Jefe de operaciones & 2 & Ninguno & $\begin{array}{l}\text { 8:00 a } 16: 00 \text { y } \\
\text { medio tiempo }\end{array}$ & Continua \\
\hline \multicolumn{5}{|l|}{ Especificaciones } \\
\hline \multicolumn{3}{|l|}{ Formación } & \multicolumn{2}{|l|}{ Habilidades } \\
\hline \multicolumn{3}{|c|}{$\begin{array}{l}\text { Estudios técnicos de electricidad, conocimiento de gasfitería } \\
\text { y construcción. Conocimiento de equipo hotelero. Soporte de } \\
\text { jardinería. Preferentemente mayor } 30 \text { años }\end{array}$} & \multicolumn{2}{|c|}{$\begin{array}{l}\text { Responsabilidad, espíritu de } \\
\text { servicio, seguridad personal. }\end{array}$} \\
\hline \multicolumn{5}{|l|}{ Descripción } \\
\hline \multicolumn{5}{|c|}{$\begin{array}{l}\text { El personal de mantenimiento debe velar por el correcto funcionamiento de equipos y } \\
\text { mueblería del hotel. Dada la necesidad de cada área esta persona será la encardada de } \\
\text { resolver problemas de gasfitería, electricidad, etc. Estará a cargo también de auditar equipos } \\
\text { y estructura de cada área. }\end{array}$} \\
\hline \multicolumn{5}{|c|}{ Actividades principales } \\
\hline \multicolumn{5}{|c|}{ Acciones de mantenimiento de construcción. } \\
\hline \multicolumn{5}{|c|}{ Acciones de auditoría a equipos y mueblería. } \\
\hline \multicolumn{5}{|c|}{ Acciones de electricidad y gasfitería. } \\
\hline \multicolumn{5}{|c|}{ Mantenimiento de jardines. } \\
\hline \multicolumn{5}{|c|}{ Turno rotativo según corresponda } \\
\hline \multicolumn{5}{|c|}{01 personal turno diario jornada completa y un adicional en medio tiempo. } \\
\hline \multicolumn{5}{|c|}{ Control de equipos. } \\
\hline
\end{tabular}




\subsection{Remuneraciones, compensaciones e incentivos.}

\section{Sistema de remuneración:}

Dado el análisis de puesto y dada la naturaleza del negocio la remuneración a los empleados se dará por tasa horaria basada en el cumplimiento de 48 horas laborables semanalmente en conformidad por lo establecido en el decreto Ley $\mathrm{N}^{\circ} 728$. Respecto al monto de las remuneraciones se tomara en cuenta la metodología planteada por el estadounidense Merrill R. Lott, se utilizará la valoración por puntos (point rating) para definir el monto de las remuneraciones a los órganos de línea y asesoría de nuestra organización, que nos permitirá un análisis cuantitativo y analítico considerando la determinación y clase de sueldos por evaluarse, así como el número de escalas necesario para cubrir los puestos determinados. $^{7}$

Consideraremos los siguientes factores de evaluación: Educación, experiencia, habilidad, esfuerzo, responsabilidad, condiciones de trabajo.

La valoración de puestos partirá del tipo de trabajo realizado en la empresa:

\footnotetext{
${ }^{7}$ Valoración por puntos: Consultado el 10 de febrero 2017 en sitio web: http://www.tic.org.ar/plataforma1/courses/PERSONAL2/document/Unidad_C/Teoria/C[1][1].6SistemasdeEvalu aci\%C3\%B3n-M\%C3\%A9tododePuntos.pdf?cidReq=PERSONAL2
} 
Tabla 75.

Puestos Ejecutivos

\begin{tabular}{|c|c|c|c|c|c|c|c|}
\hline Cargo & Educación & Experiencia & Habilidad & Esfuerzo & Responsabilidad & Condiciones de trabajo & Total \\
\hline Gerente & 200 & 200 & 150 & 150 & 150 & 150 & 1000 \\
\hline Administrador & 150 & 200 & 100 & 100 & 150 & 100 & 800 \\
\hline Contador & 150 & 200 & 100 & 100 & 100 & 100 & 750 \\
\hline Ejecutivo Comercial & 150 & 200 & 100 & 100 & 100 & 100 & 750 \\
\hline
\end{tabular}

Tabla 76.

Puestos Supervisores

\begin{tabular}{|c|c|c|c|c|c|c|c|}
\hline Cargo & Educación & Experiencia & Habilidad & Esfuerzo & Responsabilidad & Condiciones de trabajo & Total \\
\hline Supervisor HHKK & 150 & 125 & 150 & 150 & 150 & 150 & 875 \\
\hline Supervisor FD & 150 & 150 & 150 & 150 & 150 & 150 & 900 \\
\hline Jefe de Cocina & 150 & 175 & 150 & 150 & 150 & 150 & 925 \\
\hline
\end{tabular}

Tabla 77.

\section{Puestos Operativos}

\begin{tabular}{|c|c|c|c|c|c|c|c|}
\hline Cargo & Educación & Experiencia & Habilidad & Esfuerzo & Responsabilidad & Condiciones de trabajo & Tota \\
\hline Housekeeper & 100 & 100 & 100 & 100 & 150 & 150 & 700 \\
\hline Recepcionista & 150 & 100 & 100 & 100 & 150 & 150 & 750 \\
\hline conserje & 150 & 100 & 100 & 100 & 150 & 150 & 750 \\
\hline personal de cocina & 100 & 100 & 100 & 100 & 150 & 150 & 700 \\
\hline Mantenimiento & 100 & 100 & 100 & 100 & 150 & 150 & 700 \\
\hline
\end{tabular}




\section{La estimación salarial:}

Tomaremos como referencia los sueldos de mercado en sistemas hoteleros similares. Nos apoyaremos también en la información brindada por la consultora Selekto Consultores $\mathrm{SAC}^{8}$, quienes aseguran que la banda salarial está dada por los mismo empleadores, que en puestos operativos en empresas hoteleras mantienen el sueldo básico más comisiones por servicio.

Tabla 78.

Puestos Ejecutivos

\begin{tabular}{lcccc}
\hline Cargo & $\begin{array}{c}\text { Sueldo según el } \\
\text { mercado S/. }\end{array}$ & Puntaje & $\begin{array}{c}\text { Sueldo } \\
\text { estimado en S/. }\end{array}$ & $\begin{array}{c}\text { Valoración } \\
\text { estimada por } \\
\text { punto S/. }\end{array}$ \\
\hline Gerente & $3500-2500$ & 1000 & 3000 & 3,00 \\
Administrador & $3000-2500$ & 800 & 2400 & 3,00 \\
Contador & $2200-1800$ & 750 & 2250 & 3,00 \\
Ejecutivo Comercial & $2200-1800$ & 750 & 2250 & 3,00 \\
\hline
\end{tabular}

Tabla 79.

Puestos Supervisores

\begin{tabular}{lcccc}
\hline \multicolumn{1}{c}{ Cargo } & $\begin{array}{c}\text { Sueldo según el } \\
\text { mercado S/. }\end{array}$ & Puntaje & $\begin{array}{c}\text { Sueldo estimado } \\
\text { en S/. }\end{array}$ & $\begin{array}{c}\text { Valoración } \\
\text { estimada por punto } \\
\text { S/. }\end{array}$ \\
\hline Supervisor HHKK & $2000-1500$ & 675 & 1687,5 & 2,50 \\
Supervisor FD & $2500-1500$ & 675 & 1687,5 & 2,50 \\
Jefe de Cocina & $2200-1500$ & 675 & 1687,5 & 2,50 \\
\hline
\end{tabular}

\footnotetext{
${ }^{8}$ Entrevista a Caro Velez Justiniani, analista de Selekto consultores. Empresa encargada de procesos de selección y reclutamiento de la empresa consultora. (Selekto consultores en Recursos Humanos SAC)
} 
Tabla 80.

Puestos Operativos

\begin{tabular}{lcccc}
\hline \multicolumn{1}{c}{ Cargo } & $\begin{array}{c}\text { Sueldo según el } \\
\text { mercado S/. }\end{array}$ & Puntaje & $\begin{array}{c}\text { Sueldo estimado } \\
\text { en S/. }\end{array}$ & $\begin{array}{c}\text { Valoración estimada } \\
\text { por punto S/. }\end{array}$ \\
\hline Housekeeper & $1500-950$ & 525 & 1050 & 2,00 \\
Recepcionista & $1800-950$ & 550 & 1100 & 2,00 \\
Conserje & $1500-900$ & 550 & 1100 & 2,00 \\
Personal de & $1500-900$ & 525 & 1050 & 2,00 \\
cocina & $1200-850$ & 525 & 1050 & 2,00 \\
Mantenimiento & & & \\
\hline
\end{tabular}

Tabla 81.

Planilla de trabajadores:

\begin{tabular}{lcc}
\hline \multicolumn{1}{c}{ Cargo } & Departamento & $\begin{array}{c}\mathrm{N}^{\circ} \text { plazas con la misma } \\
\text { denominación }\end{array}$ \\
\hline Gerente & Gerencia & 1 \\
Administrador & Administración & 1 \\
Contador & Administración & 1 \\
Ejecutivo Comercial & Administración & 1 \\
Supervisor HHKK & HHKK & 1 \\
Supervisor FD & Front Desk & 1 \\
Jefe de Cocina & Cocina & 1 \\
Housekeeper & HHKK & 3 \\
Recepcionista & Front Desk & 3 \\
Conserje & Front Desk & 3 \\
Personal de cocina & Cocina & 3 \\
Mantenimiento & HHKK & 2 \\
Total colaboradores & & 21 \\
\hline
\end{tabular}

\section{Compensaciones}

- Sistema de seguridad social: En cumplimiento con el decreto ley $N^{\circ} 728$ que rige la actividad laboral privada se pagara el sistema de seguridad social nacional

- Fondo nacional de pensiones: pago al fondo nacional o a la AFP de elección del trabajador

- Compensación por tiempo de servicio: en cumplimiento del DL 728

- Seguro de riesgo para puestos supervisores y ejecutivos 
- Pago por puntos de producción: En este sentido el 10\% de cargo por de servicios del neto logrado por las ventas de operadores en el transcurso de cada mes calendario será dividido por igual, entre todos los trabajadores.

\section{Incentivos}

- Planes recreativos: paseos, planes vacacionales serán organizados.

\subsection{Política de Recursos Humanos}

Dada la naturaleza de la industria hotelera, donde el mayor porcentaje de costos se direcciona al pago de remuneraciones, es importante reconocer que la empresa debe centrar su atención en la mejora en la calidad del servicio que prestan.

Son derechos reconocidos de los trabajadores aquellos estipulados en el decreto Ley 728, así como los reconocidos por el ministerio de trabajo del Peru, entre los que destaca:

- Derechos de los trabajadores

- Igualdad de trato de los trabajadores

- La totalización de los periodos contratados salvo se rescinda a pedido del trabajador o por conflicto entre ambas partes

- Mantenimiento de los trabajadores en caso de sucesión de la empresa

- La protección en caso de insolvencia del empresario

- Disposiciones de seguridad y salud en el trabajo

- Carácter no remunerativo de los beneficios otorgados

- Otorgamiento cursos de capacitación 


\section{Políticas de selección:}

Dada la estrategia del albergue, es importante destacar los siguientes principios en cada proceso:

a. Proceso de reclutamiento: Función de gerencia

- Definir las características de puesto

- Espacios de reclutamiento:

1era búsqueda: radios locales, comunicación masiva en puntos comunes del poblado de Maras.

2da búsqueda: radios locales, comunicación masiva en puntos comunes de la provincia de Urubamba.

3era búsqueda: radios locales, redes sociales, comunicación escrita del departamento del Cusco.

- Elegir a los candidatos más adecuados o idóneos por medio de:

Análisis del Curriculum Vite

Análisis de recomendaciones

Entrevista de reconocimiento

Pruebas psicológicas

Examen médico (de acuerdo al puesto) 
b. Proceso de selección: Función del jefe o supervisor del departamento

- Entrevista a profundidad de los postulantes idóneos.

- Elección del personal.

- Investigación de antecedentes policiales y penales.

- Tiempo de prueba 15 días (remunerado)

- Comunicación y firma de contrato.

\section{Política de gestión total de calidad:}

- Se tomarán en cuenta los siguientes principios enfocados en la gestión de Recursos Humanos.

- Liderazgo de los gerentes y socios: el compromiso de los mandos altos y medios con la calidad, para gestionar oportunidades de mejora

- Relación con los clientes: tanto como huéspedes directos o con potenciales clientes, se debe generar espacios de reconocimiento y acciones que promuevan una mejor relación comercial

- Relación con los proveedores: se cuidará de la relación de cooperación mutua para el logro de los objetivos

- Actitud de los empleados: la búsqueda de la satisfacción de los empleados debe ir de la mano con su compromiso de lealtad y concreción de los objetivos

- Diseño del producto hotelero: todo el personal representa la diferenciación del producto, en base las necesidades del cliente

- Gestión de procesos: identificación de posibles mejoras en el proceso de producción de los servicios del hotel 
- Dirección basada en resultados: los resultados de servicio serán medidos en base el nivel de aceptación del cliente en encuestas y comentarios en redes sociales

- Sensibilidad por el cuidado del medio ambiente y el entorno social: se compensara al a entorno por el impacto que se genera.

- Cultura de mejora continua: tras procesos de evaluación de personal y metas alcanzadas.

\section{Política de asistencia:}

El registro de asistencia será obligatorio para todos los puestos de trabajo, y en cumplimiento de lo establecido por el ministerio de trabajo este debe contener:

- Nombre, razón social de la empresa y RUC

- Nombre y número de documento del trabajador

- Fecha, hora de ingreso y salida del horario de trabajo.

El no contar con registro significará falta, por lo que toda tardanza o inasistencia deberá ser justificada con visto bueno del administrador.

Es deber del empleado cumplir con el registro de su actividad laboral para fines compensatorios.

\section{Política de comunicación:}

La comunicación en la organización es un elemento esencial de acuerdo a la estrategia de la empresa. Las formas son siempre de confianza y amplias para toda la organización. 
Es política de la empresa que todas las personas conozcan las funciones y obligaciones de todas las aéreas para así conciliar el circulo de acciones a favor del logro de los objetivos.

La comunicación será clara y precisa, los medios de comunicación serán por reunión y con registro de conversación para fines de seguimiento.

La documentación para comunicar actos de felicitación será otorgada por escrito, así como las llamadas de atención (primera llamada, memorándum, etc.)

Las reuniones serán semanales, incluirán resumen de actividades de la semana, planeación de actividades de los días futuros, entrenamiento de estándares de calidad.

\section{Políticas de remuneración:}

Se entiende como todo aquello que las personas reciben a cambio de su trabajo como empleados de la empresa. Los salarios y prestaciones es la gratificación que recibirán por su labor. En este sentido gerencia cumple y garantiza la satisfacción de los empleados y genera una fuerza de trabajo productiva.

Se considera para la política de sueldos:

- Equidad Interna: Pagar en Función de las Responsabilidades

- Equidad Externa: Pagar en Función del Mercado

- Pagar en Función de Antigüedad, Inflación, Convenios 
- Pagar en función a la potencialidad y a la búsqueda de superación en beneficio del empleado y la empresa.

- Clasificación de cargos, escalas salariales para cada clase de cargo.

- Los reajustes salariales pueden darse por promoción, escalonamiento, méritos del empleado según los factores de remuneración.

Beneficios:

- Pagos financieros no monetarios ofrecidos por la empresa para garantizar mejor calidad de vida y motivación en el trabajo.

- Planes de beneficios sociales:

- Asistenciales: asistencia medico hospitalaria asistencia financiera

- Recreativos: paseos

\section{Políticas de capacitación:}

Desarrollar programas formativos efectivos:

La capacitación del personal incluirá:

1. Identificar el nivel de conocimientos, aptitudes y habilidades necesarias para obtener un mejor desempeño en las funciones a realizar como equipo y en cada área.

2. Desarrollar un programa de capacitación:

Este programa de capacitaciones se desarrollará en base a tres niveles de capacitación: 
Formación: Su propósito es impartir conocimientos básicos sobre el puesto a cubrir, esta capacitación está orientada a proporcionar una visión general del contexto en el cual la empresa se desenvuelve. Reforzando la gestión de calidad de servicios y la búsqueda de eficiencia en la operación.

Actualización: Se orienta a proporcionar conocimientos y experiencias derivados de recientes tendencias en turismo e identificación de necesidades de acuerdo con el mercado.

Especialización: Se orienta a la profundización y dominio de conocimientos y experiencias o al desarrollo de habilidades, respecto a un área determinada de actividad (del día a día o de las experiencias que brindamos como hotel vivencial). Estará especialmente dirigida a la creación de experiencias vivenciales, ya que ahí recae nuestra mayor fuerza competitiva.

Como arte de la capacitación, se trabajará también acciones que impulsen la flexibilidad de los trabajadores.

\section{Política de clima organizacional:}

Ambiente de trabajo positivo que genere satisfacción en los empleados. Dada la estrategia de la empresa, se debe mantener un clima cálido y fresco respecto el trato entre compañeros. El respeto y la confianza son esenciales para lograr que los huéspedes sientan un ambiente típico al de una familia de Maras. 
Empowerment: Los empleados tendrán la suficiente capacidad de análisis para resolver problemas comunes de la operatividad. Para esto contaran con la formación y apoyo de los supervisores.

\section{Políticas de evaluación:}

La evaluación del desempeño no es un fin en sí misma, sino un instrumento para mejorar los recursos humanos, pues así lograremos detectar problemas de supervisión, de integración del colaborador a la empresa. La empresa utilizara estos resultados a la hora de decidir cambios, renovaciones o incentivos para los colaboradores.

Etapas:

Sistema de evaluaciones
a) Implementación de la evaluación
b) Propuestas de mejora en el desempeño

Evaluaciones:

- Evaluación quincenal

- Evaluación Bi mensual

- Evaluación anual

Sistema de evaluaciones.-

La evaluación contempla la evaluación del supervisor a los colaboradores, y la presentación de resultados al trabajador, y la firma de ambas partes. La evaluación semanal preparara al equipo en la evaluación mensual, para incentivar la mejor prestación de los servicios en base al "Que" y al "como" se cumplen las funciones. 
Evaluación Bi mensual, contempla los siguientes factores de evaluación:

a) Cantidad de trabajo realizado: Se refiere al cumplimiento en el período de las tareas que han sido asignadas al trabajador, en su aspecto cuantitativo y en correspondencia con el régimen laboral en que está abarcado.

b) Calidad del trabajo realizado: Se refiere al cumplimiento en el período de las tareas que han sido asignadas al trabajador, en su aspecto cualitativo, tomando en consideración quejas de clientes internos y externos; productos rechazados por falta de calidad; incumplimiento en tiempo de las tareas asignadas y otros determinados a partir de las tareas específicas que cumple cada trabajador.

c) Eficiencia: Se refiere a la eficiencia con que se ejecutaron las tareas asignadas al trabajador, incluyendo en este caso el gasto y el ahorro de los recursos materiales utilizados.

d) Productividad: Se refiere a la productividad con que el trabajador ejecutó las tareas asignadas, incluyendo en este caso el uso adecuado del tiempo para la ejecución de estas.

e) Disciplina laboral: Se refiere a la asistencia y puntualidad en el trabajo durante el período evaluado y se incluye en su análisis, el tener aplicadas o no en dicho período medidas disciplinarias por violación de una o varias de las obligaciones o por inobservancia de una o varias de las prohibiciones establecidas en el Reglamento Disciplinario Interno de la entidad laboral y refleja la conducta y comportamiento del trabajador.

f) Cuidado de la propiedad social: Se refiere al cuidado que el trabajador ha demostrado en el periodo evaluado, sobre los medios y los recursos de su organización y de los medios que utiliza para desarrollar su trabajo. 
Implementación de la evaluación.

a) Muy Bien, equivalente a 5 puntos.

b) Bien, equivalente a 4 puntos.

c) Regular, equivalente a 3 puntos.

d) Mal, equivalente a 2 puntos.

La calificación final de la evaluación mensual se da al sumar los puntos obtenidos en cada criterio Muy bueno, bueno, regular y mal. Según los rangos de valores siguientes:

a) Mal, de 12 a 17

b) Regular, de 18 a 23

c) Bien, de 24 a 26

d) Muy Bien, de 27 a 30

Esta calificación final de la evaluación mensual del desempeño en ningún caso puede reconocerse como muy buena o buena, si en alguno de los indicadores evaluados el trabajador obtiene calificación de mal o regular en el período, es decir que es excluyente.

Propuestas de mejora en el desempeño

En esta evaluación, el evaluador debe expresar los fundamentos a las evaluaciones otorgadas y cualquier aspecto de interés que considere importante. Por su parte el avaluado podrá incluir sus avances, resultados o desacuerdos con la evaluación otorgada. 


\section{EJEMPLO DE EVALUACIÓN}

\section{Cantidad de trabajo:}

- Cumple con el contenido de trabajo asignado, sin que otros tengan que asumir sus responsabilidades.

- Participa, ayuda y coopera con sus compañeros.

- Trabaja en equipo.

\section{Calidad de trabajo:}

- Tiene facilidad para comprender y realizar las tareas.

- Domina su trabajo y es creativo es su realización. Presenta nuevas opciones.

- Realiza su trabajo en el tiempo requerido demostrando conocimiento y experiencia.

- Busca siempre una mejora continua para realizar su trabajo.

\section{Eficiencia:}

- Organiza y desarrolla con rapidez su trabajo.

- Apoya a sus compañeros y al mismo tiempo los capacita cuando ellos lo requieren, intercambia puntos de vista y propone alternativas de mejoras.

- Evitar costos de no calidad. Manejo de quejas, resuelve problemas. 


\section{Productividad:}

- No pierde el tiempo solo o con sus compañeros, realizando otras actividades ajenas a su trabajo.

- Se encuentra siempre en su área de trabajo.

- No utiliza de forma inadecuada el teléfono, no es llamado frecuentemente por personas externas.

\section{Disciplina laboral:}

- No hay que llamarle la atención por incumplimientos o incidencias.

- Es puntual en su horario de trabajo y no tiene ausencias injustificadas.

- Buena apariencia personal.

- Cumple con los estándares de presentación personal.

- Es puntual en las juntas o reuniones de trabajo.

- Asiste puntualmente a los cursos de capacitación.

- Actúa con honestidad dentro de la empresa y pone en práctica nuestros valores.

- Crea un ambiente laboral cómodo para sus compañeros.

\section{Política de seguridad y salud en el trabajo}

De acuerdo con lo estipulado se capacita en las diferencias de situación de riesgo y accidente.

El uso de indumentaria de trabajo de riesgo es obligatorio, sobre todo para el área de Housekeeping, mantenimiento y cocina. 


\section{Capitulo VII: Plan de Marketing}

\subsection{Estrategia de Segmentación}

\subsubsection{Público objetivo Turistas.}

Según el análisis desarrollado en el estudio de mercado y en base a los resultados obtenidos, el público objetivo se determina en base a las variables demográficas, psicográficas y de comportamiento, variables alternativas de segmentación según Fred R. David. ${ }^{9}$

a. Demográfica

- Edad: De 30 a 50 años.

- Sexo: Ambos

- Nacionalidad: Todas, principalmente Estados Unidos y Perú.

b. Psicográfica:

- Clase social: Clase media alta.

- Personalidad: Turistas aventureros, sociables, preocupados por la ecología y medio ambiente, y con interés por conocer historia del Cusco y gente de diversas culturas.

c. De comportamiento:

- Estado de disposición: Interesado en una experiencia de turismo vivencial.

- Actitud hacia el producto: Entusiasta.

- Beneficios buscados: Turistas que valoren la ecología.

\footnotetext{
${ }^{9}$ David Fred R. Conceptos de Administración Estratégica (9na Edición). México: Pearson Educación. 2003. P. 279
} 
Por lo tanto, el grupo objetivo desarrollado son los turistas nacionales y extranjeros, de ambos sexos entre 30 y 50 años, de clase social media alta, aventureros, sociables, entusiastas que viajan regularmente dentro de su país (peruanos) y fuera de éste (Estados Unidos) que valoren la ecología y se encuentren interesados en una experiencia de turismo vivencial, así como conocer la historia del Cusco y gente de diversas culturas.

\subsubsection{Público objetivo Operadores de Turismo}

Los operadores de turismo fueron analizados en el estudio de mercado como un cliente objetivo, sin embargo, a partir del presente capítulo serán considerados como socios estratégicos para el Ecolodge “Kachi Raqay” debido a que mediante ellos se captará el 70\% de clientes. La segmentación se determina en base a las siguientes variables:

a. Geográfica:

- Región: Cusco

b. De comportamiento:

- Beneficios buscados: Calidad, servicio, incrementar su cartera de clientes.

- Condición del usuario: Usuario potencial de servicios de turismo vivencial.

- Frecuencia de uso: Usuario moderado de servicios de turismo vivencial.

- Estado de disposición: Interesado en vender experiencia de turismo vivencial.

Por lo tanto, los operadores de turismo seleccionados como socios estratégicos son aquellos ubicados en el Cusco que busquen calidad y servicio, que sean usuarios potenciales de los servicios de turismo vivencial, es decir que se encuentren preparados operativamente 
para vender la experiencia vivencial de la empresa. Del total de operadores en Cusco se seleccionará aquellos que venden servicios de turismo y transporte al Valle Sagrado, ya que no pueden ser segmentados con la información disponible en Mincetur.

\subsection{Estrategia de posicionamiento}

La estrategia de posicionamiento es la de atributos y está dirigida al nicho de mercado que ha sido definido en la segmentación: mercado de turistas y mercado de operadores de turismo. Los atributos para posicionar en ambos mercados objetivo son los siguientes:

- Servicios de alojamiento bajo los estándares del manual de buenas prácticas de gestión de servicios para establecimientos de hospedaje del Mincetur (Ministerio de Comercio exterior y Turismo)

- Experiencia vivencial con los pobladores de la región participando en sus actividades diarias: Compras en el mercado local, elaboración de alimentos en base a la cocina tradicional de Maras.

- Infraestructura rústica a base de piedra y madera principalmente.

Los beneficios que se reforzarán en la estrategia de posicionamiento son:

a. Turistas:

- Satisfacción a las necesidades de experiencias de aventura con actividades al aire libre y ecología.

- Satisfacción de vivir una experiencia vivencial.

- Mayor conocimiento sobre la historia del Cusco y gente de diversas culturas. 
b. Operadores de turismo:

- Incrementar su cartera de proveedores con un producto de alta calidad que cumple con los estándares que promueve el Mincetur, y bajo el concepto de turismo vivencial.

\subsection{Mix de Marketing}

Kotler en su libro Fundamentos de Marketing, explica las consideraciones a tomar en cuenta según el tipo de producto o servicio que una empresa ofrece para crear valor para el cliente. Estas consideraciones son la base para la determinación de las 4ps del marketing mix del presente proyecto: Producto, precio, plaza y promoción.

Sin embargo, siguiendo los conceptos del marketing mix extendido, establecido por Booms and Bitner en el año 1981, se determinarán también las 3Ps generadas por dichos autores ya que se adaptan de mejor manera a la industria de servicios. Estas 3p son: Personas, procesos y evidencia física.

\subsubsection{Servicio}

Según Kotler, 'Los encargados de la planeación de los productos deben considerar los productos y servicios en tres niveles: Valor fundamental del producto, producto real y producto aumentado' (Kotler \& Armstrong, 2012, pág. 225). A continuación los tres niveles del Ecolodge "Kachi Raqay".

a. Valor fundamental del servicio: Es la necesidad básica que satisface el cliente con el servicio obtenido. En este nivel los clientes del Ecolodge "Kachi Raqay", satisfacen la 
necesidad de seguridad física y la necesidad fisiológica de descanso porque se hospedarán en habitaciones seguras y en un ambiente que invita a la relajación. También las necesidades de autorrealización, ego y pertenencia, al visitar un hotel que le proporcione una experiencia de viaje diferente.

b. Servicio Real: Constituye el servicio tal cual cómo se ofrecerá a los clientes lo cual involucra el número de habitaciones, y los servicios propios de un hotel como, recepción, sala de estar, restaurante/bar, security box y servicios higiénicos.

Habitaciones en Ecolodge "Kachi Raqay”: Contará con 12 habitaciones estándar, que pueden ser habitación simple, doble o matrimonial. Todas las habitaciones cuentan con los siguientes servicios:

- Calefacción.

- Baño privado con agua caliente.

- Servicio de wifi.

- Minibar.

- Room service.

Habitación estándar Matrimonial/Simple: Contará con una cama King, iluminación cálida, decorada con telares diseñados en Cusco, cortinas blackout y paredes en colores tierra que complementan el concepto de cultura andina en el diseño y la arquitectura propia del lugar en madera y piedra. Baño con aplicaciones en piedra. 


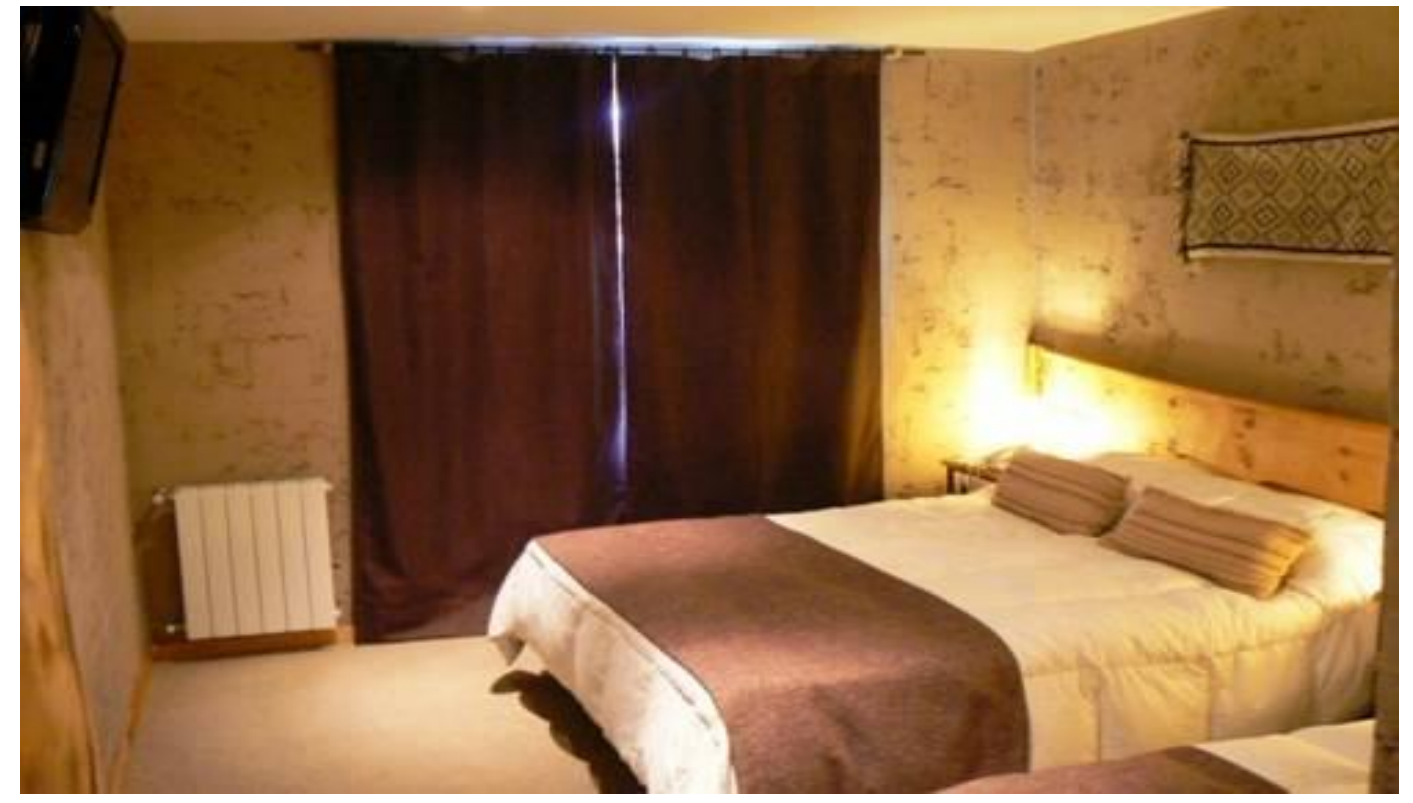

Figura 30. Tipo de habitaciones Ecolodge "Kachi Raqay".

Habitación estándar doble: Contará con dos camas de plaza y media, iluminación cálida, decorada con telares diseñados en Cusco, cortinas blackout y paredes en colores tierra que complementan el concepto de cultura andina en el diseño y la arquitectura propia del lugar en madera y piedra. Colores cálidos en tonos tierra. Baño con aplicaciones en piedra.

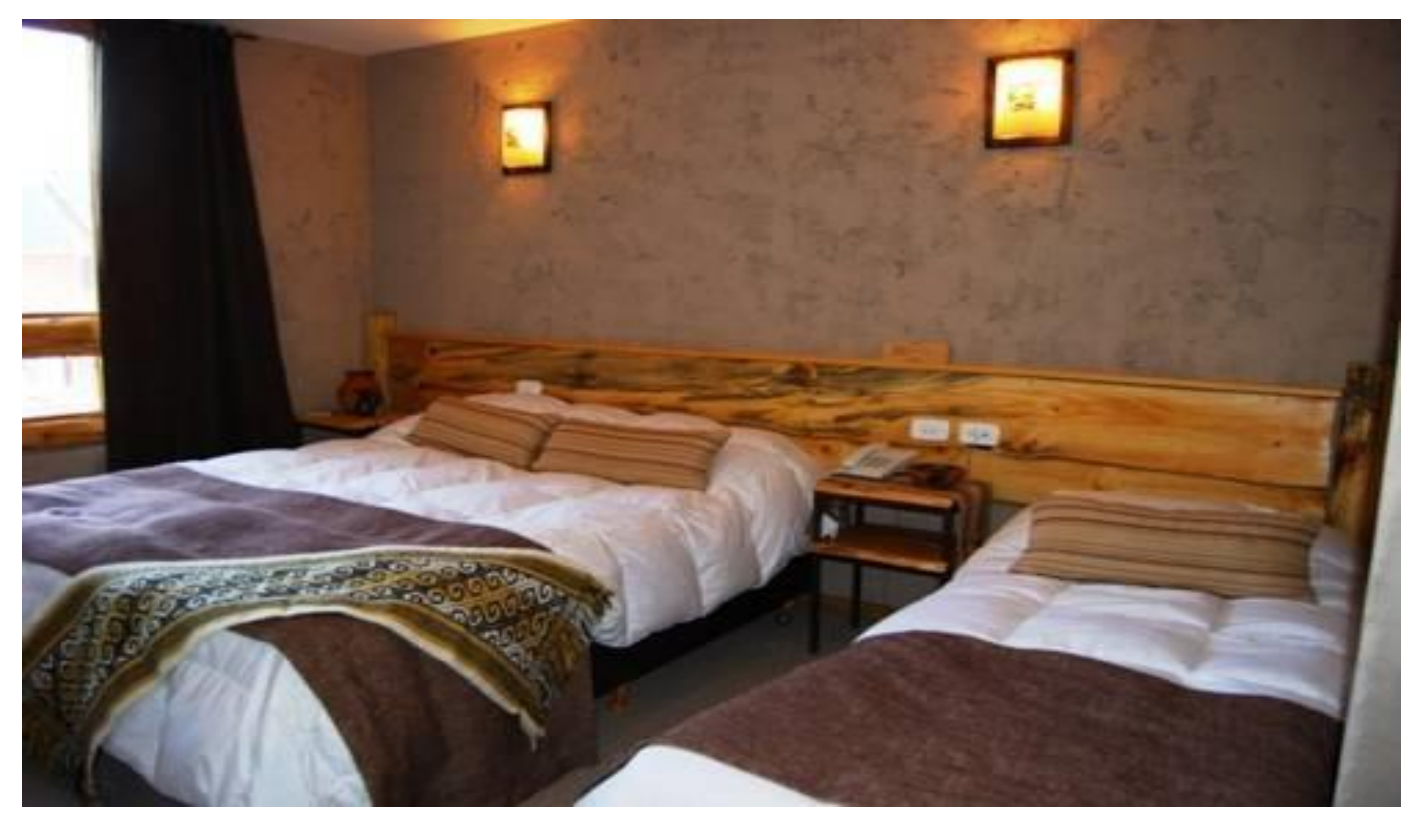

Figura 31. Tipo de habitaciones Ecolodge "Kachi Raqay”. Habitación Estándar Doble 


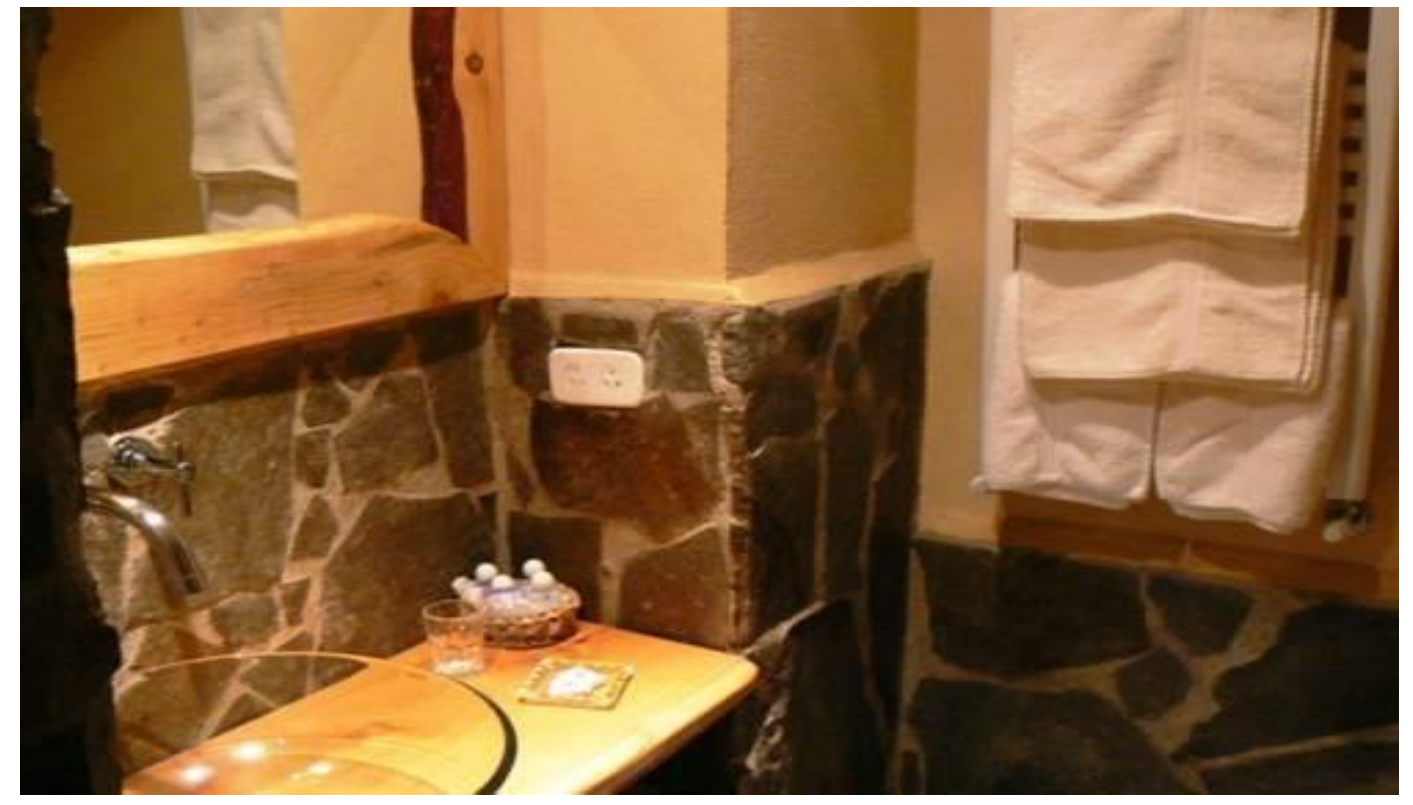

Figura 32. Baño habitación Estándar

\section{Recepción:}

Materiales que recuerdan la construcción en piedra en Cusco, colores tierra acorde a la zona y decoración con telares propios del lugar.

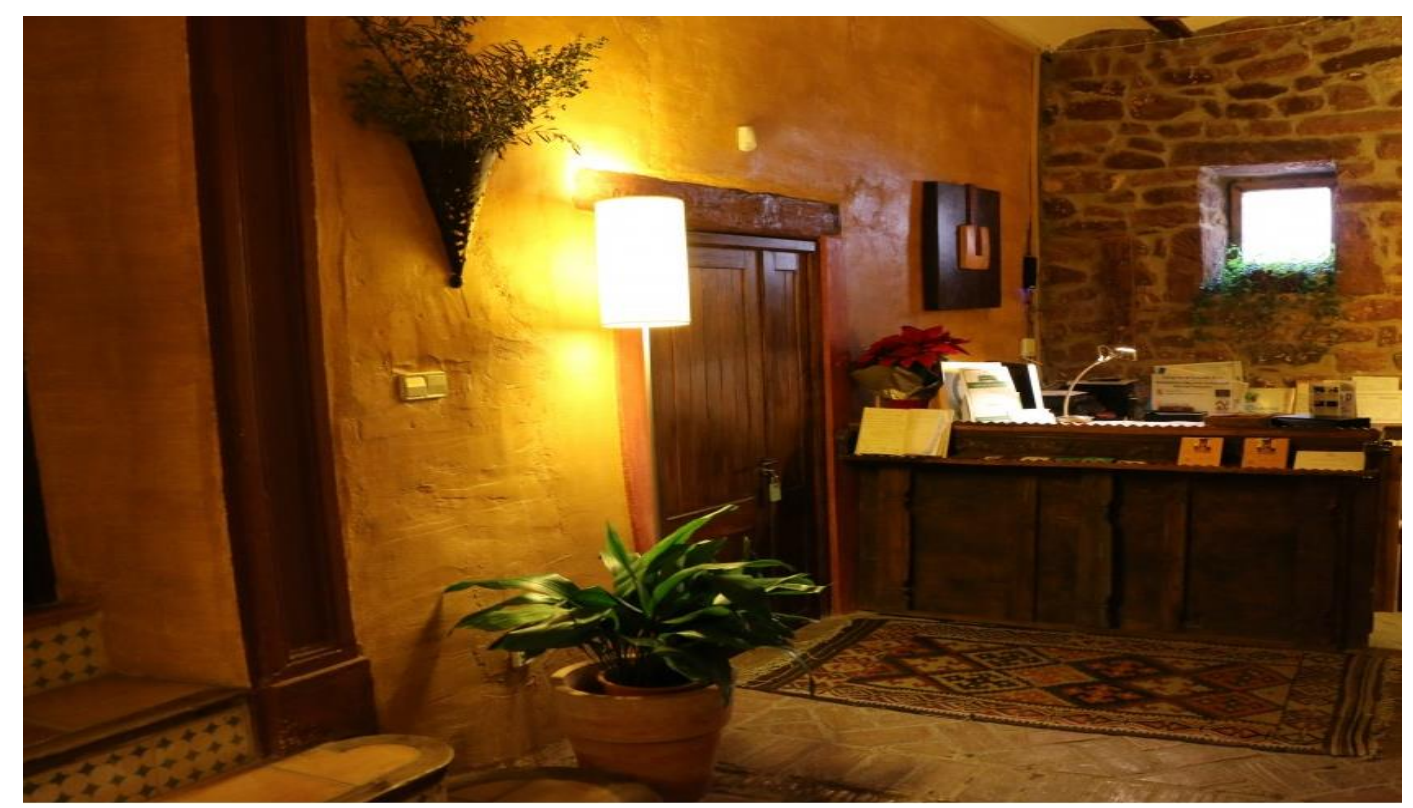

Figura 33. Recepción 


\section{Sala de Estar:}

Se encuentra ubicada de tal forma que permite la entrada de luz natural y refleja la armonía de colores y diseños propios de la zona. Decoración con telares diseñados en Cusco, que complementan el concepto de cultura andina en el diseño y la arquitectura propia del lugar en madera y piedra. Colores cálidos en tonos tierra.

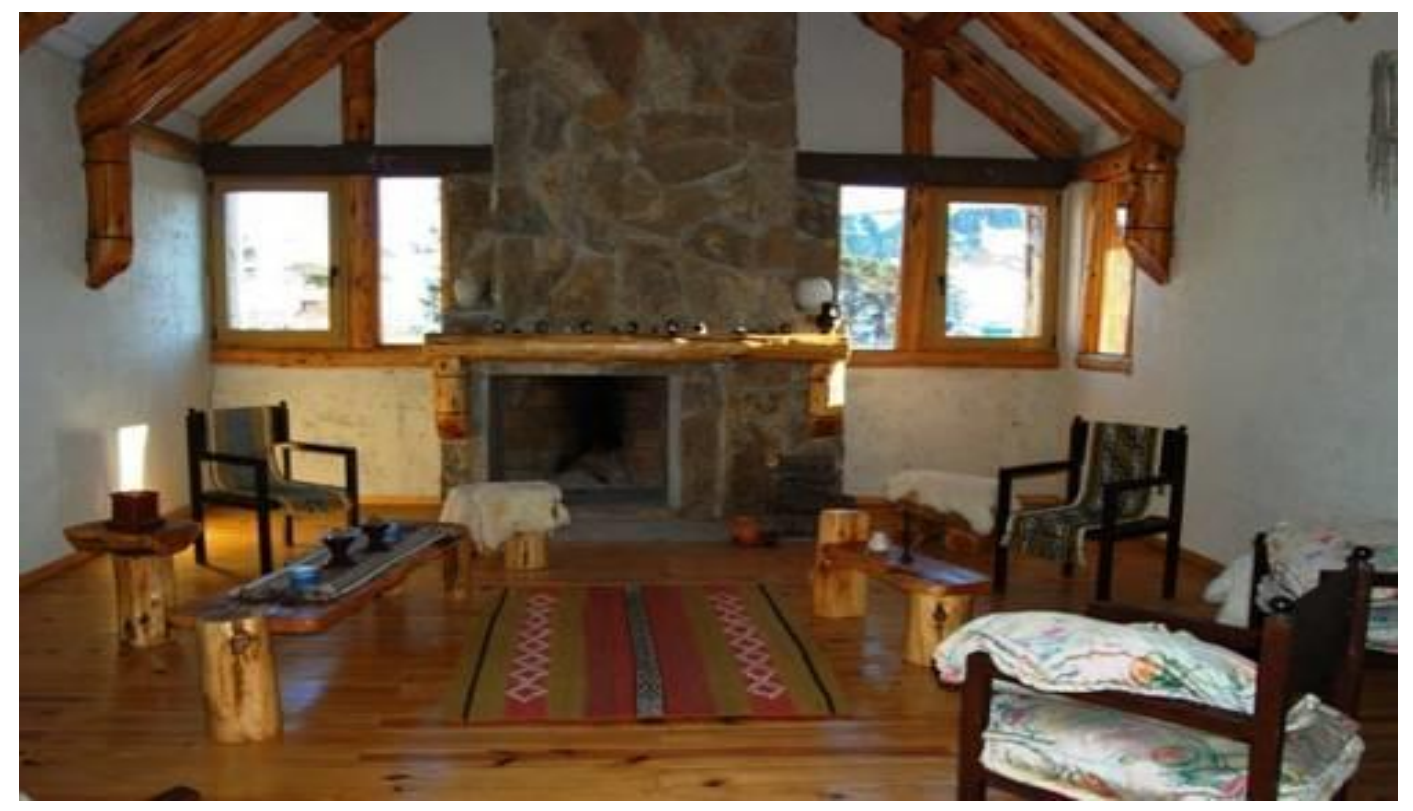

\section{Restaurante/Bar:}

Arquitectura en piedra, manteles hechos en base a telares propios del Cusco, que complementan el concepto de cultura andina en el diseño y la arquitectura propia del lugar. Colores cálidos en tonos tierra. Es comunitario para que los huéspedes compartan no sólo la mesa sino la cultura gastronómica de la zona, experiencias y felicidad sintiendo el ambiente acogedor de una comida en familia. 

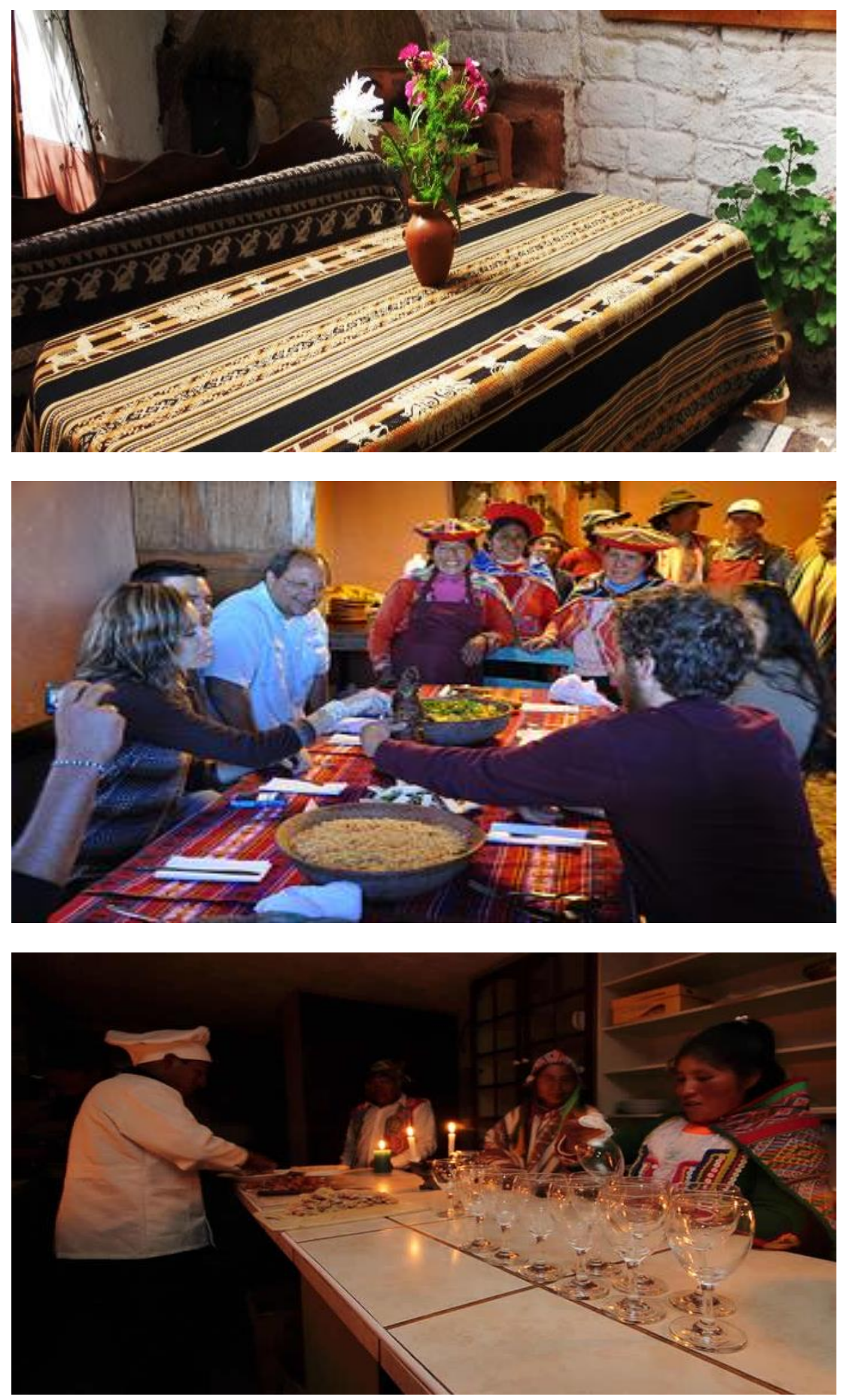

Figura 34. Restaurant/Bar 


\section{Servicios Higiénicos:}

Ubicado a un lado de la recepción, decorado en piedra y piso de colores cálidos.

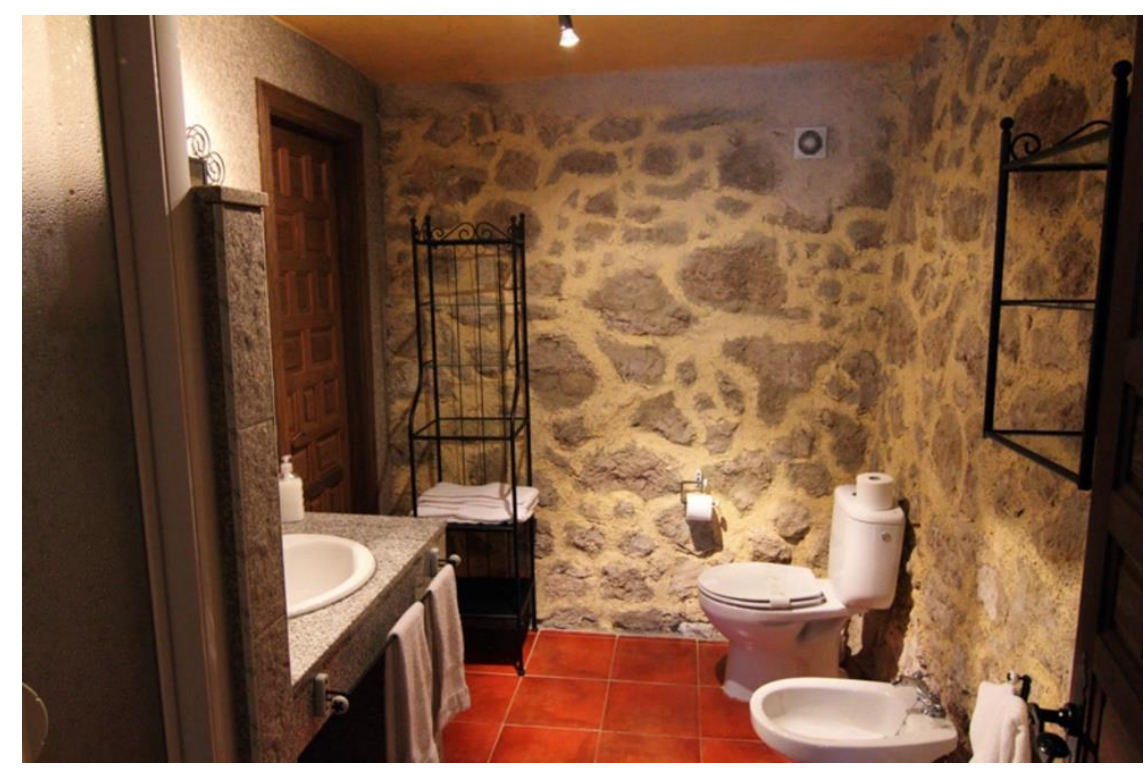

Figura 35. Servicios higiénicos

\subsubsection{Branding:}

Además de las características del producto, se debe poner especial cuidado en el diseño de la marca, por lo tanto, se detalla a continuación la creación del branding del Ecolodge "Kachi Raqay".

- Creación de Imagotipo: Se dice cuando en la representación visual de una marca existe un elemento pictográfico junto al texto que puede ser abstracto o no. Entonces nos encontramos con un elemento que podemos leer y otro que no ${ }^{10}$.

\footnotetext{
${ }^{10}$ Descripción diseño Imagotipo. Empresa Blue Design.
} 


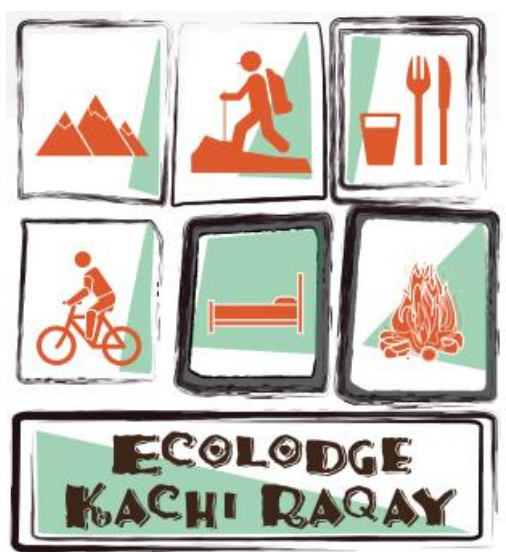

Figura 36. branding

- Descripción del Imagotipo FORMAS: El presente logo tiene como objetivo reflejar la arquitectura de las Salineras de Maras, que se ubican en la ladera del cerro en forma de terrazas o andenes. Todo esto representado en el presente imagotipo con formas entre cuadradas y rectangulares de manera irregular y bordes asimétricos poco definidos, otorgando un concepto rustico e imperfecto que denota su antigüedad y singularidad.

Representado por 3 niveles de andenes de sal los cuales contienen en orden descendente 2 hileras de iconos en figuras siluetadas de las diferentes actividades que se llevan a cabo en el lodge y en la ultima una sola figura rectangular con el nombre Ecolodge "Kachi Raqay".
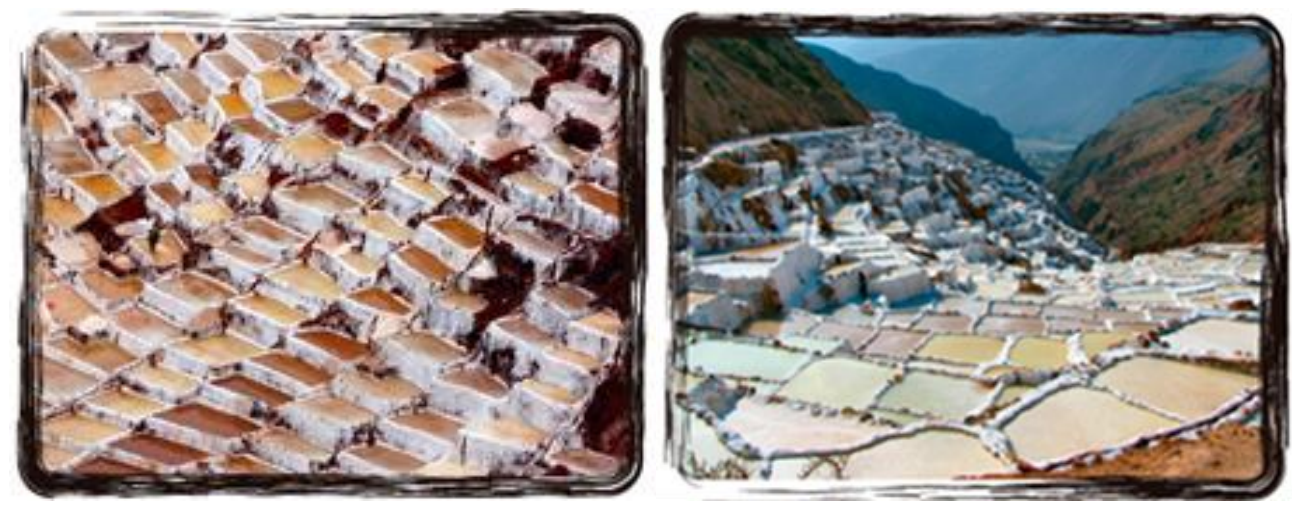

Figura 37. Formas del logotipo 
- Descripción de los Colores

Los colores del logo están representados por colores que van desde tonos alegres, aventureros hasta relajados y obscuros que transmiten la relación con la naturaleza.

○ Naranja: en los iconos siluetados; simboliza el entusiasmo y exaltación en relación con las actividades que se pueden realizar en el lodge. Utilizado en pequeñas extensiones es más funcional para el contraste con los demás elementos. Este color ayuda a mejorar la visibilidad de los elementos, tiene la característica de que es un color útil para ser visto a distancia y está pensado para ofrecer un contraste óptimo respecto al color existente en la naturaleza.

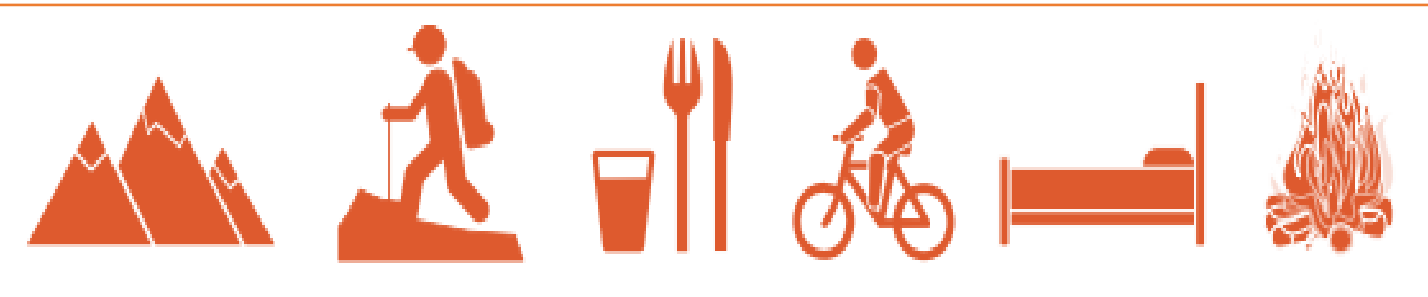

Figura 38. Íconos naranja

- Verde: Color de gran equilibrio, en este caso en un tono claro para dar contraste a los iconos naranjas. Transmitiendo el reposo y la calma que se busca en un lugar en medio de la naturaleza. Utilizado como apoyo para los iconos de las actividades sugiere humedad, frescura y vegetación, simboliza la naturaleza y crecimiento. Es un color fácil para el ojo humano y actualmente uno de los más populares en las decoraciones turísticas. 


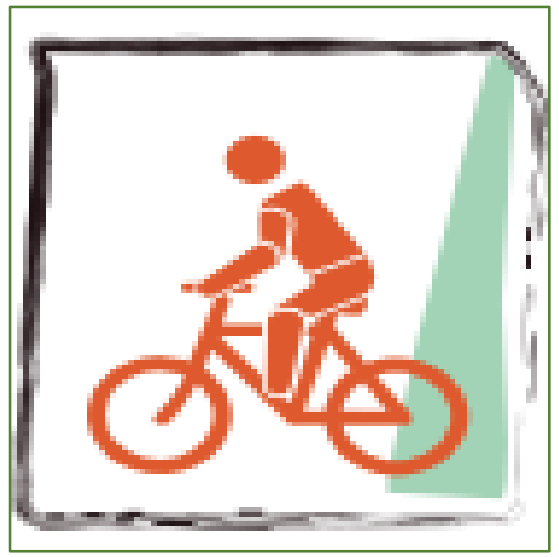

Figura 39. Ícono verde

- Café Oscuro: En los bordes de las terrazas de sal representan la fuerza con la que se desea acentuar el concepto del atractivo turístico como uno de los más importantes del lugar. El color oscuro ayuda al contraste con los demás elementos y hace resaltar la idea original. Es un color confortable identificado con la tierra que da la impresión de gravedad y equilibrio.

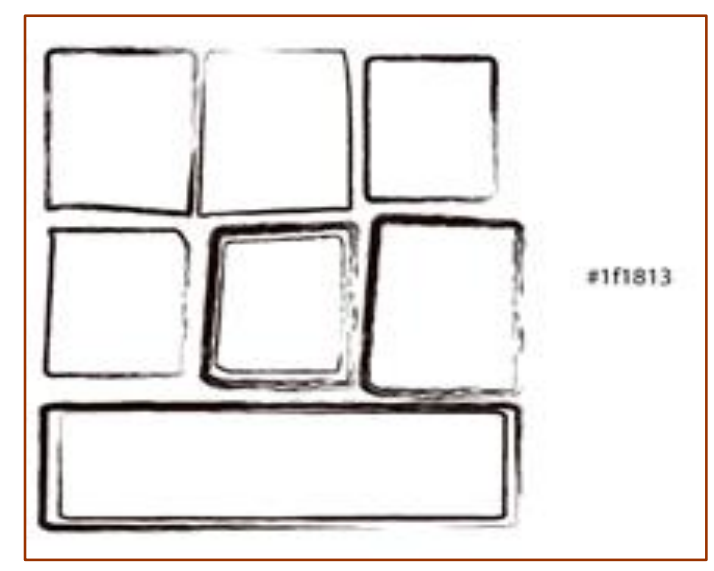

Figura 40. Ícono café oscuro

- Descripción de Fuente Tipográfica

Tipo de Fuente: Taco Modern (modificada) 
Este tipo de fuente fue elegida por los rasgos rústicos que la caracteriza. Perteneciente a las fuentes tipográficas de exhibición, por lo que su característica principal es provocar mayor atracción que las regulares.

Por sus rasgos particulares esta tipografía es utilizada única y exclusivamente, como en este caso, para un título o nombre en mayúsculas.

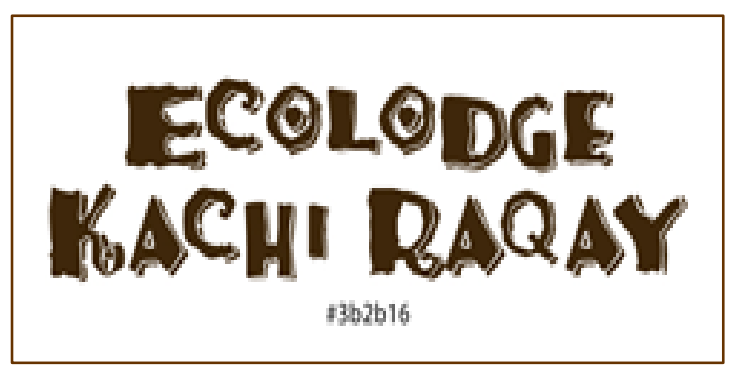

Figura 41. Tipografía

- Significado etimológico de Kachi Raqay: Deriva de dos palabras en quechua: Kachi que significa sal, y es en alusión a las salineras del poblado de Maras y Raqay, que significa galpón. Galpón de Sal es el nombre del albergue con el que se quiere dar a conocer la belleza de las Salineras de Maras en el poblado de Moray en Cusco, las cuales se encuentran a pocos kilómetros de distancia de donde estaría ubicado el albergue.

○ De albergue a ecolodge: El nombre de albergue "Hacienda Kachi Raqay" se convierte entonces en Ecolodge "Kachi Raqay", debido a que según el estudio de mercado, el 56.5\% de los turistas encuestados reconocen con mayor facilidad el término lodge y lo relacionan con las características que tendrá Kachi Raqay como alojamiento rústico y alejado de la ciudad. 
c. Servicio aumentado: Son los beneficios adicionales no esperados por el cliente. El Ecolodge "Kachi Raqay” creará valor para el cliente a través de:

- Diseño e infraestructura que promueve la integración con los paisajes naturales de Maras.

- Participación en actividades locales (Ganadería y Agricultura)

- Participación en festividades locales.

- Restaurant de comida tradicional de la zona.

- Visitas a mercados de abastos.

- Exposición de artesanías.

- Habitación con oxígeno.

- Senderismo.

- Gastronomía de la zona.

- Traslados y tickets para los atractivos turísticos.

- Paquetes especialmente diseñados para el Ecolodge "Kachi Raqay”.

- Paquetes de valor: El Ecolodge “Kachi Raqay” ofrecerá 3 paquetes especialmente creados con la finalidad de recreación, relajación y aventura de sus clientes.
a. Full day
b. Aventura en Maras
c. Experiencia Kachi Raqay

\section{Paquete Full day}

Llegada al ecolodge.

Desayuno con pan tradicional preparado en Ecolodge.

Salida a las 9am hacia el poblado de Chincheros, pueblo rodeado de hermosos paisajes y campos de cultivo. Visita a la iglesia colonial y el mercado. 
Visita a las salineras de Maras, compuesto de unos 3000 pozos de aproximadamente $5 \mathrm{~m} 2$ de donde se extrae la sal. Cosecha de sal.

Luego visita al grupo arqueológico de Moray, compuesto por terrazas o andenes circulares de distintos tamaños los cuales fueron utilizados como centro experimental agrícola por los Incas.

Regreso al ecolodge.

Almuerzo típico de la zona, donde se compartirá la preparación del mismo. Almuerzo en comunidad con los huéspedes y pobladores.

Regreso al Cusco.

\section{Paquete Aventura en Maras (2 días 1 noche)}

Primer día

Llegada al ecolodge.

Desayuno con pan tradicional preparado en Ecolodge.

Aclimatamiento en sala de estar del ecolodge, disfrutando de maravillosos relatos andinos frente a la chimenea.

Paseo en cuatrimoto.

Almuerzo típico de la zona, donde se compartirá la preparación del mismo y será en comunidad con los huéspedes y pobladores.

Fogata al aire libre.

Baño energético con sales de Maras.

Descanso 


\section{Segundo día}

- Desayuno con pan tradicional preparado en Ecolodge.

Salida a las 9am hacia el grupo arqueológico de Moray, compuesto por terrazas o andenes circulares de distintos tamaños, aqui empieza la caminata hacia una pequeña villa colonial de Maras.

Almuerzo picnic con productos tipicos de la zona.

Regreso de la caminata para llegar a las Salineras de Maras, formado por más de 3000 pozos de aproximadamente $5 \mathrm{~m}^{2}$ de donde se extrae la sal.

Caminata de 45 minutos al río Urubamba.

Regreso al Cusco.

\section{Paquete Experiencia Kachi Raqay (3 días y 2 noches)}

Primer día

Llegada al ecolodge.

Desayuno con pan tradicional preparado en Ecolodge.

Aclimatamiento en sala de estar del ecolodge, disfrutando de maravillosos relatos andinos frente a la chimenea.

Paseo en cuatrimoto.

Almuerzo típico de la zona, donde se compartirá la preparación del mismo y será en comunidad con los huéspedes y pobladores.

Fogata al aire libre.

Baño energético con sales de Maras.

Descanso

Segundo día

Desayuno con pan tradicional preparado en Ecolodge. 
Salida a las 9am hacia el grupo arqueológico de Moray, compuesto por terrazas o andenes circulares de distintos tamaños, aqui empieza la caminata hacia una pequeña villa colonial de Maras.

Almuerzo picnic con productos tipicos de la zona.

Regreso de la caminata para llegar a las Salineras de Maras, formado por más de 3000 pozos de aproximadamente $5 \mathrm{~m} 2$ de donde se extrae la sal.

Caminata de 45 minutos al río Urubamba.

Regreso al ecolodge.

Preparación de cena donde se aprenderá técnicas milenarias de gastronomía y donde dejará todo listo para la ceremonia de agradecimiento a la tierra del día siguiente. Cena en comunidad.

Descanso.

\section{Tercer día}

Saludo al amanecer, clases de yoga y desayuno orgánico en base a batidos de frutas típicas de la zona.

Salida con los pobladores para alimentar a los animales de la zona y aprender sobre sus cuidados.

Luego visita al grupo arqueológico de Moray, compuesto por terrazas o andenes circulares de distintos tamaños los cuales fueron utilizados como centro experimental agrícola por los Incas.

Regreso al ecolodge.

Almuerzo típico de la zona, donde se compartirá la preparación del mismo. Almuerzo en comunidad con los huéspedes y pobladores.

Ceremonia de agadecimiento a la tierra (pachamama) 
Regreso a Cusco.

\subsubsection{Precio}

La estrategia a desarrollar es la de estrategia por capas o descreme que consiste en colocar un nuevo producto o servicio a un precio relativamente alto para lograr mayores ingresos capa por capa de los segmentos dispuestos a pagar un precio muy alto ${ }^{11}$.

\subsubsection{Turistas}

Para determinar el precio de los paquetes que ofrece el Ecolodge Kachi Raqay, es necesario evaluar los resultados obtenidos en la encuesta (capítulo 3):

a. Gasto diario por hospedaje: Más del $50 \%$ de encuestados gastan en hospedaje entre 80 y 200 dólares por noche.

b. Gasto diario por alimentación: El 91\% de encuestados gastan en alimentación entre 40 y 120 dólares por día.

c. Gasto diario por actividades y excursiones: El 45\% de encuestados gastan en actividades y excursiones entre 80 y 200 dólares por día.

\footnotetext{
${ }^{11}$ Estrategias para la fijación de precios de nuevos productos(Fecha de consulta: 18 de febrero de 2017) disponible en https://portilloa.wordpress.com/2011/11/20/estrategias-para-la-fijacion-de-precios-de-nuevosproductos/
} 
Tabla 82.

Disposición a pagar por los turistas por un día de actividades de turismo y alimentación en Cusco (Expresada en dólares americanos)

\begin{tabular}{lccccc}
\hline \multicolumn{1}{c}{ Concepto } & $\begin{array}{c}\text { Límite } \\
\text { inferior }\end{array}$ & $\begin{array}{c}\text { Límite } \\
\text { superior }\end{array}$ & Promedio & $\begin{array}{c}\text { Porcentaje de } \\
\text { turistas dispuestos } \\
\text { a pagar ese rango }\end{array}$ & $\begin{array}{c}\text { Promedio } \\
\text { ponderado }\end{array}$ \\
\hline Alimentación & 40 & 120 & 80 & $91 \%$ & 73 \\
Actividades y excursiones & 80 & 200 & 140 & $45 \%$ & 63 \\
Dólares dispuestos a pagar & & & & & 136 \\
\hline
\end{tabular}

Nota: Estudio de mercado de este proyecto. Elaboración propia

Tabla 83.

Disposición a pagar por los turistas por una noche de alojamiento en Cusco. (Expresada en dólares americanos)

$\begin{array}{ccccc}\text { Concepto } & \begin{array}{c}\text { Límite } \\ \text { inferior }\end{array} & \begin{array}{c}\text { Límite } \\ \text { superior }\end{array} & \begin{array}{c}\text { Promedio turistas } \\ \text { dispuestos a pagar } \\ \text { ese rango }\end{array} & \begin{array}{c}\text { Promedio } \\ \text { ponderado }\end{array}\end{array}$

\begin{tabular}{llllll}
\hline $\begin{array}{l}\text { Hospedaje (1 noche) } \\
\text { Dólares dispuestos a pagar: }\end{array}$ & 80 & 200 & 140 & $50 \%$ & 70 \\
\hline
\end{tabular}

Nota: Estudio de mercado de este proyecto. Elaboración propia

El ecolodge ofrecerá un precio todo incluido por hospedaje, alimentación y

actividades. En base a los resultados obtenidos, los turistas estarían dispuestos a pagar los siguientes precios por paquete:

Tabla 84.

Disposición de los turistas a pagar por paquete (Expresada en dólares americanos)

\begin{tabular}{llc}
\hline \multicolumn{1}{c}{ Paquete } & \multicolumn{1}{c}{ Incluye } & $\begin{array}{c}\text { Dólares dispuestos a } \\
\text { pagar por paquete }\end{array}$ \\
\hline $\begin{array}{l}\text { Full day } \\
\begin{array}{l}\text { Aventura en Maras } \\
(2 \mathrm{~d} / \mathrm{n})\end{array}\end{array}$ & $\begin{array}{l}\text { Un día de actividades y alimentación } \\
\text { Dos días de actividades y alimentación } \\
\text { Una noche de hospedaje }\end{array}$ & 342 \\
$\begin{array}{l}\text { Experiencia Kachi } \\
\text { Raqay }(3 \mathrm{~d} / 2 \mathrm{n})\end{array}$ & $\begin{array}{l}\text { Tres días de actividades y } \\
\text { alimentación } \\
\text { Dos noche de hospedaje }\end{array}$ & 477 \\
\hline
\end{tabular}


Sin embargo, también debe considerarse el precio de mercado actual para paquetes similares:

\begin{tabular}{|c|c|c|c|}
\hline \multicolumn{4}{|c|}{ Paquetes de 1 día a Maras y/o Moray } \\
\hline Página web & Actividades & US\$ & $\mathrm{S} / \mathrm{s}$ \\
\hline \multirow{7}{*}{$\begin{array}{l}\text { https://www.getyourg } \\
\text { uide.com/ }\end{array}$} & Recojo del hotel en Cusco & \multirow{7}{*}{130} & \multirow{7}{*}{424} \\
\hline & Transporte privado & & \\
\hline & Guía en ingles y español & & \\
\hline & Picnic & & \\
\hline & Tickets de ingreso a Maras y Moray & & \\
\hline & Retorno a su hotel en Cusco & & \\
\hline & Recojo del hotel. & & \\
\hline https://www.machupi & Transporte turístico. & \multirow{3}{*}{120} & \multirow{2}{*}{391} \\
\hline \multirow[t]{6}{*}{ cchuviajesperu.com/ } & Servicio de guía oficial en Ingles y Español. & & \\
\hline & Tickets de ingreso. & & \\
\hline & Recojo del hotel. & \multirow{10}{*}{120} & \multirow{10}{*}{391} \\
\hline & $\begin{array}{l}\text { Transporte privado ida y vuelta para los pasajeros, } \\
\text { (HOTEL/ Km.39-HOTEL- CUSCO) }\end{array}$ & & \\
\hline & Combustible. & & \\
\hline & Guía de aventura. & & \\
\hline https://www.machupi & $\begin{array}{l}\text { Cuatrimotos personales (cada una con espejos } \\
\text { retrovisores) }\end{array}$ & & \\
\hline cchuviajesperu.com & Equipo básico (casco) guantes. & & \\
\hline & Intercomunicadores (radios). & & \\
\hline & Clases de manejo si fuera necesario. & & \\
\hline & Botiquín de primeros auxilios & & \\
\hline & $\begin{array}{l}\text { Ingresos para los lugares de atracción turística } \\
\text { (Moray y Salineras). }\end{array}$ & & \\
\hline \multicolumn{2}{|c|}{ Precio promedio por paquete full day } & 123 & 402 \\
\hline
\end{tabular}




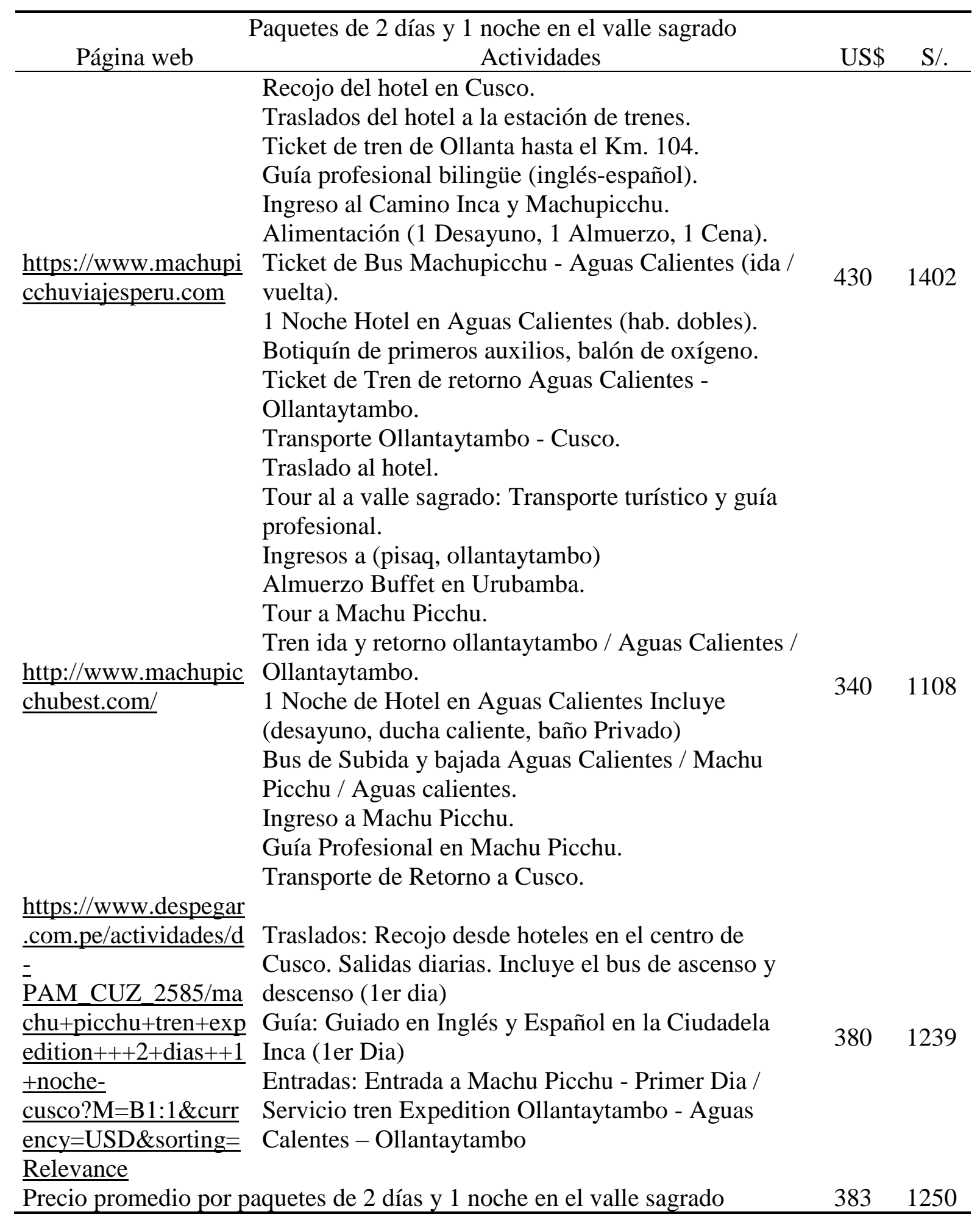




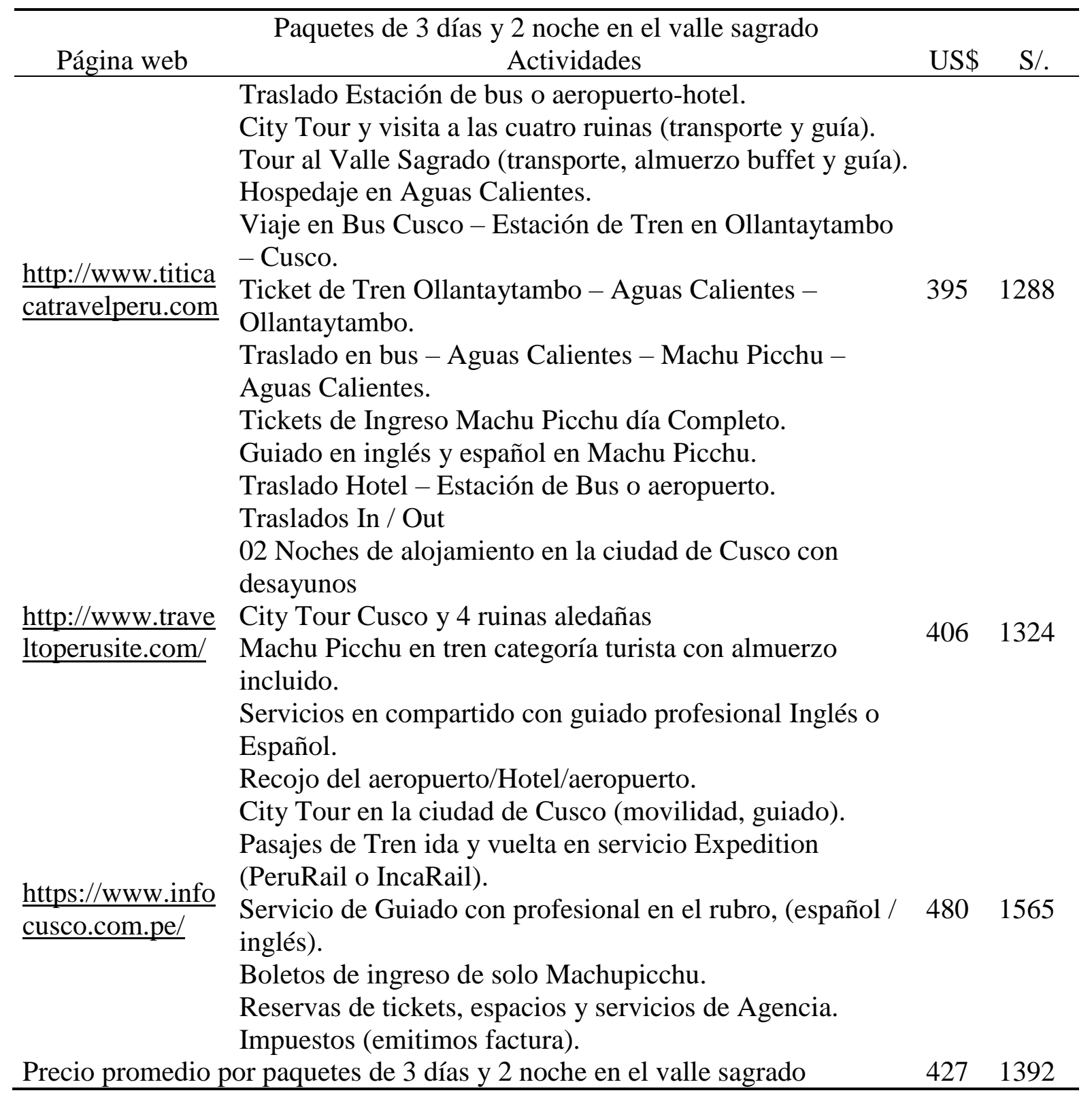

Dentro del rubro hotelero se manejan tres tipos de tarifas: precio "Rack", precio "Best Available Rate", precio “Corporativo o Confidencial”. Primero se establecen los precios basados en acomodación doble, es decir para cuartos dobles o matrimoniales, y en base a estos se calcula la tarifa para una sola persona.

Precio Rack es el más alto y el que está publicado oficialmente en la recepción del hotel y en la página web. Este precio se cobra en temporada alta. 
Para determinar el precio rack, se establece un promedio entre lo que están dispuestos a pagar los turistas y las ofertas similares del mercado, teniendo como techo máximo el precio que están dispuestos a pagar los turistas.

\section{Tabla 85.}

Precio Rack Para los paquetes del Ecolodge “Kachi Raqay”, en base a acomodación doble, expresado en dólares americanos

\begin{tabular}{lccc}
\hline \multicolumn{1}{c}{ Paquete } & $\begin{array}{c}\text { Turistas están } \\
\text { dispuestos a pagar }\end{array}$ & $\begin{array}{c}\text { Promedio de } \\
\text { opciones similares }\end{array}$ & $\begin{array}{c}\text { Precio } \\
\text { Rack }\end{array}$ \\
\hline Full day & 136 & 123 & 130 \\
Aventura en Maras & 342 & 383 & 342 \\
Experiencia Kachi Raqay & 477 & 427 & 452 \\
\hline
\end{tabular}

El mejor precio o también llamado "best available rate" que es el utilizado en temporadas bajas, generalmente es el $80 \%$ del precio RackFuente especificada no válida..

El precio corporativo o confidencial, que es el precio al que se vende los paquetes a los operadores turísticos, es en promedio un $85 \%$ del precio "best available rate", con la diferencia que se mantiene en todo el año. (Capítulo 3, investigación de mercado).

Tabla 86.

Precios por turista de los paquetes según tarifa, en base a acomodación doble (expresado en dólares americanos).

\begin{tabular}{lccc}
\hline \multicolumn{1}{c}{ Paquete } & Precio Rack & Best available rate & Precio operador \\
\hline Full day & 130 & 104 & 88 \\
Aventura en Maras & 342 & 274 & 233 \\
Experiencia Kachi Raqay & 452 & 362 & 307 \\
\hline
\end{tabular}


Según las tarifas publicadas por la empresa Peruvian Travel Service, el precio de un paquete para una persona es en promedio un $15 \%$ más caro que el precio del mismo paquete, pero en base a acomodación dobleFuente especificada no válida..

Tabla 87.

Precios por turista de los paquetes según tarifa, en base a acomodación simple (expresado en dólares americanos).

\begin{tabular}{lccc}
\hline \multicolumn{1}{c}{ Paquete } & $\begin{array}{c}\text { Precio } \\
\text { Rack }\end{array}$ & Best available rate & Precio operador \\
\hline Full day & 149 & 119 & 101 \\
Aventura en Maras & 393 & 315 & 267 \\
Experiencia Kachi Raqay & 520 & 416 & 354 \\
\hline
\end{tabular}

Tabla 88.

Precios de los paquetes por persona expresado en dólares

\begin{tabular}{llcccccc}
\hline \multirow{2}{*}{ Paquete } & \multirow{2}{*}{ Habitación } & \multicolumn{2}{c}{ Precio rack } & \multicolumn{2}{c}{ Best available rate } & \multicolumn{2}{c}{ Operador } \\
\cline { 3 - 8 } & & $\begin{array}{c}\text { Sin } \\
\text { Igv }\end{array}$ & Con Igv & Sin Igv & Con Igv & Sin Igv & Con Igv \\
\hline Full day & Sin habitación & 130 & 153 & 104 & 122 & 88 & 104 \\
& & 130 & 153 & 104 & 122 & 88 & 104 \\
\hline Aventura en & Simple & 393 & 464 & 315 & 371 & 267 & 316 \\
Maras & $\begin{array}{l}\text { Doble o } \\
\text { matrimonial }\end{array}$ & 342 & 404 & 274 & 323 & 233 & 274 \\
\hline $\begin{array}{l}\text { Experiencia kachi } \\
\text { Raqay }\end{array}$ & Simple & 520 & 614 & 416 & 491 & 354 & 417 \\
& $\begin{array}{l}\text { Doble o } \\
\text { matrimonial }\end{array}$ & 452 & 534 & 362 & 427 & 307 & 363 \\
\hline
\end{tabular}


Tabla 89.

Precios de los paquetes por persona expresado en soles, incluye pago por servicios

\begin{tabular}{llccccccc}
\hline \multirow{2}{*}{ Paquete } & \multirow{2}{*}{ Habitación } & \multicolumn{2}{c}{ Precio Rack } & \multicolumn{2}{c}{ Best Available Rate } & \multicolumn{2}{c}{ Operador } \\
\cline { 3 - 8 } & Sin habitación & 421 & 497 & 337 & 398 & 286 & 338 \\
& & 421 & 497 & 337 & 398 & 286 & 338 \\
\hline Full day & Simple & 1.278 & 1.508 & 1.023 & 1.207 & 869 & 1.026 \\
& $\begin{array}{l}\text { Doble o } \\
\text { Aventura en Matrimonial }\end{array}$ & 1.112 & 1.312 & 889 & 1.049 & 756 & 892 \\
\hline $\begin{array}{l}\text { Experiencia kachi } \\
\text { Raqay }\end{array}$ & Simple & 1.690 & 1.994 & 1.352 & 1.595 & 1.149 & 1.356 \\
& $\begin{array}{l}\text { Doble o } \\
\text { matrimonial }\end{array}$ & 1.470 & 1.734 & 1.176 & 1.387 & 999 & 1.179 \\
\hline
\end{tabular}

Para la determinación de precios se debe considerar la temporalidad propia de Cusco:

- Temporada baja: De enero a marzo.

- Temporada alta: De abril a diciembre.

\subsubsection{Socios estratégicos operadores de turismo}

Para determinar el precio de los paquetes que ofrece el Ecolodge Kachi Raqay, es necesario evaluar los resultados de la encuesta referidas a:

a. Costo diario por hospedaje: Alrededor del $32.5 \%$ de encuestados tiene como costo de hospedaje entre 80 y 121 dólares por día.

b. Costo diario por alimentación: El 32\% de los encuestados tiene costos por alimentación entre 51 y 100 dólares por día.

c. Costo diario por tour o paquete a Maras: El 90\% de encuestados tiene costos en tour o paquete a Maras entre 51 y 151 dólares por día. 
d. Costo diario por actividades y excursiones: El costo para actividades y/o excursiones va entre los 51 y 100 dólares por día.

Se debe considerar también los siguientes factores:

○ Las agencias encuestadas no proporcionan mucha información sobre el costo de sus servicios, sin embargo, se obtuvo datos referenciales.

○ Precio confidencial: $20 \%$ menos que precio rack para operadores de turismo, se mantiene todo el año.

○ Temporada baja: De enero a marzo.

○ Temporada alta: De abril a diciembre.

El albergue ofrecerá un precio full board todo incluido por hospedaje, alimentación y actividades. Tomando en cuenta los montos que los entrevistados están dispuestos a pagar por hospedaje, alimentación más actividades, el precio de los paquetes que ofrece el ecolodge podría encontrarse entre 150 y 500 dólares aproximadamente.

Tabla 90.

Precios Ecolodge Kachi Raqay: Operadores de Turismo

Tarifa operadores de turismo

\begin{tabular}{cccc}
\hline Habitaciones & Full day & Aventura en Maras $(2 \mathrm{~d} / 1 \mathrm{n})$ & Experiencia Kachi Raqay (3d/2n) \\
\hline Simple & 152 & 288 & 376 \\
Doble & 0 & 258 & 346 \\
Matrimonial & 0 & 278 & 366 \\
\hline
\end{tabular}

Fuente: Elaboración propia 


\subsubsection{Plaza}

\subsubsection{Público objetivo: Turistas.}

El Ecolodge Kachi Raqay realizará una distribución directa con su público objetivo turistas e indirecta a través de operadores de turismo, quienes se convertirán en socios estratégicos de la empresa. La distribución directa es aquella que se realiza mediante el trato personal entre el productor del servicio y el consumidor. Mientras que la distribución indirecta es aquella donde interviene un intermediario para poder llevar los servicios desde el productor hasta el consumidor ${ }^{12}$.

El Ecolodge Kachi Rapay hará uso del internet para la comunicación directa a través de la página web www.ecolodgekachiraqay.com a precio rack sin descuentos ni promociones. Las estrategias pull para este sector se detallarán en el subcapítulo promoción del plan de marketing más adelante.

\subsubsection{Público objetivo: Operadores de turismo.}

En cuanto a la distribución indirecta a través de los operadores de turismo las estrategias push se detallarán también en el subcapítulo promoción del plan de marketing.

\footnotetext{
${ }^{12}$ Distribución en la empresa (Fecha de consulta: 22 de febrero de 2017) disponible en http://www.gestiopolis.com/distribucion-en-la-empresa-presentacion/
} 


\subsubsection{Promoción}

Es de vital importancia contar con una marca que soporte todas las acciones promocionales necesarias para comunicar, informar y persuadir al cliente y otros interesados sobre la empresa, sus productos y las ofertas. ${ }^{13}$

a. Estrategia Pull: El 41\% de los turistas emplean los servicios de páginas web para organizar sus itinerarios de viaje, por ello es muy importante la comunicación con los clientes directos a través de las diferentes redes sociales y web de la empresa, por tanto se realizará lo siguiente:

- Social Media marketing:

Creación de perfil de Facebook e Instagram con el nombre Ecolodge Kachi Raqay donde se postearán fotos, actividades, promociones.

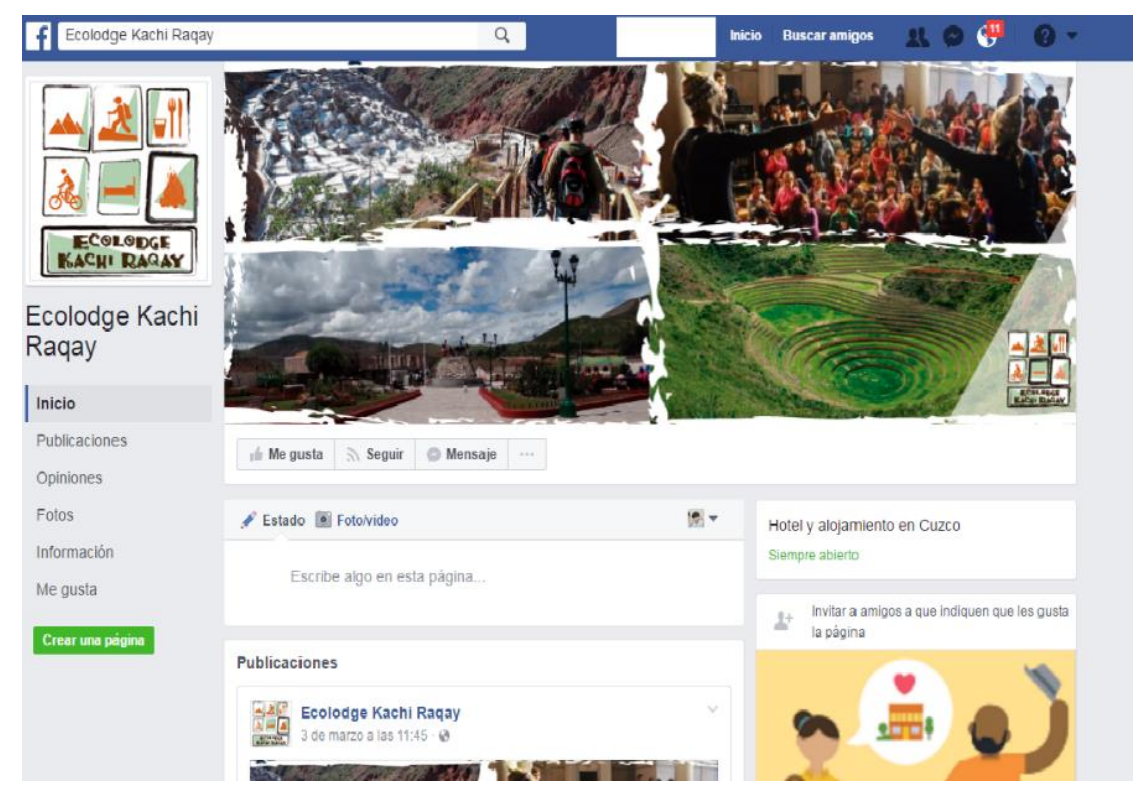

\footnotetext{
${ }^{13}$ Mezcla de promoción (Fecha de consulta: 22 de febrero 2017) disponible en https://es.wikipedia.org/wiki/Mezcla_de_promoci\%C3\%B3n
} 


\begin{tabular}{|c|c|c|c|c|}
\hline $\mathbb{M} M \cup$ & & & . $54 \%$ & \\
\hline ecokach & $y$. & & +e ill & $\vdots$ \\
\hline 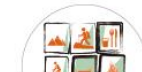 & $\begin{array}{c}19 \\
\text { publicaciones }\end{array}$ & $\begin{array}{c}33 \\
\text { seguidores }\end{array}$ & $\begin{array}{c}131 \\
\text { seguidos }\end{array}$ & \\
\hline 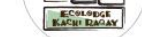 & Conta & & ar perfil & \\
\hline
\end{tabular}

\section{Ecolodge Kachi Raqay}

Hotel y Alojamiento

Cuzco, Perú

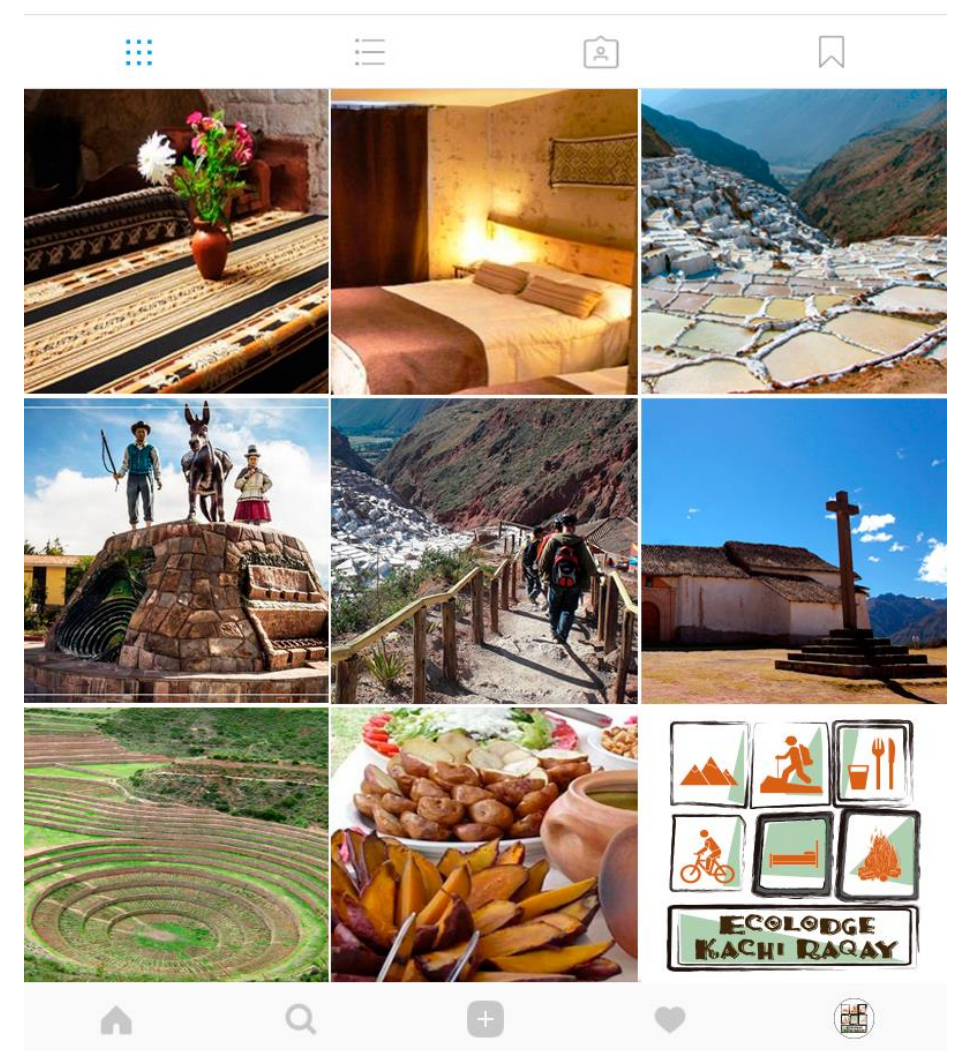

Creación de perfil en Trip Advisor, donde se pueda obtener las opiniones de los turistas que visitan el albergue y emplear las herramientas de promoción que ofrecen de forma gratuita. 


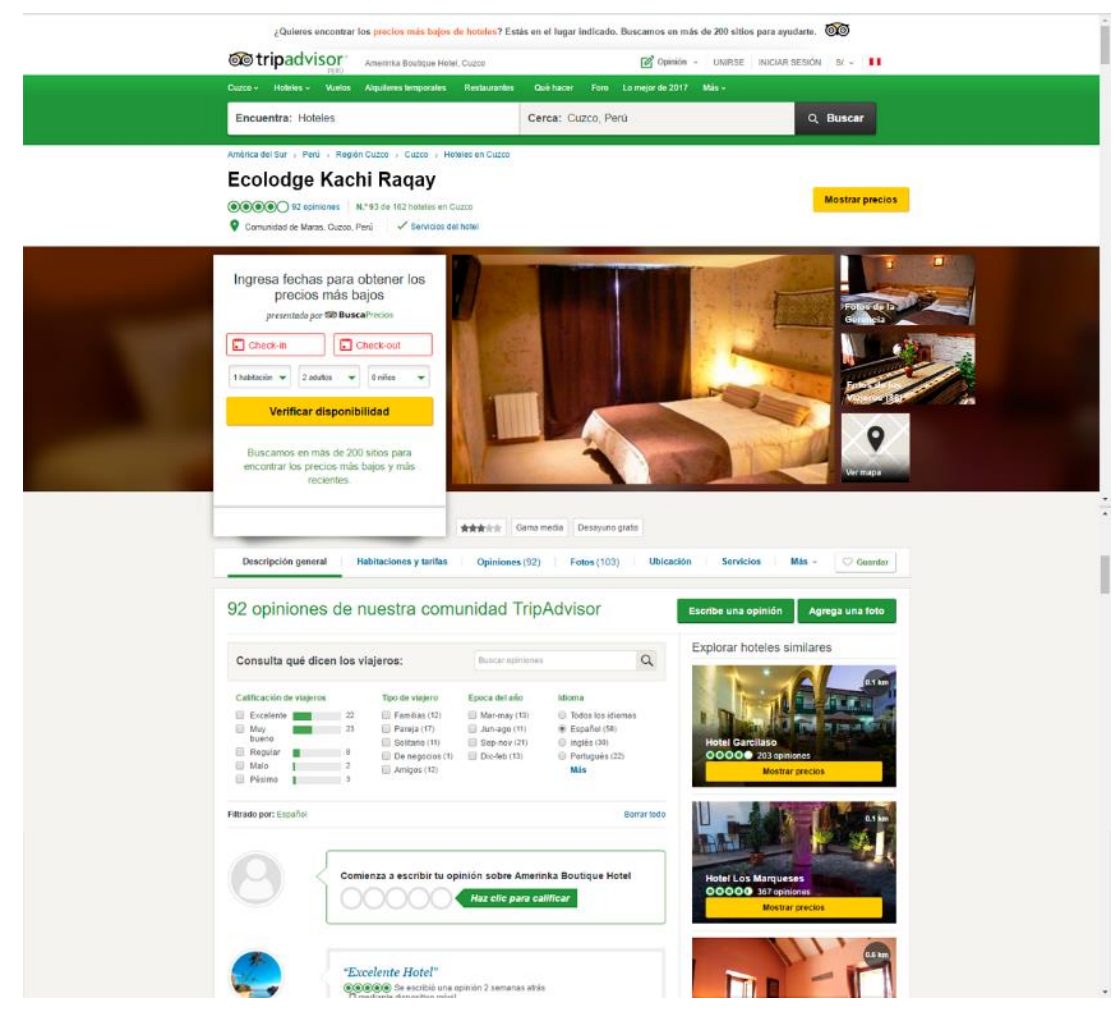

Página web de la empresa desarrollada en inglés y español.

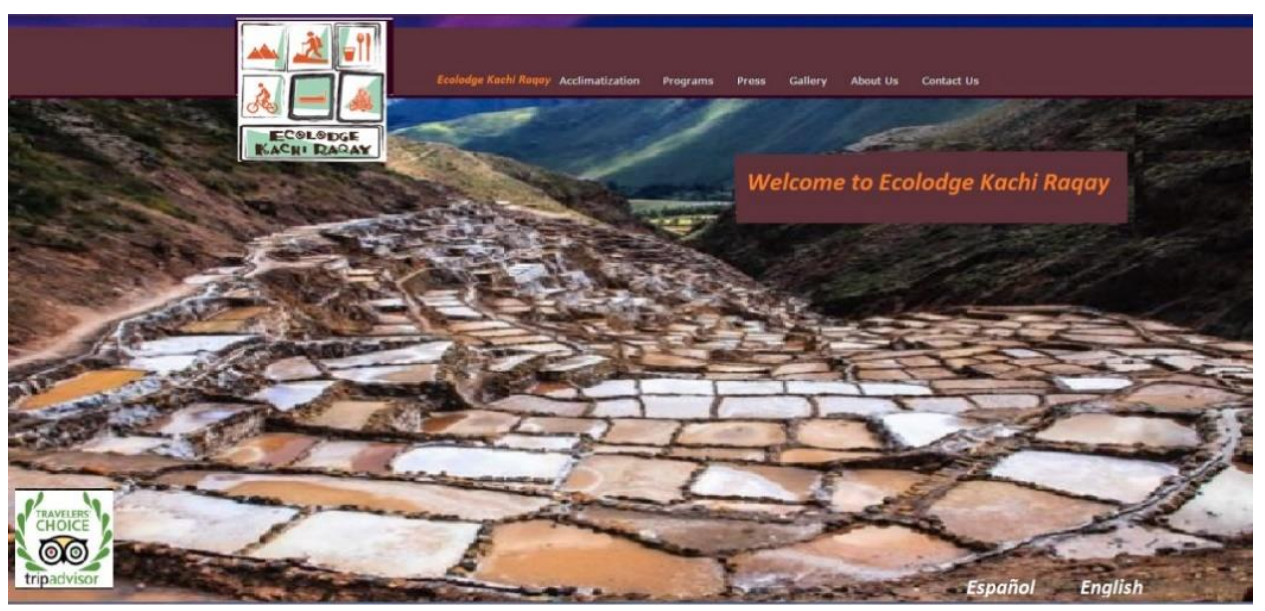

- Publicidad: En Trip Advisor y por medio de la página web del ecolodge. 
- Aplicación de herramientas SEO (Search Engine Optimization) para entrar a las primeras posiciones de resultados de búsqueda online ${ }^{14}$.Herramientas como Google Adword, Buzzsumo, Keyword organizar, Screaming Frog y Google Analytics. ${ }^{15}$

- Promoción de ventas:

Concurso Selfie Kachi Raqay: Se participará colgando una foto con el hashtag \#selfieKachiRaqay, la foto más creativa se premiará con el paquete de la elección del cliente con todos los gastos pagados para la siguiente estadía.

Escape Kachi Raqay: Para promover la venta a peruanos existirá por temporadas una tarifa de dos noches a 250 dólares.

- Marketing directo: Mediante una base de datos bien organizada de los clientes del ecolodge, se enviarán promociones o descuentos vía email.

b. Estrategia Push: El estudio arrojó que el 34.5\% de los turistas organizan su itinerario mediante el servicio de agencias de viaje, por ello, es muy importante empujar la venta a través de los canales de distribución operadores de turismo de la siguiente forma:

- Marketing directo:

Telemarketing a los principales operadores de turismo en Cusco. (Mencionados en el capítulo 2, poder de negociación de los clientes indirectos).

\footnotetext{
${ }^{14} 12$ Estrategias Pull para atraer clientes potenciales (Fecha de consulta: 18 de febrero de 2017) disponible en http://teragrowth.com/12-estrategias-pull-atraer-clientes/

155 Herramientas para optimizar tus contenidos(Fecha de consulta: 18 de febrero de 2017) disponible en https://www.40defiebre.com/herramientas-seo-contenidos/
} 
Trípticos que se entregará a los operadores de turismo en Cusco

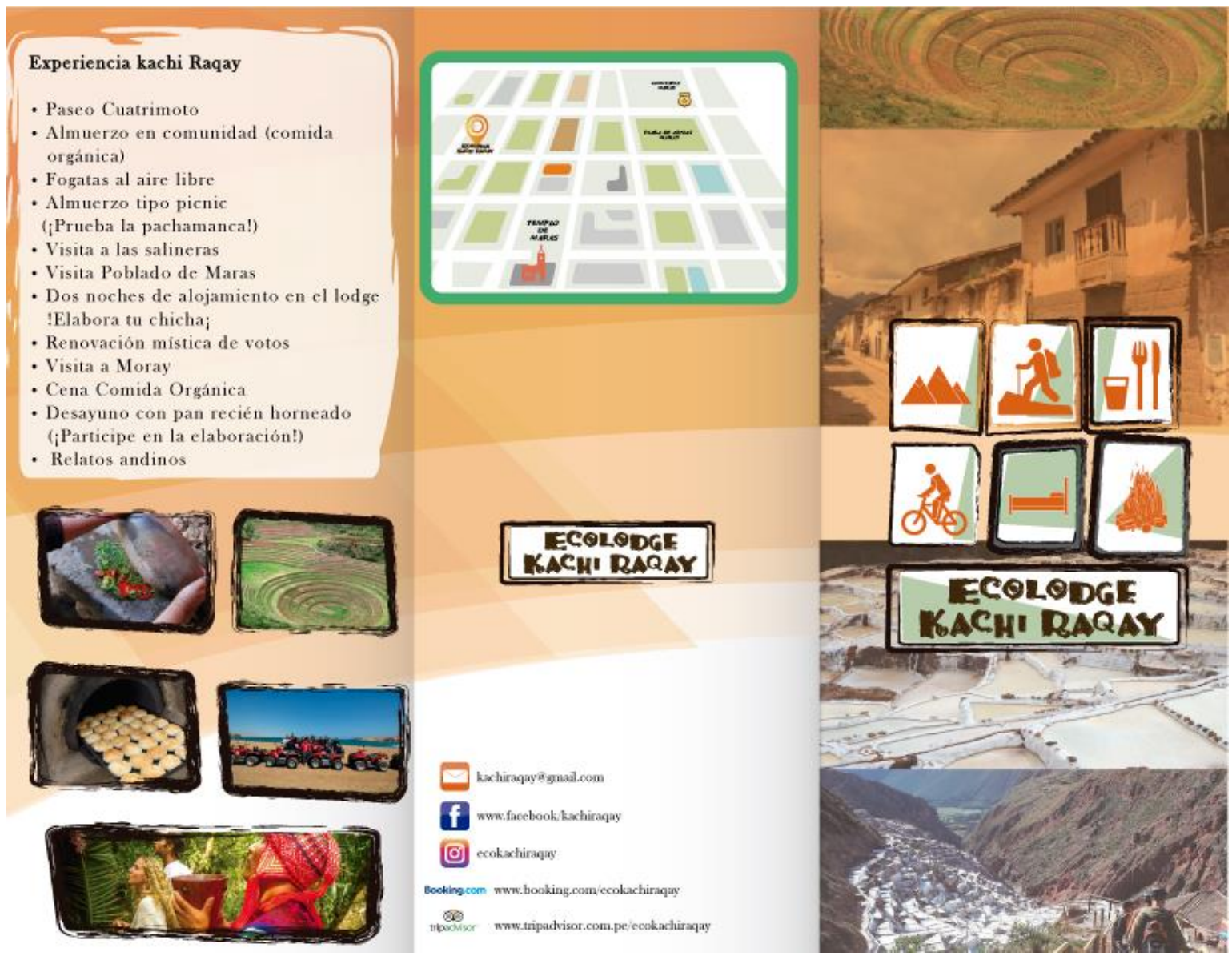




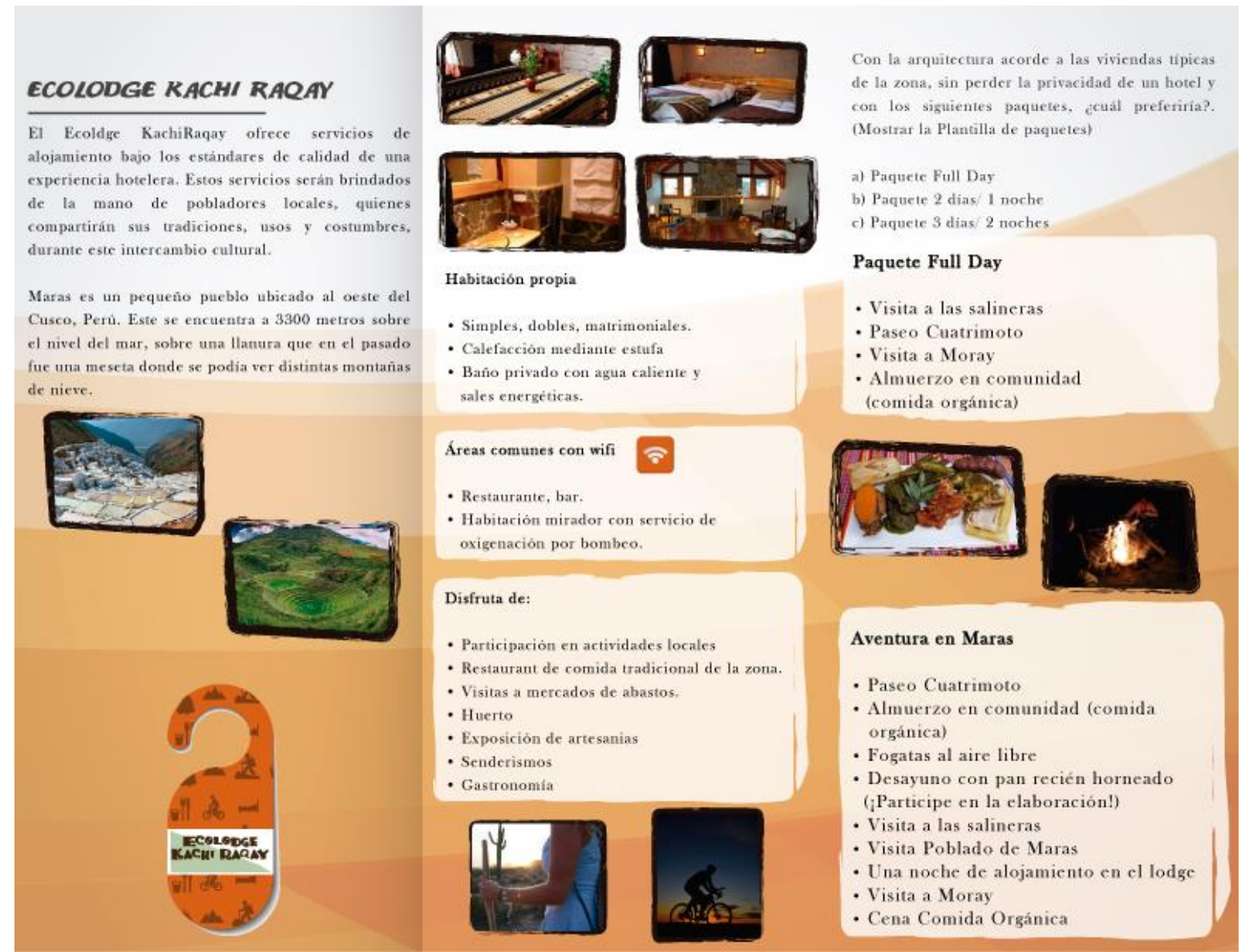

Presentaciones multimedia dando a conocer el albergue y las actividades ofrecidas.

- Incentivos en el precio:

Tarifa confidencial, $20 \%$ menos de tarifa rack (precio en temporada alta y en recepción del hotel)

- Relaciones Públicas:

Se realizarán Fam trips, estadía en el hotel destinada a los operadores de turismo para que conozcan de primera mano el albergue y las actividades que se ofrecen en él. Se realizarán famtrips en los tres paquetes que ofrece el albergue. 
También se realizarán Fam trip a a la youtuber Maud Gurunlian del programa Buen Viaje para que conozca el ecolodge y de esta forma llegar a los 33 mil suscriptores que maneja su canal.

Patrocinio a operadores de turismo para asistir a ferias de turismo internacionales como las siguientes:

- IPW Washington.

- Travel and Adventure show Washington D.C.

- Florida Huddle Tampa.

- Diversas ferias en América Latina.

\subsubsection{Personas}

Personas incluye a todo el personal envuelto directamente o indirectamente en la entrega del producto o servicio tales como empleados de atención al cliente (call center, representantes y gerentes de cuenta), clientes, personal y directivos. ${ }^{16}$

Sin embargo, los colaboradores de atención al cliente al ser la cara de la empresa son los más importantes al momento de iniciar la relación cliente-empresa, y por ello, se debe exigir calidad que genere valor al cliente en cada una de las áreas correspondientes. En el caso del ecolodge, el personal de atención al cliente está formado por el personal de frontdesk (recepción, conserjería) personal de alimentos y bebidas y personal de housekeeping; quienes en conjunto tienen un trato directo con los huéspedes y por lo tanto se exigirá cuenten con las siguientes habilidades blandas:

\footnotetext{
${ }^{16}$ Service Marketin MIx 7Ps ( Fecha de consulta: 11 de marzo 2017 disponible en http://www.toolshero.com/marketing/service-marketing-mix-7ps/
} 
- Empatía: Con compañeros de trabajo para fortalecer el clima laboral, y con los clientes para sobrellevar los diferentes tipos de personalidad que llegarán al ecolodge.

- Ética: Para hacer un uso adecuado de los instrumentos tangibles como los equipos y útiles de oficina, e intangibles como bases de datos del hotel, información de clientes y proveedores.

- Creatividad: En la solución de situaciones inesperadas.

- Escucha activa: Saber escuchar tanto halagos como críticas al servicio.

- Incentivar la tranquilidad y paciencia: Cuando se genere una situación de nervios como espera prolongada en la entrega de la habitación.

- Honestidad: Sobre lo que ofrece el hotel, para no generar una mala crítica por parte de los clientes.

- Adaptación al cambio: Actuar según el tipo de cliente que asiste al ecolodge.

- Lenguaje corporal adecuado: Desde la forma de vestir hasta la manera de expresarse.

- Trabajo bajo presión: Para soportar turnos muy ocupados o situaciones de estrés.

- Sonreír: Siempre mostrar una sonrisa natural al cliente.

- Organización: Para entregar un servicio ordenado y eficiente.

- Asertividad: Expresar de manera amable, directa y respetuosa lo que deseamos sin ir en contra de los demás. 


\subsubsection{Procesos}

En cumplimiento por lo estipulado por el Ministerio de Comercio Exterior y Turismo en el Manual de buenas prácticas de gestión de servicios para establecimientos de Hospedaje, la implementación de procesos de calidad es elemental para definir las guías del servicio, así como para fortalecer la competitividad en el sector. Esta estrategia debe incluir a los colaboradores operativos, administrativos, así como los proveedores de la empresa.

El servicio es la solución de un problema o la satisfacción de una necesidad. El personal en todos los niveles y áreas debe ser consciente de que el éxito de las relaciones entre la empresa y cada uno de los clientes depende de las actitudes y conductas que observen en la atención de las demandas de las personas que son o representan al cliente.

Así la calidad en el servicio se definirá como el grado de satisfacción que experimenta el cliente respecto el producto y la interacción con los colaboradores.

Los procesos que se describen a continuación son los relativos a la calidad del servicio en la atención al cliente dentro de las instalaciones del ecolodge:

a. Proceso de atención al cliente en recepción (sin intermediario)

- Llega cliente al ecolodge.

- Se recibe al cliente con una sonrisa en los primeros 30 segundos de interacción.

- Informa precios de los diferentes paquetes.

- Hace entrega de formularios para registro.

- Efectúa el cobro con tarjeta de crédito o efectivo. 
- Si es con tarjeta de crédito se imprime voucher y se pide la firma.

- Se entrega voucher al cliente.

- Si es efectivo se extiende la boleta correspondiente y se entrega al cliente.

- Se asigna habitación al cliente.

- Se hace entrega de las llaves.

- Se le indica horario de actividades según el paquete escogido.

- Se desea al cliente una buena estadía siempre con una sonrisa.

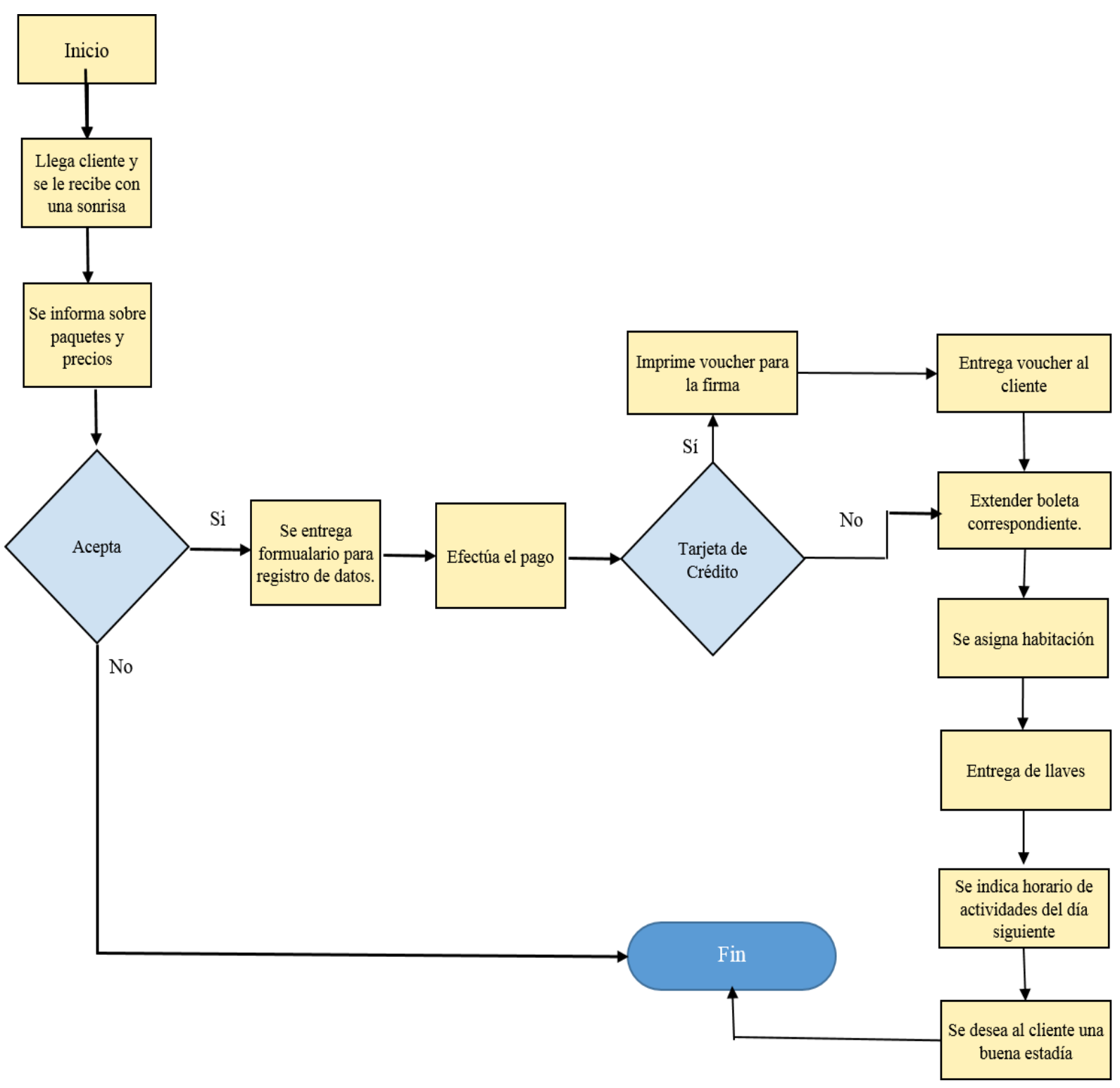

Figura 42. Diagrama de flujo proceso de recepción sin intermediario 
b. Proceso de atención al cliente en recepción(con intermediario)

- Llega cliente al ecolodge.

- Se recibe al cliente con una sonrisa en los primero 30 segundos de interacción.

- Se asigna habitación al cliente.

- Se hace entrega de las llaves.

- Se le indica horario de actividades según el paquete escogido.

- Se desea al cliente una buena estadía siempre con una sonrisa.

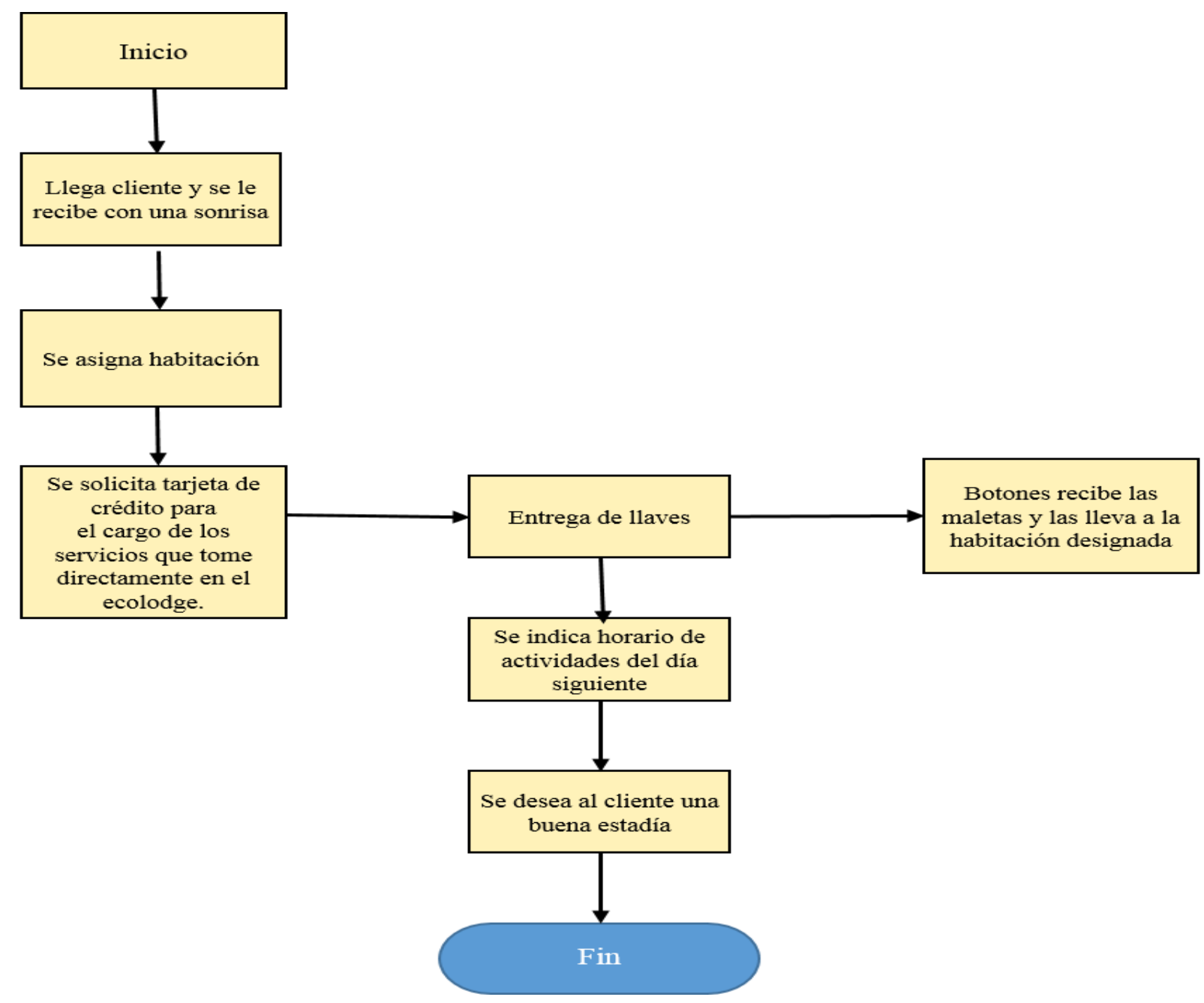

Figura 43. Diagrama de flujo proceso de recepción con intermediario

c. Proceso de atención al cliente vía telefónica.

- Se contesta al teléfono antes del tercer timbrado. 
- Se solicita nombres y apellidos al cliente.

- Se saluda al cliente por el apellido y se procede con la atención.

- Se pregunta fecha de entrada y salida.

- Se procede a tomar nota de la solicitud del cliente.

- Si no es posible dar una respuesta inmediata se indica al cliente que se le contactará nuevamente, se piden sus datos, número o email según prefiera.

- Se presentan los paquetes del ecolodge con sus precios correspondientes.

- Se registran los datos del cliente.

- Si es temporada alta se solicita una garantía inmediata mediante depósito bancario.

- Si es temporada baja se realiza la confirmación al cliente.

- Durante la interacción se evitará sonidos o movimientos que generen incomodidad para el cliente.

- Se termina el servicio con la frase: ¿hay algo más que pueda hacer por usted?

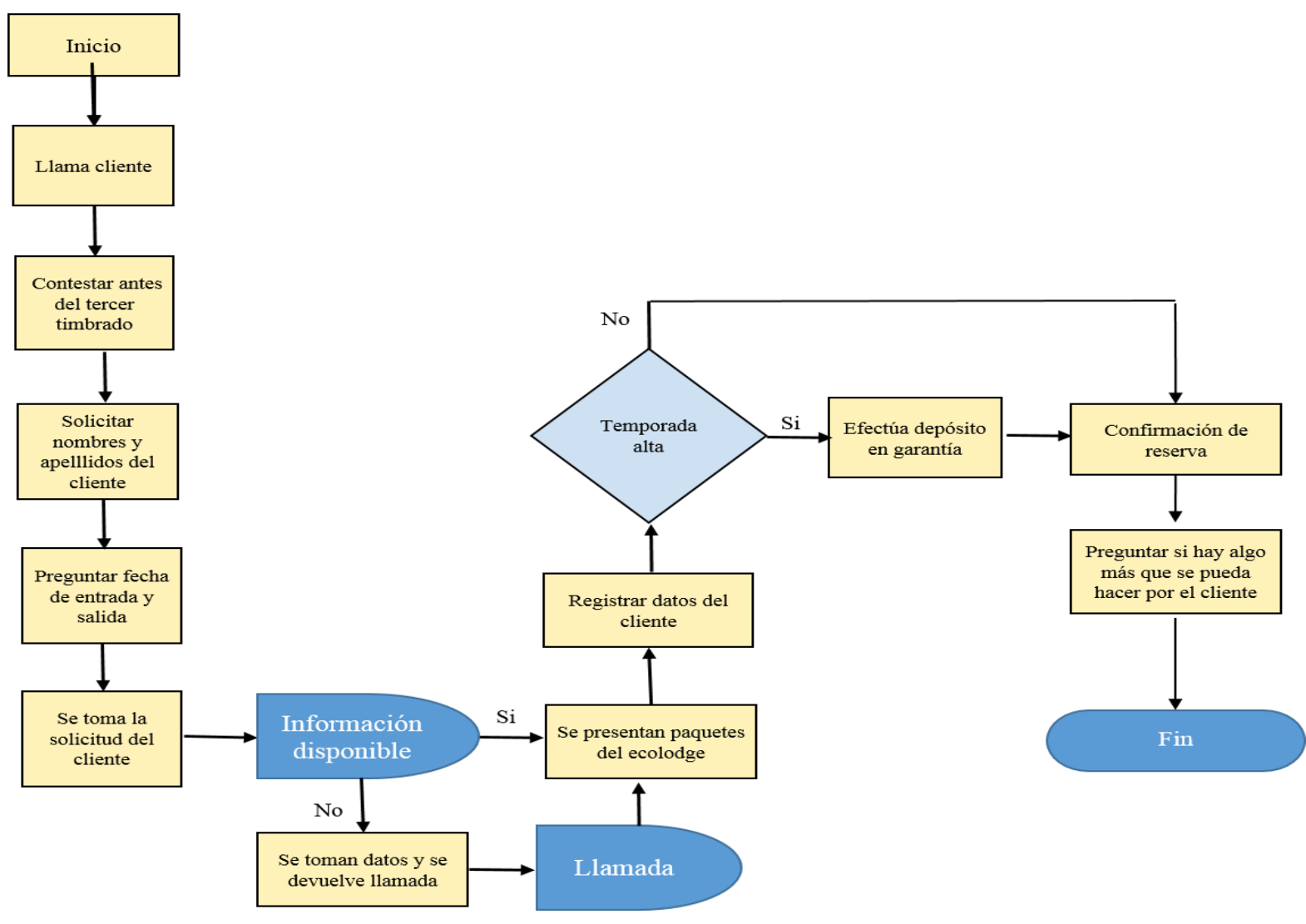


Figura 44. Diagrama de atención al cliente vía telefónica.

d. Proceso de monitoreo del nivel de satisfacción del cliente.

El proceso de verificación está dado por el monitoreo de atención e infraestructura previsto por el cliente, en base a una encuesta de satisfacción: 


\section{ENCUESTA DE CALIDAD DEL SERVICIO}

Nombre:

Nacionalidad:

- ¿Cómo se enteró usted del ecolodge?

Internet ( ) Revista () Agente de viajes ( ) Amigos ( ) Otros ()

- ¿Desearía recibir información sobre nosotros?

Si ( ) Email:
Habitación:

Fecha de salida:

- Por favor califique su experiencia durante su estadía con nosotros.

Amabilidad y eficiencia en recepción.

Excelente ( )

Bueno ( )

Regular ( )

Malo ( )

Limpieza de la habitación

Excelente ( )

Bueno ( )

Regular ( )

Malo ( )

Calidad-Precio

Excelente ( )

Bueno ( )

Regular ( )

Malo ( )

Calidad de los alimentos

Excelente ( )

Bueno ( )

Regular ( )

Malo ( )

Calidad en los servicios de restaurante y bar

Excelente ( )

Bueno ( )

Regular ( )

Malo ( )

Servicio a la habitación

Excelente ( )

Bueno ( )

Regular ( )

Malo ( )

Mantenimiento e infraestructura

Excelente ( )

Bueno ( )

Regular ( )

Malo ( )

- ¿Hay algún miembro del ecolodge que desee mencionar?

- ¿Desea realizar alguna sugerencia o comentario adicional para mejorar la experiencia en el ecolodge? 


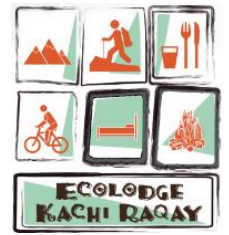

Name:

Nationality:

- How did you hear about us?

Internet ( ) News ( ) Travel agency ( )

Friends ( ) Others ( )

\section{QUALITY SERVICE SURVEY}

- Would you like to receive information about us?

Yes ( ) Email:

No ( )

- Please rate your experience during your stay with us.

Front desk: Courtesy and quality service
Excellent ( )
Good ( )
Average ( )
$\operatorname{Bad}()$

Room cleaning

Excellent ( )

Good ( )

Average ( )

$\operatorname{Bad}()$

Quality - Price

Excellent ( )

Good ( )

Average ( )

$\operatorname{Bad}()$

Food quality

Excellent ( )

Good ( )

Average ( )

$\operatorname{Bad}()$

Food and beverage quality service

Excellent ( )

Good ( )

Average ( )

$\operatorname{Bad}()$

Room service

Excellent ( )

Good ( )

Average ( )

$\operatorname{Bad}()$

Ecolodge maintenance and decoration

Excellent ( )

Good ( )

Average ( )

$\operatorname{Bad}()$

- Is there any worker you would like to mention?

- Would you like to give us any suggestion or comment to improve the experience in our ecolodge? 
Thank you.

\subsubsection{Evidencia Física}

La percepción del buen servicio que brinda el hotel se hará llegar al cliente a través de la siguiente evidencia física:

- El diseño del hotel, los muebles y la iluminación irán de acorde a la tranquilidad de la zona donde se encuentra ubicado el albergue, desde el ingreso al mismo se transmitirá la calidad del servicio que recibirá el turista hasta el momento del check out.

- El personal de recepción y en general todos los trabajadores del albergue se encontrarán correctamente vestidos y el recibimiento será cordial en la recepción del hotel.

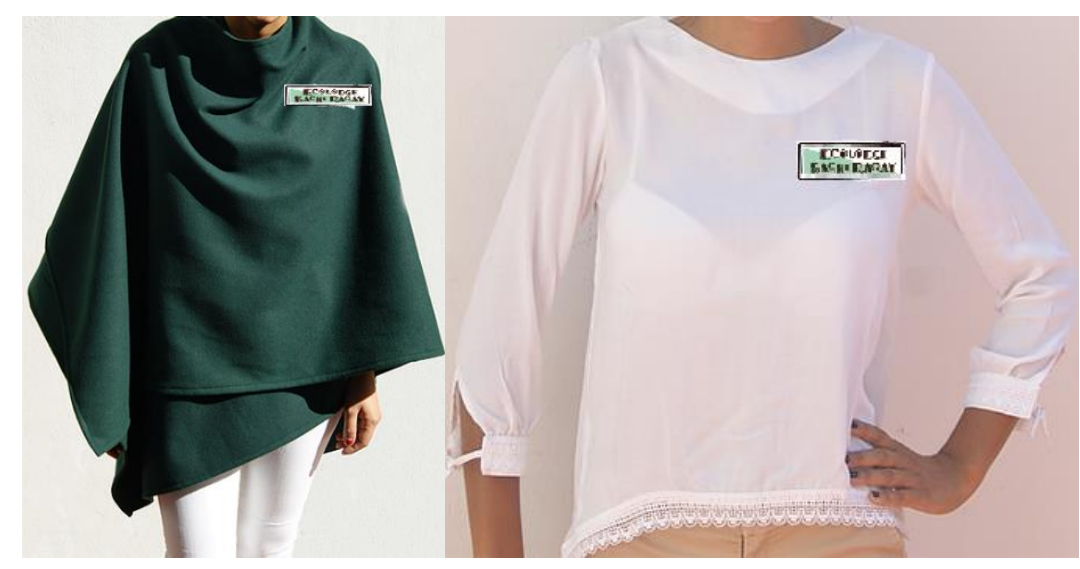

- Las llaves tendrán impresa una foto de las Salineras de Maras, la página web de la empresa y gráficos indicando las actividades que el ecolodge ofrece. 
Se colocarán trípticos acerca de los servicios del hotel en recepción.

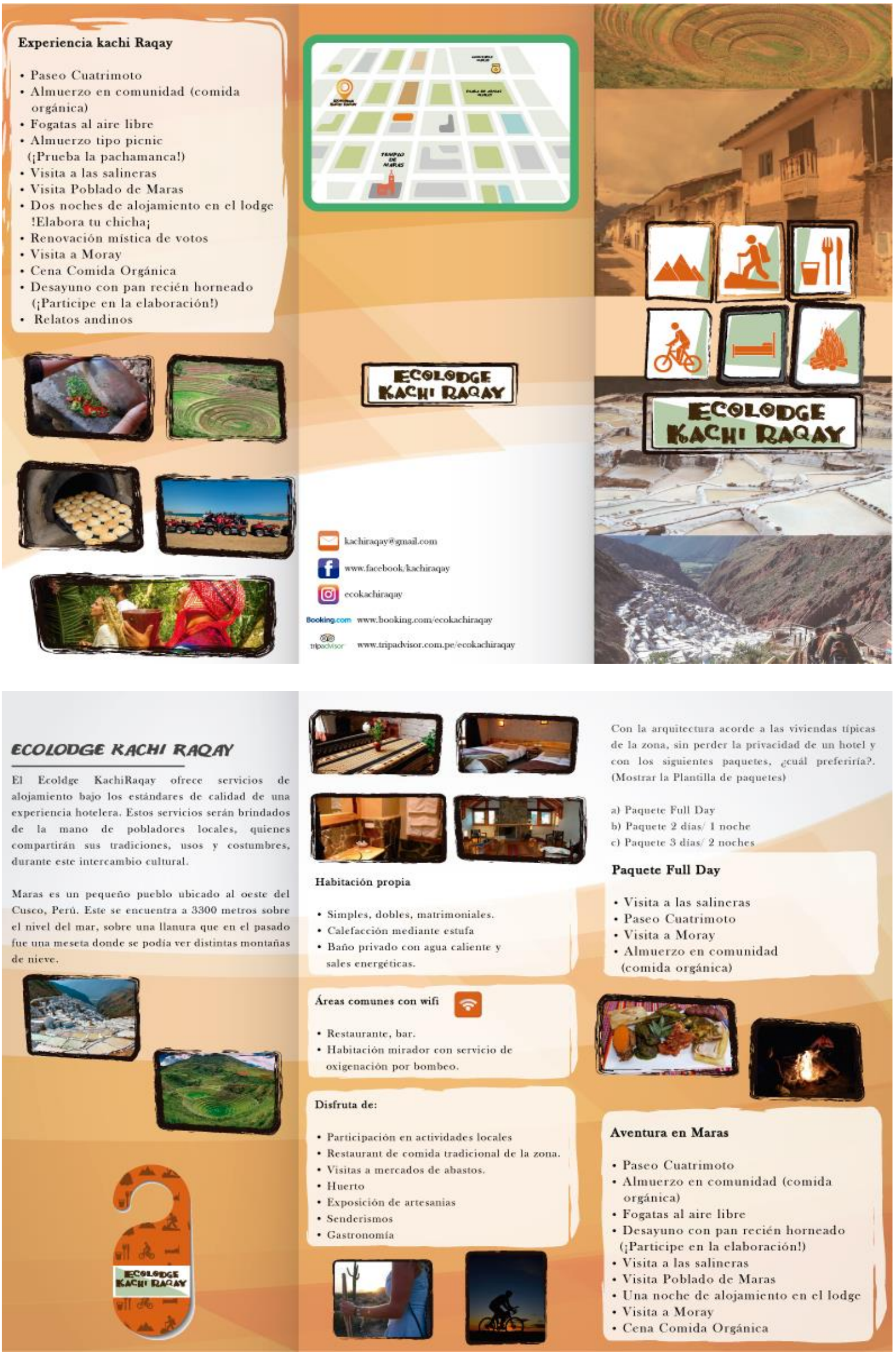


- Habrá tarjetas de presentación de los directivos del hotel, para cualquier observación que tengan los clientes.

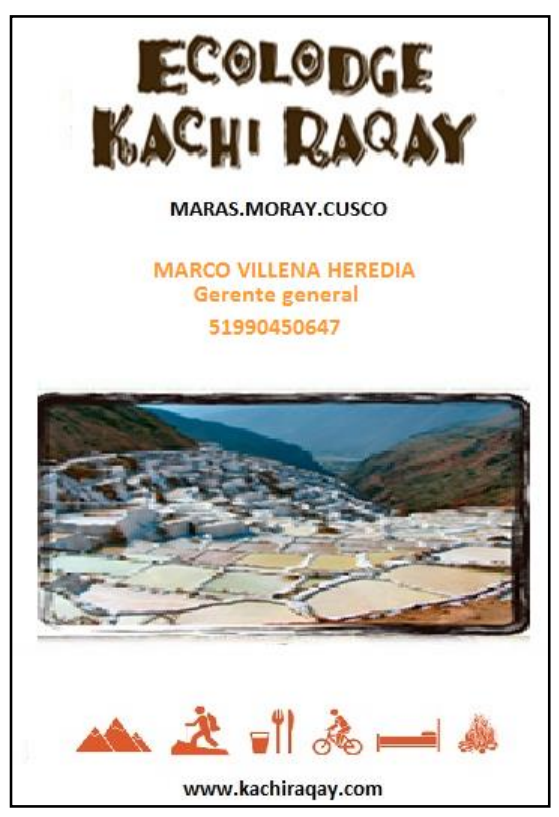

- El olor del albergue desde que se ingresa a recepción será de las fragancias típicas de la zona(eucalipto)

- La temperatura será cálida como el trato que dará el personal.

- Se escuchará música de fondo con instrumentos andinos y sonidos naturales como cascadas, lluvia, etc.

- Se proveerá de mapas para que los turistas se sientan tranquilos de dar un paseo por los alrededores.

- Las áreas de fumadores y las zonas de escape estarán debidamente señalizadas.

- Las habitaciones se encontrarán limpias, perfumadas con eucalipto, típico de la zona. 


\section{Capítulo VIII: Estudio de Inversiones y Financiamiento}

\subsection{Inversiones.}

Las inversiones están compuestas por los activos fijos, intangibles y capital de trabajo, están expresados en soles a un tipo de cambio de 3.25 soles por dólar.

\subsubsection{Inversión en activo fijo.}

La inversión en activo fijo está formada por:

1. Terreno y construcción: La inversión en terreno está calculada en base área y el precio por metro cuadrado. Como se observa en la Tabla 91 el área total es de 4,000 metros cuadrados a un precio de 29 soles el metro cuadrado.

Tabla 91.

Costo Total Terreno Ecolodge (expresado en soles)

\begin{tabular}{lccccc}
\hline Concepto & Área $\left(\mathrm{M}^{2}\right)$ & $\begin{array}{c}\text { Costo sin IGV } \\
\left(\mathrm{S} / \mathrm{M}^{2}\right)\end{array}$ & $\begin{array}{c}\text { Costo Total sin } \\
\text { IGV }(\mathrm{S} / .)\end{array}$ & IGV & $\begin{array}{c}\text { Costo Total con } \\
\text { IGV }(\mathrm{S} / .)\end{array}$ \\
\hline Terreno & 4,000 & 29 & 116,000 & 20,880 & 136,880 \\
Total & & & 116,000 & 20,880 & 136,880 \\
\hline
\end{tabular}

Nota: Tomado en base de los datos del capítulo V Ingeniería del proyecto.

En la Tabla 92 se observa el costo total de la construcción formado por las estructuras (muros y columnas), acabados (pisos, puertas y ventanas, revestimientos y baños) y las instalaciones eléctricas y sanitarias; así como también se incluye la construcción de un cerco alrededor del Ecolodge y el costo de una puerta de entrada. Como se mencionó en el capítulo 
técnico, el costo por $\mathrm{m}^{2}$ determinado para el proyecto es de S/.2,954, precio obtenido en base la tabla de valores unitarios del Colegio de Arquitectos del Perú y a la consulta al arquitecto Julian Jones del estudio Lima Design Group.

Tabla 92.

Costo Total Construcción Ecolodge (expresado en soles)

\begin{tabular}{lccccc}
\hline \multicolumn{1}{c}{ Concepto } & $\begin{array}{c}\text { Área } \\
\left(\mathrm{M}^{2}\right)\end{array}$ & $\begin{array}{c}\text { Costo sin IGV } \\
\left(\mathrm{S} / \mathrm{M}^{2}\right)\end{array}$ & $\begin{array}{c}\text { Costo Total sin } \\
\text { IGV }\end{array}$ & IGV & $\begin{array}{c}\text { Costo Total con } \\
\text { IGV }\end{array}$ \\
\hline Edificio & 1,144 & 2,954 & $3,379,147$ & 608,246 & $3,987,394$ \\
Puerta de madera $(2,2 \times 2)$ & 4 & 318 & 1,397 & 251 & 1,648 \\
$\begin{array}{l}\text { Muros perimétricos o } \\
\text { cercos de adobe }\end{array}$ & 4,000 & 10 & 40,000 & 7,200 & 47,200 \\
Total & & & $3,420,916$ & 615,765 & $4,036,681$ \\
\hline
\end{tabular}

Nota: Adaptado de la información obtenida por el Colegio de Arquitectos y Lima Design Group.

2. Equipos de Procesamiento de Datos: Formado por las computadoras e impresoras necesarias en la recepción, sala de estar, oficina y restaurantes del ecolodge ${ }^{17}$, como se observa en la Tabla 93 siguiente:

Tabla 93.

Costo Equipos de Procesamiento de Datos (expresado en soles)

\begin{tabular}{lccc}
\hline \multicolumn{1}{c}{ Activo Fijo } & Costo Total Sin IGV (S/.) & IGV & $\begin{array}{c}\text { Costo Total con IGV } \\
(\text { S/.) }\end{array}$ \\
\hline Recepción y Sala de Estar & 1,271 & 229 & 1,500 \\
Restaurante & 763 & 137 & 900 \\
Oficina & 1,271 & 229 & 1,500 \\
Total & 3,305 & 595 & 3,900 \\
\hline
\end{tabular}

Nota: Elaboración propia.

${ }^{17}$ Ver anexo XI Requerimiento de muebles y enseres 
3. Maquinaria y Equipos: Formado por la maquinaria y equipo necesario para el correcto funcionamiento de la cocina, recepción, sala de estar, oficina y dormitorios ${ }^{18}$, como se observa en la Tabla 94:

Tabla 94.

Costo Maquinaria y Equipos (expresado en soles)

\begin{tabular}{lccc}
\hline \multicolumn{1}{c}{ Activo Fijo } & Costo Total sin IGV (S/.) & IGV & $\begin{array}{c}\text { Costo Total } \\
\text { con Igv (S/.) }\end{array}$ \\
\hline Cocina & 11,397 & 2,052 & 13,449 \\
Dormitorios & 992 & 178 & 1,170 \\
Recepción y Sala de Estar & 157 & 28 & 185 \\
Oficina & 750 & 135 & 885 \\
Total & 13,296 & 2,393 & 15,689 \\
\hline Nota: Elabe & & &
\end{tabular}

Nota: Elaboración propia.

4. Muebles y Enseres: Formado por todos los muebles y enseres necesarios para las áreas de cocina, dormitorios, recepción, sala de estar, restaurantes, oficina y los baños correspondientes $^{19}$, como se observa en la Tabla 95 :

Tabla 95.

Costo Muebles y Enseres (expresado en soles)

\begin{tabular}{lccc}
\hline \multicolumn{1}{c}{ Activo Fijo } & Costo Total sin IGV & IGV & Costo Total con IGV \\
\hline Cocina & 2,462 & 443 & 2,906 \\
Dormitorios & 67,273 & 12,109 & 79,382 \\
Recepción y Sala de Estar & 4,720 & 850 & 5,570 \\
Restaurantes & 16,754 & 3,016 & 19,770 \\
Oficinas & 2,228 & 401 & 2,629 \\
Total & 93,438 & 16,819 & 110,257 \\
\hline
\end{tabular}

Nota: Elaboración propia.

${ }^{18}$ Ver anexo XI Requerimiento de muebles y enseres.

${ }^{19}$ Ver anexo XI Requerimiento de muebles y enseres. 
5. Vehículos de Transporte: El vehículo se utilizará para compras específicas de insumos en la ciudad del cusco; así como algún otro producto que se necesite con urgencia para el normal desarrollo de las actividades del Ecolodge Kachi Raqay. Adicionalmente resulta pertinente contar con un vehículo en caso de emergencias de salud con algún turista, debido a las distancias y vías de acceso. El vehículo también se usará para transportar a los turistas que no estén físicamente habilitados para las caminatas o paseos en cuatrimotos incluidas dentro de los paquetes. El vehículo para adquirir es amplio y cómodo, tiene una capacidad de transportar máximo 10 turistas, cada uno en asientos ergonómicos con cinturón de seguridad, climatizado y está equipado con primeros auxilios en caso algún turista se descompense. El transporte de los turistas desde la ciudad del Cusco a la localidad de Maras se encontrará tercerizado. Los costos del vehículo se observan en la Tabla 96.

Tabla 96.

Costo Vehículo de Transporte (expresado en soles)

\begin{tabular}{lccc}
\hline \multicolumn{1}{c}{ Modelo } & $\begin{array}{c}\text { Costo Total sin } \\
\text { IGV (S/.) }\end{array}$ & IGV & $\begin{array}{c}\text { Costo Total con } \\
\text { IGV (S/.) }\end{array}$ \\
\hline Volkswagen Transporter 2017 & 92,239 & 16,603 & 108,843 \\
Total & 92,239 & 16,603 & 108,843 \\
\hline
\end{tabular}

Nota: Tomado de neoauto en el año 2017. Recuperado de: https://neoauto.com/volkswagentransporter-2017

6. Consolidado de Activos Fijos: A continuación, se presenta en Tabla 97 el consolidado de todos los activos fijos necesarios para el proyecto: 
Tabla 97.

Consolidado Activos Fijos (expresado en soles)

\begin{tabular}{lccc}
\hline \multicolumn{1}{c}{ Activo Fijo } & Costo Total sin & \multirow{2}{*}{ IGV } & Costo Total con \\
& IGV & IGV \\
\hline Terreno y Construcción & $3,536,916$ & 636,645 & $4,173,561$ \\
Equipos de procesamiento de datos & 3,305 & 595 & 3,900 \\
Maquinaria y equipo & 13,296 & 2,393 & 15,689 \\
Mueble y enseres & 93,438 & 16,819 & 110,257 \\
Vehículo de Transporte & 92,239 & 16,603 & 108,843 \\
Total & $3,739,194$ & 673,055 & $4,412,249$ \\
\hline
\end{tabular}

Nota: Elaboración propia.

\subsubsection{Inversión en activo intangible.}

Incluye todos los gastos legales de operación, el software hotelero, gastos pre operativos (Servicios básicos de luz, agua, cable e internet para el funcionamiento del ecolodge, así como la remuneración mensual administrativa incluyendo comisiones para los primeros 3 meses de funcionamiento del ecolodge) y la creación de las páginas web del ecolodge (3 páginas a US\$ 200 cada una $)^{20}$, como se observa en la Tabla 98:

Se adjunta detalle de servicios y planilla 3 meses en la siguiente tabla:

${ }^{20}$ Ver tabla 126 
Tabla 98 .

Detalle de gastos pre-operativos (expresado en soles)

\begin{tabular}{lcccc}
\hline Gastos pre-operativos & Enero & Febrero & Marzo & 2018 \\
\hline Planilla & & & & \\
\hline Gerente & 3,879 & 3,879 & 3,879 & 11,637 \\
Administrador & 3,216 & 3,216 & 3,216 & 9,648 \\
Recepcionista & 5,340 & 5,340 & 5,340 & 16,020 \\
Contador & 3,051 & 3,051 & 3,051 & 9,153 \\
& TOTAL & & & 46,458 \\
Servicios & & & & \\
Luz & 613 & 694 & 857 & 2,164 \\
Agua & 821 & 850 & 585 & 2,256 \\
Internet + cable & 265 & 265 & 265 & 795 \\
Total & & & & 5,216 \\
\hline
\end{tabular}

Nota: Elaboración Propia.

Tabla 99.

Inversión en Activo Intangible (expresado en soles)

\begin{tabular}{lccc}
\hline Activos Intangibles & Costo Total sin IGV & IGV & Costo Total con IGV \\
\hline Aspectos legales & 1,295 & 233 & 1,528 \\
Software & 4,550 & 819 & 5,369 \\
Gastos Pre-operativos & 51,674 & 9,301 & 60,975 \\
Creación de la página web & 1,950 & 351 & 2,301 \\
TOTAL & 59,469 & 10,704 & 70,173 \\
\hline
\end{tabular}

Nota: Elaboración Propia.

\subsubsection{Inversión en capital de trabajo.}

Si bien la determinación del capital de trabajo viene dada por la diferencia entre activo corriente y pasivo corriente (gerencie, 2017) Debido a que es una empresa comercial y no de manufactura, el capital operativo necesario se estimó en base a los egresos de los 3 primeros meses de operación (Murga, 2016). 
Tabla 100.

Determinación del capital de trabajo (expresado en soles)

\begin{tabular}{|c|c|c|}
\hline Concepto de Egreso & Año & 2018 \\
\hline Costo de ventas & & $2,488,171$ \\
\hline Gastos administrativos & & 266,638 \\
\hline Gastos de ventas & & 69,634 \\
\hline Egresos para el primer año & & $2,824,443$ \\
\hline Meses al año & & 12 \\
\hline Egresos para el primer año por mes & & 235.370 \\
\hline Meses que se considerarán para el capital de trabajo & & 3 \\
\hline Capital de trabajo necesario & & 706,111 \\
\hline
\end{tabular}

Nota: Elaboración Propia

\subsubsection{Estructura de inversiones.}

La estructura de las inversiones se presenta a continuación en la Tabla 100:

Tabla 101.

Estructura de Inversiones (expresada en soles)

\begin{tabular}{lcc}
\hline Inversiones & Total & $\%$ \\
\hline Activo fijo & 3.739 .194 & $83,01 \%$ \\
Activo Intangible & 59.469 & $1,32 \%$ \\
Capital de Trabajo & 706.111 & $15,67 \%$ \\
Total & 4.504 .774 & $100,00 \%$ \\
\hline
\end{tabular}

Nota: Elaboración Propia.

\subsection{Financiamiento}




\subsubsection{Estructura de financiamiento}

Debido a que la mayoría de las entidades financieras tienen como requisito el que la empresa esté en funcionamiento ${ }^{21}$, no se tomará en cuenta el financiamiento bancario. Sin embargo, debido a que el monto es elevado se ha optado por conseguir un socio con experiencia en el rubro. Para tal efecto se entrevistó a Jorge Vaca ${ }^{22}$, gerente y accionista del hotel: Apart Hoteles Premium Suites (http://www.premiumsuites.com.bo) quien estaría interesado en participar. Debido a esto el financiamiento será 100\% con capital propio.

Tabla 102.

Estructura de Financiamiento (expresado en soles)

\begin{tabular}{lccc}
\hline Financiamiento & Total & Propio & Préstamo \\
\hline Activo fijo & $3,739,194$ & $3,739,194$ & - \\
Activo Intangible & 59,469 & 59,469 & - \\
Capital de Trabajo & 706,111 & 706,111 & - \\
Total & 4.504 .774 & 4.504 .774 & - \\
\hline
\end{tabular}

Nota: Elaboración Propia.

El capital propio sería aportado como se muestra en la Tabla 102:

Tabla 103.

Estructura de aportes del capital propio

\begin{tabular}{lrr}
\hline & APORTE & \\
Socios & Soles & $\%$ \\
\hline Verónica Indo & 337,858 & $7.50 \%$ \\
Denisse Olivos & 337,858 & $7.50 \%$ \\
Carmen Villagarcía & 337,858 & $7.50 \%$ \\
Marco Villena & 337,858 & $7.50 \%$ \\
Jorge Vaca & $3,153,342$ & $70.00 \%$ \\
\hline \multicolumn{1}{c}{ TOTAL } & $\mathbf{4 , 5 0 4 , 7 7 4}$ & $100.00 \%$ \\
\hline
\end{tabular}

Nota: Elaboración Propia.

\footnotetext{
${ }^{21}$ Ver de ejemplo el anexo XXV: Condiciones y requisitos de Mi Banco para construcción

${ }^{22}$ Ver la transcripción resumen en el anexo XXVI: Condiciones y requisitos de Mi Banco para construcción
} 


\section{Capítulo IX: Estudio de Ingresos y Costos}

\subsection{Ingresos}

\subsubsection{Ingresos por ventas.}

Los ingresos del ecolodge provienen de tres fuentes: venta directa a turistas, ventas a través de operadores turísticos y ventas por consumo en el bar.

1. Ingresos por paquetes: En la Tabla 103 se presentan los precios del ecolodge, los cuales se determinan en base a la fuente de ingreso y a la temporada de viaje. El precio rack se establece para venta directa a turistas en temporada alta, el precio best available rate para venta directa a turistas en temporada baja, y el precio operador para la venta a través de canal en ambas temporadas.

Tabla 104.

Precio por persona por paquete (expresado en dólares)

\begin{tabular}{llcccccc}
\hline \multirow{2}{*}{ Paquete } & \multicolumn{2}{c}{ Habitación } & \multicolumn{2}{c}{ Precio Rack } & \multicolumn{2}{c}{ Best Available Rate } & \multicolumn{2}{c}{ Operador } \\
\cline { 3 - 8 } & & sin IGV & con IGV & sin IGV & con IGV & sin IGV & con IGV \\
\hline Full day & Sin habitación & 130 & 153 & 104 & 122 & 88 & 104 \\
\hline Aventura en & Simple & 393 & 464 & 315 & 371 & 267 & 316 \\
Maras & Doble o matrimonial & 342 & 404 & 274 & 323 & 233 & 274 \\
\hline Experiencia & Simple & 520 & 614 & 416 & 491 & 354 & 417 \\
Kachi Raqay & Doble o matrimonial & 452 & 534 & 362 & 427 & 307 & 363 \\
\hline
\end{tabular}

Nota: Elaboración propia 
Tabla 105.

Precio por persona por paquete (expresado en soles)

\begin{tabular}{llcccccc}
\hline \multirow{2}{*}{ Paquete } & \multicolumn{2}{c}{ Habitación } & \multicolumn{2}{c}{ Precio Rack } & \multicolumn{2}{c}{$\begin{array}{c}\text { Best Available } \\
\text { Rate }\end{array}$} & \multicolumn{2}{c}{ Operador } \\
\hline & & sin IGV & con IGV & sin IGV & con IGV & sin IGV & con IGV \\
\hline Full day & Sin habitación & 421 & 497 & 337 & 398 & 286 & 338 \\
\hline Aventura en & Simple & 1,278 & 1,508 & 1,023 & 1,207 & 869 & 1,026 \\
Maras & Doble o matrimonial & 1,112 & 1,312 & 889 & 1,049 & 756 & 892 \\
\hline Experiencia & Simple & 1,690 & 1,994 & 1,352 & 1,595 & 1,149 & 1,356 \\
Kachi Raqay & Doble o matrimonial & 1,470 & 1,734 & 1,176 & 1,387 & 999 & 1,179 \\
\hline
\end{tabular}

Nota: Elaboración propia

Para obtener los ingresos por paquetes se ha calculado el precio ponderado por canal directo y por canal operador como se detalla a continuación:

Tabla 106.

Precio Ponderado Canal Directo (expresado en dólares)

\begin{tabular}{|c|c|c|c|c|c|c|}
\hline \multicolumn{4}{|c|}{ Paquetes } & \multirow{2}{*}{$\begin{array}{c}\text { Full } \\
\text { Day } \\
\text { sin IGV }\end{array}$} & \multirow{2}{*}{$\begin{array}{c}\text { Aventura } \\
\text { En Maras } \\
\text { sin IGV }\end{array}$} & \multirow{2}{*}{$\begin{array}{c}\text { Experiencia } \\
\text { Kachi Raqay } \\
\text { sin IGV }\end{array}$} \\
\hline Habitación & $\%$ & Temporada & $\%$ & & & \\
\hline \multirow[t]{2}{*}{ Simple } & $50 \%$ & Baja & $15 \%$ & 51 & 77 & 101 \\
\hline & & Alta & $85 \%$ & 358 & 543 & 718 \\
\hline \multirow[t]{2}{*}{ Doble o matrimonial } & $50 \%$ & Baja & $15 \%$ & & 67 & 88 \\
\hline & & Alta & $85 \%$ & & 472 & 625 \\
\hline Subtotal & & & & 408 & 1,159 & 1,532 \\
\hline Total Canal Directo & $65 \%$ & & & 265 & 753 & 996 \\
\hline
\end{tabular}

Nota: Elaboración propia

Tabla 107.

Precio Ponderado Canal Operador (expresado en dólares)

\begin{tabular}{lccccc}
\hline \multicolumn{2}{c}{ Paquetes } & & $\begin{array}{c}\text { Full } \\
\text { Day }\end{array}$ & $\begin{array}{c}\text { Aventura } \\
\text { en Maras }\end{array}$ & $\begin{array}{c}\text { Experiencia } \\
\text { Kachi Raqay }\end{array}$ \\
\hline Habitación & $\%$ & Operador & sin IGV & sin IGV & sin IGV \\
\hline Simple & $50 \%$ & $35 \%$ & 50 & 152 & 201 \\
Doble o matrimonial & $50 \%$ & $35 \%$ & & 132 & 175 \\
Canal operador & & & 100 & 284 & 376 \\
\hline
\end{tabular}

Nota: Elaboración propia 
A continuación, el resumen de precios ponderados por canal y el precio ponderado final por paquete que será utilizado para el cálculo de las ventas:

Tabla 108.

Precio Ponderado Final Paquetes Kachi Raqay (expresado en soles)

\begin{tabular}{lccccccc}
\hline \multirow{2}{*}{ Paquetes } & \multicolumn{2}{c}{$\begin{array}{c}\text { Full } \\
\text { Day }\end{array}$} & \multicolumn{2}{c}{$\begin{array}{c}\text { Aventura } \\
\text { en Maras }\end{array}$} & \multicolumn{2}{c}{$\begin{array}{c}\text { Experiencia } \\
\text { Kachi Raqay }\end{array}$} \\
\hline Canal & $\%$ & sin IGV & con IGV & sin IGV & con IGV & sin IGV & con IGV \\
\hline Directo & $65 \%$ & 265 & 313 & 753 & 889 & 996 & 1,175 \\
Operador & $35 \%$ & 100 & 118 & 284 & 336 & 376 & 444 \\
Pre. Ponderado final & 366 & 432 & 1,038 & 1,225 & 1,372 & 1,619 \\
\hline
\end{tabular}

Nota: Elaboración propia.

El ingreso por paquetes se obtiene multiplicando el precio ponderado final por el número de paquetes calculado en el capítulo IV $^{23}$ como se observa en la Tabla 108 a continuación:

Tabla 109.

Ingresos por paquetes 2018-2022 (expresado en soles)

\begin{tabular}{|c|c|c|c|c|c|c|c|c|c|c|c|}
\hline Años & & 2018 & & 2019 & & 2020 & & 2021 & & 2022 & \\
\hline Paquetes & Precio & $\mathrm{N}^{\circ}$ & $\mathrm{S} /$. & $\mathrm{N}^{\circ}$ & $\mathrm{S} /$. & $\mathrm{N}^{\circ}$ & $\mathrm{S} /$. & $\mathrm{N}^{\circ}$ & $\mathrm{S} /$. & $\mathrm{N}^{\circ}$ & $\mathrm{S} /$. \\
\hline Full day & 366 & 1,664 & 608,692 & 1,748 & 639,126 & 1,835 & 671,083 & 1,927 & 704,637 & 2,023 & 739,869 \\
\hline $\begin{array}{l}\text { Aventura en } \\
\text { Maras }\end{array}$ & 1,038 & 2,554 & $2,650,815$ & 2,797 & $2,902,642$ & 3,063 & $3,178,393$ & 3,354 & $3,480,341$ & 3,672 & $3,810,973$ \\
\hline $\begin{array}{l}\text { Experiencia } \\
\text { Kachi Raqay }\end{array}$ & 1,372 & 851 & $1,168,322$ & 932 & $1,279,313$ & 1,021 & $1,400,847$ & 1,118 & $1,533,928$ & 1,224 & $1,679,651$ \\
\hline Total & & & $4,427,829$ & & $4,821,081$ & & $5,250,323$ & & $5,718,905$ & & $6,230,492$ \\
\hline
\end{tabular}

Nota: Elaboración propia.

${ }^{23}$ Ver anexo XIV Ventas 
2. Ingresos Bar: El ecolodge contará con los servicios de bar en el restaurante. Los ingresos se estiman bajo el supuesto que el $11 \%$ de los turistas consume por lo menos una bebida en el bar $^{24}$ a un precio promedio de 20 soles cada una.

Tabla 110.

Ingresos Bar (expresado en soles)

\begin{tabular}{llllll}
\hline Años & 2018 & 2019 & 2020 & 2021 & 2022 \\
\hline Turistas & 5,070 & 5,477 & 5,919 & 6,398 & 6,920 \\
Promedio consumo $11 \%$ & 558 & 602 & 651 & 704 & 761 \\
Precio & 20 & 20 & 20 & 20 & 20 \\
Total & 11,155 & 12,049 & 13,021 & 14,077 & 15,223 \\
\hline
\end{tabular}

Nota: Elaboración propia

En la Tabla 110 a continuación, se presenta el total de ingresos por hospedaje y bar en el ecolodge:

Tabla 111.

Ingresos Totales Ecolodge (expresado en soles)

\begin{tabular}{llllll}
\hline Paquetes & 2018 & 2019 & 2020 & 2021 & 2022 \\
\hline Full day & 608,692 & 639,126 & 671,083 & 704,637 & 739,869 \\
Aventura en Maras & $2,650,815$ & $2,902,642$ & $3,178,393$ & $3,480,341$ & $3,810,973$ \\
Experiencia Kachi Raqay & $1,168,322$ & $1,279,313$ & $1,400,847$ & $1,533,928$ & $1,679,651$ \\
Bar & 11,155 & 12,049 & 13,021 & 14,077 & 15,223 \\
Total & $4,438,983$ & $4,833,131$ & $5,263,344$ & $5,732,982$ & $6,245,716$ \\
\hline
\end{tabular}

Nota: Elaboración propia

\footnotetext{
${ }^{24}$ Extraído de: https://peru21.pe/opinion/peruanos-beben-8-1-litros-licor-ano-157646
} 
Tabla 112.

Determinación IGV por ventas por año (expresado en soles)

\begin{tabular}{lrrlrrrr}
\hline \multirow{2}{*}{ Año/Paquetes } & $\begin{array}{r}\text { Full } \\
\text { Day }\end{array}$ & $\begin{array}{c}\text { Aventura } \\
\text { en Maras }\end{array}$ & $\begin{array}{c}\text { Experiencia } \\
\text { Kachi Raqay }\end{array}$ & Bar & $\begin{array}{c}\text { Total } \\
\text { Sin Igv }\end{array}$ & Igv & $\begin{array}{c}\text { Total } \\
\text { con Igv }\end{array}$ \\
\hline 2018 & 608,692 & $2,650,815$ & $1,168,322$ & 11,155 & $4,438,983$ & 799,017 & $5,238,000$ \\
2019 & 639,126 & $2,902,642$ & $1,279,313$ & 12,049 & $4,833,131$ & 869,964 & $5,703,094$ \\
2020 & 671,083 & $3,178,393$ & $1,400,847$ & 13,021 & $5,263,344$ & 947,402 & $6,210,746$ \\
2021 & 704,637 & $3,480,341$ & $1,533,928$ & 14,077 & $5,732,982$ & $1,031,937$ & $6,764,918$ \\
2022 & 739,869 & $3,810,973$ & $1,679,651$ & 15,223 & $6,245,716$ & $1,124,229$ & $7,369,944$ \\
\hline
\end{tabular}

Nota: Elaboración propia

\subsubsection{Recuperación capital de trabajo.}

Cómo se explicó en el inciso 8.1.3 la inversión en capital de trabajo está dada en base a los egresos de los 3 primeros meses necesarios para la operación del ecolodge. Para el cálculo de la variación del capital de trabajo se considera el incremento en las ventas de $8.8 \%$ a 8.94\% al final del quinto año. Este cálculo determina que para el año 2022 la inversión en capital de trabajo sería de 993,508 el cual se recupera al final del horizonte del proyecto, como se observa a continuación en la Tabla 112:

Tabla 113.

Recuperación del capital de trabajo (expresado en soles)

\begin{tabular}{|c|c|c|c|c|c|c|}
\hline Conceptos & & 2018 & 2019 & 2020 & 2021 & 2022 \\
\hline Ingreso por ventas & & 4.438 .983 & 4.833 .131 & 5.263 .344 & 5.732 .982 & 6.245 .716 \\
\hline Varia & & & $8,88 \%$ & $8,90 \%$ & $8,92 \%$ & $8,94 \%$ \\
\hline Capital de trabajo & & -706.111 & -768.808 & -837.242 & -911.948 & -993.508 \\
\hline Capital de trabajo incremental & -706.111 & -62.697 & -68.434 & -74.705 & -81.561 & \\
\hline Recuperación de capital de trabajo & & & & & & 993.508 \\
\hline
\end{tabular}

Nota: Elaboración Propia. 


\subsection{Costos y Gastos Anuales}

\subsubsection{Egresos desembolsables.}

\subsubsection{Presupuesto gastos por paquete}

El presupuesto de gastos por paquete incluye los siguientes conceptos: movilidad, guías, alimentos, entradas lugares turísticos, kit de amenities, actividades.

En la Tabla 113 se observa los gastos totales por paquete en el ecolodge:

Tabla 114.

Presupuesto de Gastos por Paquete ${ }^{25}$ (expresado en soles)

\begin{tabular}{lcccccc}
\hline Paquete & $\begin{array}{c}\text { Gasto por } \\
\text { Paquete }\end{array}$ & 2018 & 2019 & 2020 & 2021 & 2022 \\
\hline Paquete 1 & 291 & 484,520 & 508,746 & 534,183 & 560,893 & 588,937 \\
Paquete 2 & 455 & $1,161,429$ & $1,271,765$ & $1,392,583$ & $1,524,878$ & $1,669,741$ \\
Paquete 3 & 539 & 459,273 & 502,904 & 550,680 & 602,995 & 660,279 \\
Bebidas & 4.87 & 2,715 & 2,933 & 3,169 & 3,426 & 3,705 \\
Total & & $2,107,937$ & $2,286,348$ & $2,480,615$ & $2,692,191$ & $2,922,663$ \\
IGV & & 379,429 & 411,543 & 446,511 & 484,594 & 526,079 \\
Total Con IGV & & $2,487,366$ & $2,697,890$ & $2,927,126$ & $3,176,786$ & $3,448,742$ \\
\hline
\end{tabular}

Nota: Elaboración Propia.

\subsubsection{Presupuesto mano de obra directa}

La mano de obra directa está formada por todo el personal que presta el servicio de manera directa a los clientes del ecolodge. En la Tabla 114 se observa los sueldos mensuales y anuales según el número de trabajadores en cada puesto $^{26}$ :

\footnotetext{
${ }^{25}$ Ver detalle anexos XVI Cálculo costo por paquetes.

${ }^{26}$ Ver detalle en anexo XVII Planillas
} 
Tabla 115.

Mano de obra directa (expresado en soles)

\begin{tabular}{|c|c|c|c|c|c|c|c|c|c|c|}
\hline Cargo & $\mathrm{N}$ & $\begin{array}{l}\text { Remuneración } \\
\text { Básica }\end{array}$ & $\begin{array}{l}\text { Asignación } \\
\text { Familiar }\end{array}$ & $\begin{array}{l}\text { Remuneración } \\
\text { Mensual }\end{array}$ & $\begin{array}{c}\text { Gratificaciones } \\
\text { Totales }\end{array}$ & $\begin{array}{c}\text { Remuneración } \\
\text { Total }\end{array}$ & Essalud & $\begin{array}{c}\text { Comisiones } \\
\text { Totales }\end{array}$ & Cts Total & $\begin{array}{l}\text { Costo } \\
\text { Total } \\
\text { Anual }\end{array}$ \\
\hline $\begin{array}{l}\text { Supervisor } \\
\text { HHKK }\end{array}$ & 1 & 1,688 & 75 & 1,763 & 3,525 & 24,675 & 2,221 & 5,778 & 2,538 & 35,212 \\
\hline Supervisor FD & 1 & 1,688 & 75 & 1,763 & 3,525 & 24,675 & 2,221 & 5,778 & 2,538 & 35,212 \\
\hline Conserje & 3 & 1,100 & 75 & 1,175 & 7,050 & 16,450 & 1,481 & 17,334 & 5,557 & 76,683 \\
\hline Jefe de cocina & 1 & 1,688 & 75 & 1,763 & 3,525 & 24,675 & 2,221 & 5,778 & 2,538 & 35,212 \\
\hline Housekeeper & 3 & 1,050 & 75 & 1,125 & 6,750 & 15,750 & 1,418 & 17,334 & 5,382 & 74,219 \\
\hline Mantenimiento & 2 & 1,050 & 75 & 1,125 & 4,500 & 15,750 & 1,418 & 11,556 & 3,588 & 49,479 \\
\hline $\begin{array}{l}\text { Personal de } \\
\text { cocina }\end{array}$ & 3 & 1,050 & 75 & 1,125 & 6,750 & 15,750 & 1,418 & 17,334 & 5,382 & 74,219 \\
\hline Total & & & & & & & & & & 380,233 \\
\hline
\end{tabular}

Nota: Elaboración Propia.

Tabla 116.

Presupuesto de Mano de Obra Directa (expresado en soles)

\begin{tabular}{lccccc}
\hline Cargo & 2018 & 2019 & 2020 & 2021 & 2022 \\
\hline Supervisor HHKK & 35,212 & 35,767 & 36,374 & 37,037 & 37,760 \\
Supervisor FD & 35,212 & 35,767 & 36,374 & 37,037 & 37,760 \\
Conserje & 76,683 & 78,350 & 80,171 & 82,158 & 84,328 \\
Jefe de cocina & 35,212 & 35,767 & 36,374 & 37,037 & 37,760 \\
Housekeeper & 74,219 & 75,886 & 77,707 & 79,694 & 81,864 \\
Mantenimiento & 49,479 & 50,591 & 51,805 & 53,129 & 54,576 \\
Personal de cocina & 74,219 & 75,886 & 77,707 & 79,694 & 81,864 \\
Total & 380,233 & 388,016 & 396,512 & 405,786 & 415,911 \\
\hline
\end{tabular}

Nota: Elaboración Propia.

\subsubsection{Presupuesto de gastos administrativos}

Compuesto por lo siguiente: 
a. Remuneración Administrativos

Formado por los sueldos del gerente, el administrador, recepcionista y contador. ${ }^{27}$. En la Tabla 116 se muestra el detalle:

Tabla 117.

Remuneraciones Administrativas (expresado en soles)

\begin{tabular}{lcccccccccc}
\hline \multicolumn{1}{c}{ Cargo } & $N^{\circ}$ & $\begin{array}{c}\text { Remuneración } \\
\text { Básica }\end{array}$ & $\begin{array}{c}\text { Asignación } \\
\text { Familiar }\end{array}$ & $\begin{array}{c}\text { Remuneración } \\
\text { Mensual }\end{array}$ & $\begin{array}{c}\text { Gratificación } \\
\text { Total }\end{array}$ & $\begin{array}{c}\text { Remuneración } \\
\text { Total }\end{array}$ & EsSalud & $\begin{array}{c}\text { Comisión } \\
\text { Total }\end{array}$ & $\begin{array}{c}\text { Cts } \\
\text { Total }\end{array}$ & $\begin{array}{c}\text { Costo } \\
\text { Total } \\
\text { Anual }\end{array}$ \\
\hline Gerente & 1 & 3,000 & 75 & 3,075 & 6,150 & 43,050 & 3,875 & 5,778 & 4,069 & 56,772 \\
Administrador & 1 & 2,400 & 75 & 2,475 & 4,950 & 34,650 & 3,119 & 5,778 & 3,369 & 46,916 \\
Recepcionista & 3 & 1,100 & 75 & 1,175 & 7,050 & 16,450 & 1,481 & 17,334 & 5,557 & 76,683 \\
Contador & 1 & 2,250 & 75 & 2,325 & 4,650 & 32,550 & 2,930 & 5,778 & 3,194 & 44,452 \\
Total & & & & & & & & & & \\
\hline
\end{tabular}

Nota: Elaboración Propia.

Tabla 118.

Presupuesto Remuneraciones Administrativas (expresado en soles)

\begin{tabular}{llllll}
\hline Cargo & 2018 & 2019 & 2020 & 2021 & 2022 \\
\hline Gerente & 56,772 & 57,327 & 57,934 & 58,597 & 59,320 \\
Administrador & 46,916 & 47,471 & 48,078 & 48,741 & 49,464 \\
Recepcionista & 76,683 & 78,350 & 80,171 & 82,158 & 84,328 \\
Contador & 44,452 & 45,007 & 45,614 & 46,277 & 47,000 \\
Total & 224,821 & 228,157 & 231,798 & 235,772 & 240,111 \\
\hline
\end{tabular}

Nota: Elaboración Propia

b. Gastos de servicios.

Formado por el consumo en luz, agua, cable e internet. Para los gastos de luz y agua se recolectó información de los gastos mensuales de 3 hoteles en Cusco para determinar el gasto promedio mensual por $\mathrm{m}^{2}$. Luego, en base al tamaño del hotel de $1,144 \mathrm{~m}^{2}$, y la tasa de

${ }^{27}$ Ver detalle en Anexo XVII planillas. 
ocupabilidad anual se pudo determinar el costo anual en $\mathrm{m} 2$ para los servicios de luz y agua $^{28}$.

Para los gastos de cable e internet se considera un paquete de 256 soles mensuales.

En la Tabla 118 se detalla el consumo de luz y agua en el ecolodge:

Tabla 119.

Presupuesto de Servicio de Luz, Agua, Cable e Internet (expresado en soles)

\begin{tabular}{lccccc}
\hline Servicios & 2018 & 2019 & 2020 & 2021 & 2022 \\
\hline Tasa ocupabilidad & $53 \%$ & $55 \%$ & $58 \%$ & $61 \%$ & $64 \%$ \\
\hline Luz & 13,734 & 17,287 & 18,149 & 19,058 & 20,009 \\
Agua & 15,903 & 20,017 & 21,015 & 22,068 & 23,168 \\
Cable + Internet & 3,180 & 3,180 & 3,180 & 3,180 & 3,180 \\
Total & 32,817 & 40,483 & 42,344 & 44,306 & 46,357 \\
IGV & 5,907 & 7,287 & 7,622 & 7,975 & 8,344 \\
Total con IGV & 38,724 & 47,770 & 49,966 & 52,282 & 54,701 \\
\hline
\end{tabular}

Nota: Elaboración Propia.

c. Consumo de gasolina

En la Tabla 119 se muestra el consumo diario de gasolina se calcula en 25 soles, éste será empleado en las actividades diarias que realiza el ecolodge a los diferentes destinos turísticos. En la Tabla 120 se muestra el presupuesto por año para el consumo de combustible.

\footnotetext{
${ }^{28}$ Ver detalle en Anexo XVIII Cálculo de servicios y cálculo de costo variable unitario
} 
Tabla 120.

Costo Consumo Combustible (expresado en soles)

\begin{tabular}{cccc}
\hline Consumo Diario & $\mathrm{N}^{\circ}$ Vehículos & $\mathrm{N}^{\circ}$ Días & Total Sin IGV \\
\hline 25 & 1 & 360 & 9,000 \\
& Total & & 9,000 \\
\hline
\end{tabular}

Nota: Elaboración Propia.

Tabla 121.

Presupuesto Consumo de Combustible (expresado en soles)

\begin{tabular}{lccccc}
\hline \multicolumn{1}{c}{ Concepto } & 2018 & 2019 & 2020 & 2021 & 2022 \\
\hline Combustible & 9,000 & 9,000 & 9,000 & 9,000 & 9,000 \\
Igv & 1,620 & 1,620 & 1,620 & 1,620 & 1,620 \\
Total Con Igv & 10,620 & 10,620 & 10,620 & 10,620 & 10,620 \\
\hline
\end{tabular}

Nota: Elaboración Propia.

d. Resumen Gastos Administrativos.

En la Tabla 121 se detalla el consolidado de remuneraciones y gastos en servicios, únicamente el consumo en servicios está afecto al IGV.

Tabla 122.

Presupuesto Gastos Administrativos (expresado en soles)

\begin{tabular}{lccccc}
\hline Concepto & 2018 & 2019 & 2020 & 2021 & 2022 \\
\hline Remuneraciones & 224,821 & 228,157 & 231,798 & 235,772 & 240,111 \\
Servicios & 32,817 & 40,483 & 42,344 & 44,306 & 46,357 \\
Combustible & 9,000 & 9,000 & 9,000 & 9,000 & 9,000 \\
Total & 257,638 & 268,640 & 274,142 & 280,078 & 286,468 \\
IGV & 7,527 & 8,907 & 9,242 & 9,595 & 9,964 \\
Total con IGV & 265,165 & 277,547 & 283,384 & 289,674 & 296,432 \\
\hline
\end{tabular}

Nota: Elaboración Propia. 


\subsubsection{Presupuesto gastos de marketing y ventas}

Los gastos de marketing y ventas están formados por lo siguiente:

- Sueldo área de ventas: Un ejecutivo comercial que se encargará de vender los paquetes del ecolodge.

- Family trips: Se invitará a 24 operadores de turismo a disfrutar del paquete $\mathrm{N}^{\circ} 3$ en el ecolodge para que conozcan los servicios ofrecidos y puedan venderlos a los turistas.

- Mantenimiento página web: Se estima un pago mensual de 65 soles por monitoreo y revisión por un profesional web.

- Folletería: Se estima un gasto trimestral de 100 soles.

- Premios concurso: Constará de una canasta con sal de maras, aceite de sacha inchi y chocolates rellenos de pisco.

- Patrocinio a ferias: Se patrocinará 4 ferias por año con todos los gastos pagados a los operadores de turismo.

En la Tabla 123 se presenta un resumen de los gastos de marketing y ventas por año ${ }^{29}$ :

\footnotetext{
${ }^{29}$ Ver detalle en Anexo XIX gastos de ventas.
} 
Tabla 123.

Presupuesto de Gastos de Ventas y Marketing (expresado en soles)

\begin{tabular}{lccccc}
\hline Concepto & 2018 & 2019 & 2020 & 2021 & 2022 \\
\hline Sueldos marketing & 44,452 & 45,007 & 45,614 & 46,277 & 47,000 \\
Family Trips & 12,945 & 12,945 & 12,945 & 12,945 & 12,945 \\
Mantenimiento página web & 780 & 780 & 780 & 780 & 780 \\
Folletería & 400 & 400 & 400 & 400 & 400 \\
Premios Concurso & 2,160 & 2,160 & 2,160 & 2,160 & 2,160 \\
Patrocinio Ferias & 8,897 & 8,897 & 8,897 & 8,897 & 8,897 \\
Total & 69,634 & 70,190 & 70,797 & 71,459 & 72,183 \\
\hline
\end{tabular}

Nota: Elaboración Propia.

\subsubsection{Egresos no desembolsables.}

\subsubsection{Depreciación}

Se observa en la Tabla 124 la depreciación anual calculada en base al valor de adquisición sin IGV, y los porcentajes de depreciación correspondiente para cada activo fijo de acuerdo al artículo 22 del reglamento de la Ley de Impuesto a la Renta D.S N. 122-94-EF donde se indica que la depreciación de edificios y construcciones es del $5 \% .{ }^{30}$

\footnotetext{
${ }^{30}$ Ver detalle Anexo XX depreciación.
} 
Tabla 124.

Depreciación Anual de Activos Fijos (expresado en soles)

\begin{tabular}{lccccc}
\hline \multicolumn{1}{c}{ ACTIVO FIJO } & $\begin{array}{c}\text { VALOR DE } \\
\text { ADQUISICION }\end{array}$ & DEPRECIACION & $\begin{array}{c}\text { DEPRECIACION } \\
\text { ANUAL }\end{array}$ & $\begin{array}{c}\text { DEPRECIACION } \\
\text { ACUMULADA } \\
\text { 5TO ANO }\end{array}$ & $\begin{array}{c}\text { VALOR } \\
\text { RESIDUAL }\end{array}$ \\
\hline Terreno & 116,000 & $0 \%$ & 0 & 0 & 116,000 \\
Construcción & $3,420,916$ & $5 \%$ & 171,046 & 855,229 & $2,565,687$ \\
Equipos de & 3,305 & $25 \%$ & 826 & 3,305 & 0 \\
procesamiento de datos & & & & & 6,648 \\
Maquinaria y equipo & 13,296 & $10 \%$ & 1,330 & 6,648 & 46,719 \\
Mueble y enseres & 93,438 & $10 \%$ & 9,344 & 46,719 & 0 \\
Vehículo de Transporte & 92,239 & $20 \%$ & 18,448 & 92,239 & $2,735,054$ \\
\hline TOTAL & $3,739,194$ & & 200,993 & $1,004,140$ & \\
\hline
\end{tabular}

Nota: Elaboración Propia.

En la Tabla 125 se muestra la depreciación para los años 2018-2022:

Tabla 125.

Depreciación Anual de Activos Fijos 2018-2022 (expresado en soles)

\begin{tabular}{lcccccc}
\hline \multicolumn{1}{c}{ ACTIVO FIJO } & $\mathbf{2 0 1 8}$ & $\mathbf{2 0 1 9}$ & $\mathbf{2 0 2 0}$ & $\mathbf{2 0 2 1}$ & $\mathbf{2 0 2 2}$ & Total \\
\hline Construcción & 171,046 & 171,046 & 171,046 & 171,046 & 171,046 & 855,229 \\
Equipos de & 826 & 826 & 826 & 826 & & 3,305 \\
procesamiento de datos & & & & & & \\
Maquinaria y equipo & 1,330 & 1,330 & 1,330 & 1,330 & 1,330 & 6,648 \\
Mueble y enseres & 9,344 & 9,344 & 9,344 & 9,344 & 9,344 & 46,719 \\
Vehículo de Transporte & 18,448 & 18,448 & 18,448 & 18,448 & 18,448 & 92,239 \\
\hline TOTAL & 200,993 & 200,993 & 200,993 & 200,993 & 200,167 & $1,004,140$ \\
\hline
\end{tabular}

Nota: Elaboración Propia. 


\subsubsection{Amortización de intangibles.}

En la tabla 98 se detalló los conceptos por gastos pre-operativos que forman parte de los activos intangibles como se observa en la Tabla 126:

Tabla 126.

Amortización de Activos Intangibles (expresado en soles)

\begin{tabular}{lccc}
\hline \multicolumn{1}{c}{ Activos Intangibles } & Costo Total sin IGV (S/.) & IGV & Costo Total con IGV (S/.) \\
\hline Aspectos legales & 1,295 & 233 & 1,528 \\
Software & 4,550 & 819 & 5,369 \\
Gastos Pre-operativos & 51,674 & 9,301 & 60,975 \\
Creación de la página web & 1,950 & 351 & 2,301 \\
Total & 59,469 & 10,704 & 70,173 \\
\hline
\end{tabular}

Nota: Elaboración Propia.

A continuación, en la Tabla 127 se presenta la amortización de los activos intangibles de acuerdo a la norma de Ley de Impuesto a la Renta para los años 2018-2022

Tabla 127.

Amortización Anual de Intangibles 2018-2022 (expresado en soles)

\begin{tabular}{ccccc}
\hline 2018 & 2019 & 2020 & 2021 & 2022 \\
\hline 11,894 & 11,894 & 11,894 & 11,894 & 11,894 \\
& Total & & & 59,469 \\
\hline
\end{tabular}

Nota: Elaboración Propia. 


\section{Capítulo X: Estados Financieros Proyectados}

\subsection{Premisas del estado de resultado y del flujo de caja.}

Estado de resultados

- Horizonte de evaluación es a 5 años.

- El tipo de cambio es 3.25.

- Las operaciones inician en enero del 2018.

- Costos y precios son constantes.

- Todos los montos están expresados en soles.

- Impuesto a la renta es $29.5 \%$.

- Ingresos y egresos son al contado.

Flujo de caja

- Los ingresos y egresos están afectos al IGV, excepto mano de obra, amortizaciones y depreciaciones.

\subsection{Estado de resultados proyectado}

En el estado de resultados se presentan los ingresos por ventas y los egresos del ecolodge, para de esta forma obtener el margen de contribución, utilidad bruta y llegar finalmente a la utilidad neta. Como se observa en la Tabla 128 la utilidad neta para el primer año es de 1,036,400 soles. 
Tabla 128.

Estado de resultados (expresado en soles)

\begin{tabular}{|c|c|c|c|c|c|}
\hline Estado de resultados & 2018 & 2019 & 2020 & 2021 & 2022 \\
\hline Ventas & $4,512,908$ & $4,913,621$ & $5,351,001$ & $5,828,461$ & $6,349,736$ \\
\hline Costo de ventas & $2,475,651$ & $2,660,733$ & $2,862,282$ & $3,081,807$ & $3,320,958$ \\
\hline Utilidad Bruta & $2,037,256$ & 2,252,888 & $2,488,719$ & $2,746,654$ & $3,028,779$ \\
\hline Gastos administrativos & 261,273 & 271,798 & 276,780 & 282,149 & 287,918 \\
\hline Gastos de ventas & 68,740 & 69,217 & 69,737 & 70,304 & 70,924 \\
\hline EBITDA & $1,707,243$ & $1,911,873$ & $2,142,202$ & $2,394,201$ & $2,669,936$ \\
\hline Depreciación & 200,993 & 200,993 & 200,993 & 200,993 & 200,167 \\
\hline Amortización & 11,894 & 11,894 & 11,894 & 11,894 & 11,894 \\
\hline Utilidad operativa & $1,494,356$ & $1,698,986$ & $1,929,315$ & $2,181,314$ & $2,457,875$ \\
\hline Ingresos extraordinarios & 0 & 0 & 0 & 0 & 0 \\
\hline $\begin{array}{l}\text { Utilidad antes de } \\
\text { impuestos }\end{array}$ & $1,494,356$ & $1,698,986$ & $1,929,315$ & $2,181,314$ & $2,457,875$ \\
\hline $\begin{array}{l}\text { Impuesto a la renta } \\
(29.5 \%)\end{array}$ & 440,835 & 501,201 & 569,148 & 643,488 & 725,073 \\
\hline Utilidad Neta & $1, \mathbf{0 5 3 , 5 2 1}$ & $1,197,785$ & $1,360,167$ & $1,537,826$ & $1,732,802$ \\
\hline
\end{tabular}

Nota: Elaboración Propia

\subsection{Flujo de caja operativo proyectado}

El flujo de caja operativo es la utilidad neta más depreciación y amortización.

Tabla 129.

Flujo de Caja Operativo Proyectado (expresado en soles)

\begin{tabular}{lccccc}
\hline Flujo de caja operativo & 2018 & 2019 & 2020 & 2021 & 2022 \\
\hline Utilidad Neta & $1,053,521$ & $1,197,785$ & $1,360,167$ & $1,537,826$ & $1,732,802$
\end{tabular}


Depreciación

200,993

200,993

200,993

200,993

200,167

Amortización

$11,894 \quad 11,894 \quad 11,894 \quad 11,894 \quad 11,894$

Flujo de caja operativo

\section{$\begin{array}{lllll}1,266,408 & 1,410,672 & 1,573,054 & 1,750,713 & 1,944,863\end{array}$}

Nota: Elaboración Propia.

\subsection{Cálculo de la perpetuidad}

El valor residual se calcula porque se supone la empresa tendrá una duración mayor al horizonte del proyecto, por lo tanto, se empleará el método económico (perpetuidad) para el cálculo correspondiente del valor residual de los activos fijos, el cual consiste en determinar el valor de la empresa considerando el costo de capital y una tasa perpetua de crecimiento.

Perpetuidad creciente

$$
V R=\frac{V(1+g)}{(r-g)}
$$

Donde:

$\begin{array}{ll}\text { V: Último flujo económico } & : 1,944,863 \\ \text { r: Tasa de descuento } & : 35 \% \\ \text { g: Tasa de crecimiento } & : 4 \%\end{array}$

$V R=6,524,701$

\subsection{Flujo de caja de inversión proyectado}

Muestra la inversión en activos fijos tangibles y en activos intangibles (En la tabla 98 se detalló los conceptos por gastos pre operativos que forman parte de los activos intangibles), el capital de trabajo requerido y el incremento en capital de trabajo. 
Tabla 130.

Flujo de Caja de Inversión Proyectado (expresado en soles)

\begin{tabular}{lcccccc}
\hline Flujo de Caja de Inversión & 2017 & 2018 & 2019 & 2020 & 2021 & 2022 \\
\hline Inversión en activos fijos & $-3,739,194$ & & & & & \\
Inversión en activos intangibles & $-59,469$ & & & & & \\
Capital de trabajo incremental & $-701,416$ & $-62,281$ & $-67,980$ & $-74,209$ & $-81,019$ & \\
Valor residual & & & & & & $6,524,701$ \\
Recuperación Capital de trabajo & $-4,500,079$ & $-62,281$ & $-67,980$ & $-74,209$ & $-81,019$ & $6,524,701$ \\
\hline Flujo de Caja de Inversión & & & & & & \\
\hline
\end{tabular}

Nota: Elaboración Propia.

\subsection{Flujo de caja económico proyectado}

Diferencia entre el flujo de caja operativo y flujo de caja de inversión. Se muestra un flujo económico positivo a partir del segundo año de operación. Este flujo es utilizado para el cálculo del VANE.

Tabla 131.

Flujo de Caja Económico (expresado en soles)

\begin{tabular}{lcccccc}
\hline Flujo de Caja Económico & 2017 & 2018 & 2019 & 2020 & 2021 & 2022 \\
\hline Flujo de caja operativo & 0 & $1,266,408$ & $1,410,672$ & $1,573,054$ & $1,750,713$ & $1,944,863$ \\
Flujo de caja de Inversión & $-4,500,079$ & $-62,281$ & $-67,980$ & $-74,209$ & $-81,019$ & $6,524,701$ \\
\hline Flujo de Caja Económico & $\mathbf{- 4 , 5 0 0 , 0 7 9}$ & $\mathbf{1 , 2 0 4 , 1 2 8}$ & $\mathbf{1 , 3 4 2 , 6 9 2}$ & $\mathbf{1 , 4 9 8 , 8 4 5}$ & $\mathbf{1 , 6 6 9 , 6 9 4}$ & $\mathbf{8 , 4 6 9 , 5 6 4}$ \\
\hline
\end{tabular}

Nota: Elaboración propia. 
Dado que la estructura del financiamiento del proyecto ha cambiado al contar con un nuevo accionista, no considera el servicio de la deuda y por lo tanto no se presentará Flujo de Caja Financiero.

\subsection{Premisas del estado de situación financiera}

- Horizonte de evaluación es a 5 años.

- Se considera un inventario de 6 meses.

- El tipo de cambio es 3.25.

- Costos y precios son constantes.

- Todos los montos están expresados en soles.

- Las utilidades no serán distribuidas en el horizonte del proyecto. 
Tabla 132.

Estado de situación financiera (expresado en soles)

\begin{tabular}{|c|c|c|c|c|c|c|}
\hline Estado de situación financiera & 0 & 2018 & 2019 & 2020 & 2021 & 2022 \\
\hline \multicolumn{7}{|l|}{ ACTIVOS } \\
\hline \multicolumn{7}{|l|}{ Activos Corrientes } \\
\hline Caja & & $1,266,408$ & $1,410,672$ & $1,573,054$ & $1,750,713$ & $1,944,863$ \\
\hline Capital de trabajo & 701,416 & 701,416 & 763,697 & 831,676 & 905,885 & 986,904 \\
\hline Inventario & & 123,783 & 133,037 & 143,114 & 154,090 & 166,048 \\
\hline Total Activos Corrientes & 701,416 & $2,091,607$ & $2,307,405$ & $2,547,845$ & $2,810,689$ & $3,097,815$ \\
\hline \multicolumn{7}{|l|}{ Activos No Corrientes } \\
\hline Maquinaria y equipo, neto & 13,296 & 11,966 & 10,637 & 9,307 & 7,977 & 6,648 \\
\hline Terreno & 116,000 & 116,000 & 116,000 & 116,000 & 116,000 & 116,000 \\
\hline Edificio, neto & $3,420,916$ & $3,249,870$ & $3,078,824$ & $2,907,779$ & $2,736,733$ & $2,565,687$ \\
\hline Vehículo, neto & 92,239 & 73,792 & 55,344 & 36,896 & 18,448 & 0 \\
\hline $\begin{array}{l}\text { Mobiliario y equipo de oficina, } \\
\text { neto }\end{array}$ & 96,743 & 86,573 & 76,403 & 66,233 & 56,063 & 46,719 \\
\hline Activos intangibles & 59,469 & 47,575 & 35,681 & 23,787 & 11,894 & 0 \\
\hline Total Activos No Corrientes & $3,798,663$ & $3,585,776$ & $3,372,889$ & $3,160,002$ & $2,947,115$ & $2,735,054$ \\
\hline Total Activos & $4,500,079$ & $5,677,383$ & $5,680,294$ & $5,707,846$ & $5,757,804$ & $5,832,869$ \\
\hline \multicolumn{7}{|l|}{ PASIVOS } \\
\hline Total Pasivos & & 0 & 0 & 0 & 0 & 0 \\
\hline \multicolumn{7}{|l|}{ PATRIMONIO } \\
\hline Capital social & $4,500,079$ & $4,500,079$ & $4,500,079$ & $4,500,079$ & $4,500,079$ & $4,500,079$ \\
\hline Reserva Legal & 0 & 105,352 & 119,778 & 136,017 & 153,783 & 173,280 \\
\hline Resultados acumulados & 0 & $1,072,578$ & $1,129,953$ & $1,210,200$ & $1,311,373$ & $1,435,973$ \\
\hline Total Patrimonio & $4,500,079$ & $5,678,009$ & $5,749,811$ & $5,846,296$ & $5,965,234$ & $6,109,332$ \\
\hline Total Pasivo y Patrimonio & $4,500,079$ & $5,678,009$ & $5,749,811$ & $5,846,296$ & $5,965,234$ & $6,109,332$ \\
\hline
\end{tabular}

Nota: Elaboración propia. 


\section{Capítulo XI: Evaluación económica financiera}

\subsection{Cálculo de la tasa de descuento.}

\subsubsection{Cálculo de la tasa de descuento}

Para determinar la tasa de descuento, se analizarán dos métodos:
1. El modelo CAPM
2. Valoración de experto

\subsubsection{Determinación de la tasa de descuento mediante el CAPM}

El modelo CAPM (Capital Asset Pricing Model) es un modelo financiero que vincula, linealmente, la rentabilidad de cualquier activo financiero con el riesgo de mercado de ese activo. (Lira Briceño, Un modelo financiero: EL CAPM, 2011)

El modelo CAPM plantea una tasa de retorno esperada por los inversionistas, la cual está en función al rendimiento que se obtendría en una inversión "segura" más los rendimientos que deberían obtenerse por correr el riesgo de invertir en el activo financiero:

$$
r_{i}=r_{f}+\beta_{i}\left(r_{m}-r_{f}\right)
$$

Donde:

$r_{i}$ : Rentabilidad esperada

$r_{f}$ : Rentabilidad libre de riesgo

$\beta_{i}$ : Riesgo de mercado 
$r_{m}:$ Rendimiento de mercado

$\left(r_{m}-r_{f}\right):$ Prima por riesgo de mercado

\section{Rentabilidad libre de riesgo $\left(\boldsymbol{r}_{\boldsymbol{f}}\right)$}

Se utiliza el rendimiento promedio de los bonos de los Estados Unidos, calculado en base al último periodo similar al proyecto a evaluar (Bravo, 2008). Como en el proyecto del ecolodge Kachi Raqay, se plantea evaluar un horizonte de cinco años, se tomará el rendimiento promedio aritmético de los últimos 10 años (Damodaran, Annual Returns on Stock, T.Bonds and T.Bills: 1928 - Current, 2017)

$$
r_{f}=5,03 \%
$$

\section{Riesgo de mercado $\left(\beta_{i}\right)$}

El riesgo de mercado $\beta$, vendría a ser la pendiente dentro del modelo lineal, establecido en base al histórico del valor de las acciones de las empresas relacionadas (Bravo, 2008) que mide que tan riesgoso es un activo financiero, estableciendo la unidad como punto de referencia. Por ejemplo un $\beta=1,20(0,20$ mayor que la unidad) quiere decir que es un activo expuesto altamente a las variaciones del mercado por ende es un activo riesgoso, situación que se da generalmente en empresas pequeñas. Lo opuesto para un $\beta=0,85$ ( 0,15 menor que la unidad), sería un activo de menor riesgo.

Debido a que el financiamiento propuesto es $100 \%$ propio, para este caso se toma en cuenta el $\beta$ desapalancado de la industria hotelera (Damodaran, Betas by Sector (US), 2017)

$$
\beta_{\text {EEUU }(\text { Hotel/Gaming) }}=0,72
$$




\section{Rendimiento de mercado $\left(\boldsymbol{r}_{m}\right)$}

Este es el promedio aritmético de los últimos 10 años del rendimiento de las acciones de las empresas más representativas de los Estados Unidos, representadas en el índice S\&P 500 (Damodaran, Annual Returns on Stock, T.Bonds and T.Bills: 1928

- Current, 2017):

$$
r_{m}=8,65 \%
$$

Prima por riesgo de mercado $\left(r_{m}-r_{f}\right)$

Es la diferencia entre el rendimiento del mercado $\left(r_{m}\right)$ y la tasa libre de riesgo $\left(r_{f}\right)^{31} .($ Bravo, 2008)

$$
\left(r_{m}-r_{f}\right)=(8,65 \%-5,03 \%)=3,62 \%
$$

Cálculo del retorno esperado (rentabilidad esperada)

$$
\begin{aligned}
& r_{i}=r_{f}+\beta\left(r_{m}-r_{f}\right) \\
& r_{i}=5,03 \%+0,72(3,62 \%) \\
& r_{i}=7,64 \%
\end{aligned}
$$

Cálculo del retorno esperado para un hotel en Perú

El retorno esperado obtenido $\left(r_{i}\right)$, sería el costo del capital $(\mathrm{COK})$ o la rentabilidad nominal esperada de una empresa sin apalancamiento, en un país desarrollado. Sin embargo, para economías emergentes como el Perú, se debe incluir el riesgo país (Bravo, 2008), el cual para el 2017 es de 1,41\% (Gestión, 2017)

\footnotetext{
${ }^{31}$ Algunos autores sugieren que no se trata del mismo $r_{f}$, y en el segundo $r_{f}$ proponen utilizar el promedio geométrico de todos los rendimientos registrados desde 1928 (Lira Briceño, Determinando la tasa de descuento de un proyecto (caso práctico), 2012), sin embargo la mayoría autores consultados coinciden en que ambos $r_{f}$ se refieren a la tasa libre de riesgo, por lo cual se tomó dicha interpretación para este caso.
} 
$C O K_{\text {Perú }}=r_{i}+$ riesgo país

COK $_{\text {Perú }}=7,64 \%+1,41 \%$

COK $_{\text {Perú }}=9,05 \%$

9,05\% sería la rentabilidad para invertir dólares americanos constantes en un hotel en un país emergente como el Perú. Sin embargo, como las ventas están proyectadas en soles constantes, se debe deflactar el COK para determinar la variación que genera la diferencia de inflaciones. Para tal efecto se utilizará la fórmula:

Efecto de inflaciones diferentes: $\frac{\left(1+\pi_{P e r u ́}\right)}{\left(1+\pi_{E E U U}\right)}-1$

$\pi_{P e r u ́}:$ Inflación del Perú=3.08\%

$\pi_{\text {EEUU }}:$ Inflación de Estados Unidos=2.04\%

Efecto de inflaciones diferentes: $\frac{(1+3.08 \%)}{(1+2.04 \%)}-1=1.02 \%$

El nuevo COK sería:

$C O K_{\text {Real }}=C_{\text {Perú }}+$ efecto inflación

$\mathrm{COK}_{\text {Real }}=9.05 \%+1.02 \%$

$\mathrm{COK}_{\text {Real }}=10.06 \%$

Pero también hay un riesgo más que adicionar, que es el del proyecto en sí. Si bien debería de explorarse la rentabilidad de hoteles en la misma zona, al no haber competencia, esta tarea se hace imposible. Por lo cual, para considerar una tasa holgada, se plantea un escenario pesimista y se asume que el riesgo se duplica. 


$$
\begin{aligned}
& C O K_{\text {Albergue en } \text { Maras }}=C O K_{\text {Real }}+\text { Riesgo } \text { Maras } \\
& C O K_{\text {Albergue en } \text { Maras }}=10.06 \%+10.06 \% \\
& C O K_{\text {Albergue en Maras }}=20.12 \%
\end{aligned}
$$

\subsubsection{Determinación de la tasa de descuento mediante valoración}

\section{de experto}

Según el autor Pablo Fernández, el modelo CAPM presenta una debilidad, el trabajar con un valor Beta mal calculado ${ }^{32}$ (Fernandez, 2016). Por lo cual, entendiendo que la tasa de costo de capital COK, es la rentabilidad esperada por los accionistas, se consultó a un experto en el rubro como posible accionista.

En la entrevista descrita en el inciso 8.1.1 estructura de inversión, a Jorge $\mathrm{Vaca}^{33}$, el menciona que la utilidad esperada para hoteles de 3 estrellas en países emergentes en Latinoamérica está entre $20 \%$ y 25\% dependiendo de las características propias del proyecto. Sin embargo, para un hotel en poblados alejados donde se piensa incursionar para abrir mercado, el sugiere considerar hasta un 35\%. Debido a esto, para el proyecto se tomará en cuenta la siguiente tasa:

\footnotetext{
${ }^{32}$ El Beta en el modelo CAPM está mal calculado por 7 razones:

1. Porque los datos históricos cambian mucho de un día para otro.

2. Porque dependen de qué indice bursátil se tome como referencia.

3. Porque dependen mucho de qué periodo histórico (5 años, 3 años) y de qué rentabilidades (mensuales, anuales) se utilicen para su cálculo.

4. Porque con mucha frecuencia no sabemos si la beta de una empresa es superior o inferior a la beta de otra empresa.

5. Porque tienen muy poca relación con la rentabilidad posterior de las acciones.

6. Porque la correlación (y la $R^{2}$ ) de las regresiones que se utilizan para su cálculo son muy pequeñas.
}

${ }^{33}$ Ver la transcripción resumen en el anexo XXVI: Transcripción resumen de conversación con Jorge Vaca, accionista y gerente 


$$
\text { COK Kachi Raqay }=35 \%
$$

Costo de la deuda

Debido a que el proyecto no tendrá financiamiento bancario, no se tomará en cuenta el costo de la deuda, ya que no existe. Debido a esto tampoco se considerará ponderar un costo promedio de capital, ya que el COK ya representa la tasa a la que se descontarán los flujos del proyecto.

\subsection{Indicadores de rentabilidad.}

\subsubsection{Cálculo del VANE}

El valor actual neto económico es el resultado de actualizar los flujos de caja económicos del proyecto, usando de tasa de descuento (COK), para determinar si el valor actualizado es mayor que cero. Esto querría decir que la inversión supera el costo de oportunidad de invertirla en el mercado de capitales (Brealey, Myers, \& Allen, 2010).

Para tal efecto se utiliza la siguiente formula:

$$
V A N E=-I_{o}+\sum \frac{F C E_{i}}{(1+C O K)^{i}}
$$

Donde:

$\mathrm{I}_{\mathrm{o}}=$ Inversión inicial

$\mathrm{i}=$ Número de periodo 
$\mathrm{FCE}_{\mathrm{i}}=$ Flujo de caja económico de cada periodo

$\mathrm{COK}=$ Retorno esperado (tasa de descuento)

Reemplazando los valores se tiene:

$\mathrm{VANE}=129,311$

Como el VANE es superior a cero, quiere decir que los flujos descontados del proyecto son mayores a la inversión. Por lo tanto, se acepta el proyecto.

\subsubsection{Cálculo de la TIRE}

La tasa interna de retorno económico se define como la tasa de descuento a la cual el VANE $=0$

La regla de la tasa interna de rendimiento consiste en aceptar un proyecto de inversión si el costo de oportunidad del capital es menor que la tasa interna de rendimiento. (Brealey, Myers, \& Allen, 2010)

Su cálculo puede ser por aproximaciones sucesivas hasta lograr que la inversión sea igual a los flujos actualizados, es decir tanteo hasta que la utilidad sea cero, o mediante software. Para el presente proyecto se utilizó la fórmula "TIR" de Excel, Ms Office:

TIRE $=36.14 \%$

$\mathrm{COK}=35 \%$ 
Como la rentabilidad esperada (COK) es menor que la TIRE, se acepta el proyecto.

Como la inversión es $100 \%$ propia, al no haber deuda no se determina VANF, ni TIRF. Por lo tanto, con los indicadores calculados, se acepta el proyecto.

\subsubsection{Período de recuperación descontado}

El período de recuperación descontado es un método de valoración de proyectos de inversión, que incorpora el concepto de valor del dinero en el tiempo mediante el descuento de los flujos netos de caja de cada período, para obtener el tiempo en que se recuperará la inversión. (Brealey, Myers, \& Allen, 2010)

Para tal efecto se utiliza la siguiente fórmula:

$$
P R D=a+\frac{I_{o}-b}{F T}
$$

Donde:

$a=$ Número del período inmediatamente anterior hasta recuperar el desembolso inicial.

$\mathrm{I}_{\mathrm{o}}=$ Inversión inicial del proyecto.

$\mathrm{b}=$ Suma de los flujos descontados hasta el final del período $\mathrm{a}$.

FT = Valor del flujo de caja del año en que se recupera la inversión

Esta fórmula nos arroja el resultado mostrado en la tabla siguiente: 
Tabla 133.

Período de recuperación descontado (expresado en años)

\begin{tabular}{lcccccc}
\hline $\begin{array}{l}\text { PERIODO DE } \\
\text { RECUPERACION } \\
\text { DESCONTADO }\end{array}$ & $\mathbf{0}$ & $\mathbf{1}$ & $\mathbf{2}$ & $\mathbf{3}$ & $\mathbf{4}$ & $\mathbf{5}$ \\
\hline Flujo descontado & $-4,500,079$ & $1,625,572$ & $2,447,057$ & $3,687,721$ & $5,545,900$ & $37,977,810$ \\
Flujo acumulado & $-4,500,079$ & $-2,874,507$ & $-427,450$ & $3,260,272$ & $8,806,172$ & $46,783,982$ \\
\hline $\begin{array}{l}\text { PERIODO DE } \\
\begin{array}{l}\text { RECUPERACION } \\
\text { DESCONTADO }\end{array}\end{array}$ & & & $\mathbf{2 . 1 2}$ Años & & \\
\hline
\end{tabular}

Nota: Elaboración propia.

El período de recuperación descontado del proyecto es de dos años, un mes y dos semanas.

\subsection{Análisis del punto de equilibrio}

El punto de equilibrio es aquella cantidad de producción vendida a la cual los ingresos totales son iguales a los costos totales, es decir aquel volumen de ventas que arroja cero unidades monetarias de utilidad. (Horngren, Datar, \& Rajan, 2012)

La técnica utilizada es el análisis costo-volumen-utilidad con efectos de la mezcla de ventas sobre el ingreso para determinación del punto de equilibrio operativo.

Para su determinación es necesario determinar el costo variable unitario, la mezcla de ventas y el margen de contribución de la mezcla, los cuales serán explicados a profundidad más adelante.

Para determinar el costo variable unitario, el primer paso es diferenciar los costos fijos de los variables. 


\subsubsection{Costos fijos y costos variables.}

\subsubsection{Costos fijos.}

Son los costos que no dependen de la cantidad de paquetes que vende el ecolodge. Se detalla a continuación en la Tabla 134 los costos fijos para los años 2018-2022. Se asume que los gastos por servicios son fijos en un $15 \%$.

Tabla 134.

Costos fijos 2018-2022 (expresado en soles)

\begin{tabular}{lccccc}
\hline Costos & 2018 & 2019 & 2020 & 2021 & 2022 \\
\hline Planilla & 528,168 & 529,066 & 530,046 & 531,116 & 532,284 \\
Servicios & 4,923 & 6,073 & 6,352 & 6,646 & 6,953 \\
Gasolina & 9,000 & 9,000 & 9,000 & 9,000 & 9,000 \\
Fam Trips & 12,945 & 12,945 & 12,945 & 12,945 & 12,945 \\
Mantenimiento página web & 780 & 780 & 780 & 780 & 780 \\
Folletería & 400 & 400 & 400 & 400 & 400 \\
Premios (\#selfieKachiRaqay) & 2,160 & 2,160 & 2,160 & 2,160 & 2,160 \\
Patrocinio a operadores en ferias & 8,897 & 8,897 & 8,897 & 8,897 & 8,897 \\
Depreciación & 136,055 & 136,055 & 136,055 & 136,055 & 135,229 \\
Amortización & 11,894 & 11,894 & 11,894 & 11,894 & 11,894 \\
\hline Total & 715,222 & 717,270 & 718,529 & 719,893 & 720,543 \\
\hline
\end{tabular}

Nota: Elaboración Propia. 


\subsubsection{Costos variables.}

Son los costos que dependen de la cantidad de paquetes que vende el ecolodge. Se asume que los gastos por servicios dependen de los huéspedes en un $85 \%$.

Tabla 135.

Costos Variables 2018-2022 (expresado en soles)

\begin{tabular}{lccccc}
\hline Costos & 2018 & 2019 & 2020 & 2021 & 2022 \\
\hline Costo de ventas & $2,107,937$ & $2,286,348$ & $2,480,615$ & $2,692,191$ & $2,922,663$ \\
Servicios & 27,894 & 34,411 & 35,993 & 37,660 & 39,403 \\
Comisiones & 121,338 & 132,115 & 143,878 & 156,718 & 170,738 \\
\hline Total & $2,257,170$ & $2,452,874$ & $2,660,485$ & $2,886,570$ & $3,132,804$ \\
\hline
\end{tabular}

Nota: Elaboración Propia.

\subsubsection{Costo variable unitario}

Al ponderar los servicios y las comisiones entre el total de unidades vendidas (Ver Anexo XVIII Cálculo de servicios y cálculo de costo variable unitario), se obtienen los siguientes costos totales unitarios:

Tabla 136.

Costos totales unitarios expresados en soles (expresado en soles)

Costo Total Unitario

\begin{tabular}{lccc}
\hline & Full Day & Aventura En Maras & Experiencia Kachi Raqay \\
\hline Costos variables directos & 291 & 455 & 539 \\
Servicios y comisiones & 30 & 30 & 30 \\
\hline Costo variable total por unidad & 321 & 485 & 569 \\
\hline
\end{tabular}

Nota: Elaboración Propia. 


\subsubsection{Estado de resultados por costeo directo}

Tabla 137.

Estado de Resultados por Costeo Directo (expresado en soles)

\begin{tabular}{llllll}
\hline Concepto & 2018 & 2019 & 2020 & 2021 & 2022 \\
\hline Ingresos & $4,512,908$ & $4,913,621$ & $5,351,001$ & $5,828,461$ & $6,349,736$ \\
Costos variables & $2,239,836$ & $2,434,000$ & $2,639,931$ & $2,864,182$ & $3,108,413$ \\
Margen de contribución & $2,273,072$ & $2,479,621$ & $2,711,070$ & $2,964,280$ & $3,241,324$ \\
Costos fijos & 778,715 & 780,635 & 781,754 & 782,966 & 783,449 \\
Utilidad Operativa & $1,494,356$ & $1,698,986$ & $1,929,315$ & $2,181,314$ & $2,457,875$ \\
Ingresos Extraordinarios & & & & & 0 \\
Utilidad antes Imp. & $1,494,356$ & $1,698,986$ & $1,929,315$ & $2,181,314$ & $2,457,875$ \\
Impuesto a la renta & 440,835 & 501,201 & 569,148 & 643,488 & 725,073 \\
\hline Utilidad neta & $1,053,521$ & $1,197,785$ & $1,360,167$ & $1,537,826$ & $1,732,802$ \\
\hline Nota: Elaboración Propia & & & & & \\
\hline
\end{tabular}

\subsubsection{Análisis de la mezcla de ventas}

La mezcla de ventas consiste en la proporción de varios productos (o servicios) que componen el total de ventas unitarias de una compañía. 
Tabla 138.

Mezcla de venta (expresada en soles)

\begin{tabular}{clllll}
\hline Año & Full Day & Aventura En Maras & Experiencia Kachi Raqay & Bebidas & Ventas Totales \\
\hline 2018 & 608.692 & 2.650 .815 & 1.168 .322 & 11.155 & 4.438 .983 \\
2019 & 639.126 & 2.902 .642 & 1.279 .313 & 12.049 & 4.833 .131 \\
2020 & 671.083 & 3.178 .393 & 1.400 .847 & 13.021 & 5.263 .344 \\
2021 & 704.637 & 3.480 .341 & 1.533 .928 & 14.077 & 5.732 .982 \\
2022 & 739.869 & 3.810 .973 & 1.679 .651 & 15.223 & 6.245 .716 \\
\hline
\end{tabular}

Nota: Elaboración Propia.

Tabla 139.

Mezcla de venta (expresada en porcentaje)

\begin{tabular}{cccccc}
\hline Año & Full Day & $\begin{array}{c}\text { Aventura } \\
\text { en Maras }\end{array}$ & $\begin{array}{c}\text { Experiencia } \\
\text { Kachi Raqay }\end{array}$ & Bebidas & $\begin{array}{c}\text { Ventas } \\
\text { Totales }\end{array}$ \\
\hline 2018 & $14 \%$ & $60 \%$ & $26 \%$ & $0,3 \%$ & $100,0 \%$ \\
2019 & $13 \%$ & $60 \%$ & $26 \%$ & $0,2 \%$ & $100,0 \%$ \\
2020 & $13 \%$ & $60 \%$ & $27 \%$ & $0,2 \%$ & $100,0 \%$ \\
2021 & $12 \%$ & $61 \%$ & $27 \%$ & $0,2 \%$ & $100,0 \%$ \\
2022 & $12 \%$ & $61 \%$ & $27 \%$ & $0,2 \%$ & $100,0 \%$ \\
\hline
\end{tabular}

Nota: Elaboración Propia.

11.3.4. Cálculo del margen de contribución de la mezcla de ventas

El margen de contribución de la mezcla se obtiene multiplicando los márgenes de contribución unitarios, por la proporción resultante de la mezcla de ventas. 
Tabla 140.

Cálculo del margen de contribución por producto (expresado en porcentaje)

\begin{tabular}{lllll}
\hline & Full Day & $\begin{array}{l}\text { Aventura } \\
\text { en Maras }\end{array}$ & $\begin{array}{l}\text { Experiencia } \\
\text { Kachi Raqay }\end{array}$ & Bebidas \\
\hline Precio & 366 & 1.038 & 1.372 & 20 \\
Costo variable total por unidad & 321 & 485 & 569 & 5 \\
Contribución por producto & 45 & 553 & 803 & 15 \\
Margen de contribución por producto & $12 \%$ & $53 \%$ & $59 \%$ & $76 \%$ \\
\hline
\end{tabular}

Nota: Elaboración Propia.

Tabla 141.

Cálculo del margen de contribución de la mezcla de ventas (expresado en porcentaje)

\begin{tabular}{cccccc}
\hline Año & Full Day & $\begin{array}{c}\text { Aventura } \\
\text { en Maras }\end{array}$ & $\begin{array}{c}\text { Experiencia } \\
\text { Kachi Raqay }\end{array}$ & Bebidas & $\begin{array}{c}\text { Margen de } \\
\text { Contribución } \\
\text { de La Mezcla }\end{array}$ \\
\hline 2018 & $1.9 \%$ & $32.3 \%$ & $15.6 \%$ & $0.2 \%$ & $50 \%$ \\
2019 & $1.8 \%$ & $32.5 \%$ & $15.7 \%$ & $0.2 \%$ & $50 \%$ \\
2020 & $1.7 \%$ & $32.6 \%$ & $15.8 \%$ & $0.2 \%$ & $50 \%$ \\
2021 & $1.7 \%$ & $32.8 \%$ & $15.8 \%$ & $0.2 \%$ & $51 \%$ \\
2022 & $1.6 \%$ & $33.0 \%$ & $15.9 \%$ & $0.2 \%$ & $51 \%$ \\
\hline
\end{tabular}

Nota: Elaboración Propia.

\subsubsection{Cálculo de las ventas necesarias para alcanzar el punto de equilibrio}

Para calcular el punto de equilibrio en ventas, se realiza una regla de tres simple directa, donde el margen de contribución de la mezcla representa el costo fijo. Por ejemplo, para el año 2018 se tiene:

\begin{tabular}{cc}
\hline Margen de contribución de la mezcla & Soles \\
\hline $50 \%$ & 778.715 \\
$100 \%$ & $\mathrm{x}$ \\
\hline
\end{tabular}




$$
x=\frac{778.715}{0,5}=1,559,913 \text { soles }
$$

Tabla 142.

Punto de equilibrio de las ventas (expresado en soles)

\begin{tabular}{lccccc}
\hline Punto de equilibrio & 2018 & 2019 & 2020 & 2021 & 2022 \\
\hline Margen de la mezcla & $50 \%$ & $50 \%$ & $50 \%$ & $51 \%$ & $51 \%$ \\
Costo fijo & 778,715 & 780,635 & 781,754 & 782,966 & 783,449 \\
Punto de equilibrio en Soles & $\mathbf{1 , 5 5 9 , 9 1 3}$ & $\mathbf{1 , 5 5 7 , 3 7 1}$ & $\mathbf{1 , 5 5 3 , 4 5 0}$ & $\mathbf{1 , 5 4 9 , 9 3 0}$ & $\mathbf{1 , 5 4 5 , 1 8 2}$ \\
\hline
\end{tabular}

Nota: Elaboración Propia

Para calcular el punto de equilibrio por paquete, se multiplica el punto de equilibrio por la proporción de la mezcla de ventas:

Tabla 143.

Punto de equilibrio de las ventas por paquetes (expresado en soles)

\begin{tabular}{lccccc}
\hline \multicolumn{1}{c}{ Año } & 2018 & 2019 & 2020 & 2021 & 2022 \\
\hline Full Day & 213,911 & 205,953 & 198,075 & 190,509 & 183,050 \\
Aventura en Maras & 931,567 & 935,351 & 938,125 & 940,959 & 942,867 \\
Experiencia Kachi Raqay & 410,580 & 412,247 & 413,470 & 414,719 & 415,560 \\
Bebidas & 3,856 & 3,819 & 3,780 & 3,743 & 3,704 \\
Total & $\mathbf{1 , 5 5 9 , 9 1 3}$ & $\mathbf{1 , 5 5 7 , 3 7 1}$ & $\mathbf{1 , 5 5 3 , 4 5 0}$ & $\mathbf{1 , 5 4 9 , 9 3 0}$ & $\mathbf{1 , 5 4 5 , 1 8 2}$ \\
& & & & & \\
\hline
\end{tabular}

Nota: Elaboración Propia. 
11.3.6. Cálculo de las unidades necesarias para alcanzar el punto de equilibrio

Para tal efecto se divide las ventas entre el precio de cada paquete

Tabla 144.

Punto de equilibrio de las ventas por paquetes (expresado en unidades)

\begin{tabular}{llllll}
\hline Año & 2018 & 2019 & 2020 & 2021 & 2022 \\
\hline Full Day & 575 & 554 & 533 & 512 & 492 \\
Aventura en Maras & 883 & 887 & 889 & 892 & 894 \\
Experiencia Kachi Raqay & 294 & 296 & 296 & 297 & 298 \\
Bebidas & 193 & 191 & 189 & 187 & 185 \\
Total & $\mathbf{1 , 9 4 5}$ & $\mathbf{1 , 9 2 7}$ & $\mathbf{1 , 9 0 7}$ & $\mathbf{1 , 8 8 9}$ & $\mathbf{1 , 8 6 9}$ \\
\hline
\end{tabular}

Nota: Elaboración Propia.

Tabla 145.

Porcentaje de ventas proyectadas con respecto al punto de equilibrio

\begin{tabular}{lrrrrr}
\hline Año & 2018 & 2019 & 2020 & 2021 & 2022 \\
\hline Full Day & $289 \%$ & $316 \%$ & $344 \%$ & $376 \%$ & $411 \%$ \\
Aventura en Maras & $289 \%$ & $316 \%$ & $344 \%$ & $376 \%$ & $411 \%$ \\
Experiencia Kachi Raay & $289 \%$ & $316 \%$ & $344 \%$ & $376 \%$ & $411 \%$ \\
Bebidas & $289 \%$ & $316 \%$ & $344 \%$ & $376 \%$ & $411 \%$ \\
\hline
\end{tabular}

Nota: Elaboración Propia.

Conclusión: las unidades proyectadas de venta no solo alcanzan el punto de equilibrio, sino que lo superan hasta en 3 veces el primer año llegado a cuadruplicar el punto de equilibrio en el quinto año. 


\subsection{Análisis de sensibilidad}

El análisis de sensibilidad consiste en evaluar los resultados del proyecto, en diferentes escenarios.

Dado que el proyecto contempla turistas extranjeros, se determinaron 3 variables para aplicar análisis unidimensionales: La inversión en activo fijo, el tipo de cambio y la demanda de turistas.

\subsubsection{Análisis unidimensional}

El análisis unidimensional consiste en alterar las probabilidades de un factor, para evaluar el resultado. Para determinar los resultados se utilizó la función del Excel: “Análisis y si”, y se comparó la variable en estudio con respecto a los indicadores económicos y financieros (VANE, TIRE y PRD).

\subsubsection{Análisis unidimensional de sensibilidad al tipo de cambio}

Se toma en consideración el tipo de cambio dentro del análisis de escenarios, debido a que la industria turística genera el ingreso de divisas dados los mercados emisores que muchas veces prefiere el dólar por ser una moneda más estable para poder circular y endeudarse. En tanto al ser el turismo una industria exportadora, reconocida por ley N30641 en Perú, estamos expuestos a riesgo cambiario. 
Por otra parte, la dolarización de nuestro país responde a características de confianza que se arrastran desde los años 80 's, no responde a una medida del Banco Central de Reserva, quien solamente interviene en su regulación diaria para evitar cambios bruscos. Es de entenderse que los ingresos se puedan ver afectados de darse variación en el tipo de cambio.

Tabla 146.

Análisis de sensibilidad al tipo de cambio

\begin{tabular}{lllll}
\hline \multicolumn{2}{l}{ Tipo de cambio } & VANE & TIRE & PRD \\
Soles /Dólar & Porcentaje & 129,311 & $36.14 \%$ & 2.12 \\
\hline 3.18 & $97.8 \%$ & $-111,676$ & $34.00 \%$ & 2.19 \\
3.21 & $98.9 \%$ & 8,818 & $35.08 \%$ & 2.15 \\
3.25 & $100.0 \%$ & 129,311 & $36.14 \%$ & 2.12 \\
3.29 & $101.1 \%$ & 249,805 & $37.19 \%$ & 2.08 \\
\hline
\end{tabular}

El tipo de cambio debe ser mayor o igual a 3.21 soles por dólar para que el proyecto siga siendo rentable.

\subsubsection{Análisis unidimensional de sensibilidad a la inversión en activo fịo}

Incluimos el análisis de sensibilidad en base al activo fijo para determinar cuánto de alza del activo fijo puede soportar el proyecto. Esto porque de acuerdo al INEI los precios en materiales de construcción se han elevado a marzo 2018 en 0.17\%. El alza se ve reflejada en suministros eléctricos, productos metálicos, etc. 
Tabla 147.

Análisis de sensibilidad a la inversión en activo fijo

\begin{tabular}{lllll}
\hline \multicolumn{2}{l}{$\begin{array}{l}\text { Inversión en activo fijo } \\
\text { Soles }\end{array}$} & VANE & TIRE & PRD \\
\hline $3,610,192$ & $96.55 \%$ & 258,314 & $36 \%$ & \\
$3,739,194$ & $100.00 \%$ & 129,311 & $36 \%$ & 2.12 \\
$3,868,197$ & $103.45 \%$ & 309 & $35 \%$ & 2.15 \\
$3,997,199$ & $106.90 \%$ & $-128,693$ & $34 \%$ & 2.19 \\
\hline
\end{tabular}

La inversión en activo fijo debe ser igual o menor a S/. 3,868,197 para que el proyecto siga siendo rentable.

\subsubsection{Análisis unidimensional de sensibilidad a la demanda}

La industria turística es altamente sensible. La disminución de demanda de flujos turísticos responde a eventos sociales como las huelgas, inestabilidad política, catástrofes naturales, etc. Durante el 2017 por ejemplo el fenómeno del niño costero afecto al turismo Cusqueño aun a cuando los daños no se registraron en la ciudad. La inestabilidad política y o violencia pueden también cambiar las expectativas de demanda anual.

Asa también, es importante mencionar que la demanda turística de la región es temporal. Esta temporalidad está marcada por la época de lluvias considerada temporada baja. El bajo flujo turístico entre los meses de noviembre a marzo (con excepción del fin de año) se da por el temor de los visitantes a no lograr llegar a Machu Picchu por problemas en los rieles y/o carretera a causa de deslizamientos. 
Tabla 148.

Análisis de sensibilidad a la demanda

\begin{tabular}{llll}
\hline $\begin{array}{l}\text { Demanda } \\
\text { proyectada }\end{array}$ & VANE & TIRE & PRD \\
Porcentaje & 129,311 & $36 \%$ & \\
\hline $96 \%$ & $-77,029$ & $34 \%$ & 2.19 \\
$98 \%$ & 26,141 & $35 \%$ & 2.15 \\
$100 \%$ & 129,311 & $36 \%$ & 2.12 \\
$102 \%$ & 232,481 & $37 \%$ & 2.08 \\
\hline
\end{tabular}

Nota: Elaboración Propia.

El proyecto podría seguir siendo rentable, incluso en un escenario pesimista en que la demanda solo alcance el $92 \%$ del mercado objetivo estimado.

\subsection{Análisis de mitigación}

El análisis de mitigación consiste en evaluar los riesgos del análisis de sensibilidad del proyecto, para brindar un plan de acción ante dichos riegos. Las tres variables son: la inversión en activo fijo, el tipo de cambio y la demanda de turistas.

\subsubsection{Análisis de mitigación al tipo de cambio}

En los últimos 10 años el dólar con respecto al sol a tenido una media de S/2.94 por dólar. Inclusive, en los últimos 5 años el valor no desciende de los S/3.07 por dólar y la tendencia para lo que va del año 2018 es que podría bajar, estimando 
que en el peor de los casos llegue a $\mathrm{S} / 3.18$. El proyecto deja de ser rentable con un tipo de cambio menor a S/3.21.

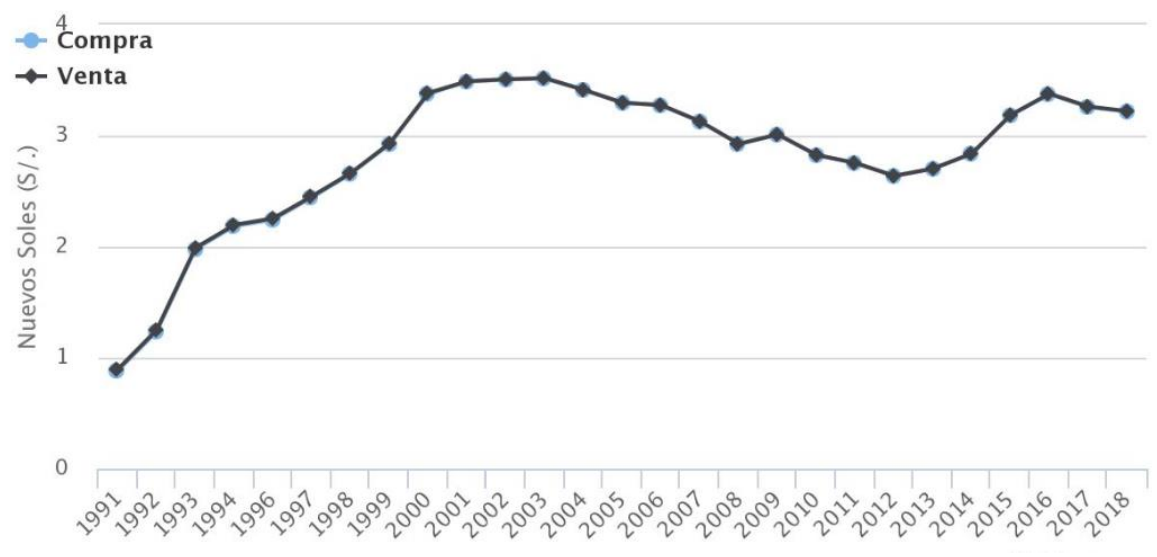

Figura 45. Cotización del dólar americano desde 1991 al 2018. Extraído de DePeru.com

Plan de mitigación: para este escenario se trabajaría con una lista de precios en soles (calculado a S/3.25). Actualizando la lista mensualmente para que el tipo de cambio a dólares no afecte los ingresos en soles, dándole más holgura al plan de negocio.

\subsubsection{Análisis de mitigación a la inversión de activo fijo}

En el caso a la inversión de activos fijos como construcción, los riesgos se dan por la ligera alza de los precios de las losetas, ladrillos, aceros y cemento, registrados en el último año. Precios que no se pueden controlar. En el caso de los activos fijos como equipos de procesamiento, maquinarias y equipos, muebles y vehículo de transporte, sería factible reducir gastos adquiriendo productos de segunda, evitando que el total de activos fijos no supere los montos máximos que afecten la rentabilidad esperada en el tiempo estimado. 
Plan de mitigación: al tener un margen mínimo de inversión antes que el proyecto deje de ser rentable $(103,45 \%)$ se presenta como primera opción adquirir el vehículo de transporte de segundo uso.

\subsubsection{Análisis de mitigación a la demanda}

El sector turismo y de hospedaje, trabaja con temporadas según el volumen de turistas que se estima visita la ciudad del Cusco, definiéndose como temporada alta (por festividades, feriados, buen clima) o baja (mal clima, desastres naturales, huelgas).

Plan de mitigación: considerando que el porcentaje mínimo de ocupabilidad tendría que ser del $98 \%$ para que el proyecto sea rentable, la solución sería que durante la temporada alta se ofrezca precios rack, los más altos. Logrando cubrir los vacíos que podría dejar la temporada baja. De igual forma se ofrecería una opción de bed \& breakfast que generaría mayor consumo al bajo flujo de turistas.

\subsubsection{Análisis de mitigación a fenómenos climatológicos}

El departamento del Cusco presenta un clima que varía en dos estaciones al año: la temporada seca y la temporada de lluvias. Los fenómenos climatológicos no se pueden controlar, y podrían durar más de lo esperado perjudicando al sector turismo reduciendo la demanda. Los meses que más se afectan por temas climatológicos son de enero a marzo (temporada de lluvias) que ocasionan inundaciones y 
deslizamientos. Estos fenómenos dificultan los accesos a la ciudad del cusco vía aérea y a sus provincias por vías terrestres, afectando la comunicación.

Plan de mitigación: para la temporada de lluvia se trabaja con los peores escenarios de ocupabilidad y con los precios más bajos (best available rate); además de organizar paquetes que estén dirigidos al mercado local, así como premiar (durante esta temporada baja) a los operadores que más vendan los paquetes con estadías, fomentando la experiencia vivencial con un mercado que posteriormente lo recomendará.

\subsubsection{Análisis de mitigación a los conflictos sociales}

Los conflictos sociales se presentan principalmente por el incumplimiento de acuerdos o porque no existen acuerdos que involucren de forma favorable a los pobladores de las zonas afectadas. Se tienen dos tipos de conflictos sociales: los locales (Maras) y los regionales (Cusco). De los conflictos sociales locales, al trabajar con una comunidad con costumbres cerradas existe un alto riesgo que los pobladores no vean con buenos ojos esta inversión, perjudicando el plan de negocios presentando su descontento mediante huelgas o paralizaciones.

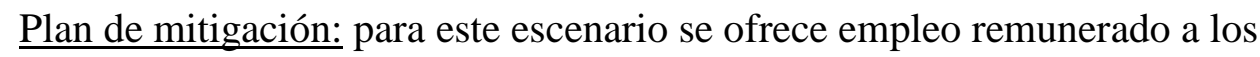
pobladores de la comunidad de Maras con un entrenamiento adecuado respetando sus costumbres y cultura. Manteniendo una buena gestión de comunicación con la comunidad donde ellos mismos entiendan su rol importante para el desarrollo del plan de negocio, generando confianza. 
De los conflictos sociales regionales, como las huelgas de maestros, médicos, etc. que implican un bloqueo de carreteras y por lo general se da en temporadas altas.

Plan de mitigación: paquetes que estén dirigidos al mercado local. De manera de verse medianamente afectados por la baja demanda extranjera, que por bloqueo de carreteras podrían cancelar su visita por el Cusco.

\subsubsection{Análisis de mitigación a la guerra de precios}

El Cusco es un destino muy concurrido por vacacionistas, la oferta hotelera sigue incrementando tanto formal como informalmente. La guerra de precios incrementa al tener mayor oferta de hospedajes. Lo favorable para el plan de negocio del Ecolodge Kachi Raqay es que en Maras aún no existe competencia directa. Sin embargo, se podría entrar en guerra de precios.

Plan de mitigación: ofrecer el precio más bajo (best available rate) a grupos de vacacionistas mayor a tres adultos, indiferente sea la temporada, resaltando la experiencia vivencial como aspecto diferencial y manteniendo la calidad de los servicios.

\subsubsection{Análisis de mitigación a emergéncias médicas en Maras}

El riesgo de estar alejados de la ciudad implica que, en caso de presentarse una emergencia médica con un huésped, la accesibilidad de la ambulancia o a una clínica 
o posta podría generar un ambiente tenso, y que el huésped se lleve una mala impresión de gestión.

Plan de mitigación: se tiene mapeada la clínica Cima en Urubamba y la posta médica, al tener un vehículo de transporte propio del Ecolodge Kachi Raqay facilitaría el traslado, en cualquier momento, a cualquiera de estos dos centros médicos a elección del huésped. 


\section{Conclusiones y Recomendaciones}

\section{Conclusiones}

- El proyecto es rentable y tiene ligera holgura financiera para operar.

- Al evaluarse el análisis unidimensional al tipo de cambio, a la inversión en activo fijo y a la demanda, se concluye que para que el proyecto siga siendo viable según los indicadores VANE y TIRE: el tipo de cambio debe ser superior a 3,21 soles por dólar, la inversión en activo fijo debe ser inferior al $103.45 \%$ proyectado, y la demanda debe ser superior al $98 \%$ del mercado objetivo estimado.

- Se concluye la existencia de una oportunidad de negocio favorable por los factores políticos, económicos, sociales, tecnológicos, legales y ecológicos. Se destaca el reconocimiento del turismo sostenible como una de las tendencias más importantes para la Organización Mundial del Turismo. Así también el plan estratégico nacional PENTUR destaca como claves en la demanda del turismo 2015-2025 al turismo vivencial, capaz de crear experiencias nuevas y satisfacer la búsqueda de autenticidad. Además, que el sector hotelero mantiene un crecimiento constante en el Perú y sobretodo en el departamento del Cusco que registra año tras año mayor cantidad de visitas por parte de turistas vacacionistas que su principal motivación es conocer Machu Picchu. Lo que representaría una gran oportunidad para el desarrollo del proyecto brindando una opción diferente de hospedaje al turista. 
- Debido al atractivo comercial que está generando Cusco, la principal barrera de entrada es la economía de escala que puede tener la competencia; el pertenecer a grupos hoteleros les permite minimizar costos (software, marketing digital, etc). En este sentido la rivalidad con los competidores es alta, pues a pesar de que muchos hospedajes no están categorizados e inscritos en la dirección de turismo, se encuentran hoteles y albergues de mayor tamaño en la zona de estudio - Urubamba. Siendo este un factor crítico de éxito a tomar en cuenta para este plan de negocios.

- Respecto a la rivalidad entre competidores actuales, el proyecto presenta una propuesta donde se combina la categoría de albergue con servicios de calidad hotelera y que ofrezcan actividades con experiencias vivenciales al huésped. Del grupo de 10 hospedajes categorizados (que se delimitó como competencia) ninguno se encuentra ubicado en la zona de Maras, lo que representa una gran oportunidad de desarrollo en la zona con las comunidades aledañas. Lo que se encuentra en la zona son diferentes comunidades y asociaciones que realizan turismo vivencial, la rivalidad con ellos no sería alta, pues el proyecto se ajusta a los requerimientos de infraestructura delimitado por MINCETUR.

- Tras el estudio de mercado realizado, se obtiene un mercado efectivo interesante del orden del 32\%, 29\% y 23\% para los paquetes Full day, Aventura en Maras, y Experiencia Kachi Raqay respectivamente, del mercado potencial hecho que lo hace viable. 
- Se concluye que el posicionamiento del ecolodge se dará en base a los atributos del proyecto, centrando el mayor esfuerzo de marketing en los operadores de turismo como socios estratégicos del proyecto, capaces de ofrecer este proyecto como una experiencia diferente a sus clientes.

- El servicio se ofrecerá a través de 3 paquetes de valor, los cuales incluyen todas las actividades vivenciales que mediante el estudio de mercado se determinaron como importantes y prioritarias para el público objetivo al momento de pensar esta experiencia.

- El precio por descreme permitirá obtener los ingresos necesarios para poder gestionar la rentabilidad del proyecto, esto sobre todo durante el primer año de operación, tiempo en que la promoción del ecolodge será intensa.

- Una de las principales conclusiones que surgieron por el estudio de mercado fue con respecto al uso del término "ecolodge" en el nombre del proyecto, debido a que es un término que ya no se usa en el reglamento de establecimientos de hospedaje en Perú, para determinar una categoría de alojamiento; sin embargo, el término está comercialmente posicionado para el público al que se dirige el proyecto, además de atractivo para el tipo de actividad del negocio. Por lo que de Albergue vivencial "La hacienda Kachi Raqay" se concluyó en que sea llamado: Ecolodge "Kachi Raqay". 
- Con respecto a la forma de promocionar el proyecto y llegar al público objetivo del Ecolodge "Kachi Raqay” se concluye como indispensable invertir en excelentes herramientas web (página web oficial, Facebook, Trip Advisor) que resulten ser amigable para ellos y tengan opción de calificar su experiencia, debido a que la mayoría de los turistas utiliza estos medios para planificar sus viajes y recoger experiencias.

- Ollantaytambo es un distrito ubicado en la provincia de Urubamba a 72 kilómetros de la ciudad del Cusco, presenta atractivos arqueológicos y tiene la estación de tren para llegar a Machu Picchu. Por la cantidad de turistas que visitan el distrito de Ollantaytambo, tanto para visitarlo o tomar el tren, ya no la estarían haciendo un destino exclusivo. La competencia en cuanto a hospedaje es alta, pero en cuanto a experiencia vivencial es nula.

Maras de encuentra a 41 kilómetros de la ciudad del Cusco, presenta atractivos turísticos y los mejores escenarios para vivir una experiencia vivencial. Alejando a los huéspedes de puntos de turismo tradicional. Dejando como mejor propuesta de experiencia vivencial al proyecto Ecolodge Kachi Raqay.

- Respecto al Aeropuerto Internacional de Chinchero, aún no se puede contar como una oportunidad que incrementará la afluencia de público hacia la zona de Maras, debido a que sigue siendo un proyecto en stand-by por parte del gobierno. 


\section{Recomendaciones}

- El Turismo es una industria sensible, se recomienda entender el riesgo y consecuencias de los factores sociales, políticos y climatológicos y su reacción en los resultados financieros. Según Mincetur entre los años 2011 al 2016 se registró un crecimiento del turismo receptivo peruano del 40\%, por otro lado, el año 2016 el número de visitantes a nuestro principal destino Machu Picchu se redujo en $4.5 \%$, esto dado a factores internacionales como la crisis económica europea, recesiones económicas de países latinoamericanos. Las intensas lluvias al norte del país marcaron la reducción de ingreso de turistas a nivel nacional. Las marchas, paralizaciones, denuncias de violencia o falta de seguridad marcan la tendencia en los factores de decisión del turista al Perú.

- Se recomienda trabajar de la mano con la comunidad de Maras, pues de sus costumbres nace la estrategia del proyecto.

- Al ser el turismo un fenómeno que produce cambios en las comunidades receptoras como en los visitantes, por la interacción entre diversas culturas. Es importante involucrar a las comunidades en las actividades turísticas, proveyendo a los residentes de herramientas de gestión que promuevan el respeto y valor por su cultura, así como el desarrollo de la población. En la otra mano deberá proveer a los turistas de información para mantener el relativismo cultural, actitud por la cual se interpretan las costumbres y creencias del pueblo de Maras de acuerdo con los parámetros de su propia cultura. Así se recomienda también la preservación del patrimonio y la belleza paisajística de la zona por parte del gobierno municipal y los pobladores de Maras, así como la implementación de modernos modelos de gestión y seguridad para los visitantes. 
- En cuanto el análisis de sensibilidad se concluyó que el proyecto deja de ser rentable si el tipo de cambio desciende a S/3.21 soles por dólar, esto debido a que de darse esta baja manteniéndose los precios en dólares, los costos se mantendrían y los ingresos descenderían. La última vez que el país manejo estas cifras fue a finales del año 2013 de acuerdo con Sunat. Por esa razón se recomienda trabajar con una lista de precios en soles (calculado a S/3.25). Actualizando la lista mensualmente para que el tipo de cambio a dólares no afecte los ingresos en soles, dándole más holgura al plan de negocio.

- Se recomienda la promoción intensa del proyecto, pues el turismo en Cusco se encuentra en un punto de estancamiento en el que se promueven sobre todo los circuitos tradicionales de City tour, visita al valle sagrado y Machu Picchu, y los no tradicionales como la montaña de siete colores por ejemplo que aun significan gran riesgo para el turista y una gestión aún empírica por parte de los pobladores. Proyectos como este generan la diversificación de la demanda, pero sobre todo impulsa la extensión del promedio de estadía de los turistas, con seguridad y con un cálculo de gasto dentro del promedio de gasto diario de los visitantes.

- Se recomienda a la gestión municipal, provincial y regional implementar - mejorar la infraestructura necesaria para la actividad turística. La recuperación y mantenimientos de vías de comunicación es urgente en la región Cusco. El estado actual de las pistas desde el aeropuerto Velazco Astete al centro histórico de la ciudad, la carretera que conectan el circuito Valle sagrado, demuestran el actual estado de abandono de las vías en la región. Es importante mencionar que la única vía para llegar a las salineras de Maras desde su plaza principal es a través de una carretera, que en muchos casos no permite la doble 
circulación de vehículos, carece de barreras de seguridad y soporta el flujo diario de al menos 1500 visitantes en temporada alta, en vehículos de alto tonelaje.

Proyectos como el nuevo aeropuerto de Chinchero, que incluye dentro de su plan maestro una vía directa a la ciudad de Cusco, no contempla el mejoramiento de la antigua vía para descongestionar los futuros flujos de turistas a la ciudad.

- Se sugiere también trabajar desde el gobierno nacional y local, acciones de prevención en temas de contaminación. Perú es conocido por la baja salubridad del agua, lo que hace que cada turista consuma agua embotellada en envases plásticos, los cuales generan toneladas diarias de plástico que no es reciclado. 


\section{Referencias}

Alcantara, A. (2005). Cultura, Educación y Turismo en Taquile. Una mirada de tendencias desde la perspectiva de sus actores. Universidad Nacional del Altiplano.

Andderson, S. W. (2011). Estadistica para negocios y economía (11a ed.). México: Cengage Learning.

Andina. (14 de Junio de 2016). Mincetur: Turismo receptivo creció más de $40 \%$ entre 2011 y 2016. Obtenido de Andina: del Perú para el Mundo web site: http://www.andina.com.pe/agencia/noticia-mincetur-turismo-receptivo-crecio-mas40-entre-2011-y-2016-617157.aspx

Asensio, R., \& Pérez Galán, B. (2012). ¿El Turismo es cosa de Pobres?: Patrimonio cultural, pueblos indígenas y nuevas formas de turismo de América Latina. Lima: Instituto de Estudios Peruanos. Obtenido de http://www.pasosonline.org/Publicados/pasosoedita/PSEdita8.pdf

BBC Mundo. (2 de Febrero de 2016). ¿Cómo se convirtió Google en la empresa más valiosa del mundo? Obtenido de BBC Mundo web site: http://www.bbc.com/mundo/noticias/2016/02/160202_google_mas_valiosa_men

Bravo, S. (2008). Teoría financiera y costo de capital. En S. Bravo, Teoría financiera y costo de capital (págs. 127-139). Lima: Universidad ESAN.

Brealey, R., Myers, S., \& Allen, F. (2010). Principios de finanzas corporativas (Novena ed.). D.F., México: McGrawHill.

CAP. (2017). Cuadro de Valores Unitarios Oficiales. Lima: CAP.

Chaparro Ortiz de Zevallos, A. (Diciembre de 2008). Los Yagua en el contecto del Turismo étnico. La construcción de la cultura para el consumo en el caso de Nuevo Perú. 
Obtenido de Resvista Anthropologica PUCP web site:

http://revistas.pucp.edu.pe/index.php/anthropologica/article/view/1615/1560

Congreso del Perú. (2008 de Junio de 28). Decreto Legislativo $N^{\circ} 1062$. Obtenido de Ley de Inocuidad de los Alimentos:

http://www.leyes.congreso.gob.pe/Documentos/DecretosLegislativos/01062.pdf

Damodaran, A. (5 de 01 de 2017). Annual Returns on Stock, T.Bonds and T.Bills: 1928 -

Current. Recuperado el 04 de 12 de 2017, de Damodaran Online:

http://pages.stern.nyu.edu/ adamodar/

Damodaran, A. (Enero de 2017). Betas by Sector (US). Recuperado el 03 de 12 de 2017, de Pages.stern.nyu.edu:

http://pages.stern.nyu.edu/ adamodar/New_Home_Page/datafile/Betas.html

Diario Gesión. (24 de Abril de 2015). Diaio Gestión. "Ahora Perú: Ventanilla Única de Turismo facilitará puesta en marcha de Proyectos Hoteleros", págs. 8-9.

Diario Gestión. (1 de Junio de 2015). "Inversiones hoteleras en el Perú sumarán US\$ 2,500 millones entre 2015 y 2021". Diario Gestión, págs.

https://gestion.pe/empresas/inversiones-hoteleras-peru-sumaran-us-2500-millonesentre-2015-y-2021-2133481.

Diario Gestión. (20 de Marzo de 2015). Diario Gestión. "Las Diez Tendencias del Viajero Digital", págs. https://gestion.pe/tendencias/diez-tendencias-nuevo-viajero-digital2126677.

Diario Gestión. (2 de Febrero de 2016). Riesgo país de Perú sube 13 puntos básicos a 2.89 puntos porcentuales. Diario Gestión, págs. 9-10.

Diario Gestión. (18 de Abril de 2017). "FMI reduce a 3.5\% su proyección de crecimiento económico de Perú para el 2017 ". Diario Gestión, págs. 
https://gestion.pe/economia/fmi-reduce-35-su-proyeccion-crecimiento-economicoperu-2017-2187626.

Diario Gestión. (15 de Febrero de 2017). "INEI: Economía Peruana creció 3.90\% en el 2016, poco más de lo que se esperaba". Diario Gestión, págs.

https://gestion.pe/economia/inei-economia-peruana-crecio-39-2016-poco-mas-lo-quese-esperaba-2182232.

DIRCETUR. (Agosto de 2016). Boletín Estadístico de Turismo. Recuperado el 08 de Abril de 2017, de Gobierno Regional de Cusco sitio web:

http://www.dirceturcusco.gob.pe/wp-content/uploads/2017/07/BOLETIN-

ESTADISTICO-2015-Final.pdf

DIRCETUR. (Agosto de 2016). Boletín Estadístico de Turismo 2015. Obtenido de Gobierno Regional de Cusco sitio web: http://www.dirceturcusco.gob.pe/wpcontent/uploads/2017/07/BOLETIN-ESTADISTICO-2015-Final.pdf

Dirección Desconcentrada de cultutra de Cusco. (2016). Antecedentes del Parque Arqueológicode Moray. Obtenido de Dirección Desconcentrada de cultutra de Cusco web site: http://www.culturacusco.gob.pe/index.php/antecedentes-moray

Dirección Regional de Comercio Exterior y Turismo. (2014). Boletín Estadístico de Turismo. Cusco. Recuperado el 08 de Abril de 2017

El Comercio. (08 de 12 de 2014). Perú es Reconocido como "Mejor destino Culinario del Mundo". Obtenido de El Comercio web site:

https://elcomercio.pe/economia/peru/peru-reconocido-mejor-destino-culinariomundo-181501

Fernandez, P. (2016). Valoración de Empresas y Sensatez. Madrid: CIF - Center for International Finance. 
Funes, M. L. (04 de Abril de 2015). Diez Tendencias del Turismo Mundial. Obtenido de ABC Economía web site: http://www.abc.es/economia/20150403/abci-tendencias-turismomundial-201504030220.html

gerencie. (04 de 10 de 2017). Capital de trabajo. Recuperado el 10 de 10 de 2017, de Sitio web de Gerencie: https://www.gerencie.com/capital-de-trabajo.html

Gestión. (2017). Riesgo país de Perú bajó dos puntos básicos a 1.41 puntos porcentuales . Gestión, Versión digital.

Hosteltur. (12 de Abril de 2014). La Tablet en la Habitación de Hotel obre todo un Mundo de Experiencias e Ingresos. Obtenido de Hoteltur web site:

https://www.hosteltur.com/147840_tablet-habitacion-hotel-abre-todo-mundoexperiencias-ingresos.html

Hosteltur. (03 de Marzo de 2015). Las Tendencias del Turismo que vienen en 2015. Obtenido de Hosteltur web site: https://www.hosteltur.com/199970_tendencias-turismo-vienen2015.html\#

Hosteltur. (24 de Febrero de 2015). Los Drones Aterrizan en el Turismo. Obtenido de Hosteltur web site: https://www.hosteltur.com/198690_drones-aterrizan-turismo.html

Keller, P. K. (2006). Dirección de Marketing. Mexico: PEARSON EDUCACIÓN.

Kotler, P., \& Armstrong, G. (2012). Fundamentos de Marketing Décimocuarta Edición. México: Pearson Educación.

Levante: El Mercantil Valenciano. (11 de Mayo de 2017). Las Apps más útiles para los viajeros. Obtenido de Levante: El Mercantil Valenciano web site: http://www.levanteemv.com/especiales/turismo/2015/06/apps-utiles-viajeros-n236_18_21324.html

Levin, R. (2004). Estadística para administración y economía. México: Pearson.

Lira Briceño, P. (15 de 12 de 2011). Un modelo financiero: EL CAPM. Recuperado el 28 de Noviembre de 2017, de Gestión: 
http://blogs.gestion.pe/deregresoalobasico/2011/12/un-modelo-financiero-elcapm.html

Lira Briceño, P. (2012). Determinando la tasa de descuento de un proyecto (caso práctico). Gestión, Versión digital.

Malhotra, N. K. (2008). Investigación de Mercados Quinta Edición. México: Pearson Educación.

Mc Daniel, C., \& Gates, R. (2016). Investigación de Mercados (10ma edición). México: Cengage Learning .

MINCETUR - NORMATIVIDAD. (Diciembre de 2016). Normatividad: Registro Calificadores de Establecimientos de Hospedaje. Obtenido de MINCETUR Web Site: https://www.mincetur.gob.pe/funciones-y-normatividad-2/normatividad/ MINCETUR - Reglamento. (2016). Reglamento De Organizacion Y Funciones Del Ministerio De Comercio Exterior Y Turismo . Obtenido de MINCETUR web site: https://www.mincetur.gob.pe/wpcontent/uploads/documentos/institucional/acerca_del_ministerio/funciones_y_normati vidad/normatividad/reglamento_de_organizacion_y_funciones_ROF/Rof_mincetur_o ficial.pdf

Mincetur. (2014). Mercado Turístico Peruano.

MINCETUR. (31 de Julio de 2016). PENTUR. Obtenido de Plan Estratégico Nacional de Turismo 2025: https://www.mincetur.gob.pe/wpcontent/uploads/documentos/turismo/documentos/PENTUR/PENTUR_Final_JULIO2 016.pdf

MINCETUR. (2017). Texto Único de Procedimientos Administrativos - TUPA. Obtenido de Establecimientos de Hospedaje: 
http://transparencia.mincetur.gob.pe/documentos/newweb/portals/0/tupa/TUPA_CO MPLETO_2017.pdf

MINCETUR. (n.d.). PENTUR. Obtenido de Plan Estratégico Nacional de Turismo (20122021):

file:///D:/Users/user/Downloads/Pentur_plan_estrategico_nacional_turismo_2012_20 21_consolidando_turismo_sostenible_resumen_ejecutivo_2012_keyword_principal.p df

Ministerio de Comercio Exterior y Turismo. (09 de Junio de 2015). Decreto Supremo 0012015-MINCETUR. Obtenido de Reglamentos de Establecimientos de Hospedaje: http://www.mincetur.gob.pe/wpcontent/uploads/documentos/turismo/funciones_y_normatividad/normatividad/prestad ores_servicios_turisticos/Decreto_Supremo_NRO_001_2015_MINCETUR_REH.pdf

Ministerio de Comercio Exterior y Turismo. (09 de Junio de 2015). Decreto Supremo 0012015-MINCETUR. Obtenido de Reglamento de Establecimientos de Hospedaje: http://www.mincetur.gob.pe/wpcontent/uploads/documentos/turismo/funciones_y_normatividad/normatividad/prestad ores_servicios_turisticos/Decreto_Supremo_NRO_001_2015_MINCETUR_REH.pdf

Ministerio de Comercio Exterior y Turismo. (2017). Directorio Nacional de Prestadores de Servicios Turisticos Calificados. Obtenido de Consultas en línea MINCETUR web site: http://consultasenlinea.mincetur.gob.pe/setregiones/(S(wyfqntyhjpk4c1oyioj5ikfk))/Reportes/WebReportes/RptListadoCoincide ncias.aspx $?$ StrTipo=2\&Var=01|||05|12||080000|

Ministerio de Economía y Finanzas. (23 de Agosto de 2010). Capítulo I: La Situación del Riesgo País. Obtenido de Ministerio de Economía y Finanzas web site: 
https://www.mef.gob.pe/es/2016-10-26-01-26-58/297-preguntas-frecuentes/2148capitulo-i-la-situacion-del-riesgo-pais

Ministerio de Economía y Finanzas. (11 de Junio de 2016). Normas Legales: Decreto Supremo 004-2016 Reglamento de Agencias de Viajes y Turismo. Obtenido de Ministerio de Economía y Finanzas:

https://www.mef.gob.pe/contenidos/servicios_web/conectamef/pdf/normas_legales_2 012/NL20160611.pdf

Ministerio del Ambiente. (15 de Octubre de 2005). Ley General del Ambiente $N^{\circ} 28611$. Obtenido de Ministerio del Ambiente web site: http://www.minam.gob.pe/wpcontent/uploads/2013/06/ley-general-del-ambiente.pdf

Montoya Pérez, M. P. (2013). Turismo Comunitario y Desarrollo Rural: Interacción y escalamiento de innovaciones. Lima: IEP; IDRC-CRDI; FIDA.

Murga, P. (06 de 12 de 2016). Cómo determinar el capital de trabajo. (M. Villena, Entrevistador)

Ochoa, C. (27 de Febrero de 2015). Muestreo probabilístico o no probabilístico. Netquest, págs. https://www.netquest.com/blog/es/blog/es/muestreo-probabilistico-o-noprobabilistico-ii.

Organización Mundial del Turismo (OMT). (17 de Enero de 2017). La Organización Mundial del Turismo da comienzo al Año Internacional del Turismo Sostenible para el Desarrollo 2017. Obtenido de Organismo Especializado de las Naciones Unidas Organización Mundial del Turismo: http://media.unwto.org/es/press-release/2017-0118/la-organizacion-mundial-del-turismo-da-comienzo-al-ano-internacional-del-tu Pacífico, I. (mayo de 2011). Artículo 229, Reserva Legal de la Ley General de Sociedades. Obtenido de http://aempresarial.com/web/revitem/5_12378_76182.pdf 
Parodi, C. (22 de Enero de 2016). "Proyecciones Economía mundial 2016". Diario Gestión, págs. http://blogs.gestion.pe/economiaparatodos/2016/01/proyecciones-economiamundial-2016.html.

Perú, C. E. (2015). Nota sectorial turismo e infraestructura hotelera Perú.

Perú, G. d. (2015). Norma Técnica A.030 Hospedaje. Obtenido de http://geo.vivienda.gob.pe/dnv/documentos/RNE/5.pdf

Perú, R. d. (09 de Junio de 2015). Decreto Supremo 001-2015-MINCEUR. Obtenido de Reglamentos de Establecimientos de Hospedaje: http://www.mincetur.gob.pe/wpcontent/uploads/documentos/turismo/funciones_y_normatividad/normatividad/prestad ores_servicios_turisticos/Decreto_Supremo_NRO_001_2015_MINCETUR_REH.pdf

Peruano, E. (14 de septiembre de 2014). Normal Legales. Obtenido de Decreto Supremo que aprueba el Reglamento de Inspecciones Técnicas de Seguridad en Edificaciones: https://www.cusco.gob.pe/wp-content/uploads/2016/09/ds-058-2014-pcm.pdf

Porter, M. E. (Enero de 2008). Estrategia Competitiva: Técnicas para el Análisis de los Sectores Industriales y de la Competencia. Obtenido de "Cinco Formas Competitivas que le dan Forma a la Estrategia":

https://utecno.files.wordpress.com/2014/05/las_5_fuerzas_competitivas_michael_porter-libre.pdf

Porter, M. (s.f.). Las Cinco Fuerzas de Porter. Obtenido de Clave para el éxito de la empresa: http://www.5fuerzasdeporter.com/

ProInversión. (2014). "Aeropuerto Internacional de Chicero (Cusco): El gran Aeropuerto Inca". Obtenido de ProInversión web site: http://www.proinversion.gob.pe/RepositorioAPS/0/1/JER/SALA_PRENSA_INFOGR AFIAS/infografia_chinchero_final.pdf 
PromPerú - Institucional. (2017). ¿Quienes somos? PromPerú. Obtenido de PromPerú web site: http://www.promperu.gob.pe/

Promperu. (2015). Perfil del turista. Lima: Grupo editorial comunica 2.

PromPerú. (30 de Noviembre de 2016). Perfil del Turista Extranjero 2015: PromPerú. Obtenido de PromPeru web site:

http://www.promperu.gob.pe/TurismoIN/sitio/VisorDocumentos?titulo=Perfil\%20del \%20Turista\%20Extranjero\%202015\&url= /Uploads/perfiles_extranjeros/38/PERFIL \%20EXTRANJERO\%20SPREAD.pdf\&nombObjeto=PerfTuristaExt\&back=/Turism oIN/sitio/PerfTuristaExt\&issuuid=1760

PromPerú. (30 de Noviembre de 2016). Perfil Del Vacacionista Nacional: El Turismo en Cifras. Obtenido de PromPerú web site: http://www.promperu.gob.pe/TurismoIn/Sitio/VisorDocumentos?titulo=Perfil\%20del \%20Vacacionista\%20Nacional\%202015\&url= /Uploads/perfiles_vacac_nac/1035/PE RFIL\%20NACIONAL\%20SPREAD.pdf\&nombObjeto=PerfVacacionistaNac\&back= /TurismoIN/Sitio/PerfVacacionistaNac\&i

Promperú. (2016). Publicación Turismo In: Conociendo al turista que visita Cusco. Cusco, Perú. Recuperado el 10 de Abril de 2017

PromPerú. (2017). Evaluación del Turismo Rural Comunitario en el Perú 2016. Obtenido de PromPerú web site: http://www.promperu.gob.pe/TurismoIN/sitio/VisorDocumentos?titulo=Turismo $\% 20$ Rural\%20Comunitario\&url= /Uploads/mercados_y_segmentos/segmentos/1020/Eval uaci\%C3\%B3n_Turismo\%20Rural\%20Comunitario_\%20TRC\%202015.pdf\&nombO bjeto=PerfilesSegmentos\&back=/TurismoIN/ 
Propia, M. E. (septiembre de 2016). Constitución y Formalización de tu Empresa en el Péru. Obtenido de Constitución y Formalización de tu Empresa en el Péru: https://mep.pe/constitucion-y-formalizacion-de-tu-empresa-en-el-peru/

Republica, C. d. (20 de enero de 2007). Ley Marco de Licencia de Funcionamiento. Obtenido de https://www.cusco.gob.pe/wp-content/uploads/2016/09/ley-28976-marco-licenciafuncionamiento.pdf

Rodriguez, E. M. (2005). Errores frecuentes en la interpretación del coeficiente de determinación lineal. Anuario jurídico y económico escurialense, 7. Recuperado el 23 de Mayo de 2017

Romero Córdova, N. H. (2016). "Potencial en recursos turísticos del centro poblado Rica Playa-Tumbes para la práctica del turismo rural". Trujillo: Universidad Nacional de Trujillo.

Sampieri Hernández, R. (2006). Medotología de la investigación. México: McGraw-Hill.

Savelli, M. P. (2017). El Diagrama o Blueprint del Servicio: Herramienta de diseño y control en la prestacion de los intangibles. Horizontes Empresariales, 63.

Schroeder. (2011). Administración de operaciones. Distrito Federal, México: Mc Graw Hill. Servicio Holandés de coperación al Desarrollo - SNV. (2016). Turismo Rural Comunitario Maras. Obtenido de Turismo Rural Comunitario web site: http://www.turismoruralcomunitario.com.pe/turismorural/experiencia.aspx?slug=mara S

SUNARP. (2017). SUNARP. Obtenido de SUNARP: https://www.sunarp.gob.pe/Infografia/INFO_p_juridicas.pdf

Taylor, S., \& Bogdan, R. (2000). Introducción a los Métodos Cualitativos de Investigación. Barcelona: Paidós. 
Vasquez, L. (31 de julio de 2015). El boon el Turismo en el Perú: de solo Machu Picchu a un país multidestino. Diario Gestión, págs. 16-17.

Vega, J. M. (2015). "Cadenas Internacionales de Hoteles Planean Inversiones en el Perú". SEMANAeconómica, 20-22.

Wings Working Together. (2017). Proyecto: Turismo Rural Comunitario en MullakasMisminay, Cusco. Obtenido de Condor Wings web site: http://www.condorwings.org/es/projects/p1pg4i/ 


\section{Anexos}

Anexo I.

Guía de pautas turista

PROYECTO: Albergue vivencial "La hacienda Kachi Raqay" ubicado en el poblado de Maras, Cusco-Perú

\section{Saludo y presentación}

1. Hola ¿En qué idioma prefieres la entrevista, español o inglés?

Hola, gracias por tu tiempo. Como sabes, estamos trabajando en un proyecto de tesis para la maestría. Para lo cual, antes de comenzar necesito tus datos:

2. ¿Cuál es tu país de origen?

3. Genero M F

4. ¿En qué rango de edad te encuentras?
a. Menos de 20 años
b. 20 a 29 años
c. 30 a 39 años
d. 40 a 49 años
e. 50 a 59 años
f. 60 años o más

5. Estado civil

\section{Estudio en profundidad}

Gracias, ahora pasaremos a las preguntas referidas al proyecto.

\section{Descripción de los hábitos de viaje y el proceso de compra de paquetes turísticos}

1. ¿Cuántas veces viajas al año aproximadamente?

2. ¿Cuáles fueron los lugares o destinos que visitaste en los últimos dos años?

3. ¿Cómo elegiste donde viajar? ¿Cómo te enteraste de estos destinos?

4. ¿Alguien influyó en la decisión? ¿De qué manera influyo?

5. ¿Para estos viajes, utilizaste alguna agencia de viajes? y si utilizaste, ¿qué te vendieron? (solo pasajes, solo el hotel, todo el paquete, etc.)

6. ¿Cómo te enteraste de esta(s) agencia(s)? ¿Cómo elegiste esta(s) agencia(s)?

7. ¿Con cuánto tiempo de anticipación planeas tus viajes?

8. Tengo entendido que viajaste al Cusco verdad, ¿Cuál fue el motivo de este viaje?

9. ¿Con quién realizaste este viaje?

10. ¿Cuánto tiempo estuviste en el Cusco?

11. ¿Cuánto gastaste por persona durante este viaje?

12. ¿Qué fue lo que más te gustó del viaje y por qué?

13. ¿Qué fue lo que no te gustó del viaje y por qué?

14. ¿Qué lugares visitaste en Cusco y por qué? Como te enteraste de estos lugares?

15. ¿Cómo llegaste al Cusco, y como llegaste a los lugares que visitaste?

16. ¿Cómo elegiste las movilidades a estos lugares?

Percepción y nivel de conocimiento de alojamientos en el Cusco

17. ¿Dónde te quedaste alojado? (Hoteles, albergues, etc.)

18. ¿Cómo elegiste este (estos) lugar(es) de hospedaje?¿Cómo te enteraste de estos lugares?

19. ¿Cuál crees que es el mejor hospedaje en Cusco?

20. ¿Qué otros hospedajes conoces? 
21. ¿Qué fue lo que más te gustó del hospedaje y por qué?

22. ¿Qué fue lo que no te gustó del hospedaje y por qué?

Conocimiento y percepción sobre el distrito de Maras

23. ¿Sabes algo del poblado de Maras en Urubamba Cusco? Si la respuesta es no, pasar a las preguntas sobre turismo vivencial.

24. ¿Visitó el distrito de Maras? ¿Por qué medio se enteró de la existencia del distrito de Maras?

25. ¿Qué atractivos turísticos visitó dentro del distrito de Maras?

26. ¿Cuál fue el motivo que lo llevó a visitar Maras y sus atractivos turísticos?

27. ¿Cuántos días permaneció en Maras? ¿Por qué?

28. ¿Qué medio de transporte utilizó para llegar a Maras?

29. ¿Qué concepto tiene de su visita a maras? ¿Cuáles son las ventajas y desventajas de su estadía?

30. ¿Recomendaría la visita a Maras a familiares y amigos?

31. ¿Luego de su experiencia, considera que conoce el distrito de Maras o le gustaría haber explorado más para conocerlo mejor?

\section{Percepción sobre el turismo vivencial}

32. ¿Qué es el turismo vivencial? ¿Ha oído hablar de él? ¿Con qué lo asocia?

33. ¿Ha tenido alguna experiencia previa con turismo vivencial? ( $\mathrm{Si}$ la respuesta es no, pasar a las preguntas de Expectativas sobre un albergue vivencial.

34. ¿Dónde fue su experiencia? ¿Dónde se hospedó y por cuánto tiempo?

35. ¿Qué le pareció el concepto de turismo vivencial?

36. ¿Cuáles considera son los aspectos negativos y positivos del turismo vivencial? ¿Por qué?

37. ¿Recomendaría este tipo de turismo a familiares y amigos?

\section{Expectativas sobre un albergue}

38. ¿Qué entiende por albergue?

39. ¿Ha visitado algún albergue durante alguno de sus viajes?

40. ¿Qué servicios considera debe tener un albergue?

Apreciación sobre los albergues en el departamento del Cusco

41. ¿Ha visitado algún albergue en el Cusco? ¿Recuerda el nombre, precio, servicios ofrecidos?

42. ¿Qué le pareció la infraestructura del albergue? ¿Contaba con los servicios que usted esperaba?

43. ¿Cuáles considera son las ventajas y desventajas del albergue que conoció en Cusco?

44. ¿Lo recomendaría a familiares y amigos?

Apreciación sobre los albergues vivenciales en el departamento del Cusco

45. ¿Sabe de algún albergue vivencial en Cusco? Si la respuesta es no, termina la entrevista y se pasa a la despedida.

46. ¿Ha visitado algún albergue vivencial en el Cusco? ¿Recuerda el nombre, precio, servicios ofrecidos?

47. ¿Dónde se encuentra ubicado el albergue vivencial que conoció en la ciudad del Cusco?

48. ¿Considera que tenía una buena ubicación? ¿Se encuentra cerca de los principales atractivos de la ciudad?

49. ¿Qué le pareció el concepto de turismo vivencial en este albergue? 
50. ¿Considera que la infraestructura, ubicación, habitaciones fueron los adecuados para un albergue vivencial?

51. ¿Qué servicios recibió durante su estadía? ¿Este servicio cumplió sus expectativas?

52. ¿Cuál es el precio que pagó por noche, considera que estuvo de acuerdo con el servicio recibido?

53. ¿Qué medios de comunicación consultó o consultaría para obtener información sobre un albergue vivencial en Cusco?

54. ¿Qué formas de pago prefiere cuando viaja por vacaciones?

55. ¿Qué promociones desea obtener cuando se encuentra en la planificación de sus viajes?

56. ¿Recomendaría el albergue vivencial a familiares y amigos?

Fin de la entrevista

Se agradece por el tiempo brindado, y en lo posible se hace entrega de un obsequio.

(Sugerencia: Objeto del mercado artesanal). 


\section{Anexo II.}

\section{Inquiry guide}

PROJECT: Homestay Hostel "La hacienda Kachi Raqay" located in Maras, Cusco-Peru

\section{Greetings and introduction}

1. Hi, Do you prefer to be interviewed in English or Spanish?

Thank you for your time. As you know, we are working on a tesis project to complete our master. Before getting started, I would require some personal data:

2. What is your country of origin?

3. Sex: $\mathrm{M}-\mathrm{F}$

4. What is your age:
a. Less than 20
b. From 20 to 29
c. 30 to 39
d. 40 to 49
e. 50 to 59
f. 60 or more

5. Marital status

\section{In-depth interview}

Thank you, now we are going to start with the questions concerning the project itself.

Description of travel habits and process involved in the buying of tourism packages

1. How often do you travel (times per year)?

2. Which places or destinations have you been for the past two years?

3. How do you choose where to travel? How do you learn about those destinations?

4. Somebody has influence on your travel decision? In which way?

5. For those travels, did you required the services of any travel agency? The answer being yes, what did they provide you with (only transportation, only hotels, all included packages, etc.)

6. How did you know about those agencies? How did you select them?

7. How long in advance do you plan your trips?

8. I understand you travelled to Cusco right, so tell me what was the purpose of this trip?

9. Who is travelling with you?

10. How much did you spend per person during this trip?

11. What did you enjoy the most during this trip and why?

12. What did you enjoy the least during this trip and why?

13. Which places did you visit in Cusco and why? How did you know about those places?

14. How did you get to Cusco (mean of transport), and how did you get to the places you travelled to?

15. How did you chose the transportation to those places

Perception and level of knowledge about accommodation offer in Cusco

16. Where did you stay in Cusco (Hotel, Hostel, etc.)

17. How did you choose this/these Accommodation(s)? How did you know about them?

18. According to you, where is the best place to stay in Cusco?

19. What other lodgings do you know?

20. What did you enjoy the most about your lodging and why?

21. What did you enjoy the least about your lodging and why? 


\section{Knowledge and perception of the Maras district}

22. Do you know the municipality of Maras in Urubamba (Cusco)? If not, go straight to the questions about homestay tourism

23. Did you visit the Maras district? How did you know about it?

24. Which tourist attraction did you visit in Maras?

25. What was the purpose of visiting Maras and its tourism highlights?

26. How long did you stay in Maras? Why?

27. Which means of transportation did you use to get to Maras?

28. What is your feeling about your visit to Maras? What do you consider as advantages \& disadvantages of your stay?

29. Would you recommend friends or family to visit Maras?

30. Further to your experience, do you consider that you've seen enough of Maras or you would have liked to explore it more?

\section{Perception of homestay tourism}

31. What is homestay tourism? Have you heard about it before? What idea of it do you have?

32. Have you ever had any experience of homestay tourism?

33. (If not, go straight to question concerning expectations about homestay hostel)

34. Where was your experience? Where did you stay and for how long?

35. How was your feeling about homestay tourism?

36. What do you consider as being the positive and negative aspects of homestay tourism? Why?

37. Would you recommend such a way of doing tourism to your friends and family?

\section{Expectation about a hostel}

38. What do you understand under the concept of hostel?

39. Have you ever visited an hostel during one of your travels

40. Which services shall be provided by a hostel?

\section{Evaluation of the hostels in Cusco area}

41. Have you ever visited any hostel in Cusco? If yes, do you remember the name, price and services provided?

42. What did you think about the hostel infrastructure? Did it offer the services your were expecting for?

43. What are the advantages and disadvantages of the hostel you stayed in?

44. Would you recommend it to your friends or family?

\section{Evaluation of the homestay hostels in Cusco area}

45. Do you know about the existence of any homestay hostel in Cusco area? If not, end the interview

46. Have you ever visited any homestay hostel in Cusco? Do you remember the name, price, services offered?

47. Where is located the homestay hostel you stayed in?

48. Do you consider that it has a good location? Is it close to city's main places of interest?

49. What did you think about the homestay tourism concept in that specific hostel?

50. Do you consider that the infrastructure, location, rooms were appropriate for a homestay experience?

51. What services were provided to you during your stay? Did they meet your needs? 
52. What is the price you paid per night, and do you think it was worth the level of services?

53. Which means of communication did you use to get information about homestay tourism in Cusco?

54. Which means of payment do you prefer when you travel for holidays?

55. Which offers would you like to receive when you plan your trip?

56. Would you recommend homestay tourism to your friends or family?

End of the interview.

Thank you for your time! 


\section{Anexo III. \\ Transcripción de entrevista turista}

\section{Entrevistado: Alvaro}

I. Saludo y presentación

1. Hola ¿En qué idioma prefieres la entrevista, español o inglés? Español.

Hola, gracias por tu tiempo. Como sabes, estamos trabajando en un proyecto de tesis para la maestría. Para lo cual, antes de comenzar necesito tus datos:

2. ¿Cuál es tu país de origen? Chile

3. Genero M F M

4. ¿En qué rango de edad te encuentras?
a. Menos de 20 años
b. 20 a 29 años
c. 30 a 39 años $(X)$
d. 40 a 49 años
e. 50 a 59 años
f. 60 años o más

5. Estado civil. Soltero

II. Estudio en profundidad

Gracias, ahora pasaremos a las preguntas referidas al proyecto.

Descripción de los hábitos de viaje y el proceso de compra de paquetes turísticos

1. ¿Cuántas veces viajas al año aproximadamente? 4

2. ¿Cuáles fueron los lugares o destinos que visitaste en los últimos dos años? 2 semanas en California, Torres del Paine Chile, Carretera Austral Chile, New York - Washington, Jamaica, Brasil, Argentina.

3. ¿Cómo elegiste donde viajar? ¿Cómo te enteraste de estos destinos? Internet

4. ¿Alguien influyó en la decisión? ¿De qué manera influyo? No

5. ¿Para estos viajes, utilizaste alguna agencia de viajes? y si utilizaste, ¿qué te vendieron? (solo pasajes, solo el hotel, todo el paquete, etc) No, yo hice el viaje

6. ¿Cómo te enteraste de esta(s) agencia(s)? ¿Cómo elegiste esta(s) agencia(s)? N/A

7. ¿Con cuánto tiempo de anticipación planeas tus viajes? 2 semanas

8. Tengo entendido que viajaste al Cusco verdad, ¿Cuál fue el motivo de este viaje? He estado 2 veces en Cusco. El primer viaje fue en la universidad y era un viaje muy de moda en ese año (2002), el segundo volví porque me encantó 2009

9. ¿Con quién realizaste este viaje? El segundo lo hice con Kevin

10. ¿Cuánto tiempo estuviste en el Cusco? 1 semana

11. ¿Cuánto gastaste por persona durante este viaje? no me acuerdo, pero no mucho.

12. ¿Qué fue lo que más te gustó del viaje y por qué? Las ruinas, la ciudad, la gente y la onda turistica que hay en cusco

13. ¿Qué fue lo que no te gustó del viaje y por qué? nada no me gustó.

14. ¿Qué lugares visitaste en Cusco y por qué? Como te enteraste de estos lugares? Todo el circuito turistico tradicional, city tour, el valle sagrado, macchu, etc. Me enteré por internet busqueda previa

15. ¿Cómo llegaste al Cusco, y como llegaste a los lugares que visitaste? En bus.

16. ¿Cómo elegiste las movilidades a estos lugares? era lo que mas se acercaba al presupuesto de viaje que llevaba. 


\section{Percepción y nivel de conocimiento de alojamientos en el Cusco}

17. ¿Dónde te quedaste alojado? (Hoteles, albergues, etc) En un hostel

18. ¿Cómo elegiste este (estos) lugar(es) de hospedaje?¿Cómo te enteraste de estos lugares? internet

19. ¿Cuál crees que es el mejor hospedaje en Cusco? Cualquiera cerca de la plaza.

20. ¿Qué otros hospedajes conoces? Loki Hostel (no se si todavia esta)

21. ¿Qué fue lo que más te gustó del hospedaje y por qué? Me acuerdo que tenia un bar y una sala de estar muy acogedora

22. ¿Qué fue lo que no te gustó del hospedaje y por qué? nada.

\section{Conocimiento y percepción sobre el distrito de Maras}

23. ¿Sabes algo del poblado de Maras en Urubamba Cusco? Si la respuesta es no, pasar a las preguntas sobre turismo vivencial. NO

24. ¿Visitó el distrito de Maras? ¿Por qué medio se enteró de la existencia del distrito de Maras?

25. ¿Qué atractivos turísticos visitó dentro del distrito de Maras?

26. ¿Cuál fue el motivo que lo llevó a visitar Maras y sus atractivos turísticos?

27. ¿Cuántos días permaneció en Maras? ¿Por qué?

28. ¿Qué medio de transporte utilizó para llegar a Maras?

29. ¿Qué concepto tiene de su visita a maras? ¿Cuáles son las ventajas y desventajas de su estadía?

30. ¿Recomendaría la visita a Maras a familiares y amigos?

31. ¿Luego de su experiencia, considera que conoce el distrito de Maras o le gustaría haber explorado más para conocerlo mejor?

\section{Percepción sobre el turismo vivencial}

32. ¿Qué es el turismo vivencial? ¿Ha oído hablar de él? ¿Con qué lo asocia? Con vivir una experiencia distinta a lo tradicional y turistico

33. ¿Ha tenido alguna experiencia previa con turismo vivencial? ( $\mathrm{Si}$ la respuesta es no, pasar a las preguntas de Expectativas sobre un albergue vivencial. NO

34. ¿Dónde fue su experiencia? ¿Dónde se hospedó y por cuánto tiempo?

35. ¿Qué le pareció el concepto de turismo vivencial?

36. ¿Cuáles considera son los aspectos negativos y positivos del turismo vivencial? ¿Por qué?

37. ¿Recomendaría este tipo de turismo a familiares y amigos?

\section{Expectativas sobre un albergue}

38. ¿Qué entiende por albergue? Lugar que te da alojamiento y comida sin grandes pretensiones.

39. ¿Ha visitado algún albergue durante alguno de sus viajes? Si, en Torres del Paine.

40. ¿Qué servicios considera debe tener un albergue? Buen baño y un lugar para descansar adecuado.

\section{Apreciación sobre los albergues en el departamento del Cusco}

41. ¿Ha visitado algún albergue en el Cusco? ¿Recuerda el nombre, precio, servicios ofrecidos? No, hostel cae dentro de la categoria de albergue?

42. ¿Qué le pareció la infraestructura del albergue? ¿Contaba con los servicios que usted esperaba? NA

43. ¿Cuáles considera son las ventajas y desventajas del albergue que conoció en Cusco? NA 
44. ¿Lo recomendaría a familiares y amigos?

\section{Apreciación sobre los albergues vivenciales en el departamento del Cusco}

45. ¿Sabe de algún albergue vivencial en Cusco? Si la respuesta es no, termina la entrevista y se pasa a la despedida. NO

46. ¿Ha visitado algún albergue vivencial en el Cusco? ¿Recuerda el nombre, precio, servicios ofrecidos?

47. ¿Dónde se encuentra ubicado el abergue vivencial que conoció en la ciudad del Cusco?

48. ¿Considera que tenía una buena ubicación? ¿Se encuentra cerca de los principales atractivos de la ciudad?

49. ¿Qué le pareció el concepto de turismo vivencial en este albergue?

50. ¿Considera que la infraestructura, ubicación, habitaciones fueron los adecuados para un albergue vivencial?

51. ¿Qué servicios recibió durante su estadía? ¿Este servicio cumplió sus expectactivas?

52. ¿Cuál es el precio que pagó por noche, considera que estuvo de acuerdo con el servicio recibido?

53. ¿Qué medios de comunicación consultó o consultaría para obtener información sobre un albergue vivencial en Cusco?

54. ¿Qué formas de pago prefiere cuando viaja por vacaciones?

55. ¿Qué promociones desea obtener cuando se encuentra en la planificación de sus viajes?

56. ¿Recomendaría el albergue vivencial a familiares y amigos?

Fin de la entrevista

Gracias por tu tiempo. 


\section{Entrevistada: Angela}

I. Saludo y presentación

1. Hola ¿En qué idioma prefieres la entrevista, español o inglés?

Español

Hola, gracias por tu tiempo. Como sabes, estamos trabajando en un proyecto de tesis para la maestría. Para lo cual, antes de comenzar necesito tus datos:

2. ¿Cuál es tu país de origen? Perú

3. Género: Femenino

4. ¿En qué rango de edad te encuentras? b. 20 a 29 años

5. Estado civil

Soltera

II. Estudio en profundidad

Gracias, ahora pasaremos a las preguntas referidas al proyecto.

\section{Descripción de los hábitos de viaje y el proceso de compra de paquetes turísticos}

1. ¿Cuántas veces viajas al año aproximadamente? 4 veces

2. ¿Cuáles fueron los lugares o destinos que visitaste en los últimos dos años? Asia, India, Bolivia, Lima, Cusco, Arequipa, Puno.

3. ¿Cómo elegiste donde viajar? ¿Cómo te enteraste de estos destinos? Por internet

4. ¿Alguien influyó en la decisión? ¿De qué manera influyo? No.

5. ¿Para estos viajes, utilizaste alguna agencia de viajes? y si utilizaste, ¿qué te vendieron? (solo pasajes, solo el hotel, todo el paquete, etc) Para Asia use una para ir a China, una vez ahí fuimos armando el viaje solos.

6. ¿Cómo te enteraste de esta(s) agencia(s)? ¿Cómo elegiste esta(s) agencia(s)? Por internet, costo beneficio.

7. ¿Con cuánto tiempo de anticipación planeas tus viajes? Depende que tan lejos: Para Asia, con un año de anticipación.

8. Tengo entendido que viajaste al Cusco verdad, ¿Cuál fue el motivo de este viaje? Vivo aquí en Cusco.

9. ¿Con quién realizaste este viaje?

10. ¿Cuánto tiempo estuviste en el Cusco?

11. ¿Cuánto gastaste por persona durante este viaje?

12. ¿Qué fue lo que más te gustó del viaje y por qué?

13. ¿Qué fue lo que no te gustó del viaje y por qué?

14. ¿Qué lugares visitaste en Cusco y por qué? ¿Como te enteraste de estos lugares?

15. ¿Cómo llegaste al Cusco, y como llegaste a los lugares que visitaste?

16. ¿Cómo elegiste las movilidades a estos lugares?

\section{Percepción y nivel de conocimiento de alojamientos en el Cusco}

17. ¿Dónde te quedaste alojado? (Hoteles, albergues, etc)

18. ¿Cómo elegiste este (estos) lugar(es) de hospedaje? ¿Cómo te enteraste de estos lugares?

19. ¿Cuál crees que es el mejor hospedaje en Cusco? Ticahuasi, en San Blas.

20. ¿Qué otros hospedajes conoces?

21. ¿Qué fue lo que más te gustó del hospedaje y por qué? Buena proporción costo beneficio, el servicio es excelente.

22. ¿Qué fue lo que no te gustó del hospedaje y por qué? 


\section{Conocimiento y percepción sobre el distrito de Maras}

23. ¿Sabes algo del poblado de Maras en Urubamba Cusco? Si, es un destino turístico que está incrementando en los últimos años. Yo por cuestiones de trabajo, en los tours que hago visito Moray, que está en Maras además de las salineras. Son destinos que son muy visitados y que me gustan mucho, especialmente Maras por como lo presentan, muy comunitario.

[...] Los turistas visitan Maras por el atractivo visual, pero lo que me parece sumamente importante es la visión con la que salen. Van por las salineras, y se les explica cómo funciona el turismo comunitario, es algo extra que los pasajeros se llevan y tienden a comprar cosas ya no necesariamente por el producto, si no por el proceso de elaboración y consideran que están ayudando este proyecto comunitario.

24. ¿Visitó el distrito de Maras? ¿Por qué medio se enteró de la existencia del distrito de Maras?

25. ¿Qué atractivos turísticos visitó dentro del distrito de Maras?

26. ¿Cuál fue el motivo que lo llevó a visitar Maras y sus atractivos turísticos?

27. ¿Cuántos días permaneció en Maras? ¿Por qué? Cuando vamos nos quedamos 30 a 40 minutos.

28. ¿Qué medio de transporte utilizó para llegar a Maras? La agencia provee el transporte.

29. ¿Qué concepto tiene de su visita a maras? ¿Cuáles son las ventajas y desventajas de su estadía? Estaban mejorando el acceso, lo cual era incómodo. Durante la época de lluvia, debido a que es de tierra, los turistas solían llenarse los zapatos con barro y eso no lo hace atractivo. Pero ahora que lo están arreglando.

[...] La ventaja es que los turistas pueden ver el proceso de cosechar la sal y eso es un plus porque vende de donde sale. Como desventaja, sería el hecho de que cobran una entrada de S/. 10 pero no incluye ni servicios higiénicos.

30. ¿Recomendaría la visita a Maras a familiares y amigos? Lo haría definitivamente.

31. ¿Luego de su experiencia, considera que conoce el distrito de Maras o le gustaría haber explorado más para conocerlo mejor? No yo creo que el espacio donde se ubica y el tiempo de visita es el adecuado. Tal vez en el poblado mismo de Maras, se puede explorar más. Hay una escultura en el medio que muestra una iglesia y unos antiguos graneros. Y eso nunca visitamos, tal vez por el tiempo.

\section{Percepción sobre el turismo vivencial}

32. ¿Qué es el turismo vivencial? ¿Ha oído hablar de él? ¿Con qué lo asocia?

Sí, he podido experimentar proyectos bajo el nombre de turismo vivencial. El común denominador es que el turista pueda experimentar la vida diaria de quienes lo están hospedando. Además de proporcionarles comidas se los involucra como parte de las actividades diarias.

33. ¿Ha tenido alguna experiencia previa con turismo vivencial? ( $\mathrm{Si}$ la respuesta es no, pasar a las preguntas de Expectativas sobre un albergue vivencial.

34. ¿Dónde fue su experiencia? ¿Dónde se hospedó y por cuánto tiempo?

En el valle sagrado de Cusco en una comunidad de tejedoras, en Puno en par de islas y también en África. El tiempo de estadía promedio fue de 2 días y una noche. En Pisac en el valle sagrado, por el tipo de tour que se organizaba, 100\% vivencial fueron 3 noches y 4 días. Ahí nos quedamos en las casas de los comuneros, en cuartos designados para tal efecto. No podría decir que estas habitaciones son diferentes a de los mismos comunarios, porque no las llegué a conocer. Aunque sea vivencial, hay como una barrera. No llegas a vivir y conocer el $100 \%$ la vida de ellos.

Es lo suficientemente real como para transmitir al turista la experiencia, pero sin transgredir la idea. El shock cultural sería muy fuerte. Dormir con un cuy corriendo 
bajo su cama podría asustarlo. La idea es venderle el concepto, bonito, real pero mejorado por decirlo así.

35. ¿Qué le pareció el concepto de turismo vivencial?

36. ¿Cuáles considera son los aspectos negativos y positivos del turismo vivencial? ¿Por qué?

Lo positivo es lo que se lleva el turista, tengo reportes donde mencionan que el momento más significativo de un pasajero durante el viaje ha sido poder experimentar un estilo de vida mucho más sencillo y que les permite valorar lo que tienen en casa.

Verlos trabajar la tierra expuesta al sol y al frio, afecta al pasajero como un cachetadon de realidad y esto me parece genial.

Sin embargo, si esto no se maneja con una buena proporción crea un aldo negativo. Lo veo reflejado en las comunidades. Dejan de ver al turista como alguien con quien pueden compartir y lo ven más como alguien del cual se puede lucrar. Ahí comienza un lado negativo.

37. ¿Recomendaría este tipo de turismo a familiares y amigos?

De hecho que sí.

\section{Expectativas sobre un albergue}

38. ¿Qué entiende por albergue?

Es un espacio que se utiliza de descanso cuando se realiza una caminata durante varios días y estas alejado de la civilización, es un lugar de descanso cómodo que reemplaza un campamento. Lo relaciono con un lodge.

39. ¿Ha visitado algún albergue durante alguno de sus viajes?

Si, varios. Trabajo con una compañía Andean Lodge que hace la ruta Ausangate. Ahí están los lodge más bonitos que he podido observar, son ideales. Están bien distribuidos a lo largo de la ruta. Después de 7 a 8 horas caminando llegar a un lugar cómodo, con agua caliente, comida y una chimenea, son recompensas que agregan valor a la experiencia.

El costo es de \$US 1400 e incluye todo, desde que te recogen del hotel hasta que te dejan en el hotel, guías, comida, albergues, absolutamente todo.

40. ¿Qué servicios considera debe tener un albergue?

Mínimo una cama cómoda y limpia, una ducha idealmente caliente y comida.

41. ¿Algún otro albergue significativo fuera de Cusco?

Si en África, después de las caminatas. Este albergue me marco porque me pareció bien planteada la idea, dentro del contexto y como lo presentaban. No son estructuras de hotel, cemento. Era como una casita lejos de tu casa.

Además, el esfuerzo físico une a la gente y encima después llegar a un lugar donde puedes compartir experiencias del día, consigue que se implante mejor la idea del viaje.

\section{Apreciación sobre los albergues en el departamento del Cusco}

42. ¿Ha visitado algún albergue en el Cusco? ¿Recuerda el nombre, precio, servicios ofrecidos?

43. ¿Qué le pareció la infraestructura del albergue? ¿Contaba con los servicios que usted esperaba?

44. ¿Cuáles considera son las ventajas y desventajas del albergue que conoció en Cusco?

45. ¿Lo recomendaría a familiares y amigos?

Apreciación sobre los albergues vivenciales en el departamento del Cusco

46. ¿Sabe de algún albergue vivencial en Cusco? 
No, la mayoría de los albergues son de este tipo: para llegar, descansar una noche y volver a partir. En los albergues de Andean Lodge no hay actividades para compartir con la comunidad.

47. ¿Ha visitado algún albergue vivencial en el Cusco? ¿Recuerda el nombre, precio, servicios ofrecidos?

48. ¿Dónde se encuentra ubicado el albergue vivencial que conoció en la ciudad del Cusco?

49. ¿Considera que tenía una buena ubicación? ¿Se encuentra cerca de los principales atractivos de la ciudad?

50. ¿Qué le pareció el concepto de turismo vivencial en este albergue?

51. ¿Considera que la infraestructura, ubicación, habitaciones fueron los adecuados para un albergue vivencial?

52. ¿Qué servicios recibió durante su estadía? ¿Este servicio cumplió sus expectativas?

53. ¿Cuál es el precio que pagó por noche, considera que estuvo de acuerdo con el servicio recibido?

54. ¿Qué medios de comunicación consultó o consultaría para obtener información sobre un albergue vivencial en Cusco?

55. ¿Qué formas de pago prefiere cuando viaja por vacaciones? Tarjeta.

56. ¿Qué promociones desea obtener cuando se encuentra en la planificación de sus viajes? Las mejores promociones son las de pasajes.

Apreciación del proyecto.

Quisiera saber tu apreciación acerca del proyecto.

57. ¿Qué te parece un albergue vivencial en el distrito de Maras, con establecimiento de hospedaje, donde el turista interviene en las experiencias diarias del poblado, pero sin llegar a involucrarlos en las casas?

Yo creo que es un gran proyecto, suena súper interesante, el pasajero no quiere venir a trabajar la tierra, está de vacaciones. Creo que un buen equilibrio entre involucrarlo y engreírlo es la fórmula mágica. O sea, hay que mostrarle un poquito, mira cómo se hace, intenta hacer esto, pero sin presionarlo. Los reportes que tengo demuestran que lo que más valora e impacta al turista es cuando se involucran con la gente y con sus actividades.

En cuando a la ubicación me parece que habría que promocionarlo fuerte, porque las salineras y el poblado se visita en un solo día. Tradicionalmente es la manera en que se vende esta zona, porque dada la cercanía la mayoría de la gente prefiere no pasar la noche ahí sino continuar hasta Urubamba. Por lo cual me parece un gran proyecto, para invitar una persona a se quede por lo menos una noche. Con el nuevo aeropuerto, yo creo que se pueden cambiar estos hábitos de viaje.

Fin de la entrevista

Gracias por tu tiempo. 


\section{Entrevistado: Gabriel Ayoroa}

\section{Saludo y presentación}

1. Hola ¿En qué idioma prefieres la entrevista, español o inglés? Ingles

Hola, gracias por tu tiempo. Como sabes, estamos trabajando en un proyecto de tesis para la maestría. Para lo cual, antes de comenzar necesito tus datos:

2. ¿Cuál es tu país de origen? Bolivia, pero vivo en Estados Unidos hace 15 años

3. Género: Masculino

4. ¿En qué rango de edad te encuentras? 34

5. Estado civil: Casado

II. Estudio en profundidad

Gracias, ahora pasaremos a las preguntas referidas al proyecto.

\section{Descripción de los hábitos de viaje y el proceso de compra de paquetes turísticos}

1. ¿Cuántas veces viajas al año aproximadamente? 3 a 4 veces

2. ¿Cuáles fueron los lugares o destinos que visitaste en los últimos dos años? Costa Rica, Perú, Colorado, California, Texas.

3. ¿Cómo elegiste donde viajar? ¿Cómo te enteraste de estos destinos? Por intereses personales, sobre todo me interesa actividades al aire libre y visitar lugares famosos por su arquitectura o su historia, por lo menos una vez.

4. ¿Alguien influyó en la decisión? ¿De qué manera influyo?

Si mi esposa, decidimos aquellos lugares que nos guste a ambos

5. ¿Para estos viajes, utilizaste alguna agencia de viajes? y si utilizaste, ¿qué te vendieron? (solo pasajes, solo el hotel, todo el paquete, etc)

No, todo lo hacemos a través de internet. Me parece que influye mucho la edad. Por ejemplo, mis amigos no usan agencias para nada, pero las personas mayores si utilizan bastante.

6. ¿Cómo te enteraste de esta(s) agencia(s)? ¿Cómo elegiste esta(s) agencia(s)?

7. ¿Con cuánto tiempo de anticipación planeas tus viajes?

Internacional que esté más o menos lejos, con un año de anticipación. Pero nacional o países limítrofes de 2 a 4 meses.

Con mucho tiempo de anticipación

8. Tengo entendido que viajaste al Cusco verdad, ¿Cuál fue el motivo de este viaje? Mi esposa fue a hacer un voluntariado y yo la iba a acompañar. Como íbamos a estar en Perú quería que conozca las ruinas y Machu Picchu, que yo ya había visitado en el 2012.

9. ¿Con quién realizaste este viaje?

Con mi esposa, y nos encontramos con amigos allá por coincidencia.

10. ¿Cuánto tiempo estuviste en el Cusco?

Una semana

11. ¿Cuánto gastaste por persona durante este viaje?

Entre US\$ 800 a US\$ 1000. (Recuerdo que pagué como US\$ 80. Por noche, pero lo más caro fue el tren y los tickets a las ruinas)

12. ¿Qué fue lo que más te gustó del viaje y por qué?

13. ¿Qué fue lo que no te gustó del viaje y por qué?

14. ¿Qué lugares visitaste en Cusco y por qué? ¿Cómo te enteraste de estos lugares? 
15. ¿Cómo llegaste al Cusco, y como llegaste a los lugares que visitaste?

En avión a Cusco, y desde el aeropuerto de Cusco todo en taxi (incluyendo las ruinas).

16. ¿Cómo elegiste las movilidades a estos lugares?

Taxi en el aeropuerto de Cusco, regateando. Pero nos costó más o menos \$US 180 para que nos lleve a todos los lugares del boleto turístico, el cual es un boleto que te incluye la entrada a varias ruinas. Este boleto me costó como \$US. 100 y lo compré en el primer lugar que visité: Chinchero donde están orgullosos del nuevo aeropuerto y nos sorprendió la fluidez de su inglés. Además, me acuerdo haber comprado un boleto aparte, más barato, para visitar otros lugares como Maras.

\section{Percepción y nivel de conocimiento de alojamientos en el Cusco}

17. ¿Dónde te quedaste alojado? (Hoteles, albergues, etc) En Ollantaytambo nos quedamos 3 noches en el hotel APU, que me parece que es la iniciativa de unos gringos que llegaron y pusieron su hotel.

18. ¿Cómo elegiste este (estos) lugar(es) de hospedaje? ¿Cómo te enteraste de estos lugares?

Trip advisor, por los comentarios de las otras personas que estuvieron allá.

19. ¿Cuál crees que es el mejor hospedaje en Cusco?

Depende mucho del objetivo de tu viaje, y de tu presupuesto.

20. ¿Qué otros hospedajes conoces?

Sé que hay hoteles de 5 estrellas, creo que había un Hilton. Pero si yo recomendara a alguien le aconsejaría algo céntrico para que puedan conocer el centro histórico y con buena vista (bonita) a la ciudad.

21. ¿Qué fue lo que más te gustó del hospedaje y por qué?

El APU estaba en el lado histórico (incaico) de Ollantaytambo, no había tráfico vehicular solo peatonal, estaba entre vertientes de agua y con vista a las ruinas, y tenía un jardín muy bonito. En resumen, su ubicación. Porque en ese tipo de viaje uno no busca un servicio 5 estrellas, para eso hay mejores opciones acá en Estados Unidos y me ahorraría el pasaje a Perú. Obviamente esperas que esté limpio y que tenga desayuno, pero la mayoría del tiempo lo pasamos fuera del hotel, ya que los tours empiezan temprano.

22. ¿Qué fue lo que no te gustó del hospedaje y por qué?

La infraestructura, porque estaba muy viejo y el piso sonaba a cada rato cuando alguien fuera de la habitación caminaba cerca.

Otra cosa a nivel general en el Perú es que no se pueda largar el papel higiénico al inodoro, y tengas un basurero lleno de tus residuos ahí. Eso me da asco.

\section{Conocimiento y percepción sobre el distrito de Maras}

23. ¿Sabes algo del poblado de Maras en Urubamba Cusco? Si la respuesta es no, pasar a las preguntas sobre turismo vivencial.

Si estuve ahí.

24. ¿Visitó el distrito de Maras? ¿Por qué medio se enteró de la existencia del distrito de Maras?

Porque estaba camino a Ollantaytambo y el taxista me comentó que había portones pintorescos porque son viejos para sacarles foto.

25. ¿Qué atractivos turísticos visitó dentro del distrito de Maras?

Las salineras, y los andenes de Moray que está a unos 15 minutos de Maras. Pero en realidad estuvimos muy pocos minutos porque fuera de llamar la atención su forma, que era como una pera o guitarra gigante, no hay nada más para hacer.

26. ¿Cuál fue el motivo que lo llevó a visitar Maras y sus atractivos turísticos? 
Porque estaba de paso en el tour.

27. ¿Cuántos días permaneció en Maras? ¿Por qué?

Ni un día, nos quedamos 15 minutos, no había mucho que hacer. Sacamos fotos, visitamos las salineras y listo.

28. ¿Qué medio de transporte utilizó para llegar a Maras?

Taxi

29. ¿Qué concepto tiene de su visita a maras? ¿Cuáles son las ventajas y desventajas de su estadía?

Maras para mí son portones antiguos y un par de burros. Ni siquiera lo asocio con los andenes de Moray.

Lo mejor comprar las sales de Maras con hierbas.

Lo peor, o desventaja, es que es un pueblo aburrido y no hay mucho que hacer.

30. ¿Recomendaría la visita a Maras a familiares y amigos?

Si están cerca si.

31. ¿Luego de su experiencia, considera que conoce el distrito de Maras o le gustaría haber explorado más para conocerlo mejor?

$\mathrm{Si}$, con 15 minutos me da la impresión de haber conocido todo y no me llama la atención conocer más.

\section{Percepción sobre el turismo vivencial}

32. ¿Qué es el turismo vivencial? ¿Ha oído hablar de él? ¿Con qué lo asocia?

El término no me es muy familiar, el concepto me suena a que es ir a quedarse en una casa familiar donde te enseñan a hacer chica o algo asi.

33. ¿Ha tenido alguna experiencia previa con turismo vivencial? ( $\mathrm{Si}$ la respuesta es no, pasar a las preguntas de Expectativas sobre un albergue vivencial.

Si en Bolivia.

34. ¿Dónde fue su experiencia? ¿Dónde se hospedó y por cuánto tiempo?

En Rurrenabaque (Beni, Bolivia) por una semana.

35. ¿Qué le pareció el concepto de turismo vivencial?

No me interesa mucho.

36. ¿Cuáles considera son los aspectos negativos y positivos del turismo vivencial? ¿Por qué?

Negativo es que te quita tiempo para conocer otras cosas del lugar, y en lo particular no me interesa. Lo positivo es aprender de la cultura.

37. ¿Recomendaría este tipo de turismo a familiares y amigos?

Nop

\section{Expectativas sobre un albergue}

38. ¿Qué entiende por albergue?

Me suena a algo más barato que un hotel, para gente joven que no tiene muchos recursos. Un lodge me suena más a una cabaña.

39. ¿Ha visitado algún albergue durante alguno de sus viajes?

Si en Europa cuando era joven.

40. ¿Qué servicios considera debe tener un albergue?

Una cama compartida y bajo precio. El término Lodge me suena a algo más exclusivo y relacionado a naturaleza, lejos del pueblo o ciudad.

\section{Apreciación sobre los albergues en el departamento del Cusco}

41. ¿Ha visitado algún albergue en el Cusco? ¿Recuerda el nombre, precio, servicios ofrecidos? 
No, solo me quedé en hoteles.

42. ¿Qué le pareció la infraestructura del albergue? ¿Contaba con los servicios que usted esperaba?

43. ¿Cuáles considera son las ventajas y desventajas del albergue que conoció en Cusco?

44. ¿Lo recomendaría a familiares y amigos?

\section{Apreciación sobre los albergues vivenciales en el departamento del Cusco}

45. ¿Sabe de algún albergue vivencial en Cusco? Si la respuesta es no, termina la entrevista y se pregunta sobre el concepto.

No.

46. ¿Si te propusiera un lodge vivencial en Maras, donde te enseñarían desde comprar los alimentos en el mercado y como prepararlos, además de tours guiados a caballo o para sacar fotos, te interesaría?

En lo personal no, pero creo que, si hay un mercado para eso, pero algo un poco más adulto, tal vez más familiar porque el concepto me parece caro.

Pero preferiría que sea en Ollantaytambo, porque Maras además de ser poco interesante está medio alto, y todo el mundo le escapa a la altura.

Fin de la entrevista

Gracias por tu tiempo. 


\section{Entrevistado: Hugo}

I. Saludo y presentación

1. Hola ¿En qué idioma prefieres la entrevista, español o inglés?

Español

Hola, gracias por tu tiempo. Como sabes, estamos trabajando en un proyecto de tesis para la maestría. Para lo cual, antes de comenzar necesito tus datos:

2. ¿Cuál es tu país de origen?

Argentina

3. Género: Masculino

4. ¿En qué rango de edad te encuentras?

Entre 20 a 29 años

5. Estado civil: Soltero

II. Estudio en profundidad

Gracias, ahora pasaremos a las preguntas referidas al proyecto.

\section{Descripción de los hábitos de viaje y el proceso de compra de paquetes turísticos}

1. ¿Cuántas veces viajas al año aproximadamente? $1 / 2$ veces al año

2. ¿Cuáles fueron los lugares o destinos que visitaste en los últimos dos años? Australia, Nepal, Tailandia, Peru.

3. ¿Cómo elegiste donde viajar? ¿Cómo te enteraste de estos destinos? Internet, Cercania.

4. ¿Alguien influyó en la decisión? ¿De qué manera influyo? Internet, boca en boca.

5. ¿Para estos viajes, utilizaste alguna agencia de viajes? y si utilizaste, ¿qué te vendieron? (solo pasajes, solo el hotel, todo el paquete, etc) Nunca jamas de los jamas voy a una agencia.

6. ¿Cómo te enteraste de esta(s) agencia(s)? ¿Cómo elegiste esta(s) agencia(s)? Las veo en la calle.

7. ¿Con cuánto tiempo de anticipación planeas tus viajes? Planear, poco y nada. Los pienso todo el rato.

8. Tengo entendido que viajaste al Cusco verdad, ¿Cuál fue el motivo de este viaje? Recorriendo latinoamerica, pase un mes en Cusco de paseo por la ciudad y sus alrededores. Alucine.

9. ¿Con quién realizaste este viaje? Solito

10. ¿Cuánto tiempo estuviste en el Cusco? 21 dias en la ciudad creo.

11. ¿Cuánto gastaste por persona durante este viaje? Creo que unos 18 soles por dia en hostal mas gastos de comida y bebida y paseos de alrededor de 40 soles estimo. Promedio de 60 soles.

12. ¿Qué fue lo que más te gustó del viaje y por qué?

Caminar la ciudad, los mercados, conocer gente, jugar basket en la altura y salir de parranda con los gringos.

13. ¿Qué fue lo que no te gustó del viaje y por qué?

No me gusto que las agencias se nieguen a dar información para la gente que quiere ir a Choquequirao sin pagar un tour. Tuve que recurrir a la buena voluntad de un 
empleado de la oficina de turismo que recopilo esta informacion por su propios medios

14. ¿Qué lugares visitaste en Cusco y por qué? Como te enteraste de estos lugares? Macchu Picchu, Choquequirao, Pisaq, Ollantaytambo, salar y otras ruinas que no recuerdo el nombre. Me entere por ver fotos en internet y de otros viajeros, y sus cuentos.

15. ¿Cómo llegaste al Cusco, y como llegaste a los lugares que visitaste? Llegue en bus nocturno desde Arequipa. Fue a todos en bus local. Excepto a Macchu Picchu y Ollantaytambo en bus y tren.

16. ¿Cómo elegiste las movilidades a estos lugares? Con el bolsillo

\section{Percepción y nivel de conocimiento de alojamientos en el Cusco}

17. ¿Dónde te quedaste alojado? (Hoteles, albergues, etc)

Eco Packers (hostal)

18. ¿Cómo elegiste este (estos) lugar(es) de hospedaje?¿Cómo te enteraste de estos lugares? Recomendación de amigo sueco no fiestero.

19. ¿Cuál crees que es el mejor hospedaje en Cusco? Eco Packers.

20. ¿Qué otros hospedajes conoces? Loki, Wild Rover,Che Lagarto, y varias pensiones llenas de argentos.

21. ¿Qué fue lo que más te gustó del hospedaje y por qué?

El precio, el ambiente, que no habia joda fuerte, el staff de puros peruanos era fenomenal.

22. ¿Qué fue lo que no te gustó del hospedaje y por qué?

Todo joya. Excepto que mi dormitorio tenia demasiadas camas, pero ese es culpa mia por ser tan miserable.

\section{Conocimiento y percepción sobre el distrito de Maras}

23. ¿Sabes algo del poblado de Maras en Urubamba Cusco? Si la respuesta es no, pasar a las preguntas sobre turismo vivencial.

No tengo ni idea.

24. ¿Visitó el distrito de Maras? ¿Por qué medio se enteró de la existencia del distrito de Maras?

25. ¿Qué atractivos turísticos visitó dentro del distrito de Maras?

26. ¿Cuál fue el motivo que lo llevó a visitar Maras y sus atractivos turísticos?

27. ¿Cuántos días permaneció en Maras? ¿Por qué?

28. ¿Qué medio de transporte utilizó para llegar a Maras?

29. ¿Qué concepto tiene de su visita a maras? ¿Cuáles son las ventajas y desventajas de su estadía?

30. ¿Recomendaría la visita a Maras a familiares y amigos?

31. ¿Luego de su experiencia, considera que conoce el distrito de Maras o le gustaría haber explorado más para conocerlo mejor?

\section{Percepción sobre el turismo vivencial}

32. ¿Qué es el turismo vivencial? ¿Ha oído hablar de él? ¿Con qué lo asocia? Acabo de googlearlo. Lo asocio con turismo. Un poco menos pasivo pero al fin al cabo un producto.

33. ¿Ha tenido alguna experiencia previa con turismo vivencial? ( $\mathrm{Si}$ la respuesta es no, pasar a las preguntas de Expectativas sobre un albergue vivencial. 
Tuve algo similar en Nepal. Llamado "home stay". Se paga un sobreprecio por quedarse en una casa de familia.

34. ¿Dónde fue su experiencia? ¿Dónde se hospedó y por cuánto tiempo?

Un día en Panauli, Nepal. Nunca mas.

35. ¿Qué le pareció el concepto de turismo vivencial?

Creo que el límite entre show y hospitalidad es demasiado fino.

36. ¿Cuáles considera son los aspectos negativos y positivos del turismo vivencial? ¿Por qué?

Positivo: Fuentes de trabajo.

Una nueva forma más activa de ir como turista

Negativo: Nada negativo.

37. ¿Recomendaría este tipo de turismo a familiares y amigos?

$\mathrm{Si}$, el que quiera que lo haga. Es más edificante sin dudas que verlo en la tele.

\section{Expectativas sobre un albergue}

38. ¿Qué entiende por albergue?

Un lugar donde uno paga dinero para poder pasar la noche.

39. ¿Ha visitado algún albergue durante alguno de sus viajes?

$\mathrm{Si}$

40. ¿Qué servicios considera debe tener un albergue?

Debe ser "bueno, bonito y barato". Y limpio. Y no estar escondido

Apreciación sobre los albergues en el departamento del Cusco

41. ¿Ha visitado algún albergue en el Cusco? ¿Recuerda el nombre, precio, servicios ofrecidos?

No

42. ¿Qué le pareció la infraestructura del albergue? ¿Contaba con los servicios que usted esperaba?

43. ¿Cuáles considera son las ventajas y desventajas del albergue que conoció en Cusco? Serían las mismas que los que se aplican a mi hostal (ver arriba).

44. ¿Lo recomendaría a familiares y amigos?

Apreciación sobre los albergues vivenciales en el departamento del Cusco

45. ¿Sabe de algún albergue vivencial en Cusco? Si la respuesta es no, termina la entrevista y se pasa a la despedida.

NO

46. ¿Ha visitado algún albergue vivencial en el Cusco? ¿Recuerda el nombre, precio, servicios ofrecidos?

47. ¿Dónde se encuentra ubicado el abergue vivencial que conoció en la ciudad del Cusco?

48. ¿Considera que tenía una buena ubicación? ¿Se encuentra cerca de los principales atractivos de la ciudad?

49. ¿Qué le pareció el concepto de turismo vivencial en este albergue?

50. ¿Considera que la infraestructura, ubicación, habitaciones fueron los adecuados para un albergue vivencial?

51. ¿Qué servicios recibió durante su estadía? ¿Este servicio cumplió sus expectativas?

52. ¿Cuál es el precio que pagó por noche, considera que estuvo de acuerdo con el servicio recibido?

53. ¿Qué medios de comunicación consultó o consultaría para obtener información sobre un albergue vivencial en Cusco?

54. ¿Qué formas de pago prefiere cuando viaja por vacaciones? 
55. ¿Qué promociones desea obtener cuando se encuentra en la planificación de sus viajes? 56. ¿Recomendaría el albergue vivencial a familiares y amigos?

Fin de la entrevista

Gracias por tu tiempo. 


\section{Entrevistado: José Carreon}

I. Saludo y presentación

1. Hola ¿En qué idioma prefieres la entrevista, español o inglés?

Español

Hola, gracias por tu tiempo. Como sabes, estamos trabajando en un proyecto de tesis para la maestría. Para lo cual, antes de comenzar necesito tus datos:

2. ¿Cuál es tu país de origen? Bolivia

3. Género: Masculino

4. ¿En qué rango de edad te encuentras?
a. Menos de 20 años
b. 20 a 29 años
c. 30 a 39 años
d. 40 a 49 años
e. 50 a 59 años
f. 60 años o más

5. Estado civil

Casado

II. Estudio en profundidad

Gracias, ahora pasaremos a las preguntas referidas al proyecto.

Descripción de los hábitos de viaje y el proceso de compra de paquetes turísticos

1. ¿Cuántas veces viajas al año aproximadamente?

6 veces al año en promedio

2. ¿Cuáles fueron los lugares o destinos que visitaste en los últimos dos años?

Estados Unidos (Miami, Orlando), Perú (Cusco y Lima), Chile (Valparaiso, Santiago), Brasil (Rio, Sao Paolo y Recife) y dentro de Bolivia a Santa Cruz.

3. ¿Cómo elegiste donde viajar? ¿Cómo te enteraste de estos destinos?

Amigos, eventos y publicidad en redes sociales.

4. ¿Alguien influyó en la decisión? ¿De qué manera influyo?

Mi esposa, es una negociación en conjunto, juega mucho el factor económico.

5. ¿Para estos viajes, utilizaste alguna agencia de viajes? y si utilizaste, ¿qué te vendieron? (solo pasajes, solo el hotel, todo el paquete, etc.)

$\mathrm{Si}$, para Cusco me vendieron pasajes, tour en Machu Picchu y el hotel en Aguas calientes. Pero dentro de la ciudad de Cusco yo solo busque el turismo.

6. ¿Cómo te enteraste de esta(s) agencia(s)? ¿Cómo elegiste esta(s) agencia(s)? Primero por un amigo, y después se volvió mi agencia de confianza. Por ejemplo me emite los pasajes más baratos, y además no necesito pagarle inmediatamente.

7. ¿Con cuánto tiempo de anticipación planeas tus viajes?

Para vuelos nacionales, dos semanas. Para internacional, de 1 a 2 meses. Salvo casos excepcionales como Brasil que tuve que planearlo con 6 meses.

8. Tengo entendido que viajaste al Cusco verdad, ¿Cuál fue el motivo de este viaje? Turismo, pero principalmente por comentarios boca a boca y publicidad en las redes sociales.

9. ¿Con quién realizaste este viaje?

Con mi esposa.

10. ¿Cuánto tiempo estuviste en el Cusco?

5 días. 3 días en Aguascalientes para el tour a Machu Picchu y 2 días en Cusco. 
11. ¿Cuánto gastaste por persona durante este viaje? El vuelo US\$ 300 y US\$ 400 en todo lo demás.

12. ¿Qué fue lo que más te gustó del viaje y por qué? Machu Picchu por ser impresionante, y un restaurante en cusco llamado papachos.

13. ¿Qué fue lo que no te gustó del viaje y por qué? El clima, estaba demasiado frio. Y el costo de las cosas, todo es muy caro.

14. ¿Qué lugares visitaste en Cusco y por qué? Como te enteraste de estos lugares?

15. ¿Cómo llegaste al Cusco, y como llegaste a los lugares que visitaste? Por avión llegamos, y en la mañana partimos en bus a Aguas calientes, de ahí en tren a Machupicchu.

16. ¿Cómo elegiste las movilidades a estos lugares?

Todas las movilidades estaban incluidas en el paquete. El tren es lo único que no estaba incluído.

Percepción y nivel de conocimiento de alojamientos en el Cusco

17. ¿Dónde te quedaste alojado? (Hoteles, albergues, etc)

Hotel de una estrella, no me acuerdo el nombre. Era algo con oro, pero estaba en la peatonal de aguas calientes.

18. ¿Cómo elegiste este (estos) lugar(es) de hospedaje?¿Cómo te enteraste de estos lugares? El de aguas calientes ya estaba incluido en el tour. En Cusco caminamos alrededor de la plaza hasta encontrar alguno barato.

19. ¿Cuál crees que es el mejor hospedaje en Cusco?

Desde afuera vi uno que me llamó la atención, que se llamaba la casona. Se veía bonito y era céntrico.

20. ¿Qué otros hospedajes conoces?

$\mathrm{Vi}$ algunos, pero no me acuerdo los nombres.

21. ¿Qué fue lo que más te gustó del hospedaje y por qué?

En el de aguas calientes, la infraestructura, sobre todo el cuarto. En el de Cusco, el desayuno. Pero en ambos casos la cercanía era lo mejor.

22. ¿Qué fue lo que no te gustó del hospedaje y por qué?

El de Cusco era muy frio y su infraestructura no era de las mejores. El de Aguas calientes tenía un desayuno que podría haber sido mejor.

\section{Conocimiento y percepción sobre el distrito de Maras}

23. ¿Sabes algo del poblado de Maras en Urubamba Cusco? Si la respuesta es no, pasar a las preguntas sobre turismo vivencial.

24. ¿Visitó el distrito de Maras? ¿Por qué medio se enteró de la existencia del distrito de Maras?

25. ¿Qué atractivos turísticos visitó dentro del distrito de Maras?

26. ¿Cuál fue el motivo que lo llevó a visitar Maras y sus atractivos turísticos?

27. ¿Cuántos días permaneció en Maras? ¿Por qué?

28. ¿Qué medio de transporte utilizó para llegar a Maras?

29. ¿Qué concepto tiene de su visita a maras? ¿Cuáles son las ventajas y desventajas de su estadía?

30. ¿Recomendaría la visita a Maras a familiares y amigos?

31. ¿Luego de su experiencia, considera que conoce el distrito de Maras o le gustaría haber explorado más para conocerlo mejor?

\section{Percepción sobre el turismo vivencial}

32. ¿Qué es el turismo vivencial? ¿Ha oído hablar de él? ¿Con qué lo asocia? 
No, pero me suena a estar en un pueblo, probablemente vivir dentro de una familia.

33. ¿Ha tenido alguna experiencia previa con turismo vivencial? ( $\mathrm{Si}$ la respuesta es no, pasar a las preguntas de Expectativas sobre un albergue vivencial.

34. ¿Dónde fue su experiencia? ¿Dónde se hospedó y por cuánto tiempo?

35. ¿Qué le pareció el concepto de turismo vivencial?

36. ¿Cuáles considera son los aspectos negativos y positivos del turismo vivencial? ¿Por qué?

Positivo, conocer una nueva cultura. Negativo, no tener privacidad.

37. ¿Recomendaría este tipo de turismo a familiares y amigos?

\section{Expectativas sobre un albergue}

38. ¿Qué entiende por albergue?

Donde vive mucha gente y conviven ayudándose entre ellos.

39. ¿Ha visitado algún albergue durante alguno de sus viajes?

No

40. ¿Qué servicios considera debe tener un albergue?

Una cocina, un lugar de limpieza. No me suena a que tenga que tener servicios, me suena a que todos los huéspedes colaboran entre si.

41. ¿A qué te suena Lodge?

Me parece que vi uno en Cartagena, me suena a un lugar barato.

\section{Apreciación sobre los albergues en el departamento del Cusco}

42. ¿Ha visitado algún albergue en el Cusco? ¿Recuerda el nombre, precio, servicios ofrecidos?

No

43. ¿Qué le pareció la infraestructura del albergue? ¿Contaba con los servicios que usted esperaba?

44. ¿Cuáles considera son las ventajas y desventajas del albergue que conoció en Cusco?

45. ¿Lo recomendaría a familiares y amigos?

\section{Apreciación sobre los albergues vivenciales en el departamento del Cusco}

46. ¿Sabe de algún albergue vivencial en Cusco? Si la respuesta es no, termina la entrevista y se pasa a la despedida.

47. ¿Ha visitado algún albergue vivencial en el Cusco? ¿Recuerda el nombre, precio, servicios ofrecidos?

48. ¿Dónde se encuentra ubicado el abergue vivencial que conoció en la ciudad del Cusco?

49. ¿Considera que tenía una buena ubicación? ¿Se encuentra cerca de los principales atractivos de la ciudad?

50. ¿Qué le pareció el concepto de turismo vivencial en este albergue?

51. ¿Considera que la infraestructura, ubicación, habitaciones fueron los adecuados para un albergue vivencial?

52. ¿Qué servicios recibió durante su estadía? ¿Este servicio cumplió sus expectactivas?

53. ¿Cuál es el precio que pagó por noche, considera que estuvo de acuerdo con el servicio recibido?

54. ¿Qué medios de comunicación consultó o consultaría para obtener información sobre un albergue vivencial en Cusco?

55. ¿Qué formas de pago prefiere cuando viaja por vacaciones?

56. ¿Qué promociones desea obtener cuando se encuentra en la planificación de sus viajes?

57. ¿Recomendaría el albergue vivencial a familiares y amigos? Propuesta 
El proyecto que estamos trabajando es un albergue vivencial, en Maras Moray en Cusco, la cual está ubicado en el valle sagrado. Su principal característica son las salineras.

Consiste en una especie de hotel ecológico, donde tienes una pieza privada. Sin embargo, puedes formar parte de la comunidad, experimentar mucho de la vida diaria. Por ejemplo, participas en hacer las compras en el mercado, como en la elaboración de comida y participas en las actividades del pueblo. Además, claro de tener los tours propios de un alojamiento campestre como equitación y sacar fotos etc.

\section{¿Estarías interesado en experimentarlo?}

Si suena bonito.

¿Cuánto estarías dispuesto a pagar esto?

Si incluyes tours, alojamiento y comida, probablemente lo mismo que gasté en Cusco: $\$ U S .70$ a \$US. 80. Y podría haber actividades extras que se deban pagar a parte.

¿Cuál crees que sería el mejor medio de difusión para hacerle publicidad?

Redes sociales definitivamente.

\section{¿Qué redes sociales?}

Facebook, twiter, pinkterest, trip advisor.

Fin de la entrevista

Gracias por tu tiempo. 


\section{Entrevistado: Nate Murphy}

I. Saludo y presentación

1. Hola ¿En qué idioma prefieres la entrevista, español o inglés?

Español

Hola, gracias por tu tiempo. Como sabes, estamos trabajando en un proyecto de tesis para la maestría. Para lo cual, antes de comenzar necesito tus datos:

2. País de origen: Unites States

3. Sexo:M

4. Edad: 34

5. Estado civil: Casado

II. Entrevista

Descripción de hábitos de viaje y proceso de decisión de compra de paquetes turísticos.

1. ¿Con qué frecuencia viaja?

Una vez al año

2. ¿Qué lugares ha visitado en los últimos dos años?

Iowa, Vermont, Perú, New York.

3. ¿Como elige estos destinos? ¿Cómo conoció acerca de estos lugares? Usualmente por eventos relacionados con la familia.

4. ¿Alguien tiene influencia en la decisión de estos viajes?

Son solo eventos familiares, de amigos a veces.

5. ¿Para estos viajes ha empleado los servicios de alguna agencia de viaje?

No.

6. ¿Porque no?

He realizado mi propia plantación de estos viajes, una vez cuando fui a Lima, confíe en las recomendaciones de la familia que nos hospedaba.

7. ¿Porque medio encontró información, online u otra forma?

Mayormente en línea y si necesitaba alguno otra información preguntaba a la familia donde ir y qué hacer.

8. ¿Cuándo fuiste a Cusco, cuál fue el propósito de este viaje?

La razón por la que fui a Cusco es porque mi iglesia patrocina un proyecto para la reconstrucción de una iglesia.

9. ¿Y este viaje fue planeado con anticipación?

El viaje fue planeado con anticipación, pero yo decidí involucrarme tres semanas antes del viaje.

10. ¿Con cuánto tiempo de anticipación planea sus viajes?

Usualmente con tres o cuatro meses de anticipación, donde voy a ir, que voy a hacer,

cómo llego ahí. 
11. ¿Quién viajó con todo al Cusco?

Viaje solo al Cusco, y en Cusco con amigos.

12. ¿Cuánto gastaron por persona en este viaje?

Yo gaste algo de 2 mil dólares.

13. ¿Qué te gustó más del Cusco?

En Cusco me gusto conocer restaurantes, y la familia donde me hospedé, fuimos también a Machu Picchu, a las ruinas y fue muy interesante, me gusto por la historia y la arquitectura que pudimos ver.

14. ¿Qué es lo que menos te gusto del Cusco?

La falta de comodidades a las que estoy acostumbrado en USA, en el Cusco no poseen esas comodidades o al menos la familia donde me hospedé y algunos restaurantes.

15. ¿Qué tipo de comodidades?

Agua caliente, presión de agua, agua limpia que se pueda tomar directo del caño, mayormente lo relacionado con el agua.

16. ¿Qué lugares conociste en el Cusco?

Plaza de Armas y un par de edificios en los alrededores incluyendo restaurantes.

17. ¿Alguna otra ciudad en Cusco?

$\mathrm{Si}$, fuimos a Lares.

18. ¿Qué tal?

Lares fue interesante, conocimos los baños termales, y además visitamos algunos lugares donde se podría construir otra iglesia para los pobladores locales.

19. ¿Como llegaste a Cusco, y a Machu Picchu y Lares?

Volé al Cusco, y en la cuidad bus y tren para Machu Picchu y bus para Lares.

20. ¿Como conseguiste este transporte?

El dueño de casa donde nos hospedamos era guía turístico, él hizo todos los arreglos referidos a transporte.

21. ¿Solo estuviste hospedado en esta casa o conociste otro tipo de hospedaje?

Estuve hospedado un par de noches en un hotel que la misma persona de la casa donde nos hospedamos nos recomendó.

22. Para ti, ¿cuál es el mejor lugar para hospedarse en el Cusco?

Creo que hospedarse en una casa es lo mejor, porque llegas a conocer a los pobladores locales y creas una relación personal con ellos.

23. ¿Conoces otro tipo de hospedaje en Cusco?

Sé que hay más hoteles y algunos hostales también pero no busque porque mi hospedaje ya estaba planeado.

24. ¿Qué te gusto más de hospedarte con esta familia?

Pasar tiempo con ellos. 
25. ¿Qué fue lo que menos te gusto?

De nuevo, la falta de comodidades, lo relativo al agua.

26. ¿Llegaste a conocer Maras en Cusco?

No.

27. ¿Has escuchado acerca de home stay?

Lo que sé es como turista llegar a una ciudad y hospedarte con una familia en vez de un hotel.

28. ¿Te has hospedado en uno?

No

29. ¿Qué concepto tienes de hotel?

Es hospedaje barato y con mucha gente usualmente en una habitación o más habitaciones en común, no tienes una habitación privada.

30. ¿Te has hospedado en uno?

No.

31. ¿En algún hotel en Cusco?

No

32. ¿Pero conoces de la existencia de hoteles en Cusco?

No.

33. ¿Si supieras de un lugar que te permite hospedarte como como una familia y te ofrece los servicios de un hotel, poder aprender cómo se alimentan y que actividades realizan para vivir, te interesaría?

$\mathrm{Si}$, suena interesante.

34. ¿Cuánto pagarías por este lugar?

Quizás 50\% más que un hotel o casi como un hotel probablemente sería interesante. 


\section{Entrevistado: Kevin}

I. Greetings and introduction

1. Hi, Do you prefer to be interviewed in English or Spanish?

Thank you for your time. As you know, we are working on a thesis project to complete our master. Before getting started, I would require some personal data:

2. What is your country of origin?

Belgium

3. Sex: $M-F$

$\mathrm{M}$

4. What is your age:
a. Less than 20
b. From 20 to 29
c. 30 to 39
d. 40 to 49
e. 50 to 59
f. 60 or more

5. Marital status

Single

II. In-depth interview

Thank you, now we are going to start with the questions concerning the project itself.

Description of travel habits and process involved in the buying of tourism packages

1. How often do you travel (times per year)? 4 times per year

2. Which places or destinations have you been for the past two years? Latin America, Europe

3. How do you choose where to travel? How do you learn about those destinations? I read about interesting places or ask advice to friends

4. Somebody has influence on your travel decision? In which way? As said above, friends/family who travelled there

5. For those travels, did you required the services of any travel agency? The answer being yes, what did they provide you with (only transportation, only hotels, all included packages, etc.)

Online booking for flights \& hotels

Local travel agency for tours

6. How did you know about those agencies? How did you select them?

I usually find them on the spot, unless I have a recommendation from friend/trustful person

7. How long in advance do you plan your trips?

A few months in advance

8. I understand you travelled to Cusco right, so tell me what was the purpose of this trip?

Discovering Inca ruins/Andean culture

9. Who is travelling with you?

I usually travel alone or with friends

10. How much did you spend per person during this trip?

$1000 \$$ in 3 weeks

11. What did you enjoy the most during this trip and why?

Machu Picchu and the sacred valley. Historical sites \& scenery 
12. What did you enjoy the least during this trip and why?

Nothing special, sometimes being harassed to buy some stuff

13. Which places did you visit in Cusco and why? How did you know about those places? I did the city tour including historical sites of Cusco. I learned about it in a travel guide.

14. How did you get to Cusco (mean of transport), and how did you get to the places you travelled to?

Public transport (cruz del sur) to Cusco, then minivan provided by the travel agency in the sacred valley (in between the archeological sites)

15. How did you chose the transportation to those places

Travel agency provided with transportation

Perception and level of knowledge about accommodation offer in Cusco

16. Where did you stay in Cusco (Hotel, Hostel, etc.)

Point Hostal

17. How did you choose this/these Accommodation(s)? How did you know about them? Travel guide

18. According to you, where is the best place to stay in Cusco?

For a solo traveller, a backpacker hostal is the best to meet people

19. What other lodgings do you know?

Hotels, lodge...

20. What did you enjoy the most about your lodging and why?

Meeting new people

21. What did you enjoy the least about your lodging and why?

Too noisy

Knowledge and perception of the Maras district

22. Do you know the municipality of Maras in Urubamba (Cusco)? If not, go straight to the questions about homestay tourism

Yes

23. Did you visit the Maras district? How did you know about it?

Yes. I was recommended to do it by the travel agency I booked Cusco city tour with.

24. Which tourist attraction did you visit in Maras?

Salineras

25. What was the purpose of visiting Maras and its tourism highlights?

Visiting salineras

26. How long did you stay in Maras? Why?

A day visit

27. Which means of transportation did you use to get to Maras?

Private minivan provided by the travel agency

28. What is your feeling about your visit to Maras? What do you consider as advantages \& disadvantages of your stay?

I enjoyed the visit but I found the place is too busy. Lack of infrastructure.

29. Would you recommend friends or family to visit Maras?

Yes

30. Further to your experience, do you consider that you've seen enough of Maras or you would have liked to explore it more?

It was a short stay but I think I've seen most of it. I'd have enjoyed to spend more time in the village. 


\section{Perception of homestay tourism}

31. What is homestay tourism? Have you heard about it before? What idea of it do you have?

Homestay tourism refer to a stay at people's house rather than in a hotel. Yes. I think it is a different and interesting way to travel.

32. Have you ever had any experience of homestay tourism?

33. (If not, go straight to question concerning expectations about homestay hostel) Yes

34. Where was your experience? Where did you stay and for how long? I had a homestay experience in France and in Patacancha (Cusco)

35. How was your feeling about homestay tourism?

I really enjoyed the experience, especially in Peru because that allows me to discover the real life of local people.

36. What do you consider as being the positive and negative aspects of homestay tourism? Why?

Positive aspects are: cultural exchange, experiencing local life, scenery, and financial support.

Negative aspects are: people are changing their habits to please the tourist, language barrier

37. Would you recommend such a way of doing tourism to your friends and family?

38. Yes, I would definitely recommend to try it once.

\section{Expectation about a hostel}

39. What do you understand under the concept of lodge?

It is an accommodation located close to some places of interest (as ex. Trekking, wildlife conservation area, archaeological sites...)

40. Have you ever visited a lodge during one of your travels No

41. Which services shall be provided by a lodge? Accomodation, restaurant, internet access, laundry, tours...

\section{Evaluation of the lodges in Cusco area}

42. Have you ever visited any lodge in Cusco? If yes, do you remember the name, price and services provided?

No

43. What did you think about the hostel infrastructure? Did it offer the services your were expecting for?

44. What are the advantages and disadvantages of the hostel you stayed in?

45. Would you recommend it to your friends or family?

\section{Evaluation of the homestay hostels in Cusco area}

46. Do you know about the existence of any homestay hostel in Cusco area? If not, end the interview

Yes, I know about some lodges (namely Andean Lodges) but I've never stayed with them.

47. Have you ever visited any homestay hostel in Cusco? Do you remember the name, price, services offered?

No

48. Where is located the homestay hostel you stayed in?

49. Do you consider that it has a good location? Is it close to city's main places of interest? 
50. What did you think about the homestay tourism concept in that specific hostel?

51. Do you consider that the infrastructure, location, rooms were appropriate for a homestay experience?

52. What services were provided to you during your stay? Did they meet your needs?

53. What is the price you paid per night, and do you think it was worth the level of services?

54. Which means of communication did you use to get information about homestay tourism in Cusco?

Internet \& travel agencies

55. Which means of payment do you prefer when you travel for holidays? Credit card

56. Which offers would you like to receive when you plan your trip? Special offers for tours \& accomodation

57. Would you recommend homestay tourism to your friends or family?

End of the interview.

Thank you for your time! 


\section{Anexo IV. \\ Guía de pautas agencia}

PROYECTO: Albergue vivencial "La hacienda KachiRaqay" ubicado en el poblado de Maras, Cusco-Perú

I. Saludo y presentación

Hola, gracias por tu tiempo. Como sabes, estamos trabajando en un proyecto de tesis para la maestría. Para lo cual, antes de comenzar necesito datos básicos de la agencia:

\section{Acerca del público objetivo}

1. ¿Cuántos empleados tiene la agencia de turismo?

2. ¿Cuántas sucursales tienen en Perú y donde están ubicados?

3. ¿Cuál es la especialidad o por qué se caracteriza la agencia?

4. ¿Podrías decirme cuantos turistas atienden al mes?

5. ¿La agencia cuenta con IATA?

\section{Acerca del proceso de compra del paquete}

6. ¿Cuáles son los principales destinos que vende la agencia?

7. ¿Cuál es la frecuencia de venta de dichos destinos? ¿A qué crees que se deba esto?

8. En estos destinos, ¿cuáles son las rutas que ofrecen?

9. ¿Cuáles son los servicios principales y secundarios que ofrecen?

10. ¿Quiénes son tus principales proveedores?, ¿Podrías enumerarlos en orden de importancia? (mínimo 3)

11. Ventajas y desventajas de trabajar con los tres principales trabajadores de hospedaje

12. ¿Qué criterios utilizan para seleccionar proveedores de hospedaje?

13. ¿Cuáles son las políticas de reserva en estos hospedajes? ¿Cómo les avisan Uds. a ellos que tienen cliente? ¿Con cuánto de anticipación les avisan?

14. ¿Cuál es o cómo funciona el proceso para pagar a los hospedajes?

15. ¿Tienen alianzas o convenios comerciales con hospedajes? ¿Con quiénes y por qué?

16. ¿En qué consisten estas alianzas o convenios comerciales?

17. ¿Cuáles son los principales problemas que ha tenido con hospedajes? ¿Cómo los solucionaron dichos problemas?

18. ¿Según la agencia cuál es el mejor hospedaje? ¿Por qué?

19. ¿Cuál es el promedio de gasto de un turista por día en hospedaje?

20. ¿Cuál es el promedio de noches de estadía de un turista?

21. ¿De qué nacionalidades son los turistas que atiende la agencia? ¿Hay alguna razón para esto?

22. ¿Han rechazado trabajar con algún hospedaje? ¿Cuál fue el motivo?

\section{Acerca del distrito de maras}

23. ¿Venden paquetes turísticos al poblado de Maras? ¿En qué consisten?

24. ¿Cuántos paquetes turísticos venden al mes al poblado de Maras?

25. ¿Cómo venden al poblado de Maras, cual es la característica principal?

26. ¿Tienen proveedores en Maras? ¿De qué servicios?

27. ¿Cuál es el tiempo de permanencia de los turistas en Maras? ¿A qué se debe esto?

28. ¿Cuánto gasta en promedio un turista en Maras? ¿Y en qué gasta?

29. ¿Cuáles son las ventajas y desventajas percibidas sobre el turismo en Maras? (Razones) 


\section{Acerca del turismo vivencial}

30. ¿Conoce el turismo vivencial? ¿Qué entiende por turismo vivencial?

31. ¿Brindan actualmente paquetes de turismo vivencial? ¿En qué consisten?

32. ¿Cuáles son las ventajas y desventajas del turismo vivencial?

33. ¿Qué tanto recomiendan a los turistas el turismo vivencial?

34. ¿Qué proveedores le brindan turismo vivencial?

35. ¿Cuál es el precio de un paquete de turismo vivencial y que incluye?

\section{Acerca de los albergues}

36. ¿Cuál es su concepto de albergue?

37. ¿Qué albergues son sus proveedores?

38. ¿Cuál es el mejor y cuál es el peor albergue? ¿Por qué?

\section{Acerca de los albergues vivenciales}

39. ¿Qué entiende por albergue vivencial?

40. ¿Cuál es la infraestructura idónea de un albergue vivencial? (Números de habitaciones, tipo de material de construcción, acabados, etc)

41. ¿Qué tipos de servicio debería brindar un albergue vivencial?

42. ¿Qué tipo de actividades debería brindar un albergue vivencial?

43. ¿Cuál debería ser el rango de precio por noche en un albergue vivencial?

44. ¿Recomienda que las actividades deberían incluirse en el precio?

45. ¿Cuáles son los medios recomendados para publicitar un albergue vivencial?

46. ¿Qué tipo de promociones ofrece generalmente un albergue de turismo vivencial?

47. ¿Qué porcentaje de sus ventas representa del turismo vivencial?

48. ¿Según su experiencia, cómo ve el futuro de los albergues de turismo vivencial? ¿Recomendaría incrementar la oferta actual? 


\section{Anexo V. \\ Transcripción de entrevista agencia}

\section{CONDOR TRAVEL}

I. Saludo y presentación

Hola, gracias por tu tiempo. Como sabes, estamos trabajando en un proyecto de tesis para la maestría. Para lo cual, antes de comenzar necesito datos básicos de la agencia:

\section{Acerca del público objetivo}

1. ¿Cuántos empleados tiene la agencia de turismo?

$\mathrm{R}$ : La agencia cuenta con aproximadamente 220 empleados

2. ¿Cuántas sucursales tienen en Perú y donde están ubicados?

R: Como propiedades propias tenemos en Lima, Cusco y Arequipa y además también tenemos un operador muy cercano a nosotros con el que siempre trabajamos que está ubicado en Puno.

3. ¿Cuál es la especialidad o por qué se caracteriza la agencia?

$\mathrm{R}$ : Condor Travel como agencia de viajes crea experiencias en nuestros pasajeros. Lo que hacemos es otorgar lo mejor del país y con eso creamos experiencias placenteras para los clientes.

4. ¿Podrías decirme cuantos turistas atienden al mes?

R: La cantidad exacta no la tengo; sin embargo, te puedo decir que estamos sobre el $60 \%$ del total de los turistas que llegan.

5. ¿La agencia cuenta con IATA?

R: Sí.

\section{Acerca del proceso de compra del paquete}

6. ¿Cuáles son los principales destinos que vende la agencia?

R: En realidad es la zona sur. Por lo general vendemos más el tema de Ica, Nazca, Arequipa, Cusco, y finalmente Puno.

7. ¿Cuál es la frecuencia de venta de dichos destinos? ¿A qué crees que se deba esto?

R: En realidad porque el punto principal a visitar en el Perú es Cusco es Machu Picchu; quizás más del 50\% hacen esta ruta. El lugar que más se visita es cusco, en definitiva. El 100\% de nuestras ventas están enfocado en este destino.

8. En estos destinos, ¿cuáles son las rutas que ofrecen?

R: En el destino Arequipa, lo que ofrecemos es una visita a la ciudad; tenemos también pernoctes en el Colca, que pueden ser entre 2 a 3 noches. En el destino del Cusco, vendemos Cusco ciudad, se vende también Valle Sagrado, muy pocas veces Valle Sur, vendemos Machu Picchu siendo este destino el 100\% de todas las ventas. En el caso de Puno, también es visita a la ciudad de Puno, visitas a Sillustani, Taquile y Uros que son los más turísticos también.

9. ¿Cuáles son los servicios principales y secundarios que ofrecen?

$\mathrm{R}$ : En realidad manejamos todos los servicios principales, valga decir, traslados, también tenemos tours, los hoteles también son servicios complementarios con nosotros, dependiendo de las agencias que lo soliciten. Tenemos algunas agencias que tienen gran demanda de hoteles de diversas categorías, tenemos otras que solo nos 
piden traslados y tenemos otras agencias que solo nos piden tours. Depende mucho del mercado, del país, del tipo de cliente que tengamos.

10. ¿Quiénes son tus principales proveedores?,¿Podrías enumerarlos en orden de importancia? (mínimo 3)

R: Si hablamos en términos de ventas serían principalmente los hoteles, como por ejemplo Marriot o Belmond si hablamos de hoteles de 5 estrellas. Tenemos muchos de estos pasajeros que van siguiendo la marca, es decir, si van a Cusco usan el Hiram Bingham, en la ciudad del Cusco se quieren hospedar en el Monasterio, en el Valle Sagrado van a Río Sagrado, en Macchu Picchu van al Santuary, van siguiendo la marca. Entonces tener un buen contacto con los hoteles es un plus para nosotros. Nosotros tenemos muy buenas tarifas con los hoteles, porque somos el monstro en Perú en ventas en el mercado turístico, entonces ellos vendrían a ser nuestros principales proveedores (Marriot y Belmond) tanto en Cusco como en Lima también. Luego tenemos hoteles de categoría menor, entre 3 y 4 estrellas que también son muy reconocidos en Lima y Cusco, como Tierra Viva, tienen también el Arawi, en caso de solo Lima el Tambo, que son Hoteles también buscados por los clientes.

11. Ventajas y desventajas de trabajar con los tres principales trabajadores de hospedaje R: Desventaja, sus políticas de cancelación. En realidad, de todos los hoteles. Una vez que nosotros realizamos la compra de la habitación tenemos un plazo para poder cancelarla, en el caso que no se cumpliera ese plazo, a nosotros nos cobran el $100 \%$ de este alojamiento. Muchas veces debido a situaciones críticas como, por ejemplo, algún tipo de desastre natural en Cusco, o algún problema con el aeropuerto de Lima o de Cusco o de Arequipa, los pasajeros no pueden llegar a su destino, o inclusive por temas de salud, no llegan a su destino, entonces muchas veces los hoteles no nos devuelven ese dinero pagado, y nosotros como Condor Travel para ofrecer un mejor servicio a los clientes tenemos que hacer la devolución. Eso es lo más difícil de todos los proveedores, tanto de hoteles como de traslado; porque a veces también tercerisamos las unidades de traslado. Una ventaja sería la calidad del servicio; otra sería la ubicación de los hospedajes, el tener una ubicación adecuada nos ayuda a que los pasajeros puedan llegar de una manera sencilla, que las unidades también puedan llegar fácilmente, en Cusco hay muchos hoteles que no tiene accesos adecuados para las unidades, entonces tenemos que enviar dos carros para que los pasajeros lleguen o quizás tienen que bajar y caminar un par de cuadras.

12. ¿Qué criterios utilizan para seleccionar proveedores de hospedaje?

R: Tenemos un departamento de calidad. Este departamento de calidad envía a una persona encargada que haga las inspecciones, lo que se evalúa es el tema se servicio al cliente, cuan nuevas son las instalaciones, el tema de los tiempos que se manejan tanto en la recepción como en restaurante, en room service. De la misma manera se tiene mucho en cuenta el tema de la ubicación, y además nosotros manejamos unas encuestas al final de cada servicio, y estas encuestas detallan el tema del hotel, qué precepciones ha tenido el cliente sobre el hotel. Todo bajo los estándares de Condor Travel. Del mismo modo manejamos un tema de incentivos con los trabajadores y con las agencias internacionales porque el cliente directo de Condor Travel son las agencias, entonces lo que hacemos es enviar a un grupo de trabajadores a un hotel X, este trabajador evalúa y envía un informe de lo que ha percibido en el hotel, igual pasa con las agencias internacionales, llegan y están 2 días en Cusco en el hotel Marriot, luego pasan a Valle Sagrado, a Río Sagrado, etc. Y también va evaluando. Entonces, 
algunas veces estos agentes de viajes extranjeros lo que hacen es chequear qué hotel le parece más adecuado y pedir que su grupo, que sus clientes lleguen especialmente a ese hotel; es de parte de cada hotel que creen fidelización de parte de los agentes y ya los agentes los toman desde su país. El departamento de calidad va una vez al año para realizar las evaluaciones, tanto nuevos ingresos como los ya existentes. Una vez que ya están en la base de datos de Condor Travel para complementar esta evaluación es percepción de los clientes, de los pasajeros.

13. ¿Cuáles son las políticas de reserva en estos hospedajes? ¿Cómo les avisan Uds. a ellos que tienen cliente? ¿Con cuánto de anticipación les avisan?

R: El tiempo de anticipación depende mucho de la venta. Hay algunos casos de agencias que nos reservan con un año de anticipación; hay otras que nos reservan con una semana que son los "last minute", va a depender mucho de esto. El contacto se hace, por lo general, a través del correo electrónico, porque cada hotel tiene un área de reservas y dentro de esa área de reservas se tiene una persona que se encarga de las agencias de viajes; entonces nosotros tenemos el contacto con esta persona encargada para solicitar disponibilidad dentro del horario de reservas; una vez que ellos nos confirman la disponibilidad confirmamos la venta, se hace el pago dependiendo el proveedor, porque en algunos casos tenemos crédito y posteriormente ya llega la venta aquí, el pasajero llega y se hospeda. Pero ese es el proceso, contactar a la persona de reservas, enviar un correo electrónico o una llamada también puede funcionar, luego ya confirmas la reserva y hacen el pago respectivo.

14. ¿Cuál es o cómo funciona el proceso para pagar a los hospedajes?

R: Puede ser al contado, una vez que se reserva la venta; algunos hoteles nos piden un $50 \%$ de adelanto, otros el 100\%; hay otros casos de marcas más reconocidas con las que sí tenemos créditos (crédito que se conserva durante todo el año y se paga pasado 30 días, por el acumulado de las reservas en esa fecha).

15. ¿Tienen alianzas o convenios comerciales con hospedajes? ¿Con quiénes y por qué? R: No tenemos ningún tipo de Alianza comercial ni convenio con hoteles. Para Control Travel lo primordial es la satisfacción del cliente, entonces al tener algún tipo de alianza o convenio comercial ya nos vemos obligados a venderlo; por lo que preferimos que tanto las agencias de viajes como los pasajeros directos nos digan que cosa prefieren y de acuerdo a esa decisión nosotros vamos a armar varias opciones.

16. ¿En qué consisten estas alianzas o convenios comerciales? R: No aplica

17. ¿Cuáles son los principales problemas que ha tenido con hospedajes? ¿Cómo los solucionaron dichos problemas?

$\mathrm{R}$ : Los principales problemas son las cancelaciones, en el caso que los clientes no están alojados. Pero cuando tenemos a los pasajeros ya en el lugar ha ocurrido alguna vez que pueden tener alguna demora en el check - In o puede ser que la comida no les caiga bien (hubo un caso de un grupo que tuvieron una cena en Arequipa y no les cayó bien la comida, como esto creó un malestar al cliente se tuvo que hacer la devolución del dinero). En estos casos se habla con el proveedor, si es que el proveedor acepta su culpa, en hora buena nos hace la devolución a nosotros y nosotros le devolvemos al cliente; pero si es que no lo hace el proveedor, la devolución la hace Condor Travel. 
En muchos casos las cuentas pueden quedar incluso en pérdida, porque en realidad preferimos mantener el nombre de Condor Travel en alto.

18. ¿Según la agencia cuál es el mejor hospedaje? ¿Por qué?

R: Dentro de los mejores tenemos a Casa Andina, Belmond, Marriot, porque son los más conocidos. En menor categoría tenemos al Tambo y Tierra Viva. Consideramos que son los mejores por los clientes, tu evalúas por qué un proveedor es bueno de acuerdo a cuantos comentarios negativos tenga. Mientras menos negativos mejor.

19. ¿Cuál es el promedio de gasto de un turista por día en hospedaje?

$\mathrm{R}$ : Dependiendo mucho de la categoría puede ser entre 150 dólares americanos por noche con desayuno incluido, si nos referimos a la media entre hoteles de todas las categorías.

20. ¿Cuál es el promedio de noches de estadía de un turista?

R: En Lima por lo general se quedan en promedio 2 noches; en Cusco pueden estar entre 3 y 4 noches; en Puno si se quedan casi igual que en Lima 2 noches, inclusive 1 noche nada más; y en Arequipa si se pueden quedar 3 noches.

21. ¿De qué nacionalidades son los turistas que atiende la agencia? ¿Hay alguna razón para esto?

R: En el caso de Condor Travel, el turista que viene de Estados Unidos es nuestro core, nuestro mercado objetivo. En realidad, estamos separados por países, bueno por continentes. Pero el que nos representa mayor ingreso es el de Estados Unidos. Esto se debe a cómo el gobierno peruano está incentivando las visitas a Perú, nos ayuda mucho que el Ministerio haga campañas fuera, así nos están llegando más turistas, tiene mucho que ver también el tema político y la estabilidad que hay en el país.

22. ¿Han rechazado trabajar con algún hospedaje? ¿Cuál fue el motivo?

R: Sí, tenemos en nuestra base de datos proveedores con los que no se pueden cotizar, porque ya han tenido problemas, muchos comentarios negativos, entonces para evitar problemas, simplemente no lo elegimos. Hay algunos casos en que las agencias piden que se dé un proveedor de baja calidad o de bajo precio, entonces no nos queda de otra nada más que elegirlos. Sin embargo, al momento de venderse, se advierte que ese proveedor es de la categoría a la que corresponde y de las características que pueda haber en el hotel, para que luego cuando lleguen al hotel no se lleven ninguna sorpresa.

\section{Acerca del distrito de maras}

23. ¿Venden paquetes turísticos al poblado de Maras? ¿En qué consisten?

R: Sí, en realidad lo que vendemos es un full day. Se recogen a los pasajeros del hotel $\mathrm{y}$ hacen la visita durante todo el día, se ofrece un almuerzo. Algunas veces se puede unir este paquete con Valle.

24. ¿Cuántos paquetes turísticos venden al mes al poblado de Maras?

R: Depende mucho de la temporada. En temporada alta puede llegar a un $40 \%$ de las ventas. Maras es un lugar conocido pero complementario, como lo que más atrae en Cusco es Macchu Picchu, todo el itinerario depende de esa visita más importante, depende mucho de por cuanto tiempo vienen al país, algunas veces vienen solo por 3 días y ya no les alcanza mucho el tiempo. 
25. ¿Cómo venden al poblado de Maras, cual es la característica principal? $\mathrm{R}$ :

26. ¿Tienen proveedores en Maras? ¿De qué servicios?

R: No. Condor Travel se encarga de hacer el tour, con respecto al tema turístico, transporte, de programa de 1 día. Con respecto al alojamiento en Maras tampoco tenemos proveedores.

27. ¿Cuál es el tiempo de permanencia de los turistas en Maras? ¿A qué se debe esto? R: Por lo general es 1 día. Depende mucho del tiempo con el que vengan al país. Algunos tienen el itinerario bien ajustado, pueden estar en el país hasta 1 semana y hacer todo súper veloz.

28. ¿Cuánto gasta en promedio un turista en Maras? ¿Y en qué gasta?

R: el paquete cuesta aproximadamente 180 dólares americanos por persona, esto incluye los traslados también y el almuerzo. Hacen un tour completo (ciudad y pueblo) con guía especializado que les va explicando todo.

29. ¿Cuáles son las ventajas y desventajas percibidas sobre el turismo en Maras? (Razones) R: En realidad no hay desventajas. Consideramos que Maras es un destino por descubrir, por eso que lo ofrecemos dentro de los paquetes. Es un lugar conocido por algunas personas y puede llegar a ser más conocido si tuvieran mejor infraestructura.

\section{Acerca del turismo vivencial}

30. ¿Conoce el turismo vivencial? ¿Qué entiende por turismo vivencial?

R: Sí conozco el turismo vivencial. Es aquel turismo en el que compartes algunas cosas con la población, puedes también compartir la manera en la que ellos viven.

31. ¿Brindan actualmente paquetes de turismo vivencial? ¿En qué consisten?

R: No. Por lo general lo que se vende es alojamiento. Puede ser en Valle Sagrado en algunos casos puede hacerse también turismo vivencial, es un mercado poco explotado hay un nicho muy pequeño de turistas que vienen especialmente a hacer turismo vivencial. En algunos ofrecen actividades para hacer, por ejemplo, pueden hacer algún tipo de tejidos. En algunos otros casos algunas agencias piden algún tipo de actividades chamánicas, ellos consideran ese como un turismo vivencial.

32. ¿Cuáles son las ventajas y desventajas del turismo vivencial?

$\mathrm{R}$ : La ventaja es que es algo nuevo, es algo que muchos otros países no ofrecen, en realidad en sur américa puede ser el continente en que más turismo vivencial se puede hacer por el tipo de cultura que tenemos. Como desventaja, de repente puede ser la calidad de los proveedores porque, si por ejemplo tenemos la actividad de tejidos, tienes a muchos proveedores que pueden hacer lo mismo; sin embargo, hay uno que es el que mejor calidad tiene, el que mejor infraestructura tiene en una casa que es segura para los pasajeros, es el tema básicamente de los proveedores.

33. ¿Qué tanto recomiendan a los turistas el turismo vivencial?

R: Lo recomendaría totalmente. Porque es algo nuevo, si tu vienes a Perú sería recomendable hacer algo distinto, no hacer algo que este ya encubado, que solo vayas al hotel - tour - hotel y no hagas más, sería mejor que vivas la experiencia, salir de esa burbuja gringa, sino que vivir más. 
34. ¿Qué proveedores le brindan turismo vivencial?

R: El más conocido puede ser Rio Sagrado que ofrece algunas actividades (tejidos).

Pero fuera de eso en Cusco no tenemos proveedores. Sin embargo, como trabajamos con una comunidad en Cusco con la que sí los turistas comparten y a través de esta actividad generan mayores ingresos también a la población, algunos turistas visitan también los colegios y generan también más ingresos para la población local. Condor Travel provee las visitas a la comunidad local y a los colegios, se le conoce como experiencia vivencial.

35. ¿Cuál es el precio de un paquete de turismo vivencial y que incluye?

R: No vendemos el paquete de turismo vivencial, sino lo que se venden son los traslados, porque lo que buscamos nosotros es contribuir con esas personas, entonces los turistas van a este lugar y algunas veces pueden hacer compras de lo que los pobladores estén vendiendo o hagan.

\section{Acerca de los albergues}

36. ¿Cuál es su concepto de albergue?

R: Sí. Son aquellos lugares en donde van personas con gustos similares que buscan muchas veces tener la misma experiencia en ese lugar en donde se hospedan. Los albergues, si bien hay algunos que pueden estar en zonas alejadas, la cantidad de servicios es menor a la de un Lodge. Algunos albergues solamente ofrecen el tema de alojamiento nada más y otros que por ahí unen algunas actividades para que sus huéspedes puedan hacerlas.

37. ¿Qué albergues son sus proveedores?

R: No, no tenemos albergues. En realidad, los que existen ahora no son de buena calidad por eso que no los tenemos todavía en nuestra base de datos.

38. ¿Cuál es el mejor y cuál es el peor albergue? ¿Por qué?

R: No Aplica

\section{Acerca de los albergues vivenciales}

39. ¿Qué entiende por albergue vivencial?

R: Entiendo que es un lugar de hospedaje en el que se ofrecen actividades complementarias para que pueda el turista disfrutar de un poquito más no del as actividades pre establecidas sino más algo local.

40. ¿Cuál es la infraestructura idónea de un albergue vivencial? (Números de habitaciones, tipo de material de construcción, acabados, etc.).

R: Para que pueda ser un albergue de calidad sería recomendable que sea un albergue pequeño, de pocas habitaciones para que así pueda ser mejor manejado el servicio. En cuanto a infraestructura, en el caso de Cusco, donde ustedes se ubicarían, sería recomendable que vaya acorde con el resto del lugar, que vaya de acuerdo a la arquitectura del lugar, que no desentone. La infraestructura también tiene que ser segura, porque si es que tenemos un hospedaje que parece que se fuera a caer, muchos turistas no van a querer quedarse. Los servicios complementarios, el tema de alimentos y bebidas, que cuente con el personal suficiente para que puedan atender a los huéspedes, porque pasa en muchos casos de hoteles que están en el Colca por ejemplo y hay grupos grandes y no hay suficiente personal para atenderlos, entonces se tiene 
que contar con esas personas, con buena calidad en la comida, tener buenos proveedores. Explotar mucho las vistas externas.

41. ¿Qué tipos de servicio debería brindar un albergue vivencial?

R: Definitivamente restaurante y bar. Además, debería tener conexión a internet, ahora en esta era no hay hotel que no tenga internet.

42. ¿Qué tipo de actividades debería brindar un albergue vivencial?

R: Sería un plus para ustedes si es que trabajaran con la comunidad que tienen alrededor. Hay algunos turistas que vienen al país buscando contribuir, dejar su granito de arena no solamente a los hoteles y restaurantes sino también a la comunidad.

Entonces, si es que tienen actividades como algún paseo guiado por un poblador sería un adicional, depende de lo que tengan alrededor, si tienen lugar para poder montar caballo que sea de un poblador también lo pueden agregar también es un plus. El Mountain Lodge of Peru, por ejemplo, tiene albergues para hacer trekking, tienen uno en Cusco y en Cañete y lo que ellos tienen es ofrecen el paquete de la caminata por muchas horas y luego llegan a su albergue que es súper lujoso que en algunos casos tiene jacuzzi en las habitaciones, entonces ofrecen adicionalmente para aquellos pasajeros que tienen ratos libres y que no han programado nada paseos a caballo, pueden hacer una comida, cocinar con la población, por lo general también hacen visitas caminado a ruinas cercanas.

43. ¿Cuál debería ser el rango de precio por noche en un albergue vivencial?

$\mathrm{R}$ : Depende mucho de los servicios que ofrezca. Si solo ofrece los servicios básicos (alojamiento, restaurante, bar e internet) podría estar entre \$80 - \$90 la noche fuera de impuestos.

44. ¿Recomienda que las actividades deberían incluirse en el precio?

R: No necesariamente, podría ser un precio aparte. Puedes cobrar el alojamiento y desayuno, ya si el cliente quiere algo adicional lo puede pagar adicional. Lo que también se recomendaría hacer es que si se tienen actividades es crear paquetes turísticos, ya con eso aseguras la venta de otras actividades y también generas más ingresos.

45. ¿Cuáles son los medios recomendados para publicitar un albergue vivencial?

R: En realidad son mucho las ferias. Hay muchos hoteles que lo que hacen es enviar a sus trabajadores de ventas a ferias, algunas veces internacionales, depende de la capacidad del hotel o sino también promocionarlo entre agencias de viaje. Nosotros tenemos a muchos proveedores que van al menos 1 o 2 veces por semana a la oficina y nos hablan de sus servicios. Hoy, por ejemplo, fueron los de Inkaterra, que nos habla de los servicios, a pensar que siguen siendo los mismos igual recordando lo que ofrecen. Otro medio para que se puedan marketear pueden ser el de revistas especializadas, dependiendo del tipo de mercado al que se dirigen. Por ejemplo, en la revista Vamos, o en el periódico, inclusive en internet que es un medio muy usado. Tienes que tener una buena página web, un buen medio de reservas a través de tu página web y tienes que estar en páginas web en las que puedas ofertar tus habitaciones (TripAdvisor, Booking, Expedia, Despegar, etc.).

46. ¿Qué tipo de promociones ofrece generalmente un albergue de turismo vivencial? R: Ustedes deberían explotar el tema de las noches, cuanto más noches mejor, ofrecer paquetes con más noches, de repente $2-3$ noches, porque como el destino de Maras, 
es básicamente de paso, de repente tengan huéspedes que solo se queden 1 noche y eso no les convendría, sería mejor ofrecer paquetes que ofrezcan las actividades que ya se hacen en el city tour para engancharlos y adicionar para el segundo o tercer día actividades vivenciales (paseos a caballos, cocina con la gente del pueblo, etc.).

47. ¿Qué porcentaje de sus ventas representa del turismo vivencial?

R: El vivencial no es un turismo ahora muy explotado, le vemos mucho futuro porque el Perú se está haciendo conocido también por ese tipo de turismo. En cuanto a las ventas no sobrepasa el $30 \%$, todavía sigue siendo muy bajo. Pero con las actividades que estamos incentivando creemos que esto va a aumentar.

48. ¿Según su experiencia, cómo ve el futuro de los albergues de turismo vivencial? ¿Recomendaría incrementar la oferta actual?

R: Yo estoy convencida de que en el futuro van a ser una parte importante del mercado. El Perú en realidad, como turismo tiene mucho por explotar, ahora en realidad nos suena mucho algunos lugares en específico, no solamente llegar a Machu Picchu y nada más; en realidad tú vas al extranjero y lo primero que te dicen de Perú es Macchu Picchu, entonces si buscamos una manera de que otros lugares también se hagan conocidos de la mano con Machu Picchu, entonces vamos a generar mayor crecimiento. En realidad, los albergues aún no son muy conocidos porque no tienen suficiente oferta, no hay muchos proveedores aún. Si es que llegan más proveedores de calidad, entonces esto va a generar que se hagan más conocidos y que ya muchos clientes no vengan solamente por hoteles que son edificios en el medio de la ciudad sino por lugares más especiales. 


\section{TRAVEX SECURITY}

I. Saludo y presentación

Hola, gracias por tu tiempo. Como sabes, estamos trabajando en un proyecto de tesis para la maestría. Para lo cual, antes de comenzar necesito datos básicos de la agencia:

\section{Acerca del público objetivo}

1. ¿Cuántos empleados tiene la agencia de turismo? 300 trabajadores

2. ¿Cuántas sucursales tienen en Perú y donde están ubicados? 1 en Miraflores

3. ¿Cuál es la especialidad o por qué se caracteriza la agencia? Por pasajeros por viajes de trabajo (corporativos)

4. ¿Podrías decirme cuantos turistas atienden al mes? No se

5. ¿La agencia cuenta con IATA? Si cuenta con una IATA

6. ¿En que área trabajas? Trabajo en el área corporativa, nosotros vendemos boletos aéreos, alojamientos y a veces nos piden traslados.

\section{Acerca del proceso de compra del paquete}

7. ¿Cuáles son los principales destinos que vende la agencia?

Todos los destinos en el Perú, y también atendemos internacional.

8. ¿Cuál es la frecuencia de venta de dichos destinos? ¿A qué crees que se deba esto?

Diario viajan más de mil personas. De lunes a viernes. Entre 5000 y 6000 a la semana. En fin de semana es menor, se tienen prsona de emergencia para justamente viajes de emergencia que a veces solicitan las empresas o para atender necesidades de pasajeros en tránsito.

9. En estos destinos, ¿cuáles son las rutas que ofrecen?

10. ¿Cuáles son los servicios principales y secundarios que ofrecen?

11. ¿Quiénes son tus principales proveedores?,¿Podrías enumerarlos en orden de importancia? (mínimo 3)

Los principales hoteles de cadena: los portales, los casa andia los hoteles Atton. Generalmente de 4 a 5 estrellas.

12. Ventajas y desventajas de trabajar con los tres principales trabajadores de hospedaje Somos la empresa más importante de viajes corporativos, por lo cual nos dan todas las facilidades que pueden. Digamos que no hay ventajas marcadas entre los hoteles.

13. ¿Qué criterios utilizan para seleccionar proveedores de hospedaje?

Hay personas especiales en la empresa encargadas de visitar los hoteles y hablan con los ejecutivos de cada hotel. Como tenemos IATA y pertenecemos a American Express, tenemos ciertos parámetros exigidos. Como 4 y 5 estrellas. Pero también hay un grupo representativo de hoteles que nos buscan y los evaluamos. 
Generalmente los hoteles ofrecen visitas guiadas para las agencias para mostrar las habitaciones, el servicio, etc.

Por ejemplo, fui al hotel Atton que está en San Isidro y nos mostraron desde el check in hasta la habitación, y nos invitaron el desayuno buffet para probar.

14. ¿Cuáles son las políticas de reserva en estos hospedajes? ¿Cómo les avisan Uds. a ellos que tienen cliente? ¿Con cuánto de anticipación les avisan?

Para esto se utiliza el sistema SABRE, que tiene toda la base de datos de viajes y hoteles y ahí se hacen las reservas. Y para los hoteles que no están incluidos o no tienen SABRE, nosotros tenemos un sistema especial interno donde están todos los hoteles que podemos vender. Entonces al reservar una habitación se prende una alarma a para nosotros y para el hotel, y ellos se ponen en contacto con nosotros para confirmar la reserva y el costo.

15. ¿Cuál es o cómo funciona el proceso para pagar a los hospedajes?

Nos dan crédito, y dependiendo del hotel se hace un cierre de cuentas (quincenal, mensual, bimensual) y les hacemos depósito a sus cuentas.

16. ¿Tienen alianzas o convenios comerciales con hospedajes? ¿Con quiénes y por qué? Convenios con todos los hoteles con los que trabajamos.

17. ¿En qué consisten estas alianzas o convenios comerciales?

Tarifas especiales pactadas anualmente, cada noviembre. Los descuentos pueden llegar hasta un $25 \%$ más baratos de lo que aparece en su página web.

18. ¿Cuáles son los principales problemas que ha tenido con hospedajes? ¿Cómo los solucionaron dichos problemas?

Más que nada limpieza, por ejemplo, en los baños o en la cama. Los pasajeros primero se quejan con el hotel, y si no están satisfechos con la respuesta, acuden a nosotros para hacer una queja más formal. Vemos de cambiarle de habitación o de hotel. Por eso utilizamos hoteles de cadena para hacer más eficiente este proceso, otras veces sobrevenden las habitaciones, pero ellos mismos solucionan.

19. ¿Según la agencia cuál es el mejor hospedaje? ¿Por qué?

Depende de la ciudad. Por ejemplo, acá en Lima las empresas eligen los Meliá o los Casa Andina. Me imagino que por el servicio.

20. ¿Cuál es el promedio de gasto de un turista por día en hospedaje?

No sé, eso depende de la empresa que los envía, ellos les asignan viáticos. En cuestión de hoteles una noche de alojamiento acá en Lima por ejemplo está entre \$US 120 a \$US 150. En Cusco es más caro de \$US 180 a \$US 200. Porque hay más demanda de hoteles.

21. ¿De qué nacionalidades son los turistas que atiende la agencia? ¿Hay alguna razón para esto?

Peruana en su mayoría por el rubro (corporativo) pero hay de todo, argentinos, españoles.

\section{Acerca del distrito de maras}

22. ¿Venden paquetes turísticos al poblado de Maras? ¿En qué consisten?

No, cuando vendemos al Cusco no incluimos tours. 
23. ¿En Cusco cuales son los principales hoteles con los que trabajan?

Libertador, Casa Andina...Casa Andina son los más grandes allá.

\section{Acerca del turismo vivencial}

24. ¿Conoce el turismo vivencial? ¿Qué entiende por turismo vivencial?

$\mathrm{Si}$, es ir a un sitio donde te enseñan las costumbres y vives lo que hace el día a día la comunidad. (ordeñar vacas, sembrar, cosechar, etc)

25. ¿Brindan actualmente paquetes de turismo vivencial?¿En qué consisten?

Sí, pero no me acuerdo en que hotel o en qué consiste, te confirmo luego.

26. ¿Cuáles son las ventajas y desventajas del turismo vivencial?

Ventajas, a parte de crear más turismo, se promociona la cultura peruana. Desventajas no veo muchas.

27. ¿Qué proveedores le brindan turismo vivencial?

Después de la entrevista confirmó que venden turismo vivencial en el hotel: casitas

del colca en Arequipa y en el hotel : Sonesta posadas del Inca Valle Sagrado-Yucay en Cusco.

28. ¿Cuál es el precio de un paquete de turismo vivencial y que incluye?

Es que depende mucho del paquete, y de la actividad. Por ejemplo tienes actividades individuales y grupales. Algunas actividades puntuales como enseñar a hacer una pachamanca o un día entero de tour.

\section{Acerca de los albergues}

29. ¿Cuál es su concepto de albergue?

Es un hospedaje sin la categorización de estrellas. Son más rústicos, duermes y convives con más gente. Están más en la Selva y son más baratos, aunque no falta alguno que es caro por estar muy metido en la selva.

30. ¿Qué albergues son sus proveedores?

31. ¿Cuál es el mejor y cuál es el peor albergue? ¿Por qué?

\section{Acerca de los albergues vivenciales}

32. ¿Qué entiende por albergue vivencial?

Un albergue en la selva, donde varias personas conviven con la naturaleza y su entorno.

33. ¿Cuál es la infraestructura idónea de un albergue vivencial? (Números de habitaciones, tipo de material de construcción, acabados, etc)

Depende el concepto de albergue que se ofrezca, hay algunos básicos como otros que tienen establos y hasta jacuzzis. Incluso dependiendo del lugar, puede incluir atractivos mismos de la zona como en Cusco hay aguas termales, por ejemplo.

34. ¿Qué tipos de servicio debería brindar un albergue vivencial?

Lo mismo que todos los hoteles, pero con menor lujo.

35. ¿Qué tipo de actividades debería brindar un albergue vivencial?

Deberían brindar más actividades al aire libre. 
36. ¿Cuál debería ser el rango de precio por noche en un albergue vivencial?

Nuevamente depende, sobre todo de la ubicación, hay desde S/. 100 hasta S/. 1000. Por ejemplo en la selva son los más caros por la misma logística que implica. Tiene que incluir comida en lo más recóndito de la selva y no tienes mercados o restaurantes cerca.

37. ¿Recomienda que las actividades deberían incluirse en el precio? Si es más práctico.

38. ¿Cuáles son los medios recomendados para publicitar un albergue vivencial? Internet, muchos videos y experiencias compartidas. Nosotros consultamos por ejemplo Trip Advisor para ver la percepción de los viajeros.

39. ¿Qué tipo de promociones ofrece generalmente un albergue de turismo vivencial?

El todo incluido es una opción práctica, pero depende mucho de la estacionalidad. Por ejemplo cuando llueve hay que bajar bastante los precios.

40. ¿Qué porcentaje de sus ventas representa del turismo vivencial? No

\section{Aceptación de propuesta}

41. ¿Qué te parecería un albergue vivencial en Maras, donde están las salineras de Maras, cerca de Ollantaytambo? Donde tienes la experiencia de vivir el día a día de los pobladores, como actividad por ejemplo esta la compra de insumos y cocinar el almuerzo con la gente del lugar. Sin embargo, tiene las características del hotel, ¿cada huésped con su habitación y la infraestructura sería más rústica?

Si tiene que ser rústica, al extranjero le gusta eso. No tiene problema de dormir en el piso. Le gusta convivir con la gente, hacer fogatitas.

42. En tu experiencia ¿A quién debería estar dirigido este albergue?

Alemanes, franceses, italianos, y a los chinos. A todos estos les encanta el turismo vivencial.

Por si acaso para este tipo de turismo hay una tendencia creciente a parejas gay.

Ah interesante, investigaremos más al respecto, gracias por tu tiempo.

Fin de la entrevista. 


\section{ANDEAN LODGE}

I. Saludo y presentación

Hola, gracias por tu tiempo. Como sabes, estamos trabajando en un proyecto de tesis para la maestría. Para lo cual, antes de comenzar necesito datos básicos de la agencia: Juan Carlos Flores, administrador.

\section{Acerca del público objetivo}

1. ¿Cuántos empleados tiene la agencia de turismo? Tiene 12 personas.

2. ¿Cuántas sucursales tienen en Perú y donde están ubicados?

Oficina principal en Cusco y tenemos representantes en varios lugares, en Lima y Arequipa, no son oficinas y funciona a nivel nacional.

3. ¿Cuál es la especialidad o por qué se caracteriza la agencia?

Ha evolucionado bastabte, ha empezado operando grupos de alta montaña en todo el Perú, Argentina, Bolivia, Chile y se ha trabajado tanto el expertise del guiado que hemos mudado a ser una agencia de turismo de lujo, ha sido un cambio bastante drástico pero que se ha logrado gracias al entrenamiento del personal y de los guías. Empezó hace 25 años y ahora si somos un agente de viajes un operador, no tenemos una página web no funcionamos así, porque lo que hacemos nos enfocamos en representar empresas, no vendemos a clientes directos representamos a cuentas bastante importantes alrededor del mundo y ellos confían sus clientes con nosotros y nosotros somos ellos en Cusco. Estamos inscritos como operador de turismo.

4. ¿Podrías decirme cuantos turistas atienden al mes?

Al año unos 400 clientes. Porque llegan en grupos. En grupos varían un montón, hay cuentas que operan parejas, otras cuentas que operan familias, pero el gran promedio es 4 personas.

5. ¿La agencia cuenta con IATA?

\section{Acerca del proceso de compra del paquete}

6. ¿Cuáles son los principales destinos que vende la agencia?

Nosotros nos enfocamos en crear destinos, y luego decirles a los agentes en el exterior esto es lo que hay nuevo de lujo, ellos deciden si lo toman o no lo toman, por lo pronto nos dicen opera Cusco en general, Lima, Machu Picchu básicamente.

7. ¿Cuál es la frecuencia de venta de estos destinos? ¿De los que propones como nuevo? Algunos productos si se están adaptando.

8. Por ejemplo, ¿cuál crees es el que más funciona con ustedes?

Creo que anden Lodges es uno de los productos que mejor ha funcionado, y eventos corporativos con gente importante, creamos experiencias en algunos espacios, como ejemplo vienen clientes y quieren una cena, le damos la cena en el XXX pero adicional a eso organizamos un bar de oxígeno, el cubo del XXX lo cerramos y ponemos oxígeno con esencias y cuatro chicas en traje de enfermera atienden bebidas vírgenes y los clientes se van después de haber tomado un trago con una chica linda y recibido oxígeno para poder aclimatarse. 
Ese tipo de actividades distintas, crear particularidades experiencias diferentes.

9. En estos destinos, ¿cuáles son las rutas que ofrecen? ¿Si hablamos de Andean Lodges? ¿Hacen una sola ruta de 7 días?

Ha crecido ha empezado como un operador con albergues turísticos en una ruta que se comparte con la comunidad pero ahora es bastante grande es una empresa que organiza eventos deportivos organiza maratones también somos un operador turístico, operamos un cliente tres estrellas en Perú en Cusco en particular, tenemos las caminatas en Auzangate que hemos hecho varias variaciones, queremos vender tambien el producto albergue también para personas que no quieren caminar, hemos creado un nuevo producto que es chilca Lodges . Todo esto refuerza la idea de turismo rural comunitario porque la gente que es socia de nosotros las comunidades tienen participación dentro de la empresa tienen $20 \%$ de participación dentro de la empresa y reciben participación de todo, creación de rutas, realización de carreras de los tours que se hagan no sólo de la ruta de Auzangate.

14. ¿Cuáles son los servicios principales y secundarios que ofrecen?

15. ¿Quiénes son tus principales proveedores?,¿Podrías enumerarlos en orden de importancia? (mínimo 3) hablando de hoteles. Vendes paquetes si te pido el nombre de tres proveedores de hoteleros con los que más trabajas con los que mejor relación tienes. Monasterio

Ananay

Palacio de Manco Capac

16. Ventajas y desventajas de trabajar con los tres principales trabajadores de hospedaje, Ventajas por eso tú contratas un proveedor, porque te da más ventajas que desventajas, calidad de servicio básicamente tienes un servicio personalizado de calidad.

17. Pero ventajas en la relación con ustedes, créditos, formas de pago Si tenemos crédito, tenemos todas las facilidades, tarifas mejoradas, acceso a algunas áreas restringidas a veces.

18. ¿Qué criterios utilizan para seleccionar proveedores de hospedaje?

Básicamente la respuesta de la gente que trabaja en el hotel, la respuesta tiene que ser rápida, eso es lo principal, si no tienes respuesta no puedes empezar a trabajar, a partir de ahí vas evaluando servicio, experiencias, depende a lo que estés apuntando, hay clientes que si prefieren buscan algo de lujo, prefieren estar en el Palacio de manco Capac y no en monasterio Porque son experiencias distintas.

19. ¿Cuáles son las políticas de reserva en estos hospedajes? ¿Cómo les avisan Uds. a ellos que tienen cliente? ¿Con cuánto de anticipación le avisa al hotel?

Ellos te dan sus políticas, dependiendo del cliente hay clientes que hacen sus reservas con anticipación, y se puede hacer una cancelación, nos dan las facilidades del caso, seguimos sus políticas, pero son bastante flexibles porque saben que son clientes importantes.

20. ¿Cuál es o cómo funciona el proceso para pagar a los hospedajes?

Crédito y pasos anticipados, las políticas como lo pidan. 
21. ¿Tienen alianzas o convenios comerciales con hospedajes? ¿Con quiénes y por qué? El compromiso de trabajar de manera continua pero no hay nada más.

22. ¿En qué consisten estas alianzas o convenios comerciales?

23. ¿Cuáles son los principales problemas que ha tenido con hospedajes? ¿Cómo los solucionaron dichos problemas? ¿Que no tengan la habitación lista, demora en la reserva?

Tal vez ese sería un problema, estaba pensando. Básicamente que no puedas hacer un check in temprano, es complicado, pero también se entiende porque si es que hay otra persona que está ocupando la habitación, y el tato que firmas un contrato es el rato que recibes las políticas y sabes que el check in es a las 12, si sabes creo no debería ser un problema, pero en servicio y calidad siempre todo funciona bajo los estándares.

24. Más que nada limpieza, por ejemplo, en los baños o en la cama.

25. ¿Según la agencia cuál es el mejor hospedaje? ¿Por qué?

26. ¿Cuál es el promedio de gasto de un turista por día en hospedaje?

En base a tus tarifas corporativas entre Monasterio y Palacio. ¿Tienes idea cuando es lo que ustedes pagan por habitación?

Creo que Monasterio la más baja es 300 usd por noche, en Ananay 150, 100 usd tal vez un poco menos.

27. ¿Cuál es el promedio de noches estadía que reservas para los turistas, en monasterio por ejemplo?

4 siempre 4

28. ¿De qué nacionalidades son los turistas que atiende la agencia? ¿Hay alguna razón para esto?

Americanos hasta el año pasado pero este año estalos iniciando una nueva cuenta de alemanes que nueve cuatro grupos al año de 15 personas puede ser que el índice de alemanes suba.

29. ¿Y era americanos porque con ellos tenías el convenio? $\mathrm{Si}$

30. ¿Has rechazado trabajar con algún hospedaje? ¿Cuál fue el motivo?

Si por el tipo de empresa yo no puedo decirles a mis clientes ahora te vas a quedar en Libertador porque mis clientes siempre me piden Monasterio, más está ligado a lo que diga el operador, yo no puedo tomar decisiones yo solo representó una marca y operó sus grupos y el decide con quien trabaja.

\section{Acerca del distrito de maras}

31. ¿Venden paquetes turísticos al poblado de Maras? ¿En qué consisten?

Si, tours a Maras Moray y almuerzos en el Parador de Maras y la Casa de Tati, No sé cómo se llama ese lugar. 
32. ¿Eso es en un día, Normalmente como es el paquete van para la mañana? Van para la mañana, visitan, almuerzan, tal vez una caminata a pichimboto o regresan en carro a Urubamba.

33. ¿Cuántos paquetes vendes al mes a maras, todos tus turistas van por este circuito? Depende de la temporada, pero la mayoría usa ese circuito porque lo convencional es ir por el valle, entonces tratamos de tener lugares poco concurridos menos congestionados, y de hecho uno de ellos es Maras porque digamos no hay tours puleros ahí.

34. ¿El turista valora esto que no esté tan saturado?

Claro Fuera de que es un atractivo natural y cultural

35. Como vendes el poblado de Maras, ¿cuál es la característica principal?

El destino de Maras por la sal y Moray por ese tema arquitectónico.

36. ¿Tienes proveedores en Maras?

Me dijiste el restaurante Parador de Maras y el restaurante de Tati, no sé cómo se llama.

37. ¿Cuánto es el tiempo de permanencia de los turistas en Maras?

1 día

38. ¿Cuánto gasta en promedio por día un turista en Maras y en qué gasta? ¿Podrías valorar el tour a Maras de ese día, cuanto, como lo costeas?

De hecho, directamente en Maras, El cliente paga sus entradas básicamente adiciona a eso tienes el servicio de guía y transporte pero que no afecta la economía de Maras, sin embargo,

39. ¿Si lo vendieras como un producto solo?

No recuerdo la verdad esta creo 280 usd por persona en una salida de dos personas; esto incluiría transporte, guía, almuerzo y las entradas. Pero depende de la actividad también por ahí hay alguien que quiera hacer bicicleta o quiera motos que hemos tenido, pero siempre una actividad de un día, pero ahí se incrementa puede ser en 80 cocos, caballos también hacemos.

40. ¿Cuáles son las ventajas y desventajas de hacer turismo en Maras?

De hecho, es un lugar bastante conocido sin embargo no tiene tanta afluencia, es una ventaja.

Una desventaja podría ser las personas que se encargan del cuidado, a veces no colaboran, los controladores a veces son malcriados y es complicado trabajar con personas así.

\section{Acerca del turismo vivencial}

41. ¿Conoce el turismo vivencial? ¿Qué entiendes por turismo vivencial?

De hecho, si conozco el turismo vivencial, lo conozco 13 años y es esto no, Compartir experiencias tanto locales como extranjeras y mezclarlas en un determinado espacio y tiempo y esto te genera un viaje, un producto experiencia. 
42. ¿Brindan actualmente paquetes de turismo vivencial? ¿En qué consisten? De hecho si, Auzangate y tenemos un circuito una ruta de caminata con albergues y los albergues son operados $100 \%$ por la gente de las comunidades, damos caballos, servicios de arreraje, llamas, administración de los albergues, guardianía, almacén, house keeping, cocina, seguridad, mantenimiento, la experiencia en este caso sería como al cliente lo involucramos en un espacio bastante bien acomodado pero tampoco muy lujoso, ósea no los ponemos en la burbuja de lujo y los dejamos en el entorno y no nos fijamos en el entorno, tratamos de combinar un poco el entorno con las comunidades que puedas encontrar dentro del albergue y eres atendido con la misma gente entonces compartes con la gente, sabes a qué se dedican, cómo se visten, que idioma hablan, y entiendes un pocos de esta la visión de estas comunidades pastoras que es totalmente distinto a una comunidad agrícola como Urubamba que es una comunidad totalmente agrícola, allá arriba se dedican a pasear sus alpacas y pastearlas.

43. ¿Cuáles son las ventajas y desventajas del turismo vivencial?

De hecho una de las ventajas es que puedes trabajar con la gente de las comunidades, y hacerles creer en su propio espacio, antiguamente la gente de los pueblos se mudaba a Pitumarca, y luego a Sicuani, a Cusco, o tal vez a Lima para poder hacer algo, crecer; una de las ventajas es que estamos en un espacio en que puedes quedarte ahí, puedes seguir vistiendo ojotas, puedes seguir vistiendo tu traje típico, puedes seguir hablando quechua, y al mismo tiempo hacer dinero, y quedarte en tu espacio, entonces estamos fortaleciendo una región un espacio cultural, natural, social de manera permanente y sostenida.

La desventaja muchas veces estos circuitos no solo dependen de nosotros, depende de otras comunidades y hay comunidades celosas del trabajo que estamos haciendo, nosotros estamos prestos a seguir poniendo más comunidades dentro delproyecto, esto es un proceso bien largo, aún estamos 13 años que se está trabajando y todavía no hay ganancias, Así es el turismo tienes que poner la semilla y regarlo, y espero que en un año un par de años este bastante mejor, y aparentemente si ese es el proceso.

43.

$100 \%$ lo ves en todos mis correos

44. ¿Qué proveedores le brindan turismo vivencial?

Ustedes son el mismo proveedor que brinda el turismo vivencial y mencionaríamos como proveedor y socio las comunidades, ahora son dos al inicio era una asociación de un grupo de personas de chilca, ahora luego se 15 años de trabajo hemos incluido a toda la comunidad de chilca ya no sólo la asociación.

Y ahora estamos incluyendo a una más que es Josefina chilca. Tenemos dos comunidades en esto.

45. ¿Cuál es el precio de un paquete de turismo vivencial y que incluye?

Este paquete es un poco más complicado, porque incrementa el costo de los albergues, tenemos 4 albergues allá, entonces tenemos que recuperar también la inversión que se ha hecho, más o menos 1500 usd por un paquete de 5 días, incluye guía, transporte, hospedaje, alimentación, fogata, lluvia, barro, estrellas y la gente lo paga.

\section{Acerca de los albergues}

46. ¿Cuál es su concepto de albergue? 
De hecho, nosotros nos llamamos albergues, pero no tenemos albergues, tenemos casitas en las montañas que son tambos, es un espacio como una casita con cuartos a los costados, área en común y una cocina, un albergue tiene cierta cantidad de habitaciones, un espacio un toque distinto a lo que tenemos nosotros pero.

El albergue es un espacio como hospedaje, pero donde confluyen personas con intereses comunes y el ministerio no tiene delimitaciones del número de habitaciones, entonces sí tienes un albergue.

Alguna vez quisimos sacar la clasificación de albergue y nos negaron porque no cumplíamos con algunos aspectos absurdos, y como no entendía que yo era albergue y lo que estaba haciendo era eso entonces no continúe con el tema.

47. Entonces no están clasificados

Dentro de Mincetur somos hospedaje sin categoría.

48. ¿Qué albergues son sus proveedores?

Seria Andean Lodge

49. ¿Si no habláramos de Andean Lodge conoces otro albergue en Cusco?

Hay varias experiencias similares, una es Montan Lodges que también tiene albergues en una ruta de caminata, sé que son albergues bastantes lujosos, pero nosotros no apuntamos a eso no queremos meter al cliente en la burbuja de lujo, estando en un espacio natural increíble.

50. ¿Cuál es el mejor y cuál es el peor albergue? ¿Por qué?

\section{Acerca de los albergues vivenciales}

51. ¿Qué entiende por albergue vivencial?

Ya lo comento.

52. ¿Cuál es la infraestructura idónea de un albergue vivencial? (Números de habitaciones, tipo de material de construcción, acabados, etc)

En Andean Lodge El acabado es piedra, cemento, barro y madera y tenemos 10 habitaciones con capacidad para 20 personas más o menos.

53. ¿Crees que tener más habitaciones de repente 20 alteraría mucho el espacio, o cuales son los criterios que ustedes han tomado para tener solo 10 habitaciones?

Se podría, De hecho, el proyecto también ha mutado bastante, al comienzo eran refugios de alta montaña, los refugios de alta montaña son como los back packers que tienen camas camarotes y pensábamos en cuatro camas camarotes y operarlos de esa manera, pero nos dimos cuenta que el mercado estaba cambiando y está apuntando a tener un poco más de confort.

Estos espacios están diseñados para sí par a 20 personas, pero hemos empezado con pocos clientes y esa ha sido la idea, por eso no hemos hecho puesto marketing porque primero teníamos que preparar el terreno, si no tienes a la gente preparada, a los comuneros felices trabajando, no puedes poner afluencia de turismo, entonces los 10 habitaciones en los 4 albergues me basta y sobra, y no quiero más ahorita porque no quiero flujo, quiero experiencia, manejo de un turismo bien bonito, tal vez en un futuro funcione un albergue más, sería chevere pero por el momento no.

54. ¿Qué tipos de servicio debería brindar un albergue vivencial 
Básicamente cama, duchas si es caliente en buena hora y comida, tus necesidades básicas.

55. ¿Qué tipo de actividades debería brindar un albergue vivencial?

Depende de a qué te quieras dedicar, te puedes mezclar, las actividades, puedes compartir con los comuneros a través de demostraciones de textiles, música, rituales pero combinado con la actividad en este caso de caminata, siempre debe tener un complemento, para que esto sea más fluido, porque si te dedicas solo a un turismo vivencial sin ningún complemento no tiene mucha rotación, no tiene mucho sentido.

56. ¿Cuál debería ser el rango de precio por noche en un albergue vivencial?

Depende de donde estés ubicados, en Racchi te cobran 80 soles por noche y te incluye desayuno, es una cama increíble. Racchi está al sur, son los primeros que han comenzado con el turismo vivencial, y han preparado camas y varias actividades para compartir con la gente local.

57. ¿Recomienda que las actividades deberían incluirse en el precio?

Si claro que sí, de hecho, es mejor que lo combines porque así la gente se va quedar más tiempo, porque si tú lo ofreces por separado, el hospedaje te cuesta esto y las actividades te cuestan esto, le das la opción de no tomarlo, a lo mejor solo hospedaje; pero si le dices esta actividad te incluye esto, ya sabes que el cliente se va a quedar más tiempo, va a tener más gasto en el lugar.

58. ¿Cuáles son los medios recomendados para publicitar un albergue vivencial? Internet si, nosotros sólo usamos internet y asistimos a ferias de turismo Especializados.

59. ¿Si te pregunto en el último año a que ferias han visitado?

El próximo año vamos a ir a Alemania, este año hemos estado en el ATA que es una asociación de agencias de aventura, ellos también organizan una reunión y el World Travel Marketing Londres

60. ¿Qué tipo de promociones ofrece generalmente un albergue de turismo vivencial? La gente local, se hace para cusqueños y peruanos, de hecho, nuestro mercado es el gringo, pero nuestra idea es que más gente, más peruanos y cusqueños conozcan el producto, así ellos mismos se van a sentir más representados por un producto que trabaja de manera sostenible, nuestras ofertas van enfocadas al mercado local. 300 usd el precio para cusqueños un grupo de 6 personas, es una inversión que nosotros hacemos en enseñar a la gente local que es lo que tienen allá.

61. ¿Qué porcentaje de sus ventas representa el turismo vivencial?

$100 \%$ y más aún si tienes a las comunidades socias porque el $20 \%$ de ganancias de la empresa, de todos los servicios, organización de carreras, el Andean Lodge, agencia de viajes va a caer ahí.

62. ¿Según tu experiencia como ves el futuro de los albergues del turismo vivencial, Recomendarías aumentar la oferta de albergues?

Definitivamente, no hay calidad de sección, somos pocos los que apuntamos a un estándar más alto, hay bastante por hacer, no hay que hablar con inversores sino con la gente del pueblo para abrirles un poquito la mente y apuesten por algo bueno. 


\section{Aceptación de propuesta}

63. ¿Qué te parecería un albergue vivencial en Mara donde están las salineras de Maras, cerca de Ollantaytambo? Donde tienes la experiencia de vivir el día a día de los pobladores, como actividad por ejemplo esta la compra de insumos y cocinar el almuerzo con la gente del lugar. ¿Sin embargo, tiene las características del hotel, cada huésped con su habitación y la infraestructura sería más rústica?

De hecho, es una buenísima idea, hay que evaluar varias cosas, entre ellas digamos el tema de experiencia se ha alzado bastando, todos te venden turismo de experiencia, hay que tratar de enfocarse en el entorno donde te encuentras, eso es importante, saber a qué se dedica tu pueblo, cual su economía principal, y reforzar todos estos aspectos y hacerlos parte de la empresa para reforzar que esto sea sostenible.

64. ¿Qué actividades me recomendarías?

Tienes todas las actividades, turismo de bicicleta, moto, caballo que hace que el cliente se quede un poco más habría que evaluar a que se dedica la gente, de qué tipo de población estamos hablamos, cuantos son jóvenes, que hacen, económicamente como se mueven, como les beneficia la sal, o como les beneficia la agricultura, porque tal ves tienes un Salar pero no le dan la importancia que es lo que está pasando,antes se sacaba un montón de sal, sin embargo se están creando mercados bien bonitos, la gente está creando sal con esencias con hierbas, esta buenísima. Sería hablar, poner una cultura de compra local, de un espacio turístico del Cusco tener un certificado que estás comprando local, a un hotel que compra sal de Maras, una certificación que le ayude al resto a reconocerlo a hacerlo suyo, que es local y eso funciona porque es local.

65. El temor es que Maras no tiene flujo, solo hay 5 establecimientos de hospedaje, desde el más bajo de calidad. No sabemos si funcionaría, son 5 y son chiquitos.

Si eres el único y sabes que solo tiene cinco sabes que vas a funcionar, el flujo lo creas tu, cuando más distracciones tengas en un espacio como este, vas a poder descentralizar chincheros, urubamba, ollantaytambo, vas a tener más opciones entonces la gente va a pensar en ti, el espacio lo vas a crear tu.

66. En tu experiencia ¿A quién debería estar dirigido este albergue?, gracias por tu tiempo. 


\section{AUQUI}

Alberto Valencia, administrador de Auqui por 4 años, entender cómo funciona la compañía y marketing.

Personal:

15 personas en la empresa, la mayor parte está concentrada en el área de servicio: ventas, operaciones y reservas. 4 personas en contabilidad.

Sucursales: Sin sucursales, cuentan con operadores en lima, Arequipa y Puno. Puntualmente el norte

Especialidad de auqui

Desde los 90 Roger Valencia (fundador), reconoció que el segmento de turismo de lujo no estaba atendido. Así se especializaron, se enfocan en el mercado norteamericano como representantes de empresas internacionales. Por ejemplo, el are de ventas está enfocada en atender a clientes corporativos y operadores de fuera. Nos enfocamos en tomo clásico.

Turistas atendidos 700 al año,

Venta de paquetes:

Especialistas en mercado de Cusco, el canal de venta es ser representantes de agencias internacionales, Lima y cusco tradicional

Servicios principales y secundarios:

Como operadores, hospedaje alimentación guías y transporte, secundarios como intereses particulares: observación de aves, ceremonias chamanicas, etc.

Principales proveedores: Belmont, inkaterra, libertador.

Depende del interés del viajero, elegimos las propiedades.

Ventajas con Belmont: muy buena relación comercial, mucha flexibilidad. Con inka terra el concepto boutique, más personal, más intimo. Inka terra pueblo por ejemplo da una sensación de cercanía con el viajero.

Criterios selección: interés del viajero y presupuesto. Flexibilidad de los hoteles, como políticas de no show, reservas, etc. Inka terra por ejemplo es muy estricto. Sol y Luna en el valle sagrado

Políticas más comunes entre proveedores:

Las reservas se reciben sin pago anticipado, lo que si pasara al reconfirmar la reserva, para esto el pago se hará entre los 60 y 45 días previos a la reserva. A partir de esta fecha la política de no show se va incrementando. En algunas ocasiones es poco usual pero se puede modificar la fecha.

Pago siempre con pago anticipado. Sin alianzas

Problemas con hospedajes: cuando se elige la acomodación equivocada para el tipo de cliente. Pequeños mal entendidos por tema de idiosincrasia. La expectativa del turista en Perú es mucho más flexible y condescendiente.

Como agencia los inconvenientes van de la mano de la flexibilidad, que rompe con la operatividad del centro de hospedaje.

Cual es mejor y porque: palacio nazarenas, por el mayordomo personalizado. Las

habitaciones son muy buenas.

Promedio de gasto: tarifa corporativa 350 dólares

Promedio de noches de estadía: mercado americano de lujo, lima y cusco 5 noches

Mercado americano: trabajamos con americanos y también alemán (gastan igual pero viajan más días)

Rechazo algún hospedaje: no pues nos fue bastante bien con los proveedores mencionados. 
Maras:

Paquetes ttcos: espacio es de paso, ruta al valle. Se programan actividades como bicicletas, caminatas o la visita a salineras y Moray. Existe una propiedad muy interesante en Maras, de propiedad de Jeremi Cornejo, llamada Iskay. Ellos ofrecen almuerzos en su casa con su propio huerto. Ellos brindan un lindo espacio para este momento y luego tomamos el valle. A veces preparamos un picnic en la zona de Tiobamba en esta zona.

Numero de paquetes vendidos al mes a maras

20 paquetes,

Como venden maras; se relaciona con la sal y el poblado.

Proveedores: iskay en maras

Tiempo de permanecía: medio día

Cuánto gasta un turista en maras, al costo: el turista no gasta en este tour, en un supuesto maras - Moray aprox 150 dólares de los cuales, solo queda a favor del poblado el costo de la entrada a las salineras.

Ventajas y desventajas del turismo en Maras:

Es un pueblo pintoresco, la belleza de la zona es muy valiosa. Respecto los inconvenientes la zona es bastante ventosa y eso incomoda durante el picnic. El pueblo crece y ahora es difícil encontrar un espacio privado para esta actividad. Creo que los esfuerzos que están haciendo los pobladores para impulsar el turismo están mal direccionados, pues el mercadillo establecido no ofrece una nueva opción.

En nuestro caso nuestros turistas no tienen contacto con las personas que venden las entradas, etc. pero si lo vemos desde un turismo más general el manejo de los espacios, y el personal no cuenta con las herramientas para atender a los turistas de manera asertiva.

Carecemos de un centro de interpretación donde las personas puedan saber que van a ver o que no pueden hacer en el atractivo que visitaran, que cuenten con personal calificado.

Turismo vivencial.

Es una de las modas más fuertes ahora. Entiendo que turismo vivencial es la oportunidad de las personas de conocer las costumbres e idiosincrasia de las personas que viven en una zona determinada, sin que esto sea una presentación artificial de dichos usos e idiosincrasia. Es una especie de inmersión real de quienes preservan su identidad.

Nuestro mercado no está interesado a estas actividades, el mercado europeo está mucho más abierto a estas actividades, pero actualmente no manejamos ese mercado. Este turismo puede tener alunas limitantes como la estacionalidad, la calidad de los servicios, etc. muchas veces no encaja con el poco tiempo de los turistas.

Ventajas: estacionalidad ubicación, depende de expectativas de los visitantes. Tal vez para nuestro mercado esta experiencia iría más de la mano de la interpretación que de la inmersión de la idiosincrasia de la zona.

Que tanto lo recomiendan: tratamos siempre a través del operador, nuestra labor está más en sugerir como podría acoplarse los nuevos servicios a los operadores.

Proveedores: los ritos por ejemplo sería un tipo de turismo vivencial, ellos lo hacen con pagos de la zona de ausangate ellos hacen pagos a la tierra y renovaciones de votos.

Cuanto podría llegar a costar. No tengo referencia clara. Pero en Raqchi se cobra 80 soles por noche, este es un ejemplo de las desventajas por el tema de ubicación.

Albergues: espacio físico con servicios mínimos necesarios que puedan ofrecer confort con las licencias propias de ser rustico, de pequeños espacios

Proveedor: andean lodges

El mejor; Montain lodges se ajusta a nuestro mercado, por los espacios de lujo que ofrecen.

Pero si el turista busca una experiencia más cercana y reconfortante y autentica pues sería

Andean lodges que tiene como principal inconveniente la altura y tiempo (tres días antes para acoplarse a la altura) 
Albergue vivencial: rustico y alejado, debería estar relacionado con la idiosincrasia de la gente, debes tener la oportunidad de entender cómo vive la gente de la zona

Infraestructura idónea: el albergue como se trabaja el lodge con capacidad, máxima de 22 personas es excelente, podría funcionar algo más pequeño pero por los flujos perderías clientes.

Servicios idóneos: baños privados, agua caliente, cama cómoda, dubet. Que la comida sea autentica posible que tengan una vertiente orgánica y la sal, pero que el procedimiento del preparado cumpla con lo exigido por temas de cuidado y la condimentación no sea exagerada. Es importante que exista una propuesta vegetariana con productos de la zona, que el lugar sea cálido, fuego chimeneas.

Actividades relacionas con cultura y activas con bicicletas caminatas, generar actividades relacionadas con la cultura local, por ejemplo, es el linderaje que se da entre diciembre y marzo las comunidades salen a marcar sus linderos, hay música cantos, este tipo de actividades como la época de siembra, etc. Para mostrar cómo estas comunidades entienden el mundo pues podría ayudar bastante.

Estas actividades deberían incluirse en el precio: aconsejo que estudies la propuesta de explora, hoteles nuevos en el valle, tienen capitales chilenos, ellos incluyen todo en el precio, así los clientes eligen las actividades que más les interesan.

Rango por precio por noche en un albergue, entre 80 y 120 días incluyendo todo, así lo vendería entre 150 dólares.

Tipo de promoción: turismo rural comentarios está auspiciado por promperu, específicamente por albergues peruanos. Pero la mejor manera son los operadores que llevaran la comunicación a tus clientes, una herramienta bastante complementaria es una página web sólida. El nivel de conversión de página sola muy difícilmente hará conversión, sugiero Trip Advisor un blog que complemente con comentarios que respalden tu oferta.

Prmociones: la mayoría se dirige al mercado local, para impulsar este turismo.

Un 10 a $15 \%$ de los clientes toma este tipo de servicios.

Recomendarías incrementar la oferta actual, el turismo deja de ver la representación artificial. Un intermedio entre ambos extremos es lo adecuado, si uno es puritano con el linderaje por ejemplo, si es solo en febrero, etc. eso quita espacio. Esta experiencia tal vez no es totalmente autentica, pero si puede tener algo muy relacionado, son las mismas personas, son los mismos sistemas de creencias, solo se hace en otro momento para que se entienda la cultura, caminado con ellos y celebrando con ellos.

Hay mucho espacio, pero debe estar ubicado en el circuito, dependiendo siempre en el mercado que te mueves. Hemos pasado de académicos a quienes hacen un check list de maravillas. Pero el europeo sigue siendo un turista más culto.

Apreciación al proyecto.

Me gusta la idea, creo que podría funcionar en maras, si la idea es vivencial necesitas un mayor espacio visual al valle, complementar con actividades relacionadas a las pozas y no solo ir a ver si no ir a hacer. Personalmente me gustaría vivirlo. 
Anexo VI.

Encuesta para el turista

Buen día, mi nombre es

somos alumnos de la Maestría de Ciencias

empresariales de la Universidad San Ignacio de Loyola. Estamos realizando una encuesta

NO

\section{PERCEPCIÓN Y NIVEL DE CONOCIMIENTO DE CUSCO}

1. ¿Cuál fue el motivo de su viaje a Cusco? Puede marcar más de una
a. Conocer la ciudadela de Machu Picchu.
b. Conocer acerca de su historia.
c. Conocer gente de diversas culturas.
d. Realizar deporte de aventura.
e. Realizar caminatas.
f. Otros: especificar

2. ¿Cómo organizó su itinerario de viaje a Cusco? Mencione las 3 opciones más utilizadas. Siendo 1 la de mayor utilización y 3 la de menor utilización

\begin{tabular}{|c|c|c|}
\hline$\#$ & Agencia de viajes & Páginas de viaje por internet \\
\hline 1 & & \\
\hline 2 & & \\
\hline 3 & & \\
\hline
\end{tabular}

3. ¿Qué servicios adquirió en la agencia de viajes y/o página de internet? Puede marcar más de una
a. Sólo pasajes.
b. Sólo hospedaje.
c. Sólo Movilidad.
d. Excursiones/actividades.
e. Pasajes + hospedajes + alimentación + movilidad + excursiones/actividades (tour completo)

4. ¿Cuánto tiempo se quedó hospedado en el Cusco?
a. Menos de 1 día
b. 1-7 días.
c. 8-15 días.
d. Más de 15 días.

5. ¿Cuál fue el presupuesto en dólares americanos por día para los siguientes rubros durante su viaje a Cusco?

\begin{tabular}{|c|c|c|c|}
\hline Dólares americanos (USD) & Hospedaje & Alimentación & $\begin{array}{l}\text { Actividades } \\
\text { excursiones }\end{array}$ \\
\hline a) Menos de USD 40 & & & \\
\hline b) Entre USD 40 y USD 80 & & & \\
\hline c) Entre USD 81 y USD 120 & & & \\
\hline d) Entre USD 121 y USD 160 & & & \\
\hline e) Entre USD 161 y USD 200 & & & \\
\hline f) Más de USD 200 & & & \\
\hline
\end{tabular}


6. Califique las siguientes actividades según su grado de satisfacción. Si no realizó ninguna actividad dejar en blanco.

\begin{tabular}{|l|c|c|c|c|c|}
\hline \multicolumn{1}{|c|}{ Actividad } & $\begin{array}{c}\text { Me gustó } \\
\text { mucho }\end{array}$ & $\begin{array}{c}\text { Me gusto } \\
\text { un poco }\end{array}$ & Indiferente & $\begin{array}{c}\text { Me } \\
\text { disgusto un } \\
\text { poco }\end{array}$ & $\begin{array}{c}\text { Me } \\
\text { disgusto } \\
\text { mucho }\end{array}$ \\
\hline Visitar Machu Picchu & & & & & \\
\hline Recorrer la ciudad de cusco & & & & & \\
\hline Conocer a los pobladores locales & & & & & \\
\hline Actividades de caminata/aventura & & & & & \\
\hline Restaurantes/Bares/Vida nocturna & & & & & \\
\hline
\end{tabular}

\section{PERCEPCIÓN Y NIVEL DE CONOCIMIENTO DE ALOJAMIENTOS EN CUSCO}

7. ¿Dónde se hospedó durante su permanencia en la ciudad de Cusco? (Puede marcar más de una opción)

\begin{tabular}{|l|l|l|}
\hline Marque $\mathrm{x}$ & Tipo de hospedaje & Nombre \\
\hline & Hotel & \\
\hline & Hostal (Backpackers) & \\
\hline & Lodge. & \\
\hline & Casa de amigo/familiar. & \\
\hline
\end{tabular}

8. ¿Dónde se hospedó durante su permanencia en la ciudad de Cusco? (Puede marcar más de una opción)

\begin{tabular}{|l|l|}
\hline Ciudad & Hospedaje \\
\hline Urubamba & \\
\hline Ollantaytambo & \\
\hline Quillabamba & \\
\hline Aguas Calientes & \\
\hline Otros: & \\
\hline No me hospedé fuera de la ciudad de Cusco & \\
\hline
\end{tabular}

9. ¿Por qué medios conoció los hospedajes mencionados? Puede marcar más de una opción
a. Recomendación de amigos/familiares.
b. Publicidad en Facebook.
c. Publicidad en página web Trip Advisor.com
d. Publicidad en página web Despegar.com
e. Publicidad en página web Expedia.com
f. Publicidad vía correo electrónico.
g. Recomendación agencia de viajes.

10. Califique según el orden de importancia el factor por el cual eligió los hospedajes mencionados, siendo 1 como el más importante y 5 como el menos importante.

\begin{tabular}{|l|l|}
\hline Factor & Calificación \\
\hline a. Precio/Oferta & \\
\hline b. Incluido en el tour & \\
\hline c. Infraestructura & \\
\hline d. Servicios incluidos/ofrecidos & \\
\hline e. Ubicación & \\
\hline f. Otros: & \\
\hline
\end{tabular}




\section{CONOCIMIENTO Y PERCEPCIÓN SOBRE EL DISTRITO DE MARAS}

11. ¿Conoce el poblado de Maras en Urubamba Cusco?
a. $\mathrm{Si}$
b. No (Si su respuesta es No pasar a pregunta 17).

12.¿Cuál fue el motivo de su viaje a Maras? Puede marcar más de una opción
a. Conocer el pueblo.
b. Conocer salineras
c. Conocer Moray
d. Estaba incluido en el tour.
e. Otros:

13. ¿Cuánto tiempo se quedó en Maras?
a. Menos de día (pasar a la pregunta 15)
b. 1-3 días
C. No (Si su respuesta es No pasar a pregunta 15).

Si respondió alternativa b o c responder la pregunta:

14. ¿Dónde se hospedó durante su permanencia en la ciudad de Maras?

\begin{tabular}{|l|l|l|}
\hline Marque $\mathrm{x}$ & Tipo hospedaje & Nombre \\
\hline & a. Hotel & \\
\hline & b. Lodge. & \\
\hline & c. Hostal (Backpackers) & \\
\hline & d. Casa de amigo/familiar & \\
\hline
\end{tabular}

15.Califique las actividades que realizó en Maras según su grado de satisfacción. Puede marcar más de una.

\begin{tabular}{|l|c|c|l|c|c|}
\hline \multicolumn{1}{|c|}{ Actividad } & $\begin{array}{c}\text { Me } \\
\text { gustó } \\
\text { mucho }\end{array}$ & $\begin{array}{c}\text { Me } \\
\text { gusto } \\
\text { un poco }\end{array}$ & Indiferente & $\begin{array}{c}\text { Me } \\
\text { disgusto } \\
\text { un poco }\end{array}$ & $\begin{array}{c}\text { Me } \\
\text { disgusto } \\
\text { mucho }\end{array}$ \\
\hline Recorrido de las salineras & & & & & \\
\hline Paseo en Bicicleta/motos & & & & & \\
\hline Paseo a Caballos & & & & & \\
\hline $\begin{array}{l}\text { Visita a los restos arqueológicos } \\
\text { de Moray }\end{array}$ & & & & & \\
\hline Caminatas & & & & & \\
\hline Comer en restaurantes & & & & & \\
\hline
\end{tabular}

16.Después de su visita a la ciudad de Maras, ¿recomendaría o no su visita como destino turístico?
a. Definitivamente si recomiendo.
b. Posiblemente si recomiendo.
c. Me sería indiferente recomendarla o no.
d. Posiblemente no recomiendo.
e. Definitivamente no recomiendo.

Si respondió d o e especifique porque 


\section{PERCEPCIÓN SOBRE EL TURISMO VIVENCIAL}

Entendiendo el turismo vivencial como aquel donde se puede experimentar y conocer la vida diaria de los pobladores; desde participar en actividades gastronómicas hasta experimentar festividades locales, además de tener los tours propios de un alojamiento campestre como equitación y sacar fotos, etc. Conteste las siguientes preguntas:

17. ¿Tiene experiencia en turismo vivencial? Si su respuesta es Sí por favor indique el tiempo de estadía durante dicha experiencia. Si su respuesta es No pase a la pregunta 18.

\begin{tabular}{|l|l|l|l|l|}
\hline & Menos de día & De 1 a 3 días & De 4 a 7 días & Más de 7 días \\
\hline Sí & & & & \\
\hline No & & \multicolumn{3}{|c}{} \\
\cline { 1 - 4 } & & &
\end{tabular}

18. ¿Qué actividades realizó durante su experiencia de turismo vivencial? Marque con una x. Puede marcar más de una opción.

\begin{tabular}{|l|l|}
\hline Actividades & Marque X \\
\hline a. Senderismo. & \\
\hline b. Festividades locales. & \\
\hline c. Gastronomía. & \\
\hline d. Ganadería. & \\
\hline e. Agricultura. & \\
\hline f. Bicicleta/Moto. & \\
\hline g. Paseo a caballo. & \\
\hline h. Artesanías. & \\
\hline i. Avistamiento de aves. & \\
\hline j. Visita parques naturales. & \\
\hline k. Visitar mercados de abastos. & \\
\hline l. Rutas temáticas. & \\
\hline m. Fotografía. & \\
\hline
\end{tabular}

\section{EXPECTATIVAS SOBRE UN LODGE}

19. ¿Qué concepto tiene de un lodge? Puede marcar más de una opción.
a. Tipo de hospedaje económico.
b. Tipo de hospedaje rústico.
c. Tipo de hospedaje alejado de la ciudad.
d. Lugar de descanso que reemplaza un campamento después de una caminata.
e. Tipo de hospedaje con habitaciones compartidas.
f. Todas las anteriores.
g. No sé lo que es un lodge

\section{EVALUACIÓN DE LODGES ACTUALES EN CUSCO}

20. ¿Ha visitado algún lodge en Cusco?
a. $\mathrm{Si}$
Indique nombre:
b. No (Pase a pregunta 22)

21. ¿Ha visitado algún lodge vivencial en Cusco?
a. $\mathrm{Si}$
Indique nombre:
b. No (Fin) 


\section{ACERCA DE UN LODGE VIVENCIAL EN EL POBLADO DE MARAS}

En la pregunta 15 respondió que conoce Maras es un poblado ubicado a $48 \mathrm{~km}$. al noroeste de la ciudad de Cusco, a $12 \mathrm{~km}$ de Urubamba y sobre los $3028 \mathrm{msnm}$. La temperatura fluctúa entre 1 a 20 grados centígrados.

Entre los principales atractivos turísticos están las salineras de Maras y la cercanía al complejo de Moray.

Entendiendo un Lodge vivencial como un alojamiento donde se tiene una pieza privada, pero se puede experimentar y conocer la vida diaria de los pobladores. Desde participar en actividades gastronómicas hasta experimentar festividades locales, además de tener los tours propios de un alojamiento campestre como equitación y sacar fotos, etc. Conteste las siguientes preguntas:

22. Valore del 1 al 5 la ventaja o desventaja más importante del poblado de Maras para usted, siendo 1 la más importante y 5 la menos importante:

\begin{tabular}{|l|l|l|}
\hline Características & Ventaja & Desventaja \\
\hline a. La cercanía a Machu Picchu. & & \\
\hline b. El estar en pleno valle sagrado & & \\
\hline c. La cercanía al nuevo aeropuerto en Chinchero & & \\
\hline d. La cercanía a las salineras de Maras & & \\
\hline e. La cercanía al complejo de Moray & & \\
\hline f. Altura (3028 msnm) & & \\
\hline g. Temperatura y clima en la ciudad. & & \\
\hline h. Acceso limitado a Internet & & \\
\hline i. Alejado de las actividades nocturnas del Cusco. & & \\
\hline
\end{tabular}

23. ¿Cuánto estaría dispuesto a pagar por alojarse una noche en un lodge vivencial en Maras?

\begin{tabular}{|l|l|l|l|}
\hline Precio en dólares americanos & Hospedaje & Alimentación & Actividades \\
\hline Menos de 50 usd & & & \\
\hline De 50 a 150 usd & & & \\
\hline De 150 a 300 usd & & & \\
\hline Más de 300 usd. & & & \\
\hline
\end{tabular}

\section{INTENSIÓN DE COMPRA}

24. Si un nuevo albergue vivencial ubicado en Maras en Urubamba, le ofreciera las siguientes características:

Habitación propia

- Cama Queen o King size

- Calefacción mediante estufa

- Baño privado con agua caliente

- Mini bar con productos locales

- Sales energéticas para baños relajantes

Áreas comunes con wifi:

- Restaurante, bar.

- Habitación mirador con servicio de oxigenación por bombeo.

Actividades al aire libre como: 
- Trekking

- Ciclismo

- Fotografías y lugares especiales para selfies.

Pregunta de intención (Mostrar plantilla)

Si usted hubiese sabido con anterioridad a su viaje al cusco de esta alternativa de visita al poblado de maras, usted:

\begin{tabular}{|l|l|c|c|}
\hline & $\begin{array}{c}\text { Paquete Full } \\
\text { Day } \\
\text { US \$ 190 }\end{array}$ & $\begin{array}{c}\text { Paquete 2 } \\
\text { días/ 1 } \\
\text { noche } \\
\text { US \$ 330 }\end{array}$ & $\begin{array}{c}\text { Paquete 3 } \\
\text { días/ 2 } \\
\text { noches } \\
\text { US \$ 440 }\end{array}$ \\
\hline Definitivamente tomaría el paquete & & & \\
\hline Posiblemente si tomaría el paquete & & & \\
\hline Me seria indiferente tomar el paquete o no & & & \\
\hline Posiblemente no tomaría el paquete & & & \\
\hline Definitivamente no tomaría el paquete & & & \\
\hline
\end{tabular}

Datos de control.

1. Género:

a. Masculino.

b. Femenino.

2. Edad:
a. Menos de 20 años.
b. Entre 21 a 29 años.
c. Entre 30 a 39 años.
d. Entre 40 a 50 años.
e. Entre 51 a 59 años.
f. 60 años a más.

3. Nacionalidad:

4. Estado civil:
a. Soltero.
b. Conviviente.
c. Casado.
d. Viudo.
e. Divorciado. 


\section{Anexo VII. \\ Tourist survey (english)}

Good morning, my name is

we are a group of students doing a master

degree in business administration at Universidad San Ignacio de Loyola. The main purpose

NO

Sun

\section{PERCEPTION AND LEVEL OF KNOWLEDGE OF CUSCO}

1. What was the main purpose of your trip to Cusco? Please select the answers that apply

a. To visit Machu Picchu.

b. To learn about city's history.

c. To meet people from various cultures.

d. For adventure sports.

e. For hiking and trekking.

f. Other (Please specify)

2. How did you plan your trip to Cusco? Specify the 3 most used options, ranging from 1 (the most used) to 3 (the least used)

\begin{tabular}{|c|c|c|}
\hline$\#$ & Travel agency & Websites \\
\hline 1 & & \\
\hline 2 & & \\
\hline 3 & & \\
\hline
\end{tabular}

3. Which services did you buy from the travel agency and/or website? Please select all the answers that apply
a. Only entrance tickets.
b. Only accommodation.
c. Only transportation.
d. Activities and excursions.
e. Tickets + Accommodation + food + transportation + activities and excursions (all- inclusive packages)

4. How many nights did you stay in Cusco?
a. Less than 1 day
b. 1-7 days.
c. 8-15 days.
d. More than 15 days.

5. In the following items, how much did you spend per night in US Dollar on your trip to Cusco?

\begin{tabular}{|l|l|l|l|}
\hline \multicolumn{1}{|c|}{ US Dollars } & Accommodation & Food & Activities \\
\hline a) Less than USD 40 & & & \\
\hline b) Between USD 40 and USD 80 & & & \\
\hline c) Between USD 81 and USD 120 & & & \\
\hline d) Between USD 121 and USD 160 & & & \\
\hline e) Between USD 161 and USD 200 & & & \\
\hline f) Over USD 200 & & & \\
\hline
\end{tabular}


6. Rate the following activities according to your satisfaction. If you did not perform any activity left blank.

\begin{tabular}{|l|l|l|l|l|l|}
\hline \multicolumn{1}{|c|}{ Activity } & $\begin{array}{c}\text { I like it } \\
\text { a lot }\end{array}$ & I liked it & $\begin{array}{c}\text { No } \\
\text { opinion }\end{array}$ & $\begin{array}{c}\text { I didn't } \\
\text { like it }\end{array}$ & $\begin{array}{c}\text { I didn't } \\
\text { like it too } \\
\text { much }\end{array}$ \\
\hline Visit to Machu Picchu & & & & & \\
\hline City sight seing of Cusco & & & & & \\
\hline Visit of local villages & & & & & \\
\hline Trekking/adventure activities & & & & & \\
\hline Restaurants/bar/clubs & & & & & \\
\hline
\end{tabular}

PERCEPTION AND LEVEL OF KNOWLEGE OF ACCOMODATION IN CUSCO

7. Where did you stay during your visit to Cusco? Please select all the answers that apply

\begin{tabular}{|l|l|l|}
\hline $\begin{array}{c}\text { Check all that } \\
\text { apply }\end{array}$ & \multicolumn{1}{|c|}{ Type of accommodation } & Name of the accommodation \\
\hline & Hotel & \\
\hline & Hostal (Backpackers) & \\
\hline & Lodge. & \\
\hline & Friend/Family house & \\
\hline
\end{tabular}

8. Below are a number of cities located in Cusco area, if you stayed in any of these cities please specify the name of the accommodation.

\begin{tabular}{|l|l|}
\hline City & Accommodation \\
\hline Urubamba & \\
\hline Ollantaytambo & \\
\hline Quillabamba & \\
\hline Aguas Calientes & \\
\hline Other: & \\
\hline I only stayed in Cusco. & \\
\hline
\end{tabular}

9. How did you hear about the above-mentioned accommodation? Please select the answers that apply
a. Friends/family recommendation.
b. Advertising on Facebook.
c. Advertising on Trip Advisor.com
d. Advertising on Despegar.com
e. Advertising on Expedia.com
f. E-mail advertising.
g. Travel agency recommendation.

10. Below are a number of statements, which is the most important factor for you when you choose an accommodation ( 1 being the most important and 6 the least important)

\begin{tabular}{|l|l|}
\hline \multicolumn{1}{|c|}{ Factor } & Rating \\
\hline a. Price/offer & \\
\hline b. Included in the tour & \\
\hline c. Infrastructure & \\
\hline d. Services offered/included & \\
\hline e. Location & \\
\hline f. Others: & \\
\hline
\end{tabular}




\section{PERCEPTION OF HOMESTAY/EXPERIMENTAL TOURISM}

Please answer the following questions understanding that the homestay/experiential tourism is the kind of tourism where you may experience and learn about the daily life and culture from localpeople; that means, to take part into their daily activities, try their local cuisine, and experience activities such as horse riding, photography, etc.

11. Have you ever tried experiential tourism? If yes, how many nights did you stay?

\begin{tabular}{|c|c|c|c|c|}
\hline & Less than 1 night & From 1 to 3 nights & From 4 to 7 nights & Over 7 nigths \\
\hline \multicolumn{5}{|l|}{ Yes } \\
\hline $\mathrm{No}$ & & & & \\
\hline & & & & \\
\hline & & & & \\
\hline
\end{tabular}

(If you answered no, go to question 13)

12. Which activities did you practice during your homestay/experiential tourism experience? Please select any that applies.

\begin{tabular}{|l|l|}
\hline Activities & Check all that apply \\
\hline a. Hiking. & \\
\hline b. Local celebrations. & \\
\hline c. Gastronomy. & \\
\hline d. Farming. & \\
\hline e. Agriculture. & \\
\hline f. Cycling/moto. & \\
\hline g. Horse riding. & \\
\hline h. Handicraft. & \\
\hline i. Bird watching. & \\
\hline j. Visit to natural parks. & \\
\hline k. Visit to local markets. & \\
\hline 1. Thematic itneraries. & \\
\hline m. Photography. & \\
\hline
\end{tabular}

\section{LODGING EXPECTATION}

13. What do you understand as a Lodge? Please select any that applies.
a. Cheap accomodation.
b. Rustic accommodation.
c. Accommodation located far from the city.
d. Resting point that replaces camping site during a hike.
e. Accommodation with shared rooms.
f. All the previous answers.
g. I have no idea

\section{RATING OF LODGES UN CUSCO}

14. Have you ever been in a homestay/experiential Lodge in Cusco?
a. Yes
Specify the name of the lodge:
b. No (Go to question 16)

15. Have you ever been in a homestay/experiential Lodge in Cusco? 

a. Yes
Specify the name of the lodge:
b. No (Go to question 16)

\section{KNOWLEDGE AND PERCEPTION ABOUT MARAS}

16. Have you ever known Maras, Urubamba Cusco?
c. Yes
d. No (If not, go to question 22)

17. What was the main purpose of you trip to Maras? Please select the answers that apply
a. To visit the village.
b. To visit the salt flats
c. To visit Moray
d. It was included in a tour.
e. Others:

18. How many nights did you stay in Maras?

\begin{tabular}{|l|l|l|}
\hline a. Less than a day (go to question 15) & b. 1-3 nights & c. 2 or more nights \\
\hline
\end{tabular}

Answer the following question if you choose alternative b or $c$ :

19 . Where did you stay during your trip to Maras?

\begin{tabular}{|l|l|l|}
\hline $\begin{array}{c}\text { Check all } \\
\text { that apply }\end{array}$ & \multicolumn{1}{|c|}{ Type of accommodation } & \multicolumn{1}{|c|}{$\begin{array}{c}\text { Name of the } \\
\text { accommodation }\end{array}$} \\
\hline & a. Hotel & \\
\hline & b. Lodge. & \\
\hline & c. Hostal(Backpackers) & \\
\hline & d. Friend/Family house & \multicolumn{1}{|c|}{} \\
\hline
\end{tabular}

20. Rate the following activities in order of satisfaction. If you did not perform any activity left blank.

\begin{tabular}{|l|l|l|l|l|l|}
\hline \multicolumn{1}{|c|}{ Activity } & $\begin{array}{c}\text { I liked it } \\
\text { a lot }\end{array}$ & $\begin{array}{c}\text { I liked } \\
\text { it }\end{array}$ & $\begin{array}{c}\text { No } \\
\text { opinion }\end{array}$ & $\begin{array}{c}\text { I didn't } \\
\text { like }\end{array}$ & $\begin{array}{c}\text { I didn't } \\
\text { like it too } \\
\text { much. }\end{array}$ \\
\hline Walking through the salt flats & & & & & \\
\hline Cycling/Moto tour & & & & & \\
\hline Horse riding & & & & & \\
\hline Visiting Moray archeological site & & & & & \\
\hline Hiking & & & & & \\
\hline Eating in local restaurants & & & & & \\
\hline
\end{tabular}

21. After your visit to Maras, how would you rate this destination?
a. Strongly recommend.
b. Recommend.
c. No opinion.
d. Not recommended.
e. Strongly not recommended

If you answer d or c, please explain why 
ABOUT A HOMESTAY/EXPERIMENTAL LODGE LOCATED IN MARAS AREA

22. As you might know Maras is a village located $48 \mathrm{~km}$ northeast Cusco, $12 \mathrm{~km}$ away from Urubamba, at an elevation of $3.028 \mathrm{~m}$. Temperature is ranging from $1^{\circ}$ to $20^{\circ} \mathrm{C}$. Between the main touristic sights are Maras' salt flats and Moray's archeological site.

If you understand an experimental Lodge as an accommodation with private room, but where you can learn and enjoy the daily life of local people. Various activities are offered, ranging from gastronomy to local celebrations, besides offering countryside lodging and activities as horse riding, photography, etc, answer the next questions:

Please rate from 1 to 5 the advantages of Maras ( 1 being the highest and 5 the lowest):

\begin{tabular}{|l|l|}
\hline Features & Rating \\
\hline a. Close to Machu Picchu. & \\
\hline b. Located in the heart of the Sacred Valley & \\
\hline c. Close to Chinchero's new airport & \\
\hline d. Close to Maras' salt flats & \\
\hline e. Close to Moray's archeological site & \\
\hline
\end{tabular}

23. Please rate from 1 to 4 the disadvantages of Maras( 1 being the highest disadvantages and 4 the lowest):

\begin{tabular}{|l|l|}
\hline Features & Rating \\
\hline a. Altitude (3028 above the sea level) & \\
\hline b. Temperature and weather in the area. & \\
\hline c. Restricted internet Access & \\
\hline d. $\quad$ Far from Cusco's nightlife. & \\
\hline
\end{tabular}

24. How much would you be willing to pay to stay in Maras?

\begin{tabular}{|l|l|l|l|}
\hline Price in USD & Accommodation & Food & Activities \\
\hline Less than 50 usd & & & \\
\hline From 50 to 150 usd & & & \\
\hline From 150 to 300 usd & & & \\
\hline More than 300 usd. & & & \\
\hline
\end{tabular}

\section{PURCHASE INTENTION}

25. If there was a new lodging in Maras, that was offering the following services:

Private room

- King size bed

- Heating

- Private bathroom with heating

- Mini bar

- Maras bat salts

Common areas with Wifi:

- Restaurant, bar.

- Observation room with oxygen tank.

Outside activities such as:

- Trekking

- Cycling

- Photography and special places for selfies. 
Please take a look at the template that survey taker will show you.

If you would have known about those packages before your visit to Cusco, would you have considered buying the following package?

\begin{tabular}{|l|l|l|l|}
\hline & $\begin{array}{c}\text { Full Day } \\
\text { US \$ 190 }\end{array}$ & $\begin{array}{c}\text { 2days/1night } \\
\text { US \$ 330 }\end{array}$ & $\begin{array}{c}\text { 3days/2nights } \\
\text { US \$ 440 }\end{array}$ \\
\hline I would definitely buy the package & & & \\
\hline I might buy the package & & & \\
\hline I would be indifferent to that package & & & \\
\hline I would probably not buy the package & & & \\
\hline I would definitely not buy the package & & & \\
\hline
\end{tabular}

Please tell us about yourself

26. Gender:

28. Nationality:
a. Male.
b. Female.

27. Age:
a. Less than 20 years old.
b. Between 21 to 29 years old.
c. Between 30 to 39 years old.
d. Between 40 to 50 years old.
e. Between 51 to 59 years old.
f. Over 60 years old.

29. Marital status:
a. Single.
b. Cohabitant.
c. Married.
d. Widow (er).
e. Divorced.

THANK YOU AND COME BACK SOON. 
Anexo VIII.

Resultados Encuesta Turista

Estadísticos

\begin{tabular}{cccccc}
\hline & & Género & $\begin{array}{c}\text { Rango de } \\
\text { Edad }\end{array}$ & Nacionalidad & $\begin{array}{c}\text { Estado } \\
\text { civil }\end{array}$ \\
\hline \multirow{2}{*}{$\mathrm{N}$} & Válido & 200 & 200 & 200 & 200 \\
& Perdidos & 0 & 0 & 0 & 0 \\
\hline
\end{tabular}

Tabla de frecuencia

Género

\begin{tabular}{cccccc}
\hline & Género & Frecuencia & $\%$ & $\begin{array}{c}\text { Porcentaje } \\
\text { válido }\end{array}$ & $\begin{array}{c}\text { Porcentaje } \\
\text { acumulado }\end{array}$ \\
\hline \multirow{3}{*}{ Válido } & Femenino & 121 & 60,5 & 60,5 & 60,5 \\
& Masculino & 79 & 39,5 & 39,5 & 100,0 \\
& Total & 200 & 100,0 & 100,0 & \\
\hline
\end{tabular}

\begin{tabular}{cccccc}
\hline Rango de Edad & Frecuencia & Porcentaje & $\begin{array}{c}\text { Porcentaje } \\
\text { válido }\end{array}$ & $\begin{array}{c}\text { Porcentaje } \\
\text { acumulado }\end{array}$ \\
\hline \multirow{6}{*}{ Válido } & Menos de 20 años & 7 & 3,5 & 3,5 & 3,5 \\
& De 21 a 29 años & 46 & 23,0 & 23,0 & 26,5 \\
& De 30 a 39 años & 77 & 38,5 & 38,5 & 65,0 \\
& De 40 a 50 años & 49 & 24,5 & 24,5 & 89,5 \\
& De 51 a 59 años & 15 & 7,5 & 7,5 & 97,0 \\
& De 60 a más & 6 & 3,0 & 3,0 & 100,0 \\
& Total & 200 & 100,0 & 100,0 & \\
\hline
\end{tabular}

Nacionalidad

\begin{tabular}{cccccc}
\hline Nacionalidad & Frecuencia & Porcentaje & $\begin{array}{c}\text { Porcentaje } \\
\text { válido }\end{array}$ & $\begin{array}{c}\text { Porcentaje } \\
\text { acumulado }\end{array}$ \\
\hline Válido & Perú & 33 & 16,5 & 16,5 & 16,5 \\
Chile & 12 & 6,0 & 6,0 & 22,5 \\
Estados Unidos & 27 & 13,5 & 13,5 & 36,0 \\
México & 3 & 1,5 & 1,5 & 37,5 \\
Canadá & 13 & 6,5 & 6,5 & 44,0 \\
Australia & 4 & 2,0 & 2,0 & 46,0 \\
Italia & 4 & 2,0 & 2,0 & 48,0 \\
Reino Unido & 3 & 1,5 & 1,5 & 49,5 \\
Corea & 1 &, 5 &, 5 & 50,0 \\
Dinamarca & 3 & 1,5 & 1,5 & 51,5 \\
Nueva Zelanda & 1 &, 5 &, 5 & 52,0 \\
Japón & 1 &, 5 &, 5 & 52,5 \\
Alemania & 7 & 3,5 & 3,5 & 56,0 \\
Suecia & 1 &, 5 &, 5 & 56,5 \\
Francia & 9 & 4,5 & 4,5 & 61,0 \\
Brasil & 31 & 15,5 & 15,5 & 76,5 \\
Irlanda & 1 &, 5 &, 5 & 77,0
\end{tabular}




\begin{tabular}{ccccc} 
España & 7 & 3,5 & 3,5 & 80,5 \\
Suiza & 1 &, 5 &, 5 & 81,0 \\
Bolivia & 7 & 3,5 & 3,5 & 84,5 \\
Colombia & 9 & 4,5 & 4,5 & 89,0 \\
Argentina & 18 & 9,0 & 9,0 & 98,0 \\
Venezuela & 1 &, 5 &, 5 & 98,5 \\
Uruguay & 2 & 1,0 & 1,0 & 99,5 \\
Panama & 1 &, 5 &, 5 & 100,0 \\
Total & 200 & 100,0 & 100,0 & \\
\hline
\end{tabular}

\section{Estado civil}

\begin{tabular}{llllll}
\hline & & Frecuencia & Porcentaje & $\begin{array}{r}\text { Porcentaje } \\
\text { válido }\end{array}$ & $\begin{array}{r}\text { Porcentaje } \\
\text { acumulado }\end{array}$ \\
\hline Válido & Soltero & 62 & 31,0 & 31,0 & 31,0 \\
& Conviviente & 31 & 15,5 & 15,5 & 46,5 \\
& Casado & 104 & 52,0 & 52,0 & 98,5 \\
& Viudo & 1 &, 5 &, 5 & 99,0 \\
& Divorciado & 2 & 1,0 & 1,0 & 100,0 \\
& Total & 200 & 100,0 & 100,0 & \\
\hline
\end{tabular}

\section{Resumen de procesamiento de casos}

\begin{tabular}{|c|c|c|c|c|c|c|}
\hline & \multicolumn{6}{|c|}{ Casos } \\
\hline & \multicolumn{2}{|r|}{ Válido } & \multicolumn{2}{|r|}{ Perdidos } & \multicolumn{2}{|r|}{ Total } \\
\hline & $\mathrm{N}$ & Porcentaje & $\mathrm{N}$ & Porcentaje & $\mathrm{N}$ & Porcentaje \\
\hline $\begin{array}{l}\text { Si hubiera sabido con anterioridad a su } \\
\text { viaje a Cusco de la alternativa PAQUETE } \\
\text { FULL DAY, usted * Género }\end{array}$ & 200 & $100,0 \%$ & 0 & $0,0 \%$ & 200 & $100,0 \%$ \\
\hline $\begin{array}{l}\text { Si hubiera sabido con anterioridad a su } \\
\text { viaje a Cusco de la alternativa PAQUETE } \\
\text { FULL DAY, usted * Rango de Edad }\end{array}$ & 200 & $100,0 \%$ & 0 & $0,0 \%$ & 200 & $100,0 \%$ \\
\hline $\begin{array}{l}\text { Si hubiera sabido con anterioridad a su } \\
\text { viaje a Cusco de la alternativa PAQUETE } \\
\text { FULL DAY, usted * Nacionalidad }\end{array}$ & 200 & $100,0 \%$ & 0 & $0,0 \%$ & 200 & $100,0 \%$ \\
\hline $\begin{array}{l}\text { Si hubiera sabido con anterioridad a su } \\
\text { viaje a Cusco de la alternativa PAQUETE } \\
\text { FULL DAY, usted } * \text { Estado civil }\end{array}$ & 200 & $100,0 \%$ & 0 & $0,0 \%$ & 200 & $100,0 \%$ \\
\hline $\begin{array}{l}\text { Si hubiera sabido con anterioridad a su } \\
\text { viaje a Cusco de la alternativa PAQUETE } \\
2 \text { DIAS Y } 1 \text { NOCHE, usted * Género }\end{array}$ & 200 & $100,0 \%$ & 0 & $0,0 \%$ & 200 & $100,0 \%$ \\
\hline $\begin{array}{l}\text { Si hubiera sabido con anterioridad a su } \\
\text { viaje a Cusco de la alternativa PAQUETE } \\
2 \text { DIAS Y } 1 \text { NOCHE, usted * Rango de } \\
\text { Edad }\end{array}$ & 200 & $100,0 \%$ & 0 & $0,0 \%$ & 200 & $100,0 \%$ \\
\hline
\end{tabular}


Si hubiera sabido con anterioridad a su

200

$100,0 \% \quad 0$

$0,0 \%$

$200 \quad 100,0 \%$ viaje a Cusco de la alternativa PAQUETE

2 DIAS Y 1 NOCHE, usted *

Nacionalidad

Si hubiera sabido con anterioridad a su viaje a Cusco de la alternativa PAQUETE

2 DIAS Y 1 NOCHE, usted * Estado civil

Si hubiera sabido con anterioridad a su viaje a Cusco de la alternativa PAQUETE $200 \quad 100,0 \% \quad 0 \quad 0,0 \% \quad 200 \quad 100,0 \%$

3 DIAS Y 2 NOCHES, usted * Género

Si hubiera sabido con anterioridad a su viaje a Cusco de la alternativa PAQUETE $200 \quad 100,0 \% \quad 0 \quad 0,0 \% \quad 200 \quad 100,0 \%$ 3 DIAS Y 2 NOCHES, usted * Rango de Edad

Si hubiera sabido con anterioridad a su viaje a Cusco de la alternativa PAQUETE 3 DIAS Y 2 NOCHES, usted * Nacionalidad

Si hubiera sabido con anterioridad a su viaje a Cusco de la alternativa PAQUETE $200 \quad 100,0 \% \quad 0 \quad 0,0 \% \quad 200 \quad 100,0 \%$ 3 DIAS Y 2 NOCHES, usted * Estado civil

Si hubiera sabido con anterioridad a su viaje a Cusco de la alternativa PAQUETE FULL DAY, usted:

\begin{tabular}{llcccc} 
& & \multicolumn{2}{c}{ Género } & Total & $\%$ \\
\hline & $\begin{array}{l}\text { Definitivamente no tomaría } \\
\text { el paquete }\end{array}$ & 16 & 13 & 29 & $15 \%$ \\
& $\begin{array}{l}\text { Posiblemente no tomaría el } \\
\text { paquete }\end{array}$ & 8 & 4 & 12 & $6 \%$ \\
$\begin{array}{l}\text { Si hubiera sabido con } \\
\begin{array}{l}\text { anterioridad a su viaje } \\
\text { a Cusco de la } \\
\text { alternativa PAQUETE }\end{array}\end{array}$ & $\begin{array}{l}\text { Me sería indiferente tomar el } \\
\text { paquete o no }\end{array}$ & 30 & 28 & 58 & $29 \%$ \\
FULL DAY, usted & $\begin{array}{l}\text { Posiblemente tomaría el } \\
\text { paquete }\end{array}$ & 40 & 24 & 64 & $32 \%$ \\
& $\begin{array}{l}\text { Definitivamente tomaría el } \\
\text { paquete }\end{array}$ & 27 & 10 & 37 & $19 \%$ \\
Total & & 121 & 79 & 200 & $100 \%$ \\
\hline
\end{tabular}


Si hubiera sabido con anterioridad a su viaje a Cusco de la alternativa PAQUETE FULL DAY, usted*Rango de Edad tabulación cruzada

\begin{tabular}{|c|c|c|c|c|c|c|c|c|c|}
\hline \multirow{2}{*}{\multicolumn{2}{|c|}{ Recuento }} & \multicolumn{6}{|c|}{ Rango de Edad } & \multirow[b]{2}{*}{ Total } & \multirow[b]{2}{*}{$\%$} \\
\hline & & Menos & $\mathrm{De}$ & De 30 & De 40 & De 51 & & & \\
\hline \multirow{5}{*}{$\begin{array}{l}\text { Si hubiera } \\
\text { sabido con } \\
\text { anterioridad } \\
\text { a su viaje a } \\
\text { Cusco de la } \\
\text { alternativa } \\
\text { PAQUETE } \\
\text { FULL } \\
\text { DAY, usted }\end{array}$} & $\begin{array}{l}\text { Definitivamente } \\
\text { no tomaría el } \\
\text { paquete }\end{array}$ & 0 & 3 & 13 & 10 & 2 & 1 & 29 & $15 \%$ \\
\hline & $\begin{array}{l}\text { Posiblemente } \\
\text { no tomaría el } \\
\text { paquete }\end{array}$ & 0 & 5 & 3 & 4 & 0 & 0 & 12 & $6 \%$ \\
\hline & $\begin{array}{l}\text { Me sería } \\
\text { indiferente } \\
\text { tomar el } \\
\text { paquete o no }\end{array}$ & 0 & 6 & 26 & 20 & 5 & 1 & 58 & $29 \%$ \\
\hline & $\begin{array}{l}\text { Posiblemente } \\
\text { tomaría el } \\
\text { paquete }\end{array}$ & 5 & 28 & 19 & 7 & 4 & 1 & 64 & $32 \%$ \\
\hline & $\begin{array}{l}\text { Definitivamente } \\
\text { tomaría el } \\
\text { paquete }\end{array}$ & 2 & 4 & 16 & 8 & 4 & 3 & 37 & $19 \%$ \\
\hline Total & & 7 & 46 & 77 & 49 & 15 & 6 & 200 & $100 \%$ \\
\hline
\end{tabular}


Si hubiera sabido con anterioridad a su viaje a Cusco de la alternativa PAQUETE FULL DAY, usted*Nacionalidad tabulación cruzada Recuento

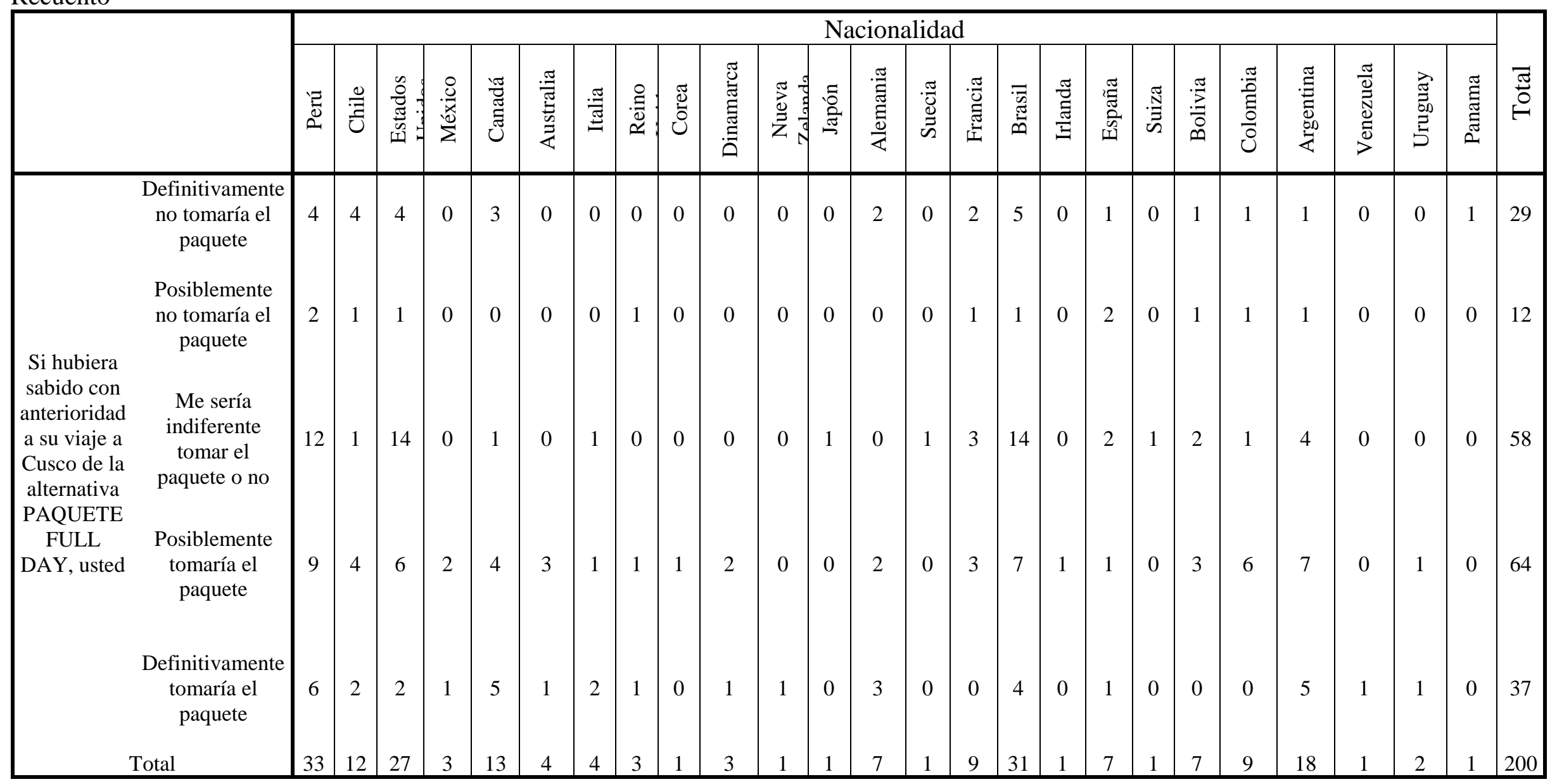


Si hubiera sabido con anterioridad a su viaje a Cusco de la alternativa PAQUETE FULL DAY, usted*Estado civil tabulación cruzada

Recuento

\begin{tabular}{|c|c|c|c|c|c|c|c|c|}
\hline & \multicolumn{5}{|c|}{ Estado civil } & \multirow{2}{*}{ Total } & \multirow{2}{*}{$\%$} \\
\hline & & Soltero & Conviviente & Casado & Viudo & Divorciado & & \\
\hline \multirow{5}{*}{$\begin{array}{l}\text { Si hubiera } \\
\text { sabido con } \\
\text { anterioridad } \\
\text { a su viaje a } \\
\text { Cusco de la } \\
\text { alternativa } \\
\text { PAQUETE } \\
\text { FULL } \\
\text { DAY, usted }\end{array}$} & $\begin{array}{l}\text { Definitivamente } \\
\text { no tomaría el } \\
\text { paquete }\end{array}$ & 7 & 8 & 14 & 0 & 0 & 29 & $15 \%$ \\
\hline & $\begin{array}{l}\text { Posiblemente } \\
\text { no tomaría el } \\
\text { paquete }\end{array}$ & 4 & 2 & 6 & 0 & 0 & 12 & $6 \%$ \\
\hline & $\begin{array}{l}\text { Me sería } \\
\text { indiferente } \\
\text { tomar el } \\
\text { paquete o no }\end{array}$ & 14 & 13 & 31 & 0 & 0 & 58 & $29 \%$ \\
\hline & $\begin{array}{l}\text { Posiblemente } \\
\text { tomaría el } \\
\text { paquete }\end{array}$ & 27 & 7 & 27 & 1 & 2 & 64 & $32 \%$ \\
\hline & $\begin{array}{l}\text { Definitivamente } \\
\text { tomaría el } \\
\text { paquete }\end{array}$ & 10 & 1 & 26 & 0 & 0 & 37 & $19 \%$ \\
\hline Total & & 62 & 31 & 104 & 1 & 2 & 200 & $100 \%$ \\
\hline
\end{tabular}

Si hubiera sabido con anterioridad a su viaje a Cusco de la alternativa PAQUETE 2 DÍAS Y 1 NOCHE, usted*Género tabulación cruzada

\begin{tabular}{lccc} 
& \multicolumn{3}{c}{ Femenino } \\
\cline { 2 - 3 } & 10 & 8 & \\
\hline Posiblemente no tomaría el paquete & 12 & 9 & 21 \\
Me sería indiferente tomar el paquete o no & 53 & 38 & 91 \\
Posiblemente tomaría el paquete & 29 & 15 & 44 \\
Definitivamente tomaría el paquete & 17 & 9 & 26 \\
Total & 121 & 79 & 200 \\
\hline
\end{tabular}

Si hubiera sabido con anterioridad a su viaje a Cusco de la alternativa PAQUETE 2 DIAS Y 1 NOCHE, usted*Rango de Edad tabulación cruzada

Recuento

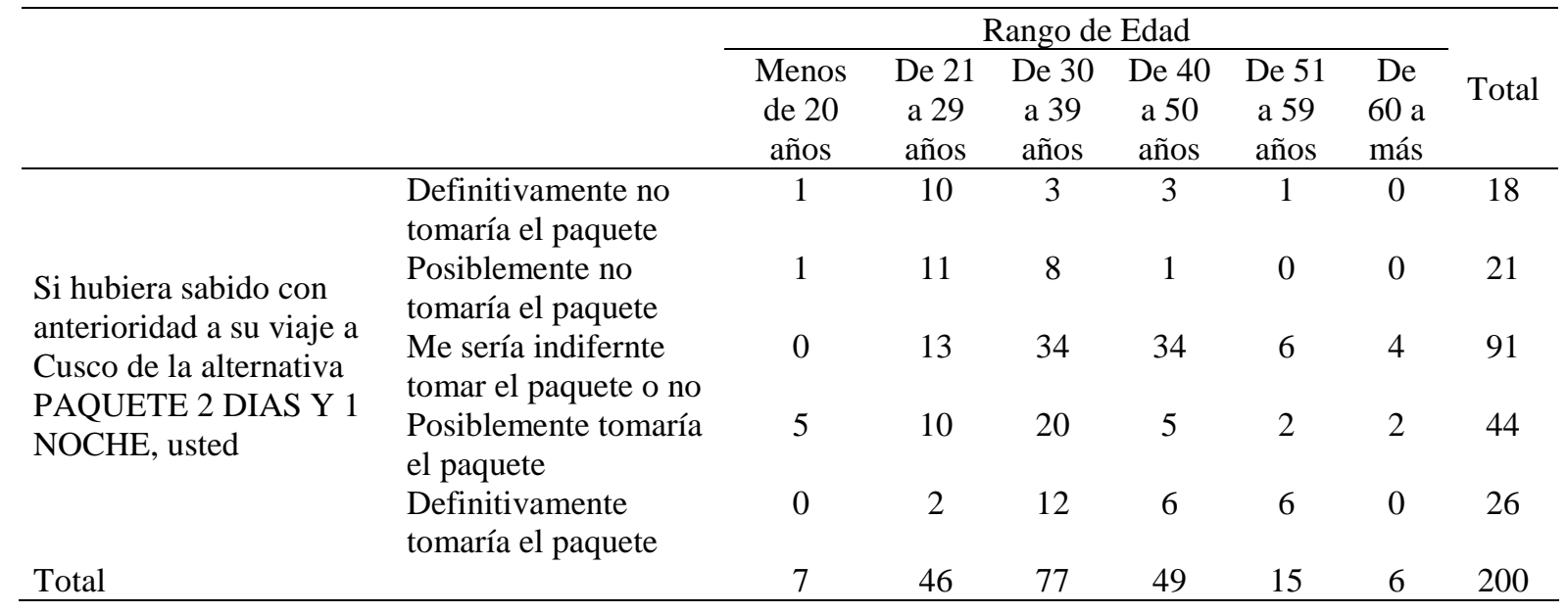


Si hubiera sabido con anterioridad a su viaje a Cusco de la alternativa PAQUETE 2 DÍAS Y 1 NOCHE, usted*Nacionalidad tabulación cruzada

Recuento

\begin{tabular}{|c|c|c|c|c|c|c|c|c|c|c|c|c|c|c|c|c|c|c|c|c|c|c|c|c|c|c|c|}
\hline & & \multicolumn{25}{|c|}{ Nacionalidad } & \multirow[b]{2}{*}{ 풍 } \\
\hline & & $\mid \begin{array}{r}\overrightarrow{0} \\
\text { D. } \\
0\end{array}$ & $\frac{\mathscr{v}}{\stackrel{U}{U}}$ & 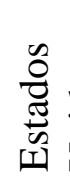 & 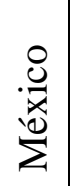 & 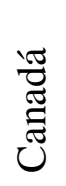 & 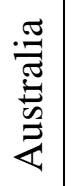 & 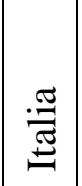 & 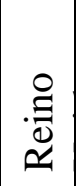 & $\begin{array}{l}\mathscr{D} \\
\tilde{0} \\
己\end{array}$ & 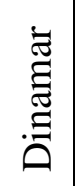 & 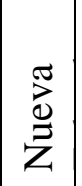 & 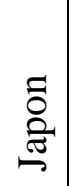 & 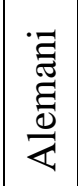 & $\begin{array}{l}\cdot \frac{\pi}{U} \\
\stackrel{\mathscr{U}}{\tilde{S}}\end{array}$ & 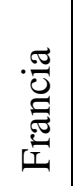 & 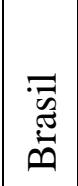 & 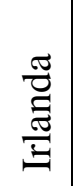 & 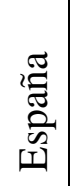 & 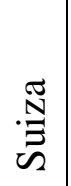 & $\begin{array}{l}\cdot \frac{\pi}{5} \\
: \\
0 \\
0\end{array}$ & है & 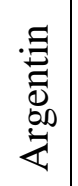 & 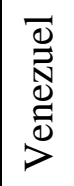 & $\begin{array}{l}\overrightarrow{\vec{E}} \\
\overrightarrow{50}_{0} \\
\overrightarrow{5}\end{array}$ & 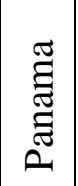 & \\
\hline & $\begin{array}{l}\text { Definitivamente } \\
\text { no tomaría el } \\
\text { paquete }\end{array}$ & 2 & 1 & 4 & 0 & 2 & 0 & 0 & 0 & 0 & $\overline{0}$ & 0 & 0 & 1 & 0 & 1 & 1 & 1 & 1 & 0 & 0 & 1 & 2 & 0 & 0 & 1 & 18 \\
\hline $\begin{array}{l}\text { a su viaje a } \\
\text { Cusco de la } \\
\text { alternativa } \\
\text { PAQUETE }\end{array}$ & $\begin{array}{l}\text { Me sería } \\
\text { indiferente } \\
\text { tomar el } \\
\text { paquete o no }\end{array}$ & 14 & 6 & 15 & 0 & 8 & 0 & 1 & 1 & 0 & 0 & 0 & 0 & 2 & 1 & 6 & 18 & 0 & 4 & 1 & 3 & 5 & 6 & 0 & 0 & 0 & 91 \\
\hline $\begin{array}{l}2 \text { DIAS Y } 1 \\
\text { NOCHE, } \\
\text { usted }\end{array}$ & $\begin{array}{l}\text { Posiblemente } \\
\text { tomaría el } \\
\text { paquete }\end{array}$ & 10 & 4 & 5 & 0 & 1 & 2 & 1 & 1 & 0 & 2 & 0 & 0 & 3 & 0 & 1 & 4 & 0 & 0 & 0 & 2 & 3 & 4 & 0 & 1 & 0 & 44 \\
\hline Total & & 33 & 12 & 27 & 3 & 13 & 4 & 4 & 3 & 1 & 3 & 1 & 1 & 7 & 1 & 9 & 31 & 1 & 7 & 1 & 7 & 9 & 18 & 1 & 2 & 1 & 200 \\
\hline
\end{tabular}


Si hubiera sabido con anterioridad a su viaje a Cusco de la alternativa PAQUETE 2 DIAS Y 1 NOCHE, usted*Estado civil tabulación cruzada

Recuento

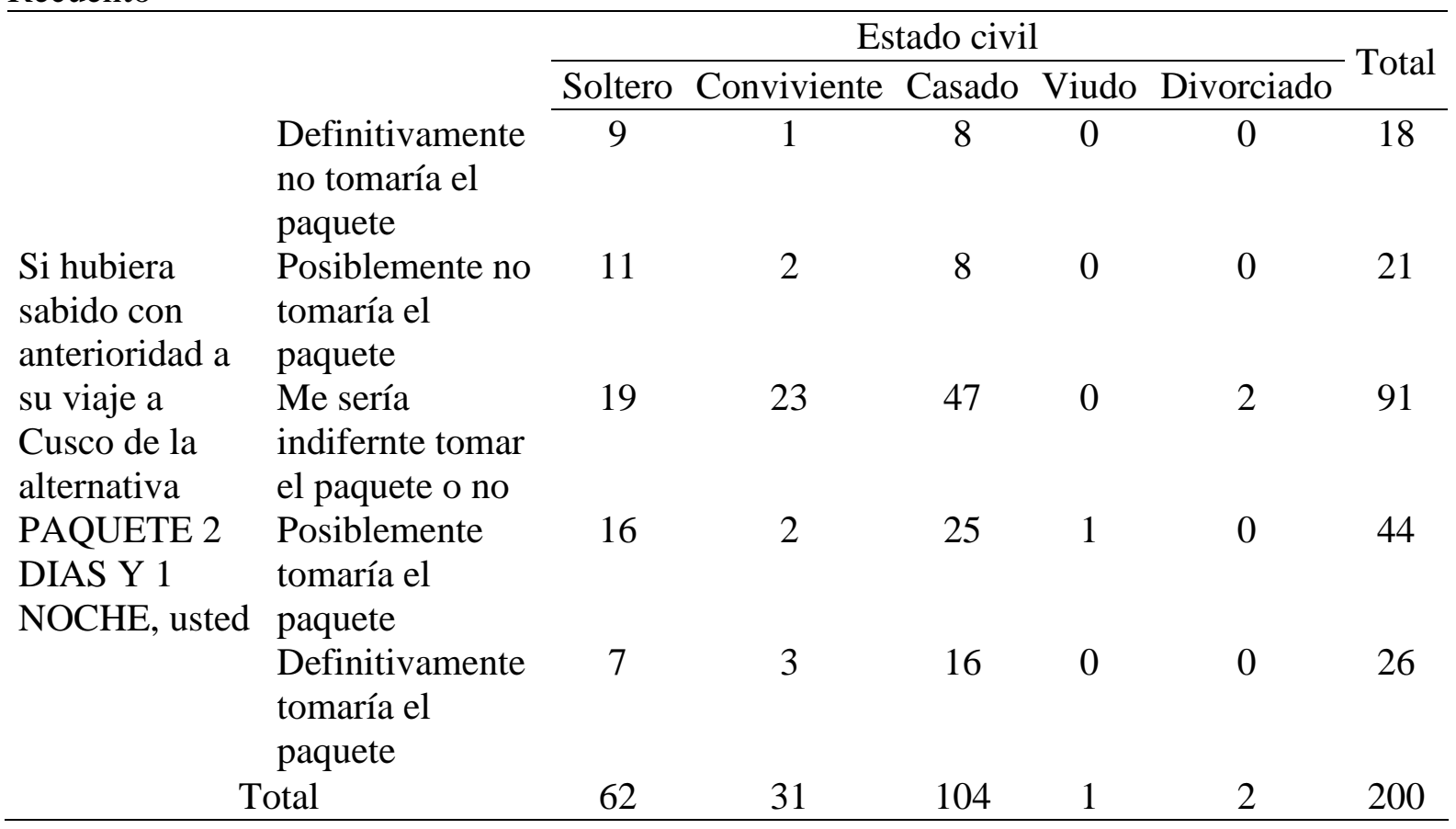

Si hubiera sabido con anterioridad a su viaje a Cusco de la alternativa PAQUETE 3 DIAS Y 2 NOCHES, usted*Género tabulación cruzada

Recuento

\begin{tabular}{|c|c|c|c|c|}
\hline & \multicolumn{2}{|c|}{ Género } & \multirow{2}{*}{ Total } \\
\hline & & Femenino & Masculino & \\
\hline \multirow{5}{*}{$\begin{array}{l}\text { Si hubiera sabido con } \\
\text { anterioridad a su viaje a } \\
\text { Cusco de la alternativa } \\
\text { PAQUETE } 3 \text { DIAS Y } 2 \\
\text { NOCHES, usted }\end{array}$} & $\begin{array}{l}\text { Definitivamente } \\
\text { no tomaría el } \\
\text { paquete }\end{array}$ & 19 & 9 & 28 \\
\hline & $\begin{array}{l}\text { Posiblemente no } \\
\text { tomaría el paquete }\end{array}$ & 16 & 19 & 35 \\
\hline & $\begin{array}{l}\text { Me sería } \\
\text { indiferente tomar } \\
\text { el paquete o no }\end{array}$ & 60 & 46 & 106 \\
\hline & $\begin{array}{l}\text { Posiblemente } \\
\text { tomaría el paquete }\end{array}$ & 13 & 2 & 15 \\
\hline & $\begin{array}{l}\text { Definitivamente } \\
\text { tomaría el paquete }\end{array}$ & 13 & 3 & 16 \\
\hline Total & & 121 & 79 & 200 \\
\hline
\end{tabular}


Si hubiera sabido con anterioridad a su viaje a Cusco de la alternativa PAQUETE 3 DIAS Y 2 NOCHES, usted*Rango de Edad tabulación cruzada

Recuento

\begin{tabular}{ccccccc}
\multicolumn{7}{c}{ Rango de Edad } \\
\cline { 1 - 5 } Menos & De & De & De & De & De & Total \\
de 20 & 21 a & 30 a & 40 a & 51 a & 60 a & \\
años & 29 & 39 & 50 & 59 & más & \\
& años & años & años & años & &
\end{tabular}

\begin{tabular}{|c|c|c|c|c|c|c|c|c|}
\hline & $\begin{array}{l}\text { Definitivamente } \\
\text { no tomaría el } \\
\text { paquete }\end{array}$ & 2 & 13 & 10 & 2 & 1 & 0 & 28 \\
\hline $\begin{array}{l}\text { Si hubiera sabido } \\
\text { con anterioridad a su }\end{array}$ & $\begin{array}{l}\text { Posiblemente no } \\
\text { tomaría el paquete }\end{array}$ & 2 & 17 & 13 & 3 & 0 & 0 & 35 \\
\hline $\begin{array}{l}\text { viaje a Cusco de la } \\
\text { alternativa } \\
\text { PAQUETE } 3 \text { DIAS }\end{array}$ & $\begin{array}{l}\text { Me sería } \\
\text { indiferente tomar } \\
\text { el paquete o no }\end{array}$ & 0 & 15 & 45 & 33 & 9 & 4 & 106 \\
\hline \multirow[t]{2}{*}{ Y 2 NOCHES, usted } & $\begin{array}{l}\text { Posiblemente } \\
\text { tomaría el paquete }\end{array}$ & 3 & 1 & 6 & 2 & 2 & 1 & 15 \\
\hline & $\begin{array}{l}\text { Definitivamente } \\
\text { tomaría el paquete }\end{array}$ & 0 & 0 & 3 & 9 & 3 & 1 & 16 \\
\hline Total & & 7 & 46 & 77 & 49 & 15 & 6 & 200 \\
\hline
\end{tabular}


Si hubiera sabido con anterioridad a su viaje a Cusco de la alternativa PAQUETE 3 DÍAS Y 2 NOCHES, usted*Nacionalidad tabulación cruzada

Recuento

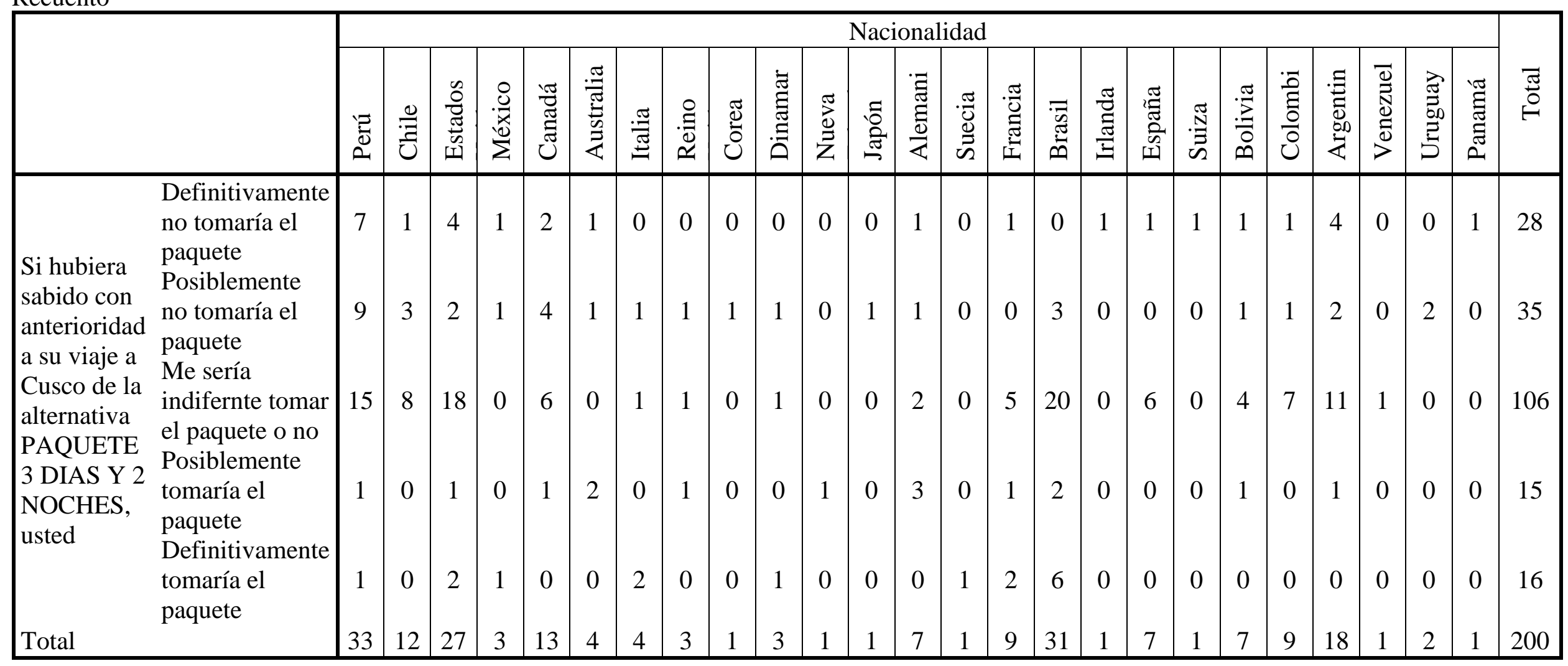


Si hubiera sabido con anterioridad a su viaje a Cusco de la alternativa PAQUETE 3 DÍAS Y 2 NOCHES, usted*Estado civil tabulación cruzada

Recuento

\begin{tabular}{|c|c|c|c|c|c|c|c|}
\hline & & \multicolumn{5}{|c|}{ Estado civil } & \multirow{2}{*}{ Total } \\
\hline & & Soltero & Conviviente & Casado & Viudo & Divorciado & \\
\hline \multirow{5}{*}{$\begin{array}{l}\text { Si hubiera } \\
\text { sabido con } \\
\text { anterioridad a } \\
\text { su viaje a } \\
\text { Cusco de la } \\
\text { alternativa } \\
\text { PAQUETE } 3 \\
\text { DIAS Y } 2 \\
\text { NOCHES, } \\
\text { usted }\end{array}$} & $\begin{array}{l}\text { Definitivamente } \\
\text { no tomaría el } \\
\text { paquete }\end{array}$ & 14 & 3 & 11 & 0 & 0 & 28 \\
\hline & $\begin{array}{l}\text { Posiblemente no } \\
\text { tomaría el } \\
\text { paquete }\end{array}$ & 18 & 4 & 11 & 1 & 1 & 35 \\
\hline & $\begin{array}{l}\text { Me sería } \\
\text { indiferente } \\
\text { tomar el paquete } \\
\text { o no }\end{array}$ & 23 & 23 & 59 & 0 & 1 & 106 \\
\hline & $\begin{array}{l}\text { Posiblemente } \\
\text { tomaría el } \\
\text { paquete }\end{array}$ & 6 & 0 & 9 & 0 & 0 & 15 \\
\hline & $\begin{array}{l}\text { Definitivamente } \\
\text { tomaría el } \\
\text { paquete }\end{array}$ & 1 & 1 & 14 & 0 & 0 & 16 \\
\hline Total & & 62 & 31 & 104 & 1 & 2 & 200 \\
\hline
\end{tabular}




\section{Anexo IX. \\ Encuesta agencia}

Buen día, mi nombre es somos alumnos de la Maestría de

Ciencias empresariales de la Universidad San Ignacio de Loyola. Estamos

NO

Sup

1. ¿En qué área de la agencia trabaja?
a) Administración
b) Marketing y ventas
c) Contabilidad y/o Finanzas
d) Recursos Humanos
e) Operaciones

2. ¿Cuál es su posición en la agencia?
a) Gerente
b) Supervisor, jefe
c) Vendedor
d) Analista
e) Atención al público (Guía, trasladista, chofer)

3. ¿Es usted quien participa de la toma de decisión en la selección de los proveedores de hospedaje?
a) $\mathrm{Si}$
b) No (Si su respuesta es NO terminar la encuesta).

4. ¿Cuáles son los principales circuitos que vende la agencia en Perú y en qué ciudades? (puede elegir más de una opción)

\begin{tabular}{|l|l|l|}
\hline \multicolumn{1}{|c|}{ Circuitos } & \multicolumn{1}{|c|}{ Ciudad } & \multicolumn{1}{c|}{ Ciudad } \\
\hline a) Circuito turístico sur altiplano & A Cusco & E \\
\hline b) Circuito turístico Fluvial amazónico & B & f \\
\hline c) Circuito turístico norte & c & g \\
\hline d) Circuito turístico central & D & h \\
\hline
\end{tabular}

5. ¿Por qué razones considera a estas ciudades como los destinos más vendidos en cada circuito? (puede marcar más de una respuesta)

\begin{tabular}{|l|c|c|c|c|c|}
\hline Ciudades & $\begin{array}{c}\text { Producto } \\
\text { turístico } \\
\text { desarrollado }\end{array}$ & $\begin{array}{c}\text { Tendencia } \\
\text { turística o } \\
\text { moda de } \\
\text { viajeros }\end{array}$ & $\begin{array}{c}\text { Alta } \\
\text { jerarquía } \\
\text { de } \\
\text { atractivo } \\
\mathrm{s}\end{array}$ & $\begin{array}{c}\text { Precio } \\
\text { de los } \\
\text { paquetes }\end{array}$ & $\begin{array}{c}\text { Otras } \\
\text { razones } \\
\text { Especifiqu } \\
\text { e: }\end{array}$ \\
\hline Ciudad Cusco & $\mathrm{Si}$ & $\mathrm{No}$ & $\mathrm{Si}$ & & \\
\hline Ciudad Puno & & $\mathrm{X}$ & & & \\
\hline Ciudad & & & & & \\
\hline Ciudad & & & & & \\
\hline
\end{tabular}

6. De acuerdo a los principales circuitos ofertados en la pregunta 4 ¿Cuál es la frecuencia de venta de dichos destinos?

\begin{tabular}{|l|l|l|l|l|}
\hline \multicolumn{1}{|c|}{ Frecuencia } & Diaria & Inter diaria & Semanal & Mensual \\
\hline a) Turístico sur altiplano & & & & \\
\hline b) Turístico Fluvial amazónico & & & & \\
\hline c) Turístico norte & & & & \\
\hline d) Turístico central & & & & \\
\hline
\end{tabular}

(De NO mencionar Cusco dentro de sus circuitos, finalizar la encuesta) 
7. De incluir Cusco dentro de sus circuitos, este se incluye al:

\begin{tabular}{|l|l|l|l|}
\hline a) Inicio de circuito & b) Final del circuito & c) Al intermedio & $\begin{array}{l}\text { d) Se vende como } \\
\text { destino único }\end{array}$ \\
\hline
\end{tabular}

8. ¿Qué factores influyen principalmente en su selección de proveedor de hospedaje en Cusco? Enumere las siguientes opciones siendo 1 el factor más influyente y 8 el menos influyente.

\begin{tabular}{|l|l|}
\hline Calidad del servicio & \\
\hline Ubicación & \\
\hline Tarifa corporativa & \\
\hline Instalaciones & \\
\hline Políticas de reservas & \\
\hline Políticas de cancelación & \\
\hline Flexibilidad & \\
\hline Número de habitaciones & \\
\hline
\end{tabular}

9. Entendiendo las alianzas comerciales como el acuerdo entre dos empresas, para brindarse facilidades comerciales mutuamente, $i s u$ agencia cuenta con alianzas o convenios comerciales con hospedajes en Cusco?
c. $\mathrm{Si}$
d. No (Si su respuesta es No pasar a pregunta 15).

10. En base a sus tres principales proveedores de hospedaje en Cusco ¿Qué tipo de alianzas o convenios comerciales mantiene? Puede marcar más de una:

\begin{tabular}{|l|l|l|l|l|l|}
\hline $\begin{array}{c}\text { Proveedor } \\
\text { de } \\
\text { hospedaje }\end{array}$ & $\begin{array}{c}\text { Tarifas } \\
\text { corporativas }\end{array}$ & Comisiones & $\begin{array}{c}\text { Habitaciones } \\
\text { Complementary }\end{array}$ & $\begin{array}{c}\text { Habitaciones } \\
\text { liberadas }\end{array}$ & otros \\
\hline 1. & & & & & \\
\hline 2. & & & & & \\
\hline 3. & & & & & \\
\hline
\end{tabular}

11. ¿Qué exige usted de estos proveedores de hospedaje para mantener estas alianzas? (puede marcar más de una)
a) Que no tenga alianza con otras agencias
b) Que tengan el sistema de reserva directa (Ejemplo: SABRE)
c) Que sean ambientalmente responsables
d) Que sean socialmente responsables con sus trabajadores
e) No les exijo nada
f) Otros, especificar:

12. En base a las tarifas que maneja con los proveedores anteriormente mencionados ¿Cuál es el promedio de costo (en dólares americanos) que la agencia paga por noche de hospedaje en una habitación simple?

\begin{tabular}{|c|c|c|l|c|}
\hline Proveedores & $\begin{array}{c}\text { Menos de USD } \\
50\end{array}$ & $\begin{array}{c}\text { Entre USD51- } \\
80\end{array}$ & Entre USD 81-120 & $\begin{array}{c}\text { Más de } \\
\text { USD121 }\end{array}$ \\
\hline & & & & \\
\hline & & & & \\
\hline & & & & \\
\hline
\end{tabular}


13. ¿Cuál es el promedio de noches de estadía de un turista en los hospedajes mencionados como principales proveedores?

\begin{tabular}{|l|l|l|l|}
\hline Proveedores & De 1 a 3 noches & De 4 a 7 noches & De 8 a 10 noches \\
\hline & & & \\
\hline & & & \\
\hline & & & \\
\hline
\end{tabular}

14. ¿Cuáles son los servicios que ofrece la agencia en Cusco? (marque con una X en cada servicio que su agencia brinda) puede marcar más de una opción

\begin{tabular}{|l|l|l|l|}
\hline & Traslados & & Guías profesionales \\
\hline & Recojo con trasladista & & Venta de tours \\
\hline $\begin{array}{l}\text { Venta de tickets de ingreso a } \\
\text { atractivos turísticos }\end{array}$ & & Reserva de Hospedaje \\
\hline Reserva de Restaurantes & & venta de boletos aéreos \\
\hline & Alquiler de equipos & & Alquiler de automóviles \\
\hline
\end{tabular}

15. ¿De qué nacionalidad son los turistas que atiende con mayor frecuencia su agencia? Pueden marcar más de una.
a) Estadounidense
b) Peruano
c) Chileno
d) Otros, especifique:

16. ¿Venden paquetes turísticos al poblado de Maras? O ¿incluyen a maras dentro de un paquete turístico al valle sagrado en Cusco?
a) Sí
No(Si su respuesta es No pasar a pregunta 23)

17. Respecto al tiempo de estadía, ¿Cuánto tiempo disponen los turistas en Maras?
a) Unas horas, como parte del Tour Valle Sagrado (pasar a pregunta 19)
b) Full-day (pasar a pregunta 19)
c) Dos días una noche
d) Mas de dos días

18. ¿Cuánto es el costo promedio para la agencia de un tour o paquete por día en Maras? (Hospedaje + Alimentación + Turismo).
a) Menos de $\$ 50$
b) Entre $\$ 51-\$ 100$
c) Entre $\$ 101-\$ 150$
d) Más de $\$ 151$

19. Cuál es el tipo de turismo que más vende, por favor marque con una $X$ (puede marcar más de una opción) y mencione dos actividades que considere principales en cada caso:

\begin{tabular}{|l|l|l|}
\hline \multicolumn{1}{|c|}{ Tipo de Turismo } & Actividad 1 & Actividad 2 \\
\hline Turismo tradicional & & \\
\hline Turismo de aventura & & \\
\hline Turismo vivencial & & \\
\hline Turismo místico & & \\
\hline Otros ¿Cuál? & & \\
\hline
\end{tabular}


20. De contar con proveedores en Maras, mencione el nombre o razón social en cada caso y marque ¿cuál fue la razón por la cual lo eligió?

\begin{tabular}{|l|l|l|l|l|}
\cline { 3 - 5 } \multicolumn{2}{l|}{} & Razones & \multicolumn{2}{l|}{} \\
\hline Servicio & Nombre del proveedor & Por ser el Único & Mejores servicios & Por la tarifa \\
\hline Hospedaje & & & & \\
\hline Testaurante & & & & \\
\hline Transporte & & & & \\
\hline
\end{tabular}

21. Respecto a la alimentación, sea con proveedores o de manera independiente, ¿qué servicio considera para su paquete a Maras? (siendo 1 el servicio que más utiliza en su paquete y 5 el menos utilizado)

Snacks o refrigerios

Picknic en la zona

Restaurante de comida típica de la zona

Restaurante de comida orgánica

No ofrece el servicio de alimentación

22. En una escala descendente siendo 1 como lo más importante y 5 como lo menos importante enumere las ventajas y desventajas del poblado de Maras. Tome en cuenta que Ventajas: 1 principal ventaja y Desventaja: 1 principal desventaja.

\begin{tabular}{|l|l|l|}
\cline { 2 - 3 } \multicolumn{1}{l|}{} & Ventaja & Desventaja \\
\hline Pueblo tradicional & & \\
\hline Destino por descubrir & & \\
\hline Aventura & & \\
\hline Organización & & \\
\hline Expresiones culturales & & \\
\hline Infraestructura & & \\
\hline Atención al cliente & & \\
\hline Ubicación & & \\
\hline Accesibilidad & & \\
\hline
\end{tabular}

23. ¿Brindan actualmente paquetes de turismo vivencial?
a) $\mathrm{Si}$
b) No (Si su respuesta es No pasar a pregunta 27).

24. Al ofertar este tipo de turismo, este se promociona como una actividad: (puede marcar más de una opción)

a) Rural, estadía y convivencia en zonas alejadas

b) Social benéfico a favor de la comunidad receptora

c) Urbana, usos y costumbres diarias de un poblador local en la ciudad

25. ¿Qué poblaciones le brindan turismo vivencial?

a) Raqchy b) Patacancha c) Misminay d) Ocongatee) otros 
26. ¿Cuál es el costo promedio por día en dólares americanos de un paquete que incluya turismo vivencial, y que actividades se incluyen dentro de este paquete?

\begin{tabular}{|l|l|l|l|l|}
\hline \multicolumn{4}{|l|}{ Expresado en US\$ } \\
\hline Actividades/Rango & $\begin{array}{l}\text { Menor a } \\
\mathbf{5 0}\end{array}$ & $\begin{array}{l}\text { Entre 51 } \\
\mathbf{y} 80\end{array}$ & $\begin{array}{l}\text { Entre 81 y } \\
\mathbf{1 0 0}\end{array}$ & $\begin{array}{l}\text { Más de } \\
\mathbf{1 0 0}\end{array}$ \\
\hline Pernocte en una comunidad & & & & \\
\hline Preparación de alimentos & & & & \\
\hline Participación en ceremonias o rituales & & & & \\
\hline Participación en actividades agrícolas & & & & \\
\hline Participación en tejidos & & & & \\
\hline $\begin{array}{l}\text { Vestimenta al turista como poblador } \\
\text { local }\end{array}$ & & & & \\
\hline
\end{tabular}

27. En orden descendente de 1 como mayor frecuencia y 3 como menor frecuencia, mencione tres proveedores de hospedaje con denominación albergue con los que trabaja su agencia de viajes:
a)
b)
c)

28. ¿Para usted, que elementos se deberían incluir en un albergue vivencial?

\begin{tabular}{|l|l|l|l|l|l|}
\hline Enunciados & $\begin{array}{c}\text { Totalmente en } \\
\text { desacuerdo }\end{array}$ & $\begin{array}{c}\text { en } \\
\text { desacuerdo }\end{array}$ & $\begin{array}{c}\text { Ni de acuerdo } \\
\text { ni en } \\
\text { desacuerdo }\end{array}$ & $\begin{array}{c}\text { de } \\
\text { acuerdo }\end{array}$ & $\begin{array}{c}\text { Totalmente } \\
\text { de acuerdo }\end{array}$ \\
\hline $\begin{array}{l}\text { elementos } \\
\text { rústicos }\end{array}$ & & & & & \\
\hline $\begin{array}{l}\text { decoración } \\
\text { típica de la } \\
\text { zona }\end{array}$ & & & & & \\
\hline $\begin{array}{l}\text { arquitectura } \\
\text { tradicional }\end{array}$ & & & & & \\
\hline tecnología & & & & & \\
\hline $\begin{array}{l}\text { personal } \\
\text { capacitado }\end{array}$ & & & & & \\
\hline $\begin{array}{l}\text { instalaciones } \\
\text { modernas }\end{array}$ & & & & & \\
\hline
\end{tabular}

29. Si un nuevo albergue vivencial ubicado en Maras en Urubamba, ofreciera las siguientes características: (MOSTRAR FOTOS)

\begin{tabular}{|l|c|c|c|}
\hline Actividades & Full Day & $2 \mathrm{~d} / 1 \mathrm{n}$ & $3 \mathrm{~d} / 2 \mathrm{n}$ \\
\hline Paseo en Cuatrimoto & $\mathrm{X}$ & $\mathrm{X}$ & $\mathrm{X}$ \\
\hline Visita al Salar y cosecha de sal & $\mathrm{X}$ & $\mathrm{X}$ & $\mathrm{X}$ \\
\hline Visita al pueblo & $\mathrm{X}$ & $\mathrm{X}$ & $\mathrm{X}$ \\
\hline $\begin{array}{l}\text { Preparación y servido del Almuerzo en comunidad, con } \\
\text { comida orgánica. }\end{array}$ & $\mathrm{X}$ & $\mathrm{X}$ & $\mathrm{X}$ \\
\hline Visita a Moray & $\mathrm{X}$ & $\mathrm{X}$ & $\mathrm{X}$ \\
\hline Horneado de pan & & $\mathrm{X}$ & $\mathrm{X}$ \\
\hline Baños energéticos & & $X$ & $X$ \\
\hline
\end{tabular}




\begin{tabular}{|c|c|c|}
\hline $\begin{array}{l}\text { Preparación y servido de la cena en comunidad, con comida } \\
\text { orgánica. }\end{array}$ & $\mathrm{X}$ & $\mathrm{X}$ \\
\hline Fogata al aire libre & $\mathrm{X}$ & $\mathrm{X}$ \\
\hline Saludo al amanecer & $\mathrm{X}$ & $\mathrm{X}$ \\
\hline Desayuno tradicional con panes horneados en comunidad & $\mathrm{X}$ & $\mathrm{X}$ \\
\hline Taller de preparación de chicha & & $\mathrm{X}$ \\
\hline Almuerzo tipo picnic & & $\mathrm{X}$ \\
\hline Ceremonia de agradecimiento a la tierra & & $\mathrm{X}$ \\
\hline Renovación mística de votos & & $\mathrm{X}$ \\
\hline Relatos andinos junto a la chimenea & & $\mathrm{X}$ \\
\hline
\end{tabular}

30. Después de haber visto el hospedaje en Maras y los paquetes usted:

\begin{tabular}{|l|c|c|c|}
\hline & $\begin{array}{c}\text { Paquete Full } \\
\text { Day } \\
\text { USD190 }\end{array}$ & $\begin{array}{c}\text { Paquete } \\
\text { 2D/1N } \\
\text { USD 330 }\end{array}$ & $\begin{array}{c}\text { Paquete } \\
\text { 3D/2N } \\
\text { USD 440 }\end{array}$ \\
\hline Definitivamente vendería el servicio & & & \\
\hline Posiblemente vendería el servicio & & & \\
\hline $\begin{array}{l}\text { Me seria indiferente vender o no el } \\
\text { servicio }\end{array}$ & & & \\
\hline Posiblemente no vendería el servicio & & & \\
\hline $\begin{array}{l}\text { Definitivamente no vendería el } \\
\text { servicio }\end{array}$ & & & \\
\hline
\end{tabular}

\section{Datos de control al final del instrumento.}

A) Nombre de la Agencia de Viajes:

C) ¿Cuántos empleados tiene la agencia de turismo?
a) Menos de 50
b) Entre 51 y 100
c) Entre 101 y 200
d) Más de 200

E) ¿Cuántos clientes por turismo receptivos atienden al mes?
a) Menos de 100
b) Entre 101 y 400
c) Entre 401 y 700
d) Más del 701

B) ¿Cuántas sedes tiene la Agencia en Perú?
a) 1b) 2c) 3 d) 4 o más

D) ¿Cuál es la especialidad de la agencia de viajes?
a) Turismo tradicional
b) Ecoturismo
c) Turismo vivencial
d) Corporativo

F) ¿La agencia cuenta con IATA?
a) Sí b) No

G) Clasificación de la agencia
a) Operador de turismo
b) Mayorista
c) Minorista 
Anexo X.

\section{Resultados encuesta agencias}

Resumen de procesamiento de casos

\begin{tabular}{|c|c|c|c|c|c|c|}
\hline & \multicolumn{6}{|c|}{ Casos } \\
\hline & \multicolumn{2}{|r|}{ Válido } & \multicolumn{2}{|r|}{ Perdidos } & \multicolumn{2}{|r|}{ Total } \\
\hline & $\mathrm{N}$ & Porcentaje & $\mathrm{N}$ & Porcentaje & $\mathrm{N}$ & Porcentaje \\
\hline $\begin{array}{l}\text { Después de haber visto el hospedaje en } \\
\text { Maras y los paquetes usted - Full day * } \\
\text { ¿Cuántas sedes tiene la Agencia en Perú? }\end{array}$ & 77 & $100,0 \%$ & 0 & $0,0 \%$ & 77 & $100,0 \%$ \\
\hline $\begin{array}{l}\text { Después de haber visto el hospedaje en } \\
\text { Maras y los paquetes usted - Full day * } \\
\text { ¿Cuántos empleados tiene la agencia de } \\
\text { turismo? }\end{array}$ & 77 & $100,0 \%$ & 0 & $0,0 \%$ & 77 & $100,0 \%$ \\
\hline $\begin{array}{l}\text { Después de haber visto el hospedaje en } \\
\text { Maras y los paquetes usted - Full day } * \\
\text { ¿Cuántos clientes por turismo receptivos } \\
\text { atienden al mes? }\end{array}$ & 77 & $100,0 \%$ & 0 & $0,0 \%$ & 77 & $100,0 \%$ \\
\hline $\begin{array}{l}\text { Después de haber visto el hospedaje en } \\
\text { Maras y los paquetes usted - Full day * ¿La } \\
\text { agencia cuenta con IATA? }\end{array}$ & 77 & $100,0 \%$ & 0 & $0,0 \%$ & 77 & $100,0 \%$ \\
\hline $\begin{array}{l}\text { Después de haber visto el hospedaje en } \\
\text { Maras y los paquetes usted - Full day * } \\
\text { Clasificación de la agencia }\end{array}$ & 77 & $100,0 \%$ & 0 & $0,0 \%$ & 77 & $100,0 \%$ \\
\hline $\begin{array}{l}\text { Después de haber visto el hospedaje en } \\
\text { Maras y los paquetes usted - 2D y } 1 \mathrm{~N} * \\
\text { ¿Cuántas sedes tiene la Agencia en Perú? }\end{array}$ & 77 & $100,0 \%$ & 0 & $0,0 \%$ & 77 & $100,0 \%$ \\
\hline $\begin{array}{l}\text { Después de haber visto el hospedaje en } \\
\text { Maras y los paquetes usted - 2D y } 1 \mathrm{~N} * \\
\text { ¿Cuántos empleados tiene la agencia de } \\
\text { turismo? }\end{array}$ & 77 & $100,0 \%$ & 0 & $0,0 \%$ & 77 & $100,0 \%$ \\
\hline $\begin{array}{l}\text { Después de haber visto el hospedaje en } \\
\text { Maras y los paquetes usted - } 2 \mathrm{D} \text { y } 1 \mathrm{~N} * \\
\text { ¿Cuántos clientes por turismo receptivos } \\
\text { atienden al mes? }\end{array}$ & 77 & $100,0 \%$ & 0 & $0,0 \%$ & 77 & $100,0 \%$ \\
\hline $\begin{array}{l}\text { Después de haber visto el hospedaje en } \\
\text { Maras y los paquetes usted - } 2 \mathrm{D} \text { y } 1 \mathrm{~N} * \text { ¿La } \\
\text { agencia cuenta con IATA? }\end{array}$ & 77 & $100,0 \%$ & 0 & $0,0 \%$ & 77 & $100,0 \%$ \\
\hline $\begin{array}{l}\text { Después de haber visto el hospedaje en } \\
\text { Maras y los paquetes usted - } 2 \mathrm{D} \text { y } 1 \mathrm{~N} * \\
\text { Clasificación de la agencia }\end{array}$ & 77 & $100,0 \%$ & 0 & $0,0 \%$ & 77 & $100,0 \%$ \\
\hline $\begin{array}{l}\text { Después de haber visto el hospedaje en } \\
\text { Maras y los paquetes usted - 3D y } 2 \mathrm{~N} * \\
\text { ¿Cuántas sedes tiene la Agencia en Perú? }\end{array}$ & 77 & $100,0 \%$ & 0 & $0,0 \%$ & 77 & $100,0 \%$ \\
\hline $\begin{array}{l}\text { Después de haber visto el hospedaje en } \\
\text { Maras y los paquetes usted - 3D y } 2 \mathrm{~N} * \\
\text { ¿Cuántos empleados tiene la agencia de } \\
\text { turismo? }\end{array}$ & 77 & $100,0 \%$ & 0 & $0,0 \%$ & 77 & $100,0 \%$ \\
\hline
\end{tabular}




\begin{tabular}{lcccccc}
\hline $\begin{array}{l}\text { Después de haber visto el hospedaje en } \\
\text { Maras y los paquetes usted - 3D y 2N * } \\
\text { ¿Cuántos clientes por turismo receptivos } \\
\text { atienden al mes? }\end{array}$ & 77 100,0\% & 0 & $0,0 \%$ & 77 & $100,0 \%$ \\
$\begin{array}{l}\text { Después de haber visto el hospedaje en } \\
\text { Maras y los paquetes usted - 3D y 2N * ¿La } \\
\text { agencia cuenta con IATA? }\end{array}$ & 77 & $100,0 \%$ & 0 & $0,0 \%$ & 77 & $100,0 \%$ \\
$\begin{array}{l}\text { Después de haber visto el hospedaje en } \\
\text { Maras y los paquetes usted - 3D y 2N * }\end{array}$ & 77 & $100,0 \%$ & 0 & $0,0 \%$ & 77 & $100,0 \%$ \\
Clasificación de la agencia & & & & & & \\
\hline
\end{tabular}

Después de haber visto el hospedaje en Maras y los paquetes usted - Full day* ¿Cuántas sedes tiene la Agencia en Perú? tabulación cruzada

Recuento

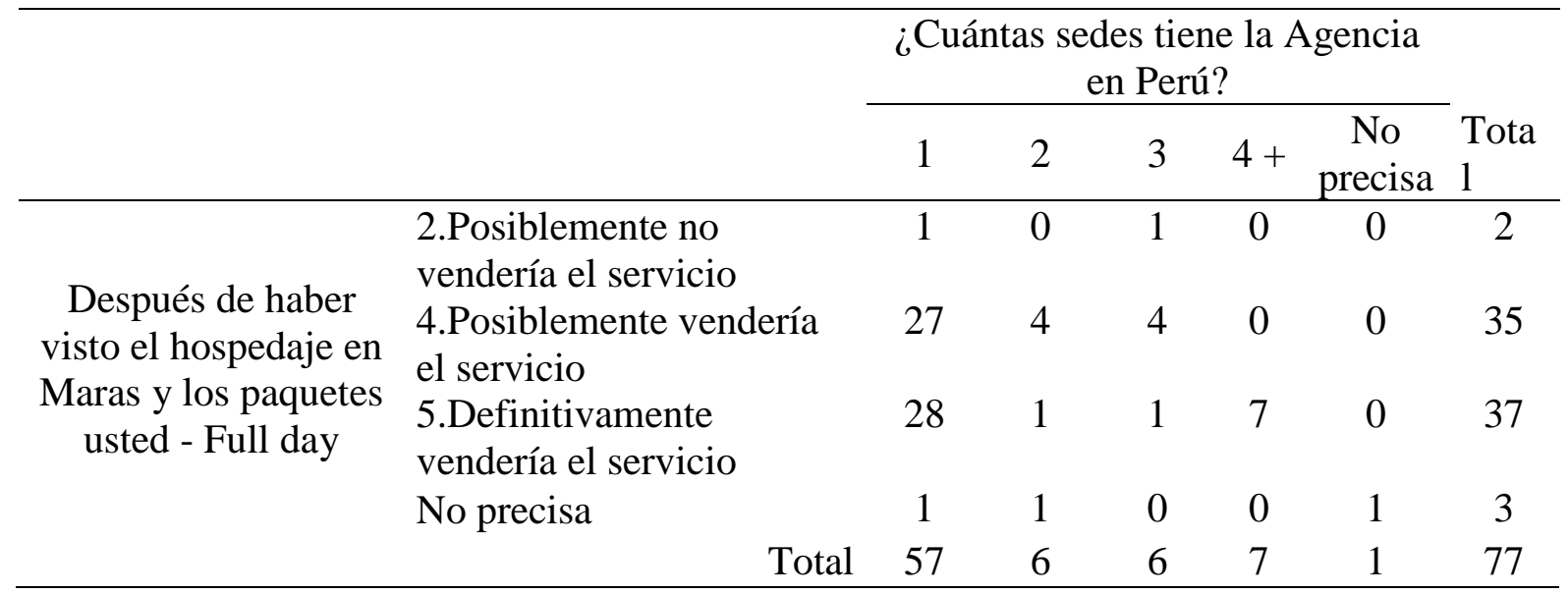

Después de haber visto el hospedaje en Maras y los paquetes usted - Full day*¿Cuántos empleados tiene la agencia de turismo? tabulación cruzada

Recuento

\begin{tabular}{llcccc}
\hline & & \multicolumn{3}{c}{ ¿Cuántos empleados tiene la } \\
& & \multicolumn{3}{c}{ agencia de turismo? } & Total \\
& & $\begin{array}{c}\text { Menos de } \\
\text { Entre 51 } \\
\text { 2.Posiblemente no }\end{array}$ & $\begin{array}{c}\text { Entre 101 } \\
\text { y 80 }\end{array}$ & y 200 & \\
\hline $\begin{array}{l}\text { Después de haber } \\
\text { visto el hospedaje en }\end{array}$ & $\begin{array}{l}\text { 4.Posiblemente vendería } \\
\text { Maras y los paquetes }\end{array}$ & 27 & 4 & 0 & 2 \\
usted - Full day & $\begin{array}{l}\text { 5.Definitivamente } \\
\text { vendería el servicio }\end{array}$ & 28 & 6 & 3 & 35 \\
No precisa & 3 & 0 & 0 & 3 \\
Total & & 60 & 10 & 7 & 77 \\
\hline
\end{tabular}


Después de haber visto el hospedaje en Maras y los paquetes usted - Full day*:Cuántos clientes por turismo receptivos atienden al mes? tabulación cruzada

Recuento

\begin{tabular}{llcccccc}
\hline & & \multicolumn{6}{c}{ ¿Cuántos clientes por turismo receptivos } \\
\cline { 3 - 7 } & & $\begin{array}{c}\text { Menos de } \\
100\end{array}$ & $\begin{array}{c}\text { Entre } \\
101 \text { y } \\
400\end{array}$ & $\begin{array}{c}\text { Entre } 401 \\
\text { y 700 }\end{array}$ & $\begin{array}{c}\text { Mas de } \\
701\end{array}$ & $\begin{array}{c}\text { No } \\
\text { precisa }\end{array}$ & Total \\
\hline $\begin{array}{l}\text { Después de haber } \\
\text { visto el } \\
\text { hospedaje en }\end{array}$ & $\begin{array}{l}\text { 2.Posiblemente no } \\
\text { vendería el servicio }\end{array}$ & 0 & 2 & 0 & 0 & 0 & 2 \\
$\begin{array}{l}\text { 4.Posiblemente } \\
\text { varas y los }\end{array}$ & 9 & 12 & 6 & 8 & 0 & 35 \\
$\begin{array}{l}\text { vendería el servicio } \\
\text { Full day }\end{array}$ & $\begin{array}{l}\text { 5.Definitivamente } \\
\text { vendería el servicio }\end{array}$ & 17 & 11 & 5 & 3 & 1 & 37 \\
Total & No precisa & 1 & 0 & 0 & 1 & 1 & 3 \\
\hline
\end{tabular}

Después de haber visto el hospedaje en Maras y los paquetes usted - Full day* ¿La agencia cuenta con IATA? tabulación cruzada

Recuento

\begin{tabular}{|c|c|c|c|c|c|}
\hline & \multicolumn{3}{|c|}{ ¿La agencia cuenta con IATA? } & \multirow[b]{2}{*}{ Total } \\
\hline & & $\mathrm{Si}$ & No & $\begin{array}{c}\text { No } \\
\text { precisa }\end{array}$ & \\
\hline Después de haber & $\begin{array}{l}\text { 2.Posiblemente no } \\
\text { vendería el servicio }\end{array}$ & 0 & 2 & 0 & 2 \\
\hline $\begin{array}{l}\text { visto el hospedaje } \\
\text { en Maras y los }\end{array}$ & $\begin{array}{l}\text { 4.Posiblemente vendería } \\
\text { el servicio }\end{array}$ & 3 & 25 & 7 & 35 \\
\hline $\begin{array}{l}\text { paquetes usted - } \\
\text { Full day }\end{array}$ & $\begin{array}{l}\text { 5.Definitivamente } \\
\text { vendería el servicio }\end{array}$ & 11 & 23 & 3 & 37 \\
\hline & No precisa & 0 & 2 & 1 & 3 \\
\hline Total & & 14 & 52 & 11 & 77 \\
\hline
\end{tabular}

Después de haber visto el hospedaje en Maras y los paquetes usted - Full day*Clasificación de la agencia tabulación cruzada

Recuento

\begin{tabular}{llccccc}
\hline & & \multicolumn{3}{c}{ Clasificación de la agencia } & \\
\cline { 3 - 6 } & & $\begin{array}{c}\text { Operador } \\
\text { de turismo }\end{array}$ & Mayorista & Minorista & $\begin{array}{c}\text { No } \\
\text { precisa }\end{array}$ & Total \\
\hline $\begin{array}{l}\text { Después de haber } \\
\text { visto el hospedaje }\end{array}$ & $\begin{array}{l}\text { 2.Posiblemente no } \\
\text { vendería el servicio }\end{array}$ & 2 & 0 & 0 & 0 & 2 \\
$\begin{array}{l}\text { 4.Posiblemente } \\
\text { vendería el servicio }\end{array}$ & 26 & 6 & 3 & 0 & 35 \\
paquetes y los & $\begin{array}{l}\text { vented - } \\
\text { 5.Definitivamente }\end{array}$ & 25 & 4 & 8 & 0 & 37 \\
vendería el servicio & No precisa & 0 & 0 & 2 & 1 & 3 \\
Total & 53 & 10 & 13 & 1 & 77 \\
\hline
\end{tabular}

*Poner como conlusión de este cuadro que en su mayoría son operadores y por eso nos vamos a enfocar en ellos (reunión con Vero 28-02-17) 
Después de haber visto el hospedaje en Maras y los paquetes usted - 2D y $1 N^{*}$ ¿Cuántas sedes tiene la Agencia en Perú? tabulación cruzada

Recuento

\begin{tabular}{|c|c|c|c|c|c|c|c|}
\hline & \multicolumn{5}{|c|}{ ¿Cuántas sedes tiene la Agencia en Perú? } & \multirow[b]{2}{*}{ Total } \\
\hline & & 1 & 2 & 3 & $\begin{array}{l}40 \\
\text { màs }\end{array}$ & $\begin{array}{c}\text { No } \\
\text { precisa }\end{array}$ & \\
\hline \multirow{6}{*}{$\begin{array}{l}\text { Después de } \\
\text { haber visto el } \\
\text { hospedaje en } \\
\text { Maras y los } \\
\text { paquetes usted } \\
\text { - 2D y } 1 \mathrm{~N}\end{array}$} & $\begin{array}{l}\text { 1.Definitivamente } \\
\text { no vendería el } \\
\text { servicio }\end{array}$ & 2 & 0 & 0 & 0 & 0 & 2 \\
\hline & $\begin{array}{l}\text { 2.Posiblemente } \\
\text { no vendería el } \\
\text { servicio }\end{array}$ & 5 & 0 & 1 & 0 & 0 & 6 \\
\hline & $\begin{array}{l}\text { 3.Me sería } \\
\text { indiferente } \\
\text { vender o no el } \\
\text { servicio }\end{array}$ & 7 & 0 & 0 & 0 & 0 & 7 \\
\hline & $\begin{array}{l}\text { 4.Posiblemente } \\
\text { vendería el } \\
\text { servicio }\end{array}$ & 22 & 4 & 1 & 3 & 0 & 30 \\
\hline & $\begin{array}{l}\text { 5.Definitivamente } \\
\text { vendería el } \\
\text { servicio }\end{array}$ & 14 & 1 & 2 & 4 & 0 & 21 \\
\hline & No precisa & 7 & 1 & 2 & 0 & 1 & 11 \\
\hline Total & & 57 & 6 & 6 & 7 & 1 & 77 \\
\hline
\end{tabular}

Después de haber visto el hospedaje en Maras y los paquetes usted - 2D y 1N*¿Cuántos empleados tiene la agencia de turismo? tabulación cruzada

Recuento

\begin{tabular}{|c|c|c|c|c|c|}
\hline & & \multicolumn{3}{|c|}{$\begin{array}{c}\text { ¿Cuántos empleados tiene la agencia } \\
\text { de turismo? }\end{array}$} & \multirow{2}{*}{ Total } \\
\hline & & $\begin{array}{l}\text { Menos de } \\
50\end{array}$ & $\begin{array}{l}\text { Entre } 51 \mathrm{y} \\
\quad 80\end{array}$ & $\begin{array}{l}\text { Entre } 101 \text { y } \\
200\end{array}$ & \\
\hline \multirow{6}{*}{$\begin{array}{l}\text { Después de haber } \\
\text { visto el hospedaje } \\
\text { en Maras y los } \\
\text { paquetes usted - } \\
2 \mathrm{D} \text { y } 1 \mathrm{~N}\end{array}$} & $\begin{array}{l}\text { 1.Definitivamente no } \\
\text { vendería el servicio }\end{array}$ & 2 & 0 & 0 & 2 \\
\hline & $\begin{array}{l}\text { 2.Posiblemente no } \\
\text { vendería el servicio }\end{array}$ & 6 & 0 & 0 & 6 \\
\hline & $\begin{array}{l}\text { 3.Me sería indiferente } \\
\text { vender o no el } \\
\text { servicio }\end{array}$ & 6 & 1 & 0 & 7 \\
\hline & $\begin{array}{l}\text { 4.Posiblemente } \\
\text { vendería el servicio }\end{array}$ & 21 & 5 & 4 & 30 \\
\hline & $\begin{array}{l}\text { 5.Definitivamente } \\
\text { vendería el servicio }\end{array}$ & 15 & 4 & 2 & 21 \\
\hline & No precisa & 10 & 0 & 1 & 11 \\
\hline Total & & 60 & 10 & 7 & 77 \\
\hline
\end{tabular}


Después de haber visto el hospedaje en Maras y los paquetes usted - 2D y 1N* ¿Cuántos clientes por turismo receptivos atienden al mes? tabulación cruzada

Recuento

\begin{tabular}{|c|c|c|c|c|c|c|c|}
\hline & \multicolumn{5}{|c|}{$\begin{array}{l}\text { ¿Cuántos clientes por turismo receptivos } \\
\text { atienden al mes? }\end{array}$} & \multirow[b]{2}{*}{ Total } \\
\hline & & $\begin{array}{l}\text { Menos } \\
\text { de } 100\end{array}$ & $\begin{array}{l}\text { Entre } 101 \\
\text { y } 400\end{array}$ & $\begin{array}{c}\text { Entre } \\
401 \mathrm{y} \\
700 \\
\end{array}$ & $\begin{array}{c}\text { Mas } \\
\text { de } 701\end{array}$ & $\begin{array}{c}\text { No } \\
\text { precisa }\end{array}$ & \\
\hline \multirow{6}{*}{$\begin{array}{l}\text { Después de } \\
\text { haber visto el } \\
\text { hospedaje en } \\
\text { Maras y los } \\
\text { paquetes usted } \\
\text { - 2D y 1N }\end{array}$} & $\begin{array}{l}\text { 1.Definitivamente } \\
\text { no vendería el } \\
\text { servicio }\end{array}$ & 2 & 0 & 0 & 0 & 0 & 2 \\
\hline & $\begin{array}{l}\text { 2.Posiblemente } \\
\text { no vendería el } \\
\text { servicio }\end{array}$ & 3 & 2 & 1 & 0 & 0 & 6 \\
\hline & $\begin{array}{l}\text { 3.Me sería } \\
\text { indiferente } \\
\text { vender o no el } \\
\text { servicio }\end{array}$ & 4 & 2 & 1 & 0 & 0 & 7 \\
\hline & $\begin{array}{l}\text { 4.Posiblemente } \\
\text { vendería el } \\
\text { servicio }\end{array}$ & 10 & 7 & 6 & 6 & 1 & 30 \\
\hline & $\begin{array}{l}\text { 5.Definitivamente } \\
\text { vendería el } \\
\text { servicio }\end{array}$ & 7 & 12 & 0 & 2 & 0 & 21 \\
\hline & No precisa & 1 & 2 & 3 & 4 & 1 & 11 \\
\hline Total & & 27 & 25 & 11 & 12 & 2 & 77 \\
\hline
\end{tabular}

Después de haber visto el hospedaje en Maras y los paquetes usted - 2D y 1N* ¿La agencia cuenta con IATA? tabulación cruzada

Recuento

\begin{tabular}{|c|c|c|c|c|c|}
\hline & & \multicolumn{3}{|c|}{$\begin{array}{c}\text { ¿La agencia cuenta con } \\
\text { IATA? }\end{array}$} & \multirow[b]{2}{*}{ Total } \\
\hline & & $\mathrm{Si}$ & No & $\begin{array}{l}\text { No } \\
\text { precisa }\end{array}$ & \\
\hline \multirow{6}{*}{$\begin{array}{l}\text { Después de haber } \\
\text { visto el hospedaje en } \\
\text { Maras y los paquetes } \\
\text { usted - } 2 \mathrm{D} \text { y } 1 \mathrm{~N}\end{array}$} & $\begin{array}{l}\text { 1.Definitivamente no vendería } \\
\text { el servicio }\end{array}$ & 0 & 2 & 0 & 2 \\
\hline & $\begin{array}{l}\text { 2.Posiblemente no vendería el } \\
\text { servicio }\end{array}$ & 0 & 6 & 0 & 6 \\
\hline & $\begin{array}{l}\text { 3.Me sería indiferente vender } \\
\text { o no el servicio }\end{array}$ & 1 & 5 & 1 & 7 \\
\hline & $\begin{array}{l}\text { 4.Posiblemente vendería el } \\
\text { servicio }\end{array}$ & 4 & 21 & 5 & 30 \\
\hline & $\begin{array}{l}\text { 5.Definitivamente vendería el } \\
\text { servicio }\end{array}$ & 8 & 12 & 1 & 21 \\
\hline & No precisa & 1 & 6 & 4 & 11 \\
\hline Total & & 14 & 52 & 11 & 77 \\
\hline
\end{tabular}


Después de haber visto el hospedaje en Maras y los paquetes usted - 2D y 1N*Clasificación de la agencia tabulación cruzada

Recuento

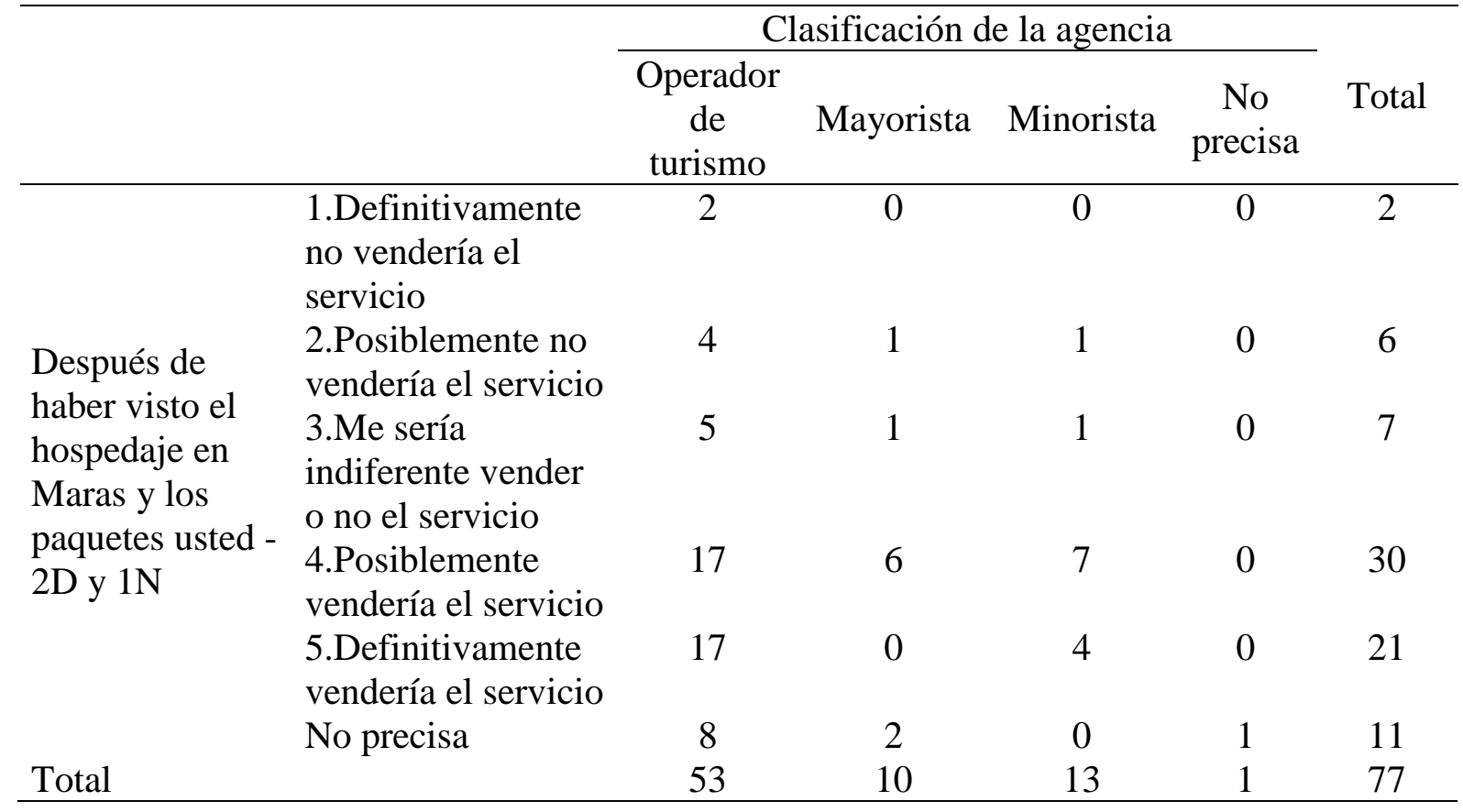

Después de haber visto el hospedaje en Maras y los paquetes usted - 3D y 2N* ¿Cuántas sedes tiene la Agencia en Perú? tabulación cruzada

Recuento

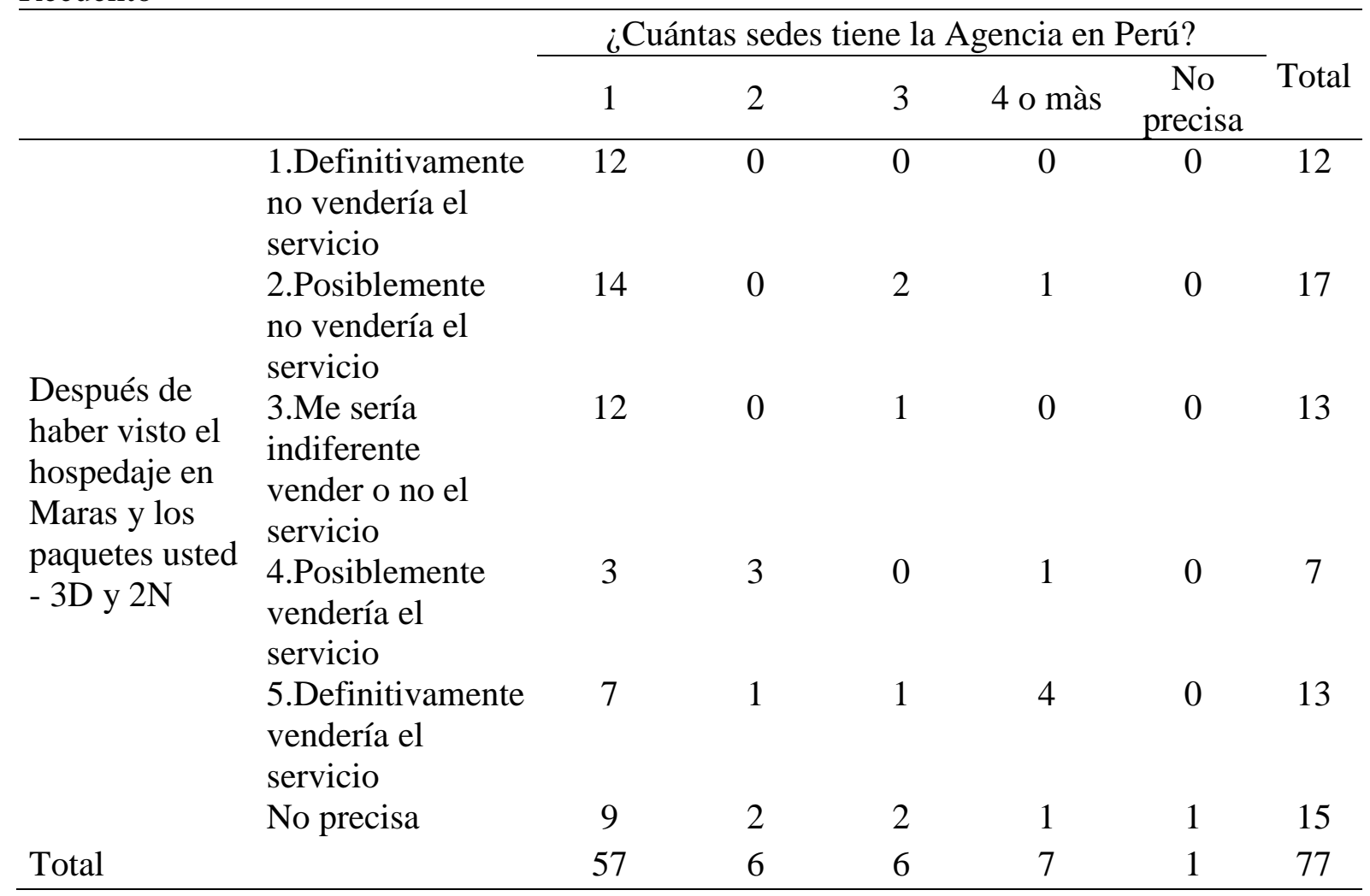


Después de haber visto el hospedaje en Maras y los paquetes usted - 3D y 2N* ¿Cuántos empleados tiene la agencia de turismo? tabulación cruzada

Recuento

Después de haber

visto el hospedaje en Maras y los paquetes usted $3 \mathrm{D}$ y $2 \mathrm{~N}$

Total

¿Cuántos empleados tiene la agencia de turismo?

Menos de Entre 51 y Entre 101 y Total

$\begin{array}{lll}50 & 80 & 200\end{array}$

1.Definitivamente no

12

0

0

vendería el servicio

2.Posiblemente no vendería el servicio

13

4

0

3.Me sería indiferente

10

3

0

vender o no el

servicio

4.Posiblemente vendería el servicio

5.Definitivamente vendería el servicio

No precisa

$\begin{array}{cccc}4 & 0 & 3 & 7 \\ 8 & 3 & 2 & 13 \\ 13 & 0 & 2 & 15 \\ 60 & 10 & 7 & 77\end{array}$

Después de haber visto el hospedaje en Maras y los paquetes usted - 3D y 2N* ¿Cuántos clientes por turismo receptivos atienden al mes? tabulación cruzada

Recuento

\begin{tabular}{|c|c|c|c|c|c|c|c|}
\hline & & \multicolumn{5}{|c|}{$\begin{array}{l}\text { ¿Cuántos clientes por turismo receptivos } \\
\text { atienden al mes? }\end{array}$} & \multirow[b]{2}{*}{ Total } \\
\hline & & $\begin{array}{l}\text { Menos } \\
\text { de } 100\end{array}$ & $\begin{array}{c}\text { Entre } 101 \\
\text { y } 400\end{array}$ & $\begin{array}{c}\text { Entre } \\
401 \mathrm{y} \\
700 \\
\end{array}$ & $\begin{array}{c}\text { Mas } \\
\text { de } 701\end{array}$ & $\begin{array}{c}\text { No } \\
\text { precisa }\end{array}$ & \\
\hline \multirow{6}{*}{$\begin{array}{l}\text { Después de } \\
\text { haber visto el } \\
\text { hospedaje en } \\
\text { Maras y los } \\
\text { paquetes usted } \\
\text { - 3D y } 2 \mathrm{~N}\end{array}$} & $\begin{array}{l}\text { 1.Definitivamente } \\
\text { no vendería el } \\
\text { servicio }\end{array}$ & 6 & 4 & 1 & 0 & 1 & 12 \\
\hline & $\begin{array}{l}\text { 2.Posiblemente } \\
\text { no vendería el } \\
\text { servicio }\end{array}$ & 3 & 12 & 1 & 1 & 0 & 17 \\
\hline & $\begin{array}{l}\text { 3.Me sería } \\
\text { indiferente } \\
\text { vender o no el } \\
\text { servicio }\end{array}$ & 5 & 3 & 4 & 1 & 0 & 13 \\
\hline & $\begin{array}{l}\text { 4.Posiblemente } \\
\text { vendería el } \\
\text { servicio }\end{array}$ & 4 & 0 & 0 & 3 & 0 & 7 \\
\hline & $\begin{array}{l}\text { 5.Definitivamente } \\
\text { vendería el } \\
\text { servicio }\end{array}$ & 7 & 4 & 0 & 2 & 0 & 13 \\
\hline & No precisa & 2 & 2 & 5 & 5 & 1 & 15 \\
\hline Total & & 27 & 25 & 11 & 12 & 2 & 77 \\
\hline
\end{tabular}


Después de haber visto el hospedaje en Maras y los paquetes usted - 3D y 2N* ¿La agencia cuenta con IATA? tabulación cruzada

Recuento

\begin{tabular}{|c|c|c|c|c|c|}
\hline & & \multicolumn{3}{|c|}{ ¿La agencia cuenta con IATA? } & \multirow{2}{*}{ Total } \\
\hline & & $\mathrm{Si}$ & No & No precisa & \\
\hline \multirow{6}{*}{$\begin{array}{l}\text { Después de haber } \\
\text { visto el hospedaje } \\
\text { en Maras y los } \\
\text { paquetes usted - } \\
3 \mathrm{D} \text { y } 2 \mathrm{~N}\end{array}$} & $\begin{array}{l}\text { 1.Definitivamente no } \\
\text { vendería el servicio }\end{array}$ & 1 & 10 & 1 & 12 \\
\hline & $\begin{array}{l}\text { 2.Posiblemente no } \\
\text { vendería el servicio }\end{array}$ & 3 & 13 & 1 & 17 \\
\hline & $\begin{array}{l}\text { 3.Me sería indiferente } \\
\text { vender o no el } \\
\text { servicio }\end{array}$ & 0 & 13 & 0 & 13 \\
\hline & $\begin{array}{l}\text { 4.Posiblemente } \\
\text { vendería el servicio }\end{array}$ & 1 & 3 & 3 & 7 \\
\hline & $\begin{array}{l}\text { 5.Definitivamente } \\
\text { vendería el servicio }\end{array}$ & 7 & 5 & 1 & 13 \\
\hline & No precisa & 2 & 8 & 5 & 15 \\
\hline Total & & 14 & 52 & 11 & 77 \\
\hline
\end{tabular}

Después de haber visto el hospedaje en Maras y los paquetes usted - 3D y $2 \mathrm{~N} *$ Clasificación de la agencia tabulación cruzada

Recuento

\begin{tabular}{|c|c|c|c|c|c|c|}
\hline \multirow[t]{2}{*}{ 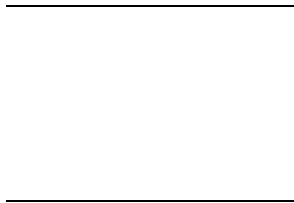 } & & \multicolumn{4}{|c|}{ Clasificación de la agencia } & \multirow[b]{2}{*}{ Total } \\
\hline & & $\begin{array}{l}\text { Operador } \\
\text { de } \\
\text { turismo }\end{array}$ & Mayorista & Minorista & $\begin{array}{c}\text { No } \\
\text { precisa }\end{array}$ & \\
\hline \multirow{6}{*}{$\begin{array}{l}\text { Después de } \\
\text { haber visto el } \\
\text { hospedaje en } \\
\text { Maras y los } \\
\text { paquetes usted - } \\
3 \mathrm{D} \text { y } 2 \mathrm{~N}\end{array}$} & $\begin{array}{l}\text { 1.Definitivamente } \\
\text { no vendería el } \\
\text { servicio }\end{array}$ & 9 & 1 & 2 & 0 & 12 \\
\hline & $\begin{array}{l}\text { 2.Posiblemente no } \\
\text { vendería el servicio }\end{array}$ & 11 & 2 & 4 & 0 & 17 \\
\hline & $\begin{array}{l}\text { 3.Me sería } \\
\text { indiferente vender } \\
\text { o no el servicio }\end{array}$ & 4 & 5 & 4 & 0 & 13 \\
\hline & $\begin{array}{l}\text { 4.Posiblemente } \\
\text { vendería el servicio }\end{array}$ & 7 & 0 & 0 & 0 & 7 \\
\hline & $\begin{array}{l}\text { 5.Definitivamente } \\
\text { vendería el servicio }\end{array}$ & 12 & 0 & 1 & 0 & 13 \\
\hline & No precisa & 10 & 2 & 2 & 1 & 15 \\
\hline Total & & 53 & 10 & 13 & 1 & 77 \\
\hline
\end{tabular}

\begin{tabular}{lcccccc}
\hline & \multicolumn{5}{c}{ Casos } \\
\cline { 2 - 7 } & \multicolumn{3}{c}{ Válido } & Perdidos & Total \\
\cline { 2 - 7 } & $\mathrm{N}$ & Porcentaje & $\mathrm{N}$ & Porcentaje & $\mathrm{N}$ & Porcentaje \\
\hline P30A*\$Especialidad_agencia & 77 & $100,0 \%$ & 0 & $0,0 \%$ & 77 & $100,0 \%$ \\
\hline
\end{tabular}


P30A*\$Especialidad_agencia tabulación cruzada

\begin{tabular}{|c|c|c|c|c|c|c|c|c|}
\hline & \multicolumn{6}{|c|}{ Especialidad_agencia $^{\mathrm{a}}$} & \multirow[b]{2}{*}{ Total } \\
\hline & & $\begin{array}{c}\text { Turismo } \\
\text { tradicional }\end{array}$ & Ecoturismo & $\begin{array}{c}\text { Turismo } \\
\text { vivencial } \\
\end{array}$ & Corporativo & Aventura & $\begin{array}{c}\text { No } \\
\text { precisa }\end{array}$ & \\
\hline $\begin{array}{l}\text { Después } \\
\text { de haber } \\
\text { visto el }\end{array}$ & $\begin{array}{l}\text { 2.Posiblemente } \\
\text { no vendería el } \\
\text { servicio }\end{array}$ & 2 & 0 & 0 & 0 & 0 & 0 & 2 \\
\hline $\begin{array}{l}\text { hospedaje } \\
\text { en Maras } \\
\text { y los }\end{array}$ & $\begin{array}{l}\text { 4.Posiblemente } \\
\text { vendería el } \\
\text { servicio }\end{array}$ & 27 & 7 & 4 & 2 & 2 & 0 & 35 \\
\hline $\begin{array}{l}\text { paquetes } \\
\text { usted - } \\
\text { Full day }\end{array}$ & $\begin{array}{l}\text { 5.Definitivamente } \\
\text { vendería el } \\
\text { servicio }\end{array}$ & 29 & 7 & 6 & 1 & 11 & 0 & 37 \\
\hline & No precisa & 2 & 0 & 0 & 0 & 0 & 1 & 3 \\
\hline Total & & 60 & 14 & 10 & 3 & 13 & 1 & 77 \\
\hline
\end{tabular}

Los porcentajes y los totales se basan en los encuestados.

a. Grupo

$\underline{\mathbf{P 3 0 B} * \$ \text { Especialidad_agencia tabulación cruzada }}$

\begin{tabular}{|c|c|c|c|c|c|c|c|c|}
\hline & \multicolumn{6}{|c|}{ Especialidad_agencia $^{a}$} & \multirow[b]{2}{*}{ Tota } \\
\hline & & $\begin{array}{c}\text { Turismo } \\
\text { tradicional }\end{array}$ & Ecoturismo & $\begin{array}{l}\text { Turismo } \\
\text { vivencial }\end{array}$ & Corporativo & Aventura & $\begin{array}{l}\text { No } \\
\text { precisa }\end{array}$ & \\
\hline \multirow{6}{*}{$\begin{array}{l}\text { Después de } \\
\text { haber visto } \\
\text { el } \\
\text { hospedaje } \\
\text { en Maras y } \\
\text { los paquetes } \\
\text { usted - 2D y } \\
1 N\end{array}$} & $\begin{array}{l}\text { 1.Definitivamente } \\
\text { no vendería el } \\
\text { servicio }\end{array}$ & 0 & 0 & 0 & 0 & 2 & 0 & 2 \\
\hline & $\begin{array}{l}\text { 2.Posiblemente no } \\
\text { vendería el } \\
\text { servicio }\end{array}$ & 5 & 1 & 0 & 0 & 1 & 0 & 6 \\
\hline & $\begin{array}{l}\text { 3. Me sería } \\
\text { indiferente vender } \\
\text { o no el servicio }\end{array}$ & 6 & 2 & 0 & 0 & 1 & 0 & 7 \\
\hline & $\begin{array}{l}\text { 4.Posiblemente } \\
\text { vendería el } \\
\text { servicio }\end{array}$ & 23 & 6 & 4 & 1 & 8 & 0 & 30 \\
\hline & $\begin{array}{l}\text { 5.Definitivamente } \\
\text { vendería el } \\
\text { servicio }\end{array}$ & 17 & 5 & 5 & 1 & 1 & 0 & 21 \\
\hline & No precisa & 9 & 0 & 1 & 1 & 0 & 1 & 11 \\
\hline Total & & 60 & 14 & 10 & 3 & 13 & 1 & 77 \\
\hline
\end{tabular}

Los porcentajes y los totales se basan en los encuestados.

a. Grupo 
P30C*\$Especialidad_agencia tabulación cruzada

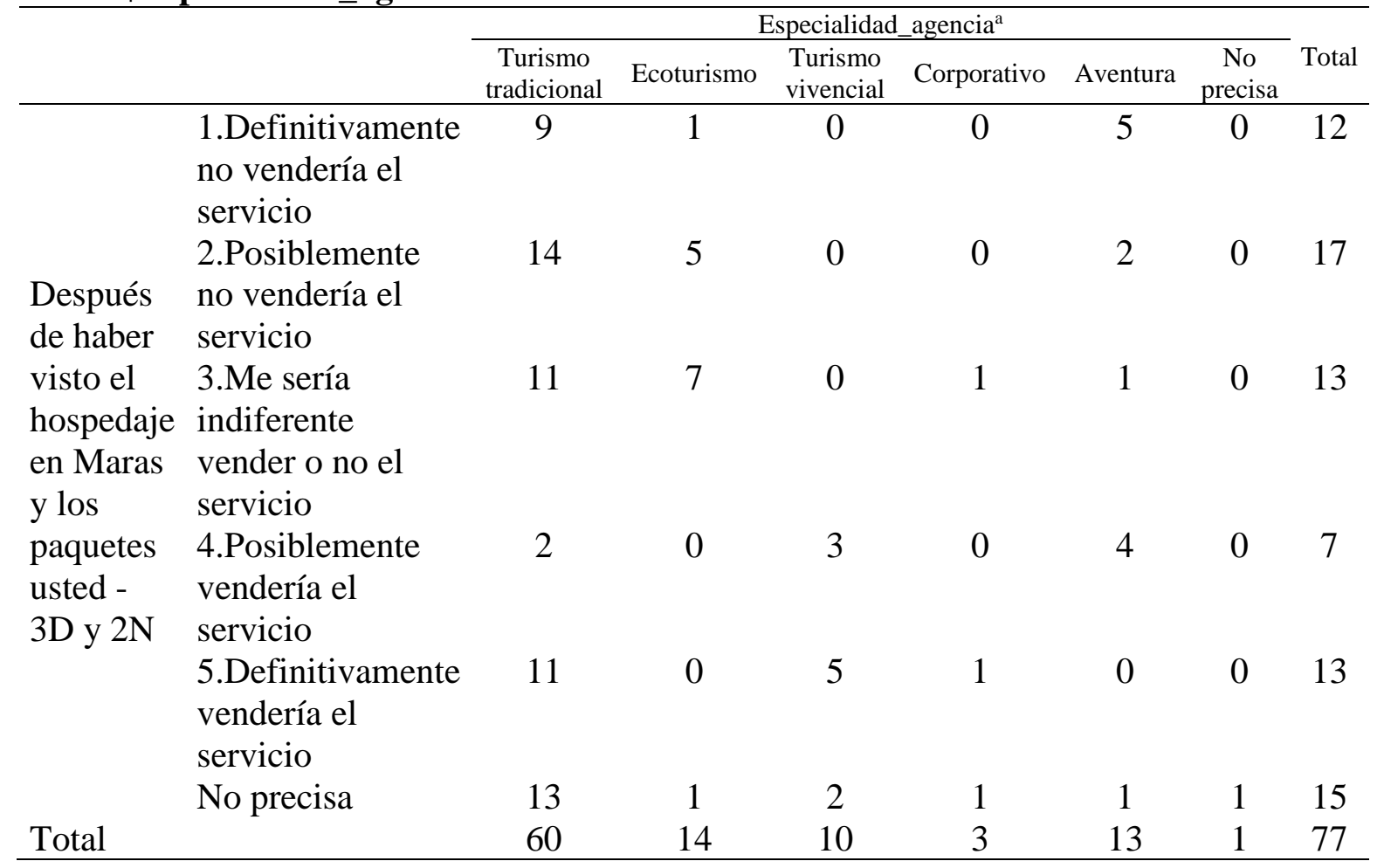

Los porcentajes y los totales se basan en los encuestados. 
Anexo XI.

Requerimiento de muebles y enseres

Por Áreas:

Recepción y Sala de estar

\begin{tabular}{lccc}
\hline Concepto & Unid. & $\begin{array}{c}\text { Precio } \\
\text { unit. (s/.) }\end{array}$ & Costo total (s/.) \\
\hline Escritorio de recepción & 1 & 1,300 & 1,300 \\
Mesa de centro & 2 & 200 & 400 \\
Computadora & 1 & 900 & 900 \\
Impresora multifuncional & 1 & 600 & 600 \\
Sillones & 3 & 300 & 900 \\
Sofá & 1 & 650 & 650 \\
Organizador de llaves & 1 & 190 & 190 \\
Alfombra central (1.40 x 2.00) & 1 & 450 & 450 \\
Teléfono inalámbrico & 1 & 185 & 185 \\
POS Visa & 1 & 0 & 0 \\
POS MasterCard & 1 & 0 & 0 \\
POS Contingencia & 1 & 0 & 0 \\
Florero de cerámica & 1 & 80 & 80 \\
Lámpara & 1 & 400 & 400 \\
Cuadros & 2 & 350 & 700 \\
Espejo & 1 & 500 & 500 \\
Total & & & 7,255 \\
\hline
\end{tabular}

Restaurante planta baja

\begin{tabular}{lccc}
\hline \multicolumn{1}{c}{ Concepto } & Unid. & $\begin{array}{c}\text { Precio } \\
\text { Unit. (S/.) }\end{array}$ & Costo Total (S/.) \\
\hline Juego de comedor cuatro sillas & 4 & 500 & 2,000 \\
Juego de comedor ocho sillas & 2 & 750 & 1,500 \\
Bar & 1 & 3,050 & 3,050 \\
Espejo pared & 1 & 750 & 750 \\
Computadora & 1 & 900 & 900 \\
Silla para barra & 1 & 99 & 99 \\
Silla para niños & 2 & 125 & 250 \\
Credenza para platos & 1 & 500 & 500 \\
Plato mediano de piedra granito & 48 & 50 & 2,400 \\
Plato grande de piedra granito & 48 & 50 & 2,400 \\
Plato hondo de madera & 48 & 10 & 480 \\
Taza de latón & 36 & 7 & 252 \\
Docena de juego de Cubiertos & 4 & 40 & 160 \\
Total & & & 14,741 \\
\hline
\end{tabular}


Baños restaurante planta baja

\begin{tabular}{lccc}
\hline Concepto & Unid. & $\begin{array}{c}\text { Precio } \\
\text { unit. (s/.) }\end{array}$ & Costo total (s/.) \\
\hline Espejo & 2 & 400 & 800 \\
Toallero & 2 & 60 & 120 \\
Porta Papel higiénico & 2 & 20 & 40 \\
Basurero & 2 & 40 & 80 \\
Total & & & 1,040 \\
\hline
\end{tabular}

$\underline{\text { Restaurante planta alta }}$

\begin{tabular}{lccc}
\multicolumn{1}{c}{ Concepto } & Unid. & $\begin{array}{c}\text { Precio } \\
\text { unit. (s/.) }\end{array}$ & Costo total (s/.) \\
\hline Juego de comedor cuatro sillas & 5 & 500 & 2500 \\
Juego de comedor ocho sillas & 1 & 750 & 750 \\
Credenza para platos & 1 & 500 & 500 \\
Silla para barra & 1 & 99 & 99 \\
Total & & & 3,849 \\
\hline
\end{tabular}

Baños restaurante planta alta

\begin{tabular}{|c|c|c|c|}
\hline Concepto & Unid. & Precio Unit. $(\mathrm{s} /)$. & Costo total (s/.) \\
\hline Espejo & 2 & 400 & 800 \\
\hline Toallero & 2 & 60 & 120 \\
\hline Porta Papel higiénico & 2 & 20 & 40 \\
\hline Basurero & 2 & 40 & 80 \\
\hline Total & & & 1,040 \\
\hline
\end{tabular}

Cocina

\begin{tabular}{lccc}
\hline \multicolumn{1}{c}{ Concepto } & Unid. & Precio unit. (s/.) & Costo total (s/.) \\
\hline Cocina industrial & 1 & 4500 & 4500 \\
Campana de extracción & 1 & 2500 & 2500 \\
Refrigeradora industrial & 1 & 2999 & 2999 \\
Licuadora & 2 & 190 & 380 \\
Extractor de jugos & 1 & 249 & 249 \\
Horno microondas & 1 & 279 & 279 \\
Cafetera & 1 & 199 & 199 \\
Batidora & 1 & 294 & 294 \\
Tostadora de pan & 1 & 150 & 150 \\
Maquina congeladora & 1 & 799 & 799 \\
Mesas de acero & 1 & 480 & 480 \\
Tachos de acero & 3 & 320 & 960 \\
Juego de ollas *10 piezas & 1 & 770 & 770 \\
Juego de sartenes*3 piezas & 3 & 34.9 & 104.7 \\
Asadera con tapa & 2 & 35.9 & 71.8 \\
1 olla a presión & 1 & 194 & 194 \\
Juego de cuchillos *12 & 1 & 200 & 200 \\
Juego de cucharones *12 & 1 & 125 & 125 \\
Horno de Barro & 1 & 1100 & 1100 \\
Total & & & 16,355 \\
\hline
\end{tabular}

Dormitorios y baños 


\begin{tabular}{|c|c|c|c|c|}
\hline Grupo & Concepto & Unid. & $\begin{array}{c}\text { Precio } \\
\text { unit. } \\
(\mathrm{s} / .) \\
\end{array}$ & $\begin{array}{l}\text { Costo total } \\
(\mathrm{s} / .)\end{array}$ \\
\hline \multirow[t]{6}{*}{ Mobiliario } & Estructura de cama Twin (Komfort) & 21 & 899 & 18879 \\
\hline & Estructura de cama King (Komfort) & 3 & 399 & 1197 \\
\hline & Mesa de noche & 18 & 69 & 1242 \\
\hline & Mesa & 3 & 59 & 177 \\
\hline & Silla & 6 & 49 & 294 \\
\hline & Tocador & 18 & 99 & 1782 \\
\hline \multirow[t]{5}{*}{ Línea Blanca } & Sábanas Twin (Mica) & 32 & 89.5 & 2864 \\
\hline & Sábanas King (Mica) & 6 & 89.5 & 537 \\
\hline & Funda almohada & 48 & & 0 \\
\hline & Toalla de manos & 36 & 49 & 1764 \\
\hline & Toalla de cuerpo & 36 & 59 & 2124 \\
\hline \multirow{7}{*}{ Equipamiento textil } & Colchón Twin (Komfort) & 21 & 650 & 13650 \\
\hline & Colchón King (Komfort) & 3 & 300 & 900 \\
\hline & Almohada & 48 & 49 & 2352 \\
\hline & Edredón & 24 & 89 & 2136 \\
\hline & Cortinas (black out) & 36 & 120 & 4320 \\
\hline & Cortinas (ducha) & 18 & 59 & 1062 \\
\hline & Alfombra central $(90 \mathrm{~cm} . \times 70 \mathrm{~cm})$ & 18 & 180 & 3240 \\
\hline \multirow{2}{*}{ Decoración } & Florero de cerámica & 9 & 80 & 720 \\
\hline & Cuadro de telares & 18 & 190 & 3420 \\
\hline \multirow[t]{2}{*}{ Iluminación } & Focos led amarillos & 72 & 15 & 1080 \\
\hline & Lámpara de mesa & 18 & 89 & 1602 \\
\hline \multirow[t]{2}{*}{ Electrodomésticos } & Estufas & 18 & 120 & 2160 \\
\hline & Teléfono & 18 & 65 & 1170 \\
\hline \multirow[t]{5}{*}{ Baño } & Espejos & 18 & 59 & 1062 \\
\hline & Sanitario (Italgrif) & 18 & 289 & 5202 \\
\hline & Ducha (Stretto) & 18 & 89 & 1602 \\
\hline & Llave para ducha (Italgrif) & 36 & 51 & 1836 \\
\hline & Lavatorio + llave de caño (Italgrif) & 18 & 69 & 1242 \\
\hline Total & & & & 62660 \\
\hline
\end{tabular}


Oficina

\begin{tabular}{|c|c|c|c|}
\hline Concepto & Unid. & $\begin{array}{c}\text { Precio } \\
\text { unit. }(\mathrm{s} / .)\end{array}$ & $\begin{array}{c}\text { Costo total } \\
(\mathrm{s} / .)\end{array}$ \\
\hline Escritorio & 1 & 1300 & 1300 \\
\hline Computadora & 1 & 900 & 900 \\
\hline Impresora multifuncional & 1 & 600 & 600 \\
\hline Trituradora de papel & 1 & 700 & 700 \\
\hline Engrapadora & 1 & 9.6 & 9.6 \\
\hline Perforador & 1 & 22.5 & 22.5 \\
\hline Archivadores & 10 & 4.5 & 45 \\
\hline Pizarra blanca & 1 & 32.3 & 32.3 \\
\hline Sillas & 2 & 185 & 370 \\
\hline Útiles de oficina & Varios & & 150 \\
\hline Teléfono inalámbrico & 1 & 185 & 185 \\
\hline Cuadros & 2 & 350 & 700 \\
\hline Total & & & 5,014 \\
\hline
\end{tabular}


Anexo XII.

Proformas de algunos muebles y enseres

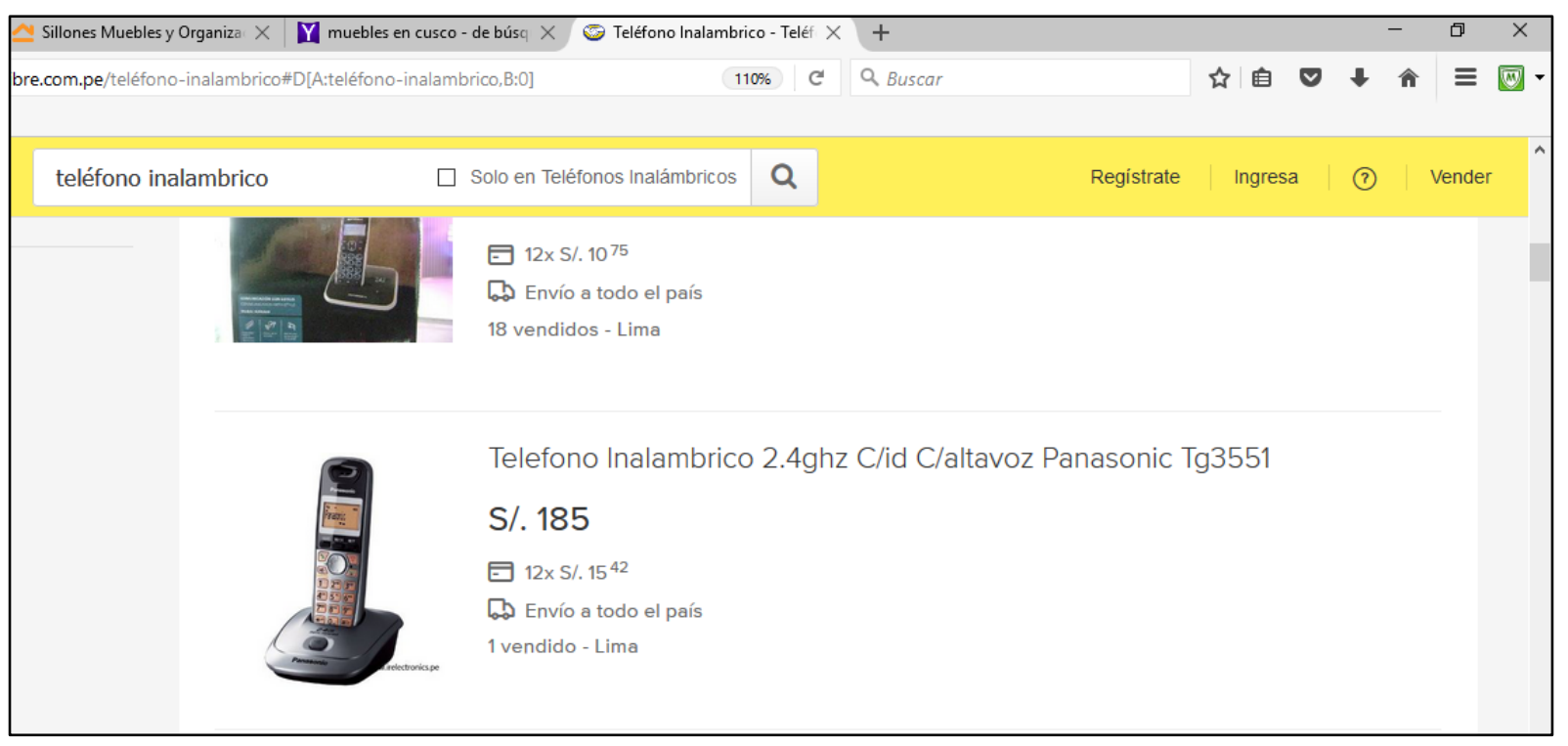

\begin{tabular}{|c|c|c|c|}
\hline ALFOMBRA LIVING $100 \%$ POLIESTER & $\begin{array}{c}\text { (2) Ubicación } \\
\text { Lima, Lima }\end{array}$ & & \\
\hline $\begin{array}{l}\text { ESCOGE LA MEJOR ALFOMBRA PARA TU SALA, COMEDOR O LUGAR QUE PREFIERAS } \\
\text { Cosido y pegado, no salen los pelos ni bota pelusa }\end{array}$ & $\begin{array}{l}100 \% \\
\text { de compradores lo } \\
\text { recomiendan }\end{array}$ & $\begin{array}{l}11 \text { meses } \\
\text { vendiendo en } \\
\text { Mercado Libre }\end{array}$ & $\begin{array}{c}53 \\
\text { ventas } \\
\text { concretadas }\end{array}$ \\
\hline $\begin{array}{l}\text { MEDIDAS: } \\
\text { ALF. LIVING } 120 \times 170 \mathrm{~S} / .350 .00\end{array}$ & \multicolumn{3}{|c|}{ Ver más datos de este vendedor } \\
\hline $\begin{array}{l}\text { ALF. LIVING } 140 \times 200 \mathrm{~S} / .450 .00 \\
\text { ALF. LIVING } 160 \times 230 \mathrm{~S} / 500.00\end{array}$ & \multirow{2}{*}{\multicolumn{3}{|c|}{ Medios de pago }} \\
\hline ALTURA PELO: $2.5 \mathrm{~cm}$ & & & \\
\hline
\end{tabular}

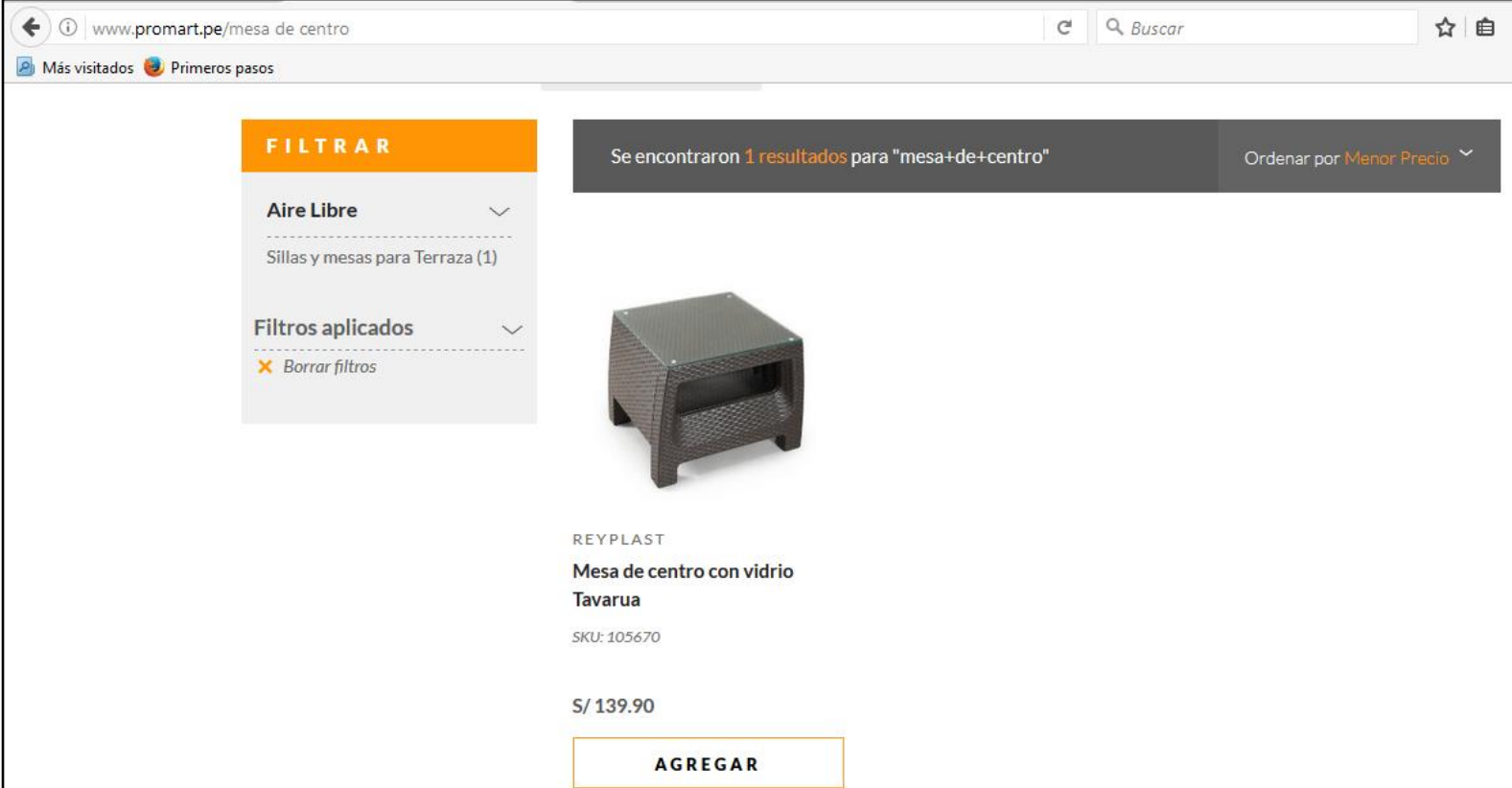




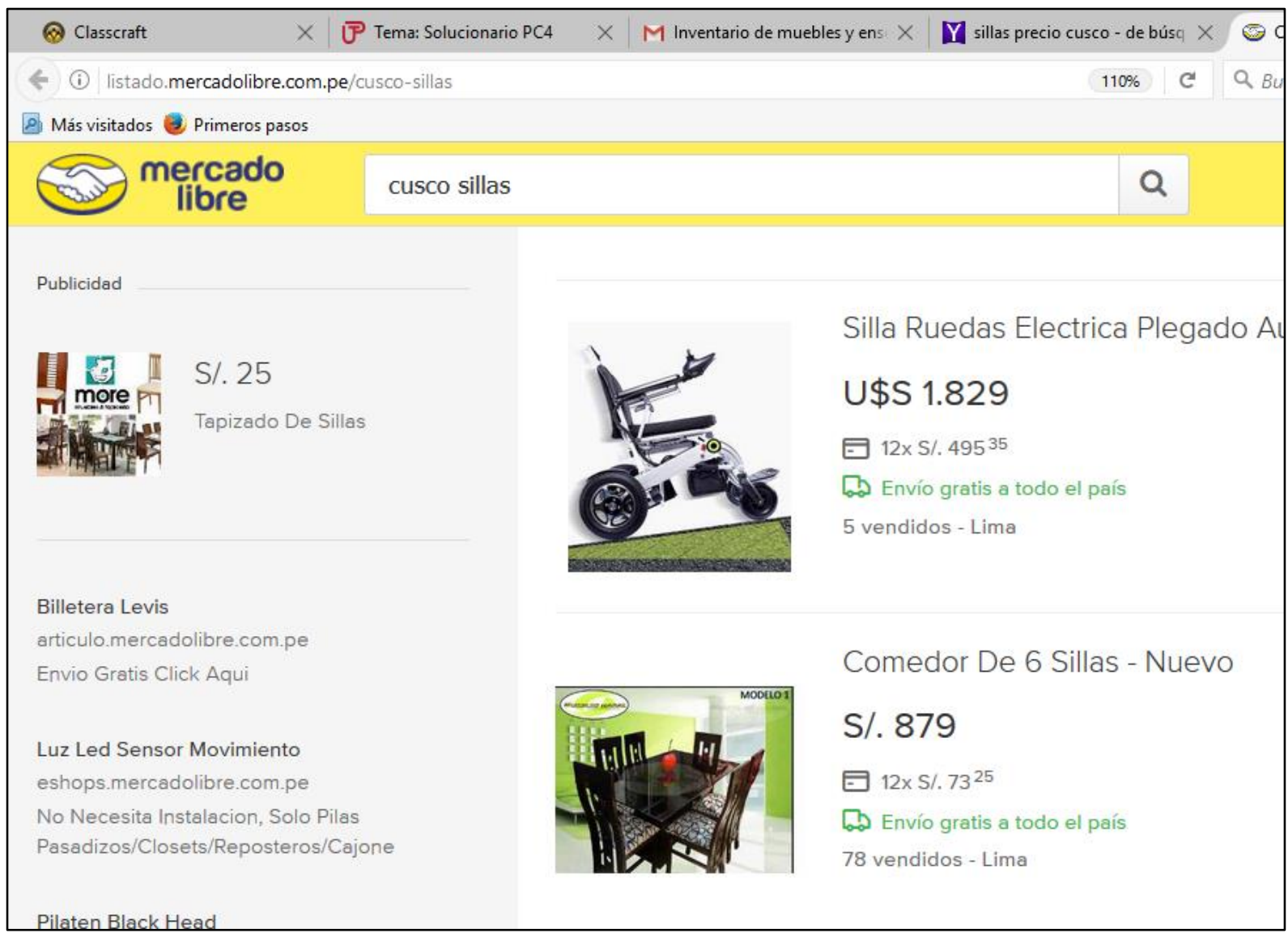

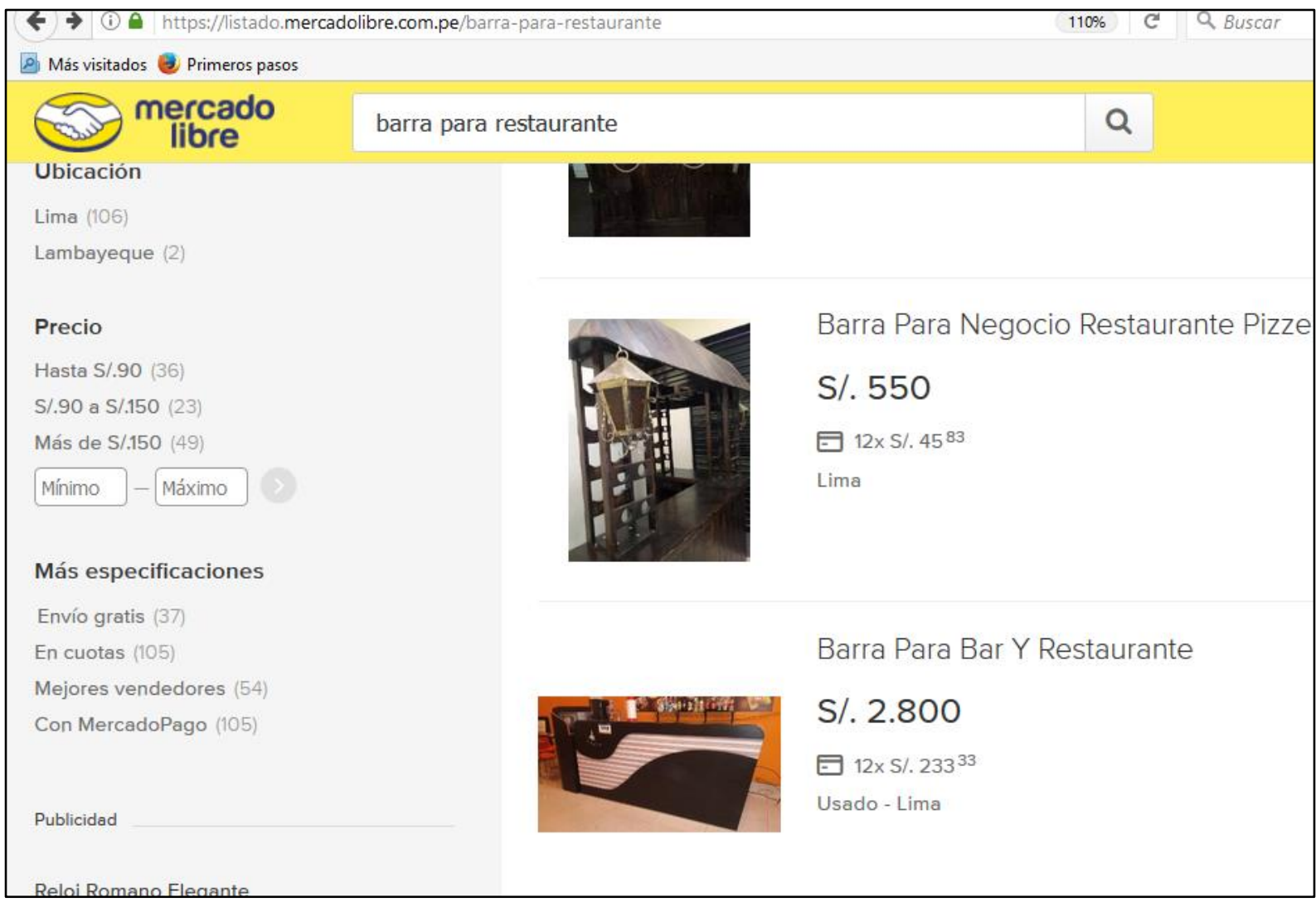




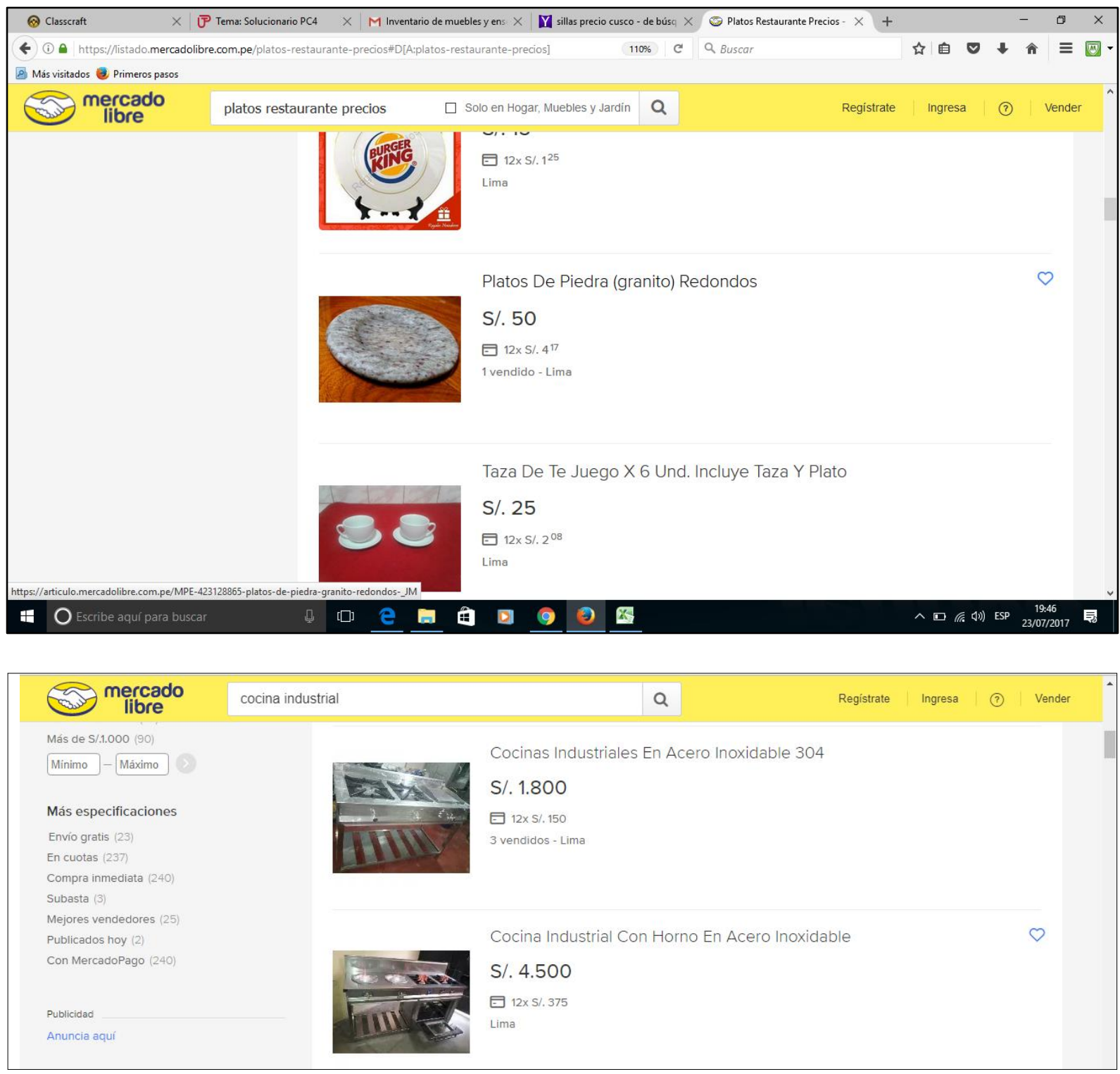

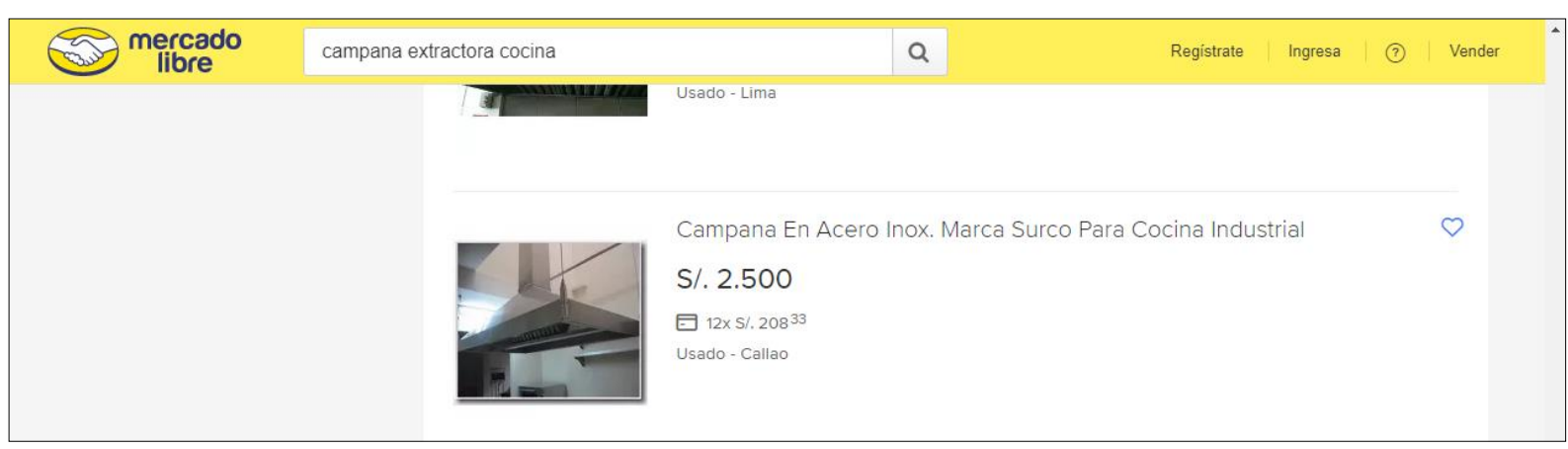




\begin{tabular}{|l|l|}
\hline $\begin{array}{l}\text { mercado } \\
\text { libre }\end{array}$ & licuadora industrial \\
Licuadora Oster Pro Semi Industrial Nueva En Caja \\
S/. 190 \\
1 vendido - Lima
\end{tabular}

\section{ASODIMAC.}

\section{Estas viendo:Refrigeradoras}

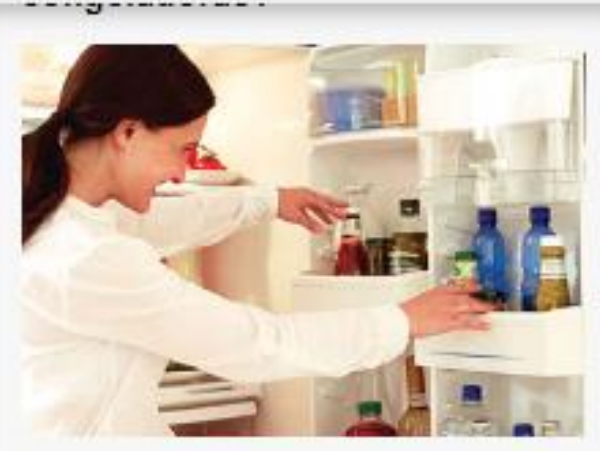

INGRESA AQUI

\section{Comparar}

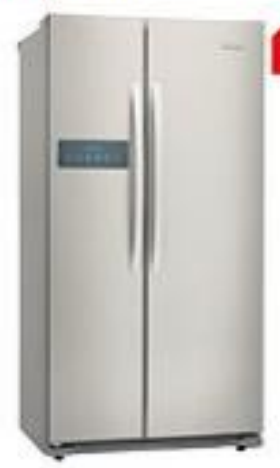

$560 L$

Electrolux

Refrigeradora $560 \mathrm{~L}$

ERSB56B2MMS

SKU:210926-3

Precio normal:

\section{$\mathrm{S} / 2,999 \mathrm{C} / \mathrm{U}$}




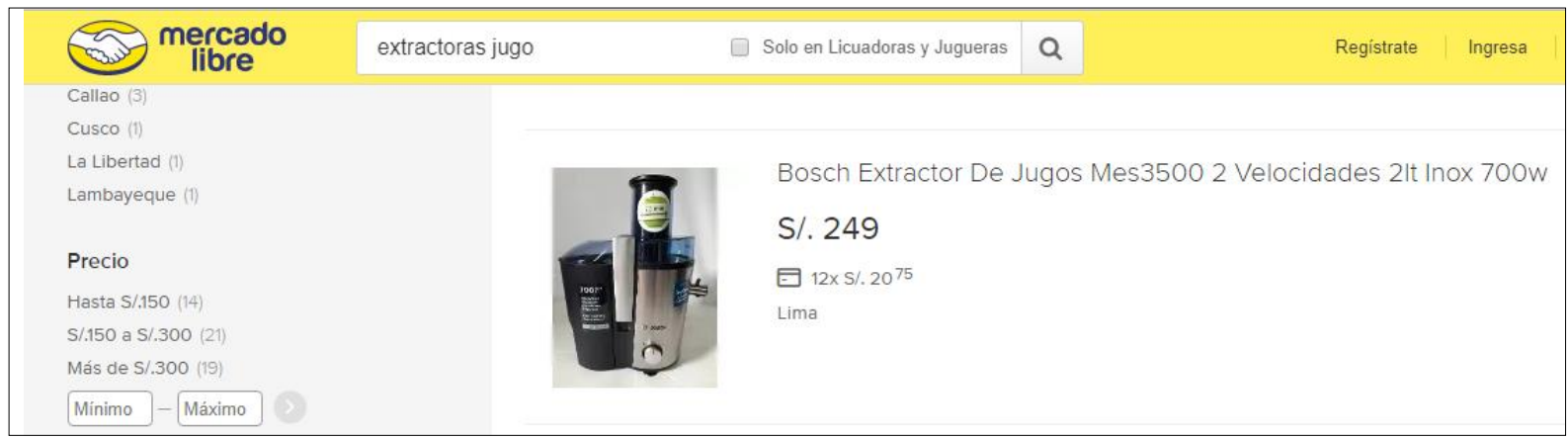

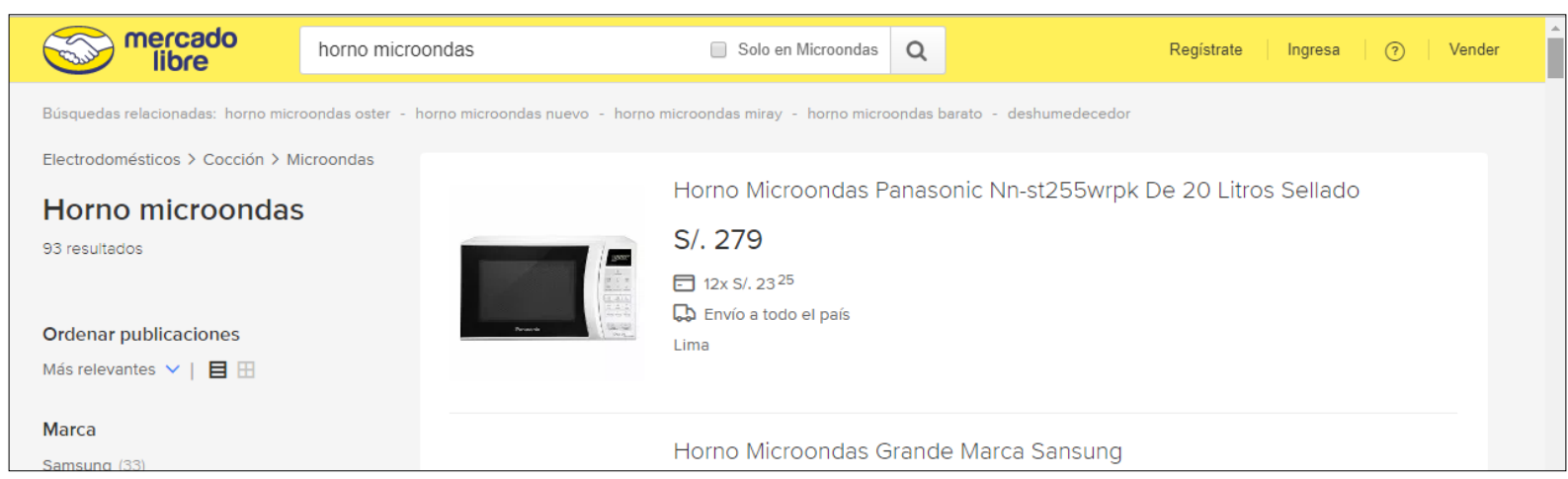

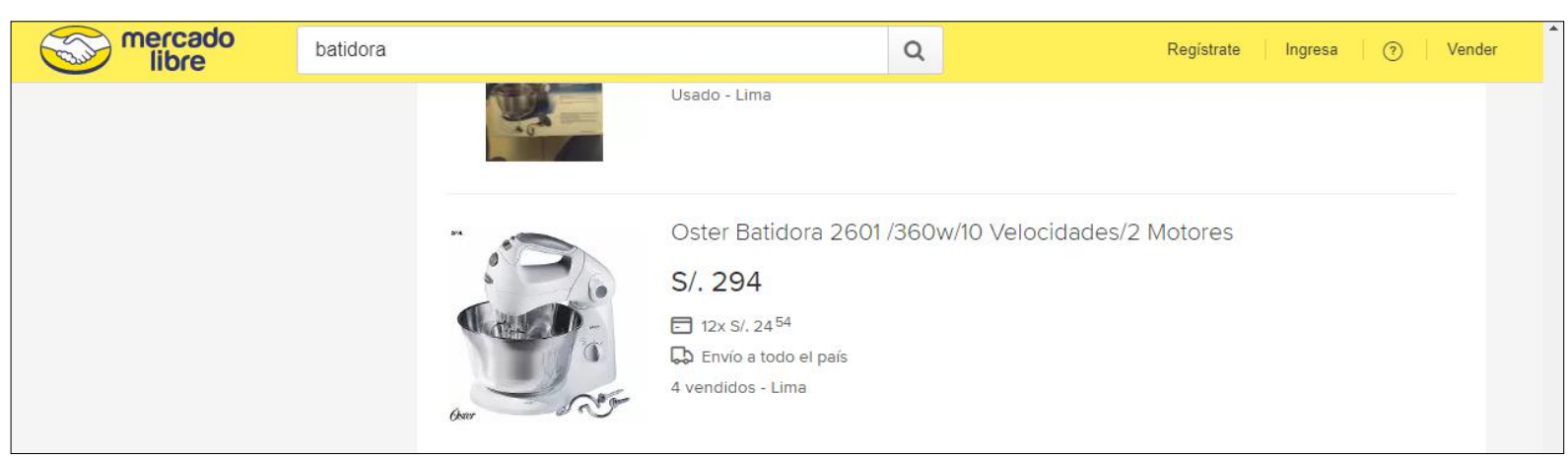

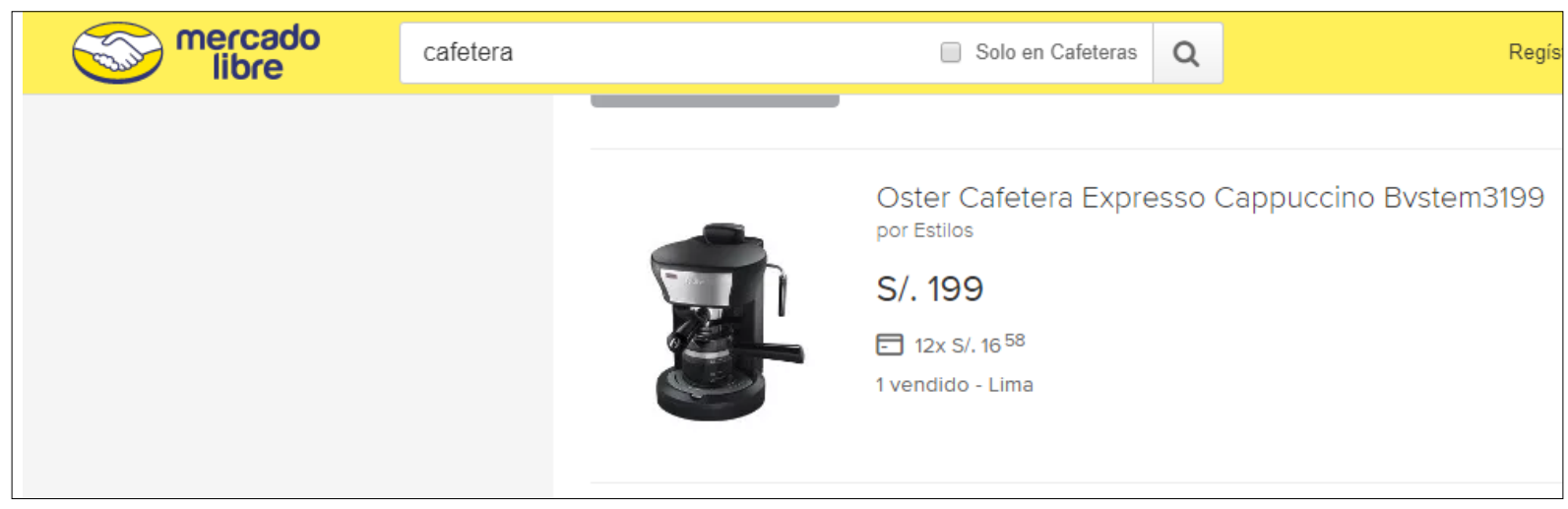




$\begin{aligned} & \text { mercado } \\ & \text { libre }\end{aligned}$
Accesorios para Herramientas (3)
Equipamiento Médico (3)
Ver todos
Condición
Nuevo (116)
Usado (2)
Ubicación

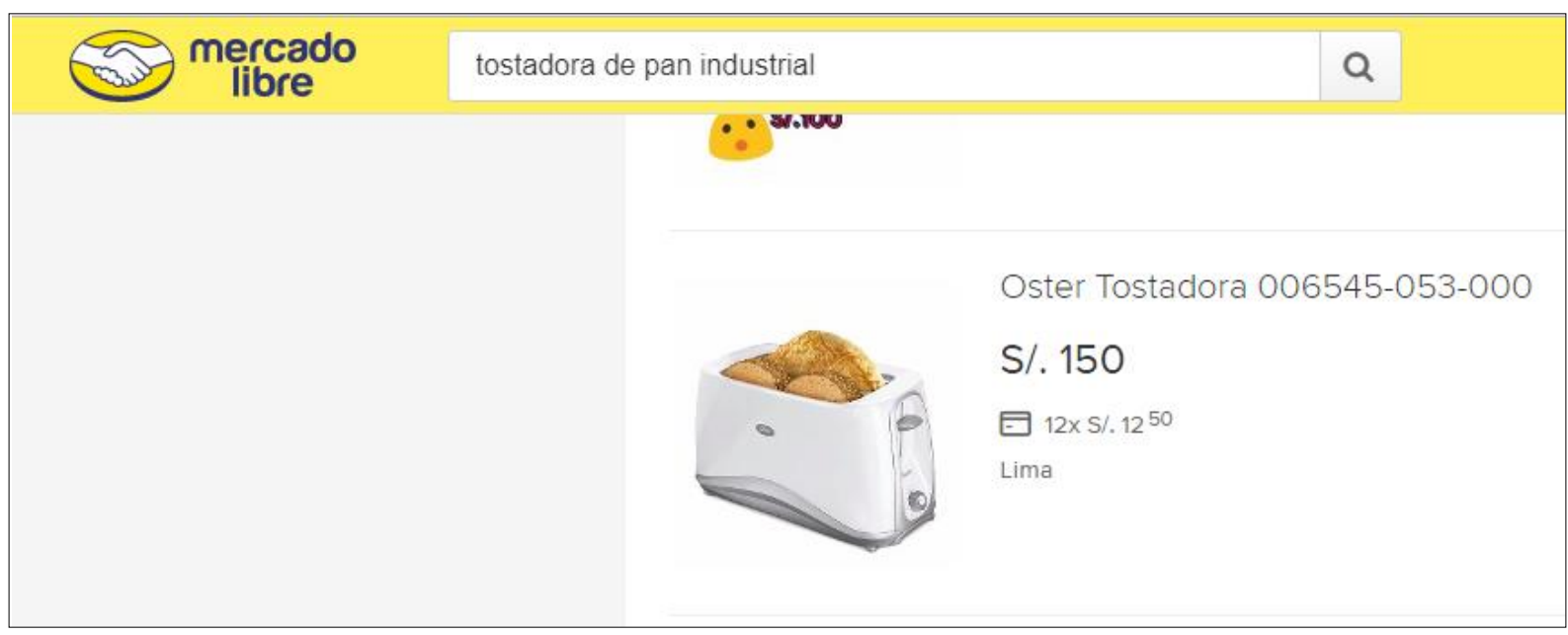

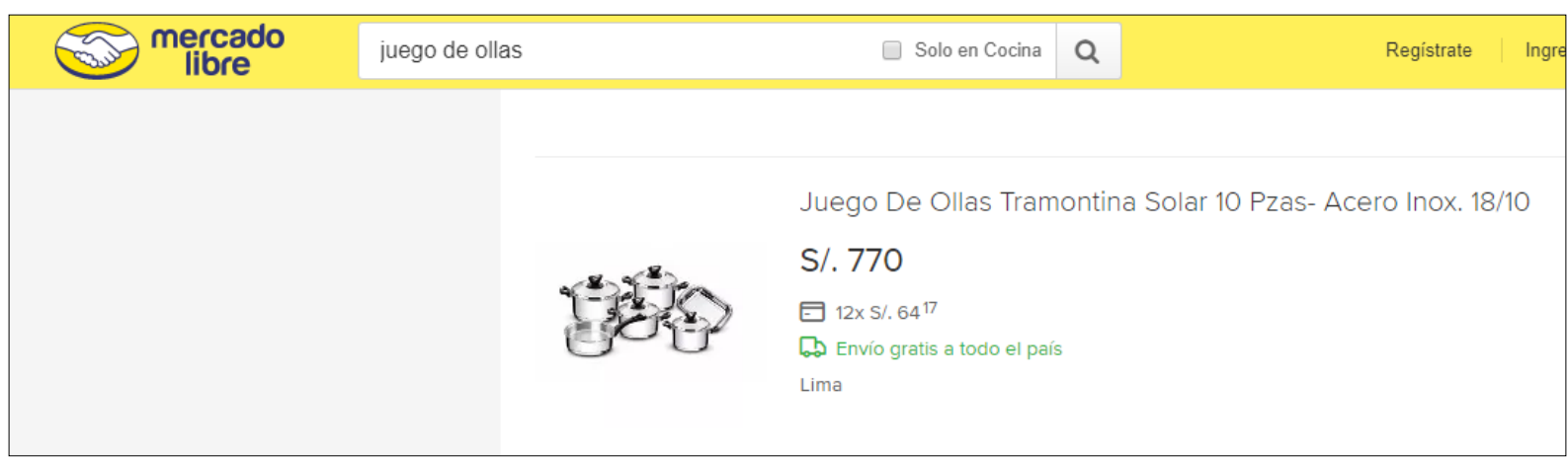




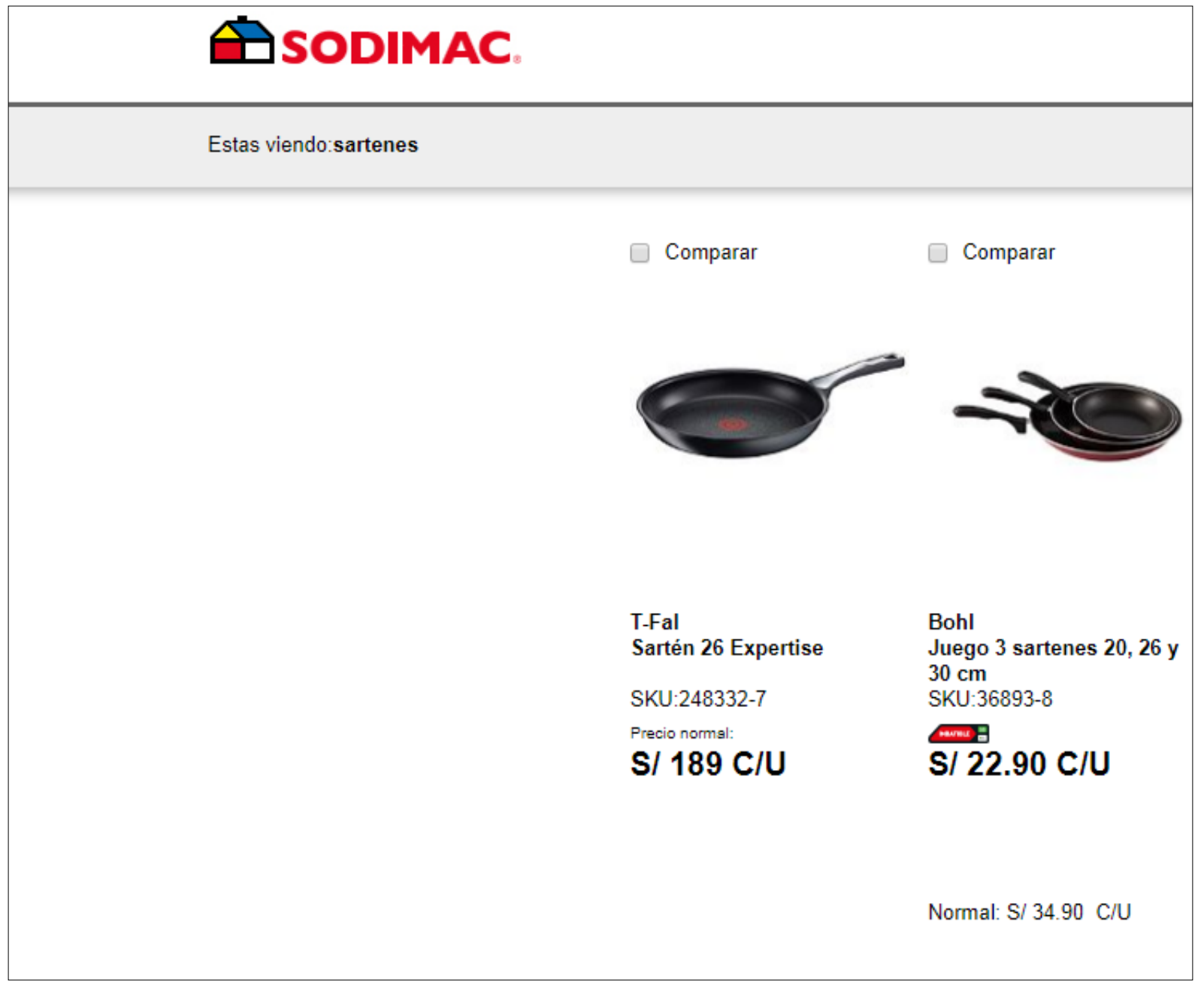

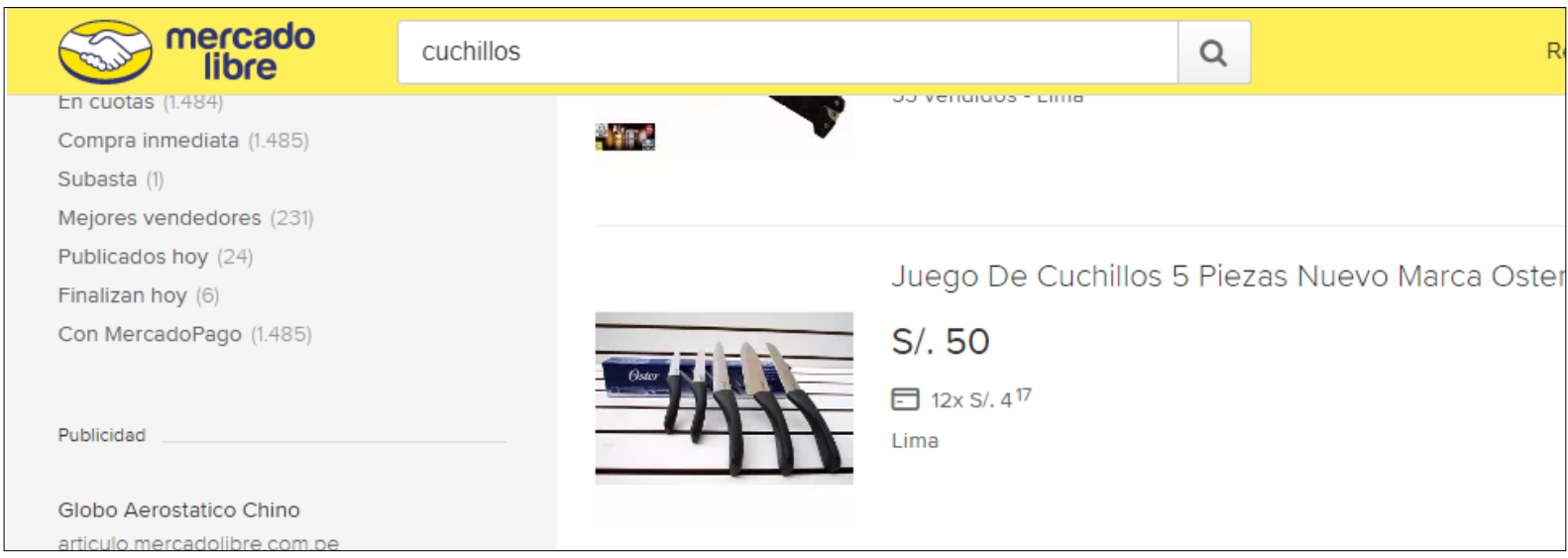




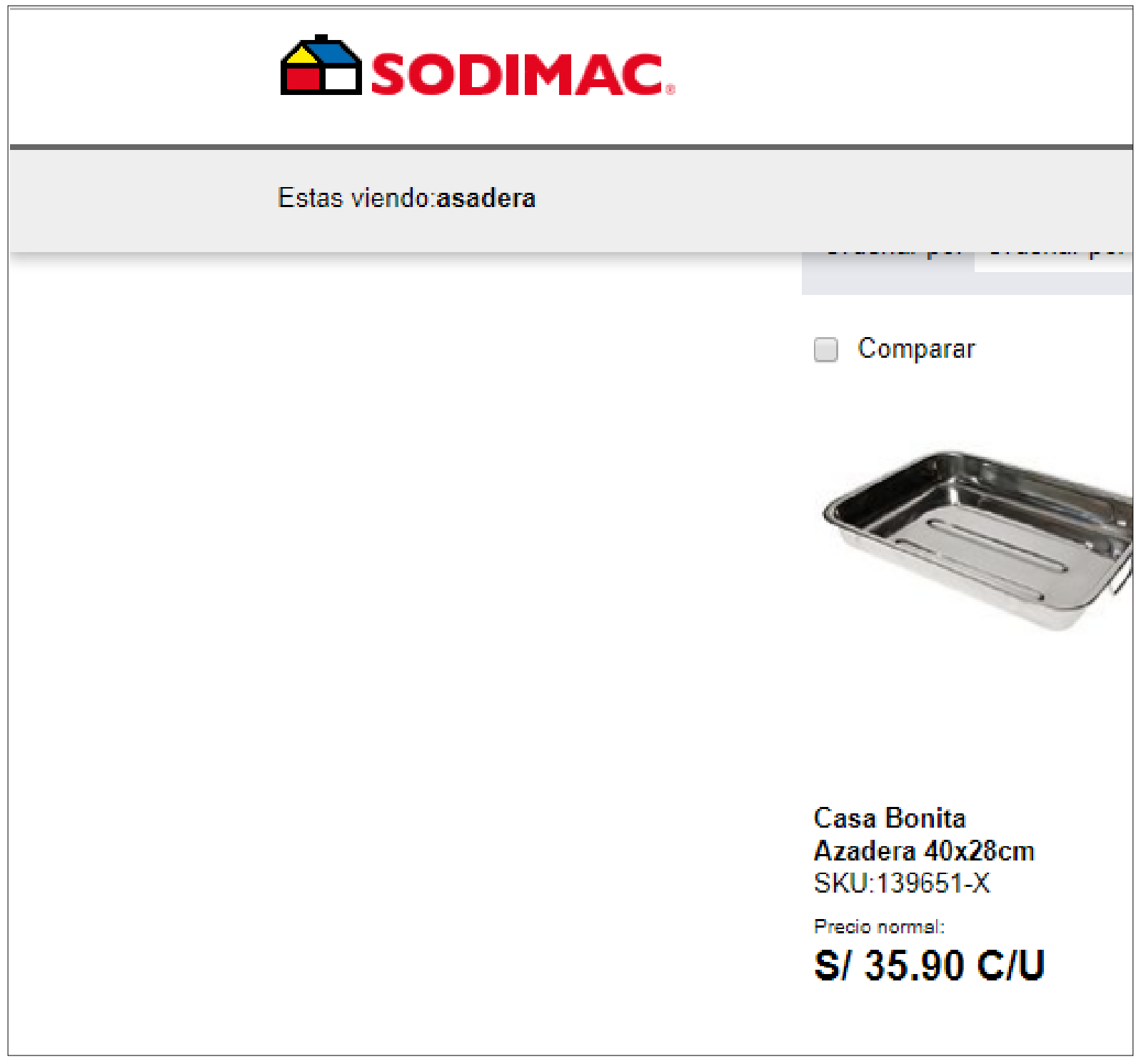

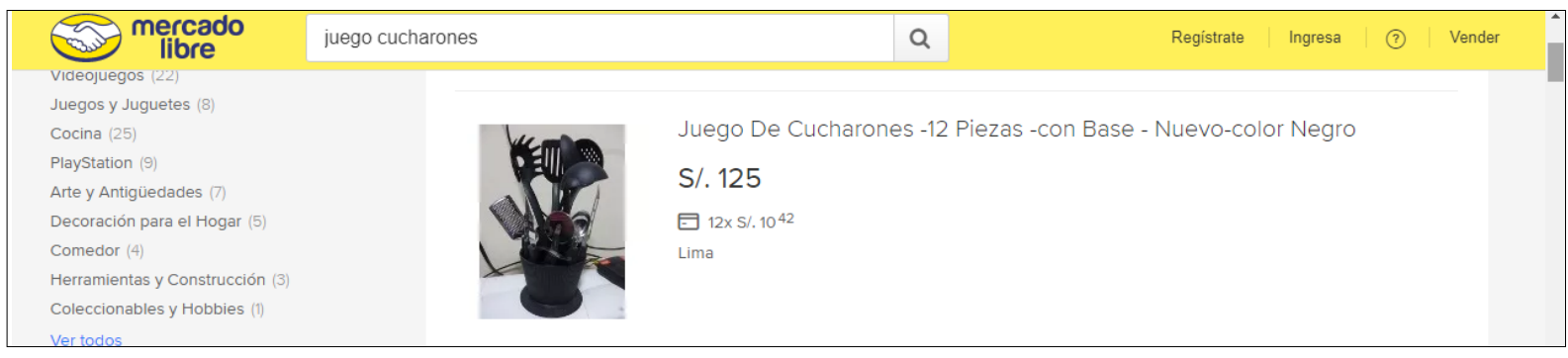




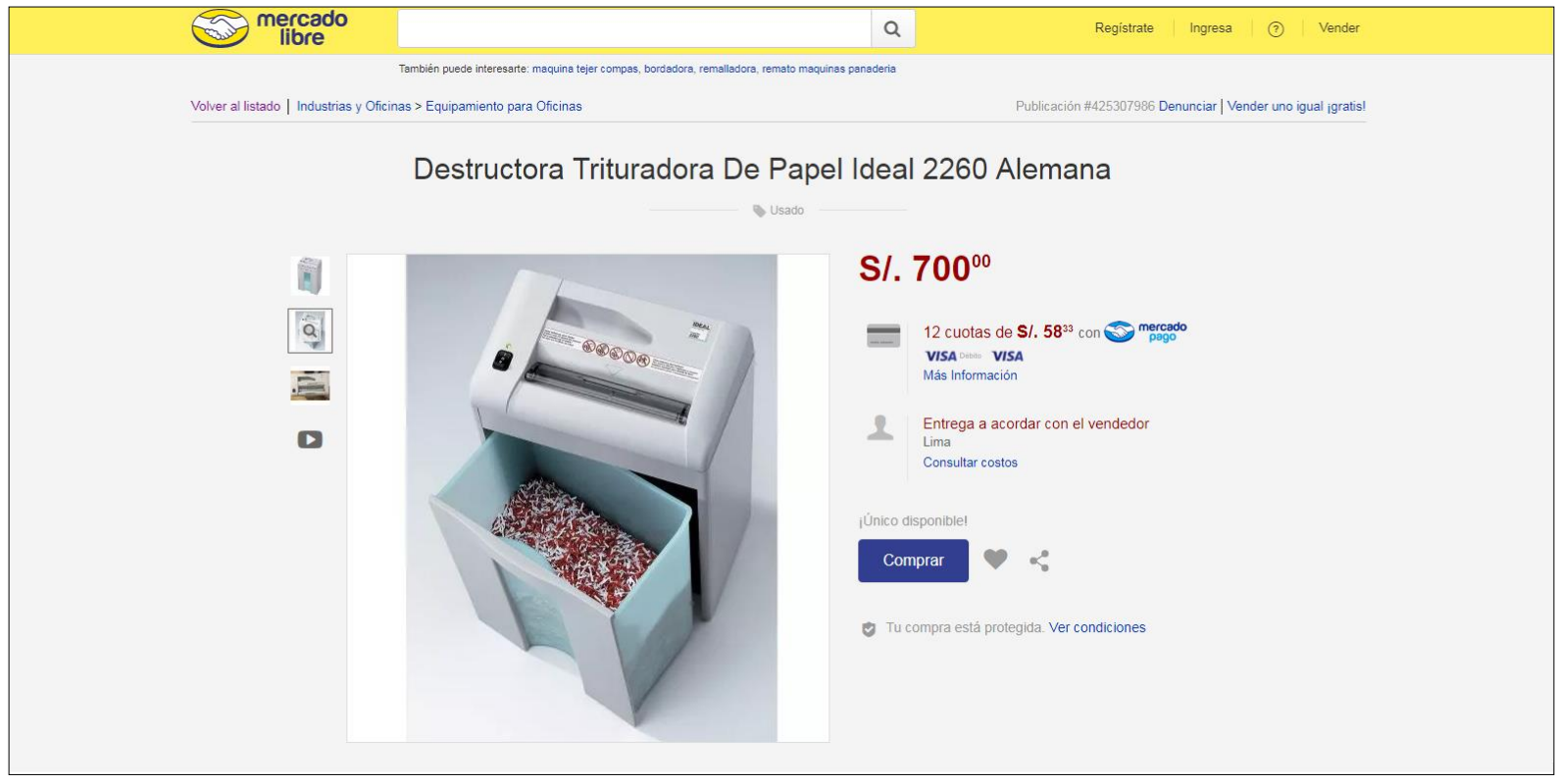

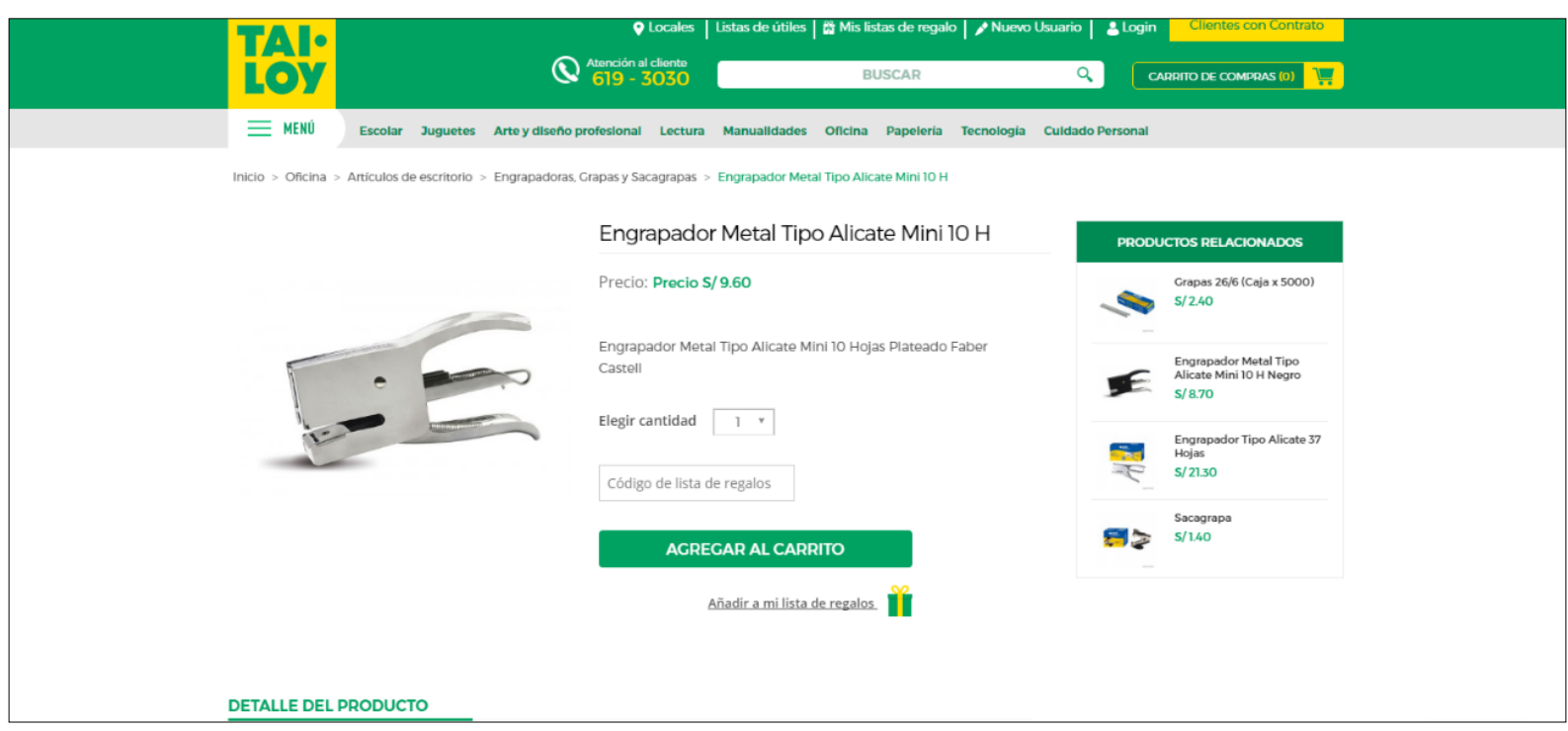

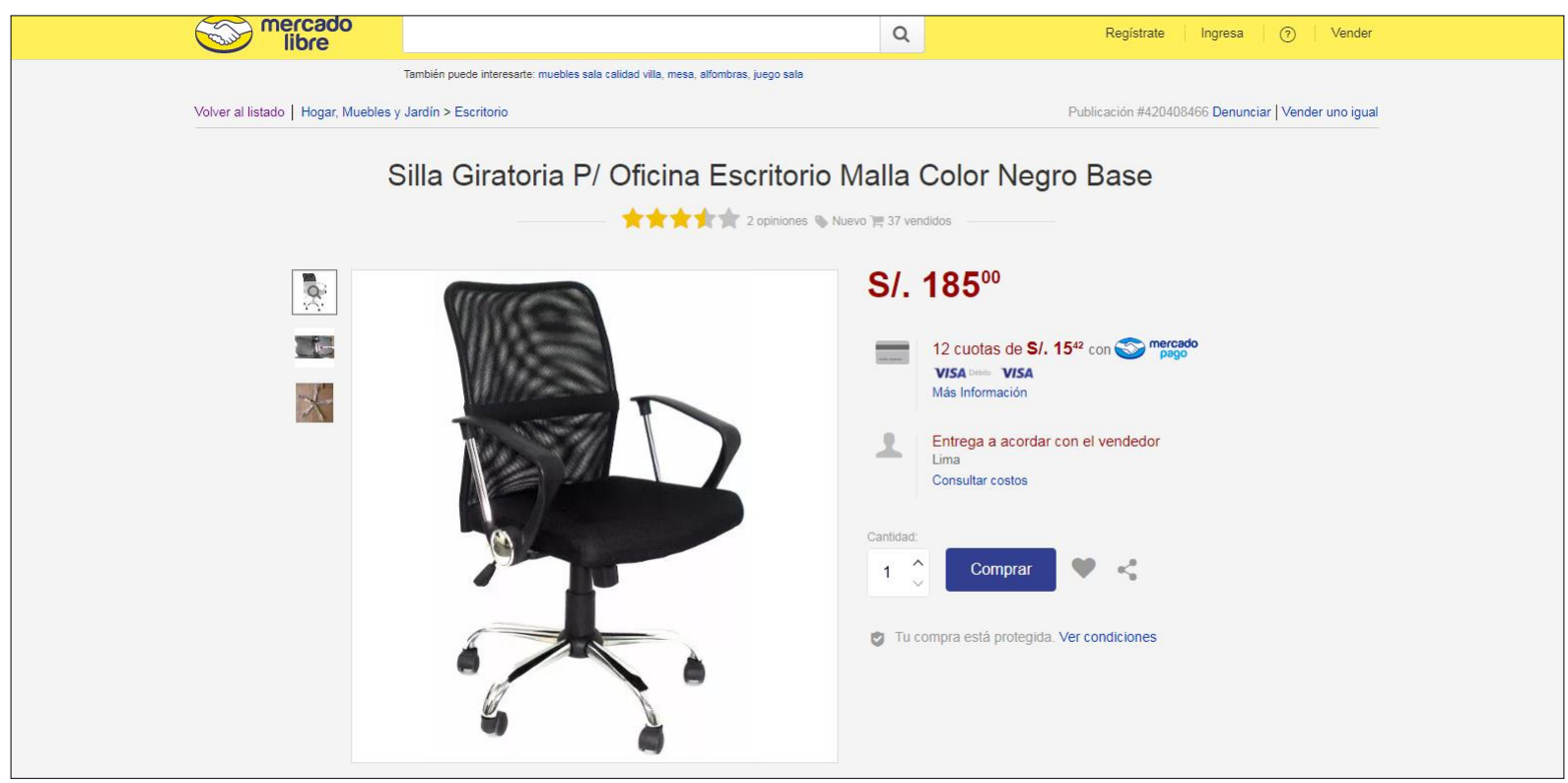




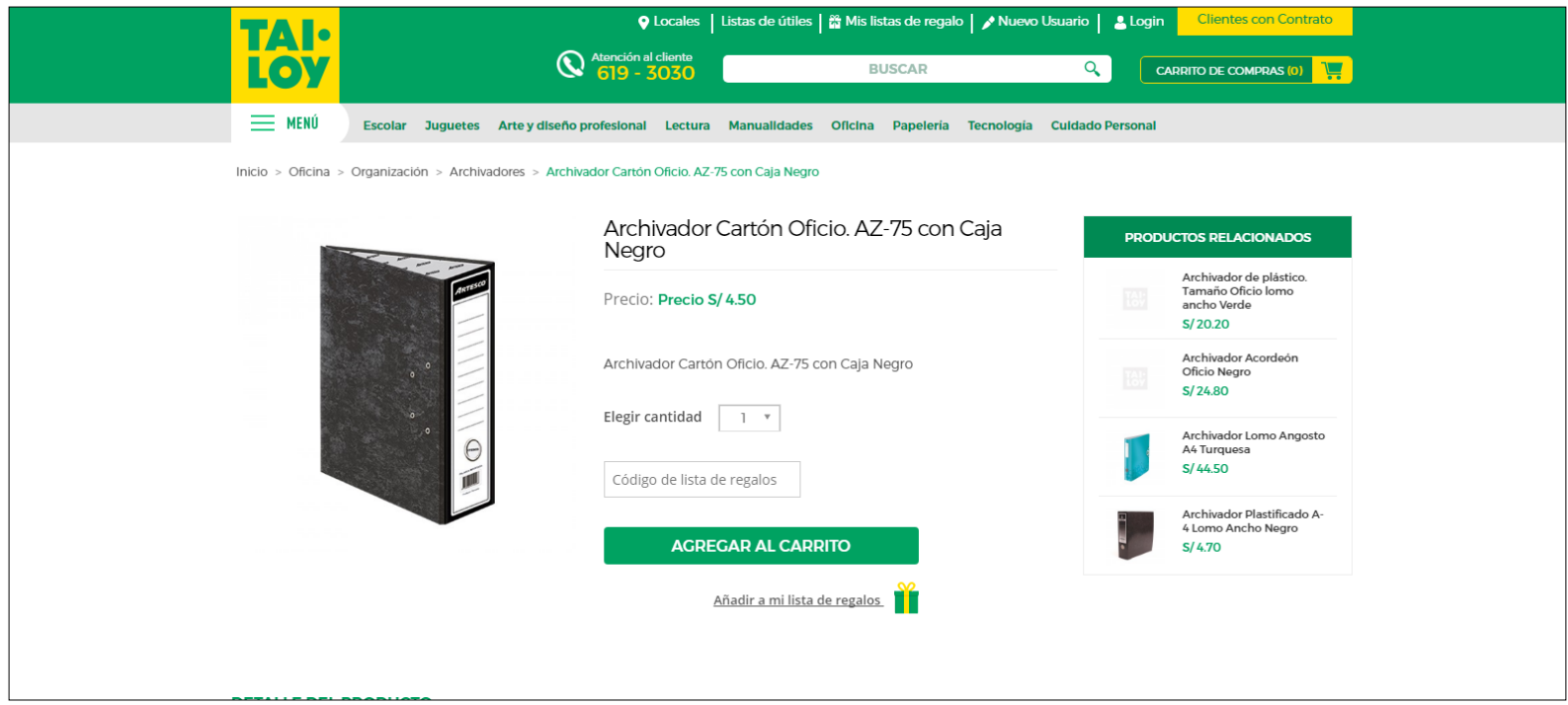

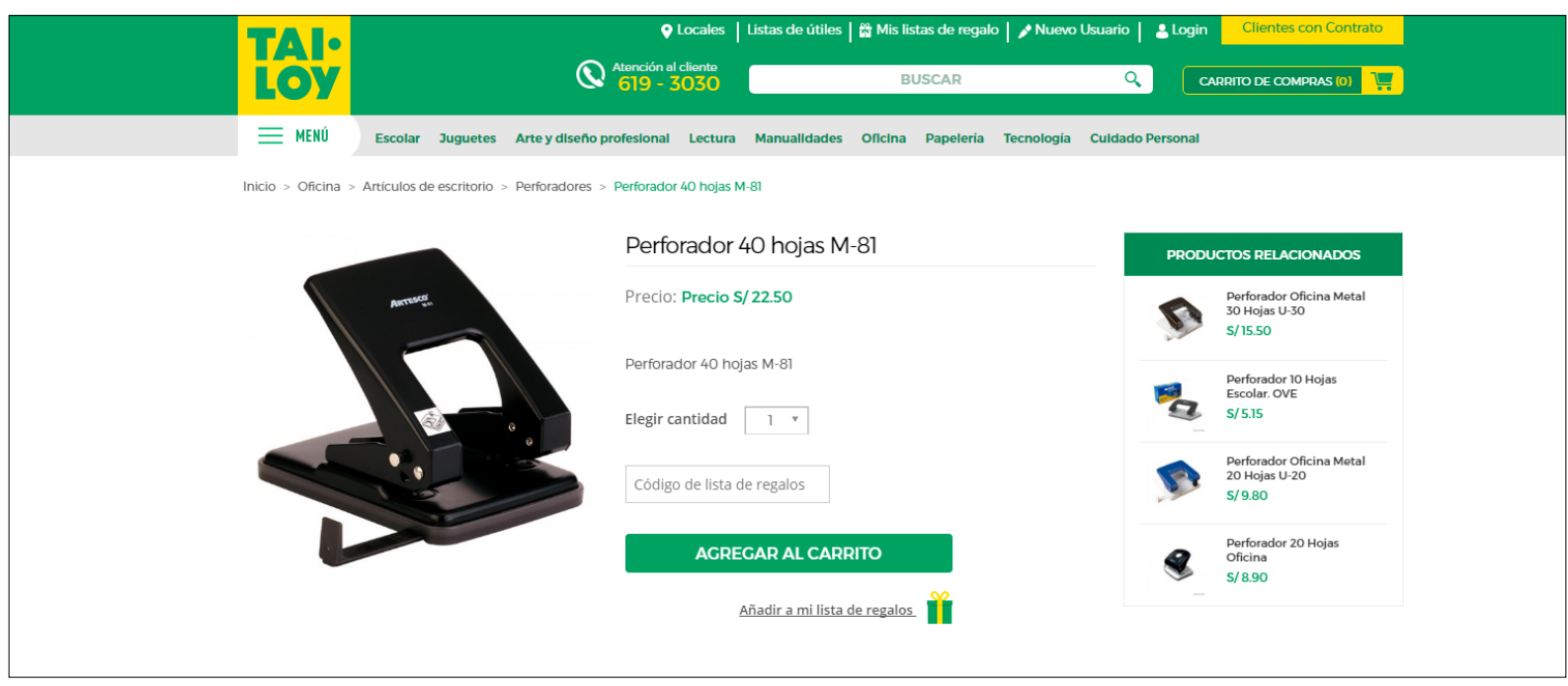

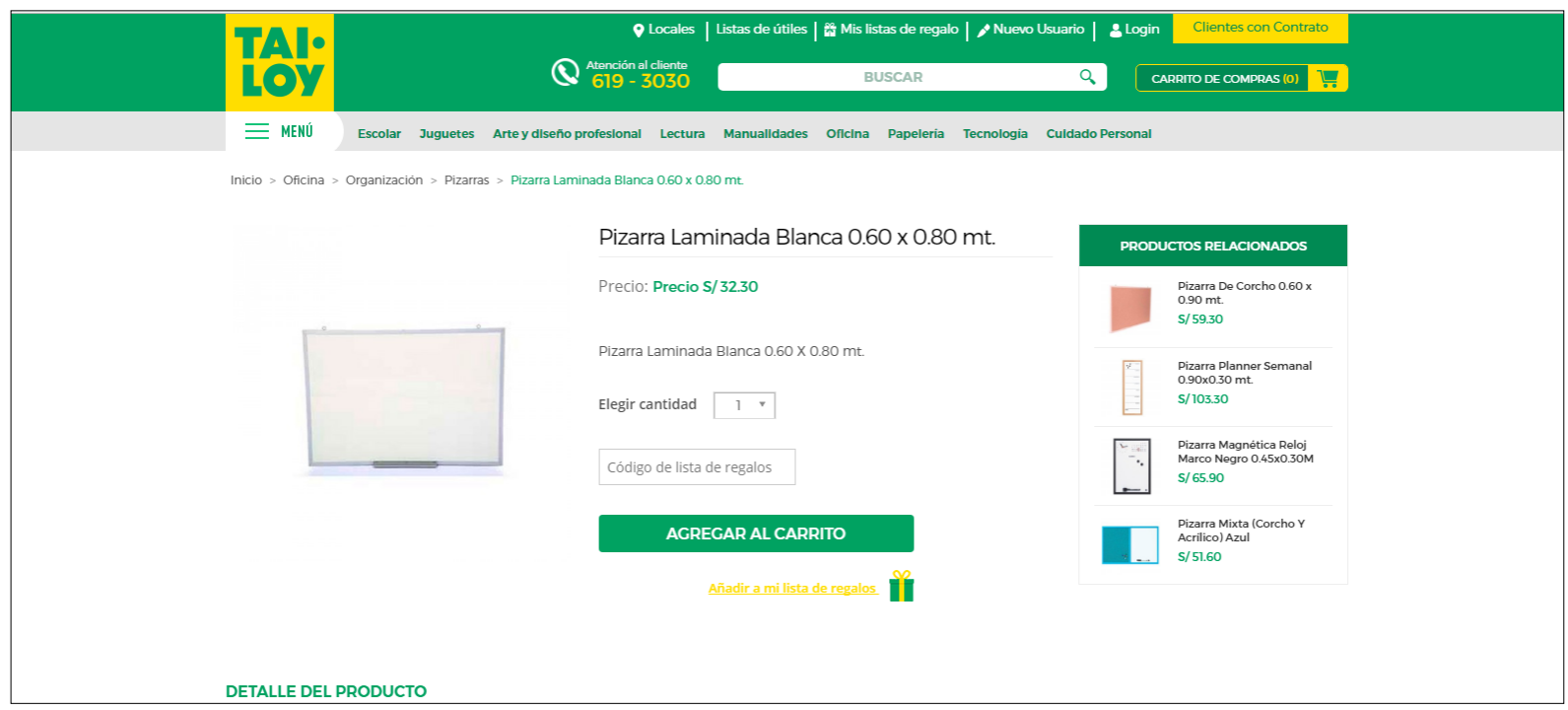


Anexo XIII.

Aspectos legales

\begin{tabular}{|c|c|c|c|c|c|c|c|}
\hline \multicolumn{2}{|l|}{ Gastos pre operativos } & \multicolumn{2}{|c|}{ Monto } & & & & \\
\hline \multicolumn{2}{|l|}{ Licencia municipal } & \multicolumn{2}{|c|}{270} & & & & \\
\hline \multicolumn{2}{|l|}{ Minuta } & \multicolumn{2}{|c|}{500} & & & & \\
\hline \multicolumn{2}{|c|}{ Constitución (Notaria y Registros) } & \multicolumn{2}{|c|}{500} & & & & \\
\hline \multicolumn{2}{|c|}{ Registro Públicos (costo mínimo) } & \multicolumn{2}{|c|}{25} & & & & \\
\hline \multicolumn{2}{|c|}{ Total } & \multicolumn{2}{|c|}{1295} & & & & \\
\hline \multicolumn{8}{|c|}{$\begin{array}{c}\text { Anexo XIV. } \\
\text { Ventas }\end{array}$} \\
\hline \multicolumn{8}{|c|}{ Ventas mensuales directas temporada baja } \\
\hline & \multicolumn{3}{|c|}{ Enero } & \multicolumn{2}{|c|}{ Febrero } & \multicolumn{2}{|l|}{ Marzo } \\
\hline Paquetes & Precio & Unid. & Total & Unid. & Total & Unid. & Total \\
\hline Full day & 337 & 54 & 18,222 & 54 & 18,222 & 54 & 18,222 \\
\hline \multirow[t]{2}{*}{ Aventura en Maras } & 1,023 & 42 & 42,447 & 42 & 42,447 & 42 & 42,447 \\
\hline & 889 & 42 & 36,910 & 42 & 36,910 & 42 & 36,910 \\
\hline \multirow[t]{2}{*}{ Experiencia kachi Raqay } & 1,352 & 14 & 18,708 & 14 & 18,708 & 14 & 18,708 \\
\hline & 1,176 & 14 & 16,268 & 14 & 16,268 & 14 & 16,268 \\
\hline Total & & 165 & 132,554 & 165 & 132,554 & 165 & 132,554 \\
\hline
\end{tabular}


Ventas mensuales directas temporada alta

\begin{tabular}{|c|c|c|c|c|c|c|c|c|c|c|c|c|c|c|c|c|c|c|c|}
\hline \multirow[b]{2}{*}{ Paquetes } & \multicolumn{3}{|c|}{ Abril } & \multirow{2}{*}{$\begin{array}{l}\text { Mayo } \\
\text { Unid. }\end{array}$} & \multicolumn{3}{|c|}{ Junio } & \multirow{2}{*}{$\begin{array}{l}\text { Julio } \\
\text { Unid. }\end{array}$} & \multicolumn{3}{|c|}{ Agosto } & \multicolumn{2}{|c|}{ Septiembre } & \multicolumn{2}{|c|}{ Octuber } & \multicolumn{2}{|c|}{ Noviembre } & \multicolumn{2}{|c|}{ Diciembre } \\
\hline & Precio & Unid. & Total & & Total & Unid. & Total & & Total & Unid. & Total & Unid. & Total & Unid. & Total & Unid. & Total & Unid. & Total \\
\hline Full day & 421 & 102 & 43,025 & 102 & 43,025 & 102 & 43,025 & 102 & 43,025 & 102 & 43,025 & 102 & 43,025 & 102 & 43,025 & 102 & 43,025 & 102 & 43,025 \\
\hline Aventura en Maras & 1,278 & 78 & 100,221 & 78 & 100,221 & 78 & 100,221 & 78 & 100,221 & 78 & 100,221 & 78 & 100,221 & 78 & 100,221 & 78 & 100,221 & 78 & 100,221 \\
\hline & 1,112 & 78 & 87,149 & 78 & 87,149 & 78 & 87,149 & 78 & 87,149 & 78 & 87,149 & 78 & 87,149 & 78 & 87,149 & 78 & 87,149 & 78 & 87,149 \\
\hline Experiencia kachi Raqay & 1,690 & 26 & 44,171 & 26 & 44,171 & 26 & 44,171 & 26 & 44,171 & 26 & 44,171 & 26 & 44,171 & 26 & 44,171 & 26 & 44,171 & 26 & 44,171 \\
\hline & 1,470 & 26 & 38,410 & 26 & 38,410 & 26 & 38,410 & 26 & 38,410 & 26 & 38,410 & 26 & 38,410 & 26 & 38,410 & 26 & 38,410 & 26 & 38,410 \\
\hline Total & & 311 & 312,976 & 311 & 312,976 & 311 & 312,976 & 311 & 312,976 & 311 & 312,976 & 311 & 312,976 & 311 & 312,976 & 311 & 312,976 & 311 & 312,976 \\
\hline
\end{tabular}

\section{Ventas mensuales indirectas temporada baja}

\begin{tabular}{llllllll}
\hline & & enero & & Febrero & \multicolumn{2}{c}{ marzo } \\
\hline Paquetes & precio & unid. & total & unid. & Total & unid. & total \\
\hline Full day & 286 & 29 & 8,340 & 29 & 8,340 & 29 & 8,340 \\
Aventura en maras & 869 & 22 & 19,427 & 22 & 19,427 & 22 & 19,427 \\
& 756 & 22 & 16,893 & 22 & 16,893 & 22 & 16,893 \\
Experiencia kachi raqay & 1,149 & 7 & 8,562 & 7 & 8,562 & 7 & 8,562 \\
& 999 & 7 & 7,446 & 7 & 7,446 & 7 & 7,446 \\
Total & & 89 & 60,669 & 89 & 60,669 & 89 & 60,669 \\
\hline
\end{tabular}

\section{Ventas mensuales indirectas temporada alta}

\begin{tabular}{|c|c|c|c|c|c|c|c|c|c|c|c|c|c|c|c|c|c|c|c|}
\hline & \multicolumn{3}{|c|}{ Abril } & \multicolumn{2}{|l|}{ Mayo } & \multicolumn{2}{|l|}{ Junio } & \multicolumn{2}{|l|}{ Julio } & \multicolumn{2}{|c|}{ Agosto } & \multicolumn{2}{|c|}{ Septiembre } & \multicolumn{2}{|c|}{ Octuber } & \multicolumn{2}{|c|}{ Noviembre } & \multicolumn{2}{|c|}{ Diciembre } \\
\hline Paquetes & Precio & Unid. & Total & Unid. & Total & Unid. & Total & Unid. & Total & Unid. & Total & Unid. & Total & Unid. & Total & Unid. & Total & Unid. & Total \\
\hline Full day & 286 & 55 & 15,754 & 55 & 15,754 & 55 & 15,754 & 55 & 15,754 & 55 & 15,754 & 55 & 15,754 & 55 & 15,754 & 55 & 15,754 & 55 & 15,754 \\
\hline Aventura en Maras & 869 & 42 & 36,696 & 42 & 36,696 & 42 & 36,696 & 42 & 36,696 & 42 & 36,696 & 42 & 36,696 & 42 & 36,696 & 42 & 36,696 & 42 & 36,696 \\
\hline & 756 & 42 & 31,910 & 42 & 31,910 & 42 & 31,910 & 42 & 31,910 & 42 & 31,910 & 42 & 31,910 & 42 & 31,910 & 42 & 31,910 & 42 & 31,910 \\
\hline Experiencia kachi Raqay & 1,149 & 14 & 16,174 & 14 & 16,174 & 14 & 16,174 & 14 & 16,174 & 14 & 16,174 & 14 & 16,174 & 14 & 16,174 & 14 & 16,174 & 14 & 16,174 \\
\hline & 999 & 14 & 14,064 & 14 & 14,064 & 14 & 14,064 & 14 & 14,064 & 14 & 14,064 & 14 & 14,064 & 14 & 14,064 & 14 & 14,064 & 14 & 14,064 \\
\hline Total & & 168 & 114,597 & 168 & 114,597 & 168 & 114,597 & 168 & 114,597 & 168 & 114,597 & 168 & 114,597 & 168 & 114,597 & 168 & 114,597 & 168 & 114,597 \\
\hline
\end{tabular}


Ventas mensuales por canal de atención

\begin{tabular}{|c|c|c|c|c|c|c|c|c|c|c|c|c|c|c|}
\hline Ene & Feb & Mar & Abr & May & Jun & Jul & Ago & \multirow{2}{*}{$\frac{\text { Set }}{312,976}$} & \multicolumn{2}{|c|}{ Oct } & \multicolumn{2}{|l|}{ Nov } & & Total 2018 \\
\hline Ventas a Turistas atendidos directamente: & 132,554 & 132,554 & 132,554 & 312,976 & 312,976 & 312,976 & 312,976 & & \multicolumn{2}{|c|}{312,976} & 312, & \multicolumn{2}{|c|}{312,976} & \multirow{2}{*}{$\begin{array}{l}312,976 \\
1,213,383 \\
\mathbf{4 , 4 2 7 , 8 2 9} \\
\end{array}$} \\
\hline $\begin{array}{l}\text { Ventas a través de operador: } \\
\text { Total }\end{array}$ & 60,669 & 60,669 & 114,597 & 114,597 & 114,597 & 114,597 & 114,597 & 114,597 & & & 114, & & 597 & \\
\hline Ventas Mensuales Bar & Ene & Feb & Mar & Abril & Mayo & Junio & Julio & Agosto & Sep. & & ubre & Nov & Dic & $\begin{array}{l}\text { Total } \\
2018\end{array}$ \\
\hline Turistas atendidos 2018 & 254 & 254 & 254 & 479 & 479 & 479 & 479 & 479 & 479 & 47 & & 479 & 479 & 5,070 \\
\hline $\begin{array}{l}\text { Turistas que consumirán por lo menos una } \\
\text { bebida del bar }\end{array}$ & 28 & 28 & 28 & 53 & 53 & 53 & 53 & 53 & 53 & 53 & & 53 & 53 & 558 \\
\hline Ventas bar & 558 & 558 & 558 & 1,053 & 1,053 & 1,053 & 1,053 & 1,053 & 1,053 & 1,0 & & 1,053 & 1,053 & 11,155 \\
\hline
\end{tabular}

\section{Resumen ventas mensuales}

\begin{tabular}{|c|c|c|c|c|c|c|c|c|c|c|c|c|c|}
\hline Ventas Mensuales 2018 & Enero & Febrero & Marzo & Abril & Mayo & Junio & Julio & Agosto & Septiembre & Octubre & Noviembre & Diciembre & Total 2018 \\
\hline Ventas a Turistas atendidos directamente: & 132,554 & 132,554 & 132,554 & 312,976 & 312,976 & 312,976 & 312,976 & 312,976 & 312,976 & 312,976 & 312,976 & 312,976 & $3,214,445$ \\
\hline Ventas a través de operador: & 60,669 & 60,669 & 60,669 & 114,597 & 114,597 & 114,597 & 114,597 & 114,597 & 114,597 & 114,597 & 114,597 & 114,597 & $1,213,383$ \\
\hline Ventas bar & 558 & 558 & 558 & 1,053 & 1,053 & 1,053 & 1,053 & 1,053 & 1,053 & 1,053 & 1,053 & 1,053 & 11,155 \\
\hline Total & 193,781 & 193,781 & 193,781 & 428,627 & 428,627 & 428,627 & 428,627 & 428,627 & 428,627 & 428,627 & 428,627 & 428,627 & $4,438,983$ \\
\hline
\end{tabular}

\section{Ventas directas temporada alta por años}

\begin{tabular}{|c|c|c|c|c|c|c|c|c|c|c|c|c|}
\hline & & & 2018 & & 2019 & & 2020 & & 2021 & & 2022 & \\
\hline Paquetes & Tipo Habitacion & Precio & Unid. & Total & Unid. & Total & Unid. & Total & Unid. & Total & Unid. & Total \\
\hline Full day & Simple & 408 & 1,082 & 441,888 & 1,136 & 463,983 & 1,193 & 487,182 & 1,252 & 511,541 & 1,315 & 537,118 \\
\hline Aventura en Maras & Simple & 1,240 & 830 & $1,029,329$ & 909 & $1,127,115$ & 995 & $1,234,191$ & 1,090 & $1,351,439$ & 1,194 & $1,479,825$ \\
\hline & Doble o matrimonial & 1,078 & 830 & 895,068 & 909 & 980,100 & 995 & $1,073,209$ & 1,090 & $1,175,164$ & 1,194 & $1,286,805$ \\
\hline Experiencia Cachy Raqay & Simple & 1,639 & 277 & 453,667 & 303 & 496,765 & 332 & 543,958 & 363 & 595,634 & 398 & 652,219 \\
\hline Total & Doble o matrimonial & 1,426 & $\begin{array}{l}277 \\
\mathbf{3 . 2 9 6}\end{array}$ & $\begin{array}{l}394,493 \\
\mathbf{3 . 2 1 4 , 4 4 5}\end{array}$ & $\begin{array}{l}303 \\
\mathbf{3 , 5 6 0}\end{array}$ & $\begin{array}{l}431,970 \\
\mathbf{3 , 4 9 9 , 9 3 3}\end{array}$ & $\begin{array}{l}332 \\
\mathbf{3 , 8 4 7}\end{array}$ & $\begin{array}{l}473,007 \\
\mathbf{3 , 8 1 1 , 5 4 7}\end{array}$ & $\begin{array}{l}363 \\
\mathbf{4 . 1 5 9}\end{array}$ & $\begin{array}{l}517,943 \\
\mathbf{4 , 1 5 1 , 7 2 1}\end{array}$ & $\begin{array}{l}398 \\
\mathbf{4 , 4 9 8}\end{array}$ & $\begin{array}{l}567,147 \\
\mathbf{4 . 5 2 3 , 1 1 5}\end{array}$ \\
\hline
\end{tabular}

\section{Ventas operador por años}

\begin{tabular}{|c|c|c|c|c|c|c|c|c|c|c|c|c|}
\hline & & & 2018 & & 2019 & & 2020 & & 2021 & & 2022 & \\
\hline Paquetes & Doble o matrimonial & Precio & Unidades & Total & Unidades & Total & Unidades & Total & Unidades & Total & Unidades & Total \\
\hline Full day & Simple & 286 & 583 & 166,803 & 612 & 175,143 & 642 & 183,901 & 674 & 193,096 & 708 & 202,750 \\
\hline Aventura en Maras & Simple & 869 & 447 & 388,549 & 489 & 425,461 & 536 & 465,880 & 587 & 510,139 & 643 & 558,602 \\
\hline & Doble o matrimonial & 756 & 447 & 337,869 & 489 & 369,966 & 536 & 405,113 & 587 & 443,599 & 643 & 485,741 \\
\hline Experiencia Cachy Raqay & Simple & 1,149 & 149 & 171,249 & 163 & 187,518 & 179 & 205,332 & 196 & 224,839 & 214 & 246,199 \\
\hline Totol & Doble o matrimonial & 999 & 149 & 148,913 & 163 & 163,059 & 179 & 178,550 & 196 & 195,512 & 214 & 214,086 \\
\hline
\end{tabular}


Ventas anuales del bar

\begin{tabular}{lcccccc}
\hline Años & & 2018 & 2019 & 2020 & 2021 & 2022 \\
\hline Turistas & $100 \%$ & 5,070 & 5,477 & 5,919 & 6,398 & 6,920 \\
Promedio consumo 11\% & $11 \%$ & 558 & 602 & 651 & 704 & 761 \\
Precio & 20 & 20 & 20 & 20 & 20 & 20 \\
Total & & 11,155 & 12,049 & 13,021 & 14,077 & 15,223 \\
\hline
\end{tabular}

\section{Resumen ventas anuales}

\begin{tabular}{|c|c|c|c|c|c|}
\hline Años & 2018 & 2019 & 2020 & 2021 & 2022 \\
\hline Ventas a Turistas atendidos directamente: & $3,214,445$ & $3,499,933$ & $3,811,547$ & $4,151,721$ & $4,523,115$ \\
\hline Ventas a través de operador: & $1,213,383$ & $1,321,148$ & $1,438,776$ & $1,567,184$ & $1,707,377$ \\
\hline Ventas bar & 11,155 & 12,049 & 13,021 & 14,077 & 15,223 \\
\hline Total & $4,438,983$ & $4,833,131$ & $5,263,344$ & $5,732,982$ & $6,245,716$ \\
\hline
\end{tabular}


Anexo XV.

Costo insumos alimentos

\begin{tabular}{|c|c|c|c|c|c|c|c|c|c|c|}
\hline Categoria & Ingrediente & Cantidad & $\begin{array}{l}\text { Unid. } \\
\text { Medida }\end{array}$ & Soles & 2017 & 2018 & 2019 & 2020 & 2021 & 2022 \\
\hline & Aceite & 360 & Ml. & 5.10 & 1,836 & 1,836 & 1,836 & 1,836 & 1,836 & 1,836 \\
\hline & Agua & 15,600 & Ml. & 3.56 & 1,282 & 1,282 & 1,282 & 1,282 & 1,282 & 1,282 \\
\hline & Azúcar & 150 & Gr. & 1.20 & 432 & 432 & 432 & 432 & 432 & 432 \\
\hline & Canela & 112 & Gr. & 0.90 & 324 & 324 & 324 & 324 & 324 & 324 \\
\hline \multirow{3}{*}{ Abarrotes } & Leche & 500 & Ml. & 3.50 & 1,260 & 1,260 & 1,260 & 1,260 & 1,260 & 1,260 \\
\hline & Carne de cerdo & 250 & Gr. & 6.00 & 2,160 & 2,160 & 2,160 & 2,160 & 2,160 & 2,160 \\
\hline & Carne de res & 250 & Gr. & 6.00 & 2,160 & 2,160 & 2,160 & 2,160 & 2,160 & 2,160 \\
\hline \multirow[t]{2}{*}{ Carnes } & Vísceras & 100 & Gr. & 3.50 & 1,260 & 1,260 & 1,260 & 1,260 & 1,260 & 1,260 \\
\hline & Culantro, orégano, wacatay & 230 & Atado & 2.50 & 900 & 900 & 900 & 900 & 900 & 900 \\
\hline \multirow{15}{*}{ Hortalizas } & Hierba buena & 15 & Atado & 0.20 & 72 & 72 & 72 & 72 & 72 & 72 \\
\hline & Ajos & 105 & Gr. & 1.75 & 630 & 630 & 630 & 630 & 630 & 630 \\
\hline & Alverjas & 60 & Gr. & 0.80 & 288 & 288 & 288 & 288 & 288 & 288 \\
\hline & Camote & 100 & Gr. & 0.63 & 227 & 227 & 227 & 227 & 227 & 227 \\
\hline & Cebolla & 300 & Gr. & 1.20 & 432 & 432 & 432 & 432 & 432 & 432 \\
\hline & Choclos & 1,100 & Gr. & 2.20 & 792 & 792 & 792 & 792 & 792 & 792 \\
\hline & Limón & 60 & Gr. & 2.20 & 792 & 792 & 792 & 792 & 792 & 792 \\
\hline & Lisas/Olluco & 300 & Gr. & 0.70 & 252 & 252 & 252 & 252 & 252 & 252 \\
\hline & Maíz morado & 150 & Gr. & 0.90 & 324 & 324 & 324 & 324 & 324 & 324 \\
\hline & Mote, habas & 650 & Gr. & 8.50 & 3,060 & 3,060 & 3,060 & 3,060 & 3,060 & 3,060 \\
\hline & Papa blanca & 1,300 & Gr. & 2.60 & 936 & 936 & 936 & 936 & 936 & 936 \\
\hline & Quinua & 500 & Gr. & 6.00 & 2,160 & 2,160 & 2,160 & 2,160 & 2,160 & 2,160 \\
\hline & Rocoto & 360 & Gr. & 3.50 & 1,260 & 1,260 & 1,260 & 1,260 & 1,260 & 1,260 \\
\hline & Manzana & 150 & Gr. & 0.80 & 288 & 288 & 288 & 288 & 288 & 288 \\
\hline & Zanahoria & 120 & Gr. & 1.30 & 468 & 468 & 468 & 468 & 468 & 468 \\
\hline \multirow[t]{10}{*}{ Frutas y Vegetales } & Zapallo & 40 & Gr. & 0.30 & 108 & 108 & 108 & 108 & 108 & 108 \\
\hline & Chuño & 100 & Gr. & 0.30 & 108 & 108 & 108 & 108 & 108 & 108 \\
\hline & Condimentos & 230 & Gr. & 2.90 & 1,044 & 1,044 & 1,044 & 1,044 & 1,044 & 1,044 \\
\hline & Esencia vainilla & 10 & M1. & 1.00 & 360 & 360 & 360 & 360 & 360 & 360 \\
\hline & Maicena & 20 & Gr. & 0.20 & 72 & 72 & 72 & 72 & 72 & 72 \\
\hline & Maní & 240 & Gr. & 2.00 & 720 & 720 & 720 & 720 & 720 & 720 \\
\hline & Mantequilla & 30 & Barra & 1.50 & 540 & 540 & 540 & 540 & 540 & 540 \\
\hline & Nata & 50 & Gr. & 6.30 & 2,268 & 2,268 & 2,268 & 2,268 & 2,268 & 2,268 \\
\hline & Panes & 6 & Unidad & 3.84 & 1,382 & 1,382 & 1,382 & 1,382 & 1,382 & 1,382 \\
\hline & Queso & 200 & Gr. & 11.00 & 3,960 & 3,960 & 3,960 & 3,960 & 3,960 & 3,960 \\
\hline Otros & Siete Harinas & 150 & Gr. & 0.50 & 180 & 180 & 180 & 180 & 180 & 180 \\
\hline TOTAL & & 23,898 & & 95.38 & 34,337 & 34,337 & 34,337 & 34,337 & 34,337 & 34,337 \\
\hline
\end{tabular}




\section{Anexo XVI. \\ Calculo costo por paquete}

Cálculo del paquete "Full Day" Expresado en soles

\begin{tabular}{ll}
\hline Concepto & Soles \\
\hline Movilidad para recoger al pasajero de Cusco-Hotel/aeropuerto & 45 \\
Guía turístico bilingüe & 30 \\
Movilidad para dejar al pasajero en Cusco-Hotel/aeropuerto & 45 \\
Alimentos & 23 \\
Entrada a las salineras & 7 \\
Cuatrimoto para las visitas programadas & 140 \\
Mate de coca (x3) & 1 \\
Costo total promedio por turista: & 291 \\
\hline
\end{tabular}

Cálculo del paquete "Aventura en Maras" Expresado en soles

\begin{tabular}{ll}
\hline Concepto & Soles \\
\hline Movilidad para recoger al pasajero de Cusco-Hotel/aeropuerto & 45 \\
Guía turístico bilingüe & 30 \\
Movilidad para dejar al pasajero en Cusco-Hotel/aeropuerto & 45 \\
Alimentos & 64 \\
Entrada a las salineras & 7 \\
Cuatrimoto para las visitas programadas & 250 \\
Madera para fogata al aire libre & 5 \\
Kit de Amenities & 8 \\
Mate de coca (x3) & 1 \\
Costo total promedio por turista: & 455 \\
\hline
\end{tabular}

Cálculo del paquete "Experiencia Kachi Raqay" Expresado en soles

\begin{tabular}{ll}
\hline Concepto & Soles \\
\hline Movilidad para recoger al pasajero de Cusco-Hotel/aeropuerto & 45 \\
Guía turístico bilingüe & 30 \\
Movilidad para dejar al pasajero en Cusco-Hotel/aeropuerto & 45 \\
Alimentos & 95 \\
Entrada a las salineras & 7 \\
Cuatrimoto para las visitas programadas & 250 \\
Madera para fogata al aire libre & 15 \\
Kit de Amenities & 16 \\
Mate de coca (x6) & 2 \\
Elaboración de chica & 4 \\
Renovación mística de votos & 30 \\
Costo total promedio por turista: & 539 \\
\hline
\end{tabular}




\section{Anexo XVII.}

Planillas

2019

\begin{tabular}{|c|c|c|c|c|c|c|c|c|c|}
\hline Cargo & $\begin{array}{c}\text { Remuneración } \\
\text { Básica }\end{array}$ & $\begin{array}{l}\text { Asignación } \\
\text { Familiar }\end{array}$ & $\begin{array}{c}\text { Remuneración } \\
\text { Mensual }\end{array}$ & $\begin{array}{c}\text { Gratificaciones } \\
\text { Totales } \\
\end{array}$ & $\begin{array}{c}\text { Remuneración } \\
\text { Total }\end{array}$ & Essalud & $\begin{array}{c}\text { Comisiones } \\
\text { Totales }\end{array}$ & Cts Total & $\begin{array}{c}\text { Costo Total } \\
\text { Anual }\end{array}$ \\
\hline Supervisor HHKK & 1,688 & 75 & 1,763 & 3,525 & 24,675 & 2,221 & 6,291 & 2,581 & 35,767 \\
\hline Supervisor FD & 1,688 & 75 & 1,763 & 3,525 & 24,675 & 2,221 & 6,291 & 2,581 & 35,767 \\
\hline Conserje & 1,100 & 75 & 1,175 & 7,050 & 16,450 & 1,481 & 18,874 & 5,685 & 78,350 \\
\hline Jefe de cocina & 1,688 & 75 & 1,763 & 3,525 & 24,675 & 2,221 & 6,291 & 2,581 & 35,767 \\
\hline Housekeeper & 1,050 & 75 & 1,125 & 6,750 & 15,750 & 1,418 & 18,874 & 5,510 & 75,886 \\
\hline Mantenimiento & 1,050 & 75 & 1,125 & 4,500 & 15,750 & 1,418 & 12,582 & 3,674 & 50,591 \\
\hline Personal de cocina & 1,050 & 75 & 1,125 & $\begin{array}{c}6,750 \\
35,625\end{array}$ & 15,750 & 1,418 & 18,874 & $\begin{array}{c}5,510 \\
28,121\end{array}$ & $\begin{array}{c}75,886 \\
388,016\end{array}$ \\
\hline Gerente & 3,000 & 75 & 3,075 & 6,150 & 43,050 & 3,875 & 6,291 & 4,112 & 57,327 \\
\hline Administrador & 2,400 & 75 & 2,475 & 4,950 & 34,650 & 3,119 & 6,291 & 3,412 & 47,471 \\
\hline Recepcionista & 1,100 & 75 & 1,175 & 7,050 & 16,450 & 1,481 & 18,874 & 5,685 & 78,350 \\
\hline Contador & 2,250 & 75 & 2,325 & $\begin{array}{c}4,650 \\
22,800\end{array}$ & 32,550 & 2,930 & 6,291 & $\begin{array}{c}3,237 \\
16,446\end{array}$ & $\begin{array}{c}45,007 \\
228,157\end{array}$ \\
\hline $\begin{array}{l}\text { Ejecutivo comercial } \\
\text { Total }\end{array}$ & 2,250 & 75 & 2,325 & 4,650 & 32,550 & 2,930 & 6,291 & 3,237 & $\begin{array}{l}45,007 \\
661,180 \\
\end{array}$ \\
\hline
\end{tabular}

\section{0}

\begin{tabular}{|c|c|c|c|c|c|c|c|c|c|}
\hline Cargo & Remuneración Básica & Asignación Familiar & $\begin{array}{l}\text { Remuneración } \\
\text { Mensual }\end{array}$ & Gratificaciones Totales & Remuneración Total & Essalud & $\begin{array}{l}\text { Comisiones } \\
\text { Totales }\end{array}$ & Cts Total & $\begin{array}{l}\text { Costo Total } \\
\text { Anual }\end{array}$ \\
\hline Supervisor HHKK & 1,688 & 75 & 1,763 & 3,525 & 24,675 & 2,221 & 6,851 & 2,627 & 36,374 \\
\hline Supervisor FD & 1,688 & 75 & 1,763 & 3,525 & 24,675 & 2,221 & 6,851 & 2,627 & 36,374 \\
\hline Conserje & 1,100 & 75 & 1,175 & 7,050 & 16,450 & 1,481 & 20,554 & 5,825 & 80,171 \\
\hline Jefe de cocina & 1,688 & 75 & 1,763 & 3,525 & 24,675 & 2,221 & 6,851 & 2,627 & 36,374 \\
\hline Housekeeper & 1,050 & 75 & 1,125 & 6,750 & 15,750 & 1,418 & 20,554 & 5,650 & 77,707 \\
\hline Mantenimiento & 1,050 & 75 & 1,125 & 4,500 & 15,750 & 1,418 & 13,703 & 3,767 & 51,805 \\
\hline Personal de cocina & 1,050 & 75 & 1,125 & $\begin{array}{l}6,750 \\
35,625\end{array}$ & 15,750 & 1,418 & 20,554 & $\begin{array}{l}5,650 \\
28,774\end{array}$ & $\begin{array}{l}77,707 \\
396,512\end{array}$ \\
\hline Gerente & 3,000 & 75 & 3,075 & 6,150 & 43,050 & 3,875 & 6,851 & 4,158 & 57,934 \\
\hline Adiministrador & 2,400 & 75 & 2,475 & 4,950 & 34,650 & 3,119 & 6,851 & 3,458 & 48,078 \\
\hline Recepcionista & 1,100 & 75 & 1,175 & 7,050 & 16,450 & 1,481 & 20,554 & 5,825 & 80,171 \\
\hline Contador & 2,250 & 75 & 2,325 & $\begin{array}{l}4,650 \\
22,800\end{array}$ & 32,550 & 2,930 & 6,851 & $\begin{array}{l}3,283 \\
16,726\end{array}$ & $\begin{array}{l}45,614 \\
231,798\end{array}$ \\
\hline $\begin{array}{l}\text { Ejecutivo comercial } \\
\text { Total }\end{array}$ & 2,250 & 75 & 2,325 & 4,650 & 32,550 & 2,930 & 6,851 & 3,283 & $\begin{array}{l}45,614 \\
\mathbf{6 7 3 , 9 2 3}\end{array}$ \\
\hline
\end{tabular}




\begin{tabular}{|c|c|c|c|c|c|c|c|c|c|}
\hline Cargo & $\begin{array}{l}\text { Remuneración } \\
\text { Básica }\end{array}$ & $\begin{array}{l}\text { Asignación } \\
\text { Familiar }\end{array}$ & $\begin{array}{c}\text { Remuneración } \\
\text { Mensual }\end{array}$ & $\begin{array}{c}\text { Gratificaciones } \\
\text { Totales }\end{array}$ & $\begin{array}{c}\text { Remuneración } \\
\text { Total }\end{array}$ & Essalud & $\begin{array}{c}\text { Comisiones } \\
\text { Totales }\end{array}$ & Cts Total & $\begin{array}{c}\text { Costo } \\
\text { Total } \\
\text { Anual } \\
\end{array}$ \\
\hline Supervisor HHKK & 1,688 & 75 & 1,763 & 3,525 & 24,675 & 2,221 & 7,463 & 2,678 & 37,037 \\
\hline Supervisor FD & 1,688 & 75 & 1,763 & 3,525 & 24,675 & 2,221 & 7,463 & 2,678 & 37,037 \\
\hline Conserje & 1,100 & 75 & 1,175 & 7,050 & 16,450 & 1,481 & 22,388 & 5,978 & 82,158 \\
\hline Jefe de cocina & 1,688 & 75 & 1,763 & 3,525 & 24,675 & 2,221 & 7,463 & 2,678 & 37,037 \\
\hline Housekeeper & 1,050 & 75 & 1,125 & 6,750 & 15,750 & 1,418 & 22,388 & 5,803 & 79,694 \\
\hline Mantenimiento & 1,050 & 75 & 1,125 & 4,500 & 15,750 & 1,418 & 14,926 & 3,869 & 53,129 \\
\hline Personal de cocina & 1,050 & 75 & 1,125 & $\begin{array}{c}6,750 \\
35,625\end{array}$ & 15,750 & 1,418 & 22,388 & $\begin{array}{c}5,803 \\
29,488\end{array}$ & $\begin{array}{c}79,694 \\
405,786\end{array}$ \\
\hline Gerente & 3,000 & 75 & 3,075 & 6,150 & 43,050 & 3,875 & 7,463 & 4,209 & 58,597 \\
\hline Adiministrador & 2,400 & 75 & 2,475 & 4,950 & 34,650 & 3,119 & 7,463 & 3,509 & 48,741 \\
\hline Recepcionista & 1,100 & 75 & 1,175 & 7,050 & 16,450 & 1,481 & 22,388 & 5,978 & 82,158 \\
\hline Contador & 2,250 & 75 & 2,325 & $\begin{array}{c}4,650 \\
22,800\end{array}$ & 32,550 & 2,930 & 7,463 & $\begin{array}{c}3,334 \\
17,031\end{array}$ & $\begin{array}{c}46,277 \\
235,772\end{array}$ \\
\hline Ejecutivo comercial & 2,250 & 75 & 2,325 & $\begin{array}{l}4,650 \\
\text { otal }\end{array}$ & 32,550 & 2,930 & 7,463 & 3,334 & $\begin{array}{c}46,277 \\
687,834 \\
\end{array}$ \\
\hline
\end{tabular}




\begin{tabular}{|c|c|c|c|c|c|c|c|c|c|}
\hline Cargo & $\begin{array}{l}\text { Remuneración } \\
\text { Básica }\end{array}$ & $\begin{array}{l}\text { Asignación } \\
\text { Familiar }\end{array}$ & $\begin{array}{l}\text { Remuneración } \\
\text { Mensual }\end{array}$ & $\begin{array}{l}\text { Gratificaciones } \\
\text { Totales }\end{array}$ & $\begin{array}{l}\text { Remuneración } \\
\text { Total }\end{array}$ & Essalud & $\begin{array}{l}\text { Comisiones } \\
\text { Totales }\end{array}$ & Cts Total & $\begin{array}{l}\text { Costo } \\
\text { Total } \\
\text { Anual }\end{array}$ \\
\hline Supervisor HHKK & 1,688 & 75 & 1,763 & 3,525 & 24,675 & 2,221 & 8,130 & 2,734 & 37,760 \\
\hline Supervisor FD & 1,688 & 75 & 1,763 & 3,525 & 24,675 & 2,221 & 8,130 & 2,734 & 37,760 \\
\hline Conserje & 1,100 & 75 & 1,175 & 7,050 & 16,450 & 1,481 & 24,391 & 6,145 & 84,328 \\
\hline Jefe de cocina & 1,688 & 75 & 1,763 & 3,525 & 24,675 & 2,221 & 8,130 & 2,734 & 37,760 \\
\hline Housekeeper & 1,050 & 75 & 1,125 & 6,750 & 15,750 & 1,418 & 24,391 & 5,970 & 81,864 \\
\hline Mantenimiento & 1,050 & 75 & 1,125 & 4,500 & 15,750 & 1,418 & 16,261 & 3,980 & 54,576 \\
\hline Personal de cocina & 1,050 & 75 & 1,125 & $\begin{array}{l}6,750 \\
35,625\end{array}$ & 15,750 & 1,418 & 24,391 & $\begin{array}{l}5,970 \\
30,267\end{array}$ & $\begin{array}{l}81,864 \\
415,911\end{array}$ \\
\hline Gerente & 3,000 & 75 & 3,075 & 6,150 & 43,050 & 3,875 & 8,130 & 4,265 & 59,320 \\
\hline Adiministrador & 2,400 & 75 & 2,475 & 4,950 & 34,650 & 3,119 & 8,130 & 3,565 & 49,464 \\
\hline Recepcionista & 1,100 & 75 & 1,175 & 7,050 & 16,450 & 1,481 & 24,391 & 6,145 & 84,328 \\
\hline Contador & 2,250 & 75 & 2,325 & $\begin{array}{l}4,650 \\
22,800\end{array}$ & 32,550 & 2,930 & 8,130 & $\begin{array}{l}3,390 \\
17,365\end{array}$ & $\begin{array}{l}47,000 \\
240,111\end{array}$ \\
\hline $\begin{array}{l}\text { Ejecutivo comercial } \\
\text { Total }\end{array}$ & 2,250 & 75 & 2,325 & 4,650 & 32,550 & 2,930 & 8,130 & 3,390 & $\begin{array}{l}47,000 \\
\mathbf{7 0 3 , 0 2 2} \\
\end{array}$ \\
\hline
\end{tabular}


Anexo XVIII.

Cálculo de servicios y cálculo de costo variable unitario

Cálculo del costo total unitario

Mercado objetivo expresado en unidades

\begin{tabular}{ccccc}
\hline Año & Full Day & Aventura En Maras & $\begin{array}{c}\text { Experiencia } \\
\text { Kachi Raqay }\end{array}$ & Total \\
\hline 2018 & 1.664 & 2.554 & 851 & 5.070 \\
2019 & 1.748 & 2.797 & 932 & 5.477 \\
2020 & 1.835 & 3.063 & 1.021 & 5.919 \\
2021 & 1.927 & 3.354 & 1.118 & 6.398 \\
2022 & 2.023 & 3.672 & 1.224 & 6.920 \\
\hline
\end{tabular}

Elaboración propia

MERCADO OBJETIVO EXPRESADO EN PORCENTAJE

\begin{tabular}{ccccc}
\hline Año & Full Day & $\begin{array}{c}\text { Aventura en } \\
\text { Maras }\end{array}$ & Experiencia Kachi Raqay & Total \\
\hline 2018 & $33 \%$ & $50 \%$ & $17 \%$ & $100 \%$ \\
2019 & $32 \%$ & $51 \%$ & $17 \%$ & $100 \%$ \\
2020 & $31 \%$ & $52 \%$ & $17 \%$ & $100 \%$ \\
2021 & $30 \%$ & $52 \%$ & $17 \%$ & $100 \%$ \\
2022 & $29 \%$ & $53 \%$ & $18 \%$ & $100 \%$ \\
\hline
\end{tabular}

Elaboración propia

Costos totales de servicios y comisiones según paquete

\begin{tabular}{ccccc}
\hline Año & Full Day & Aventura en Maras & Experiencia Kachi Raqay & Total \\
\hline 2018 & 48.987 & 75.184 & 25.061 & 149.233 \\
2019 & 53.134 & 85.043 & 28.348 & 166.526 \\
2020 & 55.765 & 93.079 & 31.026 & 179.870 \\
2021 & 58.532 & 101.885 & 33.962 & 194.379 \\
2022 & 61.438 & 111.527 & 37.176 & 210.141 \\
\hline
\end{tabular}

Elaboración propia

Costos individuales de servicios y comisiones según paquete (soles por paquete)

\begin{tabular}{ccccc}
\hline Año & Full Day & Aventura en Maras & Experiencia Kachi Raqay & Total \\
\hline 2018 & 29,43 & 29,43 & 29,43 & 29,43 \\
2019 & 30,40 & 30,40 & 30,40 & 30,40 \\
2020 & 30,39 & 30,39 & 30,39 & 30,39 \\
2021 & 30,38 & 30,38 & 30,38 & 30,38 \\
2022 & 30,37 & 30,37 & 30,37 & 30,37 \\
\hline
\end{tabular}

Elaboración propia

Conclusión: Se espera que los servicios y las comisiones incrementen los costos por cada paquete en $\mathrm{S} / .30$ 
Anexo XIX.

Gastos de ventas

$\underline{\text { Se realizarán } 3 \text { fam Trips al año }}$

\begin{tabular}{|c|c|c|}
\hline \multirow[t]{2}{*}{ Paquete: } & \multicolumn{2}{|c|}{ Experiencia kachi Raqay } \\
\hline & Marzo & Junio \\
\hline $\begin{array}{l}\text { Agencias de turismo y operadores } \\
\text { invitados }\end{array}$ & 6 & 3 \\
\hline Personas por agencia/operador: & 2 & 2 \\
\hline Total Paquetes a invitar & 12 & 6 \\
\hline Costo por paquete: & 539 & 539 \\
\hline Costo por Fam Trip & 6472.65 & 3236.325 \\
\hline \multicolumn{3}{|l|}{ Premios (\#selfieKachiRaqay) } \\
\hline \multicolumn{3}{|l|}{ Canasta: } \\
\hline Sal de Maras & 3 & 5 \\
\hline Aceite de Sacha inchi & 1 & 15 \\
\hline \multirow[t]{3}{*}{ Chocolates rellenos de pisco } & 1 & 15 \\
\hline & & Por semana \\
\hline & & Por mes \\
\hline \multicolumn{3}{|l|}{ Patrocinio a operadores en ferias } \\
\hline 2015 & 10,178 & \\
\hline 2016 & 10,483 & \\
\hline 2017 & 10,798 & \\
\hline 2018 & 11,122 & 2,224 \\
\hline
\end{tabular}




\section{Anexo XX. \\ Depreciación}

http://www.sunat.gob.pe/legislacion/renta/regla/
$\leftarrow \rightarrow$ C
(i) \& www.sunat.gob.pe/legislacion/renta/regla/

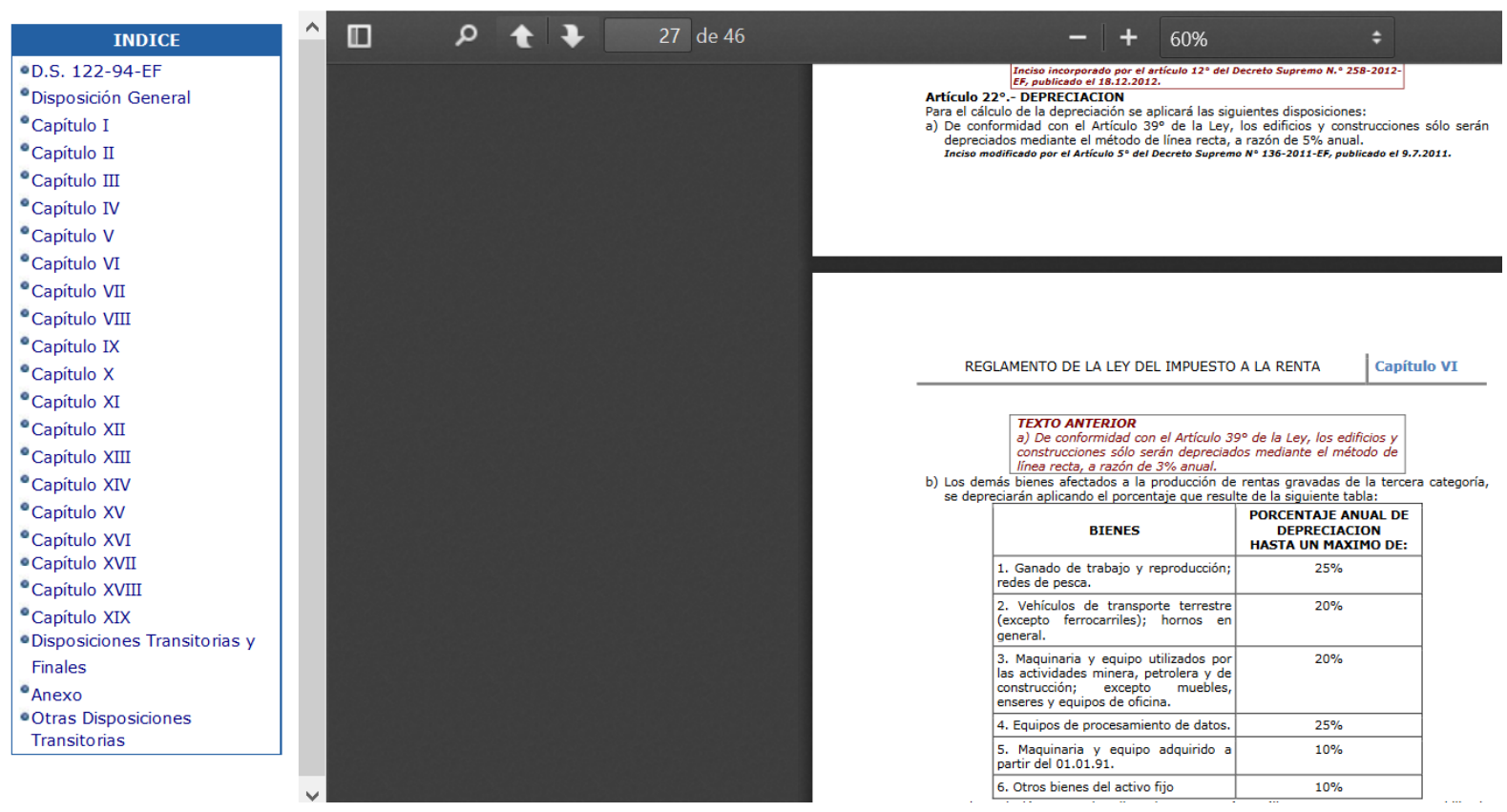

